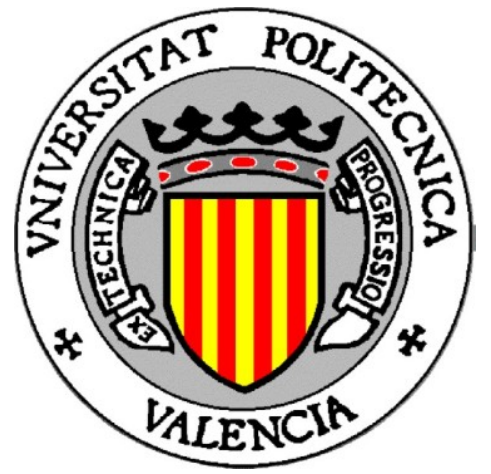

ESCUELA TÉCNICA SUPERIOR DE INGENIERIA AGRONÓMICA Y DEL MEDIO NATURAL

\title{
EFECTO DE LA ADICIÓN DE COPIGMENTOS SOBRE LA COMPOSICIÓN FENÓLICA DE VINOS TINTOS DE TEMPRANILLO ELABORADOS CON DIFERENTES TÉCNICAS DE VINIFICACIÓN
}

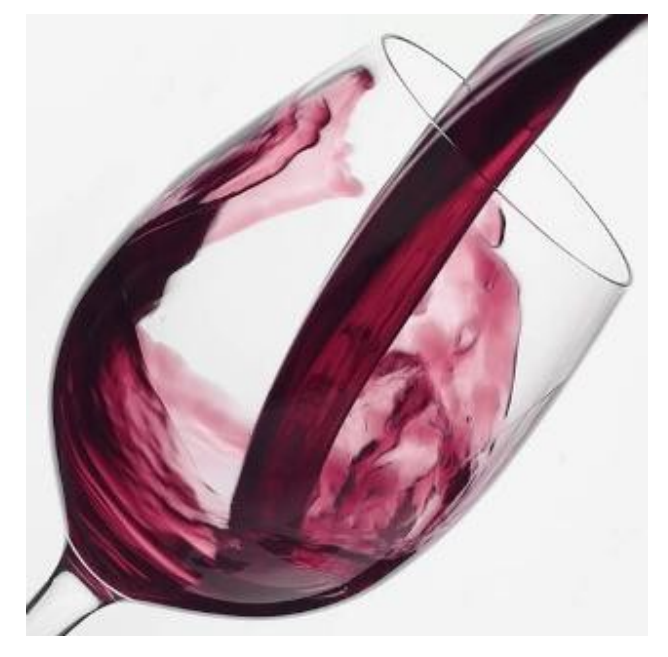

TESIS DOCTORAL

Presentada por:

José Luis Aleixandre Tudó

Dirigida por:

Dra. Inmaculada Álvarez Cano

Dra. Victoria Lizama Abad

Valencia, Marzo 2012 



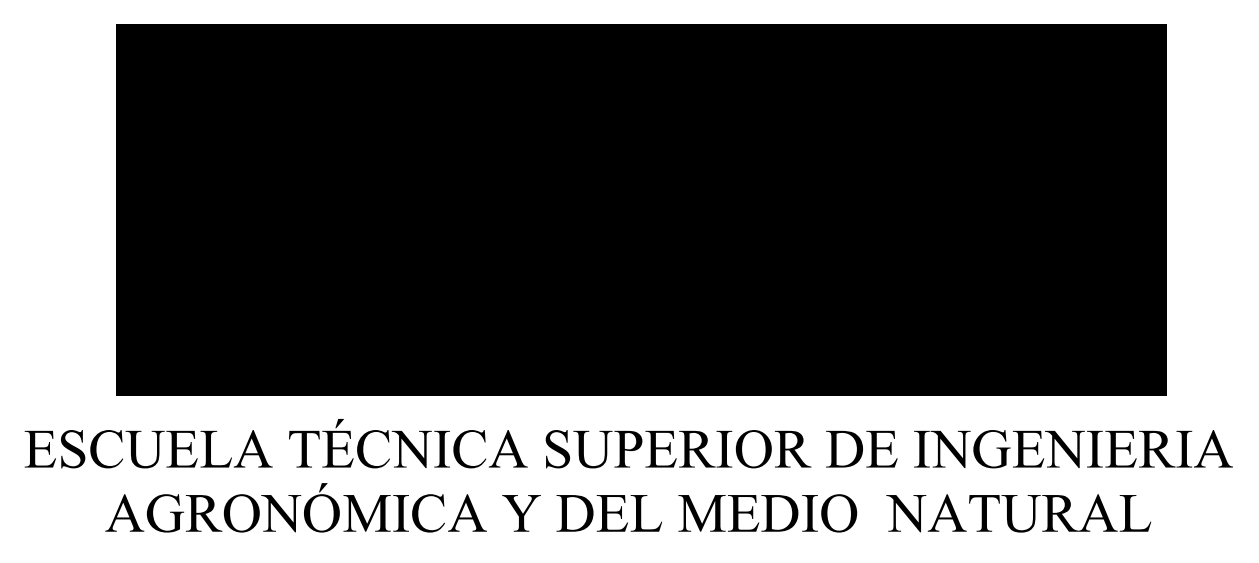

Tesis con el titulo "Efecto de la adición de copigmentos sobre la composición fenólica de los vinos tintos de Tempranillo elaborados con diferentes técnicas de vinificación" realizada bajo la dirección de las profesoras Inaculada Álvarez Cano y Victoria Lizama Abad, presentada por Jose Luis Aleixandre Tudo para optar al título de Doctor.

Valencia, Marzo de 2012

Fdo. José Luis Aleixandre Tudo

$\mathrm{V}^{\circ} \mathrm{B}^{\mathrm{o}}$ de las Directoras de la Tesis

Fdo. Inmaculada Álvarez Cano

Fdo.Victoria Lizama Abad 

La realización de este trabajo tuvo luga en el marco del proyecto AGL 2006-10723-C02-02 financiado por el Ministerio de Ciencia y Tecnología del Gobierno de España, y gracias a la financiación de la beca de Formacion de Personal Investigador (FPI), de la Universitat Politècnica de València(UPV) 



\section{AGRADECIMIENTOS}

En primer lugar agradecer a Inmaculada Álvarez y Victoria Lizama, directoras del trabajo, toda su ayuda, atención y asesoramiento que desde un principio me han brindado y por su amistosa paciencia durante todo el tiempo que he convivido con ellas para la realización de esta Tesis Doctoral.

A los compañeros que he conocido durante mis experiencias laborales y que me han ofrecido su ayuda en todo momento, en especial a $\mathrm{M}^{\mathrm{a}}$ José García, Fernando Franqueza y Juan Alberto Anaya.

A mis seres más queridos por todo su apoyo y por haberme soportado durante este tiempo, en especial a Vanesa, por estar siempre a mi lado, y a mi hermano Carlos.

A mis padres por ofrecerme la posibilidad de completar mi formación y por todo el amor y apoyo recibido. 



\section{RESUMEN}

El mercado actual del vino tinto de calidad demanda vinos de gran potencial visual, y elevada concentración tánica, pero que no resulten excesivamente astringentes ni amargos. Para conseguir una buena concentración polifenólica, limitando la extracción de estos compuestos astringentes, puede resultar interesante realizar una maceración prefermentativa previa, para acortar el tiempo de contacto entre hollejos y mostos durante la fermentación.

El color de los vinos tintos depende de la concentración de antocianos, y de su estado en el vino, el cual depende de varios factores, siendo uno de ellos el fenómeno de la copigmentación, el cual, se define como la asociación entre antocianos y otros compuestos fenólicos menos coloreados, dando lugar a moléculas de estructura compleja que aumentan la intensidad colorante de los vinos.

Por otra parte, el oxígeno juega un papel crucial en la evolución del color del vino, así como en la oxidación de los polifenoles y en la formación de complejos estables. Una técnica para estabilizar la estructura polifenólica del vino es el uso de la microoxigenación, con la finalidad de formar pequeñas cantidades de acetaldehído, que actúan como puente de unión entre los compuestos polifenólicos.

El objetivo de este trabajo es estudiar el posible incremento del color de los vinos tintos de Tempranillo y establecer una metodología de elaboración que permita incrementar la extracción fenólica y los niveles de copigmentación. Para ello se va a determinar el efecto de la adición de copigmentos, de distintas técnicas de maceración prefermantativa, y de la microoxigención sobre la composición antociánica, tánica de los vinos, así como también sobre los complejos que aparecen de las reacciones entre antocianos y taninos y que pueden influir decisivamente en la estabilidad del color de los vinos.

Los resultados obtenidos ponen de manifiesto que las técnicas enológicas aplicadas en la elaboración de los vinos de Tempranillo presentan un efecto significativo en los parámetros fenólicos analizados, relacionados con el color, los antocianos y los taninos. La adición de copigmentos contribuye de una manera positiva al incremento de algunos de los parámetros fenólicos calculados, permitiendo prolongar el tiempo de estabilidad de los vinos. 



\section{RESUM}

El mercat actual del vi negre de qualitat demanda vins de gran potencial visual i elevada concentració tànnica, però que no siguin excessivament astringents ni amargs. Per aconseguir una bona concentració fenòlica, limitant l'extracció d'aquests compostos astringents, pot resultar interessant la realització d'una maceració prefermentativa prèvia, per reduir el temps de contacte entre les pells y el most durant la fermentació.

El color dels vins negres depèn de la concentració de antocians i del seu estat en el vi, estat que depèn de diferents factors, sent un d'ells el fenomen de la copigmentació. La copigmentació es defineix com l'associació entre antocians y altres compostos fenòlics menys colorejats, donant lloc a una estructura complexa que augmenta la intensitat del color del vi.

D'altra banda l'oxigen juga un important paper en l'evolució del color del vi, així com a l'oxidació del polifenols i a la formació de compostos estables. Una tècnica per estabilitzar l'estructura polifenòlica del vi es l'ús de la microoxigenació, amb la finalitat de formar xicotetes quantitats d'acetaldehid, que actua com a pont d'unió entre els compostos fenòlics.

L'objectiu d'aquest treball es estudiar el possible increment del color en els vins negres de la varietat Tempranillo, establint una metodologia d'elaboració que incremente l'extracció fenòlica i els nivells de copigmentació. Per tant es determinarà l'efecte de l'adició de copigments, de l'aplicació de tècniques de maceració prefermentativa, amb l'aplicació de fred o mitjançant l'adició de neu carbònica, i de l'aplicació de la microoxigenació en la composició antociànica y tànnica del vins i en els compostos que influeixen decisivament a l'estabilitat del color.

Els resultats posen de manifest que les tècniques enològiques aplicades a l'elaboració del vins de Tempranillo presenta un efecte significatiu als paràmetres fenòlics analitzats, relacionats amb el color, el antocians y el tanins. L'adició de copigments contribueix a l'augment d'alguns del paràmetres fenòlics determinats, permetent prolongar l'estabilitat dels vins. 



\begin{abstract}
The current high quality red wines market demands wine with good chromatic characteristics and high tannin concentrations, but not overly astringent or bitter. In order to get a good phenolic concentration, limiting the extraction of these astringent compounds, a prefermentative cold maceration it could be interesting, decreasing the contact time between skins and must during the fermentation.

The red wines colour depends to the anthocyanin concentration and its state in the wine, which depend to several factors, being one of them the copigmentation phenomenon. Copigmentation is the association between anthocyanins and other less coloured phenolics compounds, giving place a complex structure which increases the wine colour.

Moreover the oxygen plays an important key role in the evolution of wine colour and the formation of stable compounds. A technique to stabilize the wine phenolic structure is the use of the micro-oxygenation in order to form small amounts of acetaldehyde, which acts as a bridge between the phenolic compounds.

The aim of this work is to study the colour increase and stability in red wines made from Tempranillo, establishing a winemaking methodology that allows increasing phenolic extraction and copigmentation levels. To get this purpose we are going to establish the copigment addition, the prefermentative cold maceration, with cold application or by addition of dry ice, and the micro-oxygenation effect on the anthocyanins and tannins composition and in the reactions, between anthocyanins and tannins, which decisively influence the wine colour stability.

The results obtained show that the oenological techniques applied to the Tempranillo wines have a significant effect on the analyzed phenolic parameters related with colour, anthocyanins and tannins. The addition of copigments also contributes to increase the phenolic parameters, increasing the wine stability.
\end{abstract}





\section{ÍNDICE}

\section{INTRODUCCIÓN}

1.1. LA D.O. UTIEL-REQUENA 3

1.2. LA VARIEDAD TEMPRANILLO 4

1.3. SITUACIÓN ACTUAL DEL MERCADO VITIVINÍCOLA 6

1.4. JUSTIFICACIÓN DEL TRABAJO 7

2. OBJETIVOS 13

3. ANTECEDENTES BIBLIOGRÁFICOS 17

3.1. LOS COMPUESTOS FENÓLICOS 17

3.2. POTENCIAL FENÓLICO DE LA UVA 17

3.3. CLASIFICACIÓN DE LOS COMPUESTOS FENÓLICOS SEGÚN

SU ESTRUCTURA QUÍMICA. 19

3.3.1. COMPUESTOS FLAVONOIDES 20

3.3.1.1. LOS ANTOCIANOS 20

3.3.1.2. LOS FLAVANOLES 21

3.3.1.3. FLAVONOLES, FLAVONAS Y FLAVANONOLES 24

3.3.2. COMPUESTOS NO FLAVONOIDES 25

3.3.2.1. LOS ÁCIDOS FENÓLICOS 25

3.3.2.2. LOS ESTILBENOS 26

3.4. REACTIVIDAD QUÍMICA Y EVOLUCIÓN DE LOS

COMPUESTOS FENOLICOS. 27

3.4.1. EFECTO DEL PH EN EL COLOR DE LOS ANTOCIANOS 27

3.4.2. EFECTO DE LA CONCENTRACIÓN DE SULFUROSO SOBRE LOS ANTOCIANOS. 28

3.5. REACCIONES ENTRE COMPUESTOS FENÓLICOS 29

3.5.1. REACCIONES ENZIMÁTICAS DE LOS COMPUESTOS FENÓLICOS. 29 
3.5.2. REACCIONES QUÍMICAS DE LOS COMPUESTOS

FENÓLICOS. 30

3.5.2.1. CONDENSACIÓN DE ANTOCIANOS Y TANINOS 31

3.5.2.1.1. CONDENSACIÓN TANINO-ANTOCIANO (T-A) _ 31

3.5.2.1.2. CONDENSACIÓN ANTOCIANO-TANINO (A-T) _ 32

3.5.2.1.3. POLIMERIZACIÓN POR MEDIACIÓN DEL

ACETALDEHÍDO 33

3.5.2.2. FORMACIÓN DE NUEVOS PIGMENTOS DERIVADOS DE LOS ANTOCIANOS. 33

3.5.2.3. POLIMERIZACIÓN DE TANINOS 34

3.5.2.3.1. POLIMERIZACIÓN LINEAL 35

3.5.2.3.2. POLIMERIZACIÓN CRUZADA 35

3.5.2.3.3. REACCIONES DE COMPLEJACIÓN DE LAS PROCIANIDINAS 36

3.6. ESTABILIDAD DEL COLOR MEDIANTE REACCIONES DE COPIGMENTACIÓN.

3.7. INFLUENCIA DE LA VINIFICACIÓN EN LA COMPOSICIÓN DE LOS VINOS 46

3.8. LA MACERACIÓN PREFERMENTATIVA EN FRÍO 47

3.9. PAPEL DEL OXÍGENO EN LA CALIDAD DE LOS VINOS _ 53

3.10. LA TÉCNICA DE LA MICROOXIGENACIÓN ___ 54

3.10.1. OBJETIVOS DE LA MICROOXIGENACIÓN 55

3.10.2. MOMENTOS DE APLICACIÓN DE LA MICROOXIGENACIÓN 55

3.10.3. APLICACIÓN DURANTE LA FERMENTACIÓN

ALCOHÓLICA 56

3.10.4. APLICACIÓN DESPUÉS DE LA FERMENTACIÓN ALCOHÓLICA Y ANTES DE LA FERMENTACIÓN MALOLÁCTICA. 56

3.10.5. APLICACIÓN DURANTE LA MADURACIÓN O EL ALMACENAMIENTO 57 
3.10.6. OPTIMIZACIÓN DEL PROCESO. FACTORES QUE INFLUYEN SOBRE LA DISOLUCIÓN DEL OXIGENO.

3.10.7. OTRAS APLICACIONES DE INTERÉS DE LA

MICROOXIGENACIÓN 58

3.10.8. ESTUDIOS RECIENTES SOBRE LA APLICACIÓN DE LA MICROOXIGENACIÓN 59

4. PLAN DE TRABAJO 65

5. MATERIALES Y MÉTODOS 75

5.1. MATERIALES 75

5.2. MÉTODOS ANALÍTICOS. 75

5.2.1. PARAMETROS CARACTERÍSTICOS. 76

5.2.2. PARAMETROS POLIFENÓLICOS 76

5.2.2.1. DETERMINACIONES ESPECTOFOTOMÉTRICAS 76

5.2.2.2. ANTOCIANOS COPIGMENTADOS, POLIMERIZADOS Y LIBRES 76

5.2.2.3. ANTOCIANOS TOTALES 76

5.2.2.4. DETRMINACION DE CATEQUINAS 77

5.2.2.5. ÍNDICE DE ETANOL 77

5.2.2.6. ÍNDICE DE GELATINA 77

5.2.2.7. ÍNDICE DE PVPP. 77

5.2.2.8. ÍNDICE DMACH 78

5.2.2.9. INTENSIDAD COLORANTE Y TONO O MATIZ 78

5.2.2.10. TANINOS CONDENSADOS TOTALES 78

5.2.2.11. DETERMINACIONES MEDIANTE CROMATROGRAFÍA EN FASE LÍQUIDA (HPLC) 78

5.2.2.11.1. ANÁLISIS DE LA COMPOSICIÓN FENÓLICA 78

5.3. TÉCNICA DE MICROOXIGENACIÓN 79

5.4. TRATAMIENTO ESTADÍSTICO 79

5.4.1. ANÁLSIS DE LA VARIANZA 80

5.4.2. ANÁLISIS DE COMPONENTES PRINCIPALES 80 


\section{RESULTADOS Y DISCUSIÓN}

6.1. EFECTO DE LAS PRÁCTICAS ENOLÓGICAS ENSAYADAS SOBRE LA COMPOSICIÓN POLIFENÓLICA DE LOS VINOS ELABORADOS EN 2006 83

6.1.1. ANALISIS DE LOS VINOS POSTERIORMENTE A LA FERMENTACIÓN MALOLÁCTICA 84

6.1.1.1. ANÁLISIS MULTIFACTORIAL DE LA VARIANZA DE LOS FACTORES CONSIDERADOS 84

6.1.1.2. EFECTO DE LA ADICIÓN DE COPIGMENTOS 86

6.1.1.3. EFECTO DE LAS TÉCNICAS DE VINIFICACIÓN 89 6.1.1.4. CORRELACIÓN ENTRE LOS PARÁMETROS POLIFENÓLICOS DE LOS VINOS, LA ADICIÓN DE COPIGMENTOS Y LAS TÉCNICAS DE VINIFICACIÓN 90

6.1.2. ANÁLISIS DE LOS VINOS A LOS 6 MESES DE CONSERVACIÓN 97

6.1.2.1. ANALSIS MULTIFACTORIAL DE LA VARIANZA DE LOS FACTORES CONSIDERADOS 97

6.1.2.2. EFECTO DE LA ADICIÓN DE COPIGMENTOS 101

6.1.2.3. EFECTO DE LAS TÉCNICAS DE VINIFICACIÓN 103

6.1.2.4. EFECTO DE LA MICROOXIGENACIÓN 105

6.1.2.5. EFECTO DEL MOMENTO DE ADICIÓN DE LOS COPIGMENTOS 107

6.1.2.6. CORRELACIÓN ENTRE LOS PARÁMETROS POLIFENÓLICOS DE LOS VINOS Y LOS FACTORES CONSIDERADOS 108

6.1.3. ANÁLISIS DE LOS VINOS A LOS 12 MESES DE CONSERVACIÓN 115

6.1.3.1. ANÁLSIS MULTIFACTORIAL DE LA VARIANZA DE LOS FACTORES CONSIDERADOS 115

6.1.3.2. EFECTO DE LA ADICIÓN DE COPIGMENTOS 119

6.1.3.3. EFECTO DE LAS TÉCNICAS DE VINIFICACIÓN 121 6.1.3.4. EFECTO DE LA MICROOXIGENACIÓN 122 
6.1.3.5. EFECTO DEL MOMENTO DE ADICIÓN DE LOS COPIGMENTOS 124

6.1.3.6. CORRELACIÓN ENTRE LOS PARÁMETROS POLIFENÓLICOS DE LOS VINOS Y LOS FACTORES CONSIDERADOS 124

6.1.4. EVOLUCIÓN DE LOS VINOS ELABORADOS DURANTE 12 MESES DE CONSERVACIÓN EN BOTELLA 132

6.1.4.1. EVOLUCIÓN DE LA INTENSIDAD COLORANTE 133

6.1.4.2. EVOLUCIÓN DEL TONO 134

6.1.4.3. EVOLUCIÓN DE LA CONCENTRACIÓN DE ANTOCIANOS TOTALES 136

6.1.4.4. EVOLUCIÓN DE LA PROPORCIÓN DE ANTOCIANOS COPIGMENTADOS 138

6.1.4.5. EVOLUCIÓN DE LA PROPORCIÓN DE ANTOCIANOS LIBRES 140

6.1.4.6. EVOLUCIÓN DE LA PROPORCIÓN DE ANTOCIANOS POLIMERIZADOS 140

6.1.4.7. EVOLUCIÓN DEL ÍNDICE DE PVPP 142

6.1.4.8. EVOLUCIÓN DEL ÍNDICE DE FOLIN 143

6.1.4.9. EVOLUCIÓN DE LA CONCENTRACIÓN DE CATEQUINAS 145

6.1.4.10. EVOLUCIÓN DE LA CONCENTRACIÓN DE TANINOS 146 6.1.4.11. EVOLUCIÓN DEL ÍNDICE DE DMACH 147

6.1.4.12. EVOLUCIÓN DEL ÍNDICE DE ETANOL 149

6.1.4.13. EVOLUCIÓN DE ÍNDICE DE GELATINA 150

6.2. EFECTO DE LAS PRÁCTICAS ENOLÓGICAS ENSAYADAS SOBRE LA COMPOSICIÓN POLIFENÓLICA DE LOS VINOS ELABORADOS EN 2007 152

6.2.1. ANÁLSIS DE LOS VINOS POSTERIORMENTE A LA FERMENTACIÓN MALOLÁCTICA. 152

6.2.1.1. ANALISIS MULTIFACTORIAL DE LA VARIANZA DE LOS FACTORES CONSIDERADOS 152 
6.2.1.2. EFECTO DE LA ADICIÓN DE COPIGMENTOS 154

6.2.1.3. EFECTO DE LAS TÉCNICAS DE VINIFICACIÓN 158

6.2.1.4. CORRELACIÓN ENTRE LOS PARÁMETROS POLIFENÓLICOS DE LOS VINOS, LA ADICIÓN DE COPIGMENTOS Y LAS TÉCNICAS DE VINIFICACIÓN 160 6.2.2. ANÁLISIS DE LOS VINOS A LOS 6 MESES DE CONSERVACIÓN 166

6.2.2.1. ANÁLSIS MULTIFACTORIAL DE LA VARIANZA (ANOVA) DE LOS FACTORES CONSIDERADOS 166

6.2.2.2. EFECTO DE LA ADICIÓN DE COPIGMENTOS 169

6.2.2.3. EFECTO DE LAS TÉCNICAS DE VINIFICACIÓN 172

6.2.2.4. EFECTO DE LA MICROOXIGENACIÓN 173

6.2.2.5. EFECTO DEL MOMENTO DE ADICIÓN DE LOS COPIGMENTOS 175

6.2.2.6. CORRELACIÓN ENTRE LOS PARÁMETROS POLIFENÓLICOS DE LOS VINOS, LA ADICIÓN DE COPIGMENTOS Y LAS TÉCNICAS DE VINIFICACIÓN 176

6.2.3. ANÁLISIS DE LOS VINOS A LOS 12 MESES DE CONSERVACIÓN 184

6.2.3.1. ANÁLSIS MULTIFACTORIAL DE LA VARIANZA (ANOVA) DE LOS FACTORES CONSIDERADOS 185

6.2.3.2. EFECTO DE LA ADICIÓN DE COPIGMENTOS 188

6.2.3.3. EFECTO DE LAS TÉCNICAS DE VINIFICACIÓN 190

6.2.3.4. EFECTO DE LA MICROOXIGENACIÓN 192

6.2.3.5. EFECTO DEL MOMENTO DE ADICIÓN DE LOS COPIGMENTOS 194

6.2.3.6. CORRELACIÓN ENTRE LOS PARÁMETROS POLIFENÓLICOS DE LOS VINOS, LA ADICIÓN DE COPIGMENTOS Y LAS TÉCNICAS DE VINIFICACIÓN 195

6.2.4. EVOLUCIÓN DE LOS VINOS ELABORADOS DURANTE 12 MESES DE CONSERVACIÓN EN BOTELLA 202

6.2.4.1. EVOLUCIÓN DE LA INTENSIDAD COLORANTE 204

6.2.4.2. EVOLUCIÓN DEL TONO 206 
6.2.4.3. EVOLUCIÓN DE LA CONCENTRACIÓN DE ANTOCIANOS TOTALES 207

6.2.4.4. EVOLUCIÓN DE LA CONCENTRACIÓN TOTAL DE MALVIDINA. 209

6.2.4.5. EVOLUCIÓN DE LA SUMA DE ANTOCIANIDINAS 210

6.2.4.6. EVOLUCIÓN DE LA CONCENTRACIÓN DE LOS DERIVADOS DE ANTOCIANOS 211

6.2.4.7. EVOLUCIÓN DE LA CONCENTRACION TOTAL DE ANTOCIANOS 213

6.2.4.8. EVOLUCIÓN DEL PORCENTAJE DEL COLOR QUE CORRESPONDE A LAS REACCIONES DE COPIGMENTACIÓN 215 6.2.4.9. EVOLUCIÓN DEL PORCENTAJE DEL COLOR QUE CORRESPONDE A LOS ANTOCIANOS LIBRES 216

6.2.4.10. EVOLUCIÓN DEL PORCENTAJE DEL COLOR QUE CORRESPONDE A LOS ANTOCIANOS POLIMERIZADOS 217

6.2.4.11. EVOLUCIÓN DEL ÍNDICE DE PVPP 219

6.2.4.12. EVOLUCIÓN DEL ÍNDICE DE FOLIN 220

6.2.4.13. EVOLUCIÓN DE LA CONCENTRACIÓN DE LOS ÁCIDOS FENÓLICOS 222

6.2.4.14. EVOLUCIÓN DE LA CONCENTRACIÓN DE FLAVONOLES 222

6.2.4.15. EVOLUCIÓN DE LA CONCENTRACION DE 3-FLAVANOLES 223

6.2.4.16. EVOLUCIÓN DE LA CONCENTRACION CATEQUINAS

6.2.4.17. EVOLUCIÓN DEL ÍNDICE DE DMACH 225

6.2.4.18. EVOLUCIÓN DEL ÍNDICE DE ETANOL 226

6.2.4.19. EVOLUCIÓN DE LA CONCENTRACIÓN DE TANINOS TOTALES 228

6.2.4.20. EVOLUCIÓN DEL ÍNDICE DE GELATINA 229 
6.3. EFECTO DE LAS DIFERENTES PRÁCTICAS ENOLÓGICAS ENSAYADAS SOBRE LA COMPOSICIÓN POLIFENÓLICA DE LOS VINOS ELABORADOS EN EL AÑO 2008. 231

6.3.1. ANÁLSIS DE LOS VINOS POSTERIORMENTE A LA FERMENTACIÓN MALOLÁCTICA 231

6.3.1.1. ANÁLISIS MULTIFACTORIAL DE LA VARIANZA DE LOS FACTORES CONSIDERADOS 231

6.3.1.2. EFECTO DE LA ADICIÓN DE COPIGMENTOS 234

6.3.1.3. EFECTO DE LAS TÉCNICAS DE VINIFICACIÓN 237

6.3.1.4. CORRELACIÓN ENTRE LOS PARÁMETROS POLIFENÓLICOS DE LOS VINOS, LA ADICIÓN DE COPIGMENTOS Y LAS TÉCNICAS DE VINIFICACIÓN 239

6.3.2. ANÁLISIS DE LOS VINOS A LOS 6 MESES DE CONSERVACIÓN 245

6.3.2.1. ANÁLSIS MULTIFACTORIAL DE LA VARIANZA

(ANOVA) DE LOS FACTORES CONSIDERADOS 245

6.3.2.2. EFECTO DE LA ADICIÓN DE COPIGMENTOS 248

6.3.2.3. EFECTO DE LAS TÉCNICAS DE VINIFICACIÓN 250

6.3.2.4. EFECTO DE LA MICROOXIGENACIÓN 252

6.3.2.5. EFECTO DEL MOMENTO DE ADICIÓN DE LOS COPIGMENTOS 253

6.3.2.6. CORRELACIÓN ENTRE LOS PARÁMETROS

POLIFENÓLICOS DE LOS VINOS, LA ADICIÓN DE COPIGMENTOS, LAS TÉCNICAS DE VINIFICACIÓN Y EL MOMENTO DE ADICIÓN DE LOS COPIGMENTOS 255

6.3.3. ANÁLISIS DE LOS VINOS A LOS 12 MESES DE CONSERVACIÓN 261

6.3.3.1. ANÁLSIS MULTIFACTORIAL DE LA VARIANZA (ANOVA) DE LOS FACTORES CONSIDERADOS 262

6.3.3.2. EFECTO DE LA ADICIÓN DE COPIGMENTOS 264

6.3.3.3. EFECTO DE LAS TÉCNICAS DE VINIFICACIÓN 266 6.3.3.4. EFECTO DE LA MICROOXIGENACIÓN 268 
6.3.3.5. EFECTO DEL MOMENTO DE ADICIÓN DE LOS COPIGMENTOS 269

6.3.3.6. CORRELACIÓN ENTRE LOS PARÁMETROS POLIFENÓLICOS DE LOS VINOS, LA ADICIÓN DE COPIGMENTOS, LAS TÉCNICAS DE VINIFICACIÓN Y EL MOMENTO DE ADICIÓN DE COPIGMENTOS 270

6.3.4. EVOLUCIÓN DE LOS VINOS ELABORADOS DURANTE 12 MESES DE CONSERVACIÓN EN BOTELLA 277

6.3.4.1. EVOLUCIÓN DE LA INTENSIDAD COLORANTE 279

6.3.4.2. EVOLUCIÓN DEL TONO 280

6.3.4.3. EVOLUCIÓN DE LA CONCENTRACIÓN DE ANTOCIANOS TOTALES 282

6.3.4.4. EVOLUCIÓN DE LA CONCENTRACIÓN TOTAL DE MALVIDINA 284

6.3.4.5. EVOLUCIÓN DE LA CONCENTRACIÓN DE LAS SUMA DE LAS ANTOCIANIDINAS 286

6.3.4.6. EVOLUCIÓN DE LA CONCENTRACIÓN DE LOS DERIVADOS DE ANTOCIANOS 287

6.3.4.7. EVOLUCIÓN DE LA CONCENTRACIÓN TOTAL DE ANTOCIANOS 289

6.3.4.8. EVOLUCIÓN DEL PORCENTAJE DEL COLOR QUE CORRESPONDE A LAS REACCIONES DE COPIGMENTACIÓN. 290 6.3.4.9. EVOLUCIÓN DEL PORCENTAJE DEL COLOR QUE CORRESPONDE A LOS ANTOCIANOS LIBRES 292 6.3.4.10. EVOLUCIÓN DEL PORCENTAJE DEL COLOR QUE CORRESPONDE A LOS ANTOCIANOS POLIMERIZADOS 292

6.3.4.11. EVOLUCIÓN DEL ÍNDICE DE PVPP 293

6.3.4.12. EVOLUCIÓN DEL ÍNDICE DE FOLIN 294

6.3.4.13. EVOLUCIÓN DE LA CONCENTRACIÓN DE LOS ÁCIDOS FENÓLICOS 296

6.3.4.14. EVOLUCIÓN DE LA CONCENTRACIÓN DE FLAVONOLES 297 
6.3.4.15. EVOLUCIÓN DE LA CONCENTRACION DE

3-FLAVANOLES

6.3.4.16. EVOLUCIÓN DE LA CONCENTRACIÓN DE

CATEQUINAS 299

6.3.4.17. EVOLUCIÓN DEL ÍNDICE DE DMACH 301

6.3.4.18. EVOLUCIÓN DEL ÍNDICE DE ETANOL 302

6.3.4.19. EVOLUCIÓN DE LA CONCENTRACIÓN DE TANINOS TOTALES

6.3.4.20. EVOLUCIÓN DEL ÍNDICE DE GELATINA 305

7. CONCULSIONES 295

8. BIBLIOGRAFÍA 299 ANEXOS 327 


\section{ÍNDICE DE TABLAS}

Tabla 1.1. Características de la variedad Tempranillo

Tabla 3.1. Ácidos fenólicos de la uva y el vino.

Tabla 6.1. Valores del análisis multifactorial de la varianza (ANOVA) de los factores considerados, así como de la interacción entre ambos (F-ratio y nivel de significancia estadística).

Tabla 6.2. Efecto de la adición de copigmentos sobre los valores medios de los parámetros determinados.

Tabla 6.3. Efecto de las técnicas de vinificación sobre los valores medios de los parámetros determinados.

Tabla 6.4. Matriz de correlaciones de las variables consideradas

Tabla 6.5. Autovalor, varianza explicada y acumulada para las componentes consideradas en el análisis

Tabla 6.6. Tabla de pesos de los componentes

Tabla 6.7. Valores del análisis multifactorial de la varianza (ANOVA) de los factores considerados, así como de la interacción entre ambos (F-ratio y nivel de significancia estadística).

Tabla 6.8. Efecto de la adición de copigmentos sobre los valores medios de los parámetros determinados.

Tabla 6.9. Efecto de las técnicas de vinificación sobre los valores medios de los parámetros determinados.

Tabla 6.10. Efecto de la microoxigenación sobre los valores medios de los parámetros determinados.

Tabla 6.11. Efecto del momento de adición de copigmentos sobre los valores medios de los parámetros determinados.

Tabla 6.12. Matriz de correlaciones de las variables consideradas

Tabla 6.13. Autovalor, varianza explicada y acumulada para las componentes consideradas en el análisis

Tabla 6.14. Tabla de pesos de los componentes 
Tabla 6.15. Valores del análisis multifactorial de la varianza (ANOVA) de los factores considerados, así como de la interacción entre ambos (F-ratio y nivel de significancia estadística).

Tabla 6.16. Efecto de la adición de copigmentos sobre los valores medios de los parámetros determinados.

Tabla 6.17. Efecto de las técnicas de vinificación sobre los valores medios de los parámetros determinados.

Tabla 6.18. Efecto de la microoxigenación sobre los valores medios de los parámetros determinados.

Tabla 6.19. Efecto del momento de adición de copigmentos sobre los valores medios de los parámetros determinados.

Tabla 6.20. Matriz de correlaciones de las variables consideradas

Tabla 6.21. Autovalor, varianza explicada y acumulada para las 14 componentes consideradas en el análisis

Tabla 6.22. Tabla de pesos de los componentes

Tabla 6.23. Análisis multifactorial de la varianza (F-ratio) de los factores adición de copigmentos y técnica de maceración, así como de la interacción entre ambos

Tabla 6.24. Efecto de la adición de copigmentos sobre los valores medios de los parámetros determinados.

Tabla 6.25. Efecto de las técnicas de vinificación sobre los valores medios de los parámetros determinados.

Tabla 6.26. Matriz de correlaciones de las variables consideradas

Tabla 6.27. Autovalor, varianza explicada y acumulada para las componentes consideradas en el análisis.

Tabla 6.28. Tabla de pesos de los componentes

Tabla 6.29. Valores del análisis multifactorial de la varianza (ANOVA) de los factores considerados, así como de la interacción entre ambos (F-ratios y nivel de significancia estadística).

Tabla 6.30. Efecto de la adición de copigmentos sobre los valores medios de los parámetros determinados.

Tabla 6.31. Efecto de las técnicas de vinificación sobre los valores medios de los parámetros determinados. 
Tabla 6.32. Efecto de la microoxigenación sobre los valores medios de los parámetros determinados.

Tabla 6.33. Efecto del momento de adición de copigmentos sobre los valores medios de los parámetros determinados.

Tabla 6.34. Matriz de correlaciones de las variables consideradas

Tabla 6.35. Autovalor, varianza explicada y acumulada para las componentes consideradas en el análisis

Tabla 6.36. Tabla de pesos de los componentes

Tabla 6.37. Valores del análisis multifactorial de la varianza (ANOVA) de los factores considerados, así como de la interacción entre ambos (F-ratios y nivel de significancia estadística).

Tabla 6.38. Efecto de la adición de copigmentos sobre los valores medios de los parámetros determinados.

Tabla 6.39. Efecto de las técnicas de vinificación sobre los valores medios de los parámetros determinados.

Tabla 6.40. Efecto de la microoxigenación sobre los valores medios de los parámetros determinados.

Tabla 6.41. Efecto del momento de adición de copigmentos sobre los valores medios de los parámetros determinados.

Tabla 6.42. Matriz de correlaciones de las variables consideradas

Tabla 6.43. Autovalor, varianza explicada y acumulada para las componentes consideradas en el análisis.

Tabla 6.44. Tabla de pesos de los componentes

Tabla 6.45. Análisis multifactorial de la varianza (F-ratio) de los factores adición de copigmentos y técnicas de maceración, así como de la interacción entre ambos.

Tabla 6.46. Efecto de la adición de copigmentos sobre los valores medios de los parámetros determinados.

Tabla 6.47. Efecto de las técnicas de vinificación sobre los valores medios de los parámetros determinados.

Tabla 6.48. Matriz de correlaciones de las variables consideradas

Tabla 6.49. Autovalor, varianza explicada y acumulada para las componentes consideradas en el análisis 
Tabla 6.50. Tabla de pesos de los componentes

Tabla 6.51. Valores del análisis multifactorial de la varianza (ANOVA) de los factores considerados, así como de la interacción entre ambos (F-ratios y nivel de significancia estadística).

Tabla 6.52. Efecto de la adición de copigmentos sobre los valores medios de los parámetros determinados.

Tabla 6.53. Efecto de las técnicas de vinificación sobre los valores medios de los parámetros determinados.

Tabla 6.54. Efecto de la microoxigenación sobre los valores medios de los parámetros determinados.

Tabla 6.55. Efecto del momento de adición de copigmentos sobre los valores medios de los parámetros determinados.

Tabla 6.56. Matriz de correlaciones de las variables consideradas

Tabla 6.57. Autovalor, varianza explicada y acumulada para las componentes consideradas en el análisis

Tabla 6.58. Tabla de pesos de los componentes

Tabla 6.59. Valores del análisis multifactorial de la varianza (ANOVA) de los factores considerados, así como de la interacción entre ambos (F-ratios y nivel de significancia estadística).

Tabla 6.60. Efecto de la adición de copigmentos sobre los valores medios de los parámetros determinados.

Tabla 6.61. Efecto de las técnicas de vinificación sobre los valores medios de los parámetros determinados.

Tabla 6.62. Efecto de la microoxigenación sobre los valores medios de los parámetros determinados.

Tabla 6.63. Efecto del momento de adición de copigmentos sobre los valores medios de los parámetros determinados.

Tabla 6.64. Matriz de correlaciones de las variables consideradas.

Tabla 6.65. Autovalor, varianza explicada y acumulada para las componentes consideradas en el análisis

Tabla 6.66. Tabla de pesos de los componentes 


\section{ÍNDICE DE FIGURAS}

Figura 1.1. Racimos de la variedad Tempranillo

Figura 3.1. Evolución de la concentración de antocianos y taninos durante la maduración de la uva.

Figura 3.2. Clasificación de los compuestos fenólicos

Figura 3.3. Estructura básica de los compuestos fenólicos

Figura 3.4. Estructura química de las diferentes antocianidinas

Figura 3.5. Estructura química de los flavanoles monómeros de la uva

Figura 3.6. Estructuras químicas de las proantocianidinas de tipo B

Figura 3.7. Estructura química de los flavonoles

Figura 3.8. Equilibrio de los antocianos en función del pH 28

Figura 3.9. Compuesto de adición bisulfito-antociano incoloro 29

Figura 3.10. Esquema de la oxidación de proantocianidinas 30

Figura 3.11. Condensación directa de taninos y antocianos de tipo T-A 32

Figura 3.12. Estructura de los piranoantocianos. 34

Figura 3.13. Modelo del comportamiento coloidal de los taninos. 36

Figura 3.14. Representación grafica del fenómeno de copigmentación. 37

Figura 3.15. Autoasociación de la malvidina-3-glucósido cumarato. 39

Figura 3.16. Cinética de extracción de los compuestos fenólicos durante la fermentación-maceración.

Figura 4.1. Diagrama de flujo del proceso de elaboración de los vinos. $\quad 66$

$\begin{array}{ll}\text { Figura 4.2. Esquema del diseño experimental del trabajo. } & 67\end{array}$

Figura 4.2. (Continuación) Esquema del diseño experimental del trabajo. $\quad 68$

Figura 4.2. (Continuación) Esquema del diseño experimental del trabajo. $\quad 69$

Figura 4.2. (Continuación) Esquema del diseño experimental del trabajo. $\quad 70$ 


\section{ÍNDICE DE GRÁFICOS}

Gráfico 6.1. Primera componente frente a la segunda, en función de los copigmentos ensayados.

Gráfico 6.2. Primera componente frente a la segunda componente en función de las técnicas de vinificación ensayadas.

Gráfico 6.3. Primera componente frente a la segunda, en función de los copigmentos ensayados

Gráfico 6.4. Primera componente frente a la segunda, en función de las técnicas de vinificación ensayadas.

Gráfico 6.5. Primera componente frente a la segunda, en función de la aplicación de la microoxigenación.

Gráfico 6.6. Primera componente frente a la segunda, en función del momento de adición de los copigmentos.

Gráfico 6.7. Primera componente frente a la segunda, en función de los copigmentos ensayados

Gráfico 6.8. Segunda componente frente a la tercera, en función de los copigmentos ensayados

Gráfico 6.9. Primera componente frente a la segunda, en función de las técnicas de vinificación ensayadas.

Gráfico 6.10. Segunda componente frente a la tercera, en función de las técnicas de vinificación ensayadas.

Gráfico 6.11. Primera componente frente a la segunda, en función de la aplicación de la microoxigenación.

Gráfico 6.12. Evolución de la intensidad colorante durante el periodo de conservación de los vinos en función de la aplicación de copigmentos.

Gráfico 6.13. Evolución de la intensidad colorante durante el periodo de conservación de los vinos en función de la aplicación de la microoxigenación.

Gráfico 6.14. Evolución del tono durante el periodo de conservación de los vinos en función de la técnica de vinificación aplicada.

Gráfico 6.15. Evolución del tono durante el periodo de conservación de los vinos en función de la aplicación de la microoxigenación. 
Gráfico 6.16. Evolución de los antocianos totales $(\mathrm{mg} / \mathrm{L})$ durante el periodo de conservacion de los vinos en función de los distintos copigmentos adicionados.

Gráfico 6.17. Evolución de los antocianos totales $(\mathrm{mg} / \mathrm{L})$ durante el periodo de conservación de los vinos en función de las técnicas de vinificación ensayadas.

Gráfico 6.18. Evolución de los antocianos totales $(\mathrm{mg} / \mathrm{L})$ durante el periodo de conservación de los vinos en función de la aplicación de la microoxigenación.

Gráfico 6.19. Evolución del porcentaje de antocianos copigmentados durante el periodo de conservación de los vinos en función de los distintos copigmentos adicionados

Gráfico 6.20. Evolución del porcentaje del color que corresponde a la copigmentación durante el periodo de conservación de los vinos en función de las técnicas de vinificación ensayadas.

Gráfico 6.21. Evolución de la intensidad colorante durante el periodo de conservación de los vinos en función de la aplicación de la microoxigenación.

Gráfico 6.22. Evolución del color debido a la fracción de los antocianos libres durante el periodo de conservación de los vinos en función de la técnica de vinificación aplicada.

Gráfico 6.23. Evolución del color debido a la fracción de los antocianos polimerizados durante el periodo de conservación de los vinos en función de la adicion de copigmentos.

Gráfico 6.24. Evolución del color debido a la fracción de los antocianos polimerizados durante el periodo de conservación de los vinos en función de las técnicas de vinificación ensayadas.

Gráfico 6.25. Evolución del $\%$ de antocianos polimerizados durante el periodo de conservación de los vinos en función de la aplicación de la microoxigenación.

Gráfico 6.26. Evolución del índice de PVPP durante el periodo de conservación de los vinos en función de la adicion de copigmentos.

Gráfico 6.27. Evolución del índice de PVPP durante el periodo de conservación de los vinos en función de la aplicación de la microoxigenación.

Gráfico 6.28. Evolución del índice de folin durante el periodo de conservación de los vinos en función de los distintos copigmentos adicionados 
Gráfico 6.29. Evolución del índice de polifenoles totales durante el periodo de conservación de los vinos en función de las técnicas de vinificación ensayadas.

Gráfico 6.30. Evolución del índice de polifenoles totales durante el periodo de conservación de los vinos en función de las técnicas de vinificación ensayadas.

Gráfico 6.31. Evolución de la concentracion de catequinas $(\mathrm{mg} / \mathrm{L})$ durante el periodo de conservación de los vinos en función de las técnicas de vinificación ensayadas.

Gráfico 6.32. Evolución de los taninos $(\mathrm{g} / \mathrm{L})$ durante el periodo de conservación de los vinos en función de las técnicas de vinificación ensayadas.

Gráfico 6.33. Evolución del índice de DMACH durante el periodo de conservación de los vinos en función de los distintos copigmentos adicionados.

Gráfico 6.34. Evolución índice de DMACH durante el periodo de conservación de los vinos en función de las técnicas de vinificación ensayadas.

Gráfico 6.35. Evolución del índice de DMACH durante el periodo de conservación de los vinos en función de la aplicación de la microoxigenación.

Gráfico 6.36. Evolución del índice de DMACH durante el periodo de conservación de los vinos en función de la aplicación de la microoxigenación.

Gráfico 6.37. Evolución del índice de gelatina durante el periodo de conservación de los vinos en función de los distintos copigmentos adicionados.

Gráfico 6.38. Evolución del índice de gelatina durante el periodo de conservación de los vinos en función de las diferentes técnicas de vinificación ensayadas.

Gráfico 6.39. Evolución del índice de gelatina durante el periodo de conservación de los vinos en función de la aplicación de la microoxigenación.

Gráfico 6.40. Primera componente frente a la segunda, en función de los copigmentos ensayados

Gráfico 6.41. Primera componente frente a la segunda, en función de las técnicas de vinificación ensayadas

Gráfico 6.42. Primera componente frente a la segunda, en función de los copigmentos ensayados 
Gráfico 6.43. Segunda componente frente a la tercera, en función de los copigmentos ensayados

Gráfico 6.44. Primera componente frente a la segunda, en función de las técnicas de vinificación ensayadas.

Gráfico 6.45. Primera componente frente a la segunda, en función de la aplicación de la microoxigenación

Gráfico 6.46 Primera componente frente a la segunda, en función del momento de adición de los copigmentos.

Gráfico 6.47. Primera componente frente a la segunda, en función de los copigmentos ensayados

Gráfico 6.48. Primera componente frente a la segunda, en función de las técnicas de vinificación ensayadas.

Gráfico 6.49. Primera componente frente a la segunda, en función de la aplicación de la microoxigenación

Gráfico 6.50. Primera componente frente a la segunda, en función del momento de adición de los copigmentos.

Gráfico 6.51. Evolución de la intensidad colorante durante el periodo de conservación de los vinos en función de los distintos copigmentos adicionados

Gráfico 6.52. Evolución de la intensidad colorante durante el periodo de conservación de los vinos en función de las distintas técnicas de vinificación ensayadas.

Gráfico 6.53. Evolución de la intensidad colorante durante el periodo de conservación de los vinos en función de la aplicación de la microoxigenación.

Gráfico 6.54. Evolución del tono durante el periodo de conservación de los vinos en función de los distintos copigmentos adicionados

Gráfico 6.55. Evolución de la intensidad colorante durante el periodo de conservación de los vinos en función de las distintas técnicas de vinificación ensayadas.

Gráfico 6.56. Evolución de los antocianos totales durante el periodo de conservación de los vinos en función de los distintos copigmentos adicionados.

Gráfico 6.57. Evolución de los antocianos totales durante el periodo de conservación de los vinos en función de las técnicas de vinificación ensayadas. 
Gráfico 6.58. Evolución de los antocianos totales durante el periodo de conservación de los vinos en función de la microoxigenación.

Gráfico 6.59. Evolución de los antocianos totales durante el periodo de conservación de los vinos en función de los distintos copigmentos adicionados.

Gráfico 6.60. Evolución de la concentración de malvidina durante el periodo de conservación de los vinos en función de las distintas técnicas de vinificación ensayadas.

Gráfico 6.61. Evolución de la suma de las antocianidinas durante el periodo de conservación de los vinos en función de las distintas técnicas de vinificación ensayadas.

Gráfico 6.62. Evolución de la concentración de la suma de antocianidinas durante el periodo de conservación de los vinos en función de la microoxigenación

Gráfico 6.63. Evolución de los derivados de antocianos durante el periodo de conservación de los vinos en función de los distintos copigmentos adicionados.

Gráfico 6.64. Evolución de la concentración de los derivados de antocianos durante la conservación en función de las diferentes técnicas de vinificación ensayadas.

Gráfico 6.65. Evolución de la concentración de los derivados de antocianos durante la conservación de los vinos en función de la microoxigenación.

Gráfico 6.66. Evolución de la concentración total de antocianos durante la conservación de los vinos en función de los copigmentos adicionados

Gráfico 6.67. Evolución de la concentración total de antocianos durante la conservación en función de las diferentes técnicas de vinificación ensayadas.

Gráfico 6.68. Evolución del color debido a los antocianos copigmentados durante la conservación de los vinos en función de los distintos copigmentos adicionados

Gráfico 6.69. Evolución del color debido a los antocianos libres durante la conservación de los vinos en función de los distintos copigmentos adicionados.

Gráfico 6.70. Evolución del color debido a los antocianos libres durante la conservación de los vinos en función de las técnicas de vinificación ensayadas. 
Gráfico 6.71. Evolución del color debido a los antocianos libres durante el periodo de conservación de los vinos en función de la aplicación de la microoxigenación.

Gráfico 6.72. Evolución del color debido a los antocianos polimerizados durante el periodo de conservación de los vinos en función de los copigmentos adicionados.

Gráfico 6.73. Evolución del color debido a los antocianos polimerizados durante el periodo de conservación de los vinos en función las técnicas de vinificación ensayadas.

Gráfico 6.74. Evolución del color debido a los antocianos polimerizados durante el periodo de conservación de los vinos en función la aplicación de la microoxigenación.

Gráfico 6.75. Evolución del índice de PVPP durante el periodo de conservación de los vinos en función de los distintos copigmentos adicionados.

Gráfico 6.76. Evolución del índice de PVPP durante el periodo de conservación de los vinos en función de la aplicación de la microoxigenación.

Gráfico 6.77. Evolución del índice de Folin durante el periodo de conservación de los vinos en función de los distintos copigmentos adicionados.

Gráfico 6.78. Evolución del índice de Folin durante el periodo de conservación de los vinos en función de la aplicación de la microoxigenación.

Gráfico 6.79. Evolución de la concentración de ácidos fenólicos durante la conservación de los vinos en función de los distintos copigmentos adicionados

Gráfico 6.80. Evolución de la concentración de flavonoles durante el periodo de conservación de los vinos en función de los distintos copigmentos adicionados.

Gráfico 6.81. Evolución de la concentración de flavonoles durante el periodo de conservación de los vinos en función de las técnicas de vinificación ensayadas

Gráfico 6.82. Evolución de la concentración de 3-flavanoles durante el periodo de conservación de los vinos en función de los distintos copigmentos adicionados.

Gráfico 6.83. Evolución de la concentración de 3-flavanoles durante la conservación de los vinos en función de las distintas técnicas de vinificación ensayadas. 
Gráfico 6.84. Evolución de la concentración de catequinas durante el periodo de conservación de los vinos en función de los distintos copigmentos adicionados.

Gráfico 6.85. Evolución de la concentración de catequinas durante el periodo de conservación de los vinos en función de las distintas técnicas de vinificación ensayadas.

Gráfico 6.86. Evolución de la concentración de catequinas durante el periodo de conservación de los vinos en función de la aplicación de la microoxigenación.

Gráfico 6.87. Evolución del índice de DMACH durante el periodo de conservación de los vinos en función de los distintos copigmentos adicionados.

Gráfico 6.88. Evolución del índice de DMACH durante el periodo de conservación de los vinos en función de la aplicación de la microoxigenación.

Gráfico 6.89. Evolución del índice de etanol durante el periodo de conservación de los vinos en función de las distintas técnicas de vinificación ensayadas.

Gráfico 6.90. Evolución de la concentración de taninos totales durante el periodo de conservación de los vinos en función de la aplicación de la microoxigenación.

Gráfico 6.91. Evolución del índice de gelatina durante el periodo de conservación de los vinos en función de las distintas técnicas de vinificación ensayadas.

Gráfico 6.92. Evolución del índice de gelatina durante el periodo de conservación de los vinos en función de la aplicación de la microoxigenación.

Gráfico 6.93. Primera componente frente a la segunda, en función de los copigmentos ensayados.

Gráfico 6.94. Primera componente frente a la segunda, en función de las técnicas de vinificación ensayadas.

Grafico 6.95. Primera componente frente a la segunda, en función de los copigmentos ensayados

Gráfico 6.96. Primera componente frente a la segunda, en función de las técnicas de vinificación ensayadas.

Gráfico 6.97. Primera componente frente a la segunda, en función de la aplicación de la microoxigenación. 
Gráfico 6.98. Primera componente frente a la segunda, en función del momento de adición de los copigmentos.

Gráfico 6.99. Primera componente frente a la segunda, en función de los copigmentos ensayados

Gráfico 6.100. Primera componente frente a la segunda, en función de las técnicas de vinificación ensayadas.

Gráfico 6.101. Primera componente frente a la tercera, en función de la aplicación de la microoxigenación.

Gráfico 6.102. Primera componente frente a la segunda, en función del momento de adición de los copigmentos.

Gráfico 6.103. Evolución de la intensidad colorante durante el periodo de conservación de los vinos en función de los distintos copigmentos adicionados

Gráfico 6.104. Evolución de la intensidad colorante durante el periodo de conservación de los vinos en función de la aplicación de la microoxigenación.

Gráfico 6.105. Evolución del tono durante el periodo de conservación de los vinos en función de los distintos copigmentos adicionados

Gráfico 6.106. Evolución del tono durante el periodo de conservación de los vinos en función de la aplicación de la microoxigenación.

Gráfico 6.107. Evolución de los antocianos totales durante el periodo de conservación de los vinos en función de los distintos copigmentos adicionados.

Gráfico 6.108. Evolución de los antocianos totales durante el periodo de conservación de los vinos en función de las distintas técnicas de vinificación ensayadas.

Gráfico 6.109. Evolución de los antocianos totales durante el periodo de conservación de los vinos en función de la aplicación de la microoxigenación.

Gráfico 6.110. Evolución de los antocianos totales durante el periodo de conservación de los vinos en función del momento de adición de copigmentos.

Gráfico 6.111. Evolución de la concentración de malvidinas durante el periodo de conservación de los vinos en función de los distintos copigmentos adicionados.

Gráfico 6.112. Evolución de la concentración de malvidinas durante el periodo de conservación de los vinos en función de las distintas técnicas de vinificación ensayadas. 
Gráfico 6.113. Evolución de la concentración de malvidinas durante el periodo de conservación de los vinos en función del momento de aplicación de los copigmentos.

Gráfico 6.114. Evolución de la concentración de antocianidinas durante el periodo de conservación de los vinos en función de los distintos copigmentos adicionados.

Gráfico 6.115. Evolución de la concentración de antocianidinas durante el periodo de conservación de los vinos en función de las distintas técnicas de vinificación ensayadas.

Gráfico 6.116. Evolución de la concentración de antocianidinas durante el periodo de conservación de los vinos en función del momento de aplicación de los copigmentos.

Gráfico 6.117. Evolución de la concentración de derivados de antocianos durante el periodo de conservación de los vinos en función de los distintos copigmentos adicionados.

Gráfico 6.118. Evolución de la concentración de derivados de antocianos durante el periodo de conservación de los vinos en función de las distintas técnicas de vinificación ensayadas.

Gráfico 6.119. Evolución de la concentración de antocianidinas durante el periodo de conservación de los vinos en función del momento de aplicación de los copigmentos.

Gráfico 6.120. Evolución de la concentración del total de antocianos durante el periodo de conservación de los vinos en función de los distintos copigmentos adicionados.

Gráfico 6.121. Evolución de la concentración del total de antocianos durante el periodo de conservación de los vinos en función de las distintas técnicas de vinificación ensayadas.

Gráfico 6.122. Evolución de la concentración del total de antocianos durante el periodo de conservación de los vinos en función del momento de aplicación de los copigmentos.

Gráfico 6.123. Evolución del \% de antocianos copigmentados durante el periodo de conservación de los vinos en función de la microoxigenación.

Gráfico 6.124. Evolución del \% de antocianos copigmentados durante el periodo de conservación de los vinos en función del momento de aplicación de los copigmentos. 
Gráfico 6.125. Evolución de la concentración del total de antocianos durante el periodo de conservación de los vinos en función de los distintos copigmentos adicionados.

Gráfico 6.126. Evolución del color que corresponde a polimerizaciones durante el periodo de conservación de los vinos en función de los distintos copigmentos adicionados.

Gráfico 6.127. Evolución del color que corresponde a polimerizaciones durante el periodo de conservación de los vinos en función de la aplicación de la microoxigenación.

Gráfico 6.128. Evolución del índice de PVPP durante el periodo de conservación de los vinos en función de los distintos copigmentos adicionados.

Gráfico 6.129. Evolución del índice de PVPP durante el periodo de conservación de los vinos en función del momento de aplicación de los distintos copigmentos adicionados.

Gráfico 6.130. Evolución del índice de Folin durante el periodo de conservación de los vinos en función de los distintos copigmentos adicionados.

Gráfico 6.131. Evolución del índice de Folin durante el periodo de conservación de los vinos en función de la aplicación de la mocrooxigenacion.

Gráfico 6.132. Evolución del índice de Folin durante el periodo de conservación de los vinos en función del momento de adición de copigmentos.

Gráfico 6.133. Evolución de la concentración de ácidos fenólicos durante el periodo de conservación de los vinos en función de la adición de los distintos copigmentos ensayados.

Gráfico 6.134. Evolución de la concentración de flavonoles durante el periodo de conservación de los vinos en función de la adición de los distintos copigmentos ensayados.

Gráfico 6.135. Evolución de la concentración de flavonoles durante el periodo de conservación de los vinos en función del momento de adición de los distintos copigmentos ensayados.

Gráfico 6.136. Evolución de la concentración de 3-flavanoles durante el periodo de conservación de los vinos en función de la adición de los distintos copigmentos ensayados. 
Gráfico 6.137. Evolución de la concentración de catequinas durante el periodo de conservación de los vinos en función de la adición de los distintos copigmentos ensayados.

Gráfico 6.138. Evolución de la concentración de catequinas durante el periodo de conservación de los vinos en función de la aplicación de la microoxigenacion.

Gráfico 6.139. Evolución de la concentración de catequinas durante el periodo de conservación de los vinos en función del momento de adición de los copigmentos.

Gráfico 6.140. Evolución del índice de DMACH durante el periodo de conservación de los vinos en función de la adición de los distintos copigmentos ensayados.

Gráfico 6.141. Evolución del índice de DMACH durante el periodo de conservación de los vinos en función de la aplicación de la microoxigenación.

Gráfico 6.142. Evolución del índice de DMACH durante el periodo de conservación de los vinos en función de las distintas técnicas de vinificación ensayadas.

Gráfico 6.143. Evolución del índice de etanol durante el periodo de conservación de los vinos en función de la aplicación de la microoxigenación.

Gráfico 6.144. Evolución de la concentración de taninos totales durante el periodo de conservación de los vinos en función de las distintas técnicas de vinificación ensayadas.

Gráfico 6.145. Evolución de la concentración de taninos totales durante la conservación de los vinos en función de la aplicación de la microoxigenación.

Gráfico 6.146. Evolución del índice de gelatina durante el periodo de conservación de los vinos en función de la aplicación de la microoxigenación.

Gráfico 6.147. Evolución del índice de gelatina durante el periodo de conservación de los vinos en función del momento de adición de los copigmentos. 


\section{INTRODUCCIÓN}





\section{INTRODUCCIÓN}

\subsection{LA D.O. UTIEL-REQUENA}

La Denominación de Origen Utiel-Requena está situada en el interior de la provincia de Valencia, a $70 \mathrm{~km}$. del mar Mediterráneo, con una altitud ascendente que va desde los 700 a los 900 metros en su parte más elevada. Formada por una superficie de casi 40.000 hectáreas, supone el viñedo más extenso y homogéneo de la Comunidad Valenciana.

La zona que incluye la Denominación de Origen Utiel-Requena está situada sobre una meseta de perímetro circular y unos 45 kilómetros de diámetro, siendo la única llanura del interior de Valencia. Esta pequeña meseta que bascula de NO a SE, es en realidad un apéndice de la gran unidad geomorfológica que constituye la submeseta Castellana Meridional, quedando desgajada de ella por el profundo surco que abre el río Cabriel. Las aguas de esta zona, se reparten entre dos cuencas hidrográficas, la del río Magro al Norte y la de la rambla del Caballero, afluente del Cabriel, al Sur.

A diferencia de otras denominaciones de origen, Utiel-Requena goza de una identidad geográfica homogénea y unos rasgos climáticos comunes. Su clima puede ser clasificado de tipo mediterráneo, aunque presenta rasgos de continentalidad que le vienen dados por la altitud y alejamiento del mar, características que la diferencian notablemente del resto de las comarcas de la Comunidad Valenciana. La temperatura media anual es de $14^{\circ}$, con una amplitud térmica anual de más de $17^{\circ}$. Esta ancha franja térmica da por sí sola los rasgos de continentalidad característicos del clima de la zona.

La DO Utiel-Requena es una región mayoritariamente de vinos tintos, de hecho, un $94,27 \%$ de la superficie del viñedo está cultivada de variedades tintas. Las variedades blancas representan, en consecuencia, un 5,73\% del viñedo.

Las variedades de uva protegidas por esta Denominación de Origen son:

- Tintas: Bobal, Tempranillo o Cencibel, Garnacha, Cabernet Sauvignon, Merlot y Syrah.

- Blancas: Macabeo, Merseguera, Planta Nova o Tardana, Chardonnay y Sauvignon Blanc.

De ellas, la variedad Bobal es la más extendida, ya que supone un $80 \%$ de la producción. El clima y el suelo que necesita esta variedad se adaptan perfectamente a los de la zona, presentando todas las características de una cepa autóctona. Su cultivo está muy poco extendido en otras zonas de España y aún incluso en otros países es poco conocida, aunque existen algunas plantaciones en el sur de Francia y algunas viñas en Cerdeña (Italia).

La variedad Tempranillo es la segunda en importancia en la Denominación y supone un $12 \%$ aproximadamente del cultivo total. 


\subsection{LA VARIEDAD TEMPRANILLO}

Se considera variedad principal en las Denominaciones de Origen Calatayud, Cigales, Conca de Barberá, Costers del Segre, La Mancha, Penedés, Ribera del Duero, Rioja, Somontano, Utiel-Requena, Valdepeñas y Vinos de Madrid. Esta variedad ocupa el octavo puesto en el mapa de superficie del viñedo español y el decimoquinto a escala mundial. Es una variedad tinta que se caracteriza por sus racimos de mediano tamaño, compactos, con granos de color azulado, de gran calidad y de producción moderada.

Se trata, por tanto, de la variedad tinta española de mayor calidad y fama, siendo originaria de la zona alta del Ebro entre La Rioja y Navarra, y cultivada en la actualidad por el resto de las zonas vitícolas de la península, bajo las sinonimias de Ull de Llebre en Cataluña, Cencibel en La Mancha, Escobera o Chinchillaza en Extremadura, Tinta del país en Castilla-León, Tinto fino en Madrid, Tinta Roriz en el Alto Douro portugués, así como también en lugares más lejanos como en Argentina, Australia, e incluso California bajo el nombre de Valdepeñas.

Es una variedad de uva tinta con piel gruesa, los racimos tienen forma cilíndrica y son compactos, con bayas esféricas de color negro púrpura y pulpa incolora (Figura 1.1). La piel no presenta caracteres herbáceos. Crece mejor en altitudes relativamente altas, pero puede también tolerar climas mucho más templados.

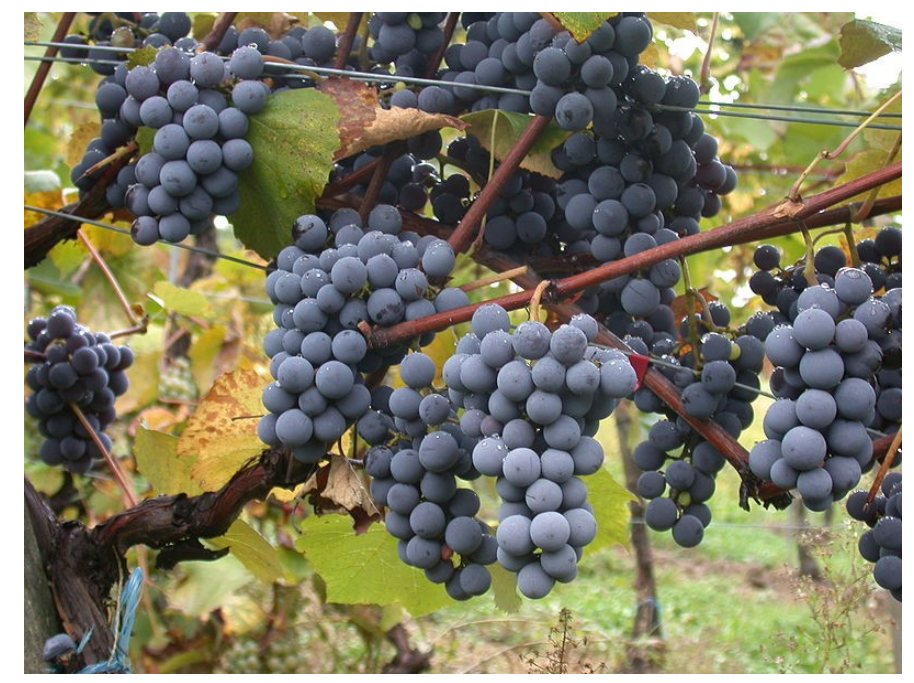

Figura 1.1. Racimos de la variedad Tempranillo

La raíz de Tempranillo absorbe potasio con facilidad, lo que incrementa sus niveles de $\mathrm{pH}$ cuando alcanza la madurez. La uva es muy susceptible a las inclemencias del tiempo, contrayéndose cuando hay sequía e hinchándose cuando hay demasiada humedad, afectando a la calidad, pues afecta al color del vino. Vegeta muy bien en suelos arcillo calcáreos, ya que los efectos de la climatología se atenúan en lugares calizos debido al efecto de la arcilla en las raíces, estos efectos son más perjudiciales en zonas arenosas, así como para viñas que tienen menos de doce años, pues las raíces son generalmente demasiado superficiales. Es muy segura en el cuajado, muy sensible a plagas y enfermedades, y poco resistente a la sequía y a temperaturas altas. La Tabla 1.1 muestra las características de algunos órganos de la planta. 
Tabla 1.1. Características de la variedad Tempranillo (Gallego, 2005).

\begin{tabular}{|c|c|c|}
\hline & Caracteres & Definición \\
\hline Pámpano joven & $\begin{array}{l}\text { Pigmentación } \\
\text { Densidad de pelos }\end{array}$ & $\begin{array}{l}\text { Media, entre rosa y granate } \\
\text { Abundante }\end{array}$ \\
\hline Pámpano & $\begin{array}{l}\text { Porte } \\
\text { Color de la cara dorsal entrenudos }\end{array}$ & $\begin{array}{l}\text { Semierguido } \\
\text { Verde con rayas rojas }\end{array}$ \\
\hline Zarcillos & Longitud & Largos, trifurcados \\
\hline Hoja adulta & $\begin{array}{l}\text { Tamaño } \\
\text { Forma del limbo } \\
\text { Hinchazón del haz } \\
\text { Forma y longitud de los dientes } \\
\text { Forma del seno peciolar } \\
\text { Pecíolo, forma y color } \\
\text { Pigmentación del envés } \\
\text { Densidad de pelos entre nervios } \\
\text { Densidad de pelos en nervios }\end{array}$ & $\begin{array}{l}\text { Grande } \\
\text { Pentagonal, lobulado, } \\
\text { bien definido y superpuesto } \\
\text { Alabeado, verde intenso } \\
\text { Grandes, ligeramente } \\
\text { convexos alternos } \\
\text { En V superpuesto } \\
\text { Largo, cilíndrico, con rayas } \\
\text { granates } \\
\text { Nula } \\
\text { Abundante, largos flexuosos } \\
\text { con tendencia algodonosa } \\
\text { Casi nula }\end{array}$ \\
\hline Racimo & $\begin{array}{l}\text { Tamaño y compacidad } \\
\text { Longitud del pedúnculo }\end{array}$ & $\begin{array}{l}\text { Mediano-grande } \\
\text { Medio }\end{array}$ \\
\hline Baya & $\begin{array}{l}\text { Tamaño } \\
\text { Forma de perfil } \\
\text { Ombligo } \\
\text { Grosor de la epidermis } \\
\text { Pigmentación de la pulpa } \\
\text { Sabores particulares } \\
\text { Facilidad separación del pedicelo } \\
\text { Formación de pepitas } \\
\text { Color principal (sin pruina) }\end{array}$ & $\begin{array}{l}\text { Medio-pequeño } \\
\text { Circular } \\
\text { Esférico } \\
\text { Grueso } \\
\text { Nula, sólo pincel y pepitas } \\
\text { Frutal-compota } \\
\text { Difícil } \\
\text { Presente } \\
\text { Azul negruzco }\end{array}$ \\
\hline
\end{tabular}

La uva Tempranillo produce un mosto equilibrado en azúcar, color y acidez, aunque esta última a veces es escasa, con muy bajo contenido en oxidasas, con el que se obtienen vinos de gran aroma, buen grado alcohólico y bastante color, siendo éste muy estable. Los vinos de Tempranillo presentan a una intensidad colorante elevada, con un color rojo rubí y borde rojo-violáceo, debido a su pH ligeramente elevado que implica el paso de las formas coloreadas de rojo de los antocianos, a un matiz más violeta. En olfacción directa destacan los aromas a rosas, frutas rojas y regaliz, superando en retroolfacción el regaliz a las rosas. El gusto residual es ácido débil en la punta de la lengua y encías, con frescura en paladar e impresión posterior muy suave. Posee un paladar franco, interesante en vino joven y aterciopelado cuando envejece. Pueden consumirse jóvenes o envejecidos durante varios años en barrica de roble, siendo la fermentación maloláctica un proceso esencial para la obtención de vinos de calidad.

Posee la virtud de las cepas frías o atlánticas, ya que tiene la facultad de soportar un largo envejecimiento en barrica y botella, si posee una buena estructura de taninos y suficiente acidez para soportar la crianza. 
Para obtener elegancia y acidez de la Tempranillo se debe cultivar en un clima fresco, pero para conseguir altos niveles de azúcar y las gruesas pieles que dan color intenso y elevada concentración de taninos, necesitan calor, y estas dos condiciones se suelen dar en las zonas altas de clima continental.

En Utiel-Requena, la variedad Tempranillo, a pesar de ser la segunda en implantación, no ha conseguido una calidad reconocida en la zona, y es por ello que no se suele comercializar su vino como monovarietal, y se utiliza mayoritariamente en coupages, junto con la autóctona Bobal, contribuyendo a incrementar la composición aromática de los vinos, y su suavidad gustativa.

La introducción de esta variedad en Utiel-Requena se realizó en la década de 1950-60, momento en el cual existía una fuerte demanda de vino y se priorizaba la cantidad por encima de la calidad, plantándose clones de esta variedad muy productivos, que tienen dificultad para madurar sus compuestos polifenólicos, e incluso en algunas zonas más frías conseguir el grado alcohólico deseado.

Como conclusión puede decirse que la tipicidad de los vinos está muy influida por las características varietales, el suelo y clima del lugar donde se cultiva y, sobre todo, por la forma y modo de elaboración y crianza de los mismos. Es pues perfectamente compatible el concepto varietal de los vinos de Tempranillo con la diferenciación de los mismos por su origen. Esta diferenciación en la tipicidad tiene sus consecuencias en las características sensoriales de los vinos de Tempranillo.

\subsection{SITUACIÓN ACTUAL DEL MERCADO VITIVINÍCOLA}

Una buena noticia para todo el que se aproxime al sector del vino, es que el consumo mundial de vino se está incrementando paulatinamente año tras año, aunque a velocidad muy lenta. Pero es interesante destacar que este crecimiento se produce en el comercio mundial de vino, pero en cambio en los países productores el consumo decrece, mientras que demandan más vino quienes no producen y por lo tanto necesitan importarlo. Ese comercio internacional de vino, fruto de la creciente globalización de costumbres y la aproximación del mundo anglosajón al vino, es el tipo de consumo que crece. Aunque todavía países como Francia, Italia o España sean los grandes consumidores de vino en el mundo, la tendencia en todos ellos ha sido a disminuir, aunque esta disminución se ha compensado con el crecimiento experimentado en otros países.

Los mercados de los grandes países productores como España, se van haciendo cada día más pequeños, mientras que las grandes oportunidades de crecimiento se encuentran en los mercados de importación. Y si esta situación es la que muestran diversas estadísticas, una primera idea de carácter estratégico puede irse abriendo paso: los mercados en crecimiento son diferentes de los que tradicionalmente hemos conocido en casa. Y si es diferente la mentalidad, los planteamientos y las formas, los recursos para afrontarlos deberán ser también diferentes. Algo debe cambiar en nuestras formas de actuación, para afrontar retos comerciales distintos a los tradicionales.

En definitiva se puede deducir que hay varios países productores, que producen mucho vino, con tendencia a generar excedentes, que imponen una creciente presión sobre los precios, con crecimientos muy importantes de nuevos competidores, entrando sobre todo en países anglosajones, nórdicos y asiáticos, no productores de vinos. Todo 
esto obliga a cualquier bodega española o mundial a plantearse con mucho cuidado cuáles son sus mercados objetivos y cuales pueden sus líneas comerciales de mayor crecimiento potencial, en función de su propia capacidad competitiva.

España es uno de los principales jugadores en el mercado mundial del vino. Como país, España está en la primera división mundial del vino, dentro del grupo de los productores tradicionales, grandes exportadores, pero con un consumo nacional decreciente, aunque con un crecimiento notable de las exportaciones, superior incluso al de nuestros principales competidores. Por todo ello, España es un actor principal en un mercado que crece a nivel mundial.

Además de lo comentado en el párrafo anterior, el carácter agrario del sector del vino en España, como en el resto de los países europeos productores, ha influido de forma determinante sobre una política y estrategia más centradas en la producción del vino que en su venta. Ésta, según muchos analistas, es la gran diferencia entre muchos productores europeos y la mentalidad competitiva de los nuevos productores. Afortunadamente esta visión tradicional está cambiando de forma vertiginosa en España.

El convencimiento de que el vino hay que venderlo, y en gran medida hay que venderlo fuera de nuestras fronteras, donde la competencia es más dura, con notable éxito reciente y más preocupada por satisfacer las necesidades del consumidor, está provocando un renovado impulso en el sector comercializador español. Un impulso donde empieza a cobrar importancia, además de la calidad del vino, el marketing, los departamentos comerciales, la preocupación por internacionalizarse y un renovado esfuerzo inversor en la distribución del producto. En definitiva, cabe destacar que el reto como país productor, y para las bodegas que aspiran a seguir creciendo a título individual, está en adaptarse a las nuevas exigencias del mercado.

Para ello, el completo conocimiento del proceso productivo se convierte en un factor fundamental y de gran importancia, sobre el que hay que actuar para conseguir la máxima calidad de los vinos elaborados. Entender perfectamente el funcionamiento de las reacciones que se producen en el vino durante su elaboración y crianza, controlar y definir los parámetros que intervienen en la aplicación de distintas técnicas enológicas, y por último, un mejor conocimiento de la composición de los vinos, ayudarán, sin duda a poder elaborar este tipo de vinos adaptados a las nuevas exigencias del mercado actual.

\subsection{JUSTIFICACIÓN DEL TRABAJO}

No cabe ninguna duda de que una de las características más importantes para el consumidor a la hora de apreciar un vino es su aspecto visual (Peynaud, 1987). El color es la carta de presentación de un vino, observándolo deducimos su edad, su estado de conservación y el tipo de vinificación llevado a cabo. La intensidad de la coloración, aun no siendo un criterio absoluto de calidad, nos da una información importante sobre la estructura, el cuerpo del vino y el sabor en boca. Además de el color, en los vinos tintos nos interesan de forma prioritaria las sensaciones gustativas y táctiles (Cacho, 2003).

Los componentes responsables de aportar estas sensaciones son los compuestos fenólicos, interviniendo de manera decisiva en la calidad del vino debido a su influencia 
sobre el color, las sensaciones gustativas y su aptitud para el envejecimiento. Los antocianos y sus pigmentos poliméricos, y los flavanoles y sus polímeros, son los compuestos fenólicos con mayor impacto sobre el vino. Mientras que los antocianos y los pigmentos poliméricos aportan al vino su color rojo, los flavanoles y sus polímeros son los responsables del cuerpo o estructura, de la astringencia y del sabor amargo. (Joslyn y Goldstein, 1964; Arnold et al., 1979; Robichaud y Noble, 1990; Guinard et al., 1986; Naish et al., 1993; Fischer et al., 1994; Thomas and Lawless, 1995; Thorngate y Noble, 1995; Kallithraka et al., 1997; Sarni-Manchado et al., 1999)

Los antocianos son los compuestos responsables del color negro y rojo de las uvas tintas. Cuando las uvas son estrujadas empiezan a formarse pigmentos poliméricos aumentando su concentración continuamente en el tiempo (Somers, 1971; Nagel y Wulf, 1979). Al final del primer año, del 50 al 70\% de los antocianos monómeros están formando parte de formas poliméricas (Ribéreau-Gayon et al., 1970; Somers, 1971; Nagel y Wulf, 1979). Estos nuevos pigmentos adquieren una gran importancia en cuanto a la estabilidad del color, presentando una mayor estabilidad frente a las variaciones de $\mathrm{pH}$ e incrementándose su resistencia a la decoloración provocada por el sulfuroso (Somers, 1971; Somers y Evans, 1977).

Una de las reacciones en la que se ven involucrados los antocianos son las reacciones de copigmentación, que consisten en la unión de las formas monómeras coloreadas de los antocianos con unos compuestos que actúan como copigmentos (Asen et al., 1972; Brouillard et el., 1989). Estas reacciones pueden suceder mediante reacciones intramoleculares, donde los copigmentos se unen mediante un enlace covalente a los antocianos, o también mediante reacciones intermoleculares, donde reaccionan mediante enlaces débiles por puente de hidrógeno con los antocianos (Eiro y Heinonen, 2002).

Las reacciones de copigmentación pueden suponer casi la mitad del color en vinos jóvenes (Boulton, 2001). Además, la copigmentación provoca un incremento en la absorbancia con respecto al antociano libre, denominándose este fenómeno como efecto hipercrómico, con un desplazamiento de la longitud de onda hacia valores superiores, entre 5-20 nm, provocando la presencia de tonos azulados dentro de la disolución roja que es el vino.

Durante la crianza y el envejecimiento de los vinos la concentración de antocianos disminuye debido a la progresiva reacción con otros compuestos fenólicos, principalmente con flavanoles (Jurd 1969; Somers 1971). Este fenómeno de asociación es el responsable del cambio de color desde tonos rojo-azulados característicos de los vinos jóvenes hacia los tonos marrón-rojizo que presentan los vinos envejecidos, que suelen ir acompañados de una disminución en la astringencia (Haslam, 1980).

Otros compuestos que intervienen en las propiedades organolépticas de los vinos son los flavanoles, que están representados por una compleja familia compuesta por las diferentes formas isoméricas de la catequina y sus polímeros. Los flavanoles polímeros reciben el nombre de proantocianidinas o taninos condensados y corresponden a cadenas de diferentes números de unidades de diversos flavanoles monómeros.

La proantocinidinas o taninos son importantes por ser los responsables de la astringencia y amargor del vino (Lea y Arnold, 1978; Haslam, 1980; Noble, 1990; Robichaud y Noble, 1990; Glories, 1999). Además, debido a su participación en reacciones de pardeamiento oxidativo, químico y enzimático, contribuyen en parte a la 
componente amarilla del color. (Glories, 1984; Junquera et al., 1992; Ribereau-Gayon, 2003a). También son responsables de la sensación de estructura o cuerpo del vino (Montedoro y Bertuccioli, 1988; Fischer y Strasser, 1999; Ribereau-Gayon, 2003a) y de la capacidad del vino para envejecer (Zamora et al., 1994; Saucier et al, 1997, Fischer y Strasser, 1999), es decir, la capacidad de mantener el color a lo largo del tiempo. Además, pueden participar en reacciones con proteínas con formación de turbidez (Cheynier y Ricardo da Silva, 1991), así como en numerosas reacciones de condensación durante la maduración y el envejecimiento del vino (Haslam, 1980).

Otra de las características sensoriales importantes en el vino es el aroma, que es posiblemente la cualidad del vino que más contribuye a su disfrute (Cacho, 2003). La importancia del aroma en la calidad del vino hace que numerosos grupos de investigación hayan dedicado su esfuerzo a conocer la composición cualitativa $\mathrm{y}$ cuantitativa de los vinos (Etievant, 1991). El análisis de estos componentes del aroma se lleva a cabo por cromatografía de gases siendo esta modalidad de detección la que revolucionó el estudio del aroma en el vino. Las familias químicas aromáticas procedentes de la uva y que aportan características varietales a los vinos son tres: terpenos, norisoprenoides y pirazinas. Además, el aroma de los vinos se debe a una mezcla muy compleja de compuestos volátiles que pueden clasificarse, en aromas varietales, prefermentativos, fermentativos y postfermentativos. El análisis sensorial de los vinos permite también una aproximación a estas características aromáticas de los vinos.

El mercado actual del vino tinto de calidad demanda vinos de gran potencial visual (Zamora, 2003), y elevada concentración tánica, pero que no resulten excesivamente astringentes ni amargos. La elaboración de este tipo de vinos no resulta sencilla, ya que siendo imprescindible una aceptable madurez polifenólica de las uvas, habría que adaptar las prácticas de vinificación para limitar al máximo la extracción de compuestos astringentes. Para conseguir una buena concentración polifenólica, limitando la extracción de estos compuestos astringentes, puede resultar interesante realizar una maceración prefermentativa previa, para acortar el tiempo de contacto entre hollejos y mostos durante la fermentación. Sin embargo, limitar la extracción de compuestos polifenólicos puede afectar a la estabilidad del color del vino en el tiempo.

La maceración prefermentativa consiste en incrementar la extracción de compuestos fenólicos en fase acuosa. De este modo se favorece la extracción de las moléculas fácilmente solubles en ausencia de etanol, pudiéndose lograr que la fermentación comience con un elevado nivel de antocianos y flavanoles de bajo peso molecular ya disueltos en el medio. Todo ello podría favorecer su combinación dando lugar a una mejor estabilización del color.

La difusión prioritaria de antocianos durante la fase prefermentativa, así como de taninos de bajo peso molecular, explicaría el aumento de color de los vinos obtenidos (Álvarez et al., 2005). La ausencia de etanol facilitaría la formación de especies polifenólicas de mayor peso molecular, lo que también contribuiría a aumentar la intensidad del color (Timberlake y Bridle, 1976). Esta práctica facilita además la manifestación de caracteres aromáticos propios de la variedad, ya que se favorece la liberación, a partir de fragmentos de hollejo, de aromas libres y ligados. Se obtienen vinos de mayor cuerpo y persistencia en boca (Flanzy, 1999), con mayores concentraciones de antocianos totales (McMahon et al., 1999), y de acetatos y esteres totales (Álvarez et el., 2005). El posible desarrollo de levaduras criofilas y su influencia 
en la liberación de ciertos aromas, especialmente ésteres volátiles (entre ellos el acetato de fenil-2-etilo, que recuerda a rosas), es otra de las ventajas citadas (Charpentier y Feuillant, 1998).

Otra de las técnicas interesantes para favorecer la extracción de compuestos polifenólicos es la aplicación de nieve carbónica para realizar la maceración prefermentativa, consiguiendo aunar la ralentización del proceso fermentativo y la desnaturalización y rotura de las células de los hollejos, por congelación de sus líquidos intracelulares, ejerciendo un efecto drástico sobre estos, desnaturalizando membranas y facilitando la salida de compuestos aromáticos y fenólicos (Reynols, 2001; Parenti et al., 2004, Álvarez et al., 2005).

Los resultado encontrados en la aplicación tanto de la maceración prefermentativa en frío como con la adición de nieve carbónica, hacen necesaria la realización de nuevos estudios, fijándose unas condiciones determinadas que nos permitan entender correctamente el funcionamiento de estos procesos para determinar un protocolo de actuación válido, con el objetivo de elaborar vinos con una concentración antociánica y tánica óptima, además de poder conseguir una mejora en la concentración y composición aromática de los vinos elaborados.

Por otra parte uno de los factores más importantes implicado en la evolución de los compuestos fenólicos en el vino tinto es el oxígeno (Ribéreau-Gayon et el., 1998). Básicamente, el oxígeno participa provocando la oxidación irreversible de los antocianos libres, pero también formando acetaldehído, que actúa como puente de unión entre antocianos y taninos, favoreciendo su polimerización. La oxidación de los antocianos representará la pérdida irreparable del color del vino, mientras que la combinación con los taninos comportará su estabilización. Además, la polimerización de los taninos se traducirá en una disminución de la astringencia del vino. Evidentemente en el conjunto de estos procesos se obtienen algunas moléculas de gran peso molecular que precipitarán.

La técnica de la microoxigenación nació en Madiran (Francia), fruto de las experiencias de Ducournau y Laplace (Ducournau y Laplace, 1993) y desde entonces se ha expandido enormemente a lo largo de muchas regiones vitivinícolas. Se fundamenta en aportar al vino pequeñas cantidades de oxígeno de forma continuada, a través de un microdifusor poroso (Moutounet et el., 1995), para reproducir e incluso acelerar el proceso de la estabilización polifenólica que tiene lugar durante la crianza del vino en barricas.

Por lo tanto, potenciando las reacciones de copigmentación, las cuales podrían permitir incrementar la calidad cromática de los vinos, junto con la aplicación de técnicas enológicas como la maceración prefermentativa, con el objetivo de incrementar el potencial fenólico y aromático, o con la adición controlada de oxígeno, la cual nos proporcionaría una mayor estabilidad del color y una mejora en las propiedades organolépticas de los vinos, nos permitirá fijar una metodología de actuación, con el objetivo de elaborar vinos de Tempranillo de máxima calidad en la Denominación de origen Utiel-Requena, adaptados a las exigencias crecientes de los mercados actuales. 

OBJETIVOS 


\section{OBJETIVOS}

El objetivo principal de este trabajo es estudiar el posible incremento de la calidad de los vinos tintos de Tempranillo. Para ello se han estudiado técnicas enológicas como la adición pre- o post- fermentativa de copigmentos, la realización de maceración prefermentativa en frío y el efecto de microoxigención (mediante la adición de acetaldehído) durante la conservación en botella. Se ha estudiado la composición polifenólica de los vinos, con el objetivo de conocer el efecto de cada una de las técnicas empleadas sobre los componentes del vino. Para conseguir el objetivo general, se plantean los siguientes objetivos parciales:

1. Estudiar el efecto de la adición de copigmentos y taninos antes y después de la fermentación, en la composición polifenólica de los vinos elaborados con la variedad Tempranillo, así como en su evaluación organoléptica.

2. Analizar el efecto de la maceración prefermentativa con adición de nieve carbónica, con respecto a la maceración prefermentativa tradicional.

3. Establecer diferencias en las reacciones de copigmentación de los distintos copigmento adicionados.

4. Identificar cual de los copigmentos adicionados contribuye a una mayor estabilidad del color de los vinos.

5. Establecer el momento óptimo de aplicación de copigmentos, con adición tanto pre- como post- fermentativamente.

6. Estudiar la interacción de la aplicación de copigmentos con la técnica de la maceración prefermentativa.

7. Evaluar el efecto de la adición de acetaldehído sobre la polimerización de los compuestos polifenólicos y sobre la composición global de los vinos elaborados.

8. Analizar el efecto de la realización conjunta de las técnicas de maceración prefermentativa y de la adición de acetaldehído, comprobando su posible compatibilidad.

9. Evaluar si las técnicas de vinificación estudiadas, adición pre- y postfermentativa de copigmentos, aplicación de técnicas de maceración prefermentativa y la adición de acetaldehído, tienen un efecto significativo sobre las características sensoriales de los vinos elaborados.

Para abordar los objetivos planteados, se ha partido de uva de la variedad Tempranillo y con ella se han elaborado diferentes tipos de vinos utilizando diferentes tecnologías de vinificación y distintos tipos de copigmentos, realizándose posteriormente las determinaciones analíticas relacionadas con el color, antocianos, taninos y sus distintas combinaciones. 





\section{ANTECEDENTES BIBLIOGRÁFICOS}





\section{ANTECEDENTES BIBLIOGRÁFICOS}

\subsection{LOS COMPUESTOS FENÓLICOS}

Los compuestos fenólicos son un grupo formado por diversas sustancias que aparecen en importantes concentraciones en la uva. Presentan gran importancia en enología, ya que se localizan en las partes sólidas de la uva (hollejo, raspón y pepitas) y son responsables del color, astringencia y estructura de los vinos, actúan como importantes reservorios de oxígeno y como sustratos para las reacciones de oscurecimiento, por lo que tienen una considerable incidencia en sus características organolépticas.

Los compuestos fenólicos son sustancias con uno o más anillos aromáticos (benceno) y, al menos, un sustituyente hidroxilo. Si en el benceno se sustituye un hidrógeno por un hidroxilo se obtiene un fenol. Existen dos grandes grupos de compuestos fenólicos: los ácidos fenólicos (benzoicos y cinámicos) y los flavonoides (flavonoles, antocianos y flavanoles). Las diferencias de estructura entre ambos grupos consisten principalmente en que los ácidos fenólicos tienen un único anillo, mientras que los flavonoides están formados por dos anillos fenólicos unidos por una cadena de tres átomos de carbono.

Durante la crianza en barrica los compuestos fenólicos experimentan importantes transformaciones que conducen a cambios notables en la composición de los vinos, por ello pueden considerarse el factor que determina su aptitud para el envejecimiento, además poseen ciertas propiedades fisiológicas tales como efecto vitamínico $\mathrm{P}$, acción bactericida, propiedad antitóxica, etc. Siendo por tanto el origen del color y de la astringencia, y según su naturaleza pueden incluso tener interés nutricional y farmacológico.

\subsection{POTENCIAL FENÓLICO DE LA UVA}

La calidad de un vino está condicionada por la calidad de la uva. La uva marca su potencial, pero es imprescindible que durante la vinificación se extraigan sus componentes, transforme el potencial fenólico de las uvas en compuestos fenólicos presentes en el vino. La calidad en la uva viene marcada por factores intrínsecos, como son la variedad y el suelo, y por otros culturales que van a condicionar su producción, composición, estado sanitario e integridad (García-Escudero y Zaballa, 1997; Sella et al, 1998; Yáñez et al., 1998; Mateus et al., 2002). El estado de madurez de la uva va a condicionar el vino que se obtendrá y sus características. La concentración de polifenoles tiende a aumentar durante toda la maduración, aunque no linealmente. Los antocianos aparecen durante el envero y se acumulan durante la maduración (Glories, 1999), produciéndose al final un descenso en su concentración que suele coincidir con la sobremaduración de la uva. La cantidad de taninos en el hollejo también va a aumentar durante el periodo de madurez, alcanzando un máximo para después mantenerse más o menos constante. En cambio, la concentración de taninos de las semillas desciende desde el envero, al mismo tiempo que aumenta su grado de polimerización (Fernández-López et al., 1992; Sella et al., 1998; Mazza et al., 1999), tal como se observa en la Figura 3.1. 
Así mismo, se ha constatado que la extracción de los compuestos fenólicos no depende únicamente de la cantidad en la que éstos se encuentren en la uva. Las paredes celulares van a formar una barrera a la difusión de antocianos, taninos y otros polifenoles de la uva al vino (Lecas y Brillouet, 1994; Kennedy et al., 2001). El proceso de maduración implica una solubilización de los polisacáridos de la pared celular del hollejo. La degradación de la pared celular durante la maduración facilitará, de esta manera, la extracción de la materia colorante durante la vinificación (Amrani Joutei y Glories, 1994).

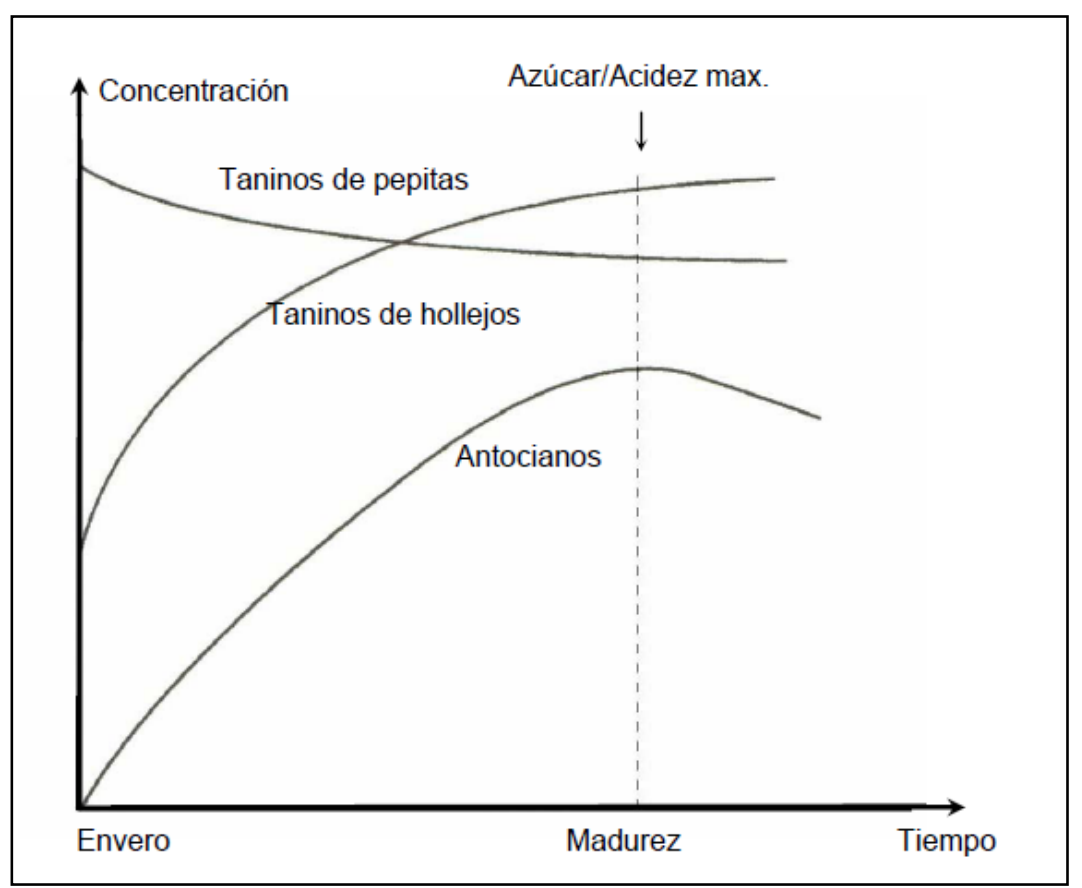

Figura 3.1. Evolución de la concentración de antocianos y taninos durante la maduración de la uva.

Los análisis clásicos de maduración (peso de 100 granos, grado Baumé, acidez total, $\mathrm{pH}$, ácido tartárico y ácido málico) proporcionan información de la madurez de la pulpa, pero no sobre la de la piel ni de la pepita (Fernández et al., 2003). Para cubrir este vacío surge el concepto de madurez fenólica (Glories y Augustin, 1993; Amrani Joutei y Glories, 1994; Izcara y González-San José, 2001), que va a tener en cuenta el contenido total de compuestos polifenólicos (Lamadon, 1995) y su facilidad de extracción de los hollejos y de las pepitas de la uva (Saint-Cricq et al., 1998).

Teniendo en cuenta tanto el contenido como la capacidad de difusión de los compuestos fenólicos, se podría adaptar la estrategia de vinificación, en función de los vinos que se pretendan elaborar (Glories, 1999 y 2001). Además, el estudio del potencial fenólico podría permitir anticipar problemas potenciales en la estabilidad y pardeamiento del vino (Mayen et al., 1995). 


\subsection{CLASIFICACIÓN DE LOS COMPUESTOS FENÓLICOS SEGÚN SU ESTRUCTURA QUÍMICA.}

Debido a su estructura química, los compuestos fenólicos se pueden subdividir en flavonoides (antocianos, flavanoles, flavonoles y flavononoles o flavonas) y no flavonoides (ácidos fenólicos, y estilbenos), según sean o no derivados de la estructura básica caracterizada por un esqueleto de 2 anillos bencénicos unidos por una cadena de 3 átomos de carbono (Figura 3.2).

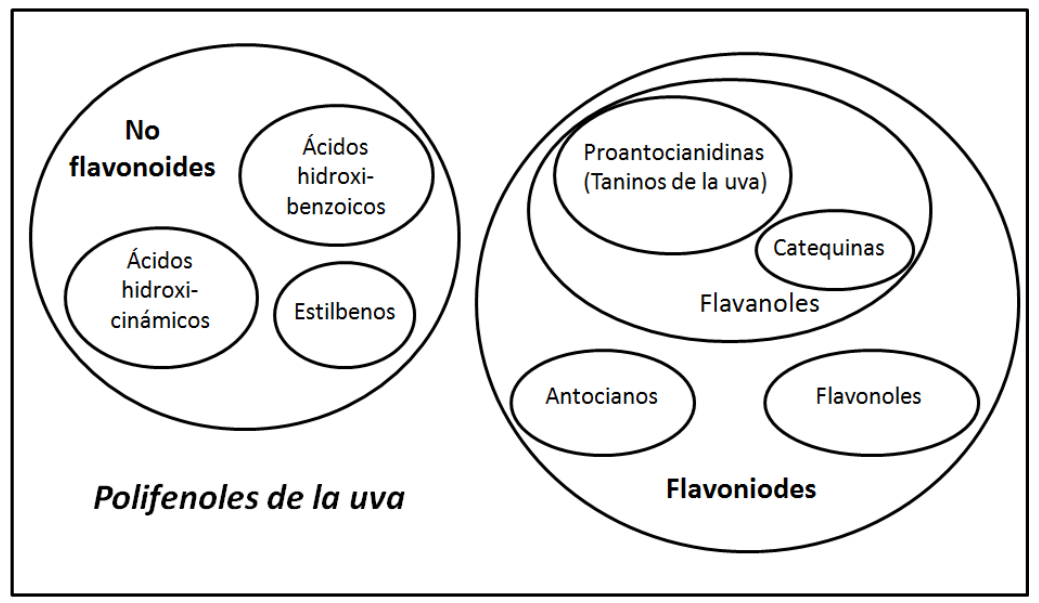

Figura 3.2. Clasificación de los compuestos fenólicos

Los más representativos son, cuantitativamente, los antocianos, catequinas y los 3-flavanoles, puesto que pueden estar presentes en concentraciones de hasta algunos gramos por litro, mientras que los otros fenoles suelen estar presentes en concentraciones de algunas decenas de $\mathrm{mg} / \mathrm{L}$. Desde el punto de vista químico, los compuestos fenólicos, se caracterizan por presentar un núcleo bencénico sustituido con uno o varios grupos hidroxilos (-OH) y una cadena lateral funcional (-R) (Figura 3.39). Como pueden tener varias funciones fenol se les denomina frecuentemente "polifenoles", de manera que existe una gran diversidad de estructuras químicas.

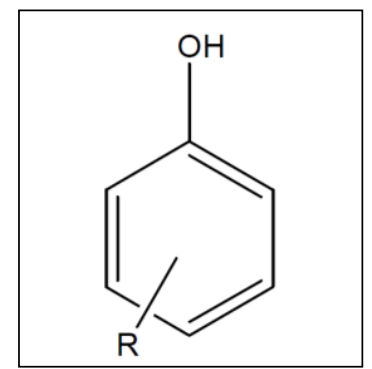

Figura 3.3. Estructura básica de los compuestos fenólicos

Los polifenoles del vino incluyen tanto a los compuestos originales de la uva como a compuestos nuevos, que aparecen como resultado de numerosos mecanismos durante las etapas de vinificación y envejecimiento del vino en barrica y/o botella. Existen muchas clasificaciones, pero es habitual hacerlo en función de su estructura, definiéndose dos grandes grupos de compuestos fenólicos, los flavoniodes y los no flavoniodes. 


\subsubsection{COMPUESTOS FLAVONOIDES}

Los flavonoides están caracterizados, por un esqueleto de base de 15 átomos de carbono $\left(\mathrm{C}_{6}-\mathrm{C}_{3}-\mathrm{C}_{6}\right)$, constituido por 2 anillos bencénicos unidos por una cadena de 3 átomos de carbono ciclada en un heterociclo oxigenado (Valls et al., 2000).

\subsubsection{LOS ANTOCIANOS}

Las antocianidinas o antocianos (del griego anthos $=$ flor y kianos $=$ azul), representan una parte importante, tanto cuantitativa como cualitativamente, de los flavonoides de las bayas de las uvas tintas y, en consecuencia, de los vinos resultantes (Valls et al., 2000). Los antocianos son las sustancias que esencialmente caracterizan las uvas y los vinos tintos, pero que están ausentes en los vinos blancos.

Desde un punto de vista general, la estructura de los antocianos se caracteriza por dos anillos bencénicos unidos por un anillo heterocíclico, que va a ser del tipo pirano o pirilio, por la asociación $\mathrm{C}_{6}-\mathrm{C}_{3}-\mathrm{C}_{6}$.

Los antocianos se diferencian por sus niveles de hidroxilación y de metilación, por la naturaleza, el número, y la posición de las osas unidas a la molécula (glucósidos de núcleo flavilium polihidroxilado y/o metoxilado), y también por la naturaleza y el número de los ácidos que esterifican los azúcares, pudiendo esterificarse con el acido cumárico, el cafeico y el acético (Gonzalez-Sanjosé et al., 1990; Mazza y Miniati, 1993). Además, se han identificado otros pigmentos derivados de las reacciones de condensación, polimerización y cicloadición de los antocianos con otros compuestos (Bakker y Timberlake, 1997; Revilla et al., 1999; Mateus y Freitas, 2001; Atanasova et al., 2002; Vivar Quintana et al., 2002; Wang et al., 2003).

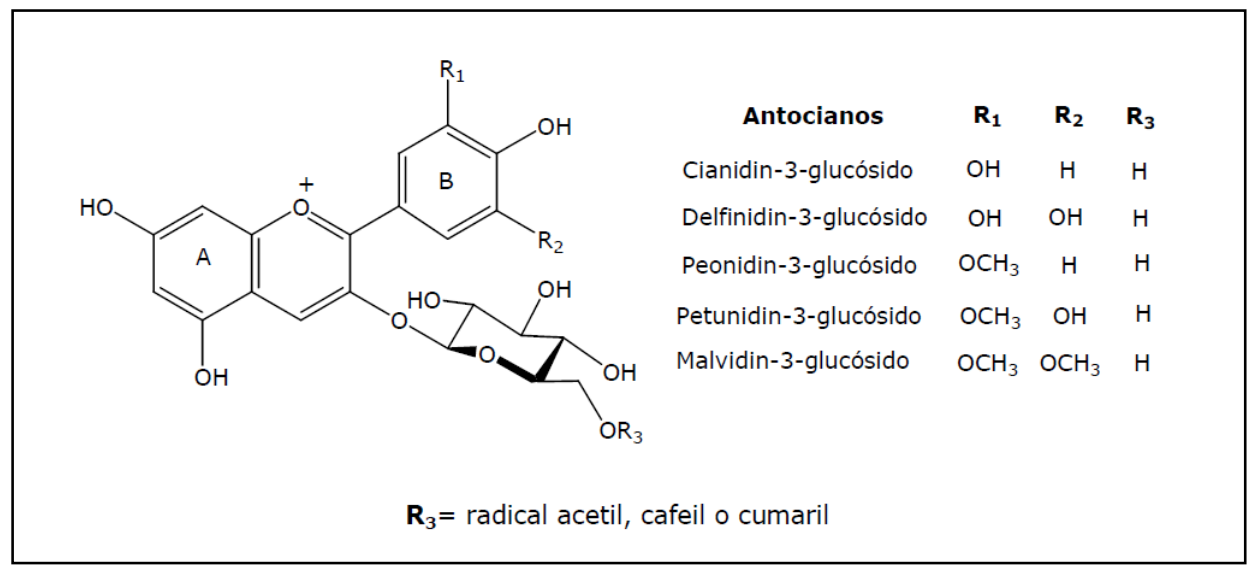

Figura 3.4. Estructura química de las diferentes antocianidinas

La variabilidad creada por esta diversidad de estructuras y la coexistencia de estas distintas moléculas en el seno de una misma planta, permite discriminar género y especie. Los antocianos, por hidrólisis, dan lugar a un azúcar (glucosa, galactosa, ramnosa) y una aglucona denominada antocianidina o antocianidol. Estas antocianidinas varían a su vez en función de los grupos que ocupan las funciones R1 y R2, como puede observarse en la figura 3.4. 
En Vitis vinifera encontramos monoglucósidos de Malvidina, Petunidina, Delfinidina, Peonidina, Cianidina. Una de las características de la especie es la glucosilación en posición 3 y la presencia mayoritaria de 3-glucósido de malvidina y de sus derivados, siendo éstos los responsable principales del color del vino tinto (Cacho, 2003). En otras especies del mismo género como Vitis riparia o Vitis rupestris, los antocianos aparecen como diglucósidos con dos moléculas de glucosa en las posiciones 3 y 5 . En estudios realizados sobre composición antociánica de diferentes cepas de $V$. vinifera, el contenido global (de $500 \mathrm{mg} / \mathrm{kg}$ hasta $3000 \mathrm{mg} / \mathrm{Kg}$ ) y los niveles de cada antociano, varían individualmente para cada variedad.

Los antocianos son, en gran medida, responsables del color de los vinos tintos jóvenes, jugando un papel fundamental a pesar del hecho de que su gran reactividad causa su desaparición progresiva durante el envejecimiento del vino. Para explicar dicha desaparición se han propuesto reacciones de oxidación de sus formas calconas con pérdida irreversible del color (Brouillard, 1982; Furtado et al., 1993), así como reacciones de asociación entre antocianos y flavanoles, dando lugar a "pigmentos poliméricos" que estabilizan el color.

El color de estos compuestos antociánicos depende principalmente de parámetros exógenos como el $\mathrm{pH}$, el nivel de sulfuroso, la temperatura, la presencia de iones metálicos, los niveles de oxígeno o de ácido ascórbico, así como de otros intrínsecos como el azúcar unido a la aglicona, las sustancias del anillo B (hidroxilación y metilación), la acilación, etc. Además es influenciable por la presencia de otros compuestos que pueden actuar como copigmentos, o con los que interaccionan dando lugar a compuestos más estables.

\subsubsection{LOS FLAVANOLES}

Los 3-flavanoles (flavan-3-ol) están presentes en la uva en estado de monómeros y bajo formas más o menos polimerizadas, constituyendo los taninos catéquicos. Estas moléculas pueden ser clasificadas en función del número de unidades flavanol elementales, pudiéndose clasificar como proantocianidinas oligoméricas (hasta 5 unidades) o poliméricas (más de 10 unidades).

Los principales 3-flavanoles monómeros de la uva son $(+)$ catequina y su isómero la (-) epicatequina. Esta última se puede encontrar bajo forma de éster gálico (3-galato de epicatequina, galocatequina, 3-galato de catequina y 3-galato de galocatequina). El término tanino, por el cual generalmente se denominan los oligómeros y polímeros de los flavanoles, hace referencia a su capacidad para interaccionar con las proteínas.

Una primera subdivisión clasifica los taninos en dos grandes grupos, los taninos hidrolizables (taninos gálicos o galotaninos, y taninos elágicos), y los taninos condensados (proantocianidinas y prodelfinidinas).

Los taninos que contiene de forma natural la uva, y por lo tanto los vinos, son los condensados. Los hidrolizables, o bien se utilizan como coadyudantes tecnológicos (auxiliares de la vinificación) o bien están presentes en el corcho de los tapones. El ácido gálico, que puede a veces estar presente en forma de triglucósido, existe en raspones y en pepitas, y en dosis limitadas en los hollejos. 
Los taninos del vino son polímeros condensados de 3-flavanoles, con un grupo $\mathrm{OH}$ en el carbono 3 (catequinas), y de 3,4-flavandioles, con un grupo $\mathrm{OH}$ en el carbono 3 y otro en el carbono 4. Ambos se pueden incluir en el grupo de los flavanos (Figura 3.5).

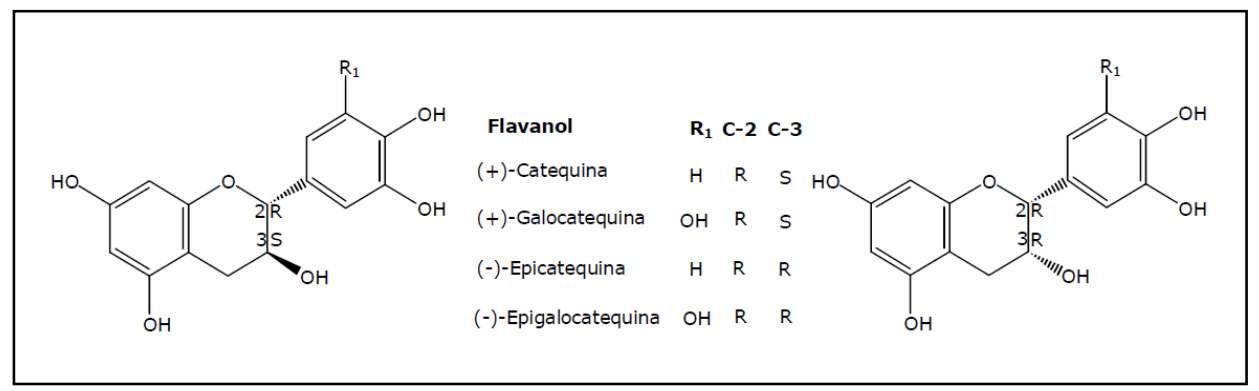

Figura 3.5. Estructura química de los flavanoles monómeros de la uva

Además poseen la propiedad de liberar antocianidinas por calentamiento en medio ácido, distinguiéndose dos grupos de proantocianidinas dependiendo de la naturaleza de la antocianidina liberada: procianidinas (polímeros de $(+)$-catequina y de (-)-epicatequina) y prodelfidinas (polímeros de (+)-galocatequina y (-)epigalocatequina); las primeras se caracterizan por liberar cianidina y las segundas por liberar delfidinas. Esta liberación de antocianos es debida a la ruptura de los enlaces interflavánicos (Porter et al., 1986), lo que permite además diferenciar estos compuestos en función del tipo de enlace interflavánico, en procianidinas de tipo $\mathrm{B}$, monómeros unidos por el carbono 4 de la unidad superior y el carbono 6 o 8 de la unidad inferior (Figura 3.6); y procinidinas de tipo A que presentan un enlace de tipo éter entre el carbono 2 de la unidad superior y los grupos hidroxilos de los carbonos 5 o 7 de la unidad inferior. Sin embargo aún no se ha comprobado la presencia de proantocinidinas de tipo A en el género Vitis (Cheynier et al., 2003).

Los 3-flavanoles tanto monómeros como en formas más o menos polimerizadas, se localizan en las semillas, aunque se han localizado también trazas de dímeros y trímeros en la pulpa (Bourzteix et al., 1986; Ricardo da Silva et al., 1992). Otra fuente importante de taninos es el hollejo de las uvas, donde se han identificado tres tipos de taninos: taninos presentes bajo forma libre en el jugo vacuolar (localizados en formas condensada en las células próximas a la epidermis y como granulaciones difusas en las células internas del mesocarpio), taninos unidos fuertemente a la membrana proteofosfolípida (tonoplasto), y taninos ligados a los polisacáridos de la pared celular (Amrani Joutei et al., 1994).

Thorngate y Singleton (1994) sugieren que durante la vinificación se extraen principalmente los taninos de las semillas localizados en las capas superficiales de la misma. Estos compuestos ocupan una posición de defensa del embrión en las envolturas externas e internas y su difusión al medio exterior depende de la solubulización de la cutícula. Los taninos de los hollejos difieren de los de las semillas por la presencia de prodelfidinas, por su mayor grado de polimerización (Di Stefano, 1995) y por el menor porcentaje de subunidades galoiladas. 


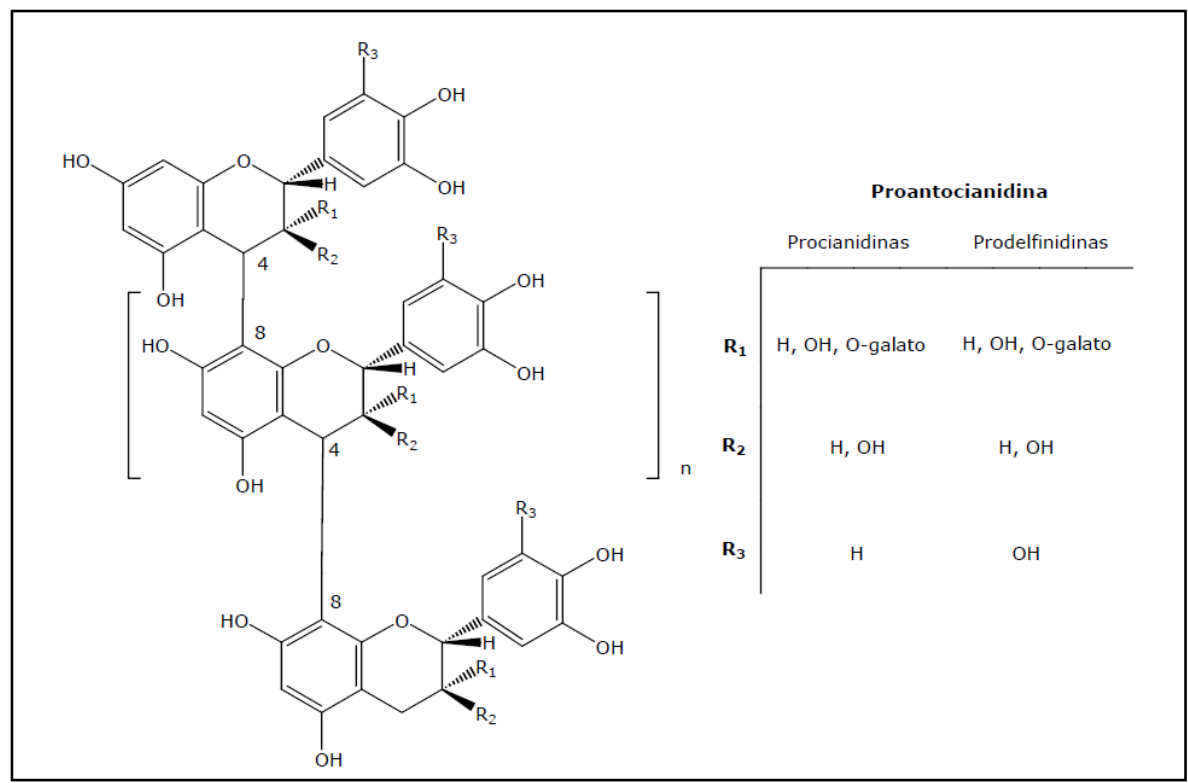

Figura 3.6. Estructuras químicas de las proantocianidinas de tipo $B$

En vinos jóvenes se encuentra con mayor frecuencia dímeros y trímeros. En los vinos viejos los polímeros sobrepasan las 10 unidades monoméricas. Estos polímeros pueden estar constituidos mayoritariamente por catequinas o por galocatequinas, dependiendo de su procedencia, bien de hollejos o de semillas. De cualquier manera, los monómeros más activos para la polimerización son las galocatequinas, dada la actividad de su grupo $\mathrm{OH}$ en el carbono 3.

Los taninos de la uva están constituidos por una proporción mayoritaria de epicatequina. Coexisten numerosas posibilidades estructurales, desde dímeros hasta polímeros de masa molecular que puede sobrepasar 24.000, pero para que éstos precipiten con las proteínas es preciso que estos compuestos tengan un peso molecular comprendido entre 500 y 3000; ya que si son demasiado voluminosos no se pueden aproximar en medida suficiente a los sitios activos de las proteínas, y por tanto no interaccionan con ellas.

La concentración de procianidinas se sitúa generalmente en valores alrededor de 200 a $700 \mathrm{mg} / \mathrm{kg}$ de uva. Existe una amplia variabilidad en las concentraciones de catequinas y proantocinidinas en raspones, pieles y semillas, en relación con la variedad de uva. Así las uvas Pinot Noir presentan valores muy altos de catequinas y proantocinidinas (Kovac et al., 1990), y también la variedad Cabernet Sauvignon ha sido descrita como una variedad con contenidos elevados de estos compuestos (Auw et al., 1996). A diferencia de lo que sucede para los antocianos, las variedades blancas no son menos ricas en taninos que las tintas (Souquet et al., 1996).

Por lo que respecta a las propiedades organolépticas de los taninos que se encuentran en las distintas partes de la baya, se puede decir que los taninos de las pieles, generalmente combinados con otros compuestos (polisacáridos, antocianos y proteínas), son de naturaleza poco astringente comparados con los de las pepitas, que presentan unas características más astringentes y amargas. Los taninos son compuestos fenólicos caracterizados por su capacidad para combinarse con las proteínas y otros polímeros como los polisacáridos. Esta característica explica sus propiedades en el curtido de las 
pieles, haciéndolas imputrescibles al reaccionar con el colágeno, y explica también su astringencia, causada por la precipitación de las proteínas y glucoproteínas de la saliva.

\subsubsection{TLAVONOLES, FLAVONAS Y FLAVANONOLES}

La estructura química de los flavonoles, flavonas y flavanonoles es muy similar. La diferencia entre las flavonas y los flavonoles está en la presencia de un grupo hidroxilo en el carbono 3 en los flavonoles, mientras que los flavanonoles no poseen el doble enlace del heterociclo central de los flavonoles (Figura 3.7).

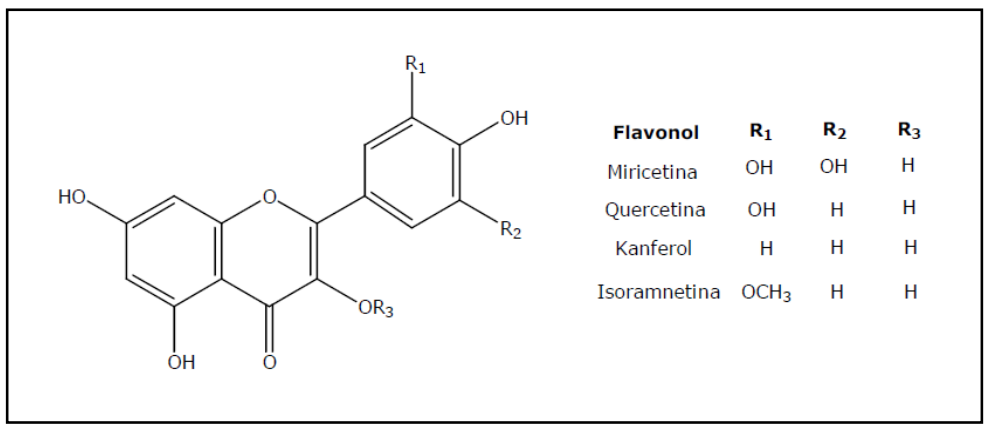

Figura 3.7. Estructura química de los flavonoles

Las flavonas solamente se han identificado en las hojas de Vitis vinifera y no en vinos. Los flavanonoles se han encontrado en la madera en forma de agliconas libres, en uvas Vitis vinifera, en vinos blancos y tintos e incluso en orujos y raspones. Entre los flavanonoles más característicos estan la astilbina y la engeletina.

Dentro de este grupo, los flavonoles son los más importantes. En las uvas de Vitis vinifera se presentan como glicósidos de cuatro agliconas importantes: miricetina, quercetina, kaemferol e isoramnetina. En el vino los flavonoles se pueden encontrar como agliconas en estado libre como consecuencia de la hidrólisis de las formas glicosiladas durante la vinificación, la maduración y/o el envejecimiento del vino (Revilla et al., 1986; García-Viguera y Bridle, 1995; Price et al., 1995; McDonal et al., 1998; Vanhoenacker et al., 2001; Ibern-Gómez et al., 2002; Zou et al., 2002; Zafrilla et al., 2003).

El contenido de flavonoles es muy variable en los vinos tintos. Estas diferencias se deben fundamentalmente a factores como la variedad de uva, clima, grosor del hollejo y momento de la recolección, pero también depende del proceso de vinificación. El contenido de flavonoles no contribuye mucho al contenido total de compuestos fenólicos en el vino (Alonso et al., 1986). Son pigmentos amarillos que participan directamente, aunque no de forma importante en el color del vino, ya que solamente contribuyen a una pequeña parte de la componente amarilla (Wulf y Nagel, 1980). Sin embargo influyen notablemente de modo indirecto en el color de los vinos tintos, ya que son capaces de actuar como copigmentos de los antocianos modificando su color (Gómez-Cordovés et al., 1995). 


\subsubsection{COMPUESTOS NO FLAVONOIDES}

Dentro de este grupo de compuestos no flavonoides, se puede incluir a los ácidos fenólicos, que podemos dividir en ácidos benzoicos $\left(\mathrm{C}_{6}-\mathrm{C}_{1}\right)$, los cuales poseen el anillo fenólico con un carbono en su cadena lateral, y ácidos cinámicos, portadores de una cadena lateral insaturada $\left(\mathrm{C}_{6}-\mathrm{C}_{3}\right)$; pero también se va a poder incluir a otros derivados fenólicos como los estilbenos.

\subsubsection{LOS ÁCIDOS FENÓLICOS}

Los ácidos fenólicos se caracterizan por la presencia de un solo anillo bencénico, por lo que no se van a poder incluir en la gran familia de los polifenoles. Se pueden subdividir en dos grupos, un primer grupo de ácidos benzoicos derivados del ácido $p$ hidroxibenzoico, y un segundo grupo constituido por los ácidos cinámicos, que se consideran derivados del ácido $p$-cumárico o ácido $p$-hidroxicinámico, incluyendo la serie de los clorogénicos. Sin embargo, algunos autores ponen en duda la presencia de estos últimos en los vinos.

La uva y el vino contienen ácidos benzoicos y ácidos cinámicos; su concentración oscila entre los $100 \mathrm{y} \operatorname{los} 200 \mathrm{mg} / \mathrm{L}$ en el vino tinto, y entre los $10 \mathrm{y}$ los $20 \mathrm{mg} / \mathrm{L}$ en el vino blanco. Se les encuentra en la uva, sobre todo en forma de combinaciones heterosídicas, siendo liberados por hidrólisis ácida, y de tipo éster (taninos gálicos y elágicos), siendo entonces liberados por hidrólisis alcalina. Las formas libres están más presentes, sobre todo en el vino tinto, debido a la hidrólisis de estas combinaciones y de las reacciones de degradación de moléculas más complejas, en particular de los antocianos, por la acción del calor.

En la tabla 3.1 se pueden contemplar las estructuras de los distintos tipos de ácidos fenólicos de la uva y del vino.

Tabla 3.1. Ácidos fenólicos de la uva y el vino.

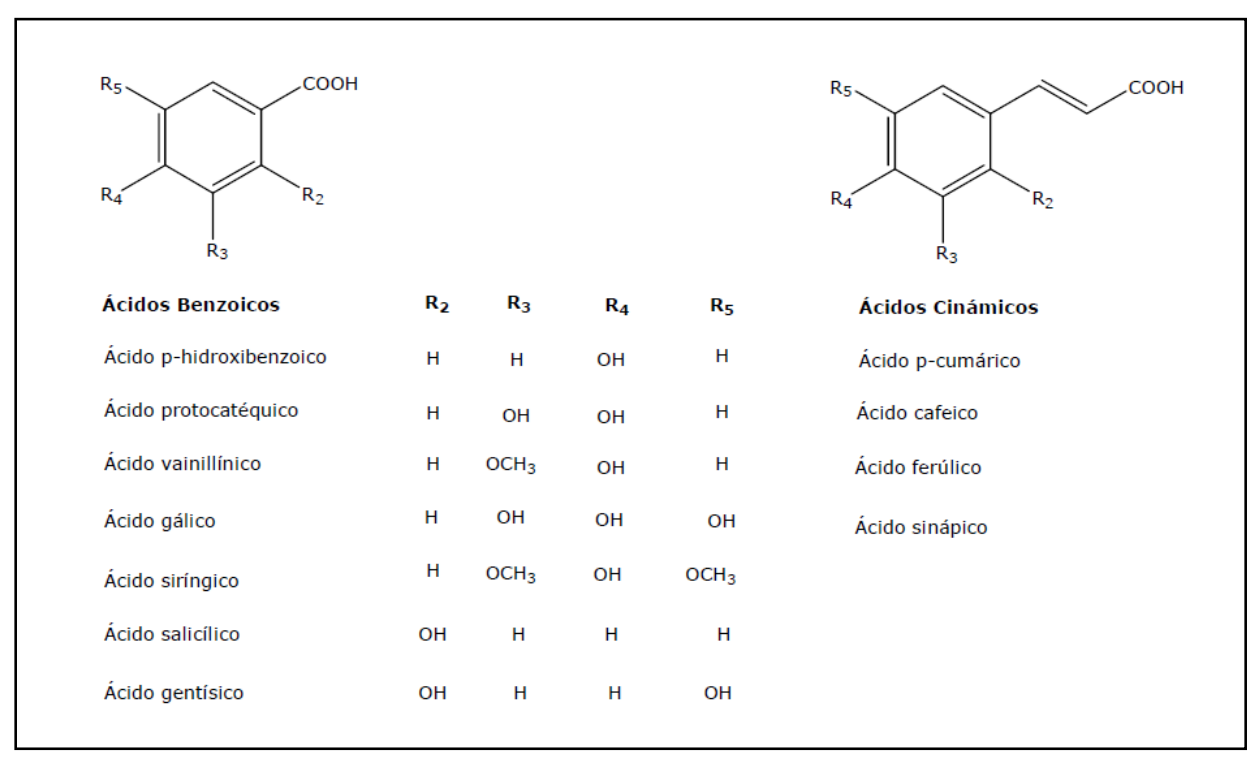

En cuanto a sus características organolépticas, los ácidos fenólicos no presentan ni sabor ni olor particulares, pero son los precursores de los fenoles volátiles, después de la acción de ciertos microorganismos. 
Los ácidos benzoicos son poco abundantes en uva blanca y algo más en tinta. En vinos su concentración va a ser mayor en los tintos, encontrándose en cantidades de 0,1 $\mathrm{mg} / \mathrm{L}$. Su mayor presencia va a ser en forma de ácido siríngico y de ácido vaníllico. En barrica de varios años hay acumulación de vaníllico y también de gálico y elágico por hidrólisis del tanino del roble, liberando además azúcares. También presentan una cierta inestabilidad, sobre todo en presencia de oxígeno y aminoácidos, tendiendo hacia formas de color amarillo-rojizo.

En la uva y en el vino están presentes muchos ácidos cinámicos. Estos se encuentran identificados en pequeña cantidad en su forma libre. Se encuentran en las vacuolas de las células del hollejo y de la pulpa sobre todo esterificados, con el ácido tartárico esencialmente, pudiendo estar igualmente esterificados con glucosa. En las concentraciones encontradas en los vinos no tienen impacto sobre las características sensoriales.

Los ácidos cinámicos son poco abundantes en uva blanca, siendo en variedades tintas bastante más abundantes, encontrándose las cantidades más altas en mostos, ya que son los principales fenoles de la pulpa. En vinos existen de 0,1 a $30 \mathrm{mg} / \mathrm{L}$ en combinación con ácido tartárico y antocianos. El p-cumárico, al igual que el cafeico, se encuentra en concentraciones de hasta $10 \mathrm{mg} / \mathrm{L}$, que suelen aumentar con la crianza en barrica hasta los $100 \mathrm{mg} / \mathrm{L}$ en tintos y hasta $5 \mathrm{mg} / \mathrm{L}$ en blancos. En barrica, por degradación de la lignina existe, debido al efecto hidrolítico, se forma alcohol coniferílico, cumarina $\mathrm{y}$, a partir del tanino del roble, escopoletina. Los ácidos cinámicos pueden presentar inestabilidad debido a la acción polifenoloxidásica sobre el cafeico derivando en colores pardos. Sus quinonas poseen una elevada reactividad participando en la oxidación y el pardeamiento de los antocianos y de los taninos. Estos ácidos se encuentran muchas veces acilando los sustitutos glucósidos de los antocianos (excepto para la variedad Pinot Noir) y además están involucrados en los procesos de copigmentación con antocianos (Brouillard y Dangles, 1994).

\subsubsection{LOS ESTILBENOS}

Dentro de los polifenoles más complejos, otra familia de moléculas va a estar presente en la uva, el vino y en las barricas de roble. Estos compuestos son los estilbenos, los cuales poseen dos ciclos bencénicos unidos generalmente por una cadena de etano o eventualmente de etileno. A este tipo pertenece el isómero trans del resveratrol, o 3,5,4'-trihidroxiestilbeno, que es producido por el viñedo en respuesta a un ataque fúngico del hongo Botrytis cinerea, siendo los compuestos que presentan esta propiedad los conocidos como fitoalexinas.

El resveratrol existe en dos formas isómeras, cis y trans, que pueden aparecer glucosiladas (piceidos) y así se han detectado en uvas y vinos. En una disolución hidroalcohólica, la estabilidad del resveratrol depende de la luz, la temperatura y el $\mathrm{pH}$. De esta forma, se ha podido comprobar que el trans-resveratrol es estable durante meses cuando está protegido de la luz, excepto a $\mathrm{pH}$ mayor o igual a 10 . La radiación ultravioleta desplaza el equilibrio isomérico hacia la formación de la forma cis. El isómero cis sólo es estable a $\mathrm{pH}$ cercanos a la neutralidad, un $\mathrm{pH}$ bajo favorece que la forma cis se isomerice a la trans, que es la forma estéricamente más estable. 
El resveratrol es capaz de inhibir la peroxidación de los lípidos de las membranas celulares. Además es efectivo como antiagregante plaquetario, vasodilatador e hipolipemiante. Más recientemente se han puesto de manifiesto otros efectos del resveratrol como antiinflamatorio y anticancerígeno. Así mismo, otros compuestos relacionados con el resveratrol, como pueden ser sus glucósidos, han demostrado capacidad antioxidante, ya que inhiben la peroxidación lipídica y la oxidación de las lipoproteínas de baja densidad o LDL.

\subsection{REACTIVIDAD QUÍMICA Y EVOLUCIÓN DE LOS COMPUESTOS FENÓLICOS.}

El color de los antocianos en disolución es dependiente del medio en el que se encuentren, estando estos equilibrios regulados por el $\mathrm{pH}$ de la solución. Por otra parte el sulfuroso agregado al vino como antiséptico y antioxidante se liga a los antocianos rápidamente dando un compuesto incoloro, que, a pesar de ser reversible, puede ocasionar una pérdida de color en el vino.

Durante la evolución del vino en el tiempo se producen una serie de reacciones entre compuestos fenólicos que van a determinar el cambio de color que se produce durante el envejecimiento del vino. Además estas reacciones también actúan sobre las características organolépticas de los vinos.

\subsubsection{EFECTO DEL PH EN EL COLOR DE LOS ANTOCIANOS}

En una disolución hidroalcohólica como es el vino, los antocianos se encuentran en diferentes formas y su equilibrio depende del pH (Figura 3.8).

A pH muy acido los antocianos existen principalmente en la forma roja de catión flavilio $(\mathrm{A}+)$. A medida que el $\mathrm{pH}$ aumenta este catión se puede transformar en la base quinónica $(\mathrm{AO})$ de color azul mediante una reacción de transferencia de protones, o bien puede evolucionar hacia la forma carbinol incolora $(\mathrm{AOH})$ mediante la hidratación de catión flavilio en posiciones $\mathrm{C} 2 \mathrm{o}$ C4. Esta a su vez puede transformarse en las calconas cis y trans, que presentan un ligero color amarillo (Brouillard, 1982). Esta transformación esta favorecida por temperaturas elevadas (Furtado et al., 1993), de manera que la calcona trans puede ser oxidada, dando lugar a ácidos fenólicos (Brouillard, 1982). Todas estas reacciones son reversibles con la única excepción de la reacción de oxidación que comportaría la perdida irreversiblemente el color del vino (King et al., 1980). Por lo tanto la estabilidad del color del vino estará muy comprometida siempre que la temperatura de conservación sea elevada ya que se favorece la formación de las calconas y su posterior oxidación.

Estudios realizados por Glories (1984) revelaron que en vinos tintos $(\mathrm{pH} \approx 3.5)$ solo un $12,2 \%$ de los antocianos libres se encuentran en la forma roja del catión flavilio, estando el equilibrio desplazado mayoritariamente hacia la forma carbinol $(45,2$ $\%$ ) y la forma calcona $(27,6 \%)$, ambas incoloras, y minoritariamente hacia la base quinónica de color azul (15\%). De modo que solo entre el 20-30 \% de los antocianos se encontrarán coloreados, ya que el resto son incoloros al $\mathrm{pH}$ del vino. 


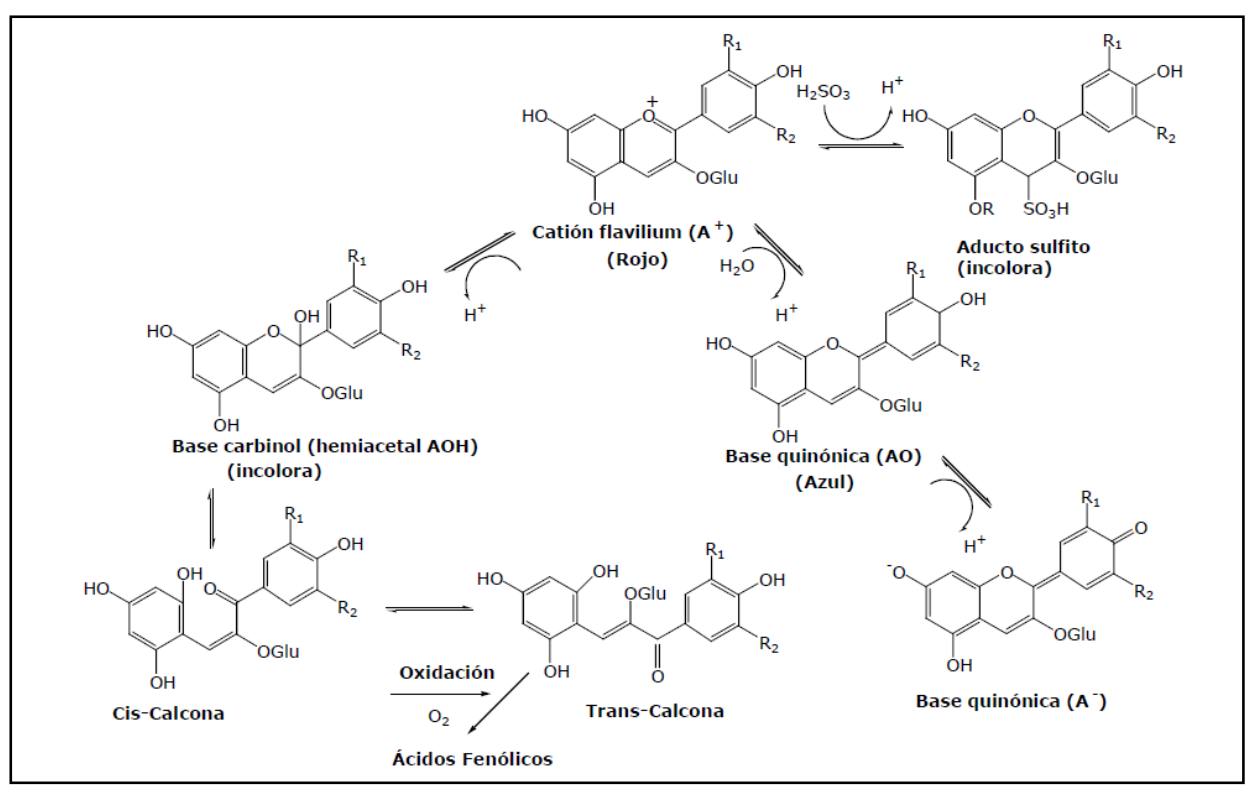

Figura 3.8. Equilibrio de los antocianos en función del pH

\subsubsection{EFECTO DE LA CONCENTRACIÓN DE SULFUROSO SOBRE LOS ANTOCIANOS.}

La habilidad del $\mathrm{SO}_{2}$ para extraer antocianos, debido a que ayuda a la degradación de las estructuras de la piel, es conocida desde hace tiempo, y muchos métodos de obtención de antocianos de los orujos utilizan grandes cantidades de éste (Mazza, 1995). Este efecto es más importante en vinos procedentes de vendimias con podredumbre, puesto que además de permitir una mayor solubilización de los compuestos fenólicos, el anhídrido sulfuroso evitara su oxidación debida a la enzima lacasa presente en este tipo de vendimia (Ribéreau-Gayon et al., 1998b).

El color de los antocianos en los vinos también se ve afectado por la presencia de anhídrido sulfuroso $\left(\mathrm{SO}_{2}\right)$, reduciendo su velocidad de degradación, pero a su vez también evita la formación de pigmentos condensados mediados por acetaldehído, además de reducir las pérdidas de color por precipitaciones durante la vinificación. De manera que el déficit de bisulfito en el vino hace aumentar la tasa de polimerización de antocianos y conduce a un envejecimiento prematuro del color (Hebrero et al., 1988). La mayor parte del anhídrido sulfuroso libre se encuentra bajo la forma de anión bisulfito $\left(\mathrm{HSO}_{3}{ }^{-}\right)$que se puede unir a las posiciones 2 ó 4 del catión flavilio, originando un aducto incoloro, estable al $\mathrm{pH}$ del vino (Figura 3.9). La reacción ocasiona la decoloración del antociano, lo que supone una pérdida temporal de la intensidad colorante, pero también le aporta estabilidad, ya que el complejo es menos sensible a los procesos de hidratación y polimerización, al tener ocupadas las posiciones reactivas (Somers, 1971; Glories, 1984). Esta reacción es reversible dependiendo de la naturaleza del antociano, del pH del vino y de la aireación. 


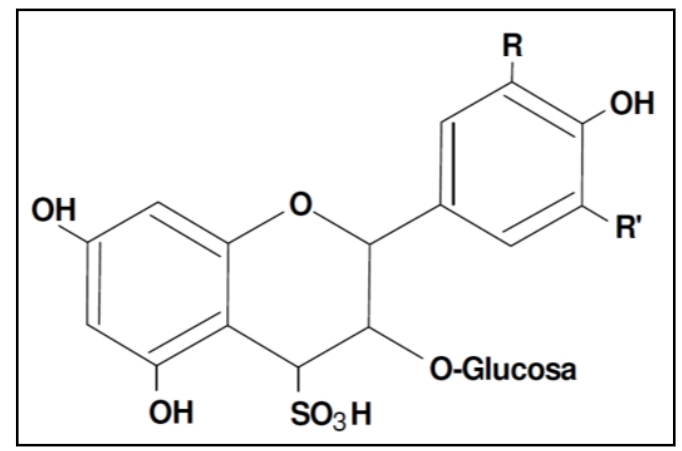

Figura 3.9. Compuesto de adición bisulfito-antociano incoloro

\subsection{REACCIONES ENTRE COMPUESTOS FENÓLICOS}

Durante la elaboración de los vinos ocurren simultáneamente dos tipos de reacciones, las reacciones enzimáticas y las reacciones químicas, ambas afectan al color del vino, pero las primeras predominan en las etapas de la elaboración mientras que las segundas comienzan a predominar en las últimas etapas cuando la actividad enzimática decrece.

\subsubsection{REACCIONES ENZIMÁTICAS DE LOS COMPUESTOS FENÓLICOS.}

Las reacciones enzimáticas en su mayoría catalizadas por las enzimas polifenoloxidasa (PPO), peroxidasa, glicosilasas y esterasas, comienzan en el estrujado, cuando se daña la estructura de la célula y en presencia de oxígeno. Entre los sustratos preferidos por la PPO destaca el ácido caftárico. El elevado potencial redox de la oquinona del ácido caftárico permite oxidar otros constituyentes del mosto, como por ejemplo otros difenoles que no son sustratos de la PPO y que sí están implicados en los fenómenos de pardeamiento oxidativo.

Las o-quinonas secundarias generadas por este fenómeno reaccionan espontáneamente con moléculas nucleófilas del mosto para formar distintos aductos que pueden incorporarse a nuevas reacciones de degradación (Sarni et al., 1996). Así la oxidación enzimática de ácidos fenólicos a quinonas, catalizada por la PPO, empieza desde el momento en el que la uvas son estrujadas. Los antocianos son sustratos pobres para la PPO, pero pueden reaccionar con las o-quinonas generadas por oxidación enzimática de otros fenoles, especialmente los antocianos orto-difenólicos (delfinidina, cianidina y petunidina), produciéndose una importante decoloración. Pero los otros antocianos también pueden reaccionar mediante la formación de aductos con oquinonas. En una disolución modelo se observo que la oxidación acoplada ocurre a más alta velocidad, lo que parcialmente protege a los antocianos que no son o-difenoles (malvidina y peonidina) de la degradación (Sarni et al., 1996).

Los antocianos también pueden ser oxidados directamente por peroxidasas y lacasas con la consecuente decoloración. La enzima lacasa, en general, parece ser más resistente a las condiciones de vinificación que la enzima PPO, y su presencia suele ser un gran problema con respecto a la calidad del vino. 
También pueden ser degradados por glicosidasas. Estas enzimas no se encuentran en la uva en cantidades significativas, generalmente se añaden durante la elaboración para liberar compuestos volátiles de sus precursores glucosídicos o pueden estar presentes como actividades secundarias en preparados enzimáticos del tipo pectinasas, e incluso pueden ser liberados por algunas cepas de levaduras durante la fermentación. Como resultado se obtienen las agliconas de los antocianos, que son más inestables en el medio, dando lugar a una pérdida de color. Esto puede ser acrecentado por la presencia de acil esterasas (Cheynier, 2003). Estas enzimas actúan sobre los esteres de los ácidos hidroxicinámicos incrementando sus respectivos ácidos libres (Wightman et al., 1997) y aumentado la actividad de la enzima polifenoloxidasa (Gunata et al., 1987), la cual va a producir la pérdida de antocianos por oxidación.

Las proantocinidinas tienen también propensión a oxidarse debido a la facilidad con que sus anillos ortodifenólicos, presentes en el anillo B, se transforman en quinonas o semi-quinonas (Figura 3.10). Estas reacciones son promovidas también por la enzima PPO. Además, esta oxidación se ve favorecida por la presencia de ácidos hidroxicinámicos, metales catalizadores como $\mathrm{Fe}$ o $\mathrm{Cu}$, oxígeno disuelto, altas temperaturas y $\mathrm{pH}$ elevado ( $>3.6)$. Los productos de esta oxidación son de color pardo y muy propensos a precipitar (Moutounet, 2000).

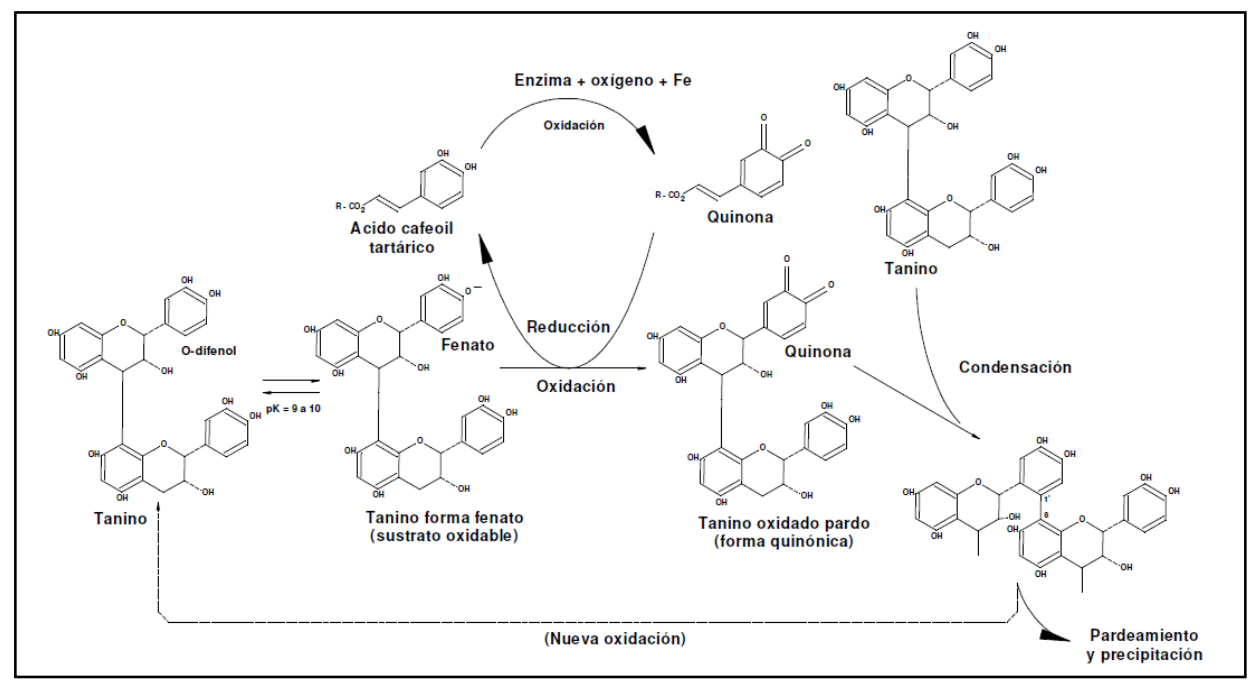

Figura 3.10. Esquema de la oxidación de proantocianidinas según Moutounet (2000)

\subsubsection{REACCIONES QUÍMICAS DE LOS COMPUESTOS FENÓLICOS.}

Durante la fermentación alcohólica y durante el envejecimiento del vino, los taninos reaccionan con los antocianos para dar compuestos coloreados. En los vinos de un año se estima que un 50\% del color puede deberse a estos agregados. En vinos más viejos esta proporción aumenta (Ribéreau-Gayon, 1982). Por lo tanto el color rojo teja de los vinos muy viejos se debe en parte a la existencia de estos compuestos y en parte al color que toman los taninos al oxidarse.

Los taninos también pueden condensarse con otros 3-flavanoles presentes en el vino, como catequinas monómeras y otras proantocinidinas. Este tipo de condensación 
es de tipo no oxidativo y conduce a un aumento en el tamaño de las moléculas, lo cual puede dar lugar a posibles precipitaciones.

La inestabilidad de los antocianos libres se ve disminuida al producirse reacciones de combinación con taninos $\mathrm{u}$ otros componentes del vino para formar pigmentos estables, que realmente son los responsables del color de los vinos en el tiempo. Teniendo en cuenta los equilibrios dependientes del $\mathrm{pH}$ del vino, son varios los mecanismos que involucran tanto al catión flavilio como a la base carbinol y que han sido propuestos para explicar la conversión de los antocianos en nuevos pigmentos poliméricos más estables.

\subsubsection{CONDENSACIÓN DE ANTOCIANOS Y TANINOS}

Estas reacciones están basadas en procesos de adición nucleofílica en donde los antocianos y los taninos pueden actuar tanto como agentes electrófilos (presentan una deficiencia de electrones y tienden a extraer moléculas con exceso de electrones) como nucleófilos. Los antocianos pueden comportarse como electrófilos, a través de la carga positiva de la forma flavilium $\left(\mathrm{A}^{+}\right)$. Los flavonoides neutros, como los taninos, muestran un exceso de electrones en las posiciones C8 y C6 y de esta manera pueden comportarse como nucleofílicos. Por otro lado las formas hidratadas de los antocianos pueden tener cierta densidad de carga negativa y actuar como nucleófilos y las rupturas de los enlaces C-C de las unidades constitutivas de los taninos, fenómeno que ocurre espontáneamente en el vino, genera carbocationes $\left(\mathrm{T}^{+}\right)$intermediarios que son electrófilos. El trabajo de Remy et al. (2000) fue uno de los primeros en confirmar la presencia en el vino de ambos tipos de compuestos, siendo estas estructuras más complejas que las de los antocianos monómeros y de color similar a la de los antocianos libres.

\subsection{CONDENSACIÓN TANINO-ANTOCIANO (T-A)}

Las procianidinas en un medio ácido como es el vino se pueden hidrolizar formando un carbocatión o catequina activada, reaccionando así con los antocianos bajo la forma hemiacetálica (Figura 3.11), produciendo un complejo incoloro que se colorea seguidamente de rojo anaranjado después de su deshidratación (Haslam, 1980). Esta condensación se ve favorecida en ausencia de oxígeno y por la temperatura, siendo esta la explicación de la evolución de los vinos almacenados en ambientes reductores como depósitos o botella. Además el carbocatión formado en este tipo de reacciones puede generar nuevas proantocinidinas, conduciendo a un aumento de su grado de polimerización, con la consiguiente disminución de la astringencia del vino. Por la tanto este tipo de reacciones dependen de la concentración de antocianos en el medio y el color varia con la naturaleza del carbocatión y el grado de polimerización. 


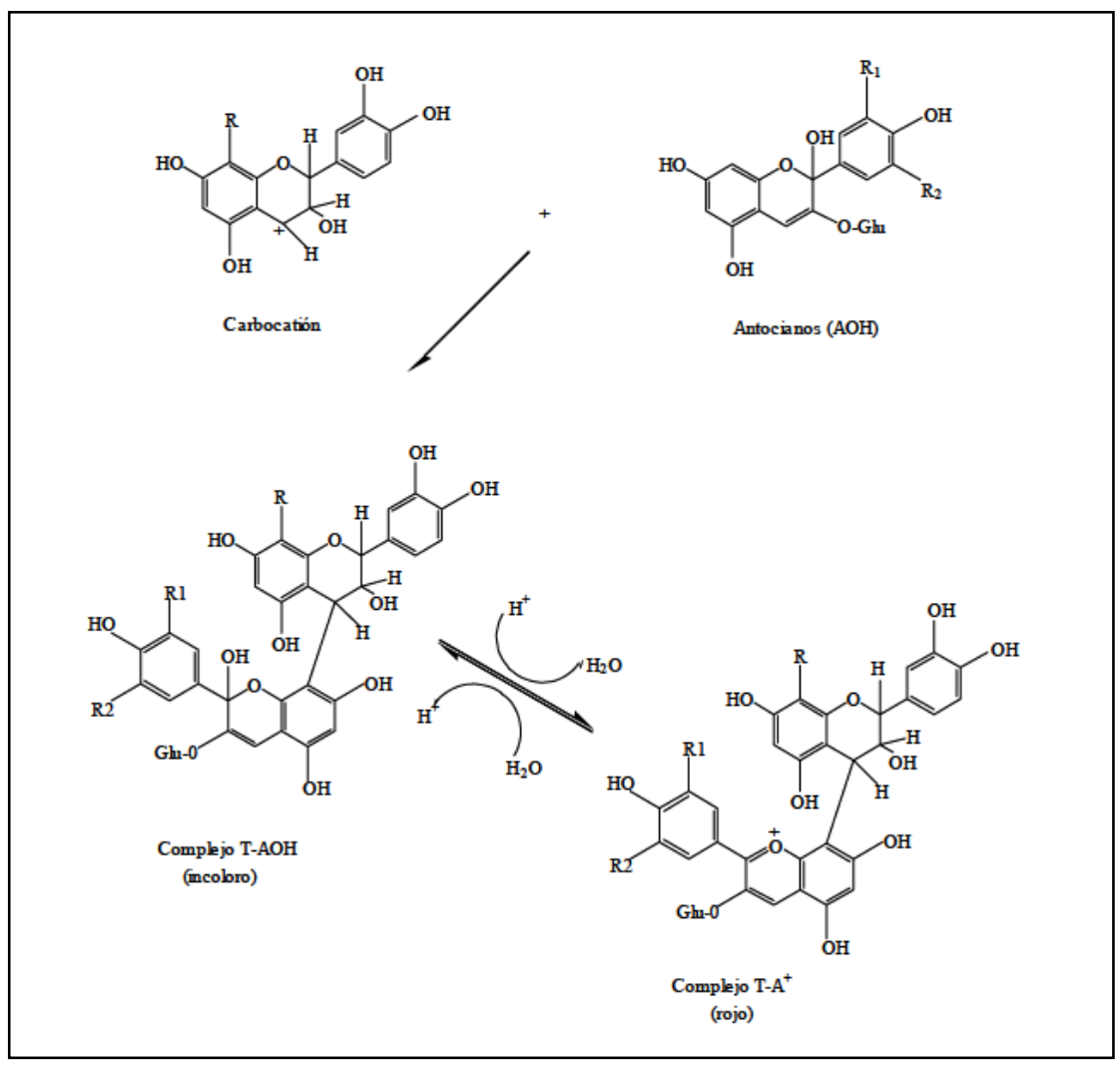

Figura 3.11. Condensación directa de taninos y antocianos de tipo T-A

\subsection{CONDENSACIÓN ANTOCIANO-TANINO (A-T)}

Los antocianos bajo su forma catiónica $\left(\mathrm{A}^{+}\right)$reaccionan con las posiciones negativas C6 ó C8 de los taninos, formando un flaveno incoloro (A-T), el cual posteriormente se puede colorear de rojo $\left(\mathrm{A}^{+}-\mathrm{T}\right)$ en presencia de oxígeno, estableciéndose un estado de equilibrio entre ambas formas. Este tipo de mecanismo involucra a la forma catiónica del antociano, cuya proporción es pequeña al $\mathrm{pH}$ del vino, lo que justifica que este proceso sea lento y de extensión limitada. La conservación al abrigo del aire de soluciones de antocianos en presencia de flavanoles y a temperaturas superiores a $20{ }^{\circ} \mathrm{C}$, produce una disminución del color que puede recuperarse después por aireación. Este tipo de compuestos pueden evolucionar a tonalidades amarillas por la aparición de estructuras xantílium (Dallas et al., 1996; Gawel et al., 2000).

Los compuestos de condensación entre antocianos y taninos $\left(\mathrm{T}_{-} \mathrm{A}^{+}\right.$y $\left.\mathrm{A}^{+}-\mathrm{T}\right)$ son de color similar a los antocianos. Pero los compuestos $\mathrm{A}^{+}-\mathrm{T}$ son resistentes a la decoloración por el $\mathrm{SO}_{2}$ debido a la sustitución de la posición 4 del anillo $\mathrm{C}$ del antocianos, mientras que los aductos $\mathrm{T}^{-} \mathrm{A}^{+}$teóricamente serían susceptibles a la decoloración por $\mathrm{SO}_{2}$ y a la hidratación. 


\subsection{POLIMERIZACIÓN POR MEDIACIÓN DEL ACETALDEHÍDO}

Tanto los antocianos como los taninos pueden unirse también por medio de una reacción en la que interviene el acetaldehído. Estos dan lugar a productos enlazados por puente de etilo, incluyendo (T-etil-T), aductos de taninos y antocianos (T-etil-A) y antocianos entre sí (A-etil-A) (Cheynier, 2003). La formación de estos compuestos implica la adición nucleofílica de antocianinas hidratadas o de unidades de taninos con el carbocatión resultante de la protonación del acetaldehído. El tamaño molecular de estos productos es variable ya que depende del número de pasos sucesivos en la reacción inducida por el acetaldehído y del tamaño y reactividad de los polifenoles, los cuales también varían desde monómeros hasta taninos con más de 25 unidades. El acetaldehído puede proceder de la oxidación del etanol, aunque también puede tener su origen en las levaduras, las bacterias acéticas y la autooxidación de compuestos fenólicos (Liu y Pilone, 2000). Los antocianos también pueden unirse de una manera similar al acetaldehído, mediante un puente donde el etanal es reemplazado por otro aldehído, o bien con el ácido glioxálico procedente de la oxidación del ácido tartárico, catalizada por hierro. De las uniones de antocianos con el ácido glioxálico se forman compuestos incoloros, que rápidamente evolucionan hacia colores amarillos (Fulcrand et al., 1997a; Es-Safi et al., 1999, Es-Safi et al., 2000).

Los pigmentos del tipo T-etil-A y A-etil-A son de color púrpura y mucho más resistentes a la decoloración por hidratación y $\mathrm{SO}_{2}$ que los antocianos libres. Como el anillo $\mathrm{C}$ de los antocianos no está sustituido en los derivados etilados, esta resistencia es debida probablemente a su envolvimiento durante la asociación molecular. Ha sido demostrado que la única forma significativa de polimerización entre antocianos en el vino es la $\mathrm{A}^{+}$-etil-AOH, en donde una unidad de antociano es incolora y la otra roja (Atanasova et al., 2002). Esto significa que la conversión de los pigmentos de la uva (70-80\% AOH, $20-25 \% \mathrm{~A}+$ al $\mathrm{pH}$ del vino) no solo produce un leve cambio de rojo a púrpura, sino también incrementa la intensidad de color.

Estudios realizados por Rivas-Gonzalo et al. (1995), Es-Safi et al. (1999) y Atanasova et al. (2002) han evidenciado que la velocidad de la reacción de condensación vía acetaldehído es mayor en presencia de oxígeno y a $\mathrm{pH}$ ácido, debido a que se favorece la formación de acetaldehído y del carbocatión. También se ha comprobado que la temperatura afecta a la evolución y acumulación de estos nuevos pigmentos, es decir, a temperaturas bajas $\left(15^{\circ} \mathrm{C}\right)$ los polímeros se acumulan lentamente y son más estables en relación a su degradación y precipitación (Baranowski y Nagel, 1983; Rivas-Gonzalo et al., 1995)

\subsubsection{FORMACIÓN DE NUEVOS PIGMENTOS DERIVADOS DE LOS ANTOCIANOS.}

En el vino se han identificado nuevos pigmentos derivados de los antocianos y conocidos con el nombre de piranoantocianos (Fulcrand et al., 1996 y 1997). Estos pigmentos se originan por reacción de los antocianos con compuestos de bajo peso molecular, principalmente metabolitos producidos por las levaduras, con un doble enlace polarizado, como el acetaldehído o el ácido pirúvico, produciéndose una reacción de cicloadición, formándose estructuras que poseen un anillo más en su composición y generando los derivados pirúvicos de los antocianos, siendo el mayoritario la malvidina3-glucósido piruvato o vitisina A, y la vitisina B, respectivamente (Figura 3.12). 
También pueden incluir especies de más peso molecular, en las cuales la unidad de piranoantociano está unida a moléculas de tanino (Francia-Aricha et al., 1997).

Los pigmentos formados absorben a longitudes de onda más bajas que los antocianos, por lo que podrían influir en el cambio de color de rojo-violeta a rojoanaranjado que sufren los vinos durante el envejecimiento (Alcalde-Eon et al., 2006). Además, estos compuestos poseen una gran estabilidad frente a las variaciones de $\mathrm{pH}$ y a la decoloración provocada por el sulfuroso, propiedades que les confieren una gran estabilidad en el tiempo.

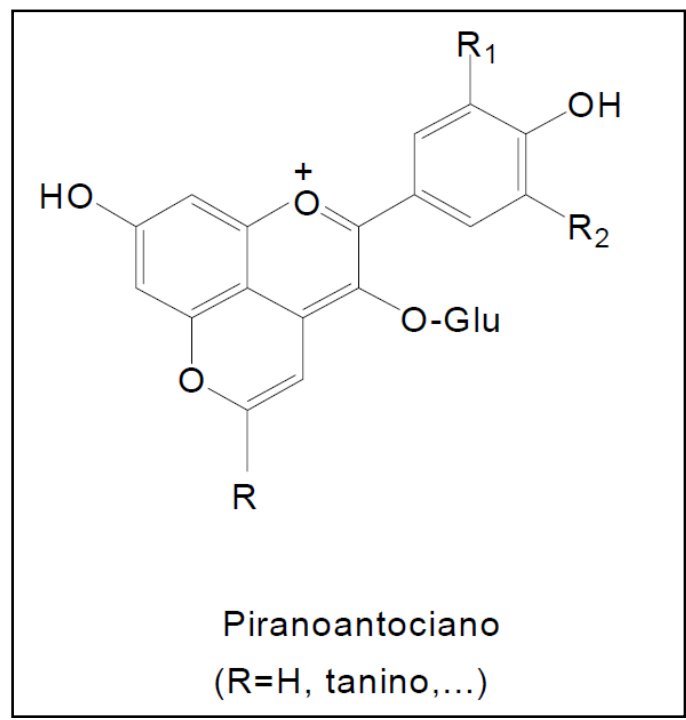

Figura 3.12. Estructura de los piranoantocianos.

Además, los antocianos pueden reaccionar con los vinilfenoles dando aductos antociano-vinilfenoles, así como pueden darse otras reacciones de condensacióncicloadición entre antocianos y vinilflavanoles, o entre derivados pirúvicos de antocianos y vinilflavanoles. Estos últimos derivados antociánicos han sido recientemente aislados y se les ha denominado "portisinas" por haber sido aislados por primera vez en vinos de Oporto (Mateus et al., 2003). Sin embargo, también han sido detectados en vinos tintos (Mateus et al., 2005 y 2006). Las portisinas, a diferencia del resto de pigmentos de cicloadición que presentan desplazamientos hacia el naranja, muestran una intensa coloración azul-violácea (Mateus et al., 2003).

\subsubsection{POLIMERIZACIÓN DE TANINOS}

Los flavanoles monómeros y sus polímeros, los taninos condensados o procianidinas, presentan una clara tendencia a polimerizar. Esta polimerización dará lugar a moléculas cada vez más grandes, lo que se traducirá inicialmente en un incremento de la astringencia (Cheynier et al., 2000), un disminución del sabor amargo (Arnold et al., 1979) y a un incremento del color amarillo del vino (Ribéreau-Gayon et al., 1999). No obstante hay que tener en cuenta que si se alcanza cierto grado de polimerización, la astringencia va disminuyendo y las moléculas se vuelven insolubles y pueden precipitar (Rivas-Gonzalo et al., 1995). 


\subsection{POLIMERIZACIÓN LINEAL}

Esta reacción se basa en la propiedad de las proantocianidinas de poder formar un carbocatión en medio ácido. En ausencia de oxígeno y a temperaturas elevadas, las procianidinas se hidrolizan formando un carbocatión, que reacciona con la carga negativa de otra procianidina, formando un polímero de mayor peso molecular mediante uniones C4-C8 o C4-C6. Este tipo de polimerización es conocida como polimerización homogénea u ordenada, también llamada polimerización lineal.

Sus efectos sobre las características organolépticas del vino se centran en una disminución del sabor amargo, un incremento de la astringencia y un aumento de la componente amarilla del color, destacando que todo ello será válido hasta que los polímeros alcancen tamaños tan grandes que precipitaran al volverse insolubles. En este caso habría una disminución de la astringencia y del sabor amargo, pero también del cuerpo y de la capacidad del vino para envejecer.

Esta reacción es reversible y por tanto el carbocatión que se forma volverá a reaccionar siguiendo el mismo mecanismo pero en sentido contrario. Sin embargo, la unión no tiene por qué ser necesariamente con la misma molécula de flavanol, sino que puede tener lugar con otra molécula presente en el medio. Todo ello origina un conjunto de reacciones de ruptura y recombinación de procianidinas, pudiéndose producir en el tiempo un incremento del grado de polimerización de las mismas. Por otra parte al no requerirse la presencia de oxígeno en estas reacciones, tendrán lugar tanto en el depósito, como en la barrica y la botella, es decir, a lo largo de todo el proceso de elaboración.

\subsection{POLIMERIZACIÓN CRUZADA}

En la actualidad se han demostrado dos tipos de reacciones que dan lugar a este mecanismo de polimerización cruzada. La primera de ellas corresponde a la polimerización mediante formación de semiquinonas con la participación del oxígeno como substrato y la presencia de hierro y/o cobre como catalizadores, y también a la formación de semiquinonas, que poseen la capacidad de formar un enlace estable mediante un mecanismo de tipo radicalario, dando lugar a la unión colateral de las dos moléculas de procianidinas.

De forma paralela también pueden ocurrir polimerizaciones con la participación del acetaldehído. El etanol en presencia de cationes hierro y/o cobre, puede ser oxidado a etanal, el cual en medio ácido puede dar lugar a un carbocatión denominado etanal activado. A su vez este carbocatión puede actuar sobre dos moléculas de flavanol provocando su unión mediante un puente de etilo. Al igual que ocurría con los polímeros generados mediante la formación de un carbocatión en medio ácido, estos polímeros están sujetos a rupturas y recombinaciones que podrían traducirse con el tiempo en un incremento del grado de polimerización (Es-Safi et al., 1999; Quintana, 2001). Además se ha sugerido que la ruptura de estos polímeros también podrían generar restos vinilflavanol que serían aun más reactivos que los restos etil-flavanol (Santos-Buelga, 2001) y podrían ser responsables de la formación de nuevos pigmentos (Francia-Aricha et al., 1997). 
Ambos tipos de mecanismos de polimerización cruzada dan lugar a la formación de compuestos amarillos pero con menor reactividad, viéndose además su astringencia disminuida por lo que participan en las sensaciones de volumen en boca de los vinos. Este tipo de reacción tiene una cinética superior a la polimerización lineal lo que conduce a la formación rápida de compuestos polímeros susceptibles de precipitar en función del grado de polimerización y de la concentración. Por último, como se requiere de la presencia de oxígeno, estos fenómenos tendrán lugar cuando se realicen trasiegos y en las barricas gracias a la microdifusión de oxígeno que tiene lugar a través de la porosidad de la madera.

\subsection{REACCIONES DE COMPLEJACIÓN DE LAS PROCIANIDINAS}

Las procianidinas también pueden dar lugar a reacciones de unión con proteínas, péptidos y polisacáridos. El modelo explicativo establecido para el comportamiento de los taninos (Figura 3.13) indica que posteriormente a los procesos de polimerización y condensación a los que son sometidas, se reúnen en agregados cada vez más grandes mediante uniones hidrófobas hasta formar partículas con propiedades coloidales que continuaran con su crecimiento hasta llegar a precipitar. Estas partículas coloidales reaccionan con las proteínas de la saliva formando agregados más grandes que también precipitarán. Estas uniones se explican por la facilidad que tienen para formar puentes de hidrógeno, interacciones hidrófobas y uniones iónicas (Saucier, 1997). Todo lo descrito anteriormente comportaría una disminución de la concentración de procianidinas en el vino y una disminución de la astringencia y del sabor amargo.

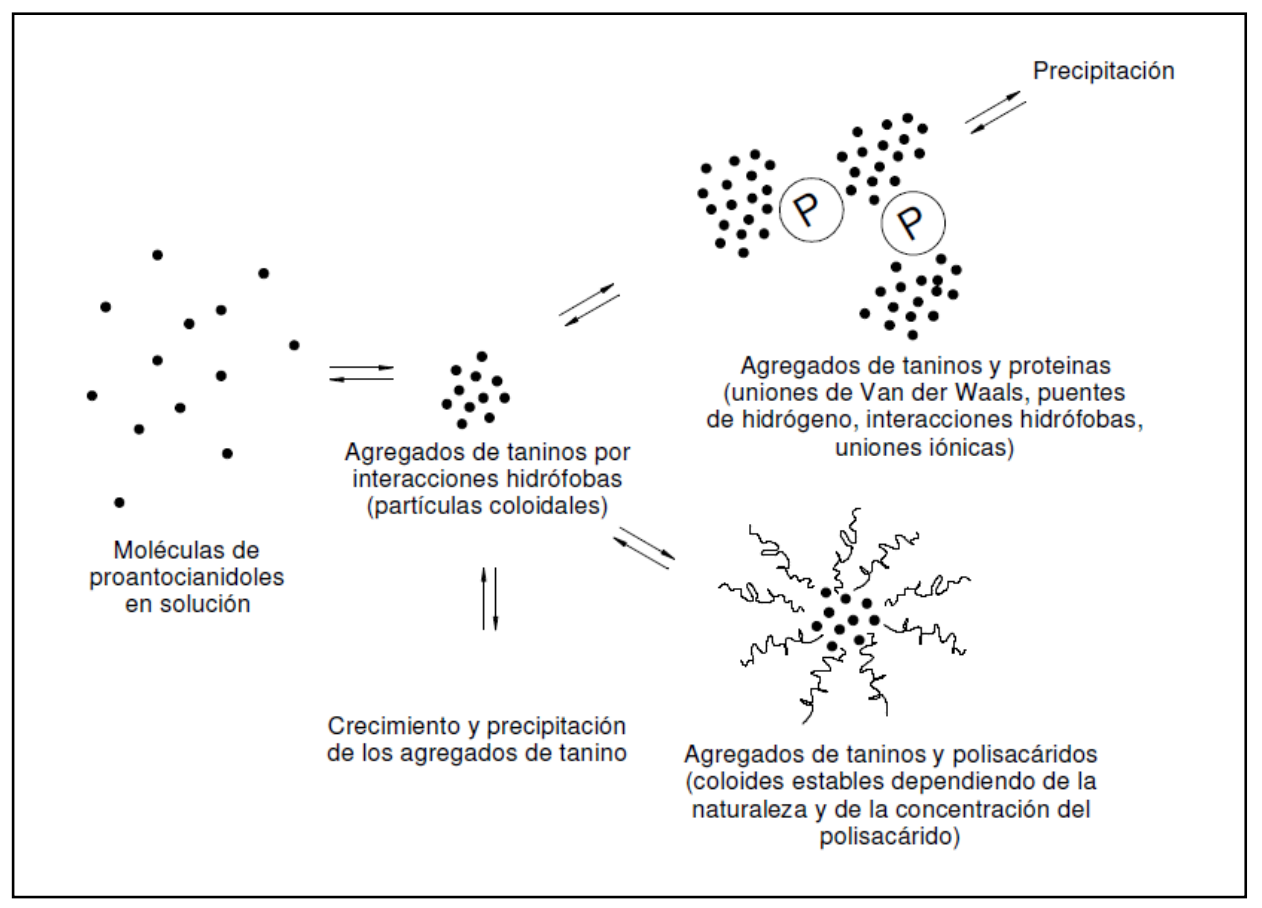

Figura 3.13. Modelo del comportamiento coloidal de los taninos.

Por otro lado los péptidos y polisacáridos tienen la capacidad de formar uniones con taninos más pequeños e impiden que crezcan los agregados de taninos, a la vez que 
bloquean los puntos activos que precipitan las proteínas y causan la sensación astringente (Saucier, 1997; Saucier et al., 2000). Los polisacáridos del vino son macromoléculas que provienen de las disgregaciones de la pared de la levadura (manoproteínas) y de la pectina de la pared celular de la baya (Doco et al., 2000). Estas sustancias cumplen una función protectora al evitar la precipitación de los taninos y de las uniones de taninos y antocianos. También tiene un efecto suavizante sobre la astringencia de los taninos.

\subsection{ESTABILIDAD DEL COLOR MEDIANTE REACCIONES DE COPIGMENTACIÓN.}

El concepto de copigmentación es el aumento de color de los pigmentos debido a la presencia de componentes incoloros. La reacción de copigmentación de los antocianos fue reportada por primera vez por Robinson y Robinson en 1931. La copigmentación es un equilibrio que implica la asociación preferencial y no covalente de los antocianos libres con un grupo de componentes, fenólicos o no, que se denominan copigmentos (sustancias poco coloreadas o incoloras), para formar complejos de apilamiento vertical tipo "sándwich" (Boulton, 2001). Su unión se mantiene por enlaces de baja energía, de tipo Van der Waals, y su estabilidad se debe a la disposición de las moléculas de azúcar del antociano en la parte externa, entre las cuales se establecen uniones mediante puentes de hidrogeno, impidiendo el acceso de las moléculas de agua al interior de estos complejos, protegiendo de este modo a los antocianos de la hidratación, y haciendo que los equilibrios se desplacen hacia las formas coloreadas.

Debido al alto porcentaje de agua en el vino, las reacciones de hidratación predominan y los antocianos se encuentran prácticamente hidratados y por tanto en su forma carbinol incolora. Sin embargo, la presencia de la glucosa en las agrupaciones tipo sándwich genera un entorno hidrofóbico, que impide el acceso de las moléculas de agua formando una barrera que impide la hidratación y la decoloración del antociano, desplazando el equilibrio de la forma carbinol incolora a la forma catión flavilio coloreada. De esta forma el proceso de copigmentación aumentara el porcentaje de antocianos que contribuyen al color del vino, explicándose así el incremento en la intensidad y estabilidad del color (Liao et al., 1992; Mirabel et al., 1999).

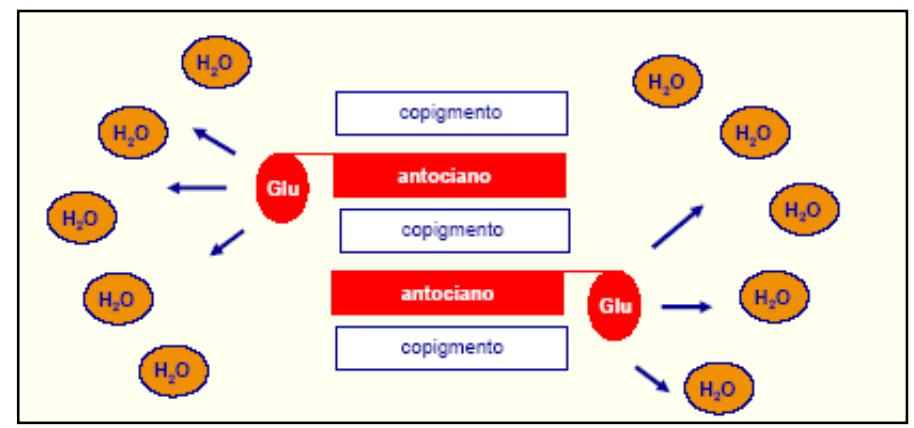

Figura 3.14. Representación grafica del fenómeno de copigmentación.

Por lo tanto los copigmentos poseen sistemas capaces de asociarse con el ión flavilium (Bakowska et al., 2002) impidiendo la decoloración del antociano. Dado que el ataque por el agua convierte al ión flavilium en la pseudobase no coloreada, se cree 
que la copigmentación es uno de los principales factores de estabilización de la estructura del flavilium in vivo (Osawa, 1982; Brouillard, 1983).

Además, los copigmentos pueden formar complejos coloreados con las formas incoloras de los antocianos (Baranac et al., 1996, 1997 a, b, c; Brouillard et al., 1989). Los cambios de color que se producen en frutos, vegetales y flores pueden ser atribuidos a estas reacciones (Asen et al., 1972; Mistry et al., 1991; Davies y Mazza, 1993). A medida que van copigmentándose se va produciendo un aumento de la intensidad del color. En la figura 3.14 se representan gráficamente todos estos fenómenos.

Las reacciones de copigmentación han sido estudiadas en soluciones modelo, encontrándose que intervienen en ellas algunos compuestos del grupo de los ácidos hidroxicinámicos y de los flavonoides, que actúan sobre la coloración de los antocianos, en distintas condiciones de $\mathrm{pH}$, temperatura y concentraciones de copigmento $\mathrm{y}$ de antociano, dando lugar a un aumento en la intensidad del color (efecto hipercrómico) y un desplazamiento de la longitud de onda a la cual se produce el máximo de absorbancia (efecto batocrómico) (Baranowwski y Nagel, 1983; Brouillard et al., 1989; Bloor y Falshaw, 2000). En algunos de estos estudios se ha investigado y precisado el mecanismo de reacción y la constante de estabilidad del complejo formado entre el antociano y el copigmento. Un incremento en la concentración de copigmentos conduce a una intensificación del color, dado que, hay un desplazamiento de las formas menos coloreadas de los antocianos libres hacia las formas coloreadas, y por otro lado, los propios antocianos copigmentados que se forman aportan mayor intensidad colorante que el catión flavilio. Estos estudios que surgieron como investigación del color en plantas y frutos, han permitido derivar estos conocimientos hacia el mundo del vino (Dangles y Brouillard, 1992; Boulton, 1996, 1997, 1999, 2001; Gómez-Mínguez y Heredia, 2004).

En los mostos y vinos, los cambios de color producidos son originados por reacciones de complejación de los antocianos con metales o de copigmentación con compuestos naturales presentes en las uvas. Las moléculas que actúan como copigmentos incluyen una gran variedad de compuestos tales como polisacáridos, ácidos orgánicos, aminoácidos, ácidos fenólicos, flavanoides e incluso los propios antocianos. Su único requisito es que deben poseer o adoptar una configuración plana para poder asociarse con los antocianos. Este fenómeno de interacción molecular es bastante frecuente entre polifenoles, y tiene lugar de forma natural en uvas y mostos, ya que éstos poseen bastante sensibilidad, no sólo por la naturaleza y concentración de pigmento y copigmento, sino también por la temperatura, $\mathrm{pH}$, y composición del medio en el que tiene lugar. Los copigmentos que están en la pulpa de la uva, tienen poco efecto en la formación de los complejos, mientras los que se encuentran en los hollejos de las uvas determinan el impacto de la copigmentación (Boulton 2001).

La copigmentación, las reacciones de condensación entre antocianos y flavanoles y las reacciones de pardeamiento de los flavanoles, han sido bien estudiadas en soluciones acuosas y en soluciones hidro-alcohólicas (Mirabel et al., 1999; Asen et al., 1972; Bakker et al., 1993; Baranac et al., 1996, 1997 a,b,c; Baranowwski y Nagel, 1983; Brouillard et al., 1989; Brouillard et al., 1991; Dangles y Brouillard, 1992; Davies y Mazza, 1993; Escribano-Bailón et al., 1996; Francia-Aricha et al., 1998; Fulcrand et al., 1997; Liao et al, 1992; Mistry et al., 1991; Santos-Buelga et al., 1995; 
Saucier et al., 1997). En otros estudios, se ha dilucidado la importancia de la condensación con acetaldehído como puente de unión entre los antocianos y los flavanoles (Saucier et al., 1997; García-Viguera et al., 1994; Guerra y Saucier, 1997; Rivas-Gonzalo et al, 1995). Sin embargo, estos procesos no son fáciles de demostrar en un medio más complejo como es el vino. Por esta razón, algunas hipótesis enunciadas para explicar los cambios que tienen lugar en el vino durante su envejecimiento, son meramente especulativas.

Según Goto y Kondo (1991), existen tres mecanismos diferentes de copigmentación de los antocianos, las copigmentaciones intramoleculares, en las cuales la parte cromófora de los antocianos se une de forma covalente con diferentes ácidos orgánicos, anillos aromáticos, flavonoides o una combinación de ellos, las copigmentaciones intermoleculares, en las que formas no coloreadas de flavonoides $\mathrm{u}$ otros compuestos fenólicos reaccionan mediante fuerzas hidrofóbicos débiles con los antocianos, y por último fenómenos de auto-asociaciones. En cuanto al fenómeno de autoasociación o autocopigmentación, los antocianos forman complejos o apilamientos con ellos mismos sin la intervención de los copigmentos. En estudios sobre los equilibrios de los antocianos Asen et al. (1972), trabajo con soluciones de cianidina-3,5diglucósido, sin la presencia de copigmentos, notando que estos no obedecían la ley de Beer salvo a muy altas diluciones. Esto demostró que el color de los antocianos no solo era dependiente del $\mathrm{pH}$ del medio acuoso, sino de la propia concentración del pigmento, atribuyendo este efecto a la autoasociación. Estudios posteriores demostraron que tanto el flavilium como la base quinoidal coloreados podían formar apilamientos entre la parte cromófora de la molécula y la parte glucosídica. Esta disposición es hidrófoba y evita la hidratación y consecuente pérdida de color del anillo pirilo (Hoshino, $1991 \mathrm{y}$ 1992). La autoasociación ha sido encontrada en soluciones modelo conteniendo etanol, pero en menor medida que en soluciones acuosas (Mazza, 1995) por lo que su rol en el vino ha recibido poca atención. Algunas variedades de uva como Pinot Noir, que carecen de antocianos acilados, tienen menor capacidad para formar compuestos de autoasociación (Figura 3.15).

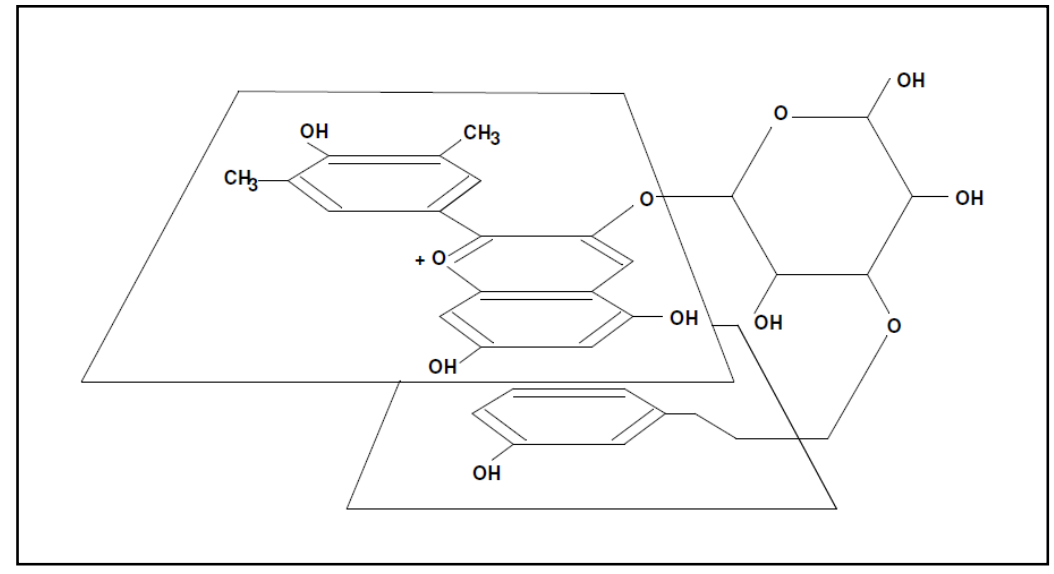

Figura 3.15. Autoasociación de la malvidina-3-glucósido cumarato.

En estudios realizados por González-Manzano et al., (2007), se observó como la autoasociación en soluciones vino-modelo utilizando diferentes antocianos (3-glucósido de malvidina, definidina y peonidina) aportaba una mayor resistencia de estos frente a la hidratación, con la consiguiente modificación del color de las soluciones, observándose 
también como a medida que aumenta el grado de metoxilación en el anillo B del antociano, mayor es la magnitud de la autoasociación. Estos fenómenos producen un incremento de la intensidad del color de las soluciones junto con un oscurecimiento de las mismas.

Por otra parte, los trabajos de Lambert et al. (2010) en los que se han estudiado parámetros termodinámicos de las reacciones de copigmentación intermolecular entre la malvidina-3-glucósido y diferentes copigmentos como el ácido cafeico, quercetina, epicatequina, catequina, dímero de procianidina y tanino de pepita, se ha observado como la reacción de autoasociación es la más favorecida termodinámicamente. Aunque no se ha encontrado un incremento del color en la solución debido a esta reacción.

La copigmentación se ve más intensamente influenciada por la estructura del copigmento y por el pH que por la estructura del antociano (Donner et al., 1998). Cuando un copigmento se añade a una solución levemente ácida de antocianos, se produce un incremento en la intensidad de color debido a la formación de complejos coloreados (Baranac et al., 1996, 1997). En general, el efecto es mucho más notorio a $520 \mathrm{~nm}$ que a $420 \mathrm{~nm}$, y depende mucho del cofactor que se utilice (Liao et al., 1992). Pero el fenómeno de la copigmentación está también fuertemente influenciado por la temperatura, el contenido en alcohol y la relación molar copigmento/antociano. Un aumento de la temperatura o del contenido en alcohol, disminuye el efecto de la copigmentación y un aumento de la relación copigmento/antociano, lo aumenta. Obviamente, un incremento en la concentración de copigmentos lleva a un mayor color en la solución debido a que desplaza las forma incoloras a coloreadas (Darías-Martín et al., 2001). Por tanto, es de esperar que durante la maceración del mosto, la mayor o menor presencia de estos copigmentos en la uva, van a influir notablemente en el futuro color del vino tinto y en su estabilidad.

Los copigmentos pueden ser estructuralmente muy distintos, tales como fenoles, metales, aminoácidos, y ácidos orgánicos (Brouillard et al., 1989). En el caso de los vinos, las principales moléculas implicadas son fenólicas, pertenecientes a los dos grandes grupos en que se clasifican actualmente los compuestos polifenólicos de la uva y el vino (Zamora, 2003), destacando entre ellos los 3-flavanoles, los ácidos fenoles, y otros polifenoles (como los propios antocianos en sus fenómenos de autoasociación).

Los copigmentos no flavonoides de las uvas carecen de color en el espectro visible, no obstante, pueden oxidarse y dar lugar al pardeamiento del mosto y del vino. No parecen ser de gran importancia en la evolución del color del vino tinto, pero sí pueden ejercer un cierto papel como copigmentos y participar por tanto en el color de vinos tintos jóvenes gracias al fenómeno de la copigmentación (Rivas-Gonzalo et al., 2003).

Los ácidos benzoicos presentes en las uvas son el ácido $p$-hidroxibenzoico, ácido protocatéquico, ácido gálico, ácido siríngico y ácido salicílico. Se localizan en los hollejos de las uvas y pepitas. Los alcoholes y aldehídos de carácter fenólico tienen una importante influencia sobre algunos aromas. De todos ellos, el ácido gálico es el que mayor interés enológico presenta, ya que se une con los flavanoles dando lugar a estructuras galoiladas que se caracterizan por su mayor astringencia (Zamora, 2003). E1 ácido gálico se encuentra también formando parte de muchos preparados tánicos comerciales. 
Los ácidos hidroxicinámicos son los principales constituyentes fenólicos de la pulpa de la uva, siendo igualmente los mayoritarios en vinos blancos. Entre ellos podemos encontrar el ácido $p$-cumárico, ácido cafeico y ácido ferúlico. Son fácilmente oxidables, influyendo en el pardeamiento de los vinos. Los ácidos $p$-cumárico y cafeico esterifican la molécula de azúcar de los antocianos, en posición 6 . El ácido cafeico ha sido identificado como esterificante del 3-glucósido de malvidol y el 3-glucósido de peonidol (Baldi et al., 1995). Su acción como copigmentos ha sido estudiada en numerosos trabajos (Darias et al., 2001 y 2002; Blomfield et al., 2003; Schwarz et al., 2005), atribuyéndoseles mayor potencial de copigmentación que a los ácidos benzoicos. Entre los ácidos hidroxicinámicos, destaca el ácido cafeico como factor de copigmentación, con un importante papel en el color de los vinos tintos al estar presente en la uva de manera natural. El ácido cafeico tiene importantes aplicaciones en medicina, habiéndose descrito como anti VIH, antiadenovirus, antiagregante, anticarcinogénico, antiedémico, antigripal, antihemolítico, antihepatotóxico, antihipercolesterilémico, antiherpético, antiinflamatorio, antimutagénico, antioxidante, bactericida, inhibidor de histamina, etc.

Los compuestos fenólicos flavonoides constituyen el grupo más importante de los polifenoles de la uva y del vino. Aunque en sentido estricto los flavonoides (estructura fenil-2-benzopirona) están representados en la uva únicamente por los flavonoles, responsables de los pigmentos amarillos de la uva, dentro de los flavonoides también se incluyen los antocianos, los 3-flavanoles (flavanos -3-ol) y los dihidroxiflavonoles (flavononoles) (Abril y Casp, 1999). Los flavonoles están únicamente presentes en los hollejos. Los principales son el kaempferol, quercetol, miricetol e isorammetol. Las formas glucosiladas son las más abundantes, pero se encuentran igualmente cantidades importantes en forma de compuestos glucurónicos. Se han observado grandes diferencias de composición entre las variedades tintas y blancas, aunque los derivados del quercetol son siempre dominantes. Su acción como copigmentos ha sido demostrada en varios estudios (Bloor y Falshaw, 2000). En soluciones modelo estos compuestos muestran que son los mejores copigmentos presentes en los vinos (Baranac et al., $1997 \mathrm{a} \mathrm{y} \mathrm{b).} \mathrm{Entre} \mathrm{los} \mathrm{flavonoles} \mathrm{destaca} \mathrm{el} \mathrm{efecto}$ copigmentante de la rutina, estos compuestos muestran una elevada solubilidad en soluciones acuosas e hidroalcohólicas, y su efecto como copigmento ha sido ensayado tanto en soluciones modelo como en vinos (Baranac et al., 1996; Hermosín et al., 2005 a y b), obteniendo mejoras importantes de la coloración de vinos tintos.

Por último, es importante destacar el efecto copigmentante de los 3-flavanoles (Boulton, 2000), menos intenso que el de los flavonoles, pero bastante significativo en el caso de la (-) epicatequina, debido a la configuración espacial casi plana, que facilita el apilamiento con los antocianos, y la formación de los complejos de copigmentación (Liao et al., 1992).

También se encuentran en la naturaleza taninos con otra configuración, formados por moléculas de ácido gálico o galotaninos (abundantes en el mirolábano, acacia) y taninos de ácido elágico o elágitaninos (roble) (Heredia y Guzmán, 1993). Los taninos, tanto los hidrolizados como los condensados, se utilizan como coadyuvantes tecnológicos, que se adicionan al mosto o al vino con diversas finalidades, tales como precipitar proteínas en desfangado o clarificación de vinos blancos, reducir el riesgo de formación de compuestos de reducción, por su efecto antioxidante por captación de radicales libres, actuando de sustratos de oxidación en lugar de los antocianos u otros 
compuestos, por su acción antiséptica, por su acción estabilizante del color, y por el aumento de la estructura tánica que proporcionan (Álvarez, 2003). La acción copigmentante de los flavanoles monómeros ha sido probada en diversos estudios (Darías-Martín et al., 1998, 2001, 2002), al igual que la de los flavanoles que forman los galotaninos (Hermosín et al., 2002, 2005a, b).

Por lo tanto dentro de los copigmentos que aparecen en el vino, los flavonoides, quercetina y kaempferol tienen un efecto fuerte; las catequinas un efecto moderado y los ácido hidroxicinámicos, cafeico y caftárico, y el ácido gálico un efecto débil. La estructura y concentración de los copigmentos, de los antocianos y el pH de la solución tienen un efecto notorio sobre el grado de copigmentación (Davies y Mazza, 1993). Parece que la mayoría de los vinos están limitados en la formación de complejos de copigmentación, no por la disponibilidad de antocianos o el $\mathrm{pH}$, sino por la disponibilidad de copigmentos.

El hecho de que las uvas contengan cantidades diferentes de compuestos incoloros que pueden hacer que los pigmentos rojos sean más intensos queda evidenciado por la capacidad de aumentar el color si se adicionan copigmentos al vino. Estos compuestos, por otra parte, ayudan a que los antocianos se encuentren en disolución en el vino resultando con ello un color más estable (Boulton, 1997). La aplicación de uva blanca en las vinificaciones en tinto en diferentes regiones (Chianti, Borgoña, Rioja) es una práctica tradicional para incrementar el potencial de color, ya que aunque la uva blanca no aporta antocianos, sí que puede aportar algunos copigmentos que refuercen el color del vino tinto y compensen sobradamente el ligero efecto de dilución que su empleo implica (Zamora, 2003). Incluso se ha demostrado recientemente que la covinificación de distintas variedades tintas, puede favorecer la copigmentación (Lorenzo et al., 2005). Dentro de los copigmentos los más estudiados han sido los flavonoles, la (+)-catequina y (-)-epicatequina (Mirabel et al., 1999; Liao et al., 1992; Escribano-Bailón et al., 1996).

La extracción de los pigmentos antes, durante y después de la fermentación vínica está lejos de ser completa, alcanzando cotas del $30-40 \%$ de los pigmentos presentes en la uva (Boulton, 2001). Distintas evidencias apuntan a que existe una especie de equilibrio de adsorción-desorción entre el medio líquido (vino) y las partes sólidas de los tejidos celulares, que hace disminuir la extracción a medida que el etanol incrementa su concentración en la solución. Esto es fácilmente demostrable si tomamos hollejos de un vino al que ya no pasan más antocianos, dado que se ha llegado al equilibrio, y los ponemos en un mosto blanco, hacia el cual migrarán rápidamente hasta el establecimiento de un nuevo equilibrio.

En este sentido, la copigmentación actúa retirando a los antocianos copigmentados fuera del pool del equilibrio de adsorción de los antocianos libres, causando por tanto una mayor extracción de pigmentos hacia el vino. Aunque las reacciones de copigmentación ya fueron enunciadas anteriormente (Robinson y Robinson, 1931), no ha sido hasta años más tarde cuando ha comenzado a prestarse mayor atención a este proceso como fenómeno que podría contribuir a explicar la coloración en vinos tintos jóvenes y plantearse como una posible etapa que facilitaría posteriores procesos de condensación, responsables del cambio de color que se produce en los tintos envejecidos (Asen et al., 1972; Baranowwski y Nagel, 1983; Brouillard et 
al, 1989, 1991; Rivas-Gonzalo et al., 1995, 2003; Boulton, 1996, 2001; Mirabel et al, 1998; Levengood, 1996; Levengood y Boulton, 1997; Gris et al, 2005), y esto ha implicado el reconocimiento de la trascendencia que estas reacciones puedan tener en la química del color de los vinos tintos.

El nivel de pigmentos de un vino puede venir predefinido por la cantidad de cofactores en la uva y el nivel de copigmentación alcanzado; así mismo, de acuerdo con numerosas investigaciones, se piensa que la copigmentación de antocianos es el primer paso hacia la formación de pigmentos poliméricos estables en los vinos tintos, bien por condensación directa de los antocianos con otros flavonoides, o por combinación de pigmentos mediante puentes de acetaldehído (Bakker et al., 1993; Mirabel et al., 1999; Liao et al., 1992; Brouillard y Dangles, 1994; Escribano-Bailón et al., 1996). Además, la copigmentación favorece la cantidad de polímeros de color rojo, protegiendo a los pigmentos de las reacciones de pardeamiento (Boulton, 1997), que implican pérdidas masivas de pigmentación y que son las principales responsables del "atejamiento" del color de los vinos tintos durante el envejecimiento. No obstante, la tasa de desaparición de antocianos y la formación de nuevos pigmentos coloreados estables se ve influida por numerosos factores como la temperatura, el $\mathrm{pH}$, los sulfitos y el contenido en oxígeno del vino (Castellari et al., 1999).

Además de proteger a los pigmentos de las reacciones de pardeamiento, la copigmentación influye sobre las reacciones de oxidación, condensación y polimerización de sustancias fenólicas ya que disminuye la cinética de las reacciones que se producen durante el envejecimiento de los vinos. Durante el primer año de conservación del vino los antocianos monoméricos (copigmentados o libres) se polimerizan con los taninos en una alta proporción. Las consecuencias de este proceso son las pérdidas en la copigmentación y la caída de la intensidad colorante del vino hasta en un $50 \%$. Parece ser que la formación de pigmento polimérico rojo está asociada a la cantidad de copigmentación inicial. Esto se debería a que los apilamientos copigmentados protegen a los antocianos contra la oxidación y favorecen la formación de uniones covalentes entre taninos y antocianos (Boulton, 2001).

La cinética de las reacciones de oxidación depende de la concentración de sustancias fenólicas en forma libre, no de su concentración en valor absoluto. Determinados flavonoides son fuertes copigmentos y rápidamente participan en reacciones de copigmentación, lo que hace que la concentración en forma libre de tales compuestos disminuya y de este modo no estén disponibles para reacciones de oxidación y polimerización (Darias-Martin et al., 2001).

Los primeros estudios sobre copigmentación en uva fueron realizados en 1972 por Asen et al., que estudiaron el incremento del color con la adición de cianidina cuando el cofactor estaba en exceso. Estudios en soluciones modelo pusieron en evidencia que los ácidos hidroxícinámicos protegen a los antocianos de uvas y vinos de la hidratación, formando complejos de copigmentación (Dangles et al., 1993; Eiro y Heinonen, 2002), así como, los ácidos cinámicos como el cafeico tienen un alto poder copigmentante y los flavanoles como la catequina forman complejos con potentes incrementos de color (60\%-70\%) y un muy ligero efecto batocrómico (Boulton, 2000). Gris et al. (2005) estudian también el efecto del ácido cafeico en la estabilidad del color, demostrando en soluciones modelo un importante efecto hipercrómico, así como una mayor estabilidad de los antocianos durante la conservación de los vinos. Baranac et al. (1996; 1997 a, b, c) muestran que, en soluciones modelo, los flavonoles son los mejores 
copigmentos presentes en uvas y vinos. Mirabel et al. (1999) determinan en soluciones modelo el efecto copigmentante de los flavanoles monómeros, catequina y epicatequina, así como de oligómeros y polímeros de proantocianidina. Liao et al. (1992) pone en evidencia que los flavanoles, a excepción de la (-)-epicatequina, tiene un menor efecto copigmentante en soluciones modelo.

Pero no es hasta la década del 2000 cuando se comienza a estudiar el fenómeno de copigmentación "in vivo", adicionando diferentes copigmentos y en distintas dosis al mosto, para establecer el efecto copigmentante de estos compuestos en el vino posteriormente a la fermentación. Debido a la débil unión que otorga la copigmentación, cuando se provoca una dilución de 25 veces con un tampón de $\mathrm{pH}$ y alcohol constante, se rompe la copigmentación y el color solo se debe a los antocianos libres y a los pigmentos poliméricos. Boulton (1999a) utilizando esta propiedad determino que en vinos de Pinot Noir jóvenes el color debido a la copigmentación era cercano al $30 \%$ del color total en promedio. También encontró que la variación en el porcentaje de copigmentación eran altas $(<50 \%)$ y se debían a las diferencias de la zona de origen de la uva, portainjerto y al manejo del viñedo.

Darias-Martín et al. (2001, 2002) estudiaron la copigmentación con ácido cafeico y catequina, ambos constituyentes naturales de las uvas y vinos, adicionando estos componentes al mosto antes de la fermentación, y establecieron que el ácido cafeico presente en mosto parece tener un notable efecto en la extracción del color, lo que puede ser debido a que contribuye a disolver más pigmentos debido a los equilibrios de copigmentación y a que los antocianos proporcionan más color cuando están copigmentados (efecto hipercrómico). En mostos de la variedad Listán Negro y Negramoll, con igualdad de dosis, el incremento de color producido por la catequina era del $10 \%$, mientras que en el caso del cafeico este incremento llegaba hasta el $60 \%$. La adición de catequina lleva a una ligera pérdida de color al envejecer el vino.

Además otros autores (Eiro y Heinonen, 2002) estudiando la eficacia de copigmentación de los ácidos clorogénico, ferúlico, rosmarínico, gálico y cafeico, llegaron a la conclusión de que las reacciones de copigmentación dependían del antociano y del copigmento y que su adición aumentaba la estabilidad del color con el almacenamiento.

También Bloomfield et al. (2003) estudian el efecto de la adición prefermentativa de ácido $p$-cumárico y encuentran que tiene un efecto significativo en el color de los vinos tintos de Cabernet Sauvignon y Pinot Noir, una variedad que no contiene antocianos acilados y que por tanto presenta un color más limitado.

La adición de rutina se ha ensayado tanto en soluciones modelo (Baranac et al., 1996) como en vinos. Hermosín et al. (2005 a), obtiene incrementos significativos en la coloración de vinos tintos mediante la adición prefermentativa de rutina. Schwarz et al., (2005) estudian el efecto de la adición de rutina, ácido cafeico y ácido $p$-cumárico a mostos de la variedad Cencibel y Cabernet Sauvignon, encontrando que la rutina potencia la copigmentación y la extracción de antocianos en los vinos de Cencibel, pero observan que los ácidos hidroxicinámicos dan lugar a resultados contradictorios, especialmente el ácido cafeico. Estos efectos aún son más significativos en los vinos de Cabernet Sauvignon, particularmente los ocasionados por rutina y ácido $p$-cumárico, 
siendo más efectiva la copigmentación en los vinos que contienen mayor cantidad de antocianos y taninos.

González-Manzano et al. (2008) evalúan la aptitud de los flavanoles para actuar como copigmentos en función de su grado de polimerización. Diferentes polímeros de catequina unidas mediante acetaldehído han sido utilizados en el estudio, observando como todos los compuestos ensayados fueron capaces de reaccionar con los antocianos, induciendo a cambios en el color de las soluciones. El mejor efecto fue el encontrado para los oligómeros con 2-3 unidades elementales de catequinas, mientras que los monómeros fueron los peores copigmentos ensayados. Por último se apreció como la formación de los complejos no fue inmediata sino que requirió un cierto tiempo lo cual nos indica que este fenómeno está controlado termodinámicamente, más que cinéticamente.

Kunsági-Máté et al. (2008) indica el mayor efecto copigmentante del acido cafeico con respecto al acido elágico en soluciones vino-modelo, demostrando la aptitud de este compuesto para participar en las reacciones de copigmentación. Por otra parte, estos mismos autores estudian las reacciones de copigmentación incrementando el grado alcohólico en las soluciones, con el objetivo de conocer realmente que es lo que ocurre durante el proceso de la fermentación, observándose como los compuestos más largos y fuertes se han formado cuando se ha superado la concentración crítica de $8 \%$ vol, permitiéndonos optimizar el proceso de elaboración para garantizar una extraordinaria estabilidad del color de los vinos tintos.

Otros estudios (Gonzalez-Manzano et al., 2009) que utilizan compuestos fenólicos extraídos de las variedades Graciano y Tempranillo, muestran como el porcentaje de copigmentación de los antocianos con los flavanoles se sitúa entre el 2-20 $\%$, indicando la importancia cualitativa de los compuestos fenólicos empleados, influenciados por la variedad y las prácticas enológicas, para la producción de un efecto positivo de copigmentación. Las soluciones de flavanoles empleadas contenían catequina, epicatequina, dímeros y trímeros de flavanoles y derivados galoilados.

Se ha estudiado también el efecto copigmentante de diferentes ácidos orgánicos (ferúlico, cafeico, gálico, tánico) en extractos de hollejos de la variedad Cabernet Sauvignon a diferente $\mathrm{pH}(1.00,2.00,3.00,3.30,3.35,3.37,4.00,4.50)$, encontrándose el máximo poder copigmentante para cada uno de los ácidos ensayados a pH 3.30. También se ha destacado el ácido tánico como mejor copigmento en las soluciones modelo empleadas, aunque por otra parte suponen que la menor capacidad de los ácidos cafeico y ferúlico como copigmentos puede ser debida a la participación de estos en la formación de piranoantocianos y no en las reacciones de copigmentación. (Gauche et al., 2010).

Los primeros resultados publicados por Álvarez et al. (2008) utilizando como copigmentos el ácido cafeico, la rutina, la $(+)$ catequina, y dos tipos de procianidinas, en vinos de la variedad Tempranillo, han mostrado que la adición prefermentativa de estos copigmentos produce un incremento de la reacciones de copigmentación que a su vez producen un incremento del color, una mayor concentración de antocianos y una mayor contribución de estos al color del vino. Resultando los taninos procedentes de uva blanca los que mostraban los mejores efectos copigmentantes, poniéndose de manifiesto la aptitud de estos compuestos para participar en las reacciones de copigmentación. Estos resultados sugieren que la concentración de copigmentos tienen una gran 
importancia en la concentración de antocianos y en el color del vino tinto, y que la composición en pigmentos y copigmentos de la uva puede tener tanta importancia como las técnicas enológicas empleadas (Boulton, 1999). Además, los copigmentos más efectivos son generalmente compuestos fenólicos monoméricos, como los ácidos hidroxicinámicos, las catequinas y los flavonoles. También se pone en evidencia en estas investigaciones que la estabilización del color durante la crianza de los vinos está influenciada por la copigmentación intramolecular que tiene lugar cuando la concentración del copigmento es elevada (Eiro y Heinonen, 2002).

\subsection{INFLUENCIA DE LA VINIFICACIÓN EN LA COMPOSICIÓN DE LOS VINOS}

La composición de los vinos depende de la concentración de la uva y de su estado de madurez, pero también del tiempo y de la temperatura de maceración y fermentación y de la frecuencia y el sistema utilizado para realizar la homogenización de la pasta. A su vez, la composición del vino varía a lo largo de los procesos de vinificación, estabilización y conservación, debido a la condensación, polimerización, oxidación y precipitación de dichas moléculas. Estas variaciones determinan cambios en la composición de los vinos, como resultado de la interacción de todos los pigmentos presentes, y según las condiciones del medio. La forma de vinificación adoptada, condiciona tanto la extracción de los compuestos, a partir de las diferentes partes del racimo, como las reacciones posteriores de estas moléculas, contribuyendo así de manera esencial a la composición final de los vinos. El desarrollo de los procesos de vinificación adaptados a la vez a la materia prima y al tipo de producto deseado implica, como base indispensable, el disponer de un conocimiento profundo de las diferentes estructuras presentes en la uva y de los mecanismos de su evolución durante la vinificación.

Las técnicas de vinificación ejercen una gran influencia en la extracción de los componentes de las uvas, afectando a la concentración y composición de los vinos. La temperatura y la duración de la maceración, la presencia o ausencia de etanol, son factores que afectan a las características y composición de los antocianos, así como a los fenómenos de copigmentación (Gómez-Miguel y Heredia, 2004).

Se ha comentado ya con anterioridad que el proceso más importante de la vinificación de tintos es la maceración y que habitualmente es realizada junto con la fermentación, extrayéndose inicialmente antocianos, y de forma progresiva taninos, a medida que aumenta el contenido alcohólico del vino. Si la maceración la prolongamos en exceso, se producirán importantes pérdidas en la concentración de antocianos, y la extracción de taninos puede ser muy elevada, presentando los vinos una excesiva astringencia ocasionada por los taninos de las pepitas. Esto es más acusado cuando la madurez de la uva no es muy elevada, y la concentración de taninos en las pepitas es alta. La regulación del proceso de maceración en cuanto a temperaturas, tiempo e intensidad de la maceración, va a condicionar el tipo de vino a obtener.

Los taninos y los antocianos presentan cinéticas de extracción diferentes. Los antocianos son extraídos rápidamente, alcanzando una concentración máxima los primeros días, degradándose después lentamente, mientras que los taninos son extraídos 
con un tiempo de latencia, por lo que va aumentando su concentración progresivamente con el tiempo de contacto (Figura 3.16). Las procianidinas se difunden más rápidamente que los taninos del ácido gálico, y el grado de polimerización medio de los taninos presentes en el mosto aumenta con el tiempo de maceración.

Estas diferencias de cinética de extracción podrían estar ligadas a las solubilidades relativas de las diversas especies moleculares y ser debidas a una mejor accesibilidad de los taninos de los hollejos. La extracción de los taninos de las semillas es máxima en presencia de sulfuroso, de alcohol y de alta temperatura, ya que durante la fermentación en vinificaciones en tinto, el sulfuroso destruye las membranas de las células. Son necesarias unas condiciones de vinificación que aumenten la riqueza en antocianos y en procianidinas de tamaño pequeño, para obtener un vino de color importante y estable en el tiempo. Parece que los tiempos de maceración relativamente cortos permiten cumplir estas condiciones.

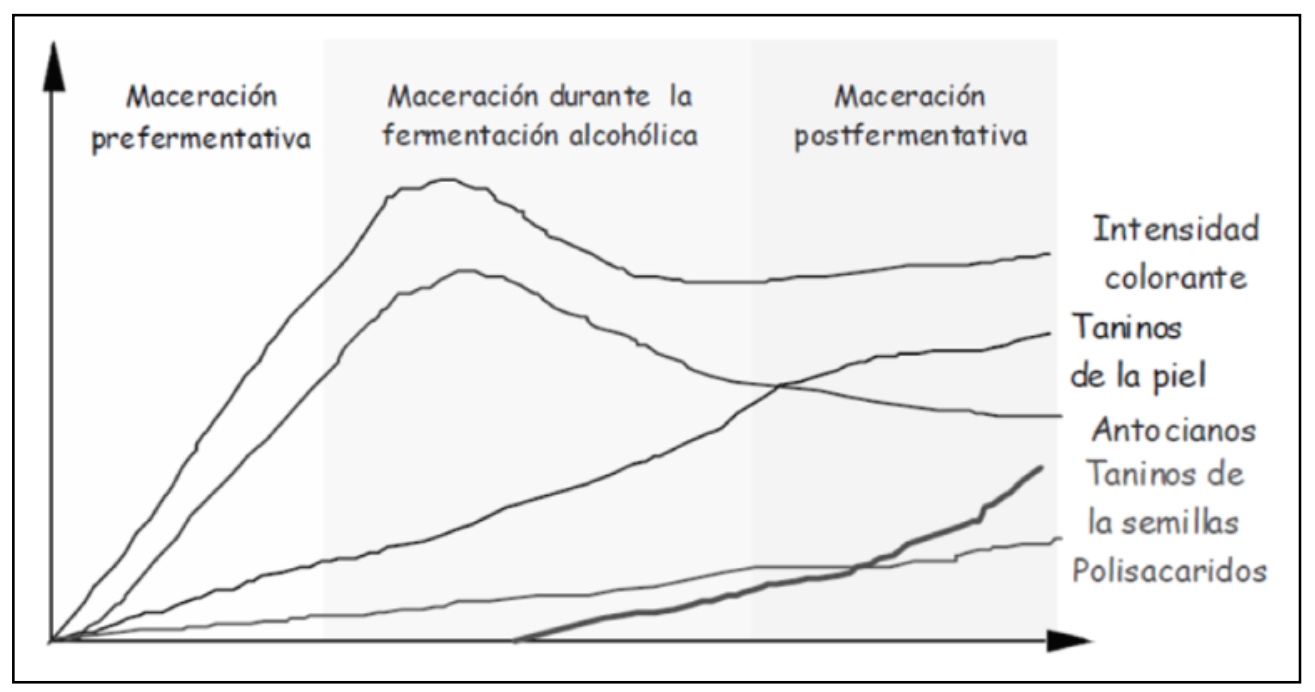

Figura 3.16. Cinética de extracción de los compuestos fenólicos durante la fermentación-maceración.

\subsection{LA MACERACIÓN PREFERMENTATIVA EN FRÍO}

Los polifenoles, taninos, antocianos y sus combinaciones, son los responsables del color de los vinos tintos y el soporte de sus características organolépticas. Durante la etapa de maceración de los vinos tintos es cuando se deben ajustar las proporciones relativas de antocianos y taninos, a fin de obtener una buena evolución del contenido polifenólico en el curso de la crianza (Glories, 1984; Glories y Galvin, 1990). En la búsqueda de la elaboración de vinos afrutados con buena estructura polifenólica, la maceración prefermentativa en frío goza de la preferencia de los enólogos, ya que esta técnica permite obtener vinos más coloreados y aromáticos. Pero necesita un buen estado sanitario y una buena madurez fenólica y tecnológica y además sigue estando asociado a unas cepas naturalmente aromáticas.

La maceración prefermentativa en frío ha sido utilizada inicialmente para aumentar la concentración de compuestos volátiles del mosto (Okubo et al., 2003; Zamora, 2004), y muchos investigadores sostienen que en la vinificación de tintos, 
puede ser una alternativa para una mayor y mejor extracción de los compuestos polifenólicos, influyendo en el aumento de la concentración de antocianos, el índice de ionización y la copigmentación de los mismos, que afecta directamente a la estabilidad del color, facilitando además la formación de estructuras poliméricas y la condensación de los taninos que a su vez dan volumen y redondez al vino (Reynols et al., 2001; Gómez-Miguez y Heredia, 2004; Álvarez et al., 2004 a,b). Se consigue con esto disminuir la intensidad de la extracción durante el proceso fermentativo, con lo que se minimiza el riesgo de extracción de taninos de las pepitas.

Durante la maceración prefermentativa tiene lugar la extracción lenta pero progresiva de los compuestos fenólicos, quizás debido a que ésta facilita un íntimo y prolongado contacto entre hollejos y mosto, que durante la fermentación se ve dificultado por la formación del sombrero, y también a la desorganización de las membranas celulares que se produce por la acción de las enzimas de la uva durante la fase prefermentativa, mayor cuanto más baja sea la temperatura inicial a que se someta la vendimia, consiguiendo mediante el enfriamiento con nieve carbónica aunar la ralentización del proceso fermentativo y la desnaturalización y rotura de las células de los hollejos, por congelación de sus líquidos intracelulares, ejerciendo un efecto drástico sobre los hollejos, desnaturalizando membranas y facilitando la salida de compuestos aromáticos y fenólicos (Reynols, 2001; Parenti et al., 2004; Álvarez et al., 2005).

Esta técnica consiste en alargar la fase prefermentativa de la maceración con el propósito de incrementar la extracción de compuestos polifenólicos en la fase acuosa, al mismo tiempo que se retrasa la formación del sombrero, logrando así un mayor contacto entre los hollejos y el mosto. De este modo se favorece la extracción de las moléculas fácilmente solubles en ausencia de etanol, como son antocianos y taninos de bajo peso molecular, favoreciéndose al mismo tiempo las combinaciones entre ellos y dando lugar a una mejor estabilidad del color. Hay que tener en cuenta que la extracción de los taninos tiene lugar preferentemente en fase alcohólica, a continuación de los antocianos, liberándose en primer lugar las moléculas pequeñas, que contribuyen a la astringencia y agresividad de los vinos en boca. Por ello, las maceraciones cortas conducen a vinos ligeros, con poca cantidad de polifenoles y bajo grado de condensación, es decir poco estables en el tiempo. Cuando el tiempo de maceración se prolonga, es posible extraer taninos más condensados que confieren al vino su estructura y mediante combinación con los antocianos dan lugar a formas más estables en el tiempo.

La piel y la pulpa son las partes de la baya más ricas en sustancias volátiles, por tanto el potencial aromático se encuentra localizado en las partes sólidas de la baya. De esto se deduce que los aromas de la piel aparecen diferentes en intensidad y en calidad a los del mosto. Las consecuencias tecnológicas de esta localización del aroma son importantes, por lo tanto se deberá tener en cuenta para explotar óptimamente el potencial aromático de la baya durante la fase prefermentativa, sin olvidar al mismo tiempo otros fenómenos que se pueden producir en esta fase de la vinificación.

La uva posee un equipamiento variado de enzimas y de precursores de aromas que pueden provocar una dinámica de transformación en potencia de la estructura $\mathrm{y}$ organización celular del grano ya vendimiado. Por otra parte, la presencia de alcohol etílico proveniente de la fermentación favorece la disolución de diversos compuestos de los hollejos en el mosto, entre otros los componentes aromáticos de la piel. Incluso se ha 
comprobado que la extracción de los terpenos está menos ligada a la duración de la maceración que a la formación de los primeros grados alcohólicos.

Por tanto, la maceración favorece los intercambios entre las partes sólidas y el mosto, lo que se acompaña a la vez de un enriquecimiento importante del mosto en compuestos terpénicos y una mejor explotación del potencial aromático.

Durante la etapa prefermentativa, es necesario que las levaduras no comiencen el proceso de fermentación, para ello la vendimia despalillada y estrujada, ha de sulfitarse y mantenerse a bajas temperaturas que no permitan la multiplicación microbiana. Puede realizarse a temperaturas próximas a los $5-8{ }^{\circ} \mathrm{C}$, enfriando previamente la pasta en un intercambiador de calor y manteniéndola durante unos días a esa temperatura en depósitos provistos de sistemas de control térmico (camisas, refrigerantes) mediante el sistema de frío de la bodega. También es posible realizar la maceración prefermentativa a temperaturas más bajas, incluso próximas a $0{ }^{\circ} \mathrm{C}$, utilizando nieve carbónica. Esta técnica ejerce un efecto drástico sobre los hollejos de la uva, facilitando la salida de los compuestos aromáticos y polifenólicos, lo que permite reducir la extracción en presencia de elevadas cantidades de alcohol, y por tanto minimizar el riesgo de extracción de compuestos indeseables de las pepitas.

El paso de la nieve carbónica a estado gaseoso induce la producción de microburbujas, desplazando al oxígeno, saturando el mosto de gas carbónico y por tanto evitando la oxidación. Al añadir nieve carbónica a la pasta, no solo se consigue bajar la temperatura del mosto, evitando así la actividad microbiana, sino que también se inhibe la acción de enzimas polifenoloxidasas, de las bacterias acéticas y de las levaduras oxidativas sin dejar a un lado la posibilidad de disminuir la dosis de sulfuroso a emplear.

El mecanismo de actuación de la maceración prefermentativa en frío en relación a los compuestos polifenólicos aún no se conoce con exactitud, pero se ha comprobado experimentalmente que tiene lugar la extracción de compuestos fenólicos, siendo el enfriamiento con nieve carbónica el método que más contribuye a la extracción de componentes del hollejo, aromas, antocianos y taninos, y a la polimerización y estabilización inicial de estos polifenoles (Flanzy, 1999; Álvarez, 2003; Zamora, 2003).

La combinación de la maceración prefermentativa en frío con adición de nieve carbónica, junto con una temperatura de fermentación que potencie la extracción de compuestos polifenólicos favorables a la calidad del vino, sin elevarse en exceso para evitar la disolución de cantidades elevadas de taninos de pepita y la pérdida de compuestos aromáticos, con una duración de la fermentación no muy elevada, que limite la cantidad de alcohol durante el proceso de maceración-fermentación y no dé lugar a una excesiva extracción de tanino de pepita, permitirá establecer un criterio enológico de gran interés en la elaboración de vinos tintos.

La maceración prefermentativa a bajas temperaturas ha sido ampliamente utilizada en la elaboración de vinos blancos, donde el procedimiento de actuación está perfectamente establecido (Parenti et al., 2004). Esta técnica es también habitualmente empleada en la elaboración de vinos rosados donde también se conoce con exactitud el protocolo de actuación, aunque en este caso hay que tener en cuenta la gran importancia que presenta tanto la duración como la temperatura a la que se realiza la operación. 
En cuanto a la elaboración de vino tinto esta técnica ha sido estudiada únicamente en algunas variedades (Pinot Noir, Merlot, Cabernet Sauvignon, Monastrell, Syrah), aunque en condiciones específicas de elaboración. A pesar de que el objetivo de esta técnica es el de incrementar la extracción de componentes del hollejo para mejorar la estabilidad del color del vino, se han observasdo resultados contradictorios en los diferenetes estudios realizados. Heatherbell et al. (1996) observan que no existen diferencias en los vinos elaborados con la variedad Pinot Noir en cuanto a la concentración de antocianos con respecto al vino testigo. Reynolds et al. (2001) determinan que la maceración prefermentativa en frío incrementa la concentración de antocianos pero únicamente cuando se acompaña la maceración con bajas temperaturas de fermentación $\left(15-20{ }^{\circ} \mathrm{C}\right.$ ), por el contrario cuando el vino es fermentado a altas temperaturas $\left(30{ }^{\circ} \mathrm{C}\right)$ no se encuentran estas diferencias. Estudios en la región francesa de Burgundy muestran como la aplicación de esta técnica no mostró ninguna influencia tanto en la concentración de taninos como en la de antocianos, a no ser que fueran suplementados con elevadas cantidades de sulfuroso $(250 \mathrm{mg} / \mathrm{L})$. Pérez-Lamela et al. (2007) en vinos elaborados en el Norte de España observan que no hay diferencias significativas en la concentración de polifenoles, antocianos, taninos, ni en el color de vinos macerados durante 7 días a temperaturas comprendidas entre $8-10{ }^{\circ} \mathrm{C}$. SotoVázquez et al. (2010) indican que estas técnicas favorecen la extracción de antocianos, además de facilitar las reacciones de copigmentación, permitiendo estos dos factores un incremento notable en la intensidad del color, aunque encuentran una baja concentración de taninos, no alcanzando los vinos elaborados la mínima concentración de taninos, de $2 \mathrm{~g} / \mathrm{L}$ establecida por Zamora-Marín como límite para destinar los vinos al proceso de crianza. Estos y otros resultados contradictorios indican que la aplicación de esta técnica previa a la fermentación depende en gran medida de la variedad empleada, del estado de madurez de la uva, de la temperatura y del tiempo de contacto entre hollejos y mosto.

A pesar de los resultados citados anteriormente, numerosos estudios muestran el efecto positivo de esta técnica obteniéndose vinos con mayor concentración tanto de antocianos como de taninos (Sacchi et al., 2005; Álvarez et al., 2006), así como de componentes del aroma e incluso de polisacáridos, compuestos que juegan un papel fundamental en las sensaciones de vino en boca.

Gómez-Plaza et al. (2000) han estudiado el efecto de bajas temperaturas de maceración $\left(5-15^{\circ} \mathrm{C}\right)$ en el proceso de elaboración de vinos tintos, encontrando como los vinos elaborados de forma tradicional mostraban concentraciones menores de antocianos, taninos y ácidos hidroxicinámicos, así como una menor intensidad colorante con respecto a los vinos macerados en frío, demostrando una vez más que esta técnica favorece la presencia de antocianos que contribuyen al color del vino.

También se han realizado estudios (Gómez-Plaza et al., 2001) cuyo objetivo fue determinar la duración óptima de la maceración en frío, con diferentes tiempos de maceración (4, 5 y 10 días) en vinos elaborados con la variedad Monastrell. Observándose como los vinos macerados durante 10 días presentan una mayor concentración de compuestos polifenólicos y una mayor intensidad colorante en el momento del embotellado. Estos vinos después de un año de embotellado muestran una intensidad colorante más alta, mayor concentración de antocianos y de compuestos 
poliméricos. Por el contrario los vinos macerados durante 4 días presentan un tono más alto con un contenido más bajo en polifenoles, determinándose por tanto un mayor efecto de esta técnica cuando se prolonga la misma durante 8-10 días.

En vinos elaborados con la variedad Cabernet Sauvignon donde se estudió el efecto de diferentes temperaturas (aplicación de frío antes de la fermentación o calentamiento una vez concluida esta) sobre la extracción de componentes del hollejo, se observó como la aplicación de frío antes de la fermentación favorecía la disolución de estos componentes en el mosto, observándose también una disminución en la extracción de taninos astringentes de las semillas (Koyama et al., 2007).

Recientemente González-Neves et al. (2010) han estudiado el perfil antociánico de vinos elaborados con la variedad Tannat, sometidos a diferentes técnicas de vinificación, con aplicación de frío antes de la fermentación, observándose una mayor extracción de antocianos y por lo tanto una mayor formación de pigmentos poliméricos. A medida que transcurre el tiempo disminuye la concentración de antocianos de la uva (monómeros) pero aumenta la concentración de pigmentos poliméricos, indicando una mayor estabilidad del color en el tiempo.

En ensayos realizados por Gordillo et al. (2010) sobre el color y la copigmentación en vinos orgánicos de Tempranillo, se ha estudiado el impacto de la maceración prefermentativa en frío sobre la composición fenólica y la magnitud de la copigmentación, encontrándose diferencias significativas tanto en la composición química como en el color de los vinos, observándose como se incrementa la concentración de los dos compuestos que intervienen directamente en el color (antocianos y taninos) y aquellos que participan en la estabilización de los antocianos mediante las reacciones de copigmentación (fenoles), así como un elevado grado de copigmentación y un oscurecimiento del color con incremento de las tonalidades violáceas.

Mientras que la maceración prefermentativa en frío ha sido indicada como una técnica que produce un efecto limitado sobre la composición polifenólica de los vinos, reduciendo en ocasiones su potencial para el envejecimiento, la congelación de la pasta antes de la fermentación ha propiciado un mayor efecto sobre la extracción de estos compuestos. La congelación incrementa el volumen de líquidos intracelulares que por congelación y ruptura de las membranas permite la disolución de los compuestos fenólicos. Couasnon (1999) ha utilizado nieve carbónica para congelar vendimia de la uva Merlot. En este trabajo, comparando con los vinos control, los resultantes de maceración prefermentativa a bajas temperaturas contienen un $52 \%$ más de taninos y un $50 \%$ más de antocianos, encontrándose resultados similares para vinos elaborados con Cabernet Sauvignon y con Cabernet Franc. Esta técnica también posibilita la rotura de las células que contienen los taninos de las semillas, incrementando su extractabilidad.

Álvarez et al. (2008) detectan en vinos de Tempranillo sometidos a maceración en frío con y sin adición de nieve carbónica, como la maceración en frío aumenta la concentración de polifenoles, de antocianos y del porcentaje de antocianos copigmentados, disminuyendo el color y la astringencia de los vinos, siendo mayores estos incrementos cuando la maceración se realiza con nieve carbónica. Además, en el análisis sensorial de los vinos sitúa a los vinos adicionados de nieve carbónica como los 
vinos con mejor color, mayor calidad aromática y sobre todo mejor valorados por los catadores.

Diferentes técnicas con aplicación de bajas temperaturas antes de la fermentación (maceración en frío, congelación superficial de las uvas, y nieve carbónica) han sido estudiadas en vinos de las variedades Syrah y Cabernet Sauvignon (Gil-Muñoz et al., 2009), encontrándose diferencias significativas en función de la técnica utilizada. La maceración en frío produce la mayor concentración de antocianos en vinos de Cabernet Sauvignon. Además, los vinos elaborados mediante estas técnicas conducen a vinos con un mejor color, mostrando los resultados que el uso de la nieve carbónica mejora los resultados obtenidos por la maceración en frío tradicional. El estudio concluye resaltando como todos los tratamientos en frío conllevan a una mejora de las características cromáticas, mostrando una mayor intensidad colorante, mayor índice de polifenoles totales y mayor concentración de antocianos resistentes al sulfuroso, encontrándose los mejores resultados cuando se aplica nieve carbónica. Sin embargo, si se tienen en cuenta parámetros económicos, la similitud entre los parámetros cromáticos encontrados hace que la maceración en frío tradicional sea la técnica más adecuada.

Estudios realizados en vinos de la variedad Syrah (Heredia et al., 2010) comparan diferentes técnicas de enfriamiento de la vendimia previamente a la maceración en frío $\left(10\right.$ días a $\left.10{ }^{\circ} \mathrm{C}\right)$, concretamente aplicación de nieve carbónica o mediante refrigeración de la vendimia a $0{ }^{\circ} \mathrm{C}$ durante 24 horas, y concluyen diciendo que la técnica empleada influye significativamente en la composición polifenólica, destacando la mayor concentración de antocianos y de compuestos fenólicos cuando la técnica empleada fue la refrigeración previa al estrujado de la uva, influyendo en el poder de copigmentación de los vinos, que a su vez se relaciona con la estabilidad del color en el tiempo. Estos resultados son contradictorios a los encontrados por otros autores, aunque quizás en este estudio no se ha utilizado una cantidad suficiente de nieve carbónica, no alcanzándose la temperatura necesaria para provocar la congelación de las células y actuando únicamente ésta únicamente como refrigerante.

Busse-valverde et al. (2010) estudian el efecto de dos técnicas de maceración en frío, mediante enfriamiento de la vendimia (manteniéndola durante 10 días a $10^{\circ} \mathrm{C}$ en cámara de refrigeración) o mediante adición de nieve carbónica (100 kg de nieve en cada depósito de 100 L) en tres vinos varietales de Monastrell, Cabernet Sauvignon y Syrah, sobre la composición proantocianidínica de los vinos, indicando como la maceración prefermentativa fue el tratamiento más efectivo, incrementando la concentración de proantocianidinas en vinos de Monastrell y Cabernet Sauvignon. Además, destacan también como ninguna de las dos técnicas ha tenido influencia en vinos de Syrah, mostrándose esta variedad a tenor de los resultados obtenidos en diferentes trabajos como la que menor aptitud presenta para ser sometida a maceraciones en frío previas a la fermentación. En cuanto al efecto sobre la composición en proantocinidinas, los resultados indican cómo se incrementa la concentración principalmente de tanino de pepita en ambas técnicas, lo cual ocurre en ausencia de alcohol, lo que nos siguiere que el etanol no siempre es un factor determinante en la extracción de este tipo de tanino. 


\subsection{PAPEL DEL OXÍGENO EN LA CALIDAD DE LOS VINOS}

El oxigeno está presente durante gran parte de la elaboración del vino, desde que la baya se rompe hasta que se consume, primero en la barrica y posteriormente en la botella. De esta forma la cantidad de oxígeno que entra en contacto con el vino a lo largo del proceso de elaboración y crianza es importante. Si este aporte se realiza de forma violenta, no controlada y en un momento inadecuado, la calidad del vino se verá afectada negativamente, dando lugar a oxidaciones y alteraciones microbiológicas. Sin embargo el efecto puede ser beneficioso, especialmente en el vino tinto, si el aporte se realiza de forma adecuada y controlada.

Durante las distintas etapas o procesos de elaboración del vino, la cantidad de oxígeno disuelto se modifica continuamente, ya que procesos como remontados, trasiegos, filtración, centrifugación, favorecen el enriquecimiento en oxígeno. Estos procesos se pueden clasificar en tratamientos con elevado nivel de oxigenación (trasiegos, centrifugación, refrigeración, estabilización tartárica, embotellado) y tratamientos con bajo nivel de oxigenación (bombeo, filtración, intercambiador de calor). El oxígeno disuelto en los mostos y vinos durante los diferentes tratamientos tecnológicos es indispensable en la evolución del vino, ya que una vez disuelto el oxígeno reacciona con los componentes del vino a través de los mecanismos de óxidoreducción (Vivas y Glories, 1995). Este fenómeno modifica la composición del vino, provocando cambios en sus características organolépticas y finalmente modificará la calidad de los vinos. Si su dosis es adecuada conducirá a vinos de buena calidad y si es excesiva o deficitaria disminuirá la calidad de los vinos.

En cuanto a los efectos positivos del oxígeno, es muy importante la eliminación de aromas de reducción, concretamente causada por derivados azufrados, que generalmente aportan olores desagradables, ya que estos compuestos que se producen durante la fermentación alcohólica por la acción de las levaduras poseen un olor particular a huevos podridos, siendo estos compuestos susceptibles de desvalorizar el aroma del vino incluso a bajas concentraciones. El sulfuro de hidrógeno $\left(\mathrm{SH}_{2}\right)$ y los compuestos azufrados de mayor volatilidad se pueden eliminar por aireación de vino o por microoxigenación.

Además el oxígeno interviene en diversas reacciones de condensación y polimerización que ocurren en el vino, que influyen favorablemente en las características sensoriales del mismo. Por ello el aporte de oxigeno adecuado favorece las reacciones de condensación antociano-tanino beneficiosas para la estabilidad del color, y en presencia de etanal favorecen las reacciones de polimerización de taninos, que además de modificar el color, influyen en las características gustativas, como la astringencia y el amargor, mejorando las características organolépticas de los vinos.

En cuanto a los efectos negativos cabe destacar como los antocianos libres y otros compuestos fenólicos son muy sensibles a la oxidación, transformándose irreversiblemente en compuestos incoloros o amarillos con la consiguiente pérdida del color. Además el oxígeno puede favorecer el desarrollo de bacterias acéticas, que elevan la acidez volátil de los vinos. Las bacterias acéticas están presentes durante todas las etapas de la elaboración y por lo tanto si encuentran condiciones favorables para su desarrollo actuarán incluso aunque la concentración de $\mathrm{SO}_{2}$ libre sea la adecuada para proteger al vino del metabolismo acético. Así mismo un incremento del oxígeno disuelto puede favorecer el crecimiento de levaduras del género Brettanomyces (Du Toit 
et al., 2005), que son levaduras de contaminación responsables de la aparición en el vino de 4-etil-fenol y de 4-etil-guayacol, compuestos que aportan aromas a establo, cuero, sudor de caballo, que no son deseables en el vino.

Estos efectos negativos del oxígeno se deben principalmente a un aporte excesivo de este. Por tanto para lograr los efectos positivos del oxígeno y reducir los negativos es necesaria una oxigenación lenta que permita el consumo de oxígeno a medida que se adiciona (microoxigenación), a diferencia de una oxigenación violenta y puntual (macrooxigenación).

Por otra parte, el anhídrido sulfuroso $\left(\mathrm{SO}_{2}\right)$ puede influir de forma decisiva en la efectividad de la microoxigenación. Este compuesto se presenta en diferentes formas químicas en función del $\mathrm{pH}$. Al $\mathrm{pH}$ del vino existe principalmente como ión bisulfito $\left(\mathrm{HSO}_{3}{ }^{-}\right)$(Boulton et al., 1996), forma responsable de la actividad antioxidante cuando se encuentra en estado libre. Este ión bisulfito puede combinarse establemente con el acetaldehído y de forma menos estable con otros compuestos (azúcares, ácido y antocianos), dando lugar al anhídrido sulfuroso combinado, el cual carece de actividad antioxidante. Por ello, la presencia de anhídrido sulfuroso libre en exceso en el vino, necesario para garantizar la actividad antimicrobiana, puede combinarse con el acetaldehído generado durante una oxigenación moderada y frenar la evolución del vino, evitando que el acetaldehído participe en las reacciones de combinación y polimerización de los antocianos y taninos, reacciones que estabilizan el color $\mathrm{y}$ disminuyen la astringencia.

\subsection{LA TÉCNICA DE LA MICROOXIGENACIÓN}

Esta técnica tuvo su origen al suroeste de Francia, concretamente en la zona de Burdeos, para aplicarla a la variedad Tannat, variedad que presenta una elevada concentración tánica (hasta $7 \mathrm{~g} / \mathrm{L}$ de taninos) y de antocianos (hasta $2 \mathrm{~g} / \mathrm{L}$ de estos compuestos), elaborándose vinos que perdían rápidamente el color y que resultaban excesivamente secantes. Esto fue lo que llevo a buscar una técnica que permitiera conservar la untuosidad y el carácter afrutado de los vinos. Los primeros ensayos realizados en 1991 muestran como los vinos sometidos a microoxigenación evolucionaban mejor, conservando el color y la fruta, destacando sobre todo la presencia de taninos mas redondos (Lemaire, 1995). Así nació esta técnica para gestionar y controlar uno de los parámetros más importantes en la elaboración de vinos, el oxígeno.

El fundamento de esta técnica surge de los intercambios gaseosos que se producen durante el periodo de crianza en barricas. Por lo tanto se pretendía realizar este aporte de oxígeno de forma controlada a los vinos que se mantenían en tanques de acero inoxidable, con el fin de reproducir los fenómenos que ocurren durante la crianza en barrica. En definitiva, la microoxigenación se fundamenta en aportar al vino pequeñas y controladas cantidades de oxígeno de forma continuada, a través de un microdifusor poroso que facilita la disolución del oxígeno en el vino (Moutounet et al., 1995), teniendo en cuenta que la velocidad de aporte de oxígeno al vino debe ser inferior a la velocidad de consumo de este, de forma que no se produzca la acumulación de oxígeno disuelto y por tanto la aparición de efectos negativos. 


\subsubsection{OBJETIVOS DE LA MICROOXIGENACIÓN}

Según (Roig y Yerle, 2003; Moutounet, 2003) los principales objetivos son:

1. Mejorar y estabilizar la intensidad y el color de los vinos, debido a que se favorecen las reacciones de condensación entre antocianos y otros compuestos flavonoides, bien de forma directa o mediada por el acetaldehído.

2. Potenciar las notas frutales y favorecer la integración de los aromas de la madera, al mismo tiempo que se reduce la intensidad de los aromas herbáceos o vegetales del vino.

3. Evitar la aparición o eliminar aromas reductivos, especialmente los derivados azufrados.

4. Mejorar las sensaciones gustativas del vino, reduciendo la sensación de aspereza y sequedad producida por los taninos, los cuales reaccionan modificando su estructura, dando lugar a una menor astringencia, ganando el vino complejidad.

Durante la microoxigenación se pueden observar dos fases distintas en la evolución del vino. La primera fase llamada fase de estructuración, se caracteriza por un aumento de la agresividad y la intensidad de los taninos, al mismo tiempo que disminuyen los aromas fermentativos, varietales y la complejidad del vino. De manera que en esta fase se refuerza la estructura tánica y se estabiliza la materia colorante, obteniéndose vinos más voluminosos y equilibrados. El final de esta fase viene determinada por la inversión de estas tendencias organolépticas.

Una vez terminada la fase de estructuración comienza la etapa de armonización, etapa en la que el vino se va haciendo cada vez más complejo, sus taninos se van redondeando y el vino comienza a ser más suave y accesible. Los objetivos de esta fase son los mismos que se busca cuando el vino se envejece en barrica: expresar al máximo las cualidades cromáticas, aromáticas y gustativas, desarrollando la complejidad aromática, mejorando la calidad tánica, estabilizando el color y eliminando olores a reducido y caracteres herbáceos. Los cambios que se producen en esta fase son reversibles, contrariamente a lo que ocurre durante la fase de estructuración. Las dosis de oxígeno usadas en esta etapa deben ser más bajas, evitando el riesgo de acumulación de oxígeno disuelto. Por lo tanto, cuanto mayor sea la fase de estructuración más necesaria es la fase de armonización y más tiempo requiere.

\subsubsection{MOMENTOS DE APLICACIÓN DE LA MICROOXIGENACIÓN}

Este tratamiento puede llevarse a cabo en cualquier etapa del proceso de elaboración o incluso durante el envejecimiento del vino. Pudiéndose aplicar durante la fermentación alcohólica, tras la fermentación maloláctica y antes o durante el envejecimiento de los vinos, realizándose en cada fase buscando diferentes fines $\mathrm{u}$ objetivos. 


\subsubsection{APLICACIÓN DURANTE LA FERMENTACIÓN ALCOHÓLICA}

Durante la multiplicación de las levaduras el oxígeno juega un papel importante sobre la formación de esteroles y ácidos grasos insaturados de la membrana celular de las levaduras. Estos compuestos son responsables de la resistencia al alcohol de estos microorganismos, asegurando un buen final de fermentación, actuando como factor de supervivencia.

Por lo tanto el objetivo principal que se persigue durante esta etapa es favorecer el crecimiento de las levaduras, evitando fermentaciones largas y lentas, asegurando el completo agotamiento de los azúcares y evitando las reacciones secundarias indeseables que podrían producir sustancias organolépticas perjudiciales. La dosis de trabajo habitual se sitúa en torno a los $6 \mathrm{~mL}$ por litro de vino, siendo el momento óptimo de aplicación durante la fase de crecimiento exponencial de las levaduras, con una duración de la operación en torno a las 24-48 horas como máximo (Anocibar, 2005).

En el proceso de elaboración de vinos tintos el oxígeno es aportado durante las operaciones de remontado, pero en la vinificación en blanco y en rosado, donde esta práctica no se realiza, la oxigenación junto con el aporte de nitrógeno asimilable nos permite asegurar la multiplicación de las levaduras, además de limitar los riesgos de parada de fermentación.

\subsubsection{APLICACIÓN DESPUÉS DE LA FERMENTACIÓN ALCOHÓLICA Y ANTES DE LA FERMENTACIÓN MALOLÁCTICA.}

El objetivo principal de la adición de oxígeno es la de estructurar y estabilizar el color del vino. Para ello interesa la formación de acetaldehído, ya que este compuesto participa en las reacciones de condensación tanino-antociano, dando lugar a nuevos pigmentos, aumentando la intensidad colorante, y el mantenimiento de los tonos rojovioláceos del vino. Además, se favorecerá la polimerización cruzada de taninos, o lo que es lo mismo, el paso de taninos verdes a taninos maduros más suaves y menos astringentes que los primeros.

Los resultados obtenidos por diversos autores (Parish et al., 2000; Bosso et al., 2000; Castellari et al., 2000; Cabanillas et al., 2001; Pour-Nikfardjam y Dykes, 2003; Pérez-Magariño y González-Sanjosé, 2002 b y 2003 a; González-Sanjosé et al., 2005; Sánchez-Iglesias et al., 2005) han puesto de manifiesto que los mayores efectos producidos por la microoxigenación se obtuvieron cuando se aplica en este momento del proceso, no observándose efectos significativos cuando la microoxigenación se realizó en otras etapas. Esto es debido a que es en este momento cuando el vino tiene la mayor cantidad de antocianos y de taninos, y por lo tanto se producen con mayor facilidad las reacciones de condensación y polimerización entre estos compuestos.

Un aspecto muy importante es la concentración de partida tanto de antocianos como de taninos, junto con un equilibrio adecuado entre ellos, para conseguir un buen rendimiento de la operación. De modo que si la concentración molar de antocianos es mucho mayor que la de taninos, como ocurre en vinos tintos poco macerados, la reacción que predomina es la de oxidación de los antocianos, lo que da lugar a una pérdida de color y a una baja polimerización tanino-antociano. En cambio, si el vino 
contiene una concentración molar de taninos mayor que la de antocianos, la reacción que predominará será la de polimerización de taninos, dando lugar a un incremento del color amarillo a lo largo de la crianza y a una disminución de la astringencia por pérdida de materia tánica. Y por último, si el vino contiene una concentración equilibrada de antocianos y de taninos, todas las reacciones serán igualmente probables y por lo tanto la microoxigenación favorecerá los procesos de polimerización tanino-antociano, estabilizando el color y disminuyendo la astringencia. Esta fase es importante porque aparte de estabilizar el color, confiere el vino una mayor resistencia a la oxidación debido a la mayor estabilidad de sus polifenoles.

A la hora de fijar la dosis de oxígeno a aplicar, hay que tener en cuenta la concentración de antocianos y de taninos y el grado de madurez de los taninos. Las dosis aplicadas serán mayores cuanto mayor sea la concentración de compuestos fenólicos presentes y cuanto mayor sea la presencia de taninos verdes. La cantidad de oxígeno que se aplica varía entre $10-60 \mathrm{~mL} / \mathrm{L} / \mathrm{mes}$ y el tiempo de aplicación se prolonga durante 2-3 semanas. Es importante destacar que la aplicación de esta técnica puede favorecer la crianza oxidativa de los vinos en madera, ya que estructura el vino antes de su envejecimiento en barrica.

\subsubsection{APLICACIÓN DURANTE LA MADURACIÓN O EL ALMACENAMIENTO}

La aplicación de la microoxigenación durante la fase de maduración o almacenamiento de los vinos únicamente es aplicable a los vinos mantenidos en depósitos y no en aquellos criados en barricas, ya que en éstos la microoxigenación se produce de forma natural a través de los poros de la barrica. Durante este periodo, la cantidad de oxígeno aportada debe ser inferior a la usada entre la fermentación alcohólica y la fermentación maloláctica, ya que en este caso el $\mathrm{pH}$ del vino aumenta tras la fermentación maloláctica provocando el desplazamiento del equilibrio de disociación de los antocianos libres hacia la forma hidratada incolora, más fácilmente oxidable que la forma catión flavilio. Por tanto, las dosis oscilaran entre 0,5-10 $\mathrm{mL} / \mathrm{L} / \mathrm{mes}$ dependiendo del tipo de vino y de la duración del tratamiento, que puede ser de entre 1 y 6 meses.

\subsubsection{OPTIMIZACIÓN DEL PROCESO. FACTORES QUE INFLUYEN SOBRE LA DISOLUCIÓN DEL OXÍGENO.}

La superficie de contacto gas/líquido $\left(\mathrm{m}^{2} / \mathrm{m}^{3}\right)$ determina la cantidad de oxígeno disuelto, así cuanto mayor sea la superficie de contacto entre el aire atmosférico y el vino, mayor será la cantidad de oxígeno disuelto (Moutounet y Vidal, 2006). Por lo tanto, es necesario conseguir la mayor superficie de contacto entre el oxígeno y el vino, asegurando la total difusión de éste. Esto depende del tipo de difusor utilizado, de las dimensiones del tanque y de la posición del difusor en el tanque. La mayor superficie de contacto se consigue con un difusor que permita la formación de burbujas lo más pequeñas posibles. También es importante que la altura mínima del tanque sea de dos metros y que el difusor este colocado a uno 10-20 $\mathrm{cm}$ del fondo del tanque, para que las microburbujas de oxígeno tengan espacio suficiente para disolverse completamente en el vino. 
Otro de los factores que va a influir en la disolución del oxígeno es la temperatura, de manera que cuanto más baja sea esta mayor será la cantidad de oxígeno disuelto. Por otra parte hay que tener en cuenta que la temperatura afecta al consumo de oxígeno, de forma que a bajas temperaturas se reduce la velocidad de las reacciones oxidativas de los compuestos fenólicos, reduciendo el consumo de oxígeno. Debido a esto hay que mantener una temperatura adecuada, que será la que mantenga en equilibrio la solubilidad y el consumo de oxígeno. Se han indicado temperaturas óptimas que oscilan entre $15-18^{\circ} \mathrm{C}$.

La turbidez es otro factor que influye en la cantidad de oxígeno disuelto, ya que las lías son grandes consumidoras de oxígeno. Para evitar el consumo incontrolado de oxígeno por parte de las lías, que impedirán conseguir el efecto estructurante deseado en el vino, es fundamental que la microoxigenación se lleve a cabo en vinos con valores de turbidez inferiores a 100 NTU. Por otra parte, la presencia de coloides en el medio dificulta la difusión homogénea del oxígeno en el tanque, siendo esta otra razón para recomendar trabajar con vino limpios, lo que además reduce los riesgos de desarrollo de microorganismos indeseables como bacterias acéticas o Brettanomyces.

\subsubsection{OTRAS APLICACIONES DE INTERÉS DE LA MICROOXIGENACIÓN}

El aporte de oxígeno durante la crianza sobre lías puede ser beneficioso para contrarrestar el efecto reductor que se produce debido al consumo de oxígeno por parte de las mismas, combinando así los efectos beneficiosos de ambos procesos, tanto en vinos blancos como en tintos, evitando la aparición de aromas desagradables producidos principalmente por los compuestos azufrados formados en este ambiente. Sin embargo, en vinos tintos la fuerte capacidad de las lías para absorber materia colorante, hace que esta aplicación se reserve a vinos muy estructurados y estables.

Otra de las técnicas en la que interviene la microoxigenación es en la combinación de virutas o trozos de madera con el aporte controlado de oxígeno. El paso del vino por barrica supone unos costes elevados para las bodegas, pudiéndose reducir mediante esta técnica que persigue simular el proceso que ocurre de forma natural durante la crianza del vino en madera. Se combina la adición de trozos de madera de distintos tamaños, tostados y procedencias, junto con la microoxigenación. Esta técnica permite aportar los compuestos de la madera combinada con el aporte lento de oxígeno. De esta forma permite cubrir dos aspectos, por un lado se logra estabilizar el color y suavizar la astringencia y por otro se logra aportar al vino aromas y componentes de la madera (compuestos volátiles, taninos, polisacáridos) que complementan sensorialmente al vino y le aportan complejidad. Con la combinación de ambas técnicas se consigue un abaratamiento notable del proceso, debido al ahorro del número de barricas, de tiempo y de mano de obra, evitándose también las mermas por evaporación.

Además de las aplicaciones comentadas, las técnicas de microoxigenación permiten la eliminación de olores herbáceos y reducidos en vinos blancos, ayudan a la estabilidad proteica de vinos blancos, pueden utilizarse para aportar oxígeno en vinos que se encuentran en barricas viejas, que han perdido parte de su capacidad para microoxigenar (mediante el uso de cliqueurs), en combinación con adición de taninos para aumentar la estructura en boca y la redondez de los vinos, y por último la 
combinación de crianza sobre lías, microoxiganación y adición de chips, puede favorecer la integración de los aromas de la madera, los aromas varietales y los fermentativos, evitando los vinos maderizados.

\subsubsection{ESTUDIOS RECIENTES SOBRE LA APLICACIÓN DE LA MICROOXIGENACIÓN}

En la última década se han realizado numerosos estudios con el objetivo de poner de manifiesto las propiedades beneficiosas de la aplicación controlada de oxígeno, y por otra parte, de estudiar la aplicación de esta técnica en diferentes vinos, con el objetivo de optimizar el proceso y conocer cuáles serán las variables que nos permitirán mejorar las propiedades organolépticas de los vinos microoxigenados.

El oxígeno disuelto lleva a la formación de etanal a partir de etanol, produciendo moléculas unidas mediante el etanal, antociano-tanino o tanino-tanino (Silva et al., 2005). Más recientemente ha sido demostrado como el etanal participa en la formación de nuevos pigmentos como las vitisinas y otros piranoantocianos (Fulcrand et al., 1998; Mateus et al., 2002). De acuerdo con estos autores el envejecimiento en barrica debería incrementar el grado de polimerización de taninos y las combinaciones taninoantociano, sugiriendo que este proceso es responsable de la estabilidad del color y de la menor astringencia observada (Fulcrand et al., 1998; Silva et al., 2005; Mateus et al., 2002, Vivas et al., 1996). Sin embargo ha sido demostrado que estos compuestos unidos mediante el acetaldehído son inestables (Escribano-Bailón et al., 2001).

Una de las variables importantes en el proceso de la microoxigenación es la presencia de sulfuroso en estado libre en el vino, el cual es capaz de reaccionar con el acetaldehído formando uniones estables y limitando por tanto la capacidad de este para participar en las reacciones de estabilización del color mencionadas con anterioridad. Para ello, Tao et al. (2007) estudian el efecto de esta técnica en vinos de Merlot con adición de distintas dosis de sulfuroso $\left(0,50,100,200 \mathrm{mg} / \mathrm{L}\right.$ de $\mathrm{SO}_{2}$, observándose un importante descenso de la concentración de antocianos monómeros y de flavanoles, mayor cuanto menor es la dosis de sulfuroso adicionado, junto con un incremento de pigmentos no decolorables por el sulfuroso, así como un incremento en la concentración de taninos. Destacando como estos cambios en los vinos no se observaron en los vinos adicionados de $200 \mathrm{mg} / \mathrm{L}$ de $\mathrm{SO}_{2}$, además de ocurrir más despacio en los vinos que fueron envejecidos en botella en ausencia de oxígeno, frente a aquellos envejecidos en barrica. Por último concluyen que la concentración de sulfuroso parece regular la fracción polifenólica, regulando la formación de pigmentos poliméricos, cambiando la composición tánica y afectando a la astringencia de los vinos.

Llaudy et al. (2006) aplican la técnica de la microoxigenación antes de la crianza en barrica, a vinos muy astringentes de Cabernet Sauvignon, encontrando una ligera disminución de la intensidad colorante, así como niveles más elevados de antocianos libres y combinados, además de compuestos antociano-tanino unidos mediante el puente de acetaldehído en los vinos microoxigenados. Por otra parte, no encuentra diferencias con respecto a la formación de nuevos pigmentos poliméricos. Y finaliza destacando que esta técnica no afecta a la concentración total de proantocianidinas pero produce un mayor grado de polimerización de taninos y una menor astringencia. 
Cano-López et al. (2006) prolongan la microoxigenación una vez terminada la fermentación maloláctica y estudian tanto las características cromáticas, como la composición antociánica (pigmentos poliméricos) en vinos de Monastrell, encontrándose con vinos vinos con una menor concentración de antocianos monómeros $\mathrm{y}$ una mayor concentración de moléculas antociano-tanino unidas mediante el acetaldehído, así como de vitisinas, con respecto a los vinos control. Además, se han encontrado diferencias en las características cromáticas, mostrando los vinos microoxigenados una mayor intensidad colorante, parámetro altamente relacionado con la alta concentración de piranoantocianos encontrada.

Con la intención de comprobar la duración del efecto de la microoxigenación durante un determinado periodo de tiempo, estos mismos autores (Cano-López et al., 2007) estudiaron el perfil antociánico en vinos de Monastrell microoxigenados durante dos etapas, entre la fermentación alcohólica y maloláctica y posteriormente a la fermentación maloláctica. Los resultados muestran una mejora en las características cromáticas de los vinos microoxigenados y como estas mejoras se mantienen después del periodo de envejecimiento en barrica o en botella. Estos vinos muestran una menor concentración de antocianos monómeros, una mayor concentración de compuestos unidos mediante el acetaldehído, así como de vitisinas con respecto a los vinos no microoxigenados. También se han encontrado diferencias en cuanto a las características cromáticas, presentando los vinos microoxigenados una mayor intensidad colorante. Además, los autores ponen de manifiesto como los vinos envejecidos en botella muestran una menor intensidad colorante con respecto a los vinos envejecidos en barrica, así como un incremento del tono y una menor cantidad de compuestos resistentes al sulfuroso, indicando que la formación de estos compuestos se ve favorecida por las condiciones oxidativas de estas.

Perez-Magariño et al. (2007) estudiaron el efecto de esta técnica aplicada después de la fermentación maloláctica en cuatro vinos varietales de Mencía, Tinta de Toro, Tinta del País y Tempranillo elaborados durante tres vendimias distintas. Los resultados muestran como disminuye la concentración global de polifenoles, pero se consigue una mayor estabilidad del color, sin que se aprecie un incremento del tono. Por lo tanto la pérdida del color que habitualmente ocurre después de la fermentación maloláctica puede ser disminuida mediante microoxigenación.

De Beer et al. (2007) microoxigenaron vinos de la variedad Pinotage sudafricana con distintas dosis de oxígeno $(2.5-5 \mathrm{mg} / \mathrm{L} / \mathrm{mes})$ durante 2, 4, 6 y 8 meses, observando como la aplicación de esta técnica durante 2 meses tuvo efectos beneficiosos en el color y en las propiedades sensoriales de los vinos. Por el contrario, la máxima cantidad de oxígeno $(5 \mathrm{mg} / \mathrm{L} / \mathrm{mes})$ durante 8 meses, tuvo un efecto negativo sobre las propiedades organolépticas de los vinos, lo cual nos indica que estas reacciones favorecidas por la presencia de oxígeno puede que no sean estables en el tiempo. Las variables del proceso, el momento de aplicación, la concentración en polifenoles de los vinos, la concentración de sulfuroso, etc., manifiestan una importante influencia sobre la estabilidad de estas reacciones.

Muchos factores pueden afectar a los resultados obtenidos cuando se aplica la microoxigenación, los más importantes son el momento de aplicación, la dosis de oxígeno y las características polifenólicas de los vinos. Gómez-Plaza et al., (2008) 
estudiando el efecto de la adición de oxígeno en vinos de Monastrell con diferentes características polifenólicas, observaron que los vinos microoxigenados muestran un mayor porcentaje de pigmentos poliméricos y un mayor color, viéndose esta formación favorecida en aquellos vinos con una elevada concentración polifenólica. El vino con menor concentración polifenólica es el menos influenciado por la microoxigenación, observándose una evolución negativa en el grado de polimerización de taninos, sugiriendo que quizás ha sufrido una sobreoxigenación.

Aunque la microoxigenación puede ser aplicada en cualquier etapa del proceso de elaboración del vino, numerosos autores creen que aplicada entre la fermentación alcohólica y la maloláctica es cuando presenta las mejores propiedades. Rayne et al. (2008) estudian las características cromáticas y algunos parámetros espectofotométricos en vinos de Merlot y Cabernet Sauvignon microoxigenados durante dos semanas, una vez finalizada la fermentación maloláctica y después de un periodo de 6 meses de crianza en barrica, observando como en los vinos microoxigenados se produce un incremento en la intensidad colorante (35\% en vinos de Merlot y $7 \%$ en vinos de Cabernet Sauvignon), un mayor color debido a los antocianos resistentes al sulfuroso (40\% y $45 \%$ respectivamente) y una mejora en el estado de envejecimiento del vino, parámetro que viene determinado por el cociente entre los compuestos resistentes al sulfuroso y la concentración total de pigmentos (10\% y $35 \%$, respectivamente). También se observó una disminución del tono en vinos de Merlot (3\%), mientras que en vinos de Cabernet Sauvignon se produjo un aumento del tono (3\%) y de la tonalidad azul $(6 \%)$.

Cejudo-Bastante et al. (2010) estudian en vinos de Cencibel la adición controlada de oxígeno a razón de $10 \mathrm{~mL} / \mathrm{L}$ durante 20 días entre la fermentación alcohólica y maloláctica, encontrándose un incremento en la concentración de las uniones antocianotanino mediadas por el acetaldehído, así como de piranoantocianos, compuestos relacionados con la estabilidad del color de los vinos en el tiempo. Además, observan como la calidad del aroma ha mejorado, apareciendo nuevos aromas (ciruela y grosella), mientras que otros se incrementan (especiado y regaliz), y disminuyen los aromas herbáceos. Los resultados sugieren que la combinación de la microoxigenación junto con el envejecimiento de los vinos en depósitos de acero, incrementan la estabilidad del color, la calidad del aroma y las características sensoriales de los vinos estudiados.

También ha sido estudiado el impacto de la aplicación moderada de oxígeno después del embotellado sobre la composición polifenólica y el color de los vinos de Garnacha, con bajos y elevados contenidos polifenólicos (Wirth et al., 2010), ensayándose cuatro dosis de oxígeno $\left(0.8,1.9,8,11.9 \mu \mathrm{LO}_{2} /\right.$ botella/día), asegurándose la adición utilizando cierres sintéticos con una determinada permeabilidad, y almacenándose estas botellas en atmósfera controlada. Durante el envejecimiento se observaron menores concentraciones de piranoantocianos y ácidos hidroxicinámicos, independientemente de la dosis de oxígeno aplicada. A medida que disminuye la concentración de sulfuroso se ve incrementada la concentración en flavanoles monómeros y la relación de antocianos que se transforman en pigmentos poliméricos, especialmente en aquellos resistentes al sulfuroso, mayor cuanto mayor es la dosis de oxígeno aplicada. Entre los pigmentos poliméricos, los piranoantocianos se incrementan con la microoxigenación y con el nivel de oxígeno aplicado, pudiendo ser considerados como marcadores de la oxidación. 
Se ha comentado anteriormente que la microoxigenación puede ser aplicada en cualquier etapa del proceso de elaboración del vino en función del objetivo buscado. Además las distintas dosis de oxigeno a aplicar están condicionadas por el momento de adición, por la concentración polifenólica de los vinos e incluso por la concentración de sulfuroso existente. Algunos autores optan por aplicar oxígeno entre fermentación alcohólica y maloláctica, aplicando dosis de $15 \mathrm{~mL} / \mathrm{L} / \mathrm{mes}$, estableciéndose a razón de los resultados obtenidos que esta dosis es la adecuada cuando el tratamiento se realiza durante esta etapa del proceso. Otros autores (Cano-López et al., 2006, 2007, 2008) aplican oxígeno de forma controlada tanto entre la fermentación alcohólica y maloláctica, como una vez finalizada esta. Las dosis empleadas varían en torno a 7,5-15 $\mathrm{mL} / \mathrm{L} / \mathrm{mes}$ entre las dos fermentaciones, y $3-5 \mathrm{~mL} / \mathrm{L} / \mathrm{mes}$ una vez terminadas. Por otra parte, también existen estudios de aplicación de la microoxigenar una vez terminada la fermentación maloláctica; tanto Rayne et al. (2008) como Perez-Magariño et al. (2007) aplican dosis entre $25-45 \mathrm{~mL} / \mathrm{L}$ de oxígeno durante periodos comprendidos entre 15-20 días respectivamente, así como dosis menores de $15 \mathrm{~mL} / \mathrm{L}$ (Llaudy et al., 2006; Tao et al., 2007). Por último en otros trabajos se aplican dosis inferiores a $1 \mathrm{~mL} / \mathrm{L} / \mathrm{mes}$, aunque se prolonga el tratamiento durante 5 meses (Wirth et al., 2010). Esta diversidad de dosis está influenciada por las características polifenólicas de los vinos ensayados, por ello algunos trabajos muestran dosis óptimas superiores a las recomendadas durante esta etapa $(0,5-10 \mathrm{~mL} / \mathrm{L} / \mathrm{mes})$ para vinos con gran carga polifenólica. 



\section{PLAN DE TRABAJO}




\section{PLAN DE TRABAJO}

En primer lugar se realizó una búsqueda bibliográfica sobre la influencia que la adición de copigmentos, las técnicas de vinificación y la aplicación controlada de oxígeno tienen sobre el aumento y la estabilidad del color, así como la composición polifenólica de los vinos tintos.

Las uvas para realizar el estudio proceden de una parcela de la bodega Chozas Carrascal, ubicada en la D.O. Utiel-Requena. El viñedo tiene 10 años de edad y es de la variedad Tempranillo injertada sobre el portainjerto 110-Richter, y está cultivada régimen de secano con riego de apoyo por goteo. El estudio se realizó durante tres vendimias consecutivas, concretamente para las vendimias 2006, 2007 y 2008.

Se controló el estado de madurez de las uvas en el período anterior a la vendimia, con el objeto de conocer con precisión el grado de madurez, y realizar la vendimia en el momento óptimo para obtener la máxima concentración polifenólica. La uva se vendimió cuando alcanzó aproximadamente los 12,5-13 ${ }^{\circ}$ Baumé y los parámetros polifenólicos eran adecuados. La uva se vendimió en cajas de plástico con capacidad aproximada para $20 \mathrm{Kg}$ de uva, trasladándose de inmediato a la bodega, una vez realizados los controles de vendimia.

Posteriormente se realizó el despalillado-estrujado de la uva y se encubó en depósitos de 50 litros de capacidad. Así mismo se realizó la determinación analítica de la composición de los mostos obtenidos, sulfitándose la uva con $5 \mathrm{~g} / \mathrm{hL}$ de $\mathrm{SO}_{2}$.

Se realizaron tres tipos de vinificaciones, todas ellas por triplicado: una convencional o tradicional sin maceración prefermentativa, otra con maceración prefermentiva en frío a baja temperatura $\left(6-8^{\circ} \mathrm{C}\right)$ durante 4 días y posterior maceraciónfermentación, y finalmente otra con maceración prefermetativa en frío con enfriamiento previo a $0{ }^{\circ} \mathrm{C}$ mediante adición de nieve carbónica, mantenimiento de bajas temperaturas $\left(6-8^{\circ} \mathrm{C}\right)$ durante 4 días, y posterior maceración-fermentación.

Para cada tipo de vinificación se introdujeron 5 variables correspondientes a cada copigmento utilizado: rutina, ácido cafeico, catequina y dos proantocianidinas comerciales, procedentes una de hollejos y otra de pepitas de uvas blancas, a una dosis de $90 \mathrm{mg} / \mathrm{kg}$ de uva, elaborando también un vino testigo sin la adición de ningún copigmento. La aplicación de los copigmentos se realizó en dos momentos distintos, prefermentativa y postfermentativamente, con el objeto de conocer la influencia del momento de la adición.

Una vez adicionados los copigmentos, y concluida la maceración prefermentativas en los vinos en los que tubo lugar, se realizó la siembra de $20 \mathrm{~g} / \mathrm{hL}$ de levaduras seleccionadas Sccharomyces cerevisiae, var. bayanus. La maceraciónfermentación de los vinos fue llevada a cabo a temperaturas de $27-28^{\circ} \mathrm{C}$ para todas las vinificaciones, aplicando dos remontados diarios con las mismas pautas de remontado para todas ellas, además de controlarse diariamente la densidad y temperatura, para el seguimiento adecuado del proceso.

Así mismo, se estableció en los vinos no criomacerados un momento óptimo de descube, a los 10 días del encubado. La maceración prefermentativa tuvo cuatro días de duración, tras la cual cada depósito alcanzo una temperatura ambiente, para realizar la siembra de levaduras. En estos depósitos se siguió la misma pauta de fermentaciónmaceración que en los que no se realizó maceración prefermentativa en cuanto a la $T^{\mathrm{a}}$ 
de fermentación, bazuqueos y momento de descube, después de la inoculación de levaduras. El la figura 4.1 se representa gráficamente el diagrama de flujo del proceso de elaboración de los vinos obtenidos.

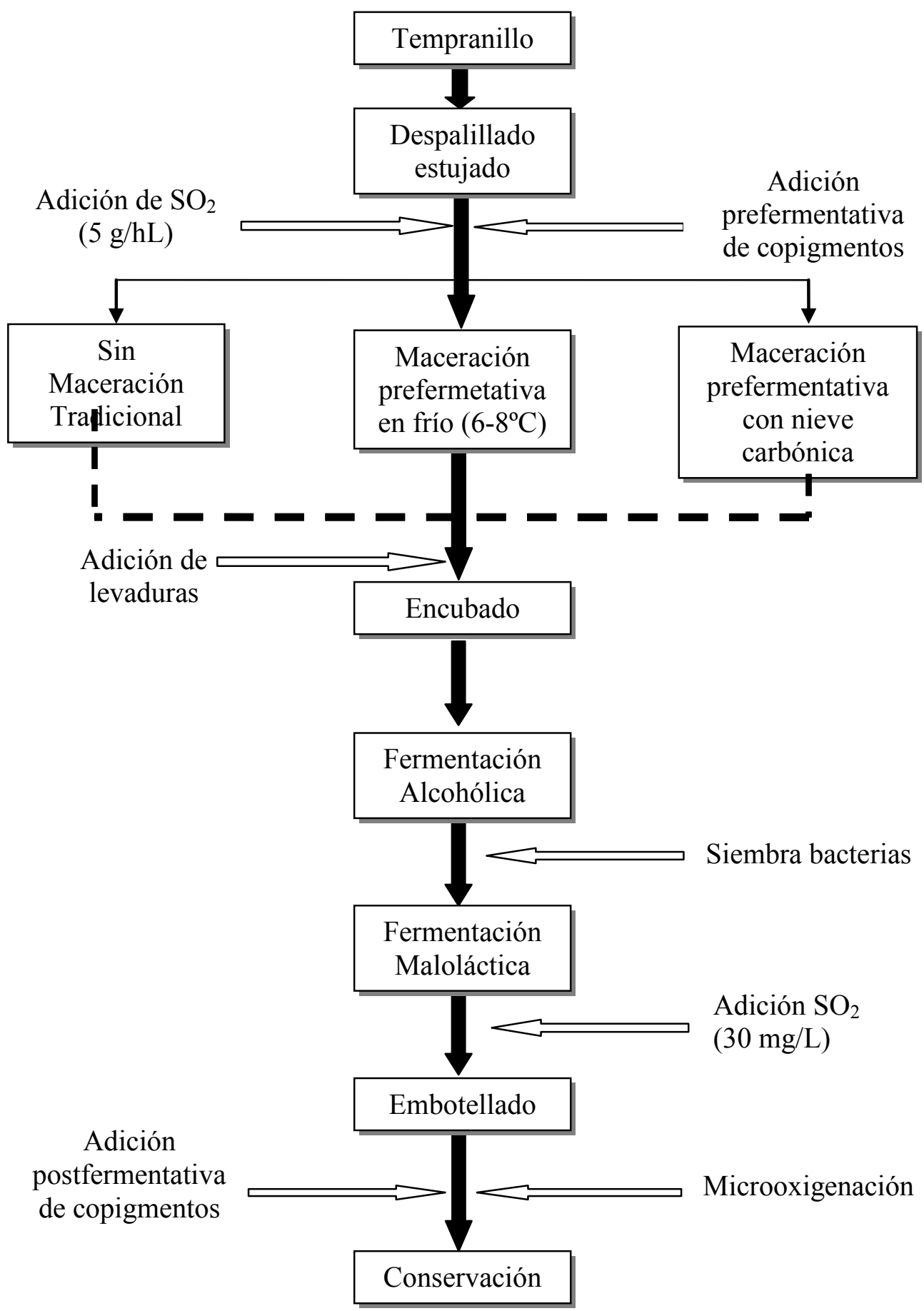

Figura 4.1. Diagrama de flujo del proceso de elaboración de los vinos. 
El descube se realizó con el mismo criterio que en los testigos, para que no hubiera diferencias en el tiempo y temperaturas de maceración fermentativa en unos y otros.

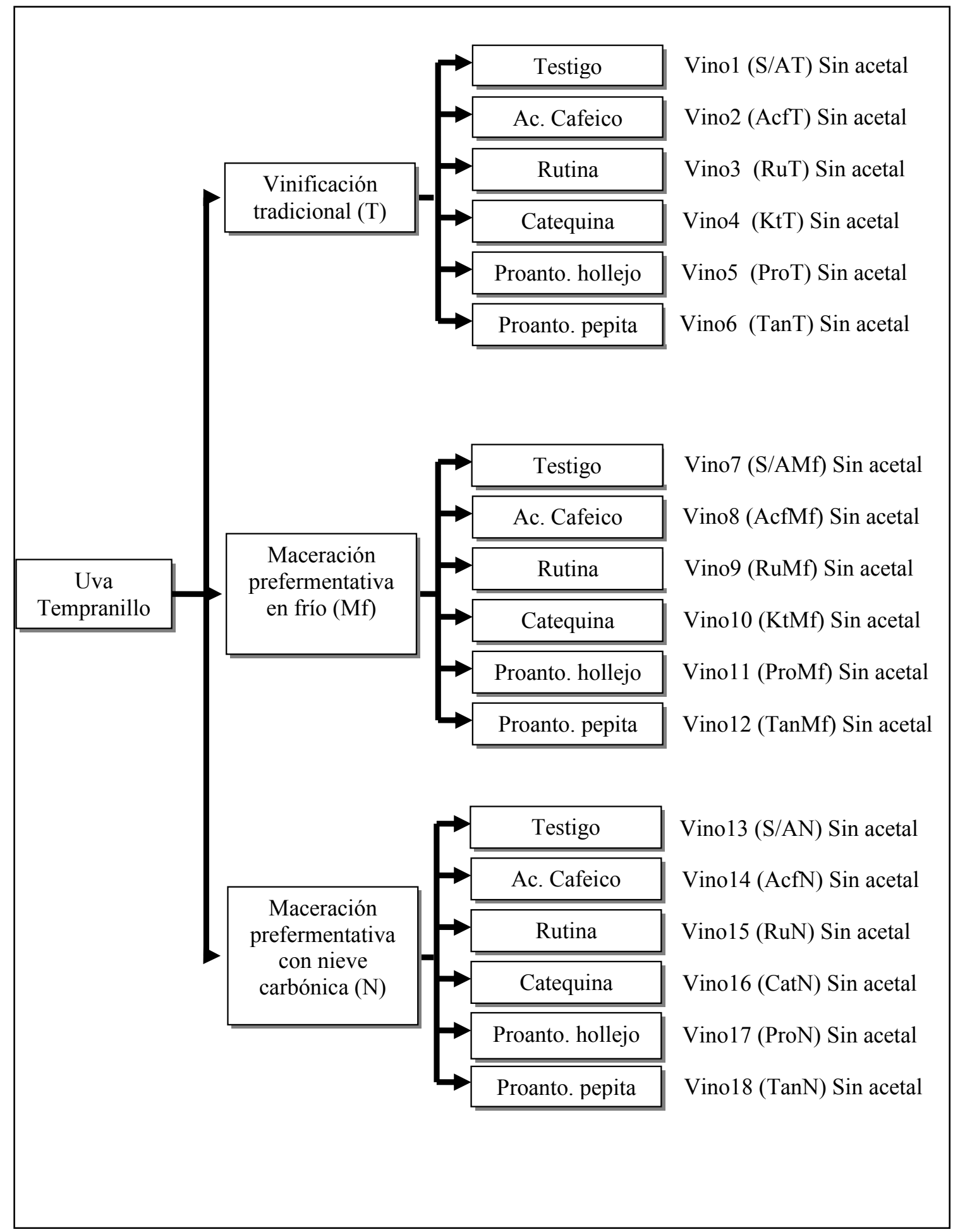

Figura 4.2. (Continuación) Esquema del diseño experimental del trabajo.

Se realizó el sangrado y prensado de los vinos, utilizando una prensa hidráulica de membrana, a baja presión (1,2 atmósferas), realizándose la mezcla del vino flor con el vino de primera prensada, dejando el vino en el mismo depósito para que termine la 
fermentación alcohólica, procurando que la temperatura no descendiera de $20{ }^{\circ} \mathrm{C}$ para que la fermentación pudiera agotar perfectamente los azúcares. La fermentación alcohólica se dio por terminada cuando los vinos tuvieron menos de $2 \mathrm{~g} / \mathrm{L}$ de azúcares reductores. En la siguiente etapa se realizó la fermentación maloláctica previa adición de $1 \mathrm{~g} / \mathrm{hL}$ de bacterias Oenococcus oeni.

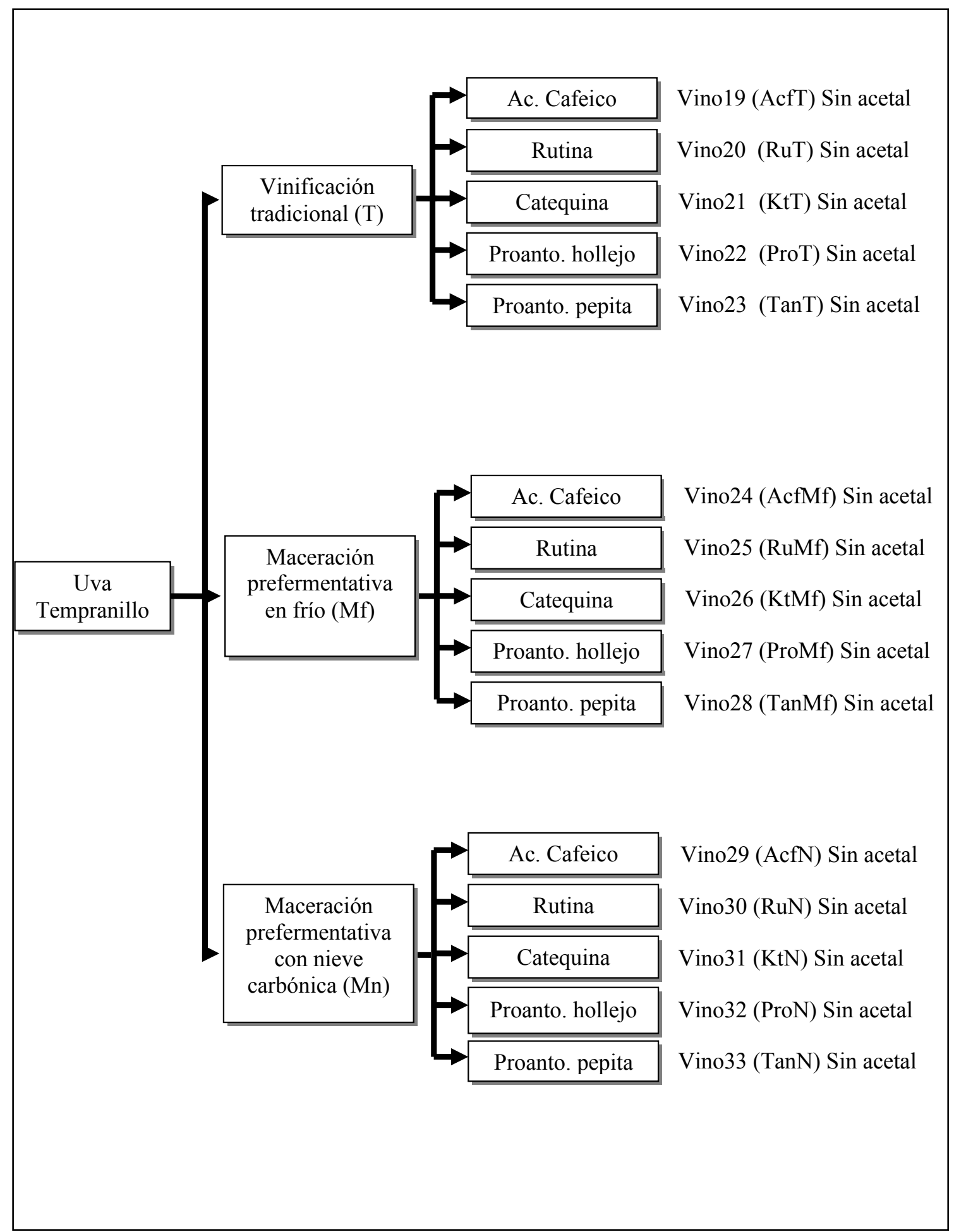

Figura 4.2. (Continuación). Esquema del diseño experimental del trabajo. 
Una vez determinada la finalización de la fermentación maloláctica mediante cromatografías de papel, los vinos se corrigieron a $30 \mathrm{mg} / \mathrm{L}$ de sulfuroso libre, se trasegaron previo enfriamiento, se homogenizaron y se embotellaron. Previamente al embotellado se realizó la adición postfermentativa de copigmentos a la dosis mencionada con anterioridad.

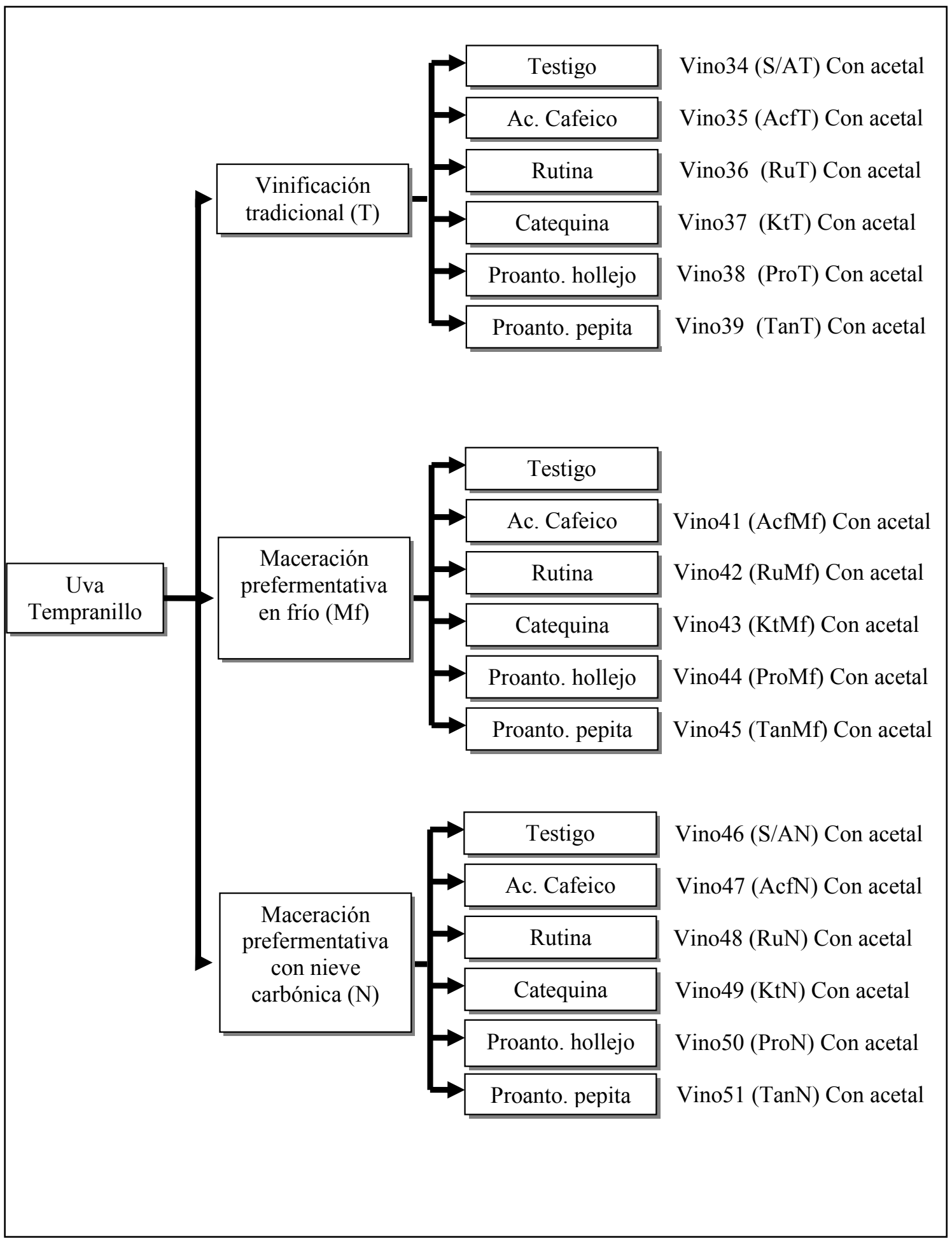

Figura 4.2. (Continuación). Esquema del diseño experimental del trabajo. 
Una vez embotellados los vinos, se determinaron analíticamente los parámetros relacionados con su composición fenólica. Se siguió la evolución de estos parámetros cada 4-5 meses durante un periodo de conservación de 24 meses.

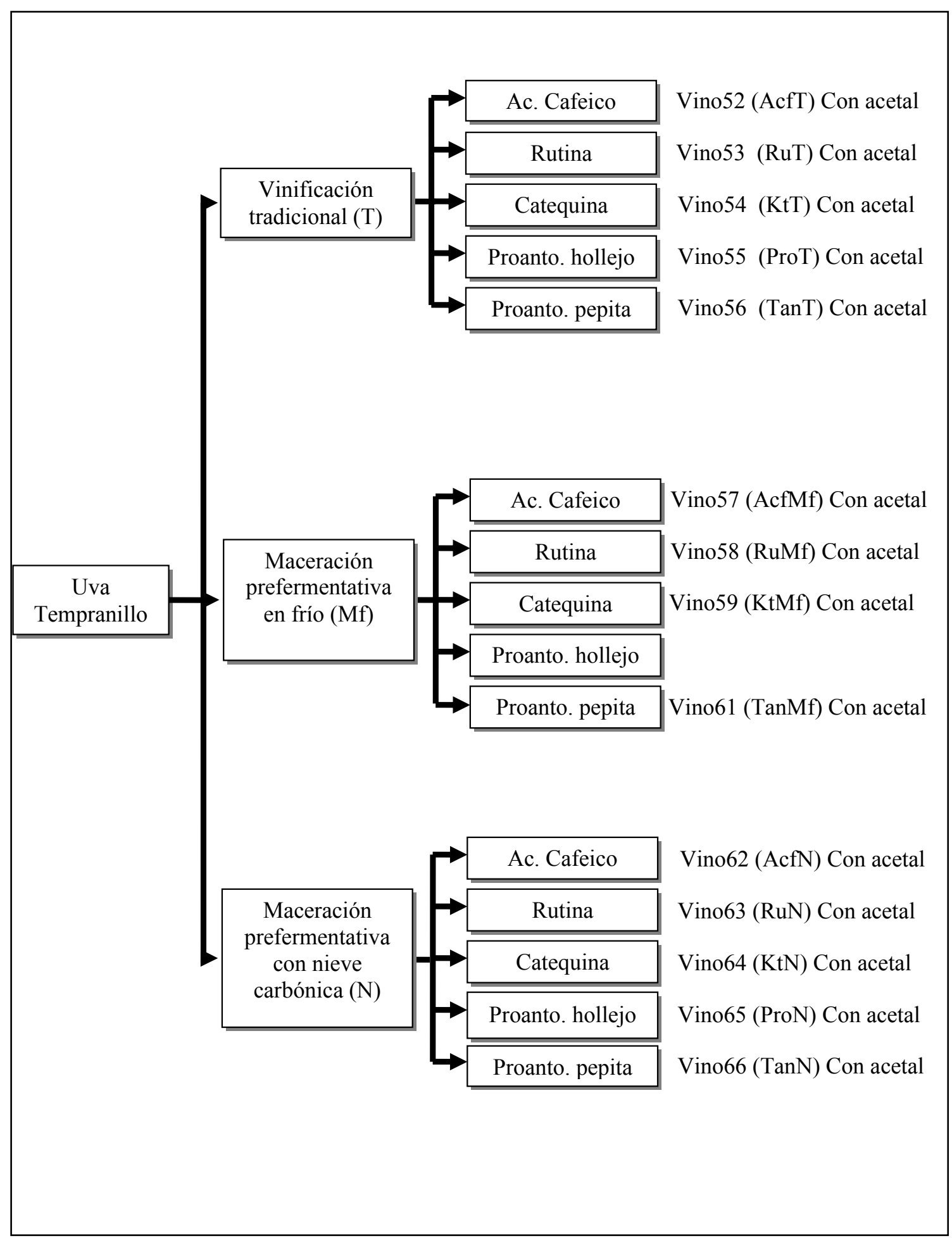

Figura 4.2. (Continuación). Esquema del diseño experimental del trabajo.

Los vinos elaborados fueron sometidos también a una adición controlada de acetaldehído, con el objetivo de conseguir de forma directa un efecto similar al que la 
microoxigenación ocasiona en los vinos (transformación de etanol en acetaldehído). Concretamente se adicionó acetaldehído a través del corcho de las botellas a razón de $2,25 \mu \mathrm{L} / \mathrm{L} / \mathrm{mes}$, durante un mes y medio, con lo que la dosis total de acetaldehído incorporada fue de $3,35 \mu \mathrm{L} / \mathrm{L}$.

También se analizaron sensorialmente los vinos obtenidos para valorar las características organolépticas de éstos. Los atributos considerados han sido el color, el aroma (tanto su intensidad como su calidad), el gusto (valorándose el amargor, la estructura y el equilibrio) y por último la evaluación global.

Finalmente se realizó el tratamiento estadístico de los resultados para comprobar si existen diferencias significativas entre los distintos tratamientos, la interpretación de los resultados obtenidos y el establecimiento de conclusiones.

La figura 4.2 recoge un esquema del diseño experimental del trabajo. En el esquema se pueden observar los 18 protocolos realizados, que corresponden a las tres técnicas de vinificación ensayadas, junto con los cinco copigmentos adicionados, más el testigo, obteniéndose cada uno de ellos por triplicado (que hacen un total de 54 vinos elaborados).

Este diseño se incremento con la adición postfermentativa de los 5 copigmentos por triplicado para los tres métodos de elaboración ensayados, con lo que se obtuvieron 15 protocolos más por triplicado (45 vinos más), puesto que no es necesario duplicar los vinos testigo, ya que en ninguno de los casos son adicionados de copigmentos. Por lo tanto, al final de la vinificación se va a valorar la composición de 99 vinos, correspondientes a los 33 diferentes tratamientos aplicados.

Finalmente este diseño experimental se duplicó durante la conservación de los vinos, con el objetivo de someter a éstos al proceso de pseudo-microoxigenación, mediante la adición de acetaldehído, por lo que durante la conservación se estudiaron 66 diferentes tratamientos por triplicado, que hacen un total de 198 vinos anuales. 


MATERIALES Y METODODOS 


\section{MATERIALES Y MÉTODOS}

\subsection{MATERIALES}

Los productos, materiales y equipos utilizados para el trabajo han sido:

1. Materia prima. Uva de la variedad Tempranillo de los viñedos de la bodega Chozas Carrascal en la D.O. Utiel-Requena.

2. Cajas de plástico de 18 a $20 \mathrm{Kg}$. de capacidad para transporte de la uva a la bodega piloto del IAD-UPV.

3. Despalilladora estrujadora de rodillos de caucho modelo 028EX marca Maquivi.

4. Prensa hidráulica vertical de membrana modelo 1248 marca Waslin-Boucher.

5. Recipientes de plástico alimentario para transporte de la uva de la despalilladora, estrujadora y a los depósitos de maceración-fermentación.

6. Depósitos de acero inoxidable de $50 \mathrm{~L}$ de capacidad, dotados con camisa de refrigeración para el control de la $\mathrm{T}^{\mathrm{a}}$.

7. Metabisulfito potásico $\left(\mathrm{SO}_{3} \mathrm{~K}_{2} \mathrm{H}\right)$ con una eficiencia del $50 \%$ a dosis de $10 \mathrm{y}$ $5 \mathrm{~g} / \mathrm{hL}$ en maceración prefermentativa y embotellado respectivamente.

8. Copigmentos comerciales: ácido cafeico (C-0625), rutina (R-5143), (+) Catequina hidrato (C-22110), todos ellos adquiridos en Sigma Chemical Company, Saint Louis, Missouri, USA. Proantocianidina de hollejo y proantocianidina de pepita de uva blanca, ambos adquiridos en Spindal (AEB Group). Todos los copigmentos se adicionaron en una dosis de $90 \mathrm{mg} / \mathrm{hL}$.

9. Estándares de malvidina-3-glucósido (S-0911, Extrasynthèse, Genay, Francia)

10. Levaduras seleccionadas Saccharomyces cerevisiae var. bayanus a dosis de 20 $\mathrm{g} / \mathrm{hL}$

11. Bacterias lácticas Oenococcus oeni a dosis de $1 \mathrm{~g} / \mathrm{hL}$.

12. Depósitos siempre llenos de acero inoxidable de 50 litros de capacidad y provistos de camisas de refrigeración

13. Equipo de frío con una potencia frigorífica de 1000 frigorías/hora modelo ATB de la empresa Direma.

\subsection{MÉTODOS ANALÍTICOS.}

Durante la elaboración de los vinos, se realizaron controles para garantizar el éxito de la fermentación y evitar desviaciones; posteriormente y una vez que concluyeron la fermentación maloláctica, fueron analizados inmediatamente y durante su conservación con una frecuencia de seis meses hasta un año posterior al embotellado. Los vinos han sido analizados en un orden aleatorio para evitar posibles errores sistemáticos. Todos los análisis se han hecho por duplicado, trabajando posteriormente con la media de los valores obtenidos. 


\subsubsection{PARÁMETROS CARACTERÍSTICOS.}

La determinación analítica de los parámetros más comunes de los vinos tales como densidad, grado alcohólico, azúcares reductores, acidez total, $\mathrm{pH}$, acidez volátil y sulfuroso total y libre se ha realizado según los métodos que aparecen en al Reglamento Oficial de la Unión Europea. (OIV, 1990).

\subsubsection{PARÁMETROS POLIFENÓLICOS}

Las determinaciones analíticas relacionadas con los polifenoles se abordan empleando básicamente dos grupos de técnicas, espectrofotométricas y HPLC. Con las técnicas espectrofotométricas se cuantifican algunos compuestos fenólicos y además se determinan interacciones entre ellos. La técnica de HPLC utilizada, se basa en la separación y cuantificación de algunos polifenoles, concretamente antocianidinas y algunos ácidos fenólicos flavanoles y flavonoles, empleando un detector Diode Array.

\subsubsection{DETERMINACIONES ESPECTOFOTOMÉTRICAS}

\subsubsection{ANTOCIANOS COPIGMENTADOS, POLIMERIZADOS Y LIBRES \\ Para determinar el porcentaje de antocianos copigmentados, libres y} polimerizados, se ajustan las muestras a $\mathrm{pH} 3,60$ y se filtran a través de una membrana de $0,45 \mu \mathrm{m}$ de tamaño de poro. De esta forma no existen condiciones particulares para cada muestra y se obtiene una base racional para comparar los componentes del color. Se añaden $20 \mu \mathrm{L}$ de una solución de acetaldehído al 10\% a $2 \mathrm{~mL}$ de muestra. Después de 45 minutos se mide su absorbancia a $520 \mathrm{~nm}\left(\mathrm{~A}^{\text {acet }}\right)$. Por otra parte se ponen $100 \mu \mathrm{L}$ de la muestra en $1900 \mu \mathrm{L}$ de solución tampón y después de algunos minutos se mide su absorbancia a $520 \mathrm{~nm}\left(\mathrm{~A}^{20}\right)$. Por último se añaden $160 \mu \mathrm{L}$ de una solución de $\mathrm{SO}_{2}$ al $5 \%$ a $2 \mathrm{~mL}$ de la muestra y se mide su absorbancia a $520 \mathrm{~nm}\left(\mathrm{~A}^{\mathrm{SO} 2}\right)$. Los resultados se expresan en porcentaje, y se calculan según las fórmulas descritas en el método.

\subsubsection{ANTOCIANOS TOTALES}

Para la determinación de los antocianos totales se utiliza el método mediante decoloración por bisulfito. Este método se basa en la propiedad que presentan estos compuestos de cambiar de estructura química con la variación del $\mathrm{pH}$ del medio en su combinación con bisulfito sódico (Ribéreau-Gayon y Stonestreet, 1965). 


\subsubsection{DETRMINACIÓN DE CATEQUINAS}

El método utilizado para determinar la concentración de catequinas es el descrito por Sun et al., (1998). Se basa en la capacidad de condensación de las catequinas con los compuestos carbonílicos en medio ácido $(\mathrm{HCl})$. En este caso, el reactivo utilizado es la vainillina en medio ácido (vainillina clorhídrica), ya que es un aldehído relativamente estable a altas concentraciones de ácidos (Pompei y Peri, 1971).

\subsubsection{5. ÍNDICE DE ETANOL}

El índice de etanol se determina siguiendo el protocolo propuesto por Glories (1978). Los taninos al combinarse con sales, péptidos y con polisacáridos precipitan en fuertes concentraciones de etanol. Una forma de determinar estos polifenoles es precipitarlos mediante el aumento de su grado alcohólico utilizando para ello etanol 96\%. La mezcla se deja reposar durante 24 horas a temperatura ambiente, después se centrífuga para eliminar el precipitado. Finalmente, previa dilución, se mide la densidad óptica

$280 \mathrm{~nm}$, y la diferencia entre el valor de ésta antes de la adición de alcohol, y la posterior, nos indica el porcentaje de taninos precipitados y por tanto combinados con polisacáridos (Glories, 1978).

\subsubsection{6. ÍNDICE DE GELATINA}

El índice de gelatina puede ser considerado como un reflejo de la astringencia del mosto o vino. Cuanto más elevado sea (superior a 50\%) el vino parecerá más astringente. El índice no caracteriza exclusivamente a las moléculas condensadas, sino también a algunos taninos poco polimerizados, ya que representa el porcentaje de taninos capaces de combinarse con la gelatina y susceptibles de intervenir a nivel de astringencia. Para determinar el índice de gelatina se utiliza el método recogido por Glories (1978).

\subsubsection{7. ÍNDICE DE PVPP.}

Para determinar el porcentaje de antocianos combinados con los taninos se utiliza el índice de polivinilpolipirrolidona (PVPP). La mayor concentración de combinaciones antocianos-taninos justifica la mayor contribución de los antocianos al color (Blouin, 1977; Vivas, 1995). El procedimiento para la determinación de este índice es introducir a $0^{\circ} \mathrm{C}, 2 \mathrm{~mL}$ de vino diluido $1 / 5$ con agua destilada y $2 \mathrm{~mL}$ de PVPP $0,6 \%$. Se agita y se deja en reposo durante 10 minutos. A continuación añadimos $6 \mathrm{~mL}$ de tricloroacético $20 \%$, se agita y se deja reposar durante 10 minutos. Se centrífuga durante 5 minutos a $4700 \mathrm{rpm}$. Posteriormente, se diluye con agua destilada media parte para obtener así una dilución de vino 1/50. Se mide en el espectrofotómetro a $280 \mathrm{~nm}$ en cubetas de $10 \mathrm{~mm}$ de paso óptico, obteniéndose de esta una DO que se corresponde con los taninos no combinados con antocianos. Por diferencia con los taninos totales obtenemos los combinados con antocianos. (Blouin, 1977). 


\subsubsection{8. ÍNDICE DMACH}

Otro método utilizado para evaluar el grado de polimerización de los taninos del mosto es el método de p-dimetilaminocinamaldehído (DMACH) propuesto por Vivas et al., (1994). Los autores proponen una nueva técnica de evaluación del grado de polimerización de taninos de la uva y vino usando un aldehído específico, el p-dimetilaminocinamaldehído (DMACH), que se usa para medir el grado de condensación de las proantocianidinas que será tanto más alto cuanto más bajo sea el índice (Vivas, 1994).

\subsubsection{INTENSIDAD COLORANTE Y TONO O MATIZ}

Para la determinación de la intensidad colorante y tonalidad se siguen los métodos oficiales de análisis de la UE (Comisión Europea, 1990). Para ello se realizan mediciones directas de la muestra a 420, 520 y $620 \mathrm{~nm}$ mediante un espectrofotómetro UV/VIS JASCO V-530 con cubetas de vidrio de $0,1 \mathrm{~cm}$ de paso de luz y utilizando el agua destilada como referencia. El valor de la intensidad colorante se obtiene mediante la suma de las absorbancias a las longitudes de onda indicadas anteriormente referidas a una cubeta de $1 \mathrm{~cm}$ de paso de luz $\mathrm{IC}=\left(\mathrm{A}_{420}+\mathrm{A}_{520}+\mathrm{A}_{620}\right)$. La tonalidad se calcula como el cociente entre la absorbancia a los 420 y $520 \mathrm{~nm}\left(\mathrm{TONO}=\mathrm{A}_{420} / \mathrm{A}_{520}\right)$ (Glories, 1978).

\subsubsection{TANINOS CONDENSADOS TOTALES}

Para determinar los taninos totales se utiliza el método recogido por Saint-Criq et al., (1998). Esta determinación se basa en la propiedad característica de los favanodioles

3-4, llamada reacción de Bate-Smith: la hidrólisis en medio ácido, con calor y en presencia de oxígeno transforma estas moléculas en antocianinas (coloreadas). El método utilizado para su determinación es el descrito por Sun et al., (1959). El método se basa en la capacidad de condensación de las catequinas con los compuestos carbonílicos en medio ácido $(\mathrm{HCl})$. El reactivo utilizado es la vainillina en medio ácido (vainillina clorhídrica), ya que ésta es un aldehído relativamente estable a altas concentraciones de ácidos. (Ribéreau-Gayon y Stonestreet, 1966), (Ribéreau-Gayon, 1979).

\subsubsection{DETERMINACIONES MEDIANTE CROMATROGRAFIA EN FASE LÍQUIDA (HPLC)}

\subsection{ANÁLISIS DE LA COMPOSICIÓN FENÓLICA}

Las muestras para realizar el estudio fueron analizadas mediante un equipo HPLC JASCO serie MD-2010 Plus (JASCO, Tokyo, Japón), equipado con un desgasificador, una bomba cuaternaria, un inyector automático, además de un compartimiento termostatizado para la columna y un detector diode array (JASCO LCNet II/ADC, Tokyo, Japón). Como fase estacionaria se ha utilizado una columna 
Gemini NX (Phenomenex, Torrance, CA), $250 \mathrm{~mm}$ x $4.6 \mathrm{~mm}$ de $5 \mu \mathrm{m}$ de tamaño de partícula. Los disolventes empleados fueron trifluoroacético al $0.1 \%$ en agua (Fase A) y acetonitrilo (Fase B), a un flujo de $0.5 \mathrm{~mL} / \mathrm{min}$, optimizándose las condiciones del gradiente, propuestas por Boido et al., (2006), a las detalladas a continuación.

Se estableció un gradiente definido por $10 \%$ de disolvente B durante 5 minutos, de 10 a $15 \%$ de disolvente $\mathrm{B}$ en 15 minutos, $15 \%$ de disolvente $\mathrm{B}$ durante 5 minutos, de 15 a $18 \%$ de disolvente B en 5 minutos y, finalmente, de 18 a $35 \%$ de disolvente $\mathrm{B}$ en 20 minutos. Identificándose el espectro desde 220 a $600 \mathrm{~nm}$.

Antes de la inyección cada muestra fue centrifugada durante 15 minutos a 4000 revoluciones por minuto y filtrada por un filtro de $0.45 \mu \mathrm{m}$, el volumen de inyección fue de $20 \mu \mathrm{L}$. Los compuestos fueron identificados de acuerdo a su tiempo de retención y a sus características espectrales. El ácido gálico y la (+)-catequina fueron cuantificados a $280 \mathrm{~nm}$ a partir de rectas patrón de calibración obtenidas de los propios compuestos. Los ácidos hidroxicinámicos fueron identificados a $316 \mathrm{~nm}$ y expresados como $\mathrm{mg} / \mathrm{L}$ de ácido cafeico. Los flavonoles fueron determinados a $365 \mathrm{~nm}$ expresados como $\mathrm{mg} / \mathrm{L}$ de rutina mediante comparación con una recta patrón obtenida a partir de rutina hidrato. Finalmente los antocianos fueron cuantificados a $520 \mathrm{~nm}$ y expresados como $\mathrm{mg} / \mathrm{L}$ de malvidina-3-glucósido por comparación con recta patrón de malvidina-3-glucosido hidrochloridro.

\subsection{TÉCNICA DE MICROOXIGENACIÓN}

Las condiciones de microoxigención requieren de depósitos con una altura superior o igual a dos metros para favorecer la formación de pequeñas burbujas de oxígeno y garantizar así su difusión en el vino. Ante la imposibilidad de elaborar cada uno de los vinos en depósitos con estas características, (ya que se necesitarían 198 depósitos especiales) y dado que se pretende que el oxígeno aportado, de una manera indirecta, se transforme en acetaldehído, se aportará ese $\mathrm{O}_{2}$ en forma de acetaldehído. La adición se realizó una vez terminada la fermentación maloláctica y en los vinos embotellados, incorporándose una disolución equivalente de acetaldehído durante un mes y medio, con una frecuencia de tres veces/semana, a través del tapón previa incorporación de agujas hipodérmicas especiales. Esta dosis de acetaldehído corresponde teóricamente a una adición de $3 \mathrm{~mL}$ de oxígeno/L/mes, incorporándose al vino finalmente, después del embotellado $4,5 \mathrm{~mL}$ de oxígeno por litro de vino. La adición se realizó para todas las muestras que lo requerían y siempre por duplicado.

\subsection{TRATAMIENTO ESTADÍSTICO}

El tratamiento estadístico de los valores obtenidos en las determinaciones analíticas de mostos y vinos, se ha llevado a cabo con el programa informático STATGRAPHICS Plus 5.1 para Windows. Se ha realizado un análisis multifactorial de la varianza (ANOVA), junto con el análisis de componentes principales (ACP) para estudiar la influencia de las prácticas prefementativas, la microoxigenación y la adición de copigmentos sobre los parámetros polifenólicos analizados en los vinos obtenidos. A 
continuación se describe el fundamento de los distintos procedimientos estadísticos empleados.

\subsubsection{ANÁLSIS DE LA VARIANZA}

El análisis de la varianza (ANOVA) engloba una serie de métodos estadísticos para contrastar diferencias entre las medias de varios grupos de datos. Mediante estos métodos se divide la variación total existente en el conjunto de datos en diversas fuentes de variación, y se determina mediante un contraste de hipótesis, si la aportación relativa de cada una de ellas a la variación total es significativa o no.

En este trabajo se han utilizados dos métodos del análisis de la varianza: el análisis unidireccional de la varianza, también llamado análisis de la varianza simple o análisis de la varianza para un solo factor; y el análisis multifactorial de la varianza, que es una generalización del anterior para el caso de dos a más variables independientes o factores. En estos modelos la variación total contenida en los datos, se debe por un lado, a la variación asignable al factor o factores considerados, y por otro, a la variación residual que se imputa a causas no controlables o no asignables al factor o factores.

Dichos factores serán, en este trabajo, la adición de copigmentos, la aplicación de diferentes técnicas de maceración prefermentativa, la microoxigenación $\mathrm{y}$, por último, el momento de la adición de los copigmentos. Por lo tanto, se trata de realizar, para cada parámetro analizado, un contraste de hipótesis que permita identificar cual de las fuentes de variación es significativa respecto a su aportación a la variación total. En definitiva se trata de determinar si las diferencias encontradas entre los valores medios que toma el parámetro analizado, en cada uno de los niveles que toman los factores, son asignables a la influencia de estos factores o no.

\subsubsection{ANÁLISIS DE COMPONENTES PRINCIPALES}

Este análisis es uno de los métodos pioneros del análisis multivariante. Consiste en una técnica de reducción de la información disponible sobre el conjunto de individuos (en nuestro caso los vinos objeto de estudio) en los cuales se han tomado diversas observaciones. El método condensa la matriz de correlaciones entre las variables en unos "componentes principales" de la variabilidad total. Es decir, permite transformar un conjunto de variables intercorrelacionadas con otro conjunto de variables no correlacionadas, denominadas componentes principales, que son combinación lineal de las variables originales.

El primer componente principal que se extrae en el análisis es el que resume lo mejor posible la información contenida en la matriz de datos original. Es decir, es el que mejor contribuye a explicar la varianza total. El segundo componente es el que resume lo mejor posible la varianza restante, siendo independiente del primero. La secuencia puede continuar extrayendo factores hasta explicar la varianza total. 



\section{RESULTADOS Y DISCUSIÓN}




\section{RESULTADOS Y DISCUSIÓN}

Este apartado está dividido en tres bloques, los cuales corresponden a cada una de las vendimias realizadas, concretamente las elaboraciones de los años 2006, 2007 y 2008. En los vinos obtenidos, se ha determinado su composición fenólica en tres momentos a lo largo de su periodo de conservación en botella. La primera analítica se realizó posteriormente al embotellado, una vez que los vinos terminaron la fermentación maloláctica. A continuación, los vinos se conservaron a $18-20{ }^{\circ} \mathrm{C}$, determinándose su composición a los 6 y 12 meses de permanencia en botella.

Para cada una de las analíticas determinadas se realizó un Análisis de la Varianza (ANOVA) multifactorial, donde se estudió el efecto de los factores considerados en este trabajo. Estos factores son la adición de copigmentos, la aplicación de diferentes técnicas de maceración prefermentativa, la microoxigenación y el momento de adición de los copigmentos, que se realizó previa o posteriormente al proceso de fermentación de los vinos. Además, se estudiaron las interacciones entre estos factores (interacciones de orden dos), con el objetivo de identificar efectos favorables por combinación de algunos de los factores estudiados.

Paralelamente, se realizó un ANOVA simple para cada uno de los factores mencionados, con la finalidad de identificar los factores que han presentado los mejores resultados con respecto a la composición fenólica de los vinos objeto de estudio.

Con el objetivo de contrastar los resultados obtenidos, los datos se sometieron a la técnica estadística del Análisis de Componentes Principales (ACP), realizándose previamente la matriz de correlaciones para comprobar la existencia de correlaciones importantes entre los parámetros estudiados. Una vez comprobada esta premisa, los datos fueron analizados mediante este tratamiento estadístico.

Ya finalmente, y para cada una de las vendimias realizadas, se analizó la evolución de los vinos, representándose la curva de evolución para cada uno de los parámetros polifenólicos determinados, con el objetivo de conocer el comportamiento individualizado de cada uno de estos parámetros polifenólicos, así como de las interacciones entre ellos a lo largo del proceso de conservación de 12 meses en botella. Con la información obtenida en el seguimiento de la evolución, se establece cuales son las técnicas o combinaciones de estas más adecuadas para conseguir vinos con características fenólicas óptimas, encaminadas a la obtención de vinos de calidad.

\subsection{EFECTO DE LAS PRÁCTICAS ENOLÓGICAS ENSAYADAS SOBRE LA COMPOSICIÓN POLIFENÓLICA DE LOS VINOS ELABORADOS EN 2006.}

La añada 20006 se caracterizó por una primavera suave, sin heladas, con pluviometría suficiente, que favoreció una brotación vigorosa; un verano largo y seco, con temperaturas medias moderadas, que provocó un estado sanitario de las uvas óptimo, propiciando una buena maduración fenólica. Fue calificada como Excelente. 


\subsubsection{ANÁLISIS DE LOS VINOS POSTERIORMENTE A FERMENTACIÓN MALOLÁCTICA}

Se ha determinado la composición fenolica de los vinos sometidos a distintas prácticas enológicas una vez finalizada la fermentación malolactica, con el objetivo de realizar un análisis comparativo de los resultados y establecer si las técnicas enológicas ensayadas dan lugar a diferencias significativas en los parámetros polifenólicos.

\subsubsection{ANÁLISIS MULTIFACTORIAL DE LA VARIANZA DE LOS FACTORES CONSIDERADOS}

En la tabla 6.1 aparecen los datos del análisis multifactorial de la varianza (ANOVA) para los factores adición de copigmentos y técnicas de maceración prefermentativa ensayadas, así como para la interacción entre ambos.

El F-ratio representa el cociente entre la variabilidad debida al efecto considerado y la varianza residual. Los valores del F-ratio pueden ser comparados entre sí en cada columna, debido a que el número de comparaciones fue el mismo en todos los casos. Un alto valor del F-ratio significa un efecto más marcado del factor sobre la variable. De acuerdo con esto, las variables son afectadas, en general, por la adición de los distintos copigmentos y las técnicas de vinificación empleadas. También se observa un marcado efecto de la interacción entre ambos factores en la mayoría de los casos, lo que indica que la composición polifenólica de los vinos adicionados de copigmentos es distinta en función de la de vinificación empleada.

Tabla 6.1. Valores del análisis multifactorial de la varianza (ANOVA) para los factores considerados y para su interacción (F-ratios y nivel de significancia estadística).

\begin{tabular}{|c|c|c|c|}
\hline $\begin{array}{l}\text { Factor } \\
\text { Variable }\end{array}$ & $\begin{array}{c}\text { A } \\
\text { Copigmentos }\end{array}$ & $\begin{array}{c}\text { B } \\
\text { Técnica }\end{array}$ & $\begin{array}{c}\mathrm{AB} \\
\text { Interacción }\end{array}$ \\
\hline I.C. & $6,07 * *$ & 9,57 & $10,4^{*}$ \\
\hline Tono & 87,4 & 10,67 & 8,05 \\
\hline Ant. Totales (mg/L) & $406,3 * * *$ & $69,18 * * *$ & $14,52 * * *$ \\
\hline \% Ant. Copigmentados & $151,72 * * *$ & $29,05 * * *$ & $14,6 *$ \\
\hline \% Ant. Libres & 27,4 & $15,33 * * *$ & $3,08 * *$ \\
\hline \% Ant. Polimerizados & 14,61 & 4,25 & 6,59 \\
\hline I. PVPP & 4,91 & 2,92 & 4,31 \\
\hline I. Folin & $61,77 * * *$ & $8,79 * * *$ & $6,97 * * *$ \\
\hline Catequinas (mg/L) & $37,78 * * *$ & 28,22 & $4,75^{* * *}$ \\
\hline Taninos & 19,16 & $15,64 *$ & 23,04 \\
\hline I. DMACH & $34,6^{* * *}$ & 35,49 & $82,68 * * *$ \\
\hline I. Etanol & $6,53 * *$ & $12,29 * *$ & $7,88 * * *$ \\
\hline I. Gelatina & $59,87 * * *$ & $64,93 * * *$ & $7,32 * * *$ \\
\hline
\end{tabular}

Los parámetros polifenólicos antocianos totales decolorables, porcentaje del color debido a las reacciones de copigmentación, índice de Folin e índice de gelatina, son los que muestran los mayores valores del F-ratio, y por lo tanto los que presentan un efecto más marcado sobre la variable adición de copigmentos. El análisis muestra la 
gran influencia de la adición de copigmentos en los antocianos, siendo las uniones entre antocianos y copigmentos los actores principales de esta interacción (Robinson y Robinson, 1931; Boutaric et al., 1937; Osawa, 1982; Mazza y Brouillard, 1987; Boulton, 2001). Las reacciones dominantes entre antocianos y copigmentos son las de copigmentación, tal como se observa en el efecto marcado del porcentaje del color debido a la copigmentación, demostrando que la adición de copigmentos incrementa rápidamente el número de estas uniones (Rivas-Gonzalo et al., 1995,2003; Boulton 1996,2001; Mirabel et el., 1999; Sacchi et al., 2005).

En cuanto al índice de Folin, la participación de los copigmentos en reacciones en las que intervienen distintos compuestos polifenólicos, especialmente antocianos, ocasiona diferencias significativas para este índice, que mide los compuestos con grupos fenol presentes en el vino, encontrándose los antocianos entre ellos (RivasGonzalo, 1995; Francia-Aricha, 1998). Por último, el importante F-ratio del índice de gelatina indica que la participación de compuestos monómeros en estas uniones produce un efecto notable en cuanto a la astringencia de los vinos (Boulton, 2001; Álvarez et al., 2008).

Junto con los efectos descritos anteriormente también se observa un efecto marcado para los parámetros catequinas e índice de DMACH. Es de esperar que la adición prefermentativa de catequinas y proantocianidina de hollejo y de pepita de uva blanca puedan contribuir, tanto a incrementar la concentración de estos compuestos, como a potenciar su grado de polimerización, valorado mediante el índice de DMACH. Bautista-Ortín et al. (2007), estudiando la concentración polifenolica en vinos de Monastrell, observan como los vinos adicionados de tanino enológico procedente de las uvas presentan una mayor concentración de estos compuestos, así como un mayor grado de polimerización de los taninos en el vino.

Para el factor técnicas de vinificación se aprecia un efecto similar al observado para la adición de copigmentos, siendo en este caso los antocianos totales decolorables, el índice de gelatina, los antocianos copigmentados, los antocianos libres y el índice de Folin los parámetros más afectados. Los resultados indican que las técnicas de maceración prefermentativa ensayadas afectan decisivamente a la concentración y el estado de los antocianos, así como a los polifenoles totales, debido al prolongado contacto en fase acuosa que se produce, que puede modificar la concentración de estos compuestos en el vino (Reynolds, 2001; Parenti et al., 2004; Álvarez et al., 2005; Heatherbell et al., 1997; Manchón et al., 2005; Gil-Muñoz et al., 2009; Gómez-Míguez et al., 2006; Gordillo et al., 2010; Koyama et al., 2007), y facilitar posibles reacciones futuras entre ellos (Kovac et al., 1992; Gordillo et al., 2010; Heredia et al., 2010).

Además de la extracción de antocianos, la extracción de otros compuestos fenólicos de bajo peso molecular durante la fase prefermentativa provocará que una parte de ellos actúen de manera decisiva en la astringencia de los vinos, justificando el elevado F-ratio encontrado para el índice de gelatina. En estudios realizados por Koyama et al. (2007), en los que comparan diferentes técnicas de maceración prefermentativa, los vinos macerados con aplicación de frío muestran la mayor concentración de antocianos, además de ser los vinos que presentan una mayor astringencia. 
Por último, es necesario destacar como la interacción entre ambos factores presenta un efecto marcadamente significativo para la mayoría de parámetros estudiados, lo cual indica que para los vinos elaborados, la adición de un determinado copigmento junto con la aplicación de una de las técnicas de vinificación ensayadas puede dar lugar a una metodología de vinificación que permita obtener vinos con unas características polifenólicas óptimas (Koyama et al., 2007; Gordillo et al., 2010; Boulton, 2001; Álvarez et al., 2008). El efecto más significativo se observa para los parámetros índice de DMACH, antocianos totales decolorables, índice de etanol, índice de gelatina e índice de Folin, parámetros relacionados tanto con la concentración como con el estado de los antocianos en los vinos, así como con la concentración total de polifenoles y con el estado de los taninos en el vino.

\subsubsection{2. $\quad$ EFECTO DE LA ADICIÓN DE COPIGMENTOS}

En la tabla 6.2 se recogen los valores medios de los parámetros polifenólicos estudiados, en función de la adición de los distintos copigmentos.

El tratamiento estadístico se ha realizando considerando conjuntamente todos los vinos en los que no se ha adicionado copigmento $(\mathrm{T})$, y todos aquellos en los que se ha adicionado el copigmento ácido cafeico (ACF), rutina (RU), catequina (KT), proantocianidina de hollejo de uva blanca (PRO) y proantocianidina de pepita de uva blanca (TAN), independientemente de la técnica de vinificación utilizada, valorando así exclusivamente el efecto de la adición de copigmentos en los vinos de Tempranillo.

Para un mismo parámetro, los tratamientos que tienen letras distintas en la misma fila, indican que existen diferencias significativas para la adición de ese copigmento, con un nivel de confianza del 95\%.

En los vinos elaborados, el efecto de la adición de copigmentos produce un incremento significativo en cuanto a la intensidad colorante, índice de Folin, índice de $\mathrm{DMACH}$, concentración de antocianos decolorables y porcentaje de color debido a la copigmentación. El incremento de color ocasionado por la adición de copigmentos no es muy elevado, pero es significativamente superior al testigo no adicionado.

La mayor concentración de antocianos totales decolorables observada con la adición de rutina, catequina y proantocianidinas de pepita, puede ser debida a un incremento en la extracción durante la vinificación debido al efecto de los copigmentos, que actúan retirando del pool de los antocianos a los antocianos libres, permitiendo una mayor disolución de estos hacia el vino (Rivas-Gonzalo et al., 1995, 2003; Boulton, 1996, 2001; Mirabel et al., 1999), así como a una mejor conservación de los antocianos en forma copigmentada, siendo estos más estables durante el proceso de vinificación, manteniéndose por tanto en el medio sin precipitar.

Podemos observar como la adición de copigmentos incrementa el porcentaje del color debido a los antocianos copigmentados, en mayor medida cuando se utilizan proantocianidinas, mientras que redujo moderadamente el porcentaje del color debido a los antocianos libres. Posteriormente a la fermentación, solo el ácido cafeico incrementa el color debido a los antocianos polimerizados. 


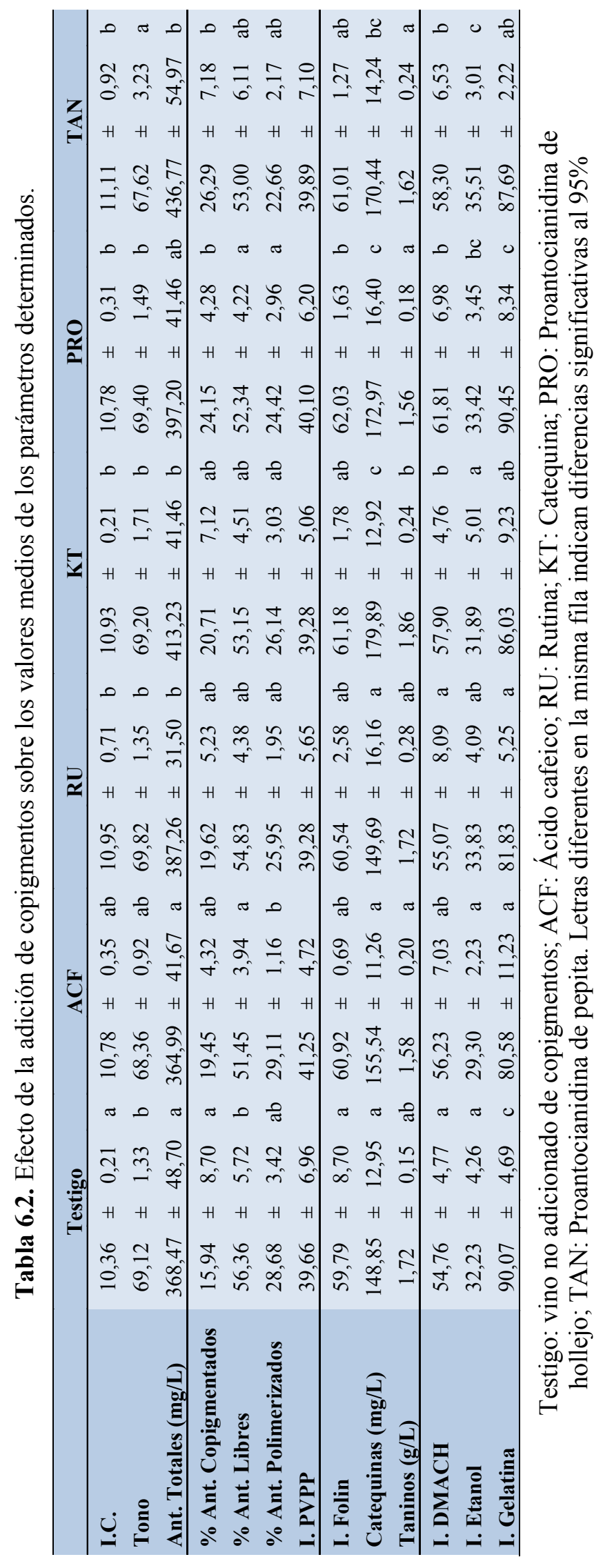


El índice de Folin se incrementa ligeramente con la adición de copigmentos, aunque los copigmentos no tienen efecto sobre la concentración total de taninos ni sobre la concentración de taninos combinados con los antocianos. La adición de procianidinas procedentes de los hollejos y de las pepitas incrementa la polimerización de taninos con polisacáridos.

La astringencia de los vinos adicionados de copigmentos es menor que la mostrada por los vinos no adicionados. Actualmente no hay un criterio único sobre el efecto de los polifenóles monómeros y poliméricos en la astringencia de los vinos, aunque parece que el rol de los compuestos monómeros es más importante de lo que se pensaba. La disminución de la astringencia observada con estos copigmentos puede deberse al hecho de que algunos componentes polifenólicos astringentes hayan sido incluidos en las reacciones de copigmentación (Koyama et al., 2007).

Este descenso de la astringencia se observa de forma más evidente en los vinos adicionados de ácido cafeico y rutina, mostrando los copigmentos de carácter tánico (catequina y proantocianidinas de pepita) valores intermedios entre los vinos anteriores y los vinos testigo, no encontrándose diferencias significativas para el copigmento proantocianidina de hollejo de uva blanca. La mayor astringencia aportada por los copigmentos de origen tánico es debido a que estos están constituidos por flavanoles monómeros y de grado de polimerización media, con gran reactividad sobre las proteínas, que precipitan ocasionando la astringencia de los vinos.

En cuanto a los copigmentos, el ácido cafeico es un ácido hidroxicinámico con gran capacidad de reacción con otros polifenoles. Es producto de la hidrólisis del ácido caftárico (Prince et al., 1994), encontrándose este ácido caftárico en grandes concentraciones, cerca de $30 \mathrm{mg} / \mathrm{L}$, en uvas de Tempranillo (Schwarz et al., 2005). La hidrólisis del ácido caftárico puede ser inducida por la exposición de las uvas al sol (Prince et al., 1994), por lo que el elevado nivel de exposición al sol durante la maduración de nuestras uvas, podría ocasionar elevadas concentraciones de ácido cafeico en todas nuestras uvas, que pueden justificar los elevados niveles de copigmentación encontrados en todos los vinos. Y además ésta podría explicar porqué la suplementación prefermentativa de ácido cafeico no produce el incremento del color debido a las reacciones de copigmentación citado por otros autores (Gris et al., 2005; Eiro y Heinonen, 2002; Darias-Martin et al., 2001, 2002; Schwarz et al., 2005; Nikfardjam et al., 2008).

El efecto copigmentante de la rutina es más fuerte que el del ácido cafeico. La rutina pertenece al grupo de los flavonoles, siendo este grupo de compuestos los considerado como mejores copigmentos (Boulton, 2001; Schwarz et al., 2005; GómezMíguez et al., 2006). La concentración de rutina en la uva es muy baja, entre 3 y $5 \mathrm{mg} / \mathrm{L}$ en uvas de Tempranillo (Schwarz et al., 2005), dando lugar las elevadas adiciones realizadas en este estudio a un incremento de la reacciones de copigmentación y a una mayor protección del color y de la concentración de antocianos (Bruchfeld, 1998).

La concentración de catequinas se incrementó en los vinos adicionados de los copigmentos catequina, proantocianidina de hollejo de uva blanca y proantocianidina de pepita de uva blanca. Los taninos de hollejo y de pepita son polímeros de flavanoles que podrían haber sido hidrolizados a monómeros o dímeros, incorporándose a los del mosto o vino, produciendo un incremento de catequinas y epicatequinas. La catequina 
es una buena molécula con propiedades copigmentantes como ha demostrado Darías et al. (2001), pudiendo explicar su presencia el efecto copigmentante encontrado cuando se adicionaron a los vinos taninos procedentes de uva blanca.

\subsubsection{EFECTO DE LAS TÉCNICAS DE VINIFICACIÓN}

En la tabla 6.3 se recogen los valores medios de los parámetros polifenólicos analizados en los vinos, considerando conjuntamente los distintos tipos de copigmentos utilizados, según que la vinificación se realice de forma tradicional, con maceración prefermentativa en frío a $6-8{ }^{\circ} \mathrm{C}$ o bien con una maceración prefermentativa con nieve carbónica.

La maceración prefermentativa tuvo un efecto positivo en la concentración total de antocianos decolorables y en el porcentaje de color debido a la copigmentación, (Koyama et al., 2007; Gordillo et al., 2010; Boulton, 2001; Álvarez et al., 2008). El incremento de estos parámetros debería incrementar la intensidad colorante, pero este incremento no es significativo. La intensidad colorante de los vinos elaborados siguiendo la vinificación tradicional es principalmente debida a la mayor contribución al color de los antocianos libres no copigmentados. Estos aportan una parte importante del color de los vinos tintos jóvenes aunque son muy inestables en presencia de oxígeno, además de muy sensibles al $\mathrm{SO}_{2}$ y a los cambios de $\mathrm{pH}$ (Brouillard., 1982; Furtado et al., 1993).

Tabla 6.3. Efecto de las técnicas de vinificación sobre los valores medios de los parámetros determinados.

\begin{tabular}{|c|c|c|c|c|c|c|c|}
\hline & \multicolumn{2}{|l|}{ Tradicional } & \multicolumn{3}{|c|}{ Frio } & \multicolumn{2}{|l|}{ Nieve } \\
\hline I.C. & $10,67 \pm 0,24$ & a & 10,87 & $\pm 0,58$ & $\mathrm{a}$ & $10,92 \pm 0,60$ & $\mathrm{a}$ \\
\hline Tono & $67,07 \pm 1,97$ & $\mathrm{a}$ & 69,69 & $\pm 0,98$ & $\mathrm{~b}$ & $70,00 \pm 0,98$ & $\mathrm{~b}$ \\
\hline Ant. Totales (mg/L) & $345,33 \pm 23,03$ & $\mathrm{a}$ & 442,52 & $\pm 33,75$ & $\mathrm{~b}$ & $419,56 \pm 45,54$ & $\mathrm{~b}$ \\
\hline \% Ant. Copigmentados & $14,22 \pm 5,89$ & $\mathrm{a}$ & 21,09 & $\pm 3,20$ & $\mathrm{~b}$ & $27,27 \pm 3,88$ & $\mathrm{c}$ \\
\hline$\%$ Ant. Libres & $59,31 \pm 2,54$ & $\mathrm{c}$ & 52,43 & $\pm 1,83$ & $\mathrm{~b}$ & $48,83 \pm 1,89$ & $\mathrm{a}$ \\
\hline \% Ant. Polimerizados & $26,47 \pm 5,09$ & $\mathrm{~b}$ & 26,38 & $\pm 2,49$ & $\mathrm{~b}$ & $24,12 \pm 3,13$ & $\mathrm{a}$ \\
\hline I. PVPP & $47,68 \pm 2,21$ & $\mathrm{~b}$ & 36,21 & $\pm 2,05$ & $\mathrm{a}$ & $35,84 \pm 1,28$ & $\mathrm{a}$ \\
\hline & $59,73 \pm 0,92$ & $\mathrm{a}$ & 61,29 & $\pm 1,35$ & $\mathrm{~b}$ & $62,44 \pm 1,25$ & $\mathrm{~b}$ \\
\hline Catec & $172,61 \pm 17,67$ & $\mathrm{~b}$ & 164,83 & $\pm 19,84$ & $\mathrm{~b}$ & $151,25 \pm 8,79$ & $\mathrm{a}$ \\
\hline Taninos (g/L) & $1,60 \pm 0,08$ & $\mathrm{a}$ & 1,66 & $\pm 0,23$ & $\mathrm{ab}$ & $1,77 \pm 0,31$ & $\mathrm{~b}$ \\
\hline I. DMACH & $57,93 \pm 2,35$ & & 58,13 & $\pm 5,28$ & & $54,48 \pm 10,04$ & \\
\hline I. Etanol & $30,86 \pm 3,50$ & $\mathrm{a}$ & 32,08 & $\pm 1,73$ & $\mathrm{a}$ & $35,15 \pm 3,17$ & $\mathrm{~b}$ \\
\hline I. Gelatina & $85,97 \pm 10,27$ & $\mathrm{~b}$ & 73,79 & $\pm 9,99$ & $\mathrm{a}$ & $79,06 \pm 9,59$ & $\mathrm{a}$ \\
\hline
\end{tabular}

Tradicional: elaboración sin maceración en frío previamente a la fermentación; Frío:

aplicación de bajas temperaturas de forma prefermentativa; Nieve: uso de nieve carbónica prefermentativamente. Letras diferentes en la misma fila indican diferencias significativas al 95\%.

El hecho de que los vinos elaborados de forma tradicional tengan un menor porcentaje del color debido a la copigmentación y un mayor porcentaje del color debido 
a los antocianos libres, podría causar inestabilidad y una mayor perdida en la concentración de antocianos y en el color con el envejecimiento.

El incremento significativo del color causado por la copigmentación de los antocianos debido a la maceración prefermentativa no tiene un efecto positivo en la intensidad colorante, pero se espera que produzca un incremento en la estabilidad del color, tal como muestran otros estudios, en los que la maceración prefermentativa en frío incrementa el color de los vinos analizados durante y después de su conservación (Reynolds et al., 2001; Parenti et al., 2004; Gómez-Plaza et al., 2001; Koyama et al., 2007; Gil-Muñoz et al., 2009).

La maceración prefermentativa en frío incrementa los valores del índice de Folin, taninos totales, y del porcentaje de taninos unidos a polisacáridos, mientras que disminuye la astringencia de los vinos. Estudios previos han puesto de manifiesto también el incremento de antocianos y de la concentración de taninos de bajo peso molecular (Brouillard, 1982, Furtado et al., 1993). Gómez-Mínguez et al. (2007), estudiando el efecto de la maceración prefermentativa, con diferentes tiempos y temperaturas, encontraron diferencias significativas con respecto al color y a la composición fenólica, además de un incremento importante de la concentración de ácido cafeico y ácido $p$-hidroxibenzoico, en los vinos criomacerados. La mayor concentración de estos compuestos, de probado efecto copigmentante, podría ser una de las causas del incremento de la fracción del color debida a la copigmentación observada para la maceración prefermentativa.

El incremento en la fracción polifenólica puede ser debida a un mayor contacto del mosto con los hollejos en ausencia de etanol (González et al., 2001, Timberlake y Bridle, 1976), potenciándose este efecto cuando la maceración es realizada con el uso de nieve carbónica. Este incremento es debido al efecto de desestructuración celular causado por la congelación de los líquidos intracelulares que provoca la rotura de las paredes de las células por la sublimación de la nieve carbónica (González et al., 2001, Reynolds et al., 2001; Fulcrand, 2006).

Al mismo tiempo que una mayor extracción fenólica, se produce una mayor extracción de polisacáridos de las células de los hollejos. Estos polisacáridos pueden reaccionar con los taninos, tan pronto como ellos son extraídos de las células de los hollejos, dando lugar a vinos con una mayor estructura, mayor volumen en boca, mayor suavidad y menor astringencia, en consonancia con resultados obtenidos por otros autores (Fulcrand, 2006).

\subsubsection{CORRELACIÓN ENTRE LOS PARÁMETROS POLIFENÓLICOS DE LOS VINOS, LA ADICIÓN DE COPIGMENTOS Y LAS TÉCNICAS DE VINIFICACIÓN.}

El Análisis de Componentes Principales es una técnica estadística de síntesis de la información o reducción de la dimensión (numero de variables). Transforma una serie de posibles variables correlacionadas en un número menor de variables no correlacionadas, llamadas componentes principales, perdiendo la menor cantidad de información posible. Los nuevos componentes principales o factores serían una combinación lineal de las variables originales que además son independientes entre sí. 
El ACP construye una transformación lineal que escoge un nuevo sistema de coordenadas para el conjunto original de datos, en el cual la varianza más grande del conjunto de datos es capturada en el primer eje, llamado el primer componente principal, la segunda varianza más grande forma el segundo eje y así sucesivamente. Para establecer si existe correlación entre las variables, debe construirse primero la matriz de covarianzas o matriz de correlaciones. Un ACP tiene sentido si existen altas correlaciones entre las variables, ya que esto es indicativo de que existe información redundante y, por tanto, pocos factores explicaran gran parte de la variabilidad total.

La matriz de correlaciones es una medida de la asociación lineal entre las variables, donde los valores están siempre comprendidos en el intervalo [-1, 1]. Si el coeficiente de correlación es próximo a 1 o a -1 existirá una correlación y, por el contrario, si es cercano a 0 , habrá una asociación lineal muy débil.

En la tabla 6.4 aparece representada la matriz de correlaciones de las variables utilizadas en el análisis, pudiendo observar como existen correlaciones fuertes, tanto positivas como negativas, entre las distintas variables ensayadas. Las coloraciones rojas corresponden a las relaciones negativas, las verdes a las positivas y, por último, las amarillas a las correlaciones débiles entre las variables relacionadas (próxima a cero).

Observamos una correlación negativa entre el índice de PVPP, que mide las uniones entre antocianos y taninos, y el tono, lo que indica que a medida que se incrementa el número de uniones antociano-tanino, disminuye la tonalidad amarilla de los vinos considerados; siendo estos compuestos responsables de una mayor estabilidad del color, protegiendo, por lo tanto, a estos compuestos de la oxidación (Cheynier et al., 1999, 2006; Vidal et al., 2002; Koyama et al., 2007).

En cuanto a los antocianos totales decolorables, se observan correlaciones negativas tanto para el índice de PVPP, el porcentaje del color que corresponde a los antocianos libres y el que corresponde a los polimerizados, aunque, por el contrario, se observa una relación positiva entre los antocianos totales y el porcentaje del color debido a la copigmentación. Este comportamiento nos indica como en estos vinos están predominando las reacciones de copigmentación en detrimento de las polimerizaciones o de las uniones con los taninos y que por lo tanto se observa un efecto positivo de la adición de copigmentos, favoreciéndose estas uniones cuando se incrementa la concentración de antocianos en los vinos. Además, se observa también una correlación negativa entre el color debido a la copigmentación y el debido tanto a los antocianos libres como a los polimerizados, confirmando lo mencionado anteriormente (Somers, 1971; Boulton, 2001).

El porcentaje del color debido a la copigmentación muestra una correlación negativa con el índice de PVPP. Esto siguiere que si los antocianos están participando en las reacciones de copigmentación no están disponibles para participar en las reacciones de polimerización con los taninos. Por el contrario, sí que se observa un efecto positivo entre el índice de PVPP y el color debido a los antocianos libres, lo cual indica que un incremento en la concentración de antocianos favorece estas reacciones siempre y cuando exista una concentración suficiente de taninos en el medio (Singleton, 1987; Ribereau-Gayon et al., 2000b; Atanasova et al., 2002a). 


\begin{tabular}{|c|c|c|c|c|c|c|c|c|c|c|c|c|c|}
\hline ви!е|әD I & $\begin{array}{l}\text { oे } \\
\text { in }\end{array}$ & $\frac{2}{0}$ & $\begin{array}{l}m \\
0 \\
i\end{array}$ & $\mid \begin{array}{l}0 \\
n \\
1 \\
1\end{array}$ & $\begin{array}{l}n \\
i \\
i\end{array}$ & $\begin{array}{l}0 \\
0 \\
0 \\
i\end{array}$ & $\frac{2}{0}$ & m. & $\begin{array}{l}\hat{n} \\
\hat{0}\end{array}$ & $\begin{array}{l}0 \\
n \\
0 \\
1\end{array}$ & $\hat{\tilde{n}}$ & $\stackrel{0}{0}$ & \\
\hline 'u!!od fuV \% & 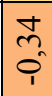 & $\begin{array}{l}\text { I } \\
0 \\
0\end{array}$ & $\stackrel{2}{0}$ & $\begin{array}{l}\tilde{n} \\
\tilde{n} \\
\hat{1}\end{array}$ & $\begin{array}{l}\tilde{n} \\
\hat{i} \\
\end{array}$ & $\begin{array}{l}0 \\
0 \\
0 \\
0\end{array}$ & $\begin{array}{l}\text { mे } \\
\text { ? } \\
\text { in }\end{array}$ & $\overrightarrow{\tilde{o}}$ & $\begin{array}{l}\tilde{\delta} \\
\delta\end{array}$ & $\begin{array}{l}n \\
\hat{n} \\
i \\
1\end{array}$ & సે & & to \\
\hline sə.xq!T •quV \% & $\begin{array}{l}n \\
\text { nn } \\
\hat{p}\end{array}$ & $\begin{array}{l}\infty \\
n \\
0 \\
0\end{array}$ & $\left|\begin{array}{c}\bar{n} \\
\hat{0}\end{array}\right|$ & $\mid \begin{array}{l}\tilde{6} \\
0 \\
1\end{array}$ & $\begin{array}{l}\text { J } \\
\text { o }\end{array}$ & $\stackrel{2}{\approx}$ & $\begin{array}{l}\text { ते } \\
\text { ô }\end{array}$ & $\frac{\infty}{\sigma_{0}^{0}}$ & 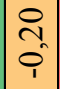 & $\begin{array}{l}n \\
\infty \\
0 \\
1 \\
1\end{array}$ & & $\begin{array}{c}\grave{\hat{\lambda}} \\
\tilde{0}\end{array}$ & â. \\
\hline • & ?f & $\begin{array}{l}\text { f } \\
\text { co } \\
1\end{array}$ & $\begin{array}{c}\bar{m} \\
\hat{0}\end{array}$ & $\overrightarrow{\sigma_{0}}$ & $\begin{array}{l}n \\
0 \\
0 \\
i\end{array}$ & $\mid \begin{array}{l}\Omega \\
\tilde{o} \\
0 \\
i\end{array}$ & $\begin{array}{l}\tilde{m} \\
\tilde{n} \\
0\end{array}$ & $\begin{array}{l}\hat{0} \\
0 \\
i\end{array}$ & $\frac{n}{0}$ & & $\left|\begin{array}{c}n \\
0 \\
0 \\
0 \\
1\end{array}\right|$ & $\begin{array}{l}m \\
\hat{\varphi}\end{array}$ & $\begin{array}{l}0 \\
n \\
0 \\
1\end{array}$ \\
\hline$(\mathrm{T} / \mathbf{\mathbf { s }}) \operatorname{sou!ur}_{\mathbf{L}}$ & $\begin{array}{l}\text { זे } \\
\text { ֶa }\end{array}$ & $\frac{n}{0}$ & $\begin{array}{l}0 \\
n \\
0\end{array}$ & $\frac{\infty}{0}$ & $\begin{array}{l}n \\
0 \\
0\end{array}$ & $\mid \begin{array}{l}0 \\
0 \\
0 \\
0\end{array}$ & ले & $\begin{array}{l}0 \\
1 \\
0 \\
i\end{array}$ & & $\frac{n}{0}$ & $\begin{array}{l}\hat{\imath} \\
\hat{\varphi}\end{array}$ & $\begin{array}{l}0 \\
0 \\
0\end{array}$ & त̂ \\
\hline $\operatorname{dd} \Lambda d{ }^{\circ} I$ & $\begin{array}{l}0 \\
0 \\
0\end{array}$ & $\begin{array}{l}n \\
0 \\
0\end{array}$ & $\begin{array}{l}2 \\
\hat{0} \\
i\end{array}$ & $\begin{array}{l}n \\
\hat{0} \\
i\end{array}$ & $\begin{array}{l}m \\
\tilde{\sigma}\end{array}$ & $\cong$ & $\frac{0}{1}$ & & $\begin{array}{l}0 \\
1 \\
i \\
i \\
1\end{array}$ & $\begin{array}{l}\hat{6} \\
0 \\
1\end{array}$ & $\mid \begin{array}{l}\infty \\
0 \\
0\end{array}$ & $\overrightarrow{\tilde{o}}$ & ले \\
\hline 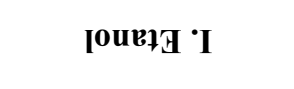 & है & 满 & $\left|\begin{array}{l}0 \\
2 \\
0 \\
0\end{array}\right|$ & $\overline{0}$ & $\begin{array}{l}0 \\
0 \\
0\end{array}$ & $\mid \begin{array}{l}2 \\
\tilde{2} \\
0 \\
1\end{array}$ & & $\begin{array}{l}0 \\
0 \\
0\end{array}$ & $\begin{array}{l}\hat{2} \\
\hat{0}\end{array}$ & $\begin{array}{l}n \\
\tilde{c} \\
0\end{array}$ & $\mid \begin{array}{l}\tilde{N} \\
0 \\
0\end{array}$ & $\mid \begin{array}{l}0 \\
\tilde{2} \\
0 \\
1\end{array}$ & $\frac{9}{0}$ \\
\hline HOVWA 'I & $\begin{array}{l} \pm \\
0 \\
0\end{array}$ & $\frac{m}{0}$ & $\begin{array}{l}\dot{1} \\
m \\
\hat{i} \\
i\end{array}$ & $\begin{array}{l}\infty \\
0 \\
0\end{array}$ & $\overline{0}$ & & $\begin{array}{l}\text { तै } \\
\text { ? }\end{array}$ & $\stackrel{\sim}{\simeq}$ & $\begin{array}{l}0 \\
\infty \\
0 \\
1\end{array}$ & $\begin{array}{l}0 \\
0 \\
0 \\
1\end{array}$ & $\stackrel{\simeq}{0}$ & $\begin{array}{l}0 \\
0 \\
0 \\
1\end{array}$ & $\begin{array}{l}0 \\
\text { m. } \\
0 \\
1\end{array}$ \\
\hline 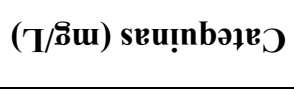 & $\hat{\delta}$ & $\begin{array}{l}0 \\
0 \\
0\end{array}$ & \begin{tabular}{|l}
$\vec{n}$ \\
$\hat{0}$ \\
$i$
\end{tabular} & $\frac{\pi}{0}$ & & $\begin{array}{l}\tilde{\sigma} \\
0\end{array}$ & $\begin{array}{l}0 \\
0 \\
\end{array}$ & $\begin{array}{l}m \\
\hat{0} \\
0\end{array}$ & $\begin{array}{l}n \\
0 \\
0\end{array}$ & $\left|\begin{array}{l}n \\
0 \\
0 \\
1\end{array}\right|$ & 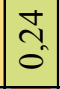 & $\begin{array}{l}\tilde{n} \\
\hat{i} \\
1\end{array}$ & $\frac{n}{0}$ \\
\hline 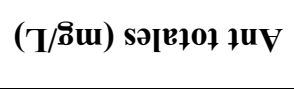 & $\begin{array}{l}\text { ñ } \\
\text { on }\end{array}$ & $\begin{array}{l}\overline{\tilde{n}} \\
\hat{\imath}\end{array}$ & $\left|\begin{array}{l}0 \\
n \\
0 \\
0\end{array}\right|$ & & $\frac{\nabla}{0}$ & $\mid \begin{array}{l}\infty \\
0 \\
0\end{array}$ & $\overline{0}$ & $\begin{array}{l}n \\
0 \\
i\end{array}$ & $\frac{\infty}{0}$ & $\overrightarrow{\sigma_{0}}$ & $\left|\begin{array}{l}0 \\
0 \\
0 \\
0\end{array}\right|$ & $\mid \begin{array}{l}2 \\
\tilde{2} \\
0\end{array}$ & $\begin{array}{l}0 \\
n \\
1 \\
1\end{array}$ \\
\hline OU0 $\mathbf{L}$ & त̂ & $\begin{array}{l}0 \\
2 \\
0 \\
0\end{array}$ & & $\begin{array}{l}0 \\
n \\
0 \\
0\end{array}$ & $\begin{array}{l}\vec{\gamma} \\
\hat{i}\end{array}$ & \begin{tabular}{|l}
$\mathbf{w}$ \\
. \\
$\hat{i}$
\end{tabular} & $\begin{array}{l}0 \\
\text { ñ. } \\
0\end{array}$ & $\begin{array}{l}\stackrel{P}{0} \\
\dot{\varphi}\end{array}$ & $\begin{array}{l}0 \\
n \\
0\end{array}$ & $\vec{m}$ & $\mid \begin{array}{c}\bar{n} \\
0 \\
i\end{array}$ & $\stackrel{1}{2}$ & $\frac{m}{i}$ \\
\hline$\cdot{ }^{\circ} \mathbf{I}$ & $\mathscr{\theta}^{\circ}$ & & $\mid \begin{array}{l}0 \\
2 \\
2 \\
0 \\
1\end{array}$ & $\begin{array}{l}\overrightarrow{\hat{N}} \\
\hat{i}\end{array}$ & for & $\frac{m}{i}$ & $\begin{array}{l}0 \\
0 \\
0\end{array}$ & $\hat{n}$ & $\stackrel{n}{0}$ & 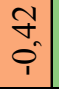 & $\mid \begin{array}{l}\infty \\
n \\
0 \\
0\end{array}$ & $\begin{array}{l}0 \\
0 \\
0\end{array}$ & $\frac{m}{0}$ \\
\hline U!! & & $0_{0}^{\circ}$ & $\begin{array}{l}\hat{y} \\
\hat{o}\end{array}$ & $\begin{array}{l}\tilde{y} \\
\tilde{0} \\
0\end{array}$ & $\hat{\tilde{o}}$ & $\stackrel{ \pm}{ \pm}$ & हे & $\begin{array}{l}0 \\
0 \\
0\end{array}$ & $\begin{array}{l}0 \\
1 \\
0 \\
0\end{array}$ & $\begin{array}{l}n \\
f \\
0 \\
0\end{array} \mid$ & $\mid \begin{array}{l}n \\
2 \\
0 \\
0 \\
1\end{array}$ & $\mid \begin{array}{l}\tilde{w} \\
\text { ?. } \\
\hat{i}\end{array}$ & $\begin{array}{l}\text { oे } \\
\text { i }\end{array}$ \\
\hline & & نِتِ & $\mid \begin{array}{l}\stackrel{g}{\Xi} \\
\stackrel{\theta}{\theta}\end{array}$ & 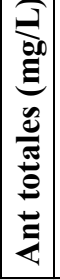 & 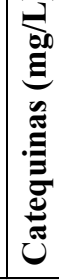 & 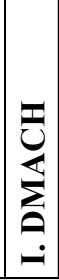 & ن & 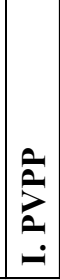 & 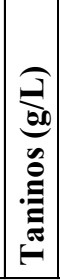 & 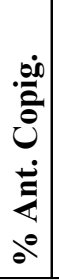 & 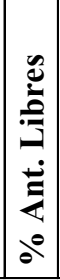 & 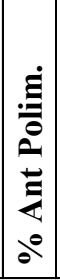 & تصّ \\
\hline
\end{tabular}


Una vez comprobado que existe correlación entre los parámetros polifenólicos se realiza el análisis factorial, que permite explicar la variabilidad de los parámetros polifenólicos con el mínimo número de factores. Una de las aproximaciones para determinar el número inicial de factores es el de seleccionar sólo aquellos factores con autovalores (eigenvalores) superiores a la unidad. Un segundo criterio de selección del numero de factores es el de determinar el porcentaje acumulado de varianza extraída por los diferentes factores.

Tabla 6.5. Autovalor, varianza explicada y acumulada para las componentes consideradas en el análisis.

\begin{tabular}{cccc}
\hline Componente & Autovalor & \% Varianza & \% Acumulado \\
\hline $\mathbf{1}$ & 4,725 & 36,344 & 36,344 \\
$\mathbf{2}$ & 2,571 & 19,776 & 56,120 \\
$\mathbf{3}$ & 1,930 & 14,846 & 70,966 \\
$\mathbf{4}$ & 1,299 & 9,992 & 80,958 \\
$\mathbf{5}$ & 0,703 & 5,407 & 86,365 \\
$\mathbf{6}$ & 0,522 & 4,013 & 90,378 \\
$\mathbf{7}$ & 0,464 & 3,569 & 93,947 \\
$\mathbf{8}$ & 0,396 & 3,044 & 96,990 \\
$\mathbf{9}$ & 0,151 & 1,158 & 98,149 \\
$\mathbf{1 0}$ & 0,103 & 0,793 & 98,941 \\
$\mathbf{1 1}$ & 0,083 & 0,636 & 99,578 \\
$\mathbf{1 2}$ & 0,049 & 0,375 & 99,953 \\
$\mathbf{1 3}$ & 0,006 & 0,047 & 100,000 \\
\hline
\end{tabular}

En la tabla 6.5 aparece tanto el autovalor como el porcentaje de varianza acumulada por los sucesivos factores, observándose como son necesarios cuatro factores para que el autovalor descienda por debajo de la unidad. Además comprobamos como el porcentaje de varianza acumulada corresponde al 80,96\%. Se han identificado cuatro patrones de comportamiento asociado, explicando entre ellos más del $80 \%$ de la variabilidad total observada en las variables originales, consiguiéndose con esto una reducción de las variables iniciales. Como norma general en la interpretación se tiende a prescindir de aquellas variables cuyo coeficiente con el factor es inferior a 0,25-0,3.

En la tabla 6.6 se observa como el primer componente presenta coeficientes positivos (asociación directa) importantes tanto para los antocianos totales como para los copigmentados, además de para el tono. Por el contrario, se observan coeficientes negativos (asociación indirecta) tanto para el índice de PVPP como para los antocianos libres. Este comportamiento nos indica que el primer componente está altamente relacionado con la concentración de antocianos y con el nivel de copigmentación de éstos, siendo, por lo tanto, un marcador de estas reacciones; revelando una vez más como el incremento de las reacciones de copigmentación permite una mayor conservación de los antocianos extraídos del hollejo durante la maceración. Este planteamiento se ve reforzado con el efecto negativo que presentan las uniones de polimerización antociano-tanino y la concentración de antocianos libres en el vino, indicando que las reacciones que predominan en estos vinos son las de copigmentación. 
El segundo componente muestra una correlación positiva entre el índice de etanol, la concentración de taninos, el porcentaje del color debido a los antocianos polimerizados, el índice de gelatina, y el tono. Por el contrario, se observa una asociación indirecta con el índice de DMACH, índice relacionado también con el estado de los taninos en los vinos, concretamente con su grado de polimerización. Este eje puede considerarse como un marcador tanto de la concentración como del estado de los taninos en los vinos, estando más relacionado con las reacciones en las que participan éstos, como podrían ser las de polimerización, que con aquellas en la que están más involucrados los antocianos, tales como las de copigmentación o polimerización.

Tabla 6.6. Tabla de pesos de los componentes

\begin{tabular}{|c|c|c|c|c|}
\hline & $\begin{array}{c}\text { Componente } \\
1 \\
\end{array}$ & $\begin{array}{c}\text { Componente } \\
2 \\
\end{array}$ & $\begin{array}{c}\text { Componente } \\
3 \\
\end{array}$ & $\begin{array}{c}\text { Componente } \\
4 \\
\end{array}$ \\
\hline I. Folin & 0,22 & 0,14 & 0,34 & 0,38 \\
\hline I.C. & $-0,24$ & 0,09 & 0,47 & $-0,22$ \\
\hline Tono & 0,30 & 0,26 & $-0,19$ & $-0,23$ \\
\hline Ant totales $(\mathrm{mg} / \mathrm{L})$ & 0,37 & $-0,17$ & 0,11 & $-0,30$ \\
\hline Catequinas $(\mathrm{mg} / \mathrm{L})$ & $-0,08$ & $-0,11$ & 0,51 & $-0,37$ \\
\hline I. DMACH & $-0,07$ & $-0,52$ & $-0,10$ & 0,21 \\
\hline I. Etanol & 0,20 & 0,30 & 0,19 & 0,51 \\
\hline I. PVPP & $-0,40$ & 0,00 & 0,25 & 0,19 \\
\hline Taninos (g/L) & 0,15 & 0,51 & 0,17 & $-0,26$ \\
\hline \% Ant. Copig. & 0,41 & $-0,14$ & 0,14 & 0,11 \\
\hline$\%$ Ant. Libres & $-0,41$ & 0,03 & 0,14 & 0,01 \\
\hline \% Ant Polim. & $-0,23$ & 0,25 & $-0,42$ & $-0,21$ \\
\hline I. Gelatina & $-0,21$ & 0,40 & $-0,10$ & 0,24 \\
\hline
\end{tabular}

Por último, el tercer componente presenta asociaciones directas con el índice de Folin, la intensidad colorante, y la concentración de catequinas, y negativo para el porcentaje de color debido a los antocianos polimerizados, parámetros que relacionan el color con la concentración de estos compuestos en los vinos. En cuanto al cuarto componente, se encontraron relaciones positivas para el índice de Folin y para el índice de etanol, y negativas tanto para la concentración de antocianos, como para la de catequinas y taninos.

Una vez comprobadas que variables están más correlacionadas con las componentes principales, se calcularon los coeficientes de las combinaciones lineales sobre las variables antiguas que definen las variables nuevas, para poder calcular a partir de ellos las nuevas coordenadas de los objetos en las componentes. Obtenidos los coeficientes de las componentes principales se representó la primera componente frente a la segunda. 
En el gráfico 6.1 aparece la representación de los vinos elaborados con los distintos copigmentos, en función de los dos primeros ejes principales. Se puede observar como los vinos muestran una disposición a lo largo del primer eje principal, aunque sin mostrar una tendencia concreta para ninguno de los copigmentos. Por el contrario, para el segundo eje la mayoría de los vinos estudiados se sitúan en su zona central, indicando que la adición de copigmentos presenta nula o baja influencia en cuanto a la concentración y estado de los taninos en los vinos, parámetros con los que está relacionado este eje.

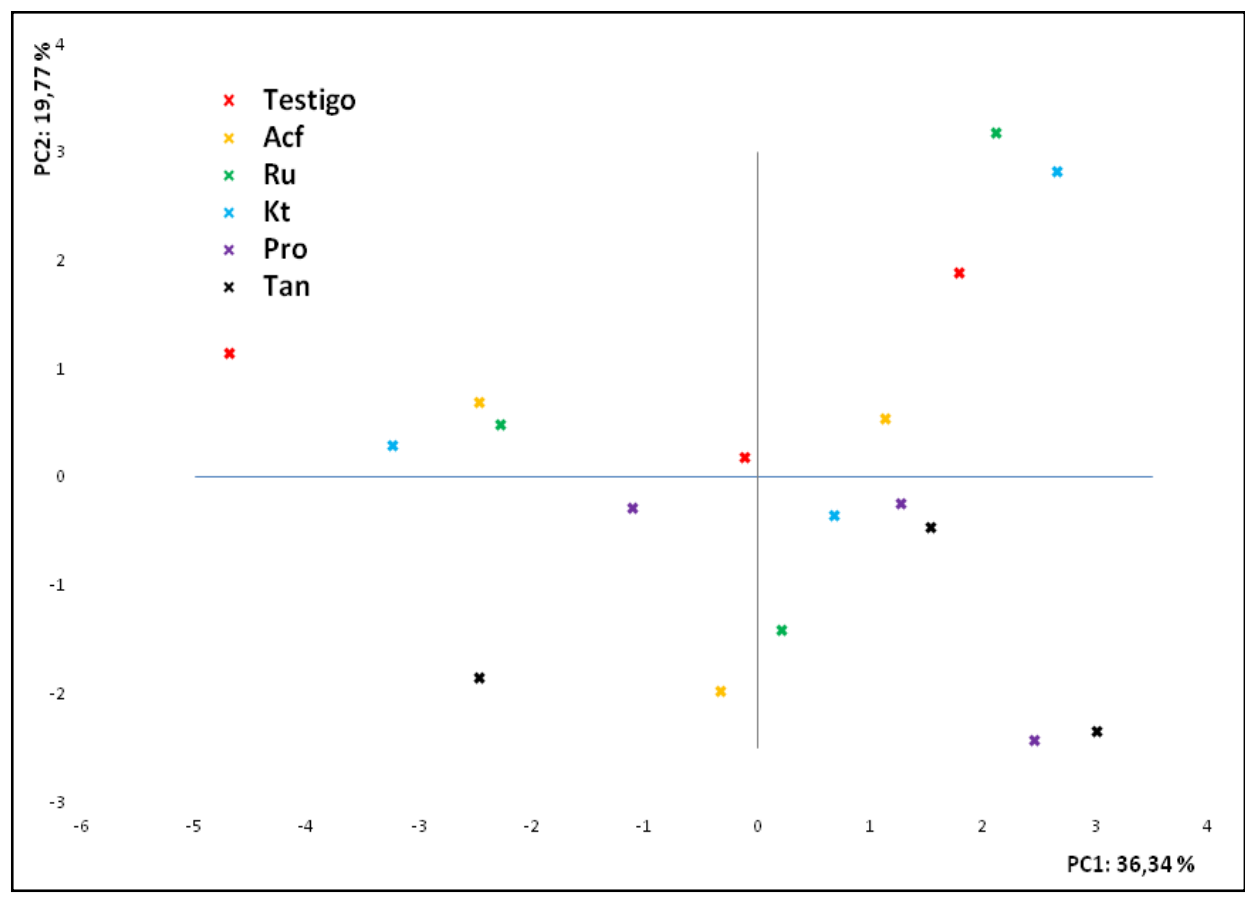

Gráfico 6.1. Primera componente frente a la segunda, en función de los copigmentos ensayados.

En el gráfico 6.2 se observa como los vinos elaborados, con cada una de las tres técnicas de vinificación ensayadas, se distribuyen a lo largo del primer eje, situándose más hacia la derecha aquellos vinos macerados prefermentativamente con nieve carbónica. Este resultado podría indicar como esta técnica, que favorece la extracción de 4compuestos de las partes sólidas de la uva, favorece tanto la extracción de antocianos como las reacciones de copigmentación en los vinos. Busse-Valverde et al. (2010) observan como en vinos de Syrah y Cabernet Sauvignon se incrementa la fracción del color en el momento del embotellado, mientras que Heredia et al. (2010), estudiando diferentes técnicas de maceración prefermentativa, concluyen que la aplicación de nieve carbónica favorece la extracción de compuestos fenólicos con elevado poder copigmentante, incrementando la estabilidad del color de los vinos.

También se observa que existe una separación en los vinos macerados con nieve carbónica a lo largo del segundo eje. Este resultado indica que en algunos de los vinos esta técnica afecta también a la concentración y al estado de los taninos en el vino y no únicamente a la concentración y al estado de los antocianos, confirmándose el efecto de extracción de compuestos fenólicos de las partes sólidas. Además, el hecho de que la 
mayor extracción se haya realizado durante la fase prefermentativa, en ausencia de alcohol, sugiere quizás que el etanol no es tan crucial en la extracción de estos compuestos. Busse-Valverde et al., (2010), en el estudio antes mencionado, observan como la aplicación de nieve carbónica incrementa la concentración de taninos en los vinos macerados, incrementando también su grado de polimerización.

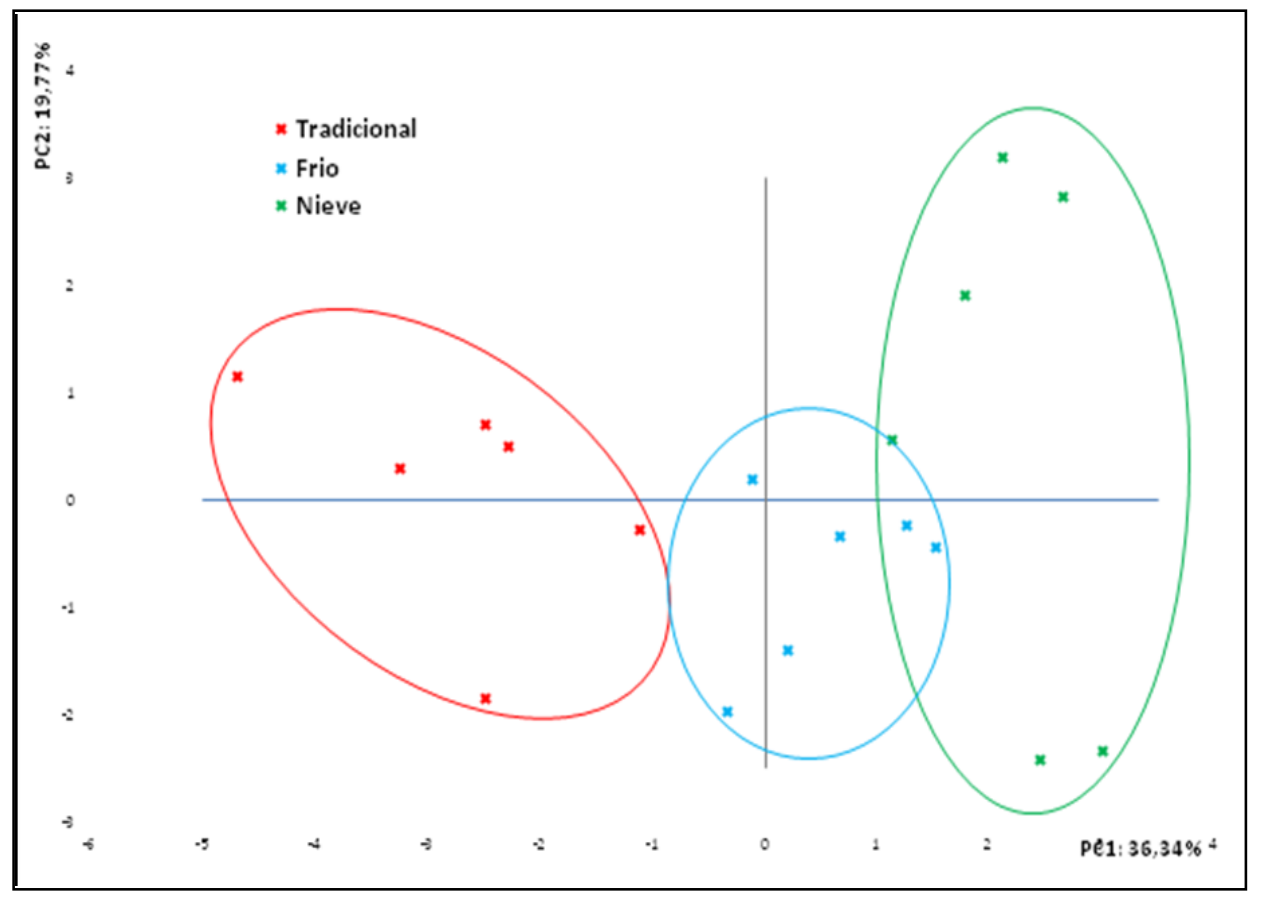

Gráfico 6.2. Primera componente frente a la segunda componente en función de las s de vinificación ensayadas.

Por otra parte, son de difícil interpretación aquellos vinos situados en la zona inferior del segundo eje principal. Quizás la adición de determinados copigmentos pertenecientes a la familia de los taninos, como la catequina y las proantocianidinas, han favorecido las reacciones de polimerización, incrementando el grado de polimerización de los taninos tal como pon de manifiesto el peso del índice de DMACH en este eje, dejando de participar estos compuestos en otro tipo de reacciones como podrían ser las uniones con polisacáridos o las uniones con los antocianos. Bautista-Ortín et al. (2007) observan como la adición de tanino enológico proantocinidínico al vino provoca un incremento en la concentración de taninos poliméricos, tanto en el momento del embotellado como a los 8 meses de conservación.

Los vinos elaborados de forma tradicional aparecen situados en la zona negativa del primer eje principal, lo cual pone de manifiesto la baja relación entre esta técnica de elaboración, la concentración de antocianos y el porcentaje del color debido a la copigmentación, mostrándose esta técnica como la menos adecuada para potenciar este tipo de reacciones. Aquellos vinos elaborados mediante maceración prefermentativa en frío se sitúan en la zona central del gráfico, mostrando una mayor afinidad por el primer componente, siendo esta técnica más adecuada que la maceración tradicional para potenciar la copigmentación. De las técnicas estudiadas, ha sido la maceración con nieve carbónica la más relacionada con el incremento de antocianos y del color debido a la copigmentación. 


\subsubsection{ANÁLISIS DE LOS VINOS A LOS 6 MESES DE CONSERVACIÓN}

La composición fenólica de los vinos se determinó de nuevo a los seis meses de conservación, procediéndose con los resultados a realizar análisis comparativo en función de las distintas prácticas enológicas ensayadas.

\subsubsection{ANÁLSIS MULTIFACTORIAL DE LA VARIANZA DE LOS FACTORES CONSIDERADOS}

En la tabla 6.7 aparecen los datos del análisis multifactorial de la varianza (ANOVA) para los factores considerados, así como para las interacciones entre ellos. En este caso se ha estudiado el efecto de cuatro factores, la adición de copigmentos, las diferentes técnicas de maceración prefermentativa ensayadas, la aplicación de la microoxigenación y, por último, la adición pre- y postfermentativa de los copigmentos.

El análisis multifactorial de la varianza pone de manifiesto que los primeros tres factores, que corresponden a los copigmentos ensayados (factor A), a las distintas técnicas de vinificación (factor B) y a la aplicación de la microoxigenación (factor C), presentan diferencias significativas en la mayoría de parámetros estudiados a los 6 meses de conservación en botella. Por el contrario para el factor D (adición pre- o postfermentativa de copigmentos), no aparecen estas diferencias para la mayoría de ellos. Además, algunas de las interacciones también presentan diferencias significativas en algunos de sus parámetros, concretamente las interacciones $\mathrm{AB}$ (copigmento $\mathrm{x}$ técnicas), $\mathrm{AD}$ (copigmento $\mathrm{x}$ adición pre/post fermentativa), $\mathrm{BC}$ (técnicas $\mathrm{x}$ microoxigenación) y $\mathrm{BD}$ (técnicas $\mathrm{x}$ adición pre/post fermentativa), lo cual indica que ese parámetro polifenólico es distinto en función de la enológica empleada.

Los parámetros antocianos totales decolorables, taninos e índice de DMACH, por este orden, son los que muestran los valores más elevados del F-ratio y por tanto aquellos en los que más influye la adición de copigmentos. Además, otros parámetros como el tono, los antocianos polimerizados, la IC y el índice de Folin muestran también diferencias significativas al nivel de confianza del 99,9\%, indicando como la adición de copigmentos afecta significativamente a la composición fenólica de los vinos (DaríasMartin et al., 2002; Sacchi et al., 2005; Soto-Vázquez et al., 2010).

Por el contrario, podemos observar que no existen diferencias significativas para el parámetro porcentaje de color debido a los antocianos copigmentados. Este parámetro no muestra diferencias entre los distintos copigmentos a los seis meses de conservación de los vinos, pero en cambio contribuía en gran medida a su diferenciación después de la fermentación maloláctica. Estos resultados nos inducen a pensar que los compuestos fenolicos que estaban formando parte de los complejos de copigmentación, pueden haberse liberado y en estos momentos pueden estar formando parte de otro tipo de reacciones, como podrían ser las reacciones de unión antociano-tanino o las polimerizaciones de ambos compuestos, tal como parece indicar el hecho de que el color debido a los antocianos polimerizados no fuese significativo en la diferenciación después de la fermentación maloláctica, y en cambio lo sea ahora. 


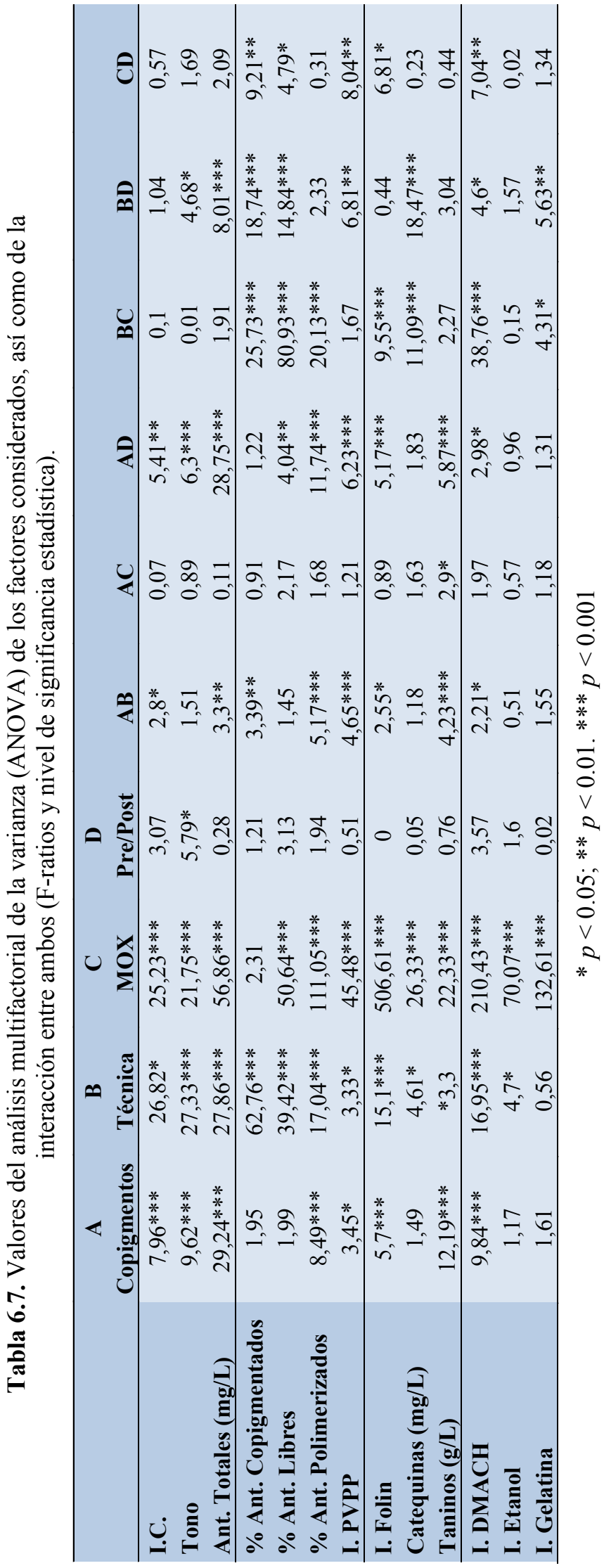


Darías-Martin et al. (2002) resaltan la importancia de la presencia de copigmentos en la extracción de antocianos y en la estabilidad del color, remarcando que la adición de ácido cafeico provocó en los vinos una mayor interacción entre los compuestos fenólicos, dando lugar a un incremento de sus reacciones de polimerización, que se manifestó en la estabilidad del color de los vinos.

Para el factor técnicas de vinificación, tal y como se observa en la tabla anterior, todos los parámetros polifenólicos presentan diferencias significativas, excepto el índice de gelatina. Este comportamiento nos indica que las distintas técnicas de maceración ensayadas presentan un marcado efecto sobre la composición fenólica de los vinos. Los parámetros más afectados son los antocianos totales decolorables, los copigmentados y los antocianos libres, tal como se observó en los vinos después de la fermentación maloláctica. El prolongado tiempo de contacto entre hollejos y mosto durante la fase prefermentativa pudo ser la causa del incremento de la concentración de antocianos en el vino (Parenti et al., 2004; Álvarez et al., 2005; Manchón et al., 2005; Gil-Muñoz et al., 2009; Gómez-Miguez et al., 2006; Gordillo et al., 2010) y de que estos compuestos aparezcan en el vino formando parte de diferentes complejos, así como en su forma libre (Koyama et al., 2007; Álvarez et al., 2008; Gordillo et al., 2010).

Podemos comprobar que no son únicamente los parámetros relacionados con la composición antociánica los que se ven afectados por las técnicas de vinificación, sino que otros parámetros relacionados con la composición tánica como el índice de Folin, el índice de DMACH y en menor medida la concentración de taninos, también muestran diferencias significativas, tal como observamos en los vinos después de la fermentación maloláctica. Estos resultados indican como la maceración prefermentativa no extrae únicamente antocianos de las partes sólidas, sino que contribuye a la solubilización de compuestos de carácter tánico hacia el vino.

Soto Vázquez et al. (2010) observaron que en la variedad Mencia, la maceración prefermentativa incrementa la concentración fenólica de los vinos, especialmente la concentración antociánica y tánica. Zini et al. (2003), estudiando el efecto de esta para la variedad Sangiovese, encuentran pequeñas diferencias para la concentración tánica en los vinos objeto de estudio. Es interesante destacar que las técnicas de vinificación influyeron en la astringencia de los vinos recién elaborados, determinada mediante el índice de gelatina, tal como se expuso en el apartado anterior, pero en cambio a los 6 meses no se aprecian diferencias en función de estas prácticas, quizás debido a que otras reacciones de estabilidad han minimizado el efecto astringente observado inicialmente.

En cuanto a la aplicación de la microoxigenación, observamos cómo esta técnica presenta un marcado efecto sobre la composición de los vinos, siendo los parámetros índice de Folin, índice de $\mathrm{DMACH}$, antocianos polimerizados e índice gelatina los que presentan un efecto más marcado sobre la variable. Todos estos parámetros están relacionados directa o indirectamente con las reacciones en las que participa el oxígeno e incluso algunos de ellos con la estabilidad de estas reacciones, manteniendo o incluso incrementando el contenido polifenólico de los vinos (GómezPlaza y Cano-López, 2011; González-del Pozo et al., 2010; Pérez-Magariño et al 2007; Cano-López et al., 2007, 2008). Por el contrario, esta técnica parece tener nulo o escaso efecto sobre el incremento de las reacciones de copigmentación (tabla 6.7). 
El análisis de la varianza muestra también algunos resultados interesantes si se analizan las interacciones entre las variables ensayadas. La interacción entre la adición de copigmentos y las técnicas de vinificación (interacción $\mathrm{AB}$ ) al cabo de seis meses no es tan significativa como después de la fermentación maloláctica, pero su efecto queda patente en las diferencias significativas encontradas para los parámetros antocianos polimerizados, índice de PVPP y taninos, parámetros favorables para la calidad de los vinos, que nos indican como la combinación de ambas prácticas podría tener un efecto positivo en cuanto a la concentración y al estado de los compuestos fenólicos en los vinos (Álvarez et al., 2008).

La interacción entre las variables adición de copigmentos y momento de adición de copigmentos (interacción AD) muestra los mayores valores del F-ratio para los parámetros antocianos totales decolorables y antocianos polimerizados, además de para el índice de PVPP y los taninos, indicando como los copigmentos adicionados podrían provocar efectos diferentes en función de si la adición se efectúa antes o posteriormente a la fermentación. A pesar de que el factor adición pre- o post fermentativa de copigmentos no presenta diferencias significativas para los parámetros ensayados, el efecto significativo observado para la interacción requiere un análisis más profundo de los datos, analizándose posteriormente el efecto de esta variable sobre los vinos.

Un efecto similar al mencionado en el párrafo anterior aparece para la interacción técnicas de vinificación con adición pre- o postfermentativa de copigmentos (interacción BD). Seguramente la adición de los copigmentos al principio de la vinificación, facilitando su presencia en el momento de máxima extracción de compuestos fenólicos, podría provocar un efecto más marcado de esta, ya que estos contaran en el vino con un mayor número de compuestos con los que poder reaccionar. Las técnicas de vinificación ejercen una gran influencia en la extracción de los componentes de las uvas, afectando a la concentración y composición de los vinos tintos; la temperatura y la duración de la maceración, y la presencia o ausencia de etanol, son factores que afectan a las características y composición de los antocianos, así como a los fenómenos de copigmentación (Gómez-Miguez y Heredia, 2004). Por ello, es posible que para cada una de las técnicas de vinificación ensayadas, el momento óptimo de la adición de los copigmentos sea distinto en función de la concentración de compuestos fenólicos en el momento de dicha adición.

Para la interacción técnicas de vinificación con microoxigenación (interacción $\mathrm{BC})$, los parámetros más importantes son el porcentaje del color que corresponde a la copigmentación, a los antocianos libres y a los polimerizados, junto con el índice de DMACH. La mayor disolución de compuestos fenólicos en el vino, causada por la maceración de las partes solidas con el mosto, debería tener un mayor efecto de la microoxigenación, ya que se encuentran en el vino una mayor concentración de compuestos que intervienen en las reacciones en las que participa el oxígeno.

Cano-López et al. (2008) observan como aquellos vinos con una mayor concentración fenólica presentan una mayor relación de pigmentos poliméricos, que incrementa la intensidad colorante de los vinos. Además, destacan como los vinos con menores concentraciones fenólicos son menos afectados por la microooxigenación, pudiendo llegar a sufrir una macrooxigenación, con oxidación de sus polifenoles e incremento del grado de polimerización de sus taninos. Los elevados F-ratio que presentan los parámetros mencionados anteriormente parecen indicar lo citado en la 
reflexión anterior, siendo éstos los que muestran un mayor efecto sobre la interacción técnicas de vinificación con microoxigenación.

\subsubsection{2. $\quad$ EFECTO DE LA ADICIÓN DE COPIGMENTOS}

En la tabla 6.8 se recogen los valores medios de los parámetros polifenólicos estudiados, en función de la adición de los distintos copigmentos. El tratamiento estadístico se ha realizando considerando conjuntamente todos los vinos, independientemente de la técnica de vinificación utilizada, del momento de adición de los copigmentos o de haberse realizado o no microoxigenación, valorando así exclusivamente el efecto de la adición de copigmentos en los vinos de Tempranillo.

El análisis de la varianza muestra como algunos de los parámetros, concretamente la intensidad colorante, el tono, los antocianos totales decolorables, el índice de DMACH, el índice de PVPP, la concentración de taninos y los antocianos polimerizados muestras diferencias significativas con respecto a los diferentes copigmentos utilizados. Por el contrario, otros parámetros como los antocianos copigmentados, los antocianos libres, el índice de Folin o el índice de gelatina, que tenían un marcado efecto diferenciador en los vinos después de la fermentación maloláctica, no manifiestan ese efecto a los seis meses, indicando que la adición de los copigmentos presenta solo un efecto momentáneo sobre estos parámetros.

Para el parámetro intensidad colorante los datos muestran como a los seis meses es el copigmento rutina el que presenta mayores diferencias con respecto a los otros copigmentos y al vino testigo. Los valores más bajos aparecen en el testigo y en los vinos adicionados de proantocianidinas, a diferencia de lo observado después de la maloláctica, momento en el cual las proantocianidinas contribuyeron al color de los vinos, en oposición a la escasa aportación al color de estos compuestos encontrada por otros investigadores (Bautista-Ortín et al., 2005; Pérez-Lamela et al., 2007). Es de destacar el efecto de los copigmentos tánicos sobre el tono, siendo las dos proantocianidinas, tanto de hollejo como de pepita, las que mayor tono mantienen al cabo de seis meses. La adición de ácido cafeico da lugar a los valores más bajos del tono, mostrando un efecto protector importante sobre la oxidación de los polifenoles.

En cuanto al comportamiento de los antocianos totales decolorables, se observa como los vinos adicionados con catequina, proantocianidina de hollejo y de pepita, presentan las mayores concentraciones. Por el contrario los copigmentos ácido cafeico y rutina muestran los valores más bajos para los antocianos decolorables. Hay que destacar que la rutina contribuyó a incrementar la concentración de antocianos decolorables después de la fermentación, pero dio lugar a un descenso significativo en los seis meses de conservación, que no se manifestó en el color, ya que son los vinos tratados con este copigmento los que más color presentan. Esta situación se justifica por el incremento observado en los antocianos polimerizados, que son mucho más estables y por tanto menos decolorables, por lo que no entrarían en su totalidad a formar parte de los antocianos valorados mediante el método de los antocianos totales decolorables con sulfuroso. 


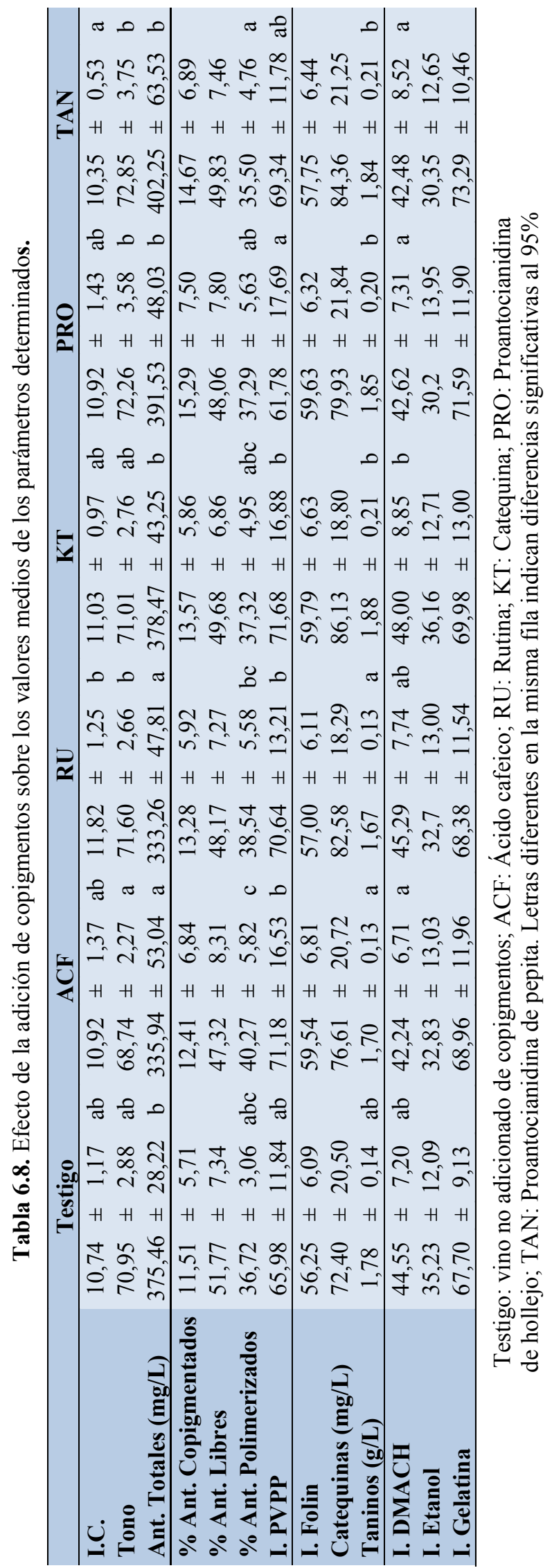


En el comportamiento del porcentaje del color debido a los antocianos copigmentados observamos un cambio importante durante estos meses de conservación, ya que inicialmente la adición de copigmentos favoreció la formación de estos complejos, pero en este momento se ha producido un descenso y no hay diferencias significativas con los vinos testigo. Cabría destacar que el porcentaje del color debido a los antocianos libres se sitúa en torno al 50\%, similar al observado inicialmente, y que ha sido el porcentaje de color debido a los antocianos polimerizados en el que se ha incrementado durante estos seis meses, siendo los copigmentos acido cafeico y rutina los que presentan los mayores porcentajes de polimerización de sus antocianos.

Los copigmentos de carácter tánico parecen manifestar un efecto protector sobre los antocianos, ya que el descenso de su concentración es menor. Los vinos adicionados con catequina y proantocianidinas muestran también los valores más altos para la concentración de taninos y más bajos para el índice de DMACH, lo que nos indica que en estos vinos es donde mejor se han mantenido los taninos y donde más polimerizados se encuentran, tal como ya observamos en los vinos después de la maloláctica.

El uso de tanino enológico procedente de la uva se considera un método interesante para mantener el color del vino, ya que reacciona con los antocianos mediante reacciones de polimerización, contribuyendo a su estabilidad (Crespy, 2003a, b; Crespy y Urban, 2002; Bautista-Ortín et al., 2007). Todavía no es muy conocido el mecanismo de estabilización de estas uniones en el tiempo, aunque parece probable que la estabilidad se puede alterar, rompiéndose estas uniones, y volviendo los compuestos iniciales a su forma libre. Cheynier et al. (2006) postulan que las moléculas de antocianos unidas mediante el acetaldehído también pueden desestabilizarse, debido a la rotura de los enlaces etílicos (Escribano-Bailón et al., 2001). Los compuestos resultantes de esta rotura pueden reaccionar con otros compuestos presentes en el medio, dano lugar a la formación de piranoantocianos, compuestos formados por antocianos monómeros y compuestos con doble enlace polarizado, como los ácidos pirúvico, cafeico, y cumárico, compuestos derivados de acetaldehído, derivados de vinilflavanoles, etc. Estos compuestos son estables frente a la decoloración por sulfuroso y el cambio de $\mathrm{pH}$, son también difícilmente precipitables, y modifican el color hacia tonos anaranjados (Atanasova et al., 2002a; Schwarz et al, 2003).

\subsubsection{EFECTO DE LAS TÉCNICAS DE VINIFICACIÓN}

En la tabla 6.9 se recogen los valores medios de los parámetros analizados en los vinos, considerando conjuntamente los distintos vinos elaborados según que la vinificación se realice de forma tradicional, con maceración prefermentativa en frío a 6$8^{\circ} \mathrm{C}$ o bien con una maceración prefermentativa usando nieve carbónica.

La maceración prefermentativa en frío muestra diferencias estadísticamente significativa para los parámetros relacionados con el color de los vinos (tono, antocianos totales decolorables, y para la fracción del color que corresponde a los antocianos copigmentados, y polimerizados), además de para el índice de Folin, y los índices de DMACH y de etanol. Esto nos indica que el prolongado tiempo de contacto entre hollejos y mosto durante la fase prefermentativa influye decisivamente en la extracción de los compuestos responsables del color en los vinos, favoreciéndose la 
disolución de componentes de bajo peso molecular en ausencia de etanol, tal como se observó después de la fermentación maloláctica, y favoreciendo también su conservación en el vino.

Tabla 6.9. Efecto de las técnicas de vinificación sobre los valores medios de los parámetros determinados.

\begin{tabular}{|c|c|c|c|c|c|c|c|c|}
\hline & \multicolumn{3}{|c|}{ Tradicional } & \multicolumn{2}{|r|}{ Frio } & \multicolumn{3}{|c|}{ Nieve } \\
\hline I.C. & 11,53 & $\pm 1,25$ & & 11,40 & $\pm 1,05$ & 9,80 & $\pm 1,29$ & \\
\hline Tono & 70,69 & $\pm 2,40$ & $\mathrm{a}$ & 69,49 & $\pm 3,00$ & 73,60 & $\pm 2,85$ & $\mathrm{~b}$ \\
\hline Ant. Totales (mg/L) & 344,47 & $\pm 33,00$ & $\mathrm{a}$ & 368,39 & $\pm 64,69 \mathrm{~b}$ & b 393,96 & $\pm 55,51$ & $\mathrm{c}$ \\
\hline \% Ant. Copig & 9,24 & $\pm 4,24$ & $\mathrm{a}$ & 12,73 & $\pm 6,19 \quad b$ & b 18,69 & $\pm 5,18$ & $\mathrm{c}$ \\
\hline$\% \mathrm{Al}$ & 52,97 & $\pm 9,22$ & $\mathrm{~b}$ & 48,12 & $\pm 6,78$ & 45,61 & $\pm \quad 3,47$ & $\mathrm{a}$ \\
\hline$\%$ An & 38,20 & $\pm 5,81$ & $\mathrm{~b}$ & 39,15 & $\pm 5,71$ & 35,70 & $\pm \quad 3,70$ & $\mathrm{a}$ \\
\hline I. PVPP & 66,27 & $\pm 12,44$ & & 71,67 & $\pm 12,93$ & 68,03 & $\pm 19,27$ & \\
\hline I. Fol & 56,73 & $\pm 5,10$ & $\mathrm{a}$ & 60,18 & $\pm 7,16 \quad b$ & 58,64 & $\pm 6,57$ & $a b$ \\
\hline Cate & 77,75 & $\pm 20,14$ & & 80,77 & $\pm 19,32$ & 84,64 & $\pm 21,27$ & \\
\hline Tanino & 1,76 & $\pm 0,13$ & & 1,83 & $\pm 0,24$ & 1,77 & $\pm \quad 0,19$ & \\
\hline I. DMA & 46,57 & $\pm 4,17$ & $\mathrm{~b}$ & 44,79 & $\pm 7,31$ & b 41,14 & $\pm 10,30$ & $\mathrm{a}$ \\
\hline I. Eta & 32,89 & $\pm 13,26$ & & 36,35 & $\pm 12,31 \mathrm{~b}$ & 28,72 & $\pm 12,38$ & $\mathrm{a}$ \\
\hline I. Gelatina & 70,50 & $\pm 12,14$ & & 69,00 & $\pm 14,10$ & 71,07 & $\pm \quad 7,48$ & \\
\hline
\end{tabular}

Tradicional: elaboración sin maceración en frío previamente a la fermentación; Frío:

aplicación de bajas temperaturas de forma prefermentativa; Nieve: uso de nieve carbónica prefermentativamente. Letras diferentes en la misma fila indican diferencias significativas al 95\%.

Los valores más elevados para los parámetros antocianos totales decolorables y porcentaje del color debido a los antocianos copigmentados, ponen de manifiesto la acción positiva de la maceración a bajas temperaturas previa a la fermentación tanto en la extracción de estos compuestos (Gil-Muñoz et al., 2009; Koyama et al., 2007; Gordillo et al., 2010), como en el incremento de las reacciones de copigmentación (Álvarez et al., 2008; Boulton, 2001), siendo estos efectos, todavía, mas importantes cuando la maceración se realiza con el uso de nieve carbónica. Seguramente el efecto de desestructuración celular causado por la nieve carbónica es el responsable de una mayor difusión de antocianos hacia el vino y por lo tanto de una mayor probabilidad de que estos participen en las reacciones de copigmentación (Heredia et al., 2010).

Además de los mencionado en el párrafo anterior, algunos autores (GómezMíguez et al., 2007) estudiando el efecto de la maceración prefermentativa observan como esta técnica incrementa también la extracción de ácido cafeico y ácido $p$ hidroxibenzoico, pudiendo ser este incremento una de las causas de la mayor fracción del color debida a la copigmentación que se observa en estos vinos.

En cuanto al tono, que indica la contribución del amarillo al color de los vinos, presenta un comportamiento contrario al mostrado para la IC, siendo los vinos macerados con nieve carbónica los que presentan los mayores valores de este parámetro, tanto ahora como después de la fermentación, lo que podría indicar una pequeña oxidación ocasionada por la manipulación en presencia de nieve carbónica. 
El índice de DMACH muestra como el efecto de desestructuración celular causado por la congelación de los líquidos intracelulares por efecto de la nieve carbónica influye en el grado de polimerización de los taninos al cabo del tiempo. Posiblemente la presencia de estos compuestos desde las primeras fases de la maceración ha permitido una polimerización más rápida, alcanzándose mayor grado de polimerización con respecto a la maceración en frío y a los vinos elaborados de forma tradicional. Busse-Valverde et al. (2010) observan como la aplicación de nieve carbónica incrementa el grado de polimerización de los taninos en vinos de Monastrell, aunque no observa el mismo comportamiento en vinos de Shiraz y Cabernet Sauvignon, indicando la importancia del factor variedad en el efecto de esta técnica.

Además de lo observado, el índice de etanol, que mide las uniones entre taninos y polisacáridos, muestra a los vinos macerados con nieve carbónica con los valores más bajos de estas uniones, comportamiento opuesto al observado después de la fermentación. Este comportamiento podría significar que a lo largo de la conservación, en estos vinos predominan las polimerizaciones entre taninos en detrimento de las uniones con polisacáridos.

Por último es importante destacar que son los vinos elaborados de forma tradicional los que presentan el mayor porcentaje del color debido a los antocianos libres, tal como se observo después de la fermentación maloláctica. Esto pone de manifiesto que las técnicas prefermentativas contribuyen a proteger a los antocianos, protegiéndolos de su oxidación y de su precipitación en el medio.

\subsubsection{EFECTO DE LA MICROOXIGENACIÓN}

En la tabla 6.10 se recogen los valores medios de los parámetros polifenólicos analizados, considerando conjuntamente todos los vinos que han sido microoxigenados, frente a aquellos a los que no se les ha realizado adición de acetaldehído.

En la tabla mostrada se observa que existen diferencias estadísticamente significativas para la mayoría de los parámetros considerados, siendo únicamente la fracción del color que corresponde a los antocianos copigmentados el parámetro que no presenta estas diferencias. Estos resultados demuestran la influencia de esta técnica sobre la composición fenólica de los vinos estudiados, actuando tanto sobre la concentración de algunos compuestos como sobre el estado de estos compuestos en el medio (Cejudo-Bastante et al., 2010; 2011).

La adición controlada de acetaldehído permite obtener vinos con una mayor concentración de taninos y de polifenoles, una mayor IC y un menor tono, siempre con diferencias estadísticamente significativas. Estos resultados demuestran los efectos positivos de esta técnica en cuanto a la protección del color en los vinos, efecto observado también por numerosos autores (Gómez-Plaza y Cano-López, 2011; CanoLópez et al., 2006, 2007; González-del Pozo et al., 2010). Por el contrario algunos autores observan efectos perjudiciales para esta técnica, en el caso de su aplicación incorrecta, debiéndose considerar parámetros como la composición fenólica de los vinos, la dosis de oxígeno incorporada o el momento de la aplicación de la microoxigenación (de Beer et al., 2007; Cano-López et al., 2010). 
Tabla 6.10. Efecto de la microoxigenación sobre los valores medios de los parámetros determinados.

\begin{tabular}{lcccccccc}
\hline & \multicolumn{3}{c}{ No MOX } & \multicolumn{4}{c}{ MOX } \\
\hline I.C. & 10,43 & \pm & 1,27 & a & 11,40 & \pm & 1,41 & b \\
Tono & 72,27 & \pm & 3,18 & b & 70,25 & \pm & 2,99 & a \\
Ant. Totales (mg/L) & 387,63 & \pm & 55,74 & b & 350,25 & \pm & 50,40 & a \\
\hline \% Ant. Copigmentados & 14,04 & \pm & 8,21 & & 13,21 & \pm & 4,36 & \\
\% Ant. Libres & 51,46 & \pm & 9,10 & b & 46,34 & \pm & 4,19 & a \\
\% Ant. Polimerizados & 34,93 & \pm & 4,15 & a & 40,45 & \pm & 4,95 & b \\
I. PVPP & 61,77 & $\pm 15,07$ & a & 75,54 & \pm & 12,07 & b \\
\hline I. Folin & 53,23 & \pm & 2,74 & a & 63,80 & \pm & 4,41 & b \\
Catequinas (mg/L) & 88,02 & $\pm 17,97$ & b & 74,09 & \pm & 20,23 & a \\
Taninos (g/L) & 1,73 & \pm & 0,16 & a & 1,85 & \pm & 0,2 & b \\
\hline I. DMACH & 49,22 & \pm & 4,54 & b & 39,11 & \pm & 7,41 & a \\
I. Etanol & 25,29 & \pm & 9,11 & a & 37,50 & \pm & 10,94 & b \\
I. Gelatina & 62,24 & $\pm 10,64$ & a & 78,14 & \pm & 5,10 & b \\
\hline
\end{tabular}

No MOX: vinos no adicionados de acetaldehído; MOX: vinos adicionados de acetaldehído. Letras diferentes en la misma fila indican diferencias significativas al 95\%

Es de destacar el efecto de esta técnica sobre la concentración de antocianos totales decolorables, comportamiento contrario al observado para el índice de Folin o la IC, destacando una vez más como no únicamente la concentración de estos compuestos determina el color del vino. Siendo, por lo tanto, más importante tanto el estado, como la presencia de los antocianos en uniones con los taninos e incluso formando parte de pigmentos poliméricos, tal como se observa en el incremento de los antocianos polimerizados, tanto entre sí como con los taninos, ocasionado por la microoxigenación.

Las reacciones de antocianos con taninos o con otras moléculas dan lugar a una gran variedad de estructuras, que presentan un amplio rango de pesos moleculares, y que incluyen tanto compuestos coloreados como compuestos incoloros. La conversión de los antocianos (75-95\% no coloreados; $5-25 \%$ coloreados) en asociaciones taninoantociano pueden no tener efecto sobre el color de los vinos, pero la formación de piranoantocianos $(100 \%$ coloreados $)$ y de moléculas unidas por acetaldehído $(50 \%$ coloreadas) cambian el color, pasando de tonos rojos a tonos anaranjados o morados, incrementando, además, la intensidad colorante y la resistencia, tanto a los cambios de pH, como al sulfuroso (Cheynier et al., 2006).

Un comportamiento similar al de los antocianos totales aparece para la concentración de catequinas. Probablemente la inclusión de estos monómeros de flavanoles en moléculas de proantocianidinas o taninos haya causado la disminución de la concentración observada (Tao et al., 2007). Este comportamiento podría verse reforzado con la mayor concentración de taninos que presentan los vinos microoxigenados con respecto a los vinos no adicionados.

En cuanto a las reacciones entre los compuestos fenólicos, cabe destacar como aquellos vinos adicionados de acetaldehído muestran mayores grados de polimerización de taninos, medidos mediante el índice de DMACH. Seguramente la presencia de acetaldehído en el vino haya favoreciendo las reacciones de polimerización cruzada 
entre taninos, reacciones que se producen en presencia de oxígeno y que presentan una cinética más rápida que la polimerización lineal. Este tipo de reacciones se caracteriza por un incremento inicial de la astringencia, que da lugar a un importante descenso al cabo del tiempo, al disminuir la reactividad de los radicales $\mathrm{OH}$ que reaccionan con las proteínas de la saliva.

Este efecto de diminución de la astringencia no ha sido observado aún en este momento del proceso de conservación ya que el índice de gelatina, que mide la astringencia de los vinos, aún es superior en los vinos microoxigenados. Posiblemente todavía no se han alcanzado en los vinos el tamaño de aquellos polímeros que produzcan esta disminución de la astringencia mencionada.

Para finalizar es necesario mencionar el comportamiento del índice de PVPP. Este índice mide las uniones mediadas por el acetaldehído entre los antocianos y los taninos, siendo por lo tanto un verdadero marcador del efecto de la microoxigenación. De nuevo aparecen diferencias estadísticamente significativas para los vinos microoxigenados con respecto a aquellos vinos que no han recibido la adición de oxígeno, mostrando el efecto protector del color que presenta este tipo de uniones. Estos resultados se ven reforzados con los resultados mostrados para el porcentaje del color que corresponde a los antocianos libres, en el que aparecen diferencias significativas para los vinos no microoxigenados, y para los antocianos polimerizados, que son superiores en los vinos adicionados de oxígeno.

\subsubsection{EFECTO DEL MOMENTO DE ADICIÓN DE LOS COPIGMENTOS}

En la tabla 6.11 se recogen los valores medios de los parámetros polifenólicos analizados en los vinos considerando conjuntamente a todos aquellos que han sido adicionados de copigmentos previamente o posteriormente a la fermentación.

Ninguno de los parámetros polifenólicos considerados presenta diferencias estadísticamente significativas entre la adición prefermentativa de copigmentos y la adición posteriormente a la fermentación de los vinos. Únicamente para el índice de Folin se han encontrado estas diferencias, siendo los vinos adicionados postfermentativamente los que presentan los mayores valores.

En este momento del proceso de conservación parece como si la adición de los copigmentos hubiera sido igual de efectiva, independientemente del momento en el que se incorporaron al vino. En algunas ocasiones la incorporación de determinados productos al vino en la fase fermentativa parece ser la técnica más adecuada debido a que estos productos pueden conseguir una mejor integración en el medio pasando a formar parte de la matriz líquida. En este caso no se observa este razonamiento concluyendo que para los parámetros fenólicos analizados no existe un efecto estadísticamente significativo entre la adición de copigmentos antes o después de la fermentación de los vinos. 
Tabla 6.11. Efecto del momento de adición de copigmentos sobre los valores medios de los parámetros determinados.

\begin{tabular}{lccc}
\hline & \multicolumn{1}{c}{ PRE } & POST \\
\hline I.C. & $10,75 \pm 1,73$ & $11,11 \pm 1,10$ \\
Tono & $71,84 \pm 3,51$ & $70,74 \pm 2,99$ \\
Ant. Totales (mg/L) & $369,70 \pm 73,84$ & $366,88 \pm 37,27$ \\
\hline \% Ant. Copigmentados & $14,32 \pm 6,51$ & $13,37 \pm 6,70$ \\
\% Ant. Libres & $48,00 \pm 7,70$ & $49,23 \pm 7,29$ \\
\% Ant. Polimerizados & $38,16 \pm 5,96$ & $37,41 \pm 5,03$ \\
I. PVPP & $69,62 \pm 19,00$ & $68,22 \pm 11,27$ \\
\hline I. Folin & $53,23 \pm 2,74$ & a & $63,80 \pm 4,41$ \\
Catequinas (mg/L) & $81,61 \pm 20,27$ & $82,23 \pm 20,23$ \\
Taninos (g/L) & $1,80 \pm 0,22$ & $1,78 \pm 0,17$ \\
\hline I. DMACH & $43,45 \pm 8,20$ & $44,80 \pm 7,91$ & \pm 10 \\
I. Etanol & $30,64 \pm 13,11$ & $28,15 \pm 12,95$ \\
I. Gelatina & $70,55 \pm 12,05$ & $70,33 \pm 11,53$ \\
\hline
\end{tabular}

PRE: adición de copigmentos previamente al inicio de la fermentación alcohólica; POST: adición de copigmentos en el embotellado. Letras diferentes en la misma fila indican diferencias estadísticamente significativas al 95\%

\subsubsection{CORRELACIÓN ENTRE LOS PARÁMETROS POLIFENÓLICOS DE LOS VINOS Y LOS FACTORES CONSIDERADOS}

Para realizar el ACP en los vinos conservados durante seis meses, se ha realizado inicialmente la transformación lineal mediante la matriz de covarianzas o matriz de correlaciones.

Para la concentración de antocianos totales observamos (tabla 6.12) como existe una correlación negativa con el parámetro IC, además de una positiva con el tono. Este comportamiento nos indica una vez más como el color de los vinos no es debido únicamente a la concentración de estos compuestos, sino más concretamente al estado que presenten los antocianos en los vinos. Aunque a mayor concentración de antocianos en el vino mayor posibilidad de que estos, en su forma libre, se oxiden favoreciendo la tonalidad amarilla de los vinos.

Es interesante destacar las correlaciones positivas del índice de Folin con el índice de etanol y el de gelatina y la negativa del índice de Folin con el índice de $\mathrm{DMACH}$, que parece indicar que en estos vinos cuando se incrementa la concentración total de polifenoles se ven favorecidas las uniones entre taninos y polisacáridos, y también de taninos entre si, uniones que pueden favorecer inicialmente el aumento de la astringencia. Este incremento del grado de polimerización de los taninos entre sí, que valora de forma inversa el índice de DMACH, puede ser la causa del aumento de la astringencia al mismo tiempo que se incrementa el tamaño molecular de los taninos (Zamora, 2003). 


\begin{tabular}{|c|c|c|c|c|c|c|c|c|c|c|c|c|c|}
\hline 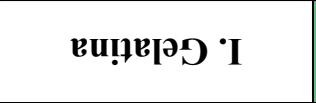 & $\begin{array}{l}0 \\
0 \\
0\end{array}$ & $\begin{array}{c}\hat{n} \\
0\end{array}$ & $\begin{array}{l}n \\
0 \\
0 \\
1\end{array}$ & $\begin{array}{l}2 \\
0 \\
0 \\
1\end{array}$ & 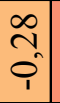 & $\begin{array}{l}\hat{\sigma}_{0} \\
\text { of }\end{array}$ & $\begin{array}{l}\infty \\
n \\
0 \\
0\end{array}$ & 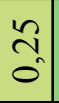 & $\begin{array}{c}\tilde{2} \\
\tilde{0} \\
0\end{array}$ & $\begin{array}{l}0 \\
0 \\
0\end{array}$ & $\begin{array}{l}0 \\
+ \\
0 \\
1\end{array}$ & $\begin{array}{c}\dot{m} \\
0 \\
0\end{array}$ & \\
\hline •u!!lod luV \% & 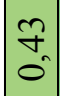 & $\begin{array}{l}\widehat{b} \\
0\end{array}$ & $\begin{array}{l}2 \\
\tilde{n} \\
0 \\
1\end{array}$ & $\begin{array}{l}n \\
0 \\
0 \\
1\end{array}$ & 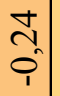 & $\frac{ \pm}{0_{0}^{\prime}}$ & $\begin{array}{l}0 \\
n \\
0\end{array}$ & $\begin{array}{l}f_{1} \\
\dot{f}^{\prime}\end{array}$ & $\begin{array}{l}\tilde{O} \\
0 \\
0\end{array}$ & 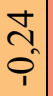 & $\begin{array}{l}n \\
n \\
0 \\
i\end{array}$ & & 峁 \\
\hline 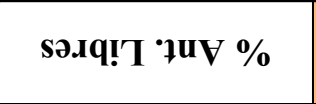 & $\begin{array}{l}0 \\
1 \\
1 \\
0 \\
1\end{array}$ & $\begin{array}{l}0 \\
0 \\
0 \\
1\end{array}$ & $\begin{array}{l}\tilde{\delta} \\
0 \\
0\end{array}$ & $\begin{array}{l}0 \\
0\end{array}$ & $\begin{array}{c}\hat{\lambda} \\
0\end{array}$ & $\frac{ \pm}{0}$ & $\begin{array}{l}0 \\
0 \\
0 \\
1\end{array}$ & $\begin{array}{l}\hat{n} \\
0 \\
1\end{array}$ & $\begin{array}{l}\text { ते } \\
\text { ? }\end{array}$ & $\begin{array}{l}\stackrel{?}{0} \\
\text { ?. }\end{array}$ & & $\begin{array}{l}n \\
n \\
0 \\
1\end{array}$ & $\begin{array}{l}\text { of } \\
\text { to } \\
\text { in }\end{array}$ \\
\hline uo̊!̣doつ ๆuV \% & $\begin{array}{l}n \\
0 \\
0 \\
1\end{array}$ & $\left.\begin{array}{l}n \\
n \\
0 \\
1\end{array}\right]$ & $\begin{array}{l}\stackrel{g}{f_{0}} \\
0_{0}\end{array}$ & $\begin{array}{l}\dot{n} \\
0 \\
0\end{array}$ & $\begin{array}{c}= \\
\overline{0} \\
1\end{array}$ & $\begin{array}{l}\text { t } \\
0 \\
0\end{array}$ & $\begin{array}{l}1 \\
\hat{1} \\
0 \\
1\end{array}$ & $\begin{array}{l}\infty \\
0 \\
0 \\
1 \\
1\end{array}$ & $\begin{array}{c}\tilde{} \\
\tilde{0}\end{array}$ & & $\begin{array}{l}? \\
0 \\
0\end{array}$ & 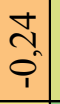 & $\begin{array}{l}0 \\
0 \\
0\end{array}$ \\
\hline$(T / \mathbf{8})$ sou!ur $_{\mathbf{L}}$ & $\begin{array}{c}\tilde{f} \\
\dot{0}\end{array}$ & $\begin{array}{l}2 \\
\dot{0} \\
0^{\prime}\end{array}$ & $\begin{array}{l}\tilde{o} \\
0\end{array}$ & $\begin{array}{c}0 \\
m \\
0 \\
0\end{array}$ & $\begin{array}{l}\infty \\
0 \\
0 \\
1\end{array}$ & $\begin{array}{l}\text { o } \\
\text { ô } \\
\text { in }\end{array}$ & $\begin{array}{c}\vec{\vdots} \\
\vdots \\
0\end{array}$ & $\begin{array}{c}\text { i } \\
0 \\
0\end{array}$ & & $\begin{array}{l}\tilde{N} \\
\tilde{0}\end{array}$ & $\begin{array}{l}0 \\
\text { N } \\
0 \\
1\end{array}$ & $\begin{array}{c}\tilde{O} \\
0 \\
0\end{array}$ & $\begin{array}{l}\tilde{n} \\
\tilde{n}^{2}\end{array}$ \\
\hline $\operatorname{dd} \Lambda d^{*} I$ & $\begin{array}{l}n \\
\tilde{o} \\
0\end{array}$ & $\begin{array}{c}n \\
0 \\
0\end{array} \mid$ & 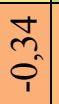 & 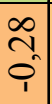 & $\begin{array}{l}\tilde{1} \\
\hat{1} \\
1\end{array}$ & $\begin{array}{l}\text { m } \\
\text { ?. } \\
\hat{1}\end{array}$ & $\vec{\sigma}_{0}$ & & 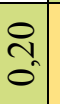 & $\begin{array}{l}\infty \\
0 \\
0 \\
0 \\
1\end{array}$ & $\begin{array}{l}\tilde{n} \\
\hat{1} \\
1\end{array}$ & $\begin{array}{l}q_{1} \\
0 \\
0\end{array}$ & 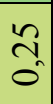 \\
\hline IOUвд • I & $\left|\begin{array}{l}\infty \\
0 \\
0 \\
0\end{array}\right|$ & $\begin{array}{l}n \\
\tilde{\sigma}_{n} \\
n^{\prime}\end{array}$ & $\begin{array}{l}0 \\
+ \\
1 \\
1 \\
1\end{array}$ & $\begin{array}{l}0 \\
m \\
i \\
1\end{array}$ & $\begin{array}{l}\stackrel{1}{N} \\
0 \\
1\end{array}$ & $\begin{array}{l}\tilde{2} \\
\text { ? } \\
\text { ? }\end{array}$ & & $\begin{array}{l}\overrightarrow{\sigma_{0}} \\
\tilde{o}^{\prime}\end{array}$ & $\begin{array}{l}\stackrel{ \pm}{\sim} \\
0 \\
0\end{array}$ & 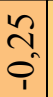 & $\begin{array}{l}0 \\
0 \\
0 \\
1\end{array}$ & $\begin{array}{l}8 \\
n \\
0\end{array}$ & $\begin{array}{l}\infty \\
n \\
n \\
0\end{array}$ \\
\hline HOVWA 'I & $\begin{array}{l}0 \\
0 \\
0 \\
1\end{array}$ & $\begin{array}{l}0 \\
0 \\
0 \\
1\end{array}$ & $\begin{array}{l}\hat{0} \\
0^{\prime}\end{array}$ & $\overline{\sigma^{\prime}}$ & 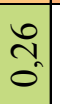 & & $\begin{array}{l}2 \\
\tilde{2} \\
\hat{i}\end{array}$ & $\begin{array}{l}m \\
\tilde{m} \\
\hat{\rho}\end{array}$ & $\begin{array}{l}\text { ôt } \\
\text { p. }\end{array}$ & $\begin{array}{l} \pm \\
0 \\
0 \\
1\end{array}$ & $\begin{array}{l} \pm \\
0^{\prime}\end{array}$ & $\begin{array}{c} \pm \\
\\
\end{array}$ & $\begin{array}{l}\text { fे } \\
\text { of }\end{array}$ \\
\hline (T/o̊u) seu!nbəłв & 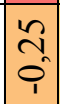 & $\begin{array}{l}\overline{1} \\
\bar{i}\end{array}$ & $\begin{array}{l} \pm \\
0^{\prime}\end{array}$ & $\begin{array}{l}8 \\
8 \\
0\end{array}$ & & $\begin{array}{l}\text { ṽ } \\
\text { ป̂. }\end{array}$ & $\begin{array}{l}\stackrel{1}{\sim} \\
0 \\
i\end{array}$ & $\begin{array}{l}\tilde{N} \\
\hat{1} \\
1\end{array}$ & $\begin{array}{l}\infty \\
0 \\
0 \\
0\end{array}$ & $\begin{array}{l}\bar{Z} \\
\overline{0} \\
\end{array}$ & $\begin{array}{c}\hat{v}_{0} \\
\sigma^{\prime}\end{array}$ & $\begin{array}{l}\text { ป̀ } \\
0 \\
1\end{array}$ & 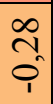 \\
\hline 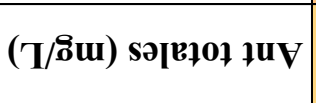 & $\begin{array}{l}n \\
0 \\
i\end{array}$ & \begin{tabular}{|l|}
$n$ \\
0 \\
0 \\
1
\end{tabular} & $\stackrel{N}{\tilde{0}}$ & & $\begin{array}{l}8 \\
0 \\
0\end{array}$ & $\overline{0}$ & $\begin{array}{l}0 \\
\tilde{2} \\
\hat{1}\end{array}$ & 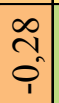 & $\begin{array}{c}0 \\
\text { n. } \\
0\end{array}$ & $\begin{array}{c}\stackrel{+}{n} \\
0 \\
0\end{array}$ & $\begin{array}{l}\tilde{0} \\
0\end{array}$ & $\begin{array}{l}n \\
0 \\
0 \\
1\end{array}$ & $\begin{array}{l}20 \\
0 \\
0\end{array}$ \\
\hline OUOL & $\begin{array}{l}\stackrel{1}{\sim} \\
\stackrel{1}{i}\end{array}$ & $\begin{array}{l}n \\
n \\
0 \\
1\end{array}$ & & $\frac{N}{\sigma^{\prime}}$ & $\underset{0^{\prime}}{ \pm}$ & $\hat{\delta}$ & $\begin{array}{l}0 \\
\dot{1} \\
0 \\
1\end{array}$ & $\begin{array}{c}\tilde{m} \\
m \\
\hat{1}\end{array}$ & $\begin{array}{l}\tilde{O}^{\prime} \\
0\end{array}$ & $\begin{array}{l}\sigma_{\dot{t}} \\
\sigma_{0}\end{array}$ & $\begin{array}{l}\tilde{O} \\
0 \\
0\end{array}$ & $\begin{array}{c}0 \\
n \\
0 \\
1\end{array}$ & $\begin{array}{l}20 \\
0 \\
0\end{array}$ \\
\hline$\cdot 2 \cdot I$ & $\begin{array}{l}n \\
\tilde{m} \\
0\end{array}$ & & $\begin{array}{l}n \\
n \\
0 \\
1\end{array}$ & $\begin{array}{l}n \\
0 \\
0 \\
1\end{array}$ & $\begin{array}{c}= \\
\overline{0} \\
1\end{array}$ & $\begin{array}{l}\text { J } \\
0 \\
0\end{array}$ & $\stackrel{n}{\vartheta_{0}}$ & $\frac{n}{0}$ & $\begin{array}{l}2 \\
0_{0}^{\prime}\end{array}$ & $\begin{array}{l}n \\
n \\
0 \\
1\end{array}$ & $\begin{array}{l}0 \\
0 \\
0\end{array}$ & $\begin{array}{l}\hat{6} \\
0 \\
0\end{array}$ & הิ \\
\hline U!! & & $\begin{array}{l}n \\
\tilde{2} \\
0\end{array}$ & \begin{tabular}{l}
\multirow{2}{n}{} \\
$\hat{0}$ \\
1
\end{tabular} & $\begin{array}{l}n \\
0 \\
0 \\
1\end{array}$ & $\begin{array}{l}n \\
\\
0 \\
1\end{array}$ & $\begin{array}{l}8 \\
\text { : } \\
\text { in }\end{array}$ & $\begin{array}{l}\infty \\
0 \\
0 \\
0\end{array}$ & $\begin{array}{c}\hat{m} \\
0\end{array}$ & $\tilde{\sigma}_{0}$ & $\begin{array}{l}0 \\
0 \\
0 \\
1\end{array}$ & \begin{tabular}{l}
$\infty$ \\
\multirow{1}{1}{} \\
0
\end{tabular} & $\begin{array}{c}\tilde{f} \\
\tilde{0}\end{array}$ & $\frac{\circ}{0}$ \\
\hline & 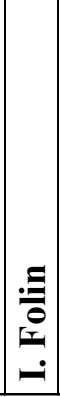 & ن & $\stackrel{\stackrel{\Xi}{0}}{\stackrel{\theta}{*}}$ & 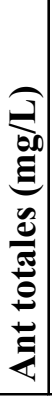 & 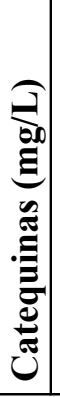 & لـ & 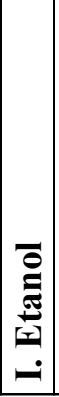 & $\mid \begin{array}{c}\hat{a} \\
\vec{a} \\
\vec{a} \\
\dot{a}\end{array}$ & 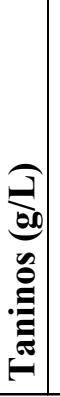 & 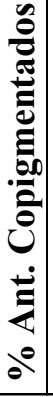 & 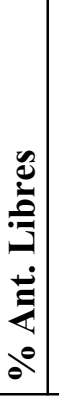 & 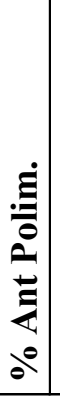 & تٍِّ \\
\hline
\end{tabular}


El porcentaje del color que corresponde a los antocianos copigmentados presenta correlaciones negativas tanto para la intensidad colorante como para el porcentaje del color que corresponde a los antocianos libres, por el contrario presenta una correlación positiva para la concentración de antocianos totales. La mayor concentración de antocianos en el medio puede facilitar las reacciones de copigmentación, en detrimento de las formas libres, que a su vez son las que mayor intensidad colorante presentan. Por otra parte parece que el efecto de desplazamiento de la longitud de onda máxima de las moléculas de copigmentación (efecto batocrómico) provoca una disminución de la absorbancia a $520 \mathrm{~nm}$, junto con una disminución en la intensidad colorante de los vinos. Además si estos compuestos están formando parte de complejos de copigmentación no se encuentran en forma libre en los vinos, justificándose la correlación negativa encontrada para estos parámetros.

Tabla 6.13. Autovalor, varianza explicada y acumulada para las componentes consideradas en el análisis

\begin{tabular}{cccc}
\hline Componente & Autovalor & \% Varianza & \% Acumulado \\
\hline $\mathbf{1}$ & 4,534 & 32,383 & 32,383 \\
$\mathbf{2}$ & 2,945 & 21,039 & 53,421 \\
$\mathbf{3}$ & 1,521 & 10,866 & 64,288 \\
$\mathbf{4}$ & 1,454 & 10,386 & 74,674 \\
$\mathbf{5}$ & 0,810 & 5,789 & 80,463 \\
$\mathbf{6}$ & 0,753 & 5,376 & 85,839 \\
$\mathbf{7}$ & 0,566 & 4,04 & 89,88 \\
$\mathbf{8}$ & 0,445 & 3,175 & 93,055 \\
$\mathbf{9}$ & 0,277 & 1,98 & 95,035 \\
$\mathbf{1 0}$ & 0,255 & 1,822 & 96,857 \\
$\mathbf{1 1}$ & 0,197 & 1,41 & 98,267 \\
$\mathbf{1 2}$ & 0,166 & 1,186 & 99,453 \\
$\mathbf{1 3}$ & 0,075 & 0,536 & 99,989 \\
$\mathbf{1 4}$ & 0,002 & 0,011 & 100 \\
\hline
\end{tabular}

También se observan algunas correlaciones importantes en las que se ven involucrados los antocianos polimerizados. Concretamente están correlacionados positivamente con la intensidad colorante, lo que demuestra que un incremento en la polimerización de estos compuestos da lugar a un color más intenso y seguramente más estable que para los antocianos libres. Además las correlaciones negativas con el tono, los antocianos totales y los antocianos libres demuestran en mayor medida el razonamiento sugerido.

En la tabla 6.13 aparece tanto el autovalor como el porcentaje de varianza acumulada por los sucesivos factores, observándose como son necesarios cuatro factores para que el autovalor descienda por debajo de la unidad. Además comprobamos como el porcentaje de varianza acumulada corresponde al 74.67\%.

Se han identificado cuatro patrones de comportamiento asociado, explicando entre ellos más del $70 \%$ de la variabilidad total observada en las variables originales, consiguiéndose con esto una reducción de las variables iniciales. 
En la tabla 6.14 aparecen los valores de los coeficientes de correlación de los parámetros polifenólicos de los vinos, para cada una de los cuatro componentes principales identificados.

Tabla 6.14 Tabla de pesos de los componentes

\begin{tabular}{lcccc}
\hline & Componente & Componente & Componente & Componente \\
& 1 & 2 & 3 & 4 \\
\hline I. Folin & 0,37 & $-0,23$ & $-0,14$ & $-0,20$ \\
I.C. & 0,32 & 0,24 & 0,29 & $-0,19$ \\
Tono & $-0,30$ & $-0,31$ & $-0,03$ & $-0,09$ \\
Ant totales (mg/L) & $-0,28$ & $-0,38$ & $-0,04$ & $-0,16$ \\
Catequinas (mg/L) & $-0,17$ & 0,13 & 0,15 & $-0,31$ \\
I. DMACH & $-0,24$ & 0,22 & 0,50 & 0,05 \\
I. Folin & $-0,01$ & $-0,16$ & 0,63 & $-0,34$ \\
I. Etanol & 0,37 & $-0,02$ & $-0,03$ & $-0,15$ \\
I. PVPP & 0,26 & $-0,04$ & $-0,16$ & 0,17 \\
Taninos (g/L) & 0,15 & $-0,36$ & 0,05 & $-0,38$ \\
\% Ant. Copigm. & $-0,13$ & $-0,46$ & 0,15 & 0,36 \\
\% Ant. Libres & $-0,16$ & 0,32 & $-0,33$ & $-0,51$ \\
\% Ant Polim. & 0,37 & 0,11 & 0,26 & 0,27 \\
I. Gelatina & 0,31 & $-0,32$ & 0,01 & $-0,16$ \\
\hline
\end{tabular}

El primer componente principal presenta coeficientes positivos para los parámetros IC, índice de Folin, índice de etanol, índice de PVPP, antocianos polimerizados e índice de gelatina, y coeficientes negativos para el tono y los antocianos totales decolorables. Este primer componente podría estar relacionado con aquellos vinos que muestran una importante concentración de compuestos fenólicos. Además, el resto de parámetros con asociación directa están relacionados con el estado de los compuestos fenolicos en el vino, bien relacionados con la astringencia o las uniones tanino-polisacárido, o bien con las uniones antociano-tanino o las polimerizaciones de los antocianos. A modo de resumen este primer componente podría corresponder a vinos en los que los compuestos fenólicos están formando parte de complejos que permiten una mejor estabilidad de los compuestos polifenoles en el tiempo.

El segundo componente únicamente presenta coeficientes positivos para el parámetro antocianos libres, por el contrario presenta coeficientes negativos importantes para los parámetros tono, antocianos totales decolorables, taninos, antocianos copigmentados y gelatina. Lo cual podría corresponder en su parte negativa a vinos con una adecuada concentración antociánica y tánica donde predominan las reacciones de copigmentación y donde los taninos todavía no están demasiado polimerizados, manteniendo en gran parte su astringencia.

Los coeficientes más relacionados con el tercer componente principal son el índice de DMACH, la intensidad colorante y el porcentaje del color debido a la polimerización. Este componente podría estar relacionado con vinos que presentan elevados grados de polimerización, tanto de antocianos como de taninos, ayudando 
estas polimerizaciones al mantenimiento del color de los vinos.

Por último el cuarto componente, relacionado de forma positiva con los antocianos copigmentados y polimerizados, podría ser interpretado como un marcador de estas reacciones. Además presenta asociación indirecta (coeficiente negativo) con la concentración de catequinas, la concentración de taninos y el porcentaje del color debido a los antocianos libres.

Esta situación difiere ligeramente de la observada en los vinos después de la fermentación maloláctica, en los cuales los componentes principales 1 y 2 estaban más decantados hacia específicas familias polifenólicas, relacionándose el componente $1 \mathrm{con}$ los antocianos en sus diversos estados, y el componente 2 con la concentración y el estado de los taninos. A los seis meses de conservación intervienen muchos más factores en la evolución de los vinos, por lo que el peso de los distintos compuestos en las funciones discriminantes es más aleatorio, cobrando más peso las reacciones de polimerización, como pone en evidencia el peso de los componentes 3 y 4.

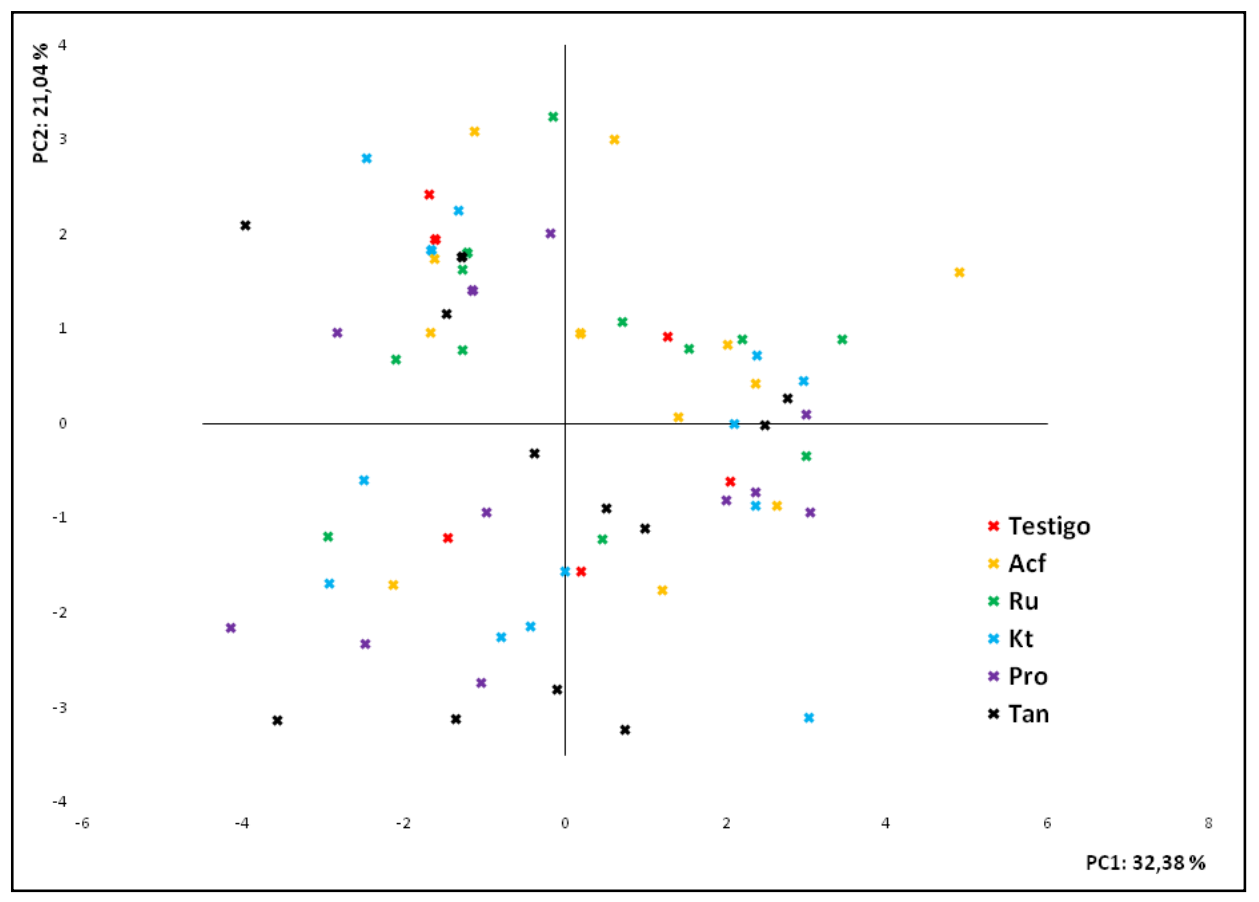

Gráfico 6.3. Primera componente frente a la segunda, en función de los copigmentos ensayados

Una vez comprobadas que variables están más correlacionadas con las componentes principales, se calcularon los coeficientes de las combinaciones lineales sobre las variables antiguas que definen las variables nuevas (loadings), para poder calcular a partir de ellos las nuevas coordenadas de los objetos en las componentes (scores). Obtenidos los coeficientes de las componentes principales se representó la primera componente frente a la segunda.

En el gráfico 6.3 aparecen los vinos elaborados en función de los distintos copigmentos ensayados, representándose la primera componente frente a la segunda, no se observa ninguna tendencia clara, ya que los vinos se sitúan aleatoriamente a lo largo 
de los ejes principales, tanto en su parte positiva como en la negativa. Destacando como no existe ningún copigmento que presente un comportamiento diferenciador frente a los vinos no adicionados o frente al resto de los copigmentos ensayados. Observándose un resultado similar cuando se representó la segunda componente frente a la tercera. Este comportamiento aún es más imprevisible que el observado en los vinos después de la fermentación maloláctica, poniendo de manifiesto que el efecto de la adición de copigmentos en el vino se va minimizando con el tiempo.

A continuación se muestran los vinos elaborados en función de la técnica de vinificación empleada, representándose la primera componente frente a la segunda (gráfico 6.4). La distribución de los vinos presenta diferencias según la técnica empleada en su elaboración. Los vinos elaborados con nieve carbónica se sitúan tanto en la zona negativa del primer, como del segundo eje principal, indicando la relación de estos vinos con los coeficientes negativos de estos dos componentes.

El primer componente en su parte negativa está relacionado con el tono y los antocianos totales, lo cual nos indica que estos vinos presentan una concentración antociánica importante pero que todavía existen muchos de ellos en su forma libre, posibilitando la oxidación de estos $\mathrm{y}$, por lo tanto, el incremento de la coloración amarilla de los vinos.

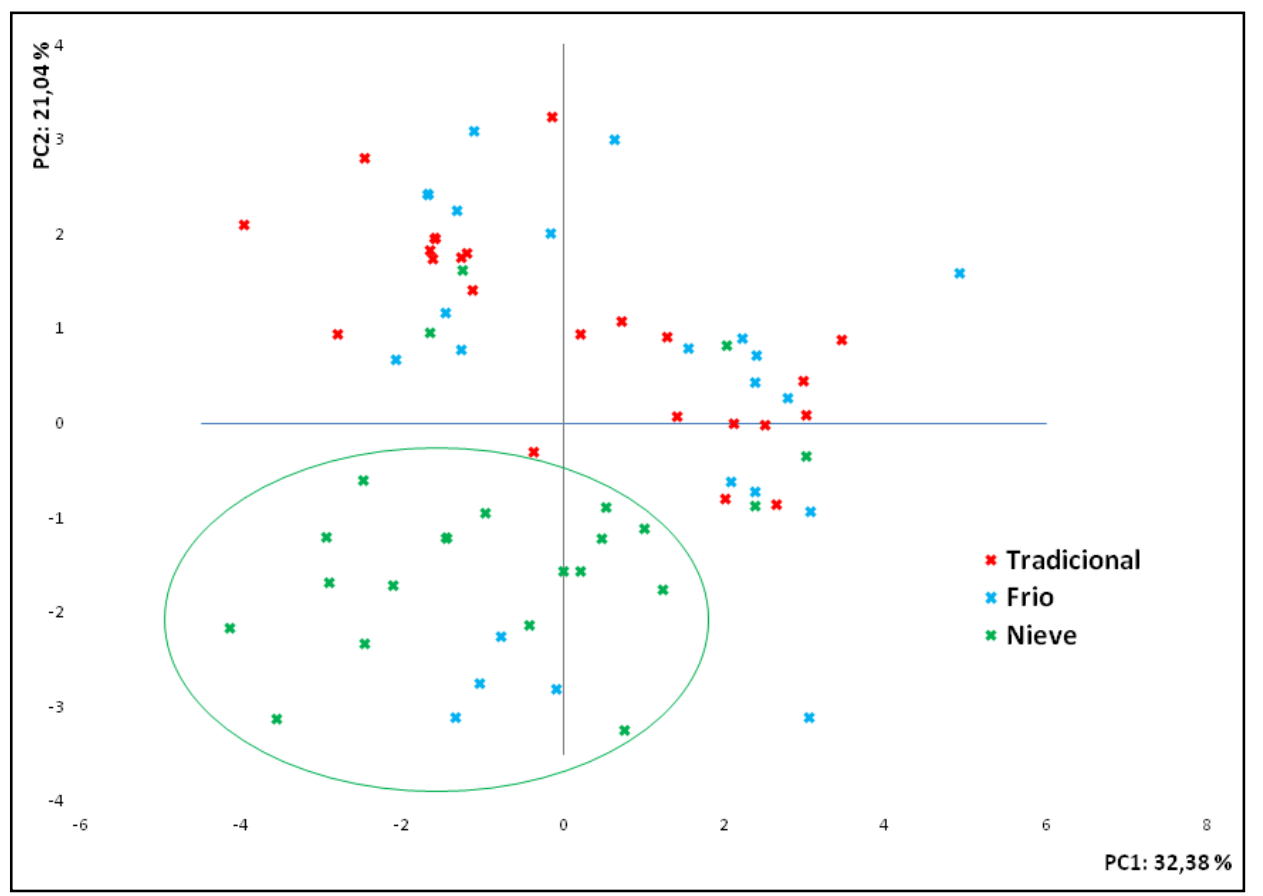

Gráfico 6.4. Primera componente frente a la segunda, en función de las técnicas de vinificación ensayadas.

Por otra parte el segundo componente, en su parte negativa corresponde a vinos que presentan una adecuada concentración antociánica y tánica donde predominan las reacciones de copigmentación y los taninos todavía no están demasiado polimerizados, manteniendo en gran parte su astringencia

Los vinos elaborados de forma tradicional o macerados prefermentativamente en 
frío presentan una dispersión mucho más importante que la observada después de la fermentación maloláctica, viéndose reducido su efecto con el tiempo de conservación.

En el gráfico 6.5 se han representado los vinos elaborados en función de la técnica de la microoxigenación. La adición controlada de acetaldehído separa perfectamente a lo largo del primer eje principal aquellos vinos adicionados, de aquellos no microoxigenados; situándose los vinos adicionados en la zona positiva del primer eje principal, altamente relacionado con parámetros polifenólicos que determinan algunas de las reacciones mediadas por el oxígeno, junto con parámetros relacionados con el color y la concentración total de polifenoles.

Podríamos concluir diciendo que en estos vinos, sometidos a la adición controlada de acetaldehído, los compuestos fenólicos están formando parte de complejos que permiten un incremento de la intensidad colorante (Cano-López et al., 2006, 2007, 2008, 2010; Wirth et al., 2010; Rayne et al., 2008), además de una mejor estabilidad de esta materia colorante en el tiempo (Gómez-Plaza y Cano-López, 2011; Cano-López et al., 2006, 2007; González-del Pozo et al., 2010), manteniendo, por tanto, una importante concentración fenólica (Gómez-Plaza y Cano-López, 2011; Gonzálezdel Pozo et al., 2010; Pérez-Magariño et al., 2007).

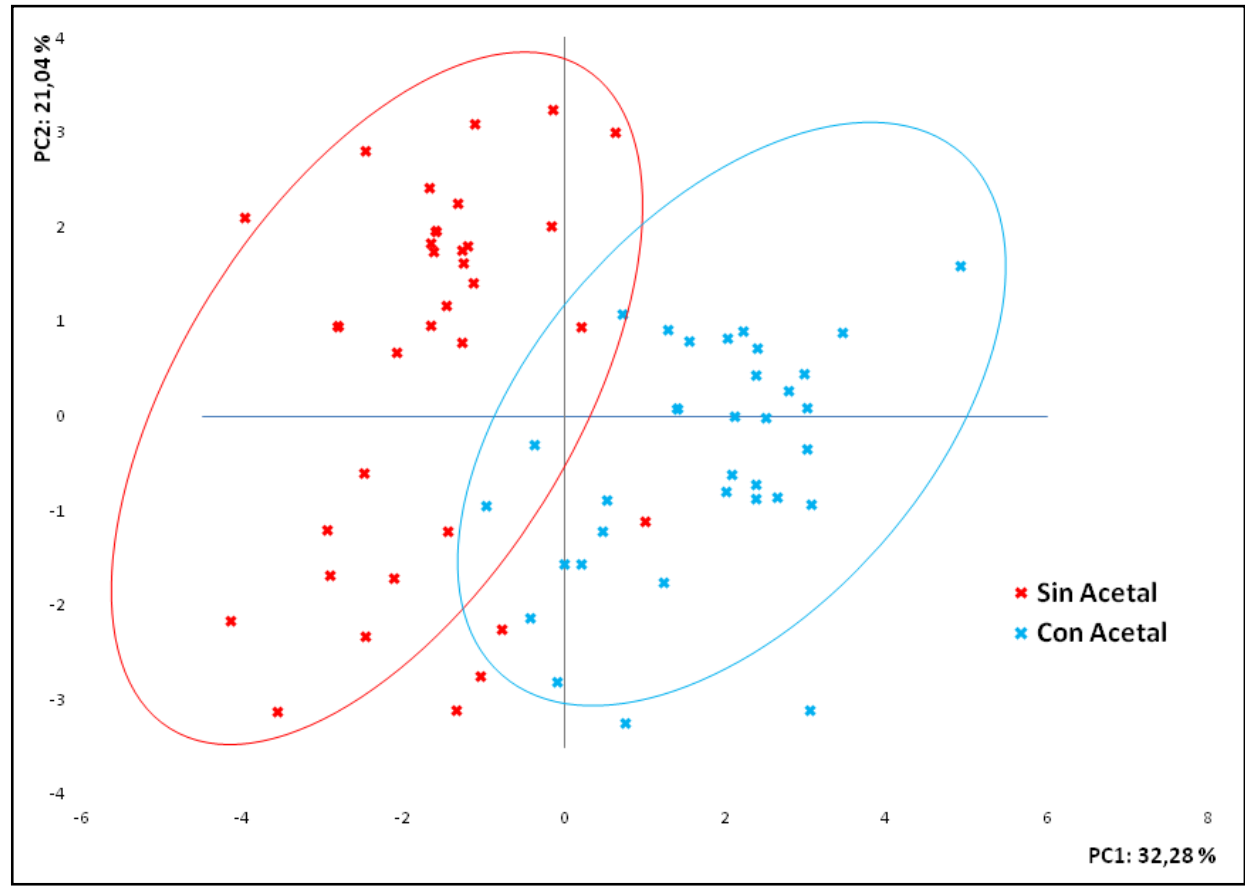

Gráfico 6.5. Primera componente frente a la segunda, en función de la aplicación de la microoxigenación.

Por último se ha representado el efecto de la adición pre- o postfermentativa de copigmentos. En el gráfico 6.6 aparece la representación de los vinos elaborados en función de la primera componente frente a la segunda, donde los vinos aparecen aleatoriamente distribuidos a lo largo de los componentes principales representados. Este comportamiento nos confirma que el momento de adición de los copigmentos no presenta ninguna diferencia según se hayan adicionado previamente o posteriormente a la fermentación, mostrando los vinos elaborados características similares.

Esta distribución aleatoria no permite caracterizar los vinos en función de los 
coeficientes que definen a los componentes principales identificados, como tampoco permitió hacerlo el análisis de la varianza realizado de forma independiente con cada uno de los compuestos polifenólicos determinados en los vinos.

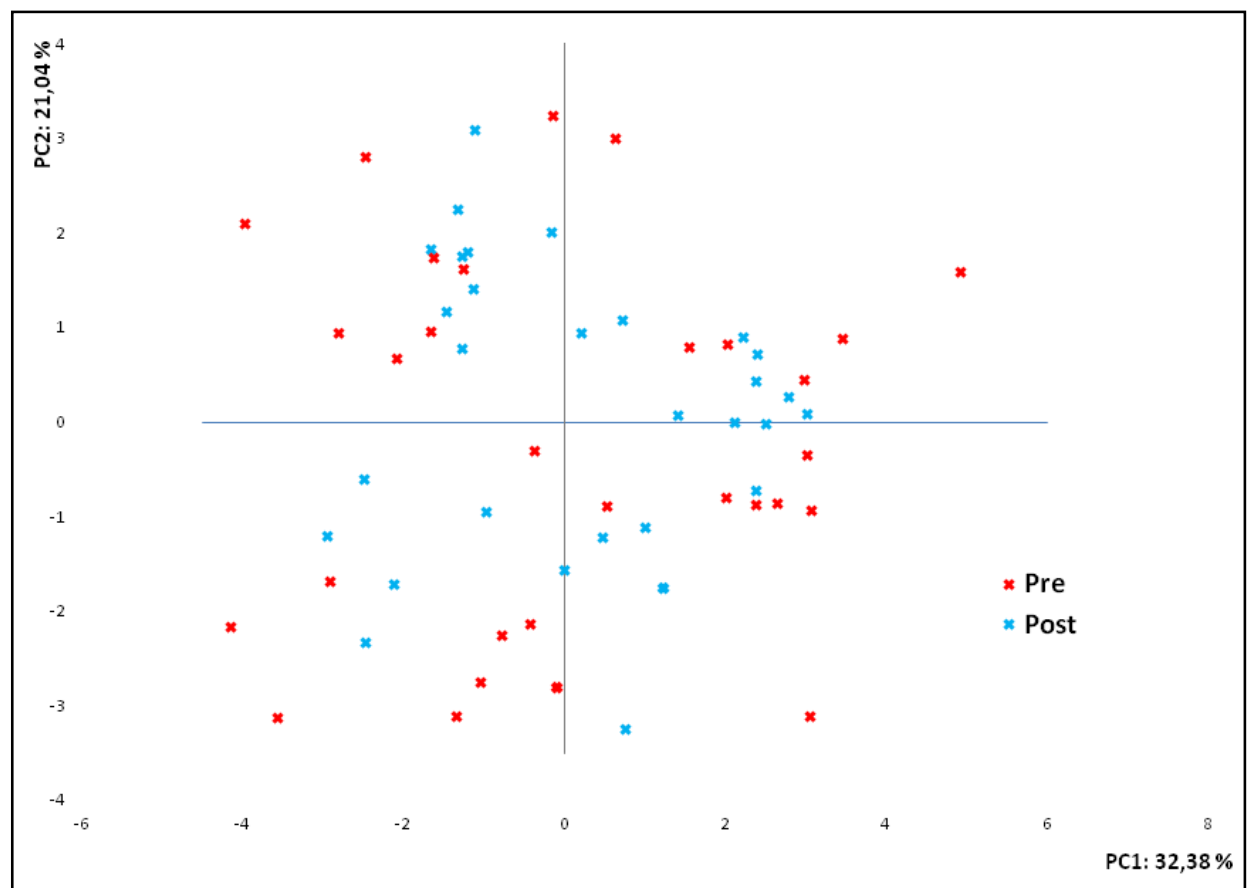

Gráfico 6.6. Primera componente frente a la segunda, en función del momento de adición de los copigmentos.

\subsubsection{ANÁLISIS DE LOS VINOS A LOS 12 MESES DE CONSERVACIÓN}

La composición fenólica de los vinos se determinó una vez concluida la fermentación maloláctica, realizándose un análisis comparativo de las distintas prácticas enológicas ensayadas.

\subsubsection{ANÁLSIS MULTIFACTORIAL DE LA VARIANZA DE LOS FACTORES CONSIDERADOS}

La tabla 6.15 recoge el análisis multifactorial de la varianza (ANOVA) para los ensayos adición de copigmentos, técnicas de maceración prefermentativa, aplicación de la microoxigenación y adición pre- o postfermentativa de copigmentos, así como para las interacciones entre ellos. Los elevados valores de F-ratio observados indican un significativo efecto del ensayo sobre el parámetro polifenólico estudiado. 


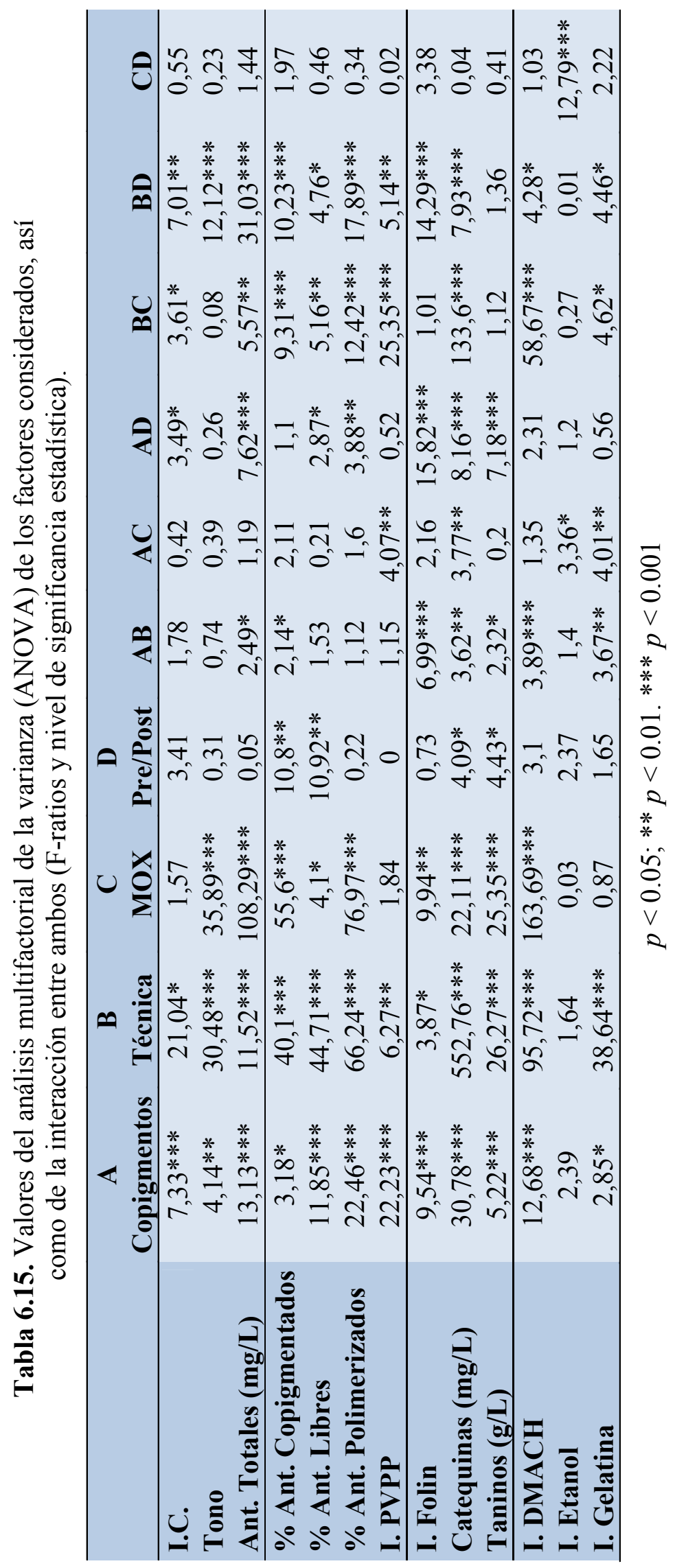


La adición de copigmentos, las diferentes técnicas de vinificación y la aplicación de la microoxigenación presentan diferencias estadísticamente significativas para la mayoría de parámetros polifenólicos determinados, tal como observamos en los vinos después de la fermentación, y al cabo de seis meses. Estas técnicas enológicas demuestran presentar un marcado efecto sobre la composición fenólica de los vinos elaborados, influyendo tanto en el color, como en la concentración de los principales compuestos fenólicos. Por el contrario la adición de copigmentos previamente o posteriormente a la fermentación parce ser una técnica con muy baja o nula influencia sobre la composición fenólica de los vinos.

La interacción entre la adición de copigmentos y las técnicas de vinificación (interacción $\mathrm{AB}$ ), entre los factores $\mathrm{AD}$ (copigmento $\mathrm{x}$ adición pre- o postfermentativa de copigmentos), $\mathrm{BC}$ (técnica de vinificación $\mathrm{x}$ microoxigenación) y $\mathrm{BD}$ (técnica de vinificación $\mathrm{x}$ adición pre- o postfermentativa de copigmentos), muestran diferencias estadísticas para la mayoría de parámetros polifenólicos, mostrando como la combinación de estas técnicas podría tener una influencia positiva sobre la composición de los vinos. Estas diferencias significativas entre las interacciones indican como la combinación entre la aplicación de determinadas prácticas enológicas podría tener un efecto positivo en la composición fenólica y por lo tanto en la calidad organoléptica de los vinos elaborados.

Para el factor adición de copigmentos los parámetros catequinas, índice de PVPP, porcentaje del color que corresponde a los antocianos polimerizados, antocianos totales decolorables, índice de DMACH y porcentaje del color debido a los antocianos libres, son los que presentan los mayores valores del F-ratio y por lo tanto el efecto más marcado sobre la variable. Como podemos observar muchos de estos parámetros están relacionados con las interacciones entre compuestos fenólicos, siendo las interacciones entre antocianos y taninos, la polimerización de antocianos y el grado de polimerización de taninos algunos de los parámetros con mayor efecto sobre la variable adición de copigmentos.

Se observa, en cambio, un efecto mínimo del color debido a las reacciones de copigmentación entre los testigos y los vinos adicionados de copigmentos. Este comportamiento, ya observado a los seis meses, nos indica que durante la conservación en botella también influyen otras reacciones distintas a las de copigmentación sobre el color de los vinos objeto del estudio. También Hermosín et al. (2005) observaron que la fracción del color que corresponde a copigmentación disminuye durante la conservación de los vinos, conjuntamente con la disminución de la concentración de antocianos monómeros y de flavonoles. Durante la conservación de los vinos se observa una disminución de los antocianos copigmentados, y aunque la cantidad de antocianos monómeros es suficiente para que sigan existiendo estos complejos de copigmentación, el ratio entre antocianos y cofactores es probablemente demasiado bajo para que se observen efectos muy significativos en el color. El incremento del efecto de la fracción de color debido a los antocianos polimerizados, ya observada al cabo de seis meses de conservación, en detrimento de la fracción copigmentada, nos permite deducir que los antocianos resultantes de la rotura de los copigmentos, podrían estar incrementando la fracción polimerizada. Según Ribereau-Gayon et al. (1970), al final del primer año de 
conservación, el $50-70 \%$ de los antocianos han reaccionado para dar lugar a pigmentos poliméricos.

Las técnicas de vinificación ensayadas dan lugar a diferencias estadísticamente significativas al $99,9 \%$ para la mayoría de parámetros determinados. Siendo las catequinas, el índice de $\mathrm{DMACH}$, las fracciones del color que corresponden a los antocianos copigmentados, libres y polimerizados, la concentración de taninos y el índice de gelatina los que presentan un efecto más marcado sobre las diferentes técnicas de vinificación empleadas. Los resultados concuerdan con lo observado al cabo de seis meses de conservación, y ponen de manifiesto el gran efecto de las técnicas de vinificación sobre la composición polifenólica de los vinos, que no se minimiza durante la conservación. El índice de gelatina, que ha tenido un peso importante en los vinos después de la maloláctica, vuelve a tenerlo de nuevo al año de conservación. Este diferente comportamiento de la astringecia puede ser debido a los cambios ocurridos en el grado de polimerización de los taninos, y en las reacciones de estos con otros compuestos, que van ocasionando modificaciones en la astringencia.

A diferencia de lo observado con respecto a la adición de copigmentos, las técnicas de vinificación muestran una gran influencia sobre la fracción de antocianos copigmentados tanto después de la fermentación maloláctica como durante la conservación de los vinos. La maceración prefermentativa, que actúa alargando la fase previa a la fermentación, favoreciendo la extracción de las moléculas solubles en ausencia de etanol, incrementa considerablemente el color debido a la fracción copigmentada, tal como pudimos observar en los vinos después de la maloláctica, y tal como observaron otros investigadores (Boulton, 2001; Álvarez et al., 2008). Este gran incremento de la copigmentación puede ser la causa de la estabilidad de estos complejos a lo largo del tiempo, y de que su peso siga siendo importante en la diferenciación.

La microoxigenación afecta significativamente a la mayoría de los parámetros polifenólicos, especialmente al índice de $\mathrm{DMACH}$, antocianos totales, antocianos polimerizados, antocianos copigmentados y tono. A pesar de haber sido aplicada durante un corto período de tiempo, sus efectos siguen manifestándose una vez transcurridos 12 meses de conservación de los vinos en botella, incluso se observa una influencia sobre los antocianos copigmentados que no se aprecio a los seis meses.

La interacción entre la adición de copigmentos y las técnicas de vinificación (interacción $\mathrm{AB}$ ) sigue siendo significativa al cabo de 12 meses para los parámetros índice de Folin, índice de DMACH, índice de gelatina, y concentración de catequinas y taninos, manifestando el importante efecto que la interacción de estas técnicas tiene en los compuestos polifenólicos relacionados con las procianidinas y su estado en el vino. El efecto sobre los antocianos, aunque aún presente, ha ido perdiendo significación a medida que transcurre la conservación de los vinos.

A los doce meses de conservación se observa una ligera interacción entre la adición de copigmentos y la microoxigenación (AC), que no había sido observada a los seis meses, relacionada también con el estado de las proantocianidinas en el vino, ya que afecta a la concentración de catequinas, índice de DMACH e índice de gelatina.

Para la interacción entre los factores adición de copigmentos frente al momento de adición de los mismos (interacción $\mathrm{AD}$ ), previamente o posteriormente a la fermentación, los mayores valores para el F-ratio aparecen para los parámetros índice de Folin, antocianos totales, taninos y catequinas. Estos parámetros están relacionados con 
la concentración total de polifenoles y con los principales compuestos fenólicos determinados, sugiriendo, quizás, la necesidad de aplicar los copigmentos en el momento de máxima concentración fenólica, momento en el cual estos cofactores serán más efectivos (Gómez-Míguez y Heredia, 2004).

Los parámetros catequinas, índice de DMACH, índice de PVPP, antocianos polimerizados y antocianos copigmentados, son los que presentan un efecto más marcado sobre la interacción de las técnicas de vinificación, con la aplicación de la microoxigenación (BC). La estabilización del color de los vinos tintos precisa de la formación de acetaldehído para favorecer las polimerizaciones y combinación de los antocianos y la procianidinas. La microoxigenación, junto con el incremento de la concentración fenólica por aplicación de técnicas de maceración prefermentativa, podría dar lugar a una metodología de vinificación que permita obtener vinos más equilibrados y con un color más estable, que sean mejor valorados organolépticamente (Cano-López et al., 2008).

Por último la interacción entre las técnicas de vinificación y el momento de adición de los copigmentos (BD) presenta diferencias significativas para los parámetros antocianos totales decolorables, antocianos polimerizados, índice de Folin, tono, antocianos copigmentados y catequinas. El efecto de esta interacción está relacionado con lo comentado en los párrafos anteriores. La aplicación de los copigmentos en vinos que presenten una adecuada concentración fenólica y la aplicación de estos en el momento de máxima concentración podrían determinar una metodología de vinificación que nos permitiría elaborar vinos aceptados tanto organolépticamente como cromáticamente por los consumidores.

\subsubsection{I EFECTO DE LA ADICIÓN DE COPIGMENTOS}

La tabla 6.16 muestra los valores medios de los parámetros polifenólicos estudiados, en función de la adición de los distintos copigmentos. El tratamiento estadístico se ha realizando considerando conjuntamente todos los vinos, independientemente de la técnica de vinificación utilizada, del momento de adición de los copigmentos o de la microoxigenación, valorando así exclusivamente el efecto de la adición de copigmentos en los vinos de Tempranillo.

Con respecto a los antocianos totales decolorables, observamos que son los copigmentos de carácter tánico los que muestran los mayores valores para este parámetro, con diferencias estadísticamente significativas, tal como se observó a los seis meses de conservación. Por el contrario los copigmentos ácido cafeico y rutina muestran valores inferiores de estos compuestos, pero en cambio tienen valores superiores de antocianos polimerizados, tal como se observó a los 6 meses, y la estabilidad del color de estos compuestos puede ser la causa de que las diferencias de color sean mínimas con respecto a los otros copigmentos, o incluso superior como en el caso de la rutina. 


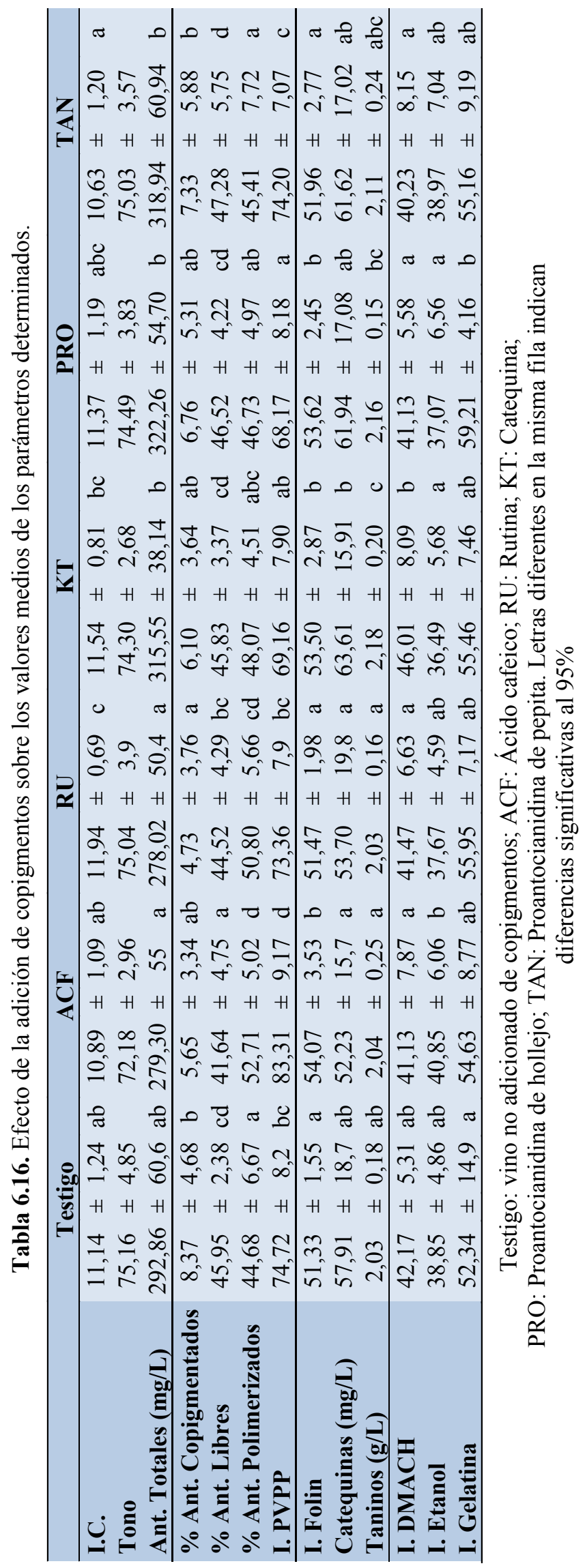


Las procianidinas procedentes de uva blanca son el copigmento que más contribuye a incrementar la fracción de color debida a los antocianos copigmentados durante la fermentación y a mantenerla en estado copigmentado durante la conservación de los vinos, en detrimento de la fracción polimerizada. Además de proteger a los pigmentos de las reacciones de pardeamiento, la copigmentación influye sobre las reacciones de oxidación, condensación y polimerización de sustancias fenólicas, ya que disminuye la cinética de las reacciones que se producen durante el envejecimiento de los vinos. Parece ser que la formación de pigmento polimérico rojo está asociada a la cantidad de copigmentación inicial. Esto se debería a que los apilamientos copigmentados protegen a los antocianos contra la oxidación y favorecen la formación de uniones covalentes entre taninos y antocianos (Boulton, 2001).

La adición de copigmentos de naturaleza tánica también ocasiona una mayor concentración de taninos y de polifenoles, siendo los vinos adicionados con proantocianidinas los que muestran un mayor grado de polimerización de sus taninos. Las distintas reacciones de condensación, polimerización, oxidación, etc., que tienen lugar entre los polifenoles a lo largo de la conservación, afectan al grado de astringencia de los taninos, observándose a los 12 meses que los vinos más astringentes son los suplementados con procianidinas procedentes de hollejos.

\subsubsection{EFECTO DE LAS TÉCNICAS DE VINIFICACIÓN}

En la tabla 6.17 se recogen los valores medios de los parámetros polifenólicos analizados, considerando conjuntamente los distintos vinos elaborados según que la vinificación se realice de forma tradicional, con maceración prefermentativa en frío a 6-8 ${ }^{\circ} \mathrm{C}$ o bien con una maceración prefermentativa adicionando nieve carbónica.

La mayoría de los parámetros polifenólicos determinados presentan diferencias estadísticamente significativas para los vinos elaborados, demostrando como la aplicación de la maceración prefermentativa, no solo provoca un efecto sobre la composición fenólica de los vinos, sino que este efecto se mantiene a los 12 meses de conservación de los vinos en botella. También Gómez-Plaza et al. (2001) observaron que la maceración prefermentativa afecta a los parámetros polifenólicos, incrementando su concentración en el momentel embotellado. Además, después de un año de envejecimiento los vinos elaborados con 10 días de maceración prefermentativa presentan un mayor color, mayor concentración de antocianos y un mayor contenido en pigmentos poliméricos, que contribuyen a la estabilidad del color de los vinos con el paso del tiempo.

Las técnicas de vinificación ensayadas no afectan significativamente al color, pero si a la concentración de antocianos y al estado de estos en el vino, correspondiendo a los vinos macerados con nieve carbónica los valores más elevados de antocianos totales decolorables y antocianos copigmentados, tal como se observó después de de la fermentación maloláctica y a los seis meses de conservación. La maceración prefermentativa con nieve carbónica se muestra como la técnica que presenta los mayores valores del porcentaje del color debido a la copigmentación, con diferencias estadísticamente significativas. En cambio, esta técnica presenta un menor incremento 
del color correspondiente a los antocianos polimerizados, quizás debido a que aún mantiene un porcentaje importante de antocianos formando parte de las reacciones de copigmentación. Estos compuestos poliméricos van incrementando su concentración con el tiempo (Somers, 1971; Nugel and Wulf, 1979), de forma que al final del primer año del 50 al $70 \%$ de los antocianos han reaccionado para dar lugar a pigmentos poliméricos (Ribereau-Gayon et la., 1970; Somers, 1971; Nugel and Wulf, 1979).

Tabla 6.17. Efecto de las técnicas de vinificación sobre los valores medios de los parámetros determinados.

\begin{tabular}{|c|c|c|c|c|c|c|c|c|}
\hline & \multicolumn{3}{|c|}{ Tradicional } & \multicolumn{3}{|c|}{ Frio } & \multicolumn{2}{|c|}{ Nieve } \\
\hline I.C. & 11,57 & $\pm \quad 1,05$ & & 11,80 & $\pm \quad 0,49$ & & $10,42 \pm$ & $=1,10$ \\
\hline Tono & 75,87 & 2,63 & b & 71,18 & 3,18 & $\mathrm{a}$ & $75,83 \pm$ & 2,72 \\
\hline Ant. Tot: & 294,20 & $\pm 45,22$ & $\mathrm{a}$ & 287,51 & $\pm 69,64$ & $\mathrm{a}$ & $324,01 \pm$ & $=41,72$ \\
\hline$\%$ Ant & 3,29 & 1,93 & & 6,98 & 4,41 & $\mathrm{~b}$ & $8,69 \pm$ & 4,97 \\
\hline$\% \mathrm{~A}$ & 45,98 & 5,00 & $\theta$ & 41,30 & 3,78 & $\mathrm{a}$ & $47,32 \pm$ & 3,24 \\
\hline$\% \mathrm{~A}$ & 50,76 & 4,04 & b & 51,73 & $\pm \quad 6,61$ & $\mathrm{~b}$ & $43,99 \pm$ & 4,66 \\
\hline I. PV & 76,90 & 7,20 & $\mathrm{~b}$ & 73,00 & $\pm 11,01$ & $\mathrm{a}$ & $71,32 \pm$ & 9,06 \\
\hline I. Folin & 52,58 & 2,39 & & 53,36 & $\pm \quad 3,61$ & & $52,39 \pm$ & 2,31 \\
\hline Cate & 60,58 & $\pm 13,44$ & b & 40,23 & 9,41 & $\mathrm{a}$ & $74,85 \pm$ & 7,14 \\
\hline Tanir & 2,03 & $\pm \quad 0,16$ & $\mathrm{a}$ & 2,02 & 0,22 & $\mathrm{a}$ & $2,24 \pm$ & 0,17 \\
\hline I. DM & 46,50 & 9,01 & & 42,63 & 4,63 & $\mathrm{~b}$ & $36,90 \pm$ & 3,52 \\
\hline I. Eta & 39,19 & 7,24 & & 37,14 & 6,02 & & $38,47 \pm$ & 4,44 \\
\hline I. Gelatina & 50,51 & $\pm 10,11$ & & 61,71 & 5,47 & & $55,01 \pm$ & 4,87 \\
\hline
\end{tabular}

Tradicional: elaboración sin maceración en frío previamente a la fermentación; Frío: aplicación de bajas temperaturas de forma prefermentativa; Nieve: uso de nieve carbónica prefermentativamente. Letras diferentes en la misma fila indican diferencias significativas al $95 \%$.

También para la concentración de catequinas y taninos, la maceración prefermentativa con aplicación de nieve carbónica, aparece como la técnica más favorable, pudiendo atribuirse al efecto de desestructuración celular ocasionado por la congelación debida a la nieve carbónica, el hecho de que los vinos presenten una mayor concentración de los principales compuestos fenólicos transcurrido un año desde el embotellado (Couasnon, 1999; Sacchi et al., 2005). Además, afecta positivamente al grado de polimerización de los taninos, tal como pone de manifiesto el índice de DMACH. La maceración prefermentativa en frío presenta menor grado de polimerización que la aplicación de nieve carbónica, pero mayor que la vinificación tradicional, con diferencias significativas. La presencia de una mayor concentración de compuestos tánicos con un grado de polimerización superior, ocasiona una mayor astringencia en los vinos sometidos a maceración prefermentativa, tanto en frío como con nieve carbónica.

\subsubsection{4. $\quad$ EFECTO DE LA MICROOXIGENACIÓN}

En la tabla 6.18 se recogen los valores medios de los parámetros polifenólicos analizados en los vinos, considerando conjuntamente a todos aquellos vinos que han sido microoxigenados frente a aquellos vinos a los que no se les ha realizado adición de 
acetaldehído.

La aplicación controlada de acetaldehído posteriormente a la finalización de la fermentación, da lugar a diferencias estadísticas para muchos de los parámetros que caracterizan la composición fenólica de los vinos, que ya se manifestaron a los seis meses de conservación, y que aún se mantienen después de transcurridos 12 meses desde el embotellado.

Los parámetros tono, antocianos totales, porcentaje del color que corresponde a la copigmentación, polifenoles totales y taninos presentan diferencias significativas, mostrando los valores más elevados los vinos no microoxigenados. Por otra, parte para el porcentaje del color correspondiente a los antocianos polimerizados, los mayores valores se presentan para los vinos microoxigenados, con diferencias significativas.

Tabla 6.18. Efecto de la microoxigenación sobre los valores medios de los parámetros determinados.

\begin{tabular}{lcllllll}
\hline & \multicolumn{1}{c}{ No MOX } & \multicolumn{3}{c}{ MOX } \\
\hline I.C. & 11,17 & $\pm 1,24$ & & 11,35 & $\pm 0,94$ & \\
Tono & 75,80 & $\pm 3,04$ & b & 72,78 & $\pm 3,48$ & a \\
Ant. Totales (mg/L) & 330,74 & $\pm 33,53$ & b & 273,08 & \pm & 58,41 & a \\
\hline \% Ant. Copigmentados & 8,24 & $\pm 4,58$ & b & 4,39 & $\pm 3,66$ & a \\
\% Ant. Libres & 45,41 & $\pm 4,01$ & & 44,33 & $\pm 5,45$ & \\
\% Ant. Polimerizados & 46,35 & $\pm 5,27$ & a & 51,31 & $\pm 6,15$ & b \\
I. PVPP & 74,23 & $\pm 9,79$ & & 73,25 & $\pm 9,15$ & \\
\hline I. Folin & 53,33 & $\pm 2,77$ & b & 52,22 & $\pm 2,83$ & a \\
Catequinas (mg/L) & 56,52 & $\pm 16,20$ & & 60,59 & $\pm 18,73$ & \\
Taninos (g/L) & 2,17 & $\pm 0,19$ & b & 2,03 & $\pm 0,21$ & a \\
\hline I. DMACH & 45,57 & $\pm 7,62$ & b & 38,45 & $\pm 4,88$ & a \\
I. Etanol & 38,56 & $\pm 6,64$ & & 37,98 & $\pm 5,38$ & \\
I. Gelatina & 56,92 & $\pm 8,24$ & & 54,56 & $\pm 8,68$ & \\
\hline
\end{tabular}

No MOX: vinos no adicionados de acetaldehído; MOX: vinos adicionados de acetaldehído. Letras diferentes en la misma fila indican diferencias significativas al 95\%.

La concentración de antocianos totales decolorables y copigmentados, la de polifenoles totales y la de catequinas ha sufrido una importante caída en los vinos microoxigenados los últimos meses de conservación. A pesar de ello, no se observan diferencias en el color, quizás debido al incremento de las reacciones de polimerización de antocianos, observadas ya en la analítica realizada a los 6 meses, y al hecho probable de que se hayan formado otros compuestos más complejos que contribuyen a la estabilidad del color (Atanasova et al., 2002a).

El grado de polimerización de los taninos es superior en los vinos adicionados de acetaldehído, tal como se observó a los seis meses, comprobándose que el efecto polimerizante del acetaldehído se mantiene en el tiempo, a pesar de haber sido aplicado durante un periodo muy corto. El incremento inicial de la astringencia observado a los seis meses, dio lugar a un importante descenso al cabo del tiempo, no observándose 
diferencias significativas entre los vinos al cabo de doce meses.

\subsubsection{EFECTO DEL MOMENTO DE ADICIÓN DE LOS COPIGMENTOS}

En la tabla 6.19 se recogen los valores medios de los parámetros polifenólicos analizados, considerando conjuntamente a todos aquellos que han sido adicionados de copigmentos previamente o posteriormente a la fermentación de los vinos.

Tabla 6.19. Efecto del momento de adición de copigmentos sobre los valores medios de los parámetros determinados.

\begin{tabular}{lclclll}
\hline & \multicolumn{2}{c}{ PRE } & \multicolumn{2}{c}{ POST } \\
\hline I.C. & 11,12 & $\pm 0,93$ & 11,43 & $\pm 1,22$ & \\
Tono & 74,35 & $\pm 3,93$ & 74,06 & $\pm 3,01$ & \\
Ant. Totales (mg/L) & 303,41 & $\pm 52,17$ & 302,21 & $\pm 58,58$ \\
\hline \% Ant. Copigmentados & 5,29 & $\pm 3,75$ & a & 6,94 & $\pm 5,07$ & b \\
\% Ant. Libres & 46,11 & $\pm 5,05$ & b & 44,21 & $\pm 4,56$ & a \\
\% Ant. Polimerizados & 48,61 & $\pm 6,21$ & 48,87 & $\pm 6,25$ & \\
I. PVPP & 73,64 & $\pm 8,71$ & 73,64 & $\pm 10,47$ \\
\hline I. Folin & 52,78 & $\pm 2,69$ & 53,06 & $\pm 3,12$ \\
Catequinas (mg/L) & 57,76 & $\pm 17,90$ & 59,47 & $\pm 17,24$ \\
Taninos (g/L) & 2,08 & $\pm 0,21$ & 2,13 & $\pm 0,21$ \\
\hline I. DMACH & 42,50 & $\pm 7,93$ & 41,49 & $\pm 7,07$ \\
I. Etanol & 38,99 & $\pm 6,61$ & 37,44 & $\pm 5,59$ \\
I. Gelatina & 56,70 & $\pm 6,67$ & 55,46 & $\pm 8,45$ \\
\hline
\end{tabular}

PRE: adición de copigmentos previamente al inicio de la fermentación alcohólica; POST: adición de copigmentos en el embotellado. Letras diferentes en la misma fila indican diferencias estadísticamente significativas al 95\%

El momento de adición de los copigmentos no presenta ningún efecto significativo para los parámetros polifenólicos determinados. La adición de los compigmentos previamente o posteriormente a la fermentación de los vinos no produce ningún efecto sobre el color, la concentración de los principales compuestos fenólicos o sobre el estado de estos compuestos. Únicamente aparecen unas mínimas diferencias en la fracción del color debido a los antocianos libres.

\subsubsection{CORRELACIÓN ENTRE LOS PARÁMETROS POLIFENÓLICOS DE LOS VINOS Y LOS FACTORES CONSIDERADOS}

Antes de realizar el ACP en los vinos conservados durante doce meses se ha estudiado la matriz de covarianzas o matriz de correlaciones entre las variables determinadas (Tabla 6.20).

La concentración de antocianos totales decolorables muestra una correlación positiva con el tono. Este comportamiento indica como una mayor concentración de estos compuestos en el vino trae consigo un incremento en la tonalidad amarilla. La metodología analítica utilizada para la determinación de estos compuestos, que 
determina aquellos antocianos decolorables por el sulfuroso que presentan la posición 4 del catión flavilio libre, puede hacerlos también fácilmente atacables por el oxígeno y muy susceptibles a la degradación (Giusty y Wrolstad, 2003; Rein, 2005; CastañedaOvando et al., 2009). Este razonamiento justifica que, a pesar de que se incremente la concentración de los antocianos que aportan el color rojo a los vinos tintos, se produzca al mismo tiempo un incremento de la componente amarilla.

\begin{tabular}{|c|c|c|c|c|c|c|c|c|c|c|c|c|c|}
\hline ви!หฺวग I & సે & $\begin{array}{l}\stackrel{0}{\circ} \\
0^{\prime}\end{array}$ & $\begin{array}{l}\hat{y} \\
\hat{0} \\
1\end{array} \mid$ & 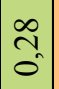 & 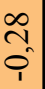 & $\begin{array}{l}= \\
0 \\
i\end{array}$ & $\begin{array}{l}n \\
0 \\
i\end{array}$ & $\begin{array}{l}\frac{a}{i} \\
\hat{\varphi}\end{array}$ & $\begin{array}{c}0 \\
\frac{1}{0}\end{array}$ & $\begin{array}{c}0 \\
m_{0} \\
0\end{array}$ & 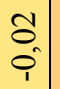 & $\begin{array}{l}\hat{2} \\
\hat{c}\end{array}$ & \\
\hline 'u!!Od luV \% & $\begin{array}{l}\text { ñ. } \\
\hat{i}\end{array}$ & $\begin{array}{l}0 \\
? \\
0 \\
0\end{array}$ & \begin{tabular}{|l|}
$\hat{\sigma}$ \\
0 \\
0
\end{tabular} & $\begin{array}{l}\hat{n} \\
0 \\
i\end{array}$ & $\begin{array}{l}\infty \\
n \\
n \\
? \\
1\end{array}$ & $\begin{array}{l}n \\
0\end{array}$ & $\begin{array}{l}\overline{0} \\
0 \\
0 \\
1\end{array}$ & $\begin{array}{l}\stackrel{ \pm}{\mathrm{N}} \\
0\end{array}$ & $\begin{array}{l}0 \\
\\
i \\
i\end{array}$ & $\begin{array}{l}0 \\
: \\
0 \\
i\end{array}$ & ? & & $\stackrel{\circ}{\hat{1}}$ \\
\hline sә.xq!T ’quV \% & 8 & $\begin{array}{l}n \\
2 \\
0 \\
i\end{array}$ & $\left|\begin{array}{l}a \\
n \\
0\end{array}\right|$ & $\begin{array}{l}\infty \\
n \\
0\end{array}$ & $\begin{array}{l}n \\
n \\
0 \\
0\end{array}$ & $\left|\begin{array}{l}0 \\
0 \\
0 \\
1\end{array}\right|$ & $\begin{array}{l}\overline{0} \\
0 \\
0\end{array}$ & $\begin{array}{l}2 \\
\hat{0} \\
\hat{i}\end{array}$ & $\overrightarrow{\vec{\sigma}_{0}}$ & $\begin{array}{l}2 \\
0 \\
i\end{array}$ & & $\begin{array}{l}2 \\
0 \\
i \\
1\end{array}$ & $\begin{array}{l}0 \\
0 \\
0\end{array}$ \\
\hline s!!doつ ’quV \% & तै & $\begin{array}{l}\text { fo } \\
\stackrel{0}{1}\end{array}$ & $\begin{array}{c}\vec{n} \\
0\end{array}$ & $\begin{array}{l}8 \\
8 \\
0\end{array}$ & $\begin{array}{l}\tilde{n} \\
\tilde{0}\end{array}$ & 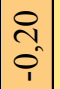 & $\begin{array}{l}\overrightarrow{0} \\
0\end{array}$ & $\begin{array}{l} \pm \\
\dot{\varphi}\end{array}$ & $\hat{n}$ & & $\begin{array}{l}0 \\
\dot{0} \\
i\end{array}$ & $\begin{array}{l}0 \\
0 \\
0 \\
1\end{array}$ & 今) \\
\hline 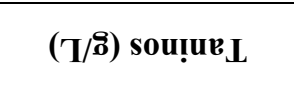 & $F_{0}$ & $\begin{array}{l}\text { 尺े } \\
\text { i } \\
1\end{array}$ & $\left|\begin{array}{l}\infty \\
\multirow{2}{0}{} \\
0\end{array}\right|$ & $\begin{array}{l}\infty \\
0 \\
0\end{array}$ & $\begin{array}{l}0 \\
+ \\
0 \\
0\end{array}$ & $\begin{array}{l}\tilde{n} \\
\hat{i} \\
1\end{array}$ & $\begin{array}{l}0 \\
0 \\
0 \\
1\end{array}$ & $\begin{array}{l}n \\
0 \\
i\end{array}$ & & $\begin{array}{l}n \\
\tilde{0} \\
\tilde{a}\end{array}$ & $\vec{\sigma}$ & $\begin{array}{l}0 \\
? \\
i \\
i\end{array}$ & $\begin{array}{l}0 \\
0 \\
0\end{array}$ \\
\hline $\operatorname{dd} \Lambda d{ }^{\circ} I$ & $\stackrel{0}{0}$ & $\begin{array}{l}\text { I } \\
0 \\
0\end{array}$ & \begin{tabular}{l|}
0 \\
0 \\
0 \\
1
\end{tabular} & \begin{tabular}{l|}
$\infty$ \\
0 \\
0 \\
1
\end{tabular} & $\begin{array}{l}2 \\
\frac{0}{i}\end{array}$ & $\begin{array}{l}\overrightarrow{0} \\
0\end{array}$ & $\begin{array}{l}0 \\
\tilde{m} \\
0\end{array}$ & & $\begin{array}{l}n \\
0 \\
i \\
1\end{array}$ & $\begin{array}{l} \pm \\
\\
\end{array}$ & $\frac{9}{0}$ & \begin{tabular}{l}
\multirow{2}{\Delta}{} \\
$\vdots$ \\
0
\end{tabular} & $\frac{0}{0}$ \\
\hline IOUв] ' I I & $\frac{m}{0}$ & $\begin{array}{l}n \\
1 \\
0 \\
1\end{array}$ & $\begin{array}{l}0 \\
0 \\
0\end{array} \mid$ & \begin{tabular}{|l|}
$\infty$ \\
0 \\
0 \\
1
\end{tabular} & $\begin{array}{l}\text { ô } \\
\text { के }\end{array}$ & $\left|\begin{array}{l}\delta \\
\delta \\
0\end{array}\right|$ & & 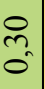 & $\begin{array}{l}0 \\
0 \\
0 \\
1\end{array}$ & $\begin{array}{l}\overrightarrow{0} \\
0\end{array}$ & $\begin{array}{l}\overrightarrow{0} \\
0\end{array}$ & $\begin{array}{l}\overrightarrow{0} \\
i \\
i\end{array}$ & $\frac{n}{0}$ \\
\hline HOVWA 'I & $\hat{0}$ & $\begin{array}{l}2 \\
\text { ñ. } \\
0\end{array}$ & $\left|\begin{array}{c}0 \\
0 \\
0\end{array}\right|$ & $\mid \begin{array}{l}\infty \\
0 \\
0 \\
0\end{array}$ & 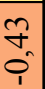 & & $\begin{array}{l}1 \\
\tilde{O} \\
0\end{array}$ & $\begin{array}{l}\overline{0} \\
0 \\
0\end{array}$ & $\begin{array}{l}n \\
\tilde{n} \\
0 \\
1\end{array}$ & 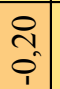 & $\begin{array}{l} \\
0 \\
0 \\
1\end{array}$ & $\frac{I}{0^{\prime}}$ & $\bar{z}$ \\
\hline $\begin{array}{c}\text { (T/8̊u) } \\
\text { seu!nbəłeว }\end{array}$ & $\begin{array}{l}\text { I } \\
0 \\
0\end{array}$ & $\begin{array}{l}0 \\
+ \\
0 \\
1\end{array}$ & $\begin{array}{l}\tilde{n} \\
\hat{0}\end{array}$ & $\begin{array}{l}\infty \\
\tilde{m} \\
0\end{array}$ & & $\begin{array}{l}f \\
\tilde{c} \\
i\end{array}$ & $\begin{array}{l}\tilde{1} \\
0 \\
0 \\
1\end{array}$ & $\frac{a}{\vec{p}}$ & $\begin{array}{l}0 \\
+ \\
0\end{array}$ & $\begin{array}{l}\tilde{N} \\
0\end{array}$ & $\begin{array}{l}n \\
n \\
0\end{array}$ & $\begin{array}{l}\infty \\
n \\
0 \\
0\end{array}$ & $\begin{array}{l}\text { क } \\
\text { ô } \\
0 \\
1\end{array}$ \\
\hline 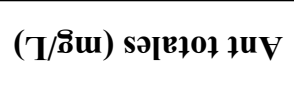 & $\begin{array}{l}\mathfrak{q}_{\alpha} \\
0\end{array}$ & $\begin{array}{l}\bar{n} \\
\text { o. } \\
1\end{array}$ & $\begin{array}{l}0 \\
0 \\
0\end{array}$ & & $\begin{array}{l}\infty \\
\text { ? } \\
0\end{array}$ & $\left|\begin{array}{l}0 \\
0 \\
0 \\
0\end{array}\right|$ & $\begin{array}{l}\infty \\
0 \\
0 \\
1\end{array}$ & $\begin{array}{l}\infty \\
\vec{c} \\
i\end{array}$ & $\begin{array}{l}\infty \\
0 \\
0 \\
0\end{array}$ & $\begin{array}{l}8 \\
0 \\
0\end{array}$ & $\begin{array}{l}\infty \\
2 \\
0 \\
0\end{array}$ & $\begin{array}{c}\hat{\infty} \\
0 \\
1\end{array}$ & \begin{tabular}{l}
$\infty$ \\
\multirow{N}{*}{} \\
0
\end{tabular} \\
\hline OUOL & $\begin{array}{l}0 \\
0 \\
0\end{array}$ & $\begin{array}{l}\text { ?2 } \\
\text { ? } \\
?\end{array}$ & & $\begin{array}{l}\hat{0} \\
0\end{array}$ & $\begin{array}{l}\hat{n} \\
\hat{0} \\
0\end{array}$ & $\begin{array}{l}0 \\
0 \\
0\end{array}$ & $\begin{array}{l}n \\
0 \\
0\end{array}$ & $\begin{array}{l}0 \\
\hat{\varphi} \\
i\end{array}$ & \begin{tabular}{l}
$\infty$ \\
\multirow{1}{*}{} \\
0
\end{tabular} & $\begin{array}{c}\vec{m} \\
0\end{array}$ & ڤે & $\begin{array}{l}\hat{6} \\
0 \\
1\end{array}$ & $\begin{array}{l}\hat{N} \\
\hat{i}\end{array}$ \\
\hline$\cdot \mathrm{P} \cdot \mathbf{I}$ & 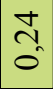 & & $\left|\begin{array}{c}1 \\
\tilde{0} \\
1\end{array}\right|$ & $\begin{array}{l}\bar{n} \\
\hat{i}\end{array}$ & $\begin{array}{l}0 \\
+ \\
0 \\
1 \\
1\end{array}$ & $\begin{array}{c}2 \\
3 \\
0\end{array}$ & $\begin{array}{l}n \\
n \\
0 \\
1\end{array}$ & $\begin{array}{l}\tilde{\delta} \\
\delta \\
0\end{array}$ & $\begin{array}{l}2 \\
0 \\
1 \\
1\end{array}$ & $\begin{array}{l}\stackrel{1}{t} \\
\stackrel{1}{1}\end{array}$ & $\begin{array}{l}n \\
n \\
0 \\
1\end{array}$ & $\begin{array}{l}0 \\
n \\
0 \\
0\end{array}$ & $\stackrel{\circ}{\circ}$ \\
\hline U!ן & & 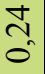 & $\left|\begin{array}{l}0 \\
0 \\
0\end{array}\right|$ & $\begin{array}{l}\hat{\mathfrak{t}} \\
\hat{0}\end{array}$ & $\begin{array}{l} \pm \\
0 \\
0\end{array}$ & $\left|\begin{array}{l}0 \\
0 \\
0\end{array}\right|$ & $\begin{array}{l}m \\
0\end{array}$ & $\begin{array}{l}8 \\
8 \\
0\end{array}$ & $\begin{array}{l}\overrightarrow{J_{0}} \\
0\end{array}$ & $\begin{array}{c}1 \\
3 \\
0\end{array}$ & $\begin{array}{l}8 \\
8\end{array}$ & $\begin{array}{l}\tilde{\hat{n}} \\
\hat{i}\end{array}$ & हे \\
\hline & : & نبِ & 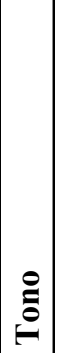 & 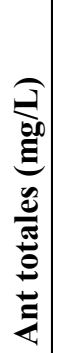 & 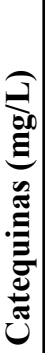 & 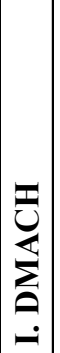 & 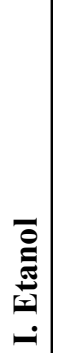 & 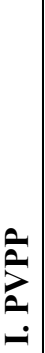 & 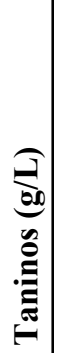 & 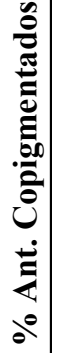 & 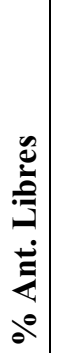 & 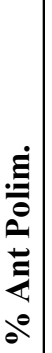 & تُّ \\
\hline
\end{tabular}


Además, esta misma observación realizada para los antocianos totales decolorables, se observa también para la concentración de catequinas, mostrando una correlación positiva con el tono. Estos compuestos que se definen como monómeros de proantocianidinas poseen la capacidad de reaccionar entre ellos mismos o con otros compuestos, pero también pueden ser atacados por el oxígeno, aportando a los vinos un incremento en la componente amarilla, que mide el tono.

Tal y como podemos observar en la tabla anterior, la concentración de taninos presenta una correlación positiva con la concentración de antocianos decolorables. Además de la correlación positiva con los taninos, la concentración de antocianos totales decolorables muestra correlaciones positivas tanto para el porcentaje del color debido a copigmentación, como al debido a los antocianos libres. Por el contrario, se observa una correlación negativa para estos compuestos y para el porcentaje del color debido a polimerizaciones.

La correlación positiva con los antocianos copigmentados ha sido observada a lo largo del proceso de conservación (Versari et al., 2008, Eiro y Heinonen, 2002), lo que indica que una mayor concentración de antocianos en los vinos permite que los cofactores puedan actuar como copigmentos, catalizando este tipo de reacciones.

Tabla 6.21. Autovalor, varianza explicada y acumulada para las 14 componentes consideradas en el análisis

\begin{tabular}{ccccc}
\hline Componente & Autovalor & \% Varianza & \% Acumulado \\
\hline $\mathbf{1}$ & 4,761 & 34,005 & 34,005 \\
$\mathbf{2}$ & 2,311 & 16,509 & 50,515 \\
$\mathbf{3}$ & 1,820 & 12,999 & 63,514 \\
$\mathbf{4}$ & 1,423 & 10,161 & 73,674 \\
$\mathbf{5}$ & 0,951 & 6,794 & 80,469 \\
$\mathbf{6}$ & 0,825 & 5,894 & 86,363 \\
$\mathbf{7}$ & 0,672 & 4,801 & 91,164 \\
$\mathbf{8}$ & 0,371 & 2,647 & 93,811 \\
$\mathbf{9}$ & 0,258 & 1,845 & 95,656 \\
$\mathbf{1 0}$ & 0,234 & 1,674 & 97,329 \\
$\mathbf{1 1}$ & 0,174 & 1,243 & 98,572 \\
$\mathbf{1 2}$ & 0,148 & 1,054 & 99,626 \\
$\mathbf{1 3}$ & 0,052 & 0,374 & 100,000 \\
$\mathbf{1 4}$ & 0,000 & 0,000 & 100,000 \\
\hline
\end{tabular}

La correlación positiva con el porcentaje del color debido a los antocianos libres podría ser otro indicativo de que en estos vinos muchos de los pigmentos poliméricos formados a lo largo del proceso de conservación han perdido su estabilidad, rompiéndose las moléculas de partida, reforzándose esta teoría con la correlación negativa que presenta para las polimerizaciones, la cual nos indica que si se incrementa la concentración de antocianos decolorables, que se encuentran mayoritariamente en su forma libre, se reduce el color debido a polimerizaciones. 
Las correlaciones positivas que aparecen para el tono y la concentración de catequinas con el porcentaje del color que corresponde a los antocianos libres, demuestran una vez más la menor resistencia de los antocianos monómeros a la acción del oxígeno (Castañeda-Ovando et al., 2009) y la mayor concentración de catequinas por la rotura de las uniones entre antocianos y estos compuestos.

Por último los antocianos polimerizados presentan un gran número de correlaciones importantes con otros parámetros. Concretamente presentan una correlación positiva con la IC, indicando como son los compuestos poliméricos los verdaderamente responsables del color de los vinos viejos (Castañeda-Ovando et al., 2009; Cheynier et la., 2006; Malien-Aubert et al., 2002). Además de correlaciones negativas con el tono, las catequinas y los taninos, y con el color que corresponde tanto a los antocianos libres como a los copìgmentados.

En la tabla 6.21 aparece tanto el eigenvalor como el porcentaje de varianza acumulada por los sucesivos factores, observándose como son necesarios cuatro factores para que el autovalor descienda por debajo de la unidad. Además comprobamos como el porcentaje de varianza acumulada corresponde al 73,67\%.

Se han identificado cuatro patrones de comportamiento asociado, explicando entre ellos más del $70 \%$ de la variabilidad total observada en las variables originales, consiguiéndose con esto una reducción de las variables iniciales.

En la tabla 6.22 aparecen los valores de los coeficientes de las ecuaciones que forman cada uno de los cuatro componentes principales identificados.

Tabla 6.22. Tabla de pesos de los componentes

\begin{tabular}{lcccc}
\hline & Componente & Componente & Componente & Componente \\
& $\mathbf{1}$ & $\mathbf{2}$ & $\mathbf{3}$ & $\mathbf{4}$ \\
\hline IPT & $-0,13$ & 0,44 & $-0,18$ & $-0,25$ \\
I.C. & 0,26 & 0,34 & $-0,09$ & 0,25 \\
Tono & $-0,33$ & 0,13 & 0,38 & 0,06 \\
Ant totales (mg/L) & $-0,40$ & 0,28 & $-0,02$ & 0,02 \\
Catequinas (mg/L) & $-0,32$ & $-0,25$ & 0,18 & 0,07 \\
I. DMACH & 0,12 & 0,44 & 0,31 & 0,15 \\
I. Folin & 0,12 & 0,53 & 0,25 & $-0,01$ \\
I. Etanol & 0,00 & $-0,04$ & 0,22 & $-0,63$ \\
I. PVPP & 0,12 & 0,05 & 0,20 & $-0,56$ \\
Taninos (g/L) & $-0,36$ & 0,12 & $-0,13$ & $-0,02$ \\
\% Ant. Copigmentados & $-0,29$ & 0,08 & $-0,33$ & $-0,27$ \\
\% Ant. Libres & $-0,31$ & $-0,04$ & 0,30 & 0,26 \\
\% Ant Polim. & 0,44 & $-0,03$ & 0,01 & 0,00 \\
I. Gelatina & $-0,06$ & 0,19 & $-0,57$ & 0,04 \\
\hline
\end{tabular}

El primer componente principal está altamente relacionado con los parámetros intensidad colorante y porcentaje del color que corresponde a las polimerizaciones, pudiéndose identificar este índice con aquellos vinos que presentan una buena 
concentración de pigmentos poliméricos, compuestos responsables del color en los vinos envejecidos. Por el contrario presenta relaciones negativas con parámetros como el tono, los antocianos totales, las catequinas y los taninos, y el porcentaje del color debido a las reacciones de copigmentación o a los antocianos libres.

El segundo eje principal identificado está relacionado positivamente (asociación directa) con los parámetros índice de Folin, IC, antocianos totales decolorables e índice de DMACH. Este eje podría estar relacionado con aquellos vinos que presentan una importante concentración fenólica, con una concentración antociánica que permite mantener unas buenas características cromáticas y con un importante grado de polimerización de taninos, que permite mantener las características de estructura y cuerpo de los vinos elaborados.

Las asociaciones directas más importantes son las que presentan el tono, el índice de DMACH y el porcentaje del color que corresponde a los antocianos libres. Por el contrario se encuentran asociaciones indirectas para los antocianos copigmentados y el índice de gelatina en el tercer componente principal identificado. Este índice podría estar relacionado en su parte positiva con vinos con una elevada presencia de antocianos libres, fácilmente oxidables, al mismo tiempo que con un elevado grado de polimerización de los taninos presentes en el medio. Por el contrario en su parte negativa este eje podría estar relacionado con la copigmentación.

Por último el cuarto eje principal presenta relaciones positivas, únicamente, con los antocianos libres y negativas para el índice de etanol, el índice de PVPP y para los antocianos copigmentados.

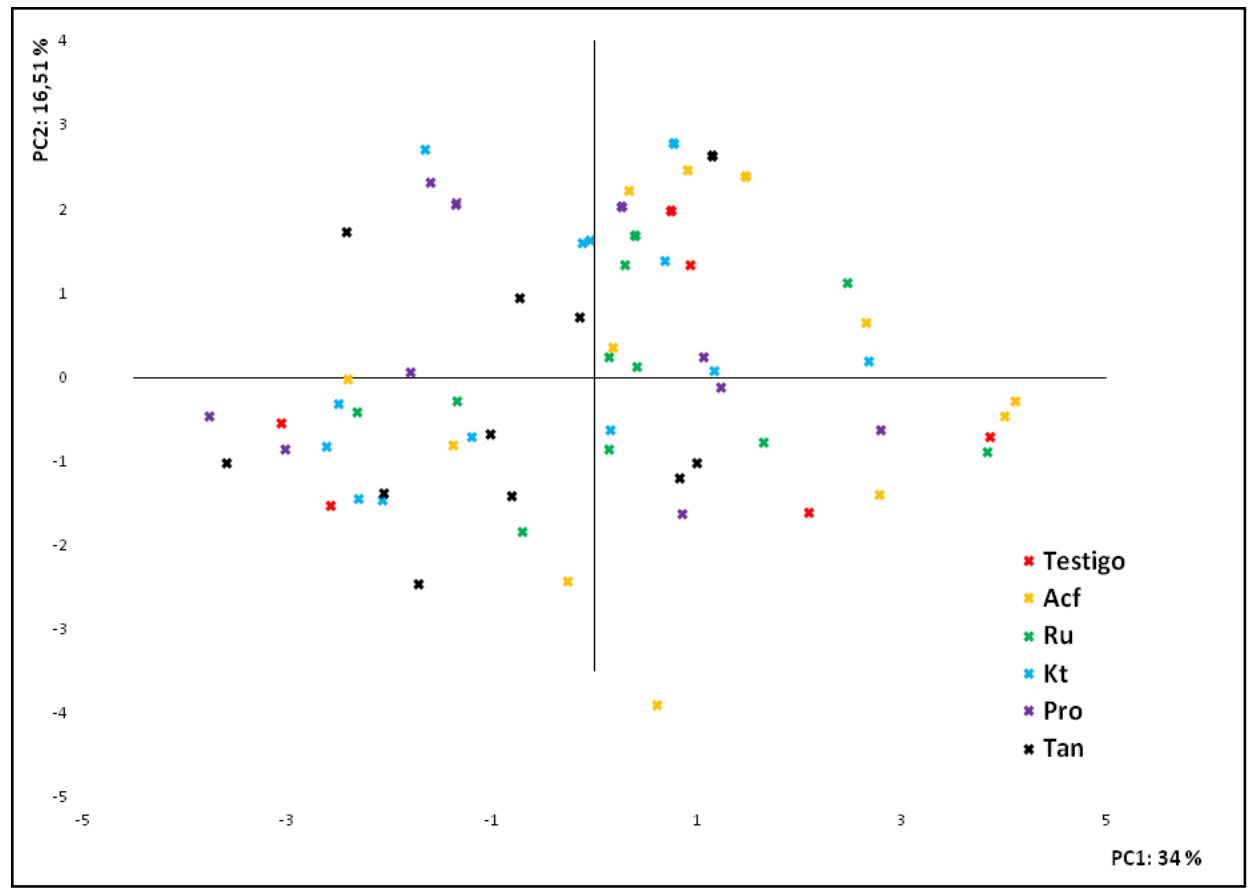

Gráfico 6.7. Primera componente frente a la segunda, en función de los copigmentos ensayados

Una vez comprobadas que variables están más correlacionadas con las componentes principales, se calcularon los coeficientes de las combinaciones lineales, para poder calcular a partir de ellos las nuevas coordenadas de los objetos en las 
componentes. En los gráficos mostrados (Gráfico 6.7 y Gráfico 6.8) donde se representan los vinos elaborados en función de los distintos copigmentos ensayados, no se observa ninguna tendencia determinada, ya que los vinos se sitúan aleatoriamente a lo largo de los ejes principales. Destacando que ningún copigmento presenta un comportamiento diferenciador frente a los vinos no adicionados o frente al resto de los copigmentos ensayados.

El único comportamiento observado es la presencia de parte de los vinos elaborados en la zona negativa del tercer eje principal, relacionado con el parámetro que mide el porcentaje del color que corresponde a la copigmentación. Este comportamiento parece indicar que la adición de copigmentos puede afectar a las reacciones de copigmentación entre los distintos polifenoles, a pesar de que ninguno de los copigmentos permite diferenciar a los vinos objeto de estudio.

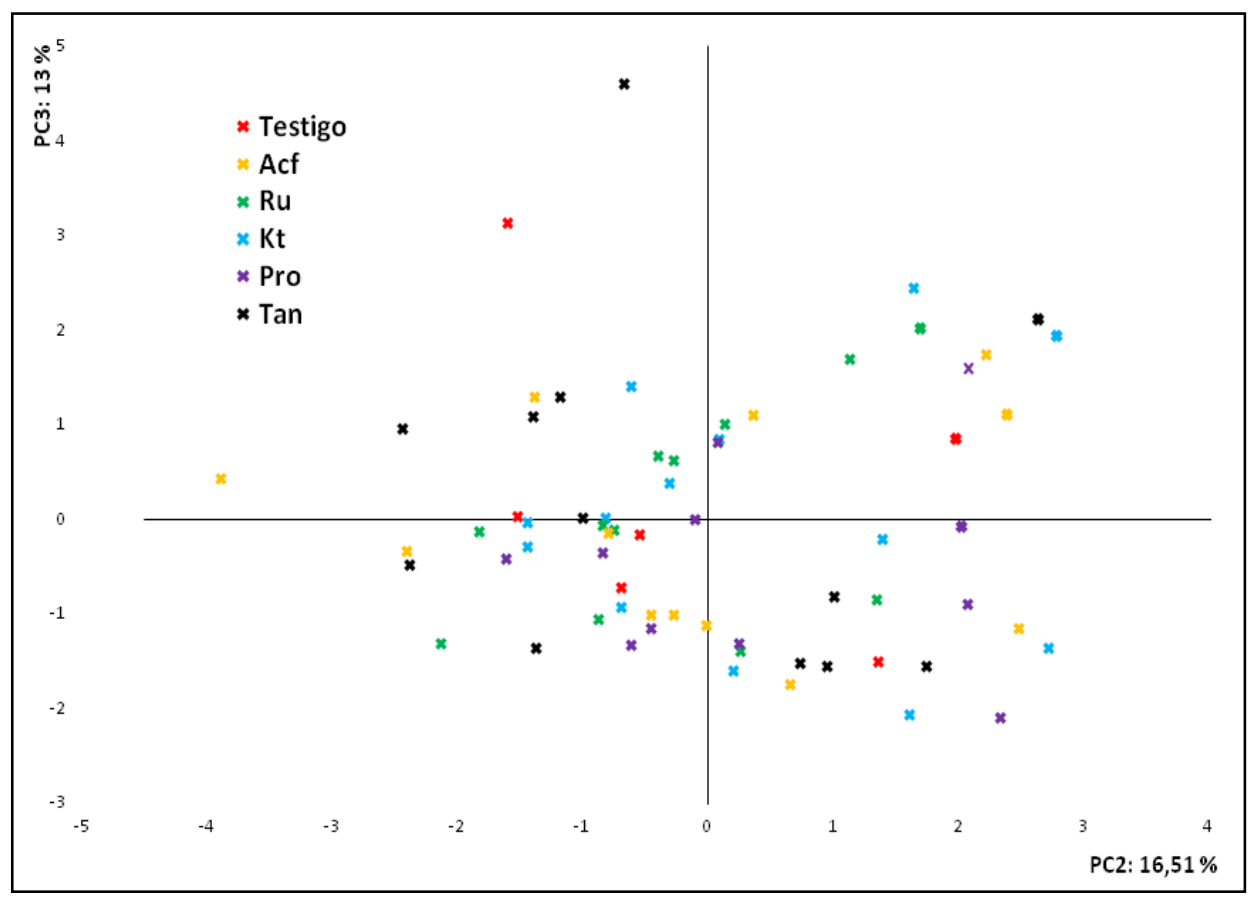

Gráfico 6.8. Segunda componente frente a la tercera, en función de los copigmentos ensayados

A continuación se recoge la representación de los vinos elaborados en función de la técnica de vinificación utilizada. Se ha representado de nuevo la primera componente frente a la segunda (gráfico 6.9) y la segunda componente frente a la tercera (gráfico 6.10).

El primer componente principal identificado separa los vinos a lo largo del eje, observándose como aquellos vinos macerados prefermentativamente usando nieve carbónica se sitúan en la zona negativa del gráfico. Estos vinos están relacionados con parámetros como el tono, la concentración de antocianos totales, copigmentados, catequinas y taninos, parámetros que han mostrado una mayor concentración en los vinos criomacerados al cabo de 12 meses

Por el contrario, se observa cómo algunos de los vinos elaborados de forma tradicional o macerados a bajas temperaturas, están situados en la zona positiva del 
primer componente. Estos vinos se caracterizan por tener una mayor concentración de pigmentos poliméricos, en detrimento de los complejos de copigmentación.

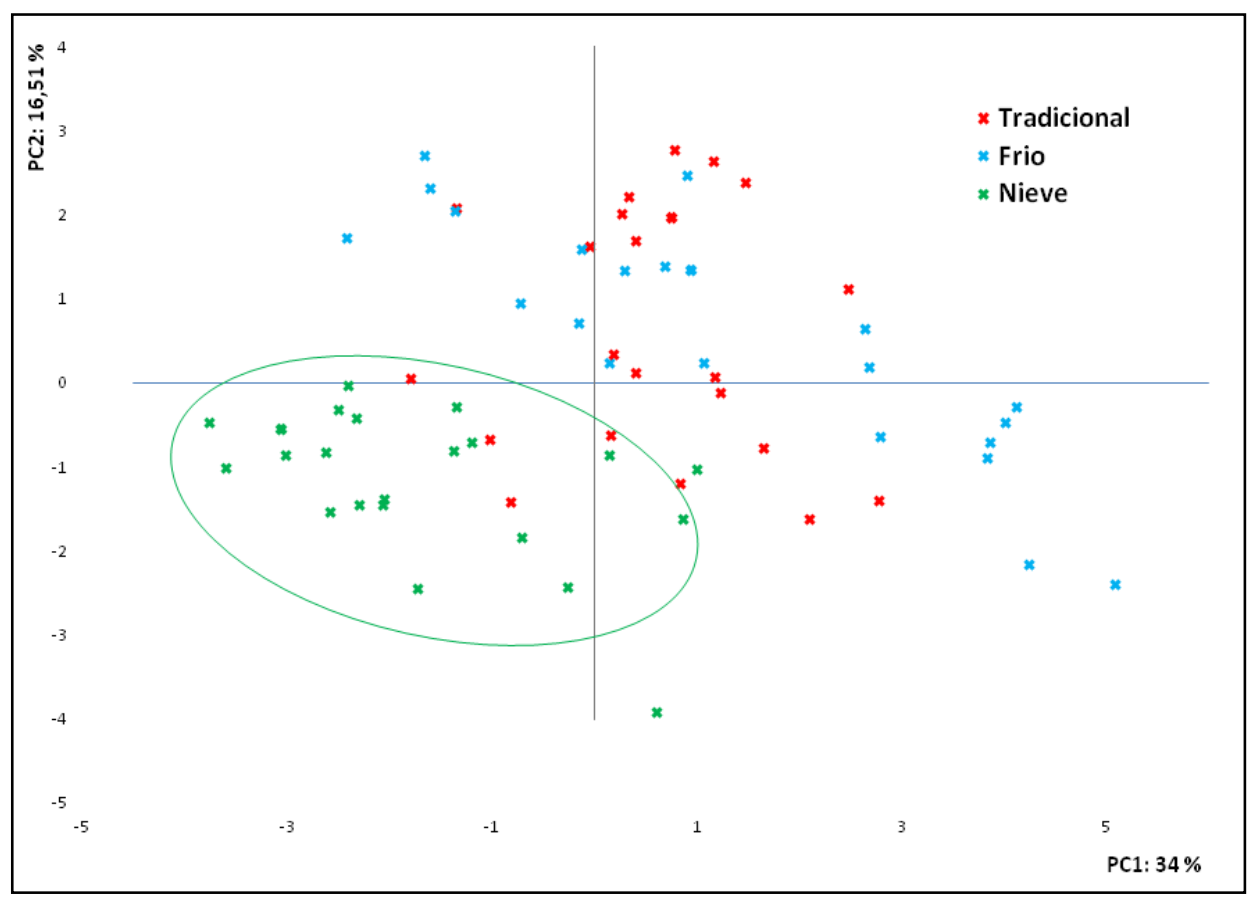

Gráfico 6.9. Primera componente frente a la segunda, en función de las técnicas de vinificación ensayadas.

Los vinos macerados con nieve carbónica se sitúan en la zona negativa del segundo eje, mientras que las otras dos técnicas de vinificación ensayadas se distribuyen a lo largo del eje, tanto en su zona positiva como en la negativa. Los vinos, macerados con aplicación de frío o elaborados de forma tradicional se diferencian de los de nieve carbónica por su concentración fenólica y por el grado de polimerización de sus taninos.

En cuanto al tercer componente, nos permite una separación entre los vinos macerados prefermentativamente (parte negativa del eje) y los vinos elaborados de forma tradicional, situados en la parte positiva. Este tercer componente, en su parte negativa corresponde a vinos que presentan un menor tono, menor color debido a los antocianos libres y menor grado de polimerización de sus taninos, mientras que para los vinos elaborados de forma tradicional son los antocianos copigmentados y el índice de gelatina los que más contribuyen a esa diferenciación.

A continuación se representa en los ejes principales identificados los vinos elaborados en función de la técnica de la microoxigenación. En el gráfico 6.11 se observa como la primera componente no permite separar los vinos microoxigenados de aquellos no adicionados de oxígeno. Por el contrario la segunda componente sí que separa los vinos en función de la aplicación o no de esta técnica, situándose los vinos microoxigenados en la zona negativa del eje, mientras que los no microoxigenados se sitúan en la zona positiva. 


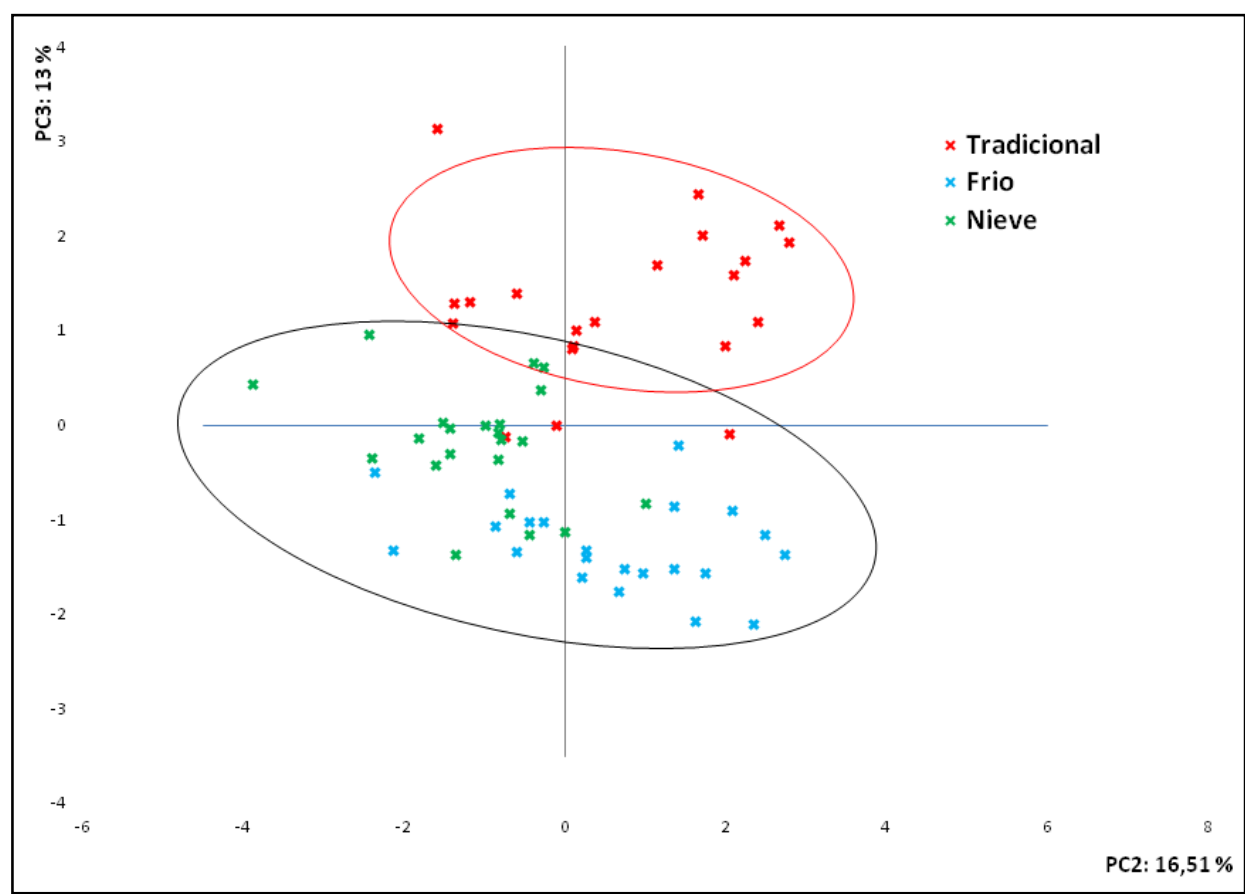

Gráfico 6.10. Segunda componente frente a la tercera, en función de las técnicas de vinificación ensayadas.

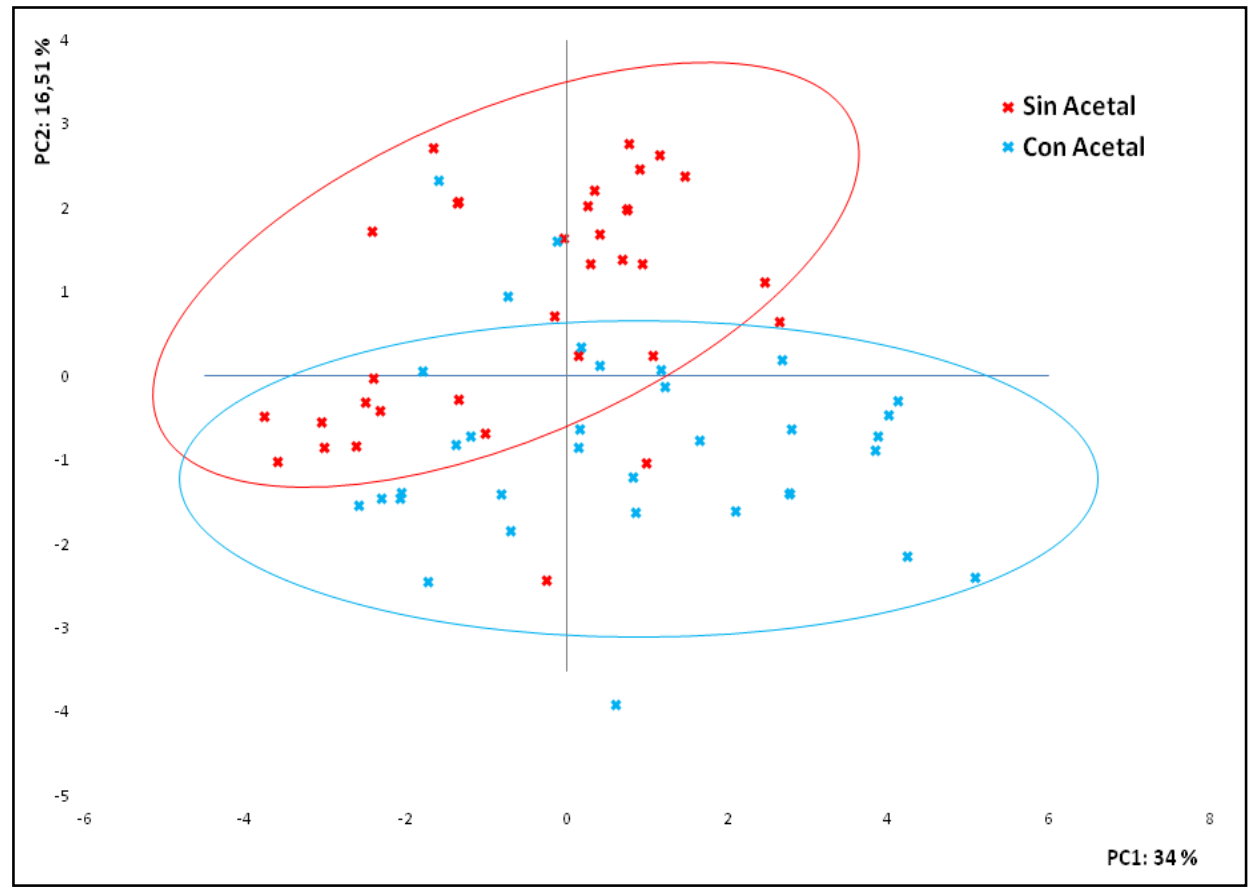

Gráfico 6.11. Primera componente frente a la segunda, en función de la aplicación de la microoxigenación.

Este segundo componente en su parte positiva se relaciona con la concentración total de antocianos y polifenoles, y en menor medida con la de taninos, siendo los vinos 
no microoxigenados los que presentan las concentraciones más elevadas. También el índice de DMACH se correlaciona de forma positiva con los vinos no microoxigenados, pero debido a que el grado de polimerización de los taninos es inverso a éste, serían los vinos microoxigenados los que podrían diferenciarse por su alto grado de polimerización. Esto parece indicarnos que los vinos microoxigenados han sufrido una mayor evolución durante los 12 meses de conservación, produciéndose una mayor precipitación de sus compuestos polifenólicos.

Por último la representación del efecto de la adición pre- o postfermentativa de copigmentos, en función de los tres primeros ejes principales (datos no mostrados), ha dado lugar a una distribución aleatoria que nos indica que el momento de adición de los copigmentos no da lugar a diferencias remarcables, mostrando los vinos elaborados características similares. Esta distribución aleatoria no permite caracterizar los vinos en función de los coeficientes que definen a los componentes principales identificados.

\subsubsection{EVOLUCIÓN DE LOS VINOS ELABORADOS DURANTE 12 MESES DE CONSERVACIÓN EN BOTELLA}

Con el fin de estimar la eficacia de las distintas técnicas aplicadas en el presente trabajo, así como de establecer los mecanismos que tienen lugar durante los doce meses de seguimiento, se estudiará cada uno de los parámetros polifenólicos por separado en función de los distintos factores ensayados.

El análisis multifactorial de la varianza realizado, (tablas 6.1, 6.7 y 6.15) muestra como los factores adición de copigmentos, aplicación de las diferentes técnicas de vinificación ensayadas y aplicación de la microoxigenación, afectan significativamente a la composición fenólica de los vinos tanto después de su elaboración como durante su conservación. Por el contrario el factor momento de adición de copigmentos no da lugar a diferencias estadísticamente significativas para la mayoría de parámetros determinados.

Las interacciones encontradas entre estos factores (copigmentos $\mathrm{x}$ técnica de vinificación, copigmentos $\mathrm{x}$ momentos de adición de los copigmentos, técnica de vinificación $\mathrm{x}$ microoxigenación y técnica de vinificación $\mathrm{x}$ momento de adición de los copigmentos) indican que para los vinos de Tempranillo elaborados, la combinación de estas técnicas podría dar lugar a una metodología de vinificación que permita conseguir una composición fenólica óptima.

Por otra parte, el análisis de componentes principales no ha permitido clasificar los diferentes copigmentos utilizados en el estudio, en función de su poder copigmentante. A pesar de que se observa un efecto positivo de la adición de copigmentos en la composición fenólica de los vinos, no se ha podido establecer de forma precisa que copigmentos son los que presentan las mejores propiedades.

En cuanto a las diferentes técnicas de vinificación utilizadas, el análisis de componentes principales ha permitido su diferenciación, mostrándose la maceración prefermentativa con aplicación de nieve carbónica como la técnica más adecuada para favorecer tanto la copigmentación, como la estabilidad fenólica y del color de los vinos elaborados (gráficos 6.2, 6.4, 6.7). 
Hay que destacar como únicamente se observaron diferencias entre la vinificación tradicional y la maceración prefermentativa con aplicación de bajas temperaturas en el análisis posterior a la fermentación de los vinos (gráfico 6.2), despareciendo estas diferencia para los análisis realizados a los 6 y a los 12 meses de conservación de los vinos en botella (gráficos 6.4, 6.7).

Para la técnica de la microoxigenación, el análisis de componentes principales provocó la separación de los vinos en función de la aplicación controlada de acetaldehído; manteniéndose estas diferencias entre los diferentes vinos elaborados durante todo el proceso de conservación (gráficos 6.5, 6.11). Los vinos microoxigenados son los que presentaron las mejores características fenólicas, manteniendo en mayor medida la estabilidad del color durante el periodo de conservación.

Por último únicamente destacar que la adición pre- o postfermentativa de compigmentos no presentó diferencias cuando los parámetros polifenólicos fueron sometidos al análisis de componentes principales, concluyendo que la adición de copigmentos en un determinado momento del proceso de elaboración no tiene influencia sobre la composición fenólica de los vinos.

Para poder resumir la evolución de los parámetros polifenólicos a lo largo de la conservación, y poder establecer la mejor metodología en función del objetivo deseado, se va a representar la evolución de cada uno de los parámetros por separado, con cada una de las técnicas ensayadas.

\subsubsection{I EVOLUCIÓN DE LA INTENSIDAD COLORANTE}

La adición de copigmentos y la aplicación de la microoxigenación afectan significativamente a la intensidad colorante de los vinos. En la gráfico 6.12 podemos observar como a lo largo del proceso de conservación el efecto de la adición de rutina se va haciendo más evidente, adquiriendo valores significativamente superiores a los seis y doce meses (tablas 6.2, 6.8 y 6.16).

Además, la intensidad colorante de los vinos microoxigenados presenta a lo largo del proceso de conservación valores más elevados que los vinos no microoxigenados (gráfico 6.13), con diferencias significativas a los 6 meses de permanencia en botella (tabla 6.10). Al final del periodo de conservación, las diferencias se han minimizado (tabla 6.18), por lo que la aplicación de esta técnica no modifica significativamente el color de los vinos, a diferencia de lo observado por otros autores (Cano-López et al. 2006, 2007, 2008, 2010; Wirth et al., 2010; Rayne et al., 2008). 


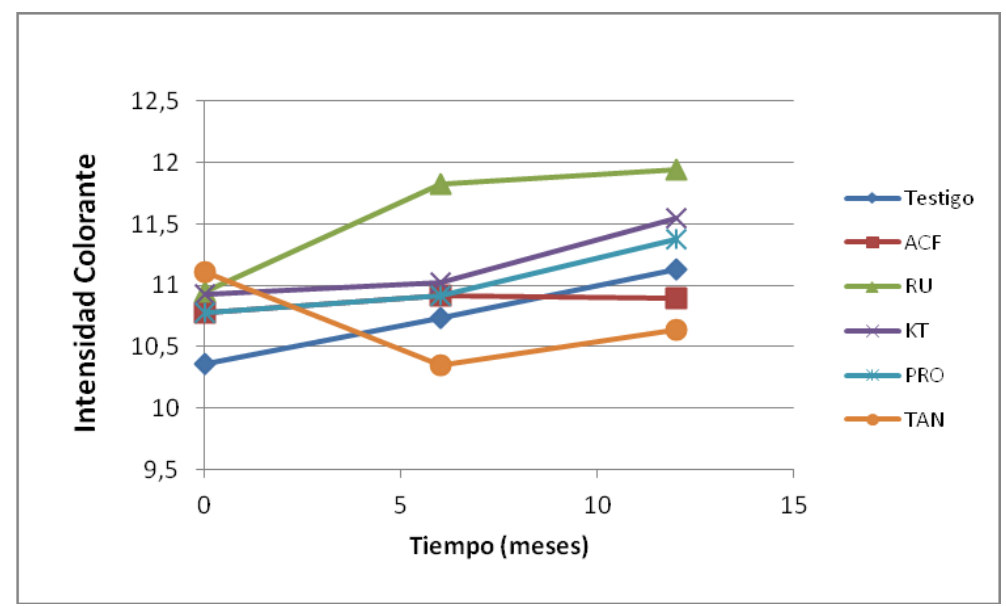

Gráfico 6.12. Evolución de la intensidad colorante durante el periodo de conservación de los vinos en función de la aplicación de copigmentos.

De las técnicas ensayadas, solo la aplicación de rutina permite incrementar el color de los vinos de Tempranillo cuando estos son valorados después de un periodo de conservación de 12 meses. Aquellas uvas con problemas de color debido a las condiciones edafoclimáticas, clon cultivado, etc., podrían conseguir mediante la adición de rutina mejorar su color e incluso incrementarlo durante la conservación. El momento en el que se adicione la rutina no ha provocado la aparición de diferencias estadístiamente significativas en el presente estudio, por lo que no influiría en el resultado final el momento de adición.

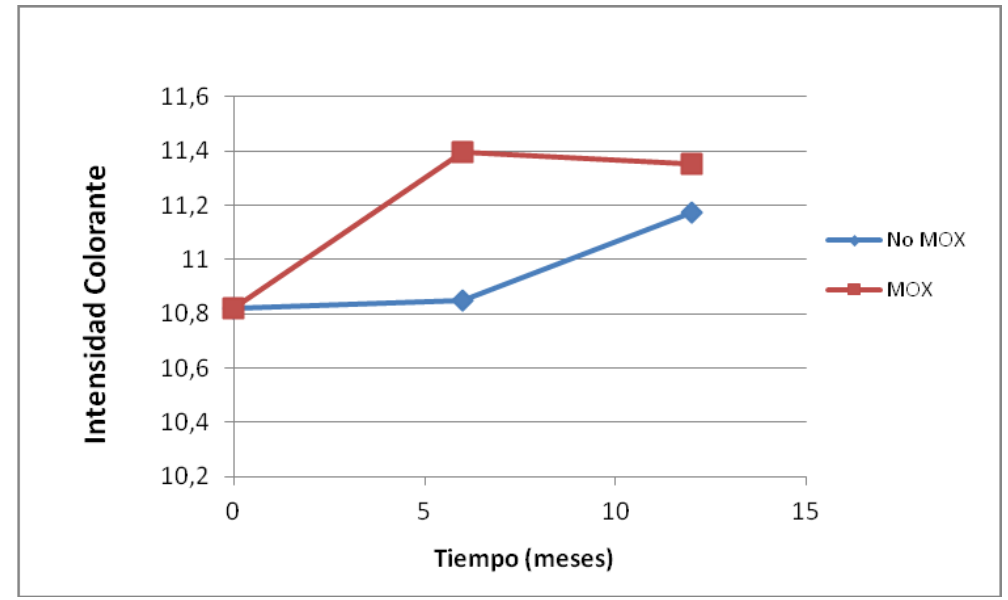

Gráfico 6.13. Evolución de la intensidad colorante durante el periodo de conservación de los vinos en función de la aplicación de la microoxigenación.

\subsubsection{2. $\quad$ EVOLUCIÓN DEL TONO}

La adición de copigmentos da lugar a pequeñas diferencias en el tono de los vinos suplementados con copigmentos, que no llegan a ser significativas a los 12 meses de conservación.

Las técnicas de vinificación influyen sobre la tonalidad amarilla de los vinos (gráfico 6.14), tal como hemos apreciado en las tablas 6.3, 6.9 y 6.17. La maceración 
con nieve carbónica es un factor de riesgo de oxidación importante por la gran disolución del oxígeno originada a tan bajas temperaturas, y aunque el $\mathrm{CO}_{2}$ actúa desalojando al oxígeno del mosto, la manipulación que tiene lugar puede dejar al vino temporalmente desprotegido.

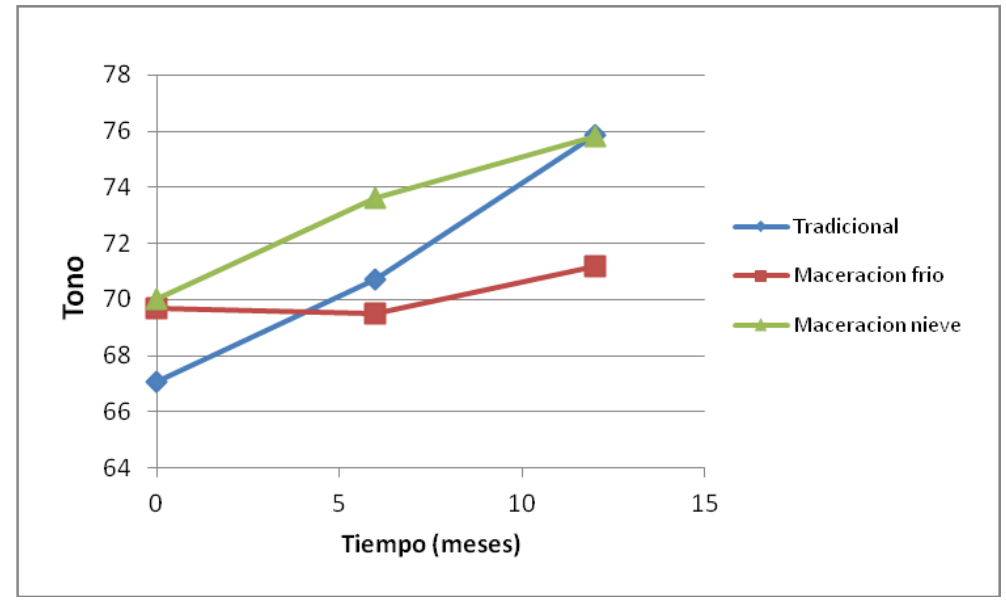

Gráfico 6.14. Evolución del tono durante el periodo de conservación de los vinos en función de la técnica de vinificación aplicada.

Cuando estudiamos el efecto de la microoxigenación sobre el tono (gráfico 6.15), se observa que aquellos vinos que no han sido microoxigenados presentan un mayor tono, manteniéndose estas diferencias hasta el final de la conservación (tablas 6.10, 6.18). Estos resultados son opuestos a los observados por otros autores, que aprecian incrementos del tono en los vinos microoxigenados, (De Beer et al., 2007; Cano-López et al., 2010), debido a la dificultad de ajustar la dosis de oxígeno a las necesidades de los vinos, en función de la composición fenólica, así como también la frecuencia y la duración de la microoxigenación. En nuestro caso, al no haber aplicación directa de oxigeno, la tonalidad amarilla no se incrementa en los vinos microoxigenados.

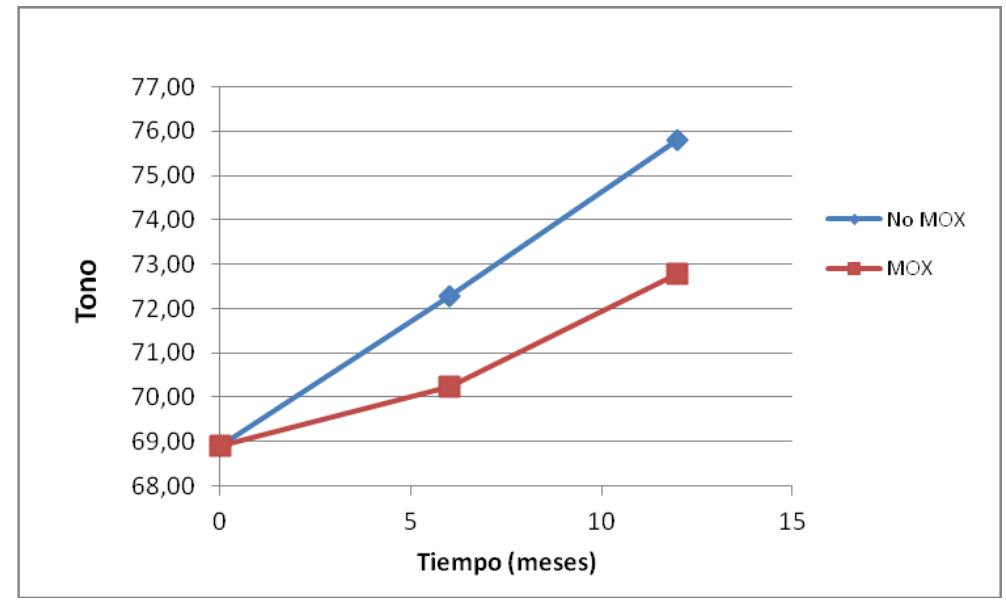

Gráfico 6.15. Evolución del tono durante el periodo de conservación de los vinos en función de la aplicación de la microoxigenación. 
La aplicación de la maceración prefermentativa con nieve carbónica y de la microoxigenación requiere unas condiciones muy controladas para evitar riesgos de oxidación, sobre todo en aquellas variedades oxidativas o con un bajo potencial polifenólico que no contribuya lo suficiente a la protección frente al oxígeno.

\subsubsection{EVOLUCIÓN DE LA CONCENTRACIÓN DE ANTOCIANOS TOTALES}

La concentración total de antocianos decolorables es uno de los parámetros más afectados por las distintas técnicas ensayadas.

En el gráfico 6.16 aparece la evolución de la concentración de antocianos totales decolorables (mg/L) en los vinos adicionados de los distintos copigmentos. Los copigmentos catequina, proantocianidina de hollejo y de pepita de uva blanca son los que presentan una mayor capacidad para mantener la concentración de antocianos en solución a lo largo del periodo de conservación. Este comportamiento pone de manifiesto el efecto protector del color que presentan estos copigmentos de carácter tánico, protegiendolos frente a la degradación (Crespy, 2003 a y b; Crespy y Urban, 2002; Zamora, 2003; Bautista-Ortín et al., 2007). Por el contrario los copigmentos ácido cafeico y rutina no presentan este efecto observado, presentando a lo largo de la conservación valores inferiores a los vinos no adicionados de copigmentos (tablas 6.2, 6.8 y 6.16).

Con respecto a la influencia de las técnicas de vinificación, los vinos macerados en frío son los que muestran los mayores valores para la concentración de antocianos decolorables posteriormente a la fermentación (gráfico 6.17), observándose diferencias significativas para esta técnica y para la aplicación de nieve carbónica, con respecto a la vinificación tradicional (tabla 6.3).

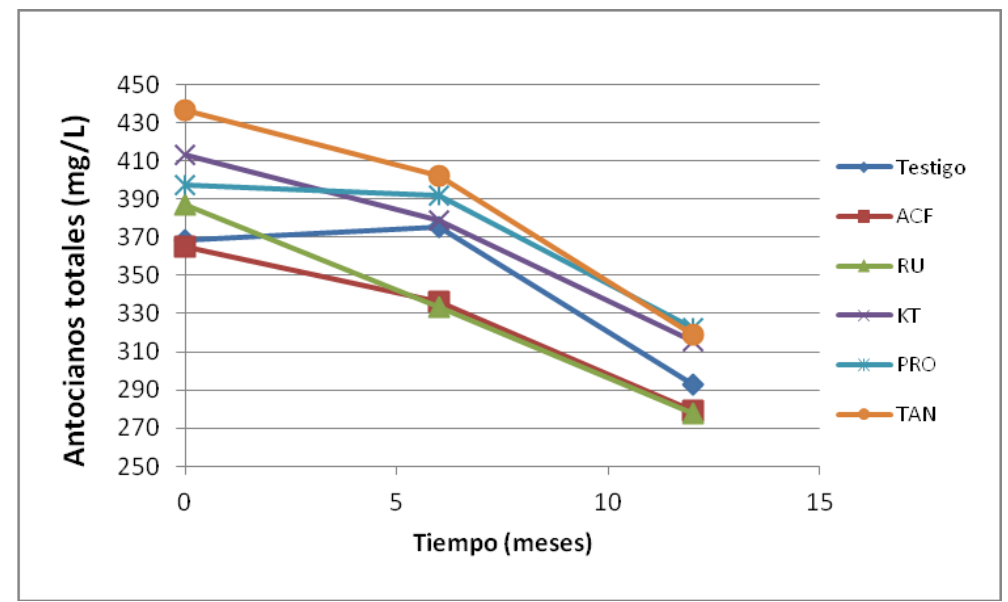

Gráfico 6.16. Evolución de los antocianos totales $(\mathrm{mg} / \mathrm{L})$ durante el periodo de conservacion de los vinos en función de los distintos copigmentos adicionados.

Estas diferencias se mantienen a lo largo del proceso de conservación (tabla 6.9), a pesar de que al final del periodo de evolución en botella los vinos macerados en frío no muestran diferencias significativas con los vinos elaborados de forma tradicional, manteniéndose únicamente las diferencias para el uso de la nieve carbónica (tabla.6.17), quizás debido a la mayor estabilidad de los antocianos provocada por su 
elevada extracción y rápida interacción, con formación de pigmentos poliméricos, más estables (Gil-Muñoz et al., 2009).

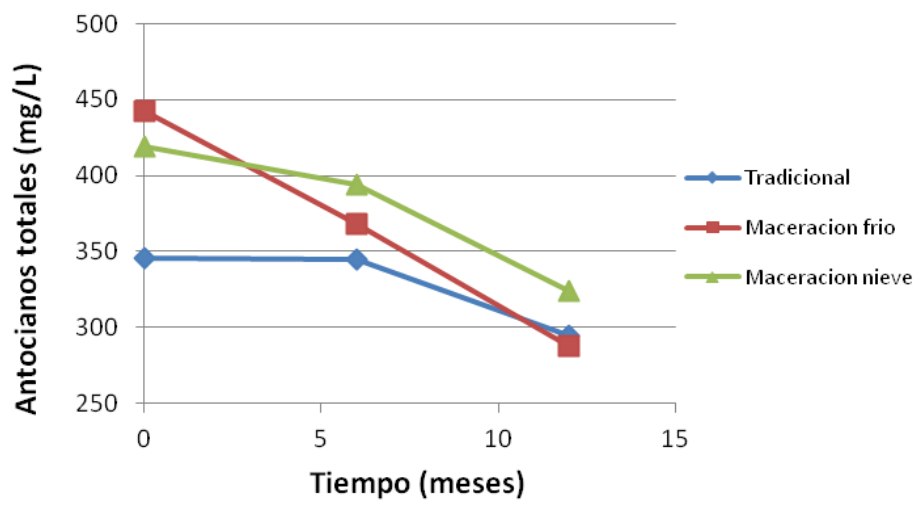

Gráfico 6.17. Evolución de los antocianos totales ( $\mathrm{mg} / \mathrm{L}$ ) durante el periodo de conservación de los vinos en función de las técnicas de vinificación ensayadas.

En el gráfico 6.18 aparece la evolución de la concentración de antocianos totales decolorables a lo largo de la conservación de los vinos, observándose una disminución de su concentración, más pronunciada en aquellos vinos que han sido microoxigenados (tabla 6.10, 6.18). La aplicación de la microoxigenación ha ocasionado una más rápida evolución, con unos niveles de precipitación superiores a los encontrados en los vinos no microoxigenados, aunque destacando como esta menor concentración no se traduce en una pérdida del color, tal como pudimos observar en el gráfico 6.13.

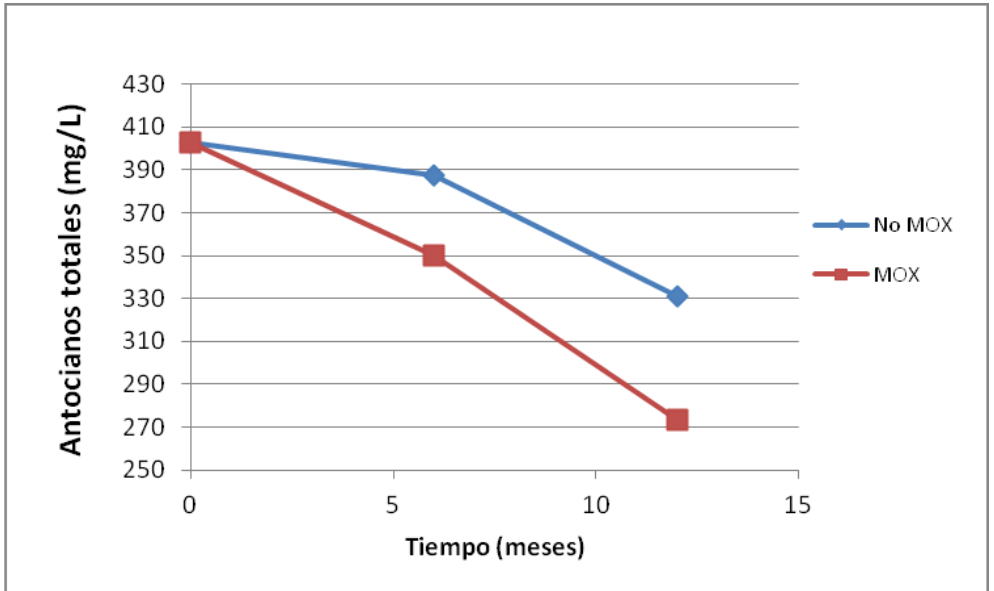

Gráfico 6.18. Evolución de los antocianos totales $(\mathrm{mg} / \mathrm{L})$ durante el periodo de conservación de los vinos en función de la aplicación de la microoxigenación.

La aplicación de copigmentos de carácter tánico, junto con la aplicación de la maceración prefermentativa con nieve carbónica, parecen ser las prácticas recomendadas para minimizar el efecto de precipitación de antocianos observado. 


\subsubsection{EVOLUCIÓN DE LA PROPORCIÓN DE ANTOCIANOS COPIGMENTADOS}

El porcentaje del color que corresponde a los antocianos que se encuentran en forma copigmentada presenta una tendencia decreciente a lo largo de los 12 meses de conservación. Esta fracción del color que es responsable del 20-30\% del color en vinos jóvenes, disminuye progresivamente a lo largo del tiempo, llegando a porcentajes inferiores al 10\% a los 12 meses de permanencia de los vinos en la botella.

Posteriormente a la fermentación de los vinos se observa un efecto positivo de la adición de copigmentos (tabla 6.2), presentando valores superiores a los del testigo no adicionado, manteniendose este efecto a los 6 meses de permanencia del vino en la botella (tabla 6.8). Por el contrario, a los 12 meses de conservación, los vinos testigo son los que presentan un porcentaje del color que corresponde a un mayor grado de copigmentación (tabla 6.16). Esta evolución mostrada en la gráfica 6.19 pone de manifiesto, en primer lugar, la débil estabilidad que presentan estas uniones en los vinos (Hermosín et al., 2005; Gómez-Míguez et al., 2006) y, en segundo lugar, una evolucion más rápida de los vinos adicionados, manteniendo el testigo un mayor porcentaje de copigmentación al cabo de 12 meses, aunque sin diferencias estadísticamente significativas.

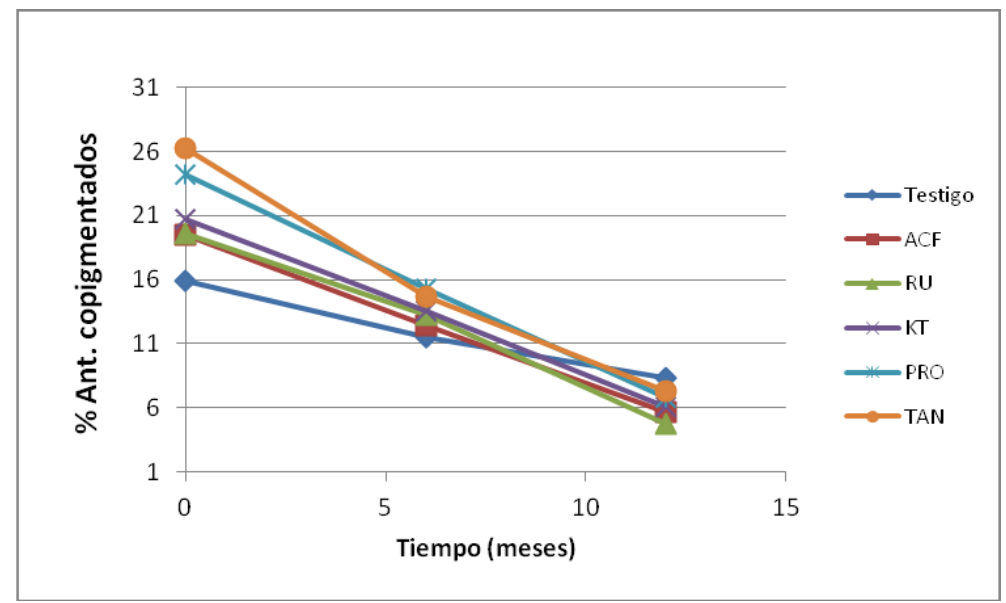

Gráfico 6.19. Evolución del porcentaje de antocianos copigmentados durante el periodo de conservación de los vinos en función de los distintos copigmentos adicionados.

A tenor de los resultados obtenidos, la adición de copigmentos podría ser una técnica adecuada para aquellos vinos que van a ser consumidos jóvenes, durante un periodo de tiempo no superior a 6-8 meses de conservación en la botella. Lorenzo et al. (2005), estudiando la co-vinificación de Monastrell con Cabernet Sauvignon observa como se favorece la copigmentación dando paso a una mayor estabilidad de los antocianos y a una mayor facilidad de polimerización, destacando como la copigmentación fue más importante en los vinos jovenes que en aquellos enevejecidos.

El porcentaje del color que corresponde a los antocianos copigmentados muestra a lo largo del proceso de conservación la influencia de las técnicas de maceración prefermentativa, que presentan valores significativamente superiores a la vinificacion tradicional (tablas 6.3, 6.9, 6.17). 


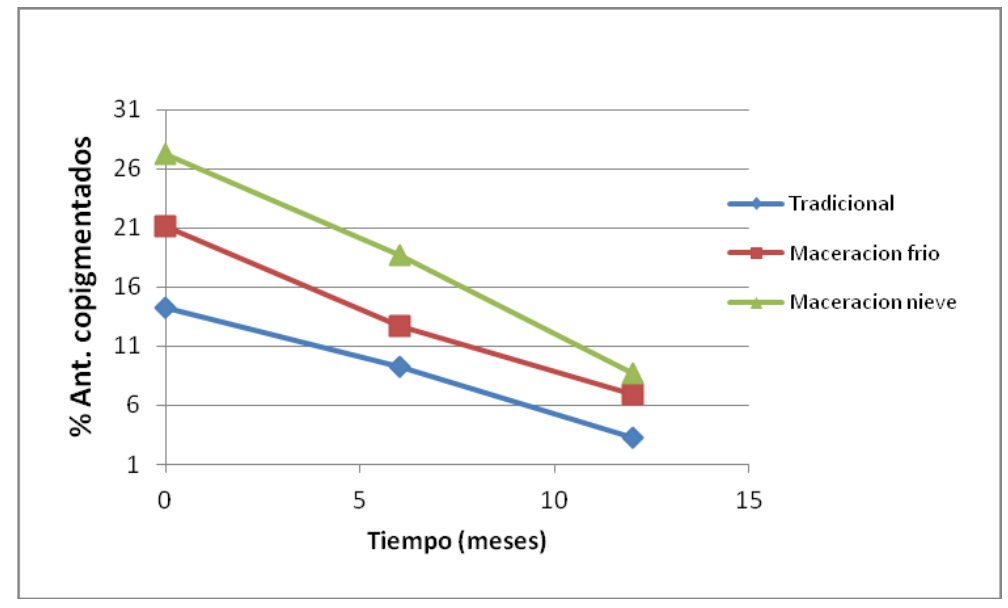

Gráfico 6.20. Evolución del porcentaje del color que corresponde a la copigmentación durante el periodo de conservación de los vinos en función de las técnicas de vinificación ensayadas.

En el gráfico 6.20 se observa como la maceración con aplicación de nieve carbónica presenta también diferencias con respecto a la maceración con aplicación de frío, aunque al final del proceso de conservación estas diferencias hayan desaparecido. Estas técnicas permiten una mayor difusión de antocianos y de otros compuestos que podrían actuar como cofactores o copigmentos, incrementándose el número de éstos en los vinos macerados prefermentativamente, siendo este comportamiento más acusado para el uso de la nieve carbónica, tal como observaron otros investigadores (Koyama et al., 2007; Gordillo et al., 2010; Álvarez et al., 2008; Boulton, 2001).

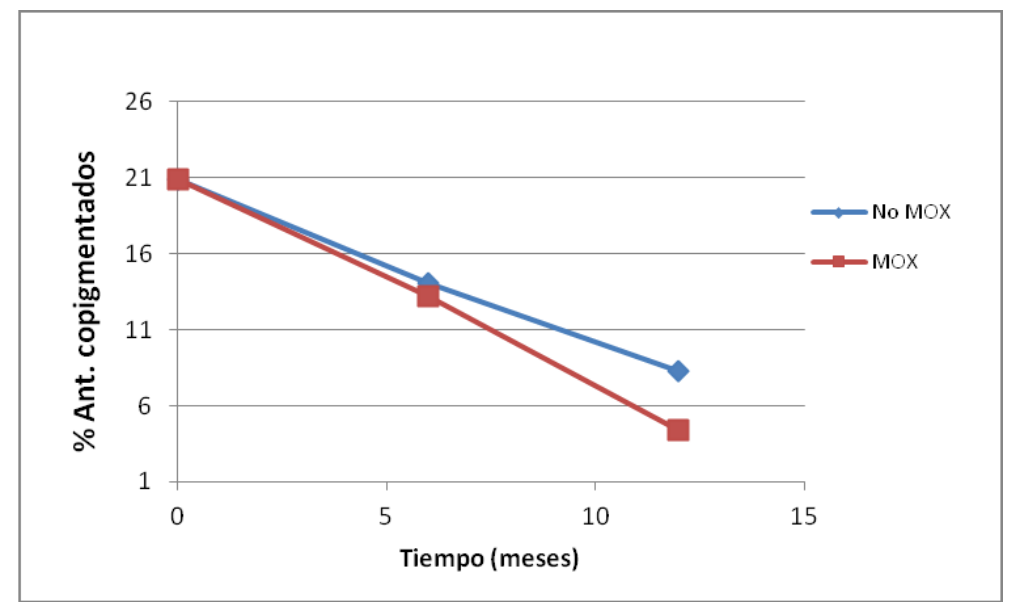

Gráfico 6.21. Evolución de la intensidad colorante durante el periodo de conservación de los vinos en función de la aplicación de la microoxigenación.

El efecto de la microoxigenación sobre los antocianos copigmentados observado en las tablas 6.10, 6.18 se manifiesta en el último período de conservación, ocasionando la microoxigenación un mayor descenso de color debido a los antocianos copigmentados (gráfico 6.21), que posiblemente permita a los antocianos liberados de las reacciones de copigmentación intervenir en otras reacciones. 


\subsubsection{EVOLUCIÓN DE LA PROPORCIÓN DE ANTOCIANOS LIBRES}

El porcentaje de color debido a los antocianos que se encuentran en forma libre, sufre un descenso durante la conservación en todos los ensayos realizados, no apreciándose diferencias significativas entre las distintas técnicas aplicadas, al final del período de conservación. Podemos observar como después de la fermentación maloláctica, el color debido a los antocianos libres es superior en los vinos sin adición de copigmentos (tabla 6.2), y en los macerados de forma tradicional (tabla 6.3), que son los que presentan un menor color debido a las reacciones de copigmentación, pero a medida que trascurre la conservación, y se van rompiendo los complejos de copigmentación, las diferencias se van minimizando.

La maceración tradicional inicialmente incrementa el color debido a los antocianos libres (tablas 6.3, 6.9 y 6.17), pero tal como observamos en el gráfico 6.22, a los 12 meses no hay diferencias. Las técnicas de microoxigenación tampoco dan lugar a diferencias significativas con respecto a los vinos no microoxigenados.

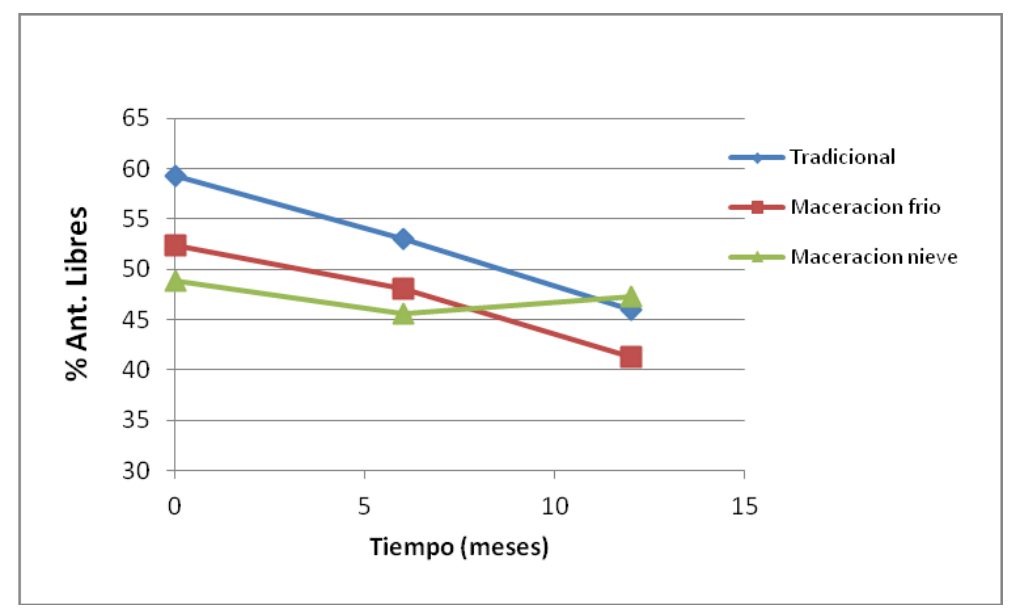

Gráfico 6.22. Evolución del color debido a la fracción de los antocianos libres durante el periodo de conservación de los vinos en función de la técnica de vinificación aplicada.

\subsubsection{EVOLUCIÓN DE LA PROPORCIÓN DE ANTOCIANOS POLIMERIZADOS}

En el gráfico 6.23 se representada la evolución del porcentaje del color debido a los antocianos polimerizados, observándose un incremento de la fracción de antocianos polimerizados conforme transcurre el tiempo, afectando la adición de copigmentos significativamente a estas reacciones, dando lugar a un diferente comportamiento a lo largo de todo el proceso de conservación de los vinos (tablas 6.2, 6.8, 6.13).

El ácido cafeico es el que presenta un mejor comportamiento, sugiriendo que la adición de este ácido fenólico puede contribuir al color de los vinos incrementando la estabilidad de la materia colorante de éstos, incluso posteriormente a un prolongado proceso de envejecimiento en botella, tal como observó Darías-Martín et al. (2001).

Las técnicas de vinificación ensayadas afectan significativamente al porcentaje de estas uniones a lo largo de la conservación de los vinos. Tal y como se observa en el 
gráfico 6.24, en el que aparece representada la evolución de estas uniones durante los 12 meses de conservación, la maceración con aplicación de nieve carbónica aparece como la técnica que menor impacto presenta sobre estas reacciones, con diferencias significativas con respecto a la vinificación tradicional y a la maceración con aplicación de bajas temperaturas (tabla 6.3, 6.9, 6.17).

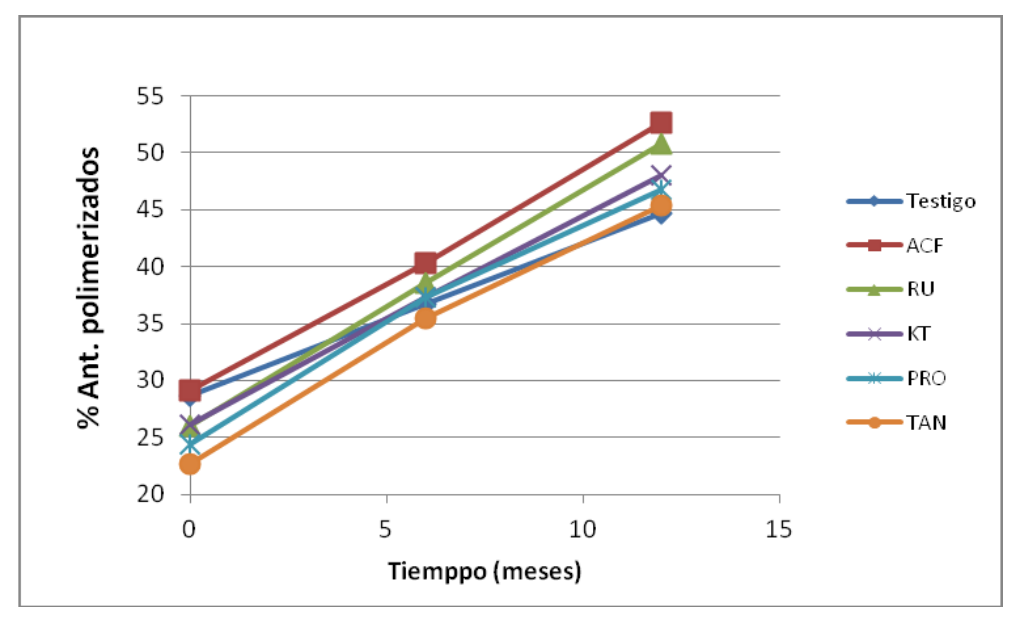

Gráfico 6.23. Evolución del color debido a la fracción de los antocianos polimerizados durante el periodo de conservación de los vinos en función de la adicion de copigmentos.

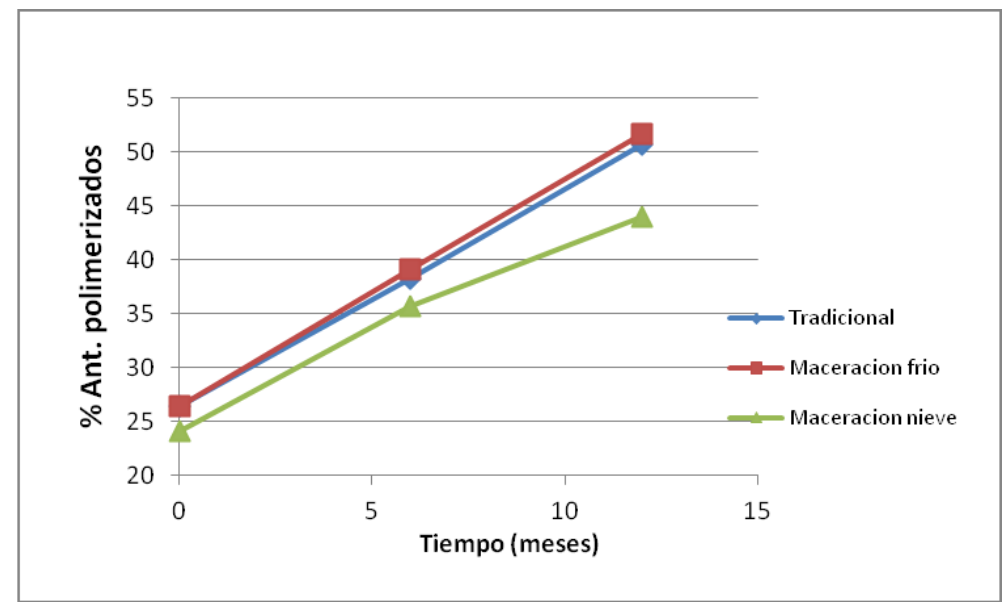

Gráfico 6.24. Evolución del color debido a la fracción de los antocianos polimerizados durante el periodo de conservación de los vinos en función de las técnicas de vinificación ensayadas.

Probablemente la mayor participacion de los antocianos en las reacciones de copigmentación cuando se utiliza la maceración con adición de nieve carbónica, podría ser la causa de este comportamiento (gráfico 6.20). La mayor extracción de cofactores o copigmentos durante la fase prefermentativa habría dado lugar a un incremento y a una mayor permanencia de los complejos de copigmentación (Schawrz et al., 2005; BusseValverde et al., 2010; Heredia et al., 2010), en detrimento de la polimerización de los antocianos, lo que posiblemente sea un inconveniente para mantener la estabilidad de los antocianos en el tiempo. 
En el gráfico 6.25 se observa la evolución del porcentaje de antocianos polimerizados a lo largo de la conservación de los vinos y como la aplicación de la microoxigenación incrementa el porcentaje de estas uniones con diferencias significativas durante todo el periodo de envejecimiento en botella (tablas 6.10, 6.18).

El comportamiento de los antocianos polimerizados, junto con el observado para los antocianos totales, pone de manifiesto que la microoxigenación favorece las uniones entre los antocianos y otros compuestos fenólicos para formar compuestos más estables en el tiempo, responsables de gran parte del color de los vinos envejecidos (CastañedaOvando et al., 2009; Cheynier et al., 2006; Malien-Aubert et al., 2002).

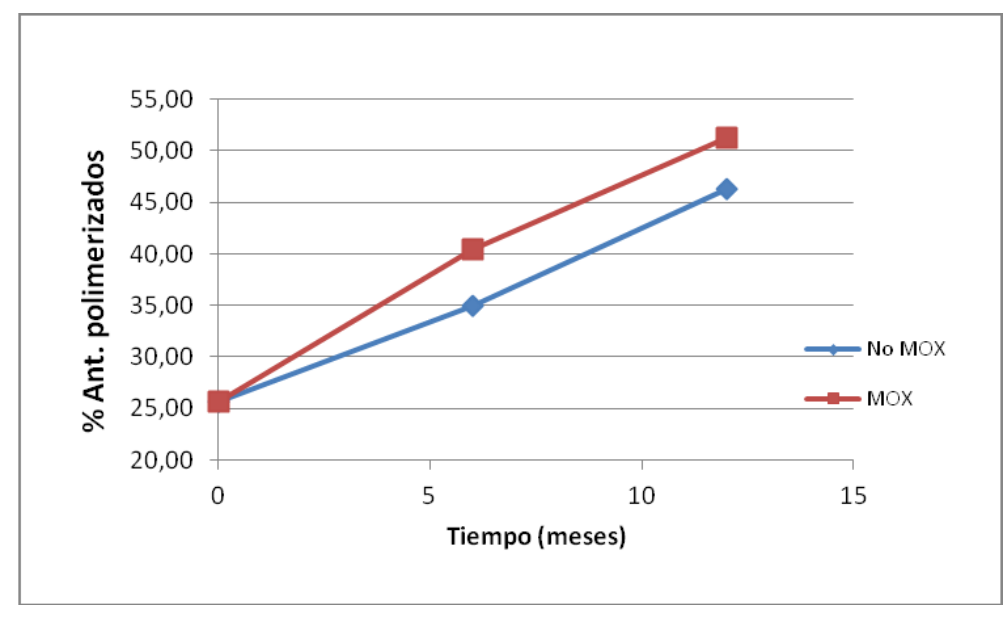

Gráfico 6.25. Evolución del \% de antocianos polimerizados durante el periodo de conservación de los vinos en función de la aplicación de la microoxigenación.

\subsubsection{7. $\quad$ EVOLUCIÓN DEL ÍNDICE DE PVPP}

En el gráfico 6.26 aparece representada la evolución del índice de PVPP a lo largo de la conservación de los vinos, en función de los distintos copigmentos ensayados. La aplicación de esta técnica incrementa la unión entre antocianos y taninos, siendo los copigmentos ácido cafeico, rutina y catequina los que presentan diferencias significativas a los 6 meses del embotellado (tabla 6.8). Por el contrario, únicamente el copigmento ácido cafeico mantiene estas diferencias al final de la conservación de los vinos en botella (tabla 6.16).

La adición de copigmentos favorece el incremento de estas uniones, seguramente debido a la mayor presencia de copigmentación inicial, que permite mantener mayor cantidad de antocianos en los vinos, y que estos intervengan en mayor medida en las reacciones de polimerización, tal como observaron otros autores (Cheynier et al., 2006; Vidal et al., 2002). 


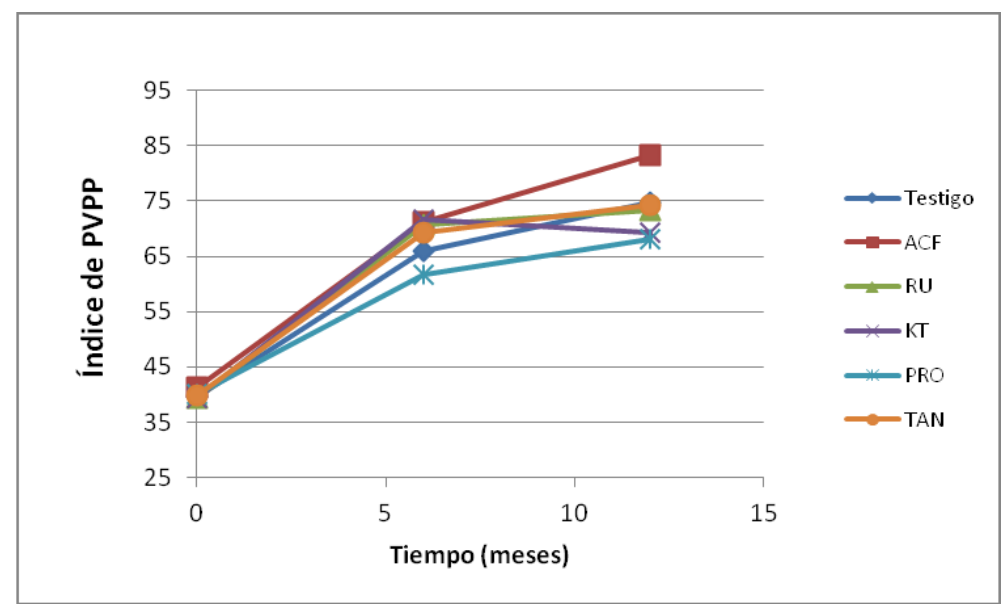

Gráfico 6.26. Evolución del índice de PVPP durante el periodo de conservación de los vinos en función de la adicion de copigmentos.

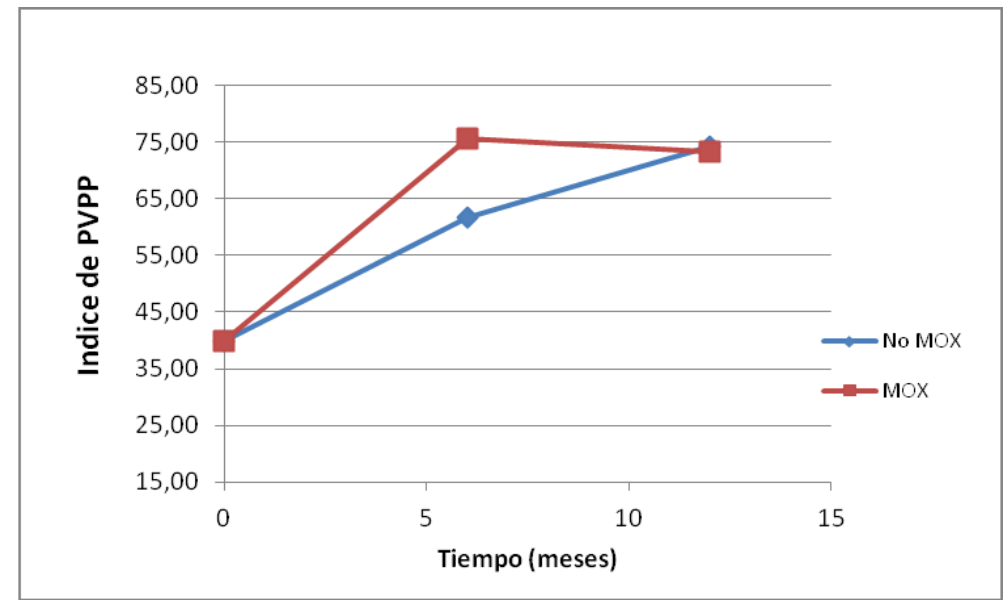

Gráfico 6.27. Evolución del índice de PVPP durante el periodo de conservación de los vinos en función de la aplicación de la microoxigenación.

La microoxigenación favorece el incremento de las uniones entre antocianos y taninos a los 6 meses de conservación (tabla 6.10), desapareciendo las diferencias significativas al final del proceso (tabla 6.18). En el gráfico 6.27 se observa el comportamiento mencionado, influyendo decisivamente las características del vino en la eficacia y efecto de esta técnica.

\subsubsection{8. $\quad$ EVOLUCIÓN DEL ÍNDICE DE FOLIN}

En el gráfico 6.28 aparece la evolución del índice de Folin, que mide la concentración total de compuestos con grupo fenol, para los vinos elaborados en función de los distintos copigmentos adicionados. A lo largo del proceso de conservación, se observa un descenso de la concentración total de polifenoles en los vinos elaborados. Esta pérdida del contenido polifenólico se debe fundamentalmente al gran tamaño molecular de los nuevos compuestos formados durante la conservación, que pueden llegar a la insolubilización, precipitando y disminuyendo su contenido en 
los vinos (García-Falcón et al., 2006; Monagas et al., 2006; Castillo-Sánchez et al., 2008; María-Burin et al., 2011).

La adición de copigmentos provoca, a lo largo del periodo de conservación, una menor disminución en la concentración polifenólica de los vinos, observándose como los copigmentos ácido cafeico, catequina y proantocianidina de hollejo de uva blanca presentan los mayores efectos protectores frente a la pérdida de estos compuestos.

La participación de los antocianos en las reacciones de copigmentación y posteriormente en reacciones de condensación y/o polimerización, entre si o con otros compuestos, provoca un efecto favorable sobre la composición polifenólica de los vinos elaborados, manteniendo unos valores más elevados de este índice, siendo, por lo tanto, una técnica adecuada para mantener la estabilida del color y de aquellos compuestos que participan en la percepción organoléptica de los vinos (Rivas-Gonzalo, 1995; Francia-Aricha, 1998).

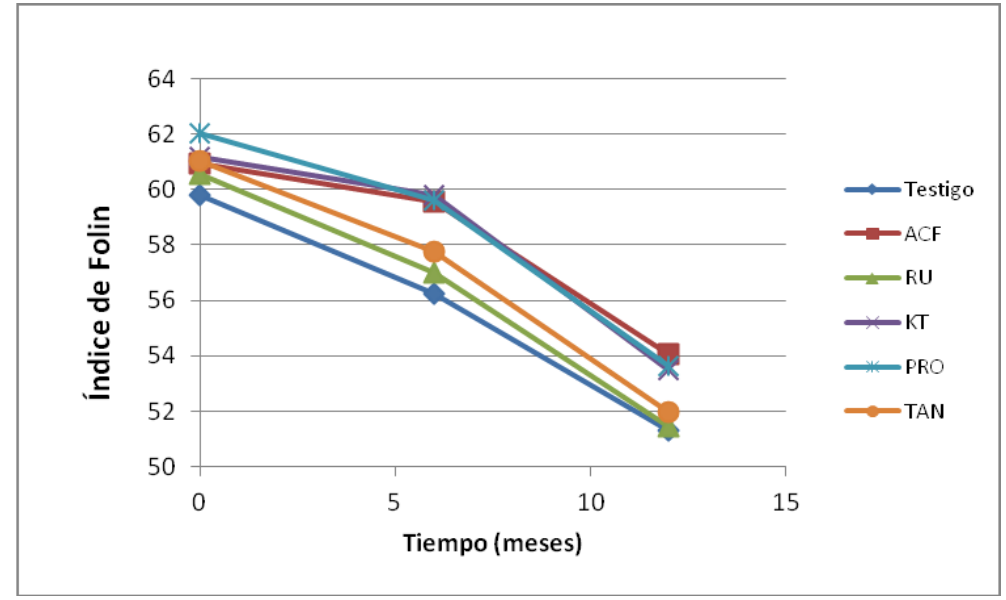

Gráfico 6.28. Evolución del índice de Folin durante el periodo de conservación de los vinos en función de los distintos copigmentos adicionados

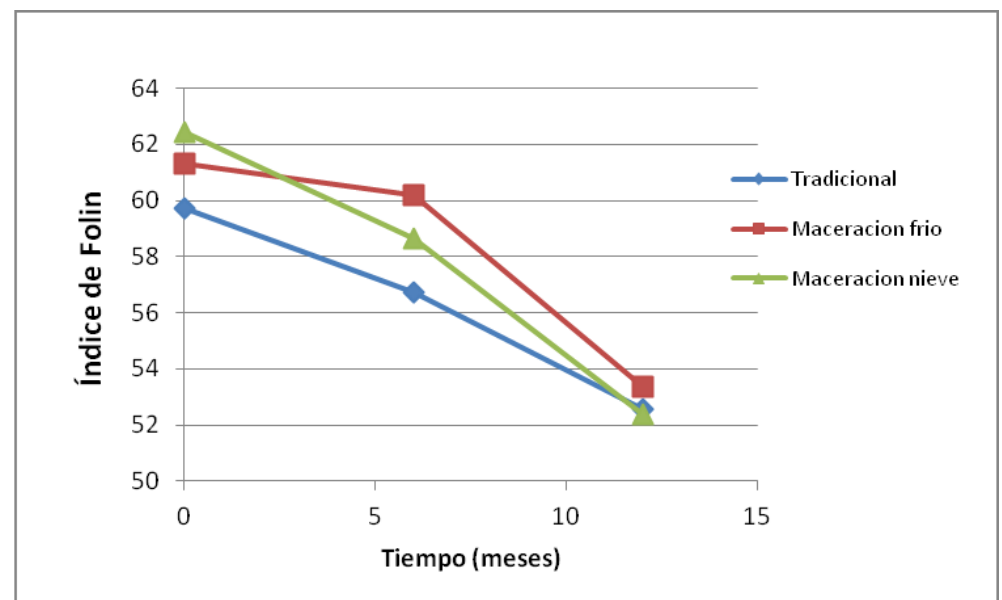

Gráfico 6.29. Evolución del índice de Folin durante el periodo de conservación de los vinos en función de las técnicas de vinificación ensayadas.

El gráfico 6.29 representa la evolución del contenido fenólico de los vinos (índice de Folin) durante la conservación en botella. 
La maceración prefermentativa, tanto mediante la aplicación de frío como mediante el uso de la nieve carbónica, provoca una mayor extracción del contenido polifenólico presente en las partes sólidas de la uva (Koyama et al., 2007; Gil-Muñoz et al., 2009; Gordillo et al., 2010; Soto-Vázquez et al., 2010; Zini et al., 2003), con respecto a una vinificación tradicional. Este hecho provoca que después de la fermentación el índice de Folin sea superior en los vinos que han sido sometidos a dicha maceración prefermentativa, manteniéndose esta concentración durante la mayor parte del proceso de conservación estudiado.

Sin embargo, a los 12 meses de conservación en botella, el uso de la nieve carbónica no presenta ninguna diferencia frente a la vinificación tradicional, indicando una evolución más rápida de estos vinos, provocando una mayor precipitación del material fenólico (tabla 6.17).

En el gráfico 6.30 aparece representada la evolución del índice de Folin durante los 12 meses de conservación de los vinos en botella. La aplicación de la microoxigenación favorece el mantenimiento de la concentración fenólica a los 6 meses de la conservación de los vinos con diferencias significativas (tabla 6.10), desapareciendo éstas al final del periodo de envejecimiento (tabla 6.18). Esta técnica, podría ser adecuada para favorecer la estabilidad del contenido fenólico de los vinos (Gómez-Plaza y Cano-López, 2011; González del Pozo et al., 2010; Pérez-Magariño et al., 2007; Cejudo-Bastante et al., 2010, 2011), aunque su efecto está supeditado a factores como el contenido fenólico, las condiciones de conservación o la estabilidad de la materia colorante.

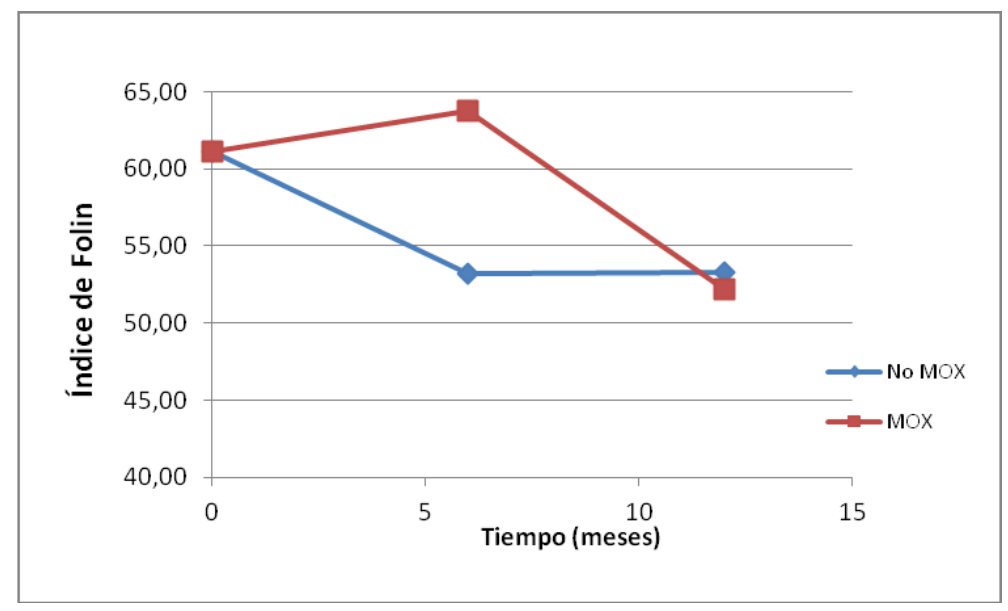

Gráfico 6.30. Evolución del índice de polifenoles totales durante el periodo de conservación de los vinos en función de las técnicas de vinificación ensayadas.

\subsubsection{EVOLUCIÓN DE LA CONCENTRACIÓN DE CATEQUINAS}

La adición de copigmentos no afecta a la concentración de catequinas, ni tampoco la microoxigenación, no obserbándose diferencias a lo largo de la conservación entre los vinos estudiados.

En el gráfico 6.31 aparece representada la evolución de la concentración de catequinas en función de las técnicas de vinificación aplicadas. Se observa que durante 
la conservación, la concentración de catequinas se reduce, quizás debido a la participación de estos compuestos en reacciones de polimerización, entre sí o con otras moléculas (antocianos, proteínas, polisacáridos, etc.). La maceración prefermentativa con adición de nieve carbónica presenta valores significativamente inferiores después del embotellado (tabla 6.3), aunque, por el contrario, al final del envejecimiento es la técnica que mantiene los valores más elevados de estos compuestos (tabla 6.17).

El hecho de que la adición de nieve carbónica mantenga la mayor cantidad de catequinas monómeros, así como la menor cantidad de antocianos polimerizados, puede sugerir que su aplicación podría ser interesante en los vinos que van a ser sometidos a un prolongado proceso de permanencia en botella, ralentizando el proceso de precipitación debido a la formación de grandes polímeros, y contribuyendo de forma directa en las sensaciones de estructura y cuerpo de los vinos (Busse-Valverde et al., 2010; Gawel, 1998; Vidal et al., 2003; Cheynier et al., 2006).

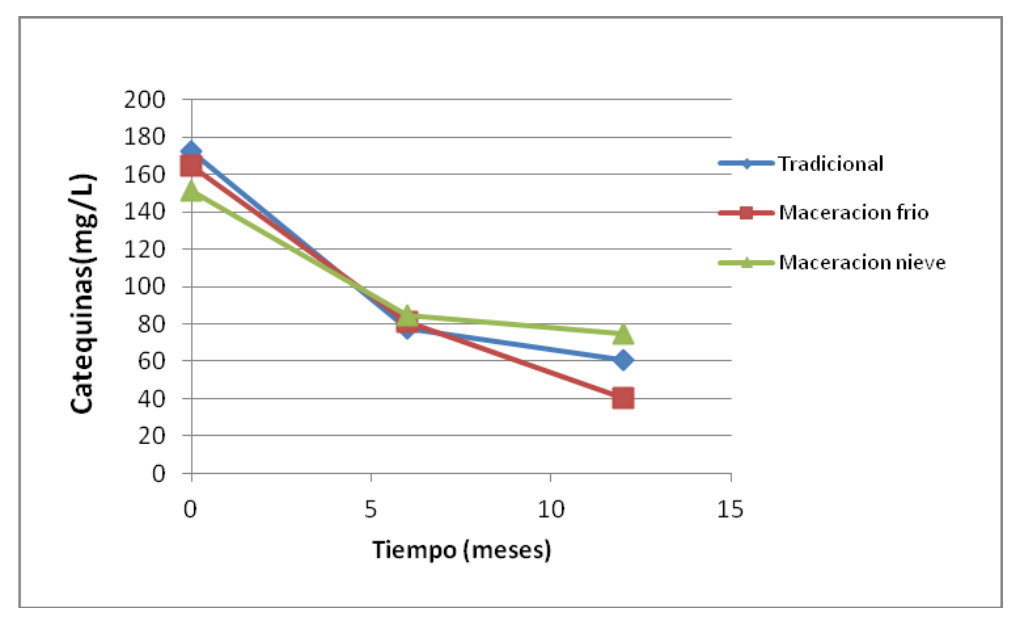

Gráfico 6.31. Evolución de la concentracion de catequinas durante el periodo de conservación de los vinos en función de las técnicas de vinificación ensayadas.

\subsubsection{EVOLUCIÓN DE LA CONCENTRACIÓN DE TANINOS}

La evolución de la concentración de taninos a lo largo del periodo de conservación de los vinos sometidos a distintas técnicas de maceración, aparece representada en el gráfico 6.32, observándose un ligero incremento a lo largo de este periodo, provocado por reacciones de condensación de monómeros de catequinas, sin llegar a pesos moleculares tan elevados que provoquen precipitación y con ello una disminución de la concentración de taninos.

En los vinos analizados después de la fermentación la aplicación de nieve carbónica favorece una mayor extracción de taninos (tabla 6.3), indicando que esta técnica incrementa la extracción de taninos de las partes sólidas, a pesar de no existir alcohol durante la maceración prefermentativa, estas diferencias se mantienen al final del proceso de conservación (tabla 6.17). Busse-Valverde et al. (2010) observan que en los vinos elaborados con la variedad Monastrell, la aplicación de nieve carbónica en la etapa prefermentativa también incrementa la concentración tánica, destacando como este aumento se debe principalmente a tanino de la semilla y sugiriendo que la presencia de etanol no es tan crucial en la extracción de estos compuestos. 


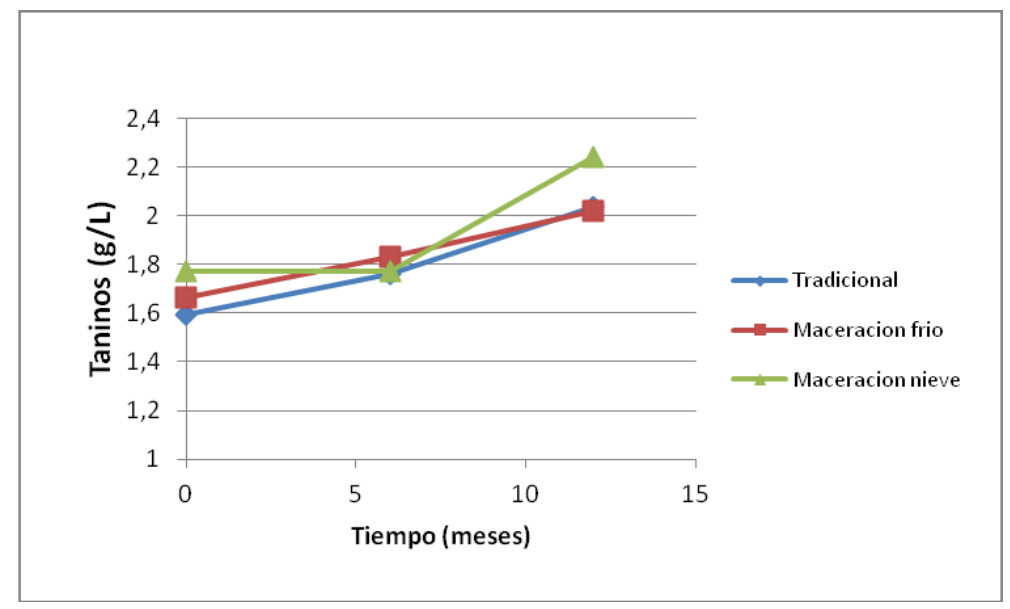

Gráfico 6.32. Evolución de los taninos ( $\mathrm{g} / \mathrm{L}$ ) durante el periodo de conservación de los vinos en función de las técnicas de vinificación ensayadas

\subsubsection{I EVOLUCIÓN DEL ÍNDICE DE DMACH}

La adición de copigmentos afecta decisivamente al grado de polimerización de taninos medido mediante el índice de DMACH. En el gráfico 6.33 aparece representada la evolución a lo largo de 12 meses, observándose como el copigmento catequina es el que muestra el menor grado de polimerización durante la conservación de los vinos en botella (tabla 6.16). Evidentemente, la adición de este compuesto monómero incrementa su concentración en los vinos, y con ello el menor porcentaje de polimerización observado.

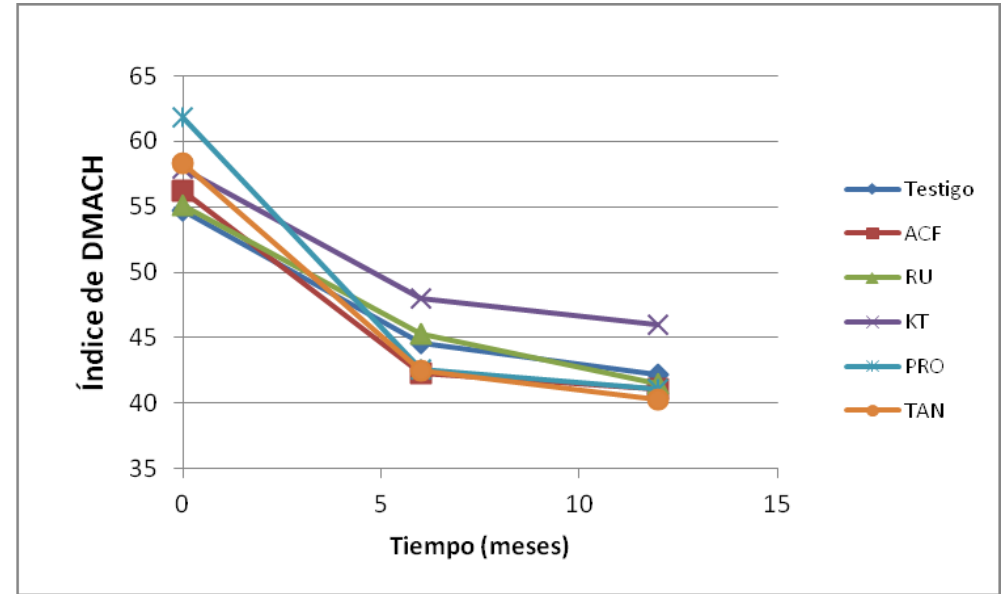

Gráfico 6.33. Evolución del índice de DMACH durante el periodo de conservación de los vinos en función de los distintos copigmentos adicionados

De nuevo las técnicas de maceración prefermentativa son las que presentan valores más bajos para el índice de $\mathrm{DMACH}$, indicando un mayor grado de polimerización de los taninos en el vino. La mayor y más rápida extracción de compuestos fenólicos de las partes solidas durante la fase prefermentativa provoca que estas moléculas empiecen antes a reaccionar entre sí, alcanzándose mayores grados de polimerización que en aquellos vinos elaborados de forma tradicional. Existiendo al 
final del periodo de conservación de los vinos diferencias significativas entre cada una de las técnicas de vinificación ensayadas (tabla 6.17).

En el gráfico 6.34 aparece representada la evolución, a lo largo de 12 meses, del grado de polimerización de los taninos, en función de las distintas técnicas de vinificación ensayadas. Podemos destacar que la aplicación de nieve carbónica podría ser una técnica adecuada para favorecer la polimerización de los taninos, logrando una más rápida disminución de la astringencia, siempre y cuando se alcancen los tamaños moleculares necesarios.

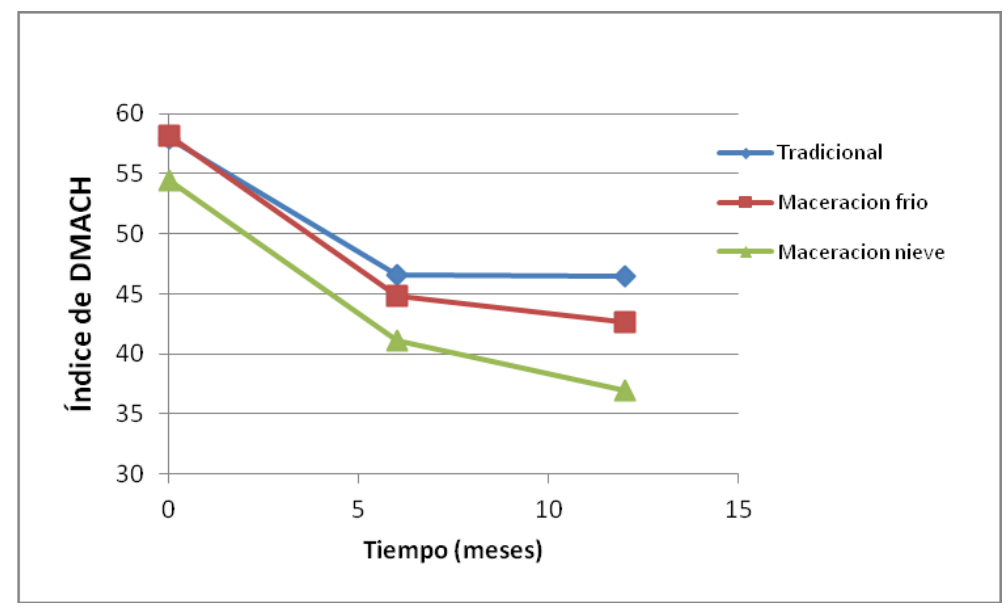

Gráfico 6.34. Evolución índice de DMACH durante el periodo de conservación de los vinos en función de las técnicas de vinificación ensayadas.

Durante el periodo de conservación de los vinos, los parámetros índice de Folin, concentracion de antocianos, concentración de taninos, porcentaje de antocianos copigmentados e índice de DMACH presentan diferencias significativas, observándose como la técnica de maceración prefermentativa afecta a la concentración y estabilidad de los principales compuestos fenólicos presentes en el vino.

La microoxigenación afecta de forma significativa al índice de DMACH; mostrando, tal y como se observa en el gráfico 6.35., como aquellos vinos microoxigenados presentan a lo largo de la conservación mayor grado de polimerización de estos compuestos.

La evolución del grado de polimerización de los taninos muestra como a lo largo de la conservación se incrementa el tamaño molecular medio de estos compuestos, manteniéndose las diferencias significativas durante los 12 meses de permanencia de los vinos en la botella (tablas 6.10, 6.18). La participación del acetaldehído en la polimerización de los taninos, provocará la formación de grandes polímeros insolubles que precipitarán, viéndose reducida la astringencia de los vinos.

La aplicación de la técnica de la microoxigenación se presenta como una práctica que permite mejorar la concentración y estabilidad de los principales compuestos fenólicos, característicos de los vinos tintos. A lo largo del proceso de conservación, la aplicación controlada de oxígeno actuó sobre los parámetros polifenólicos intensidad colorante (IC), tono, antocianos totales, índice de DMACH y porcentaje del color que corresponde a los antocianos polimerizados. 


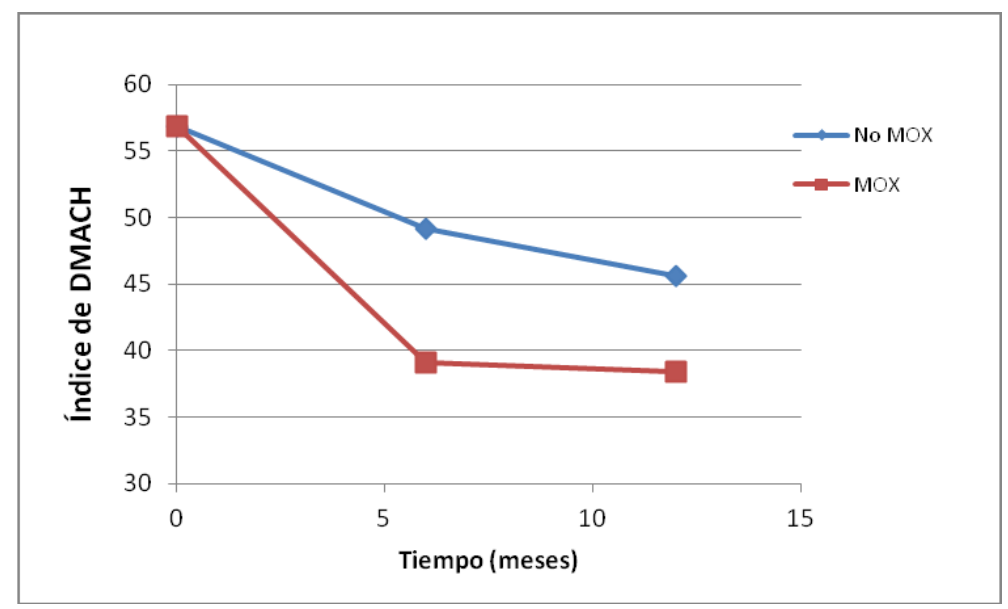

Gráfico 6.35. Evolución del índice de DMACH durante el periodo de conservación de los vinos en función de la aplicación de la microoxigenación.

\subsubsection{EVOLUCIÓN DEL ÍNDICE DE ETANOL}

Tanto para los distintos copigmentos adicionados como para las diferentes técnicas de maceración prefermentativa ensayadas no se han observado diferencias estadísticamente significativas, indicando el efecto nulo de ambas técnicas sobre las reacciones entre taninos y polisacáridos, péptido o sales, que mide este parámetro.

Tampoco las técnicas de vinificación han dado lugar a diferencias significativas en el índice de etanol de los vinos elaborados.

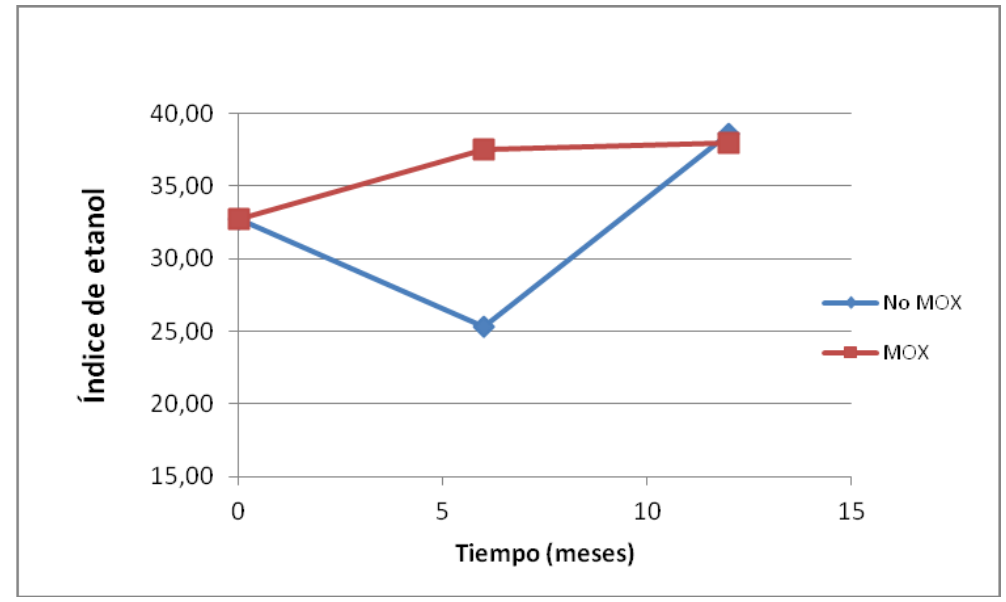

Gráfico 6.36. Evolución del índice de DMACH durante el periodo de conservación de los vinos en función de la aplicación de la microoxigenación.

El efecto de la microoxigenación sobre el índice de etanol aparece representado en el gráfico 6.36. La evolución de este índice durante la conservación de los vinos microoxigenados muestra diferencias significativas a los 6 meses de la conservación (tabla 6.10), minimizándose estas al final del proceso de conservación (tabla 6.18).

Probablemente la adición de acetaldehído ha contribuido también a polimerizar los taninos con los polisacáridos, tal como hemos observado para la polimerización de 
los taninos entre sí, favoreciéndose estas uniones en los vinos, y por consiguiente incrementando la sensación de suavidad y untuosidad que los complejos taninopolisacárido proporcionan. En los vinos no microoxigenados se observa un incremento de estos complejos en los últimos meses de conservación, sin que aparentemente exista una causa que lo justifique, y este incremento tan importante en los vinos no microoxigenados hace que las diferencias a los 12 meses sean mínimas, en contra de lo esperado al observar la evolución de este parámetro los primeros meses.

\subsubsection{EVOLUCIÓN DE ÍNDICE DE GELATINA}

En el gráfico 6.37 aparece representada la evolución del índice de gelatina durante la conservación de los vinos en función de la adición de los distintos copigmentos ensayados. La adición de copigmentos afecta significativamente a la astringencia de los vinos posteriormente al embotellado (tabla 6.2), mostrándose esta adición como una técnica adecuada para disminuir la astringencia de aquellos vinos que van a ser consumidos en un periodo de tiempo relativamente corto.

Los vinos adicionados con los copigmentos ácido cáfeico y rutina son los que presentan una menor astringencia. La interacción de estos antocianos monómeros con los taninos astringentes ha sido probablemente la causa del comportamiento observado (Koyama et al., 2007).

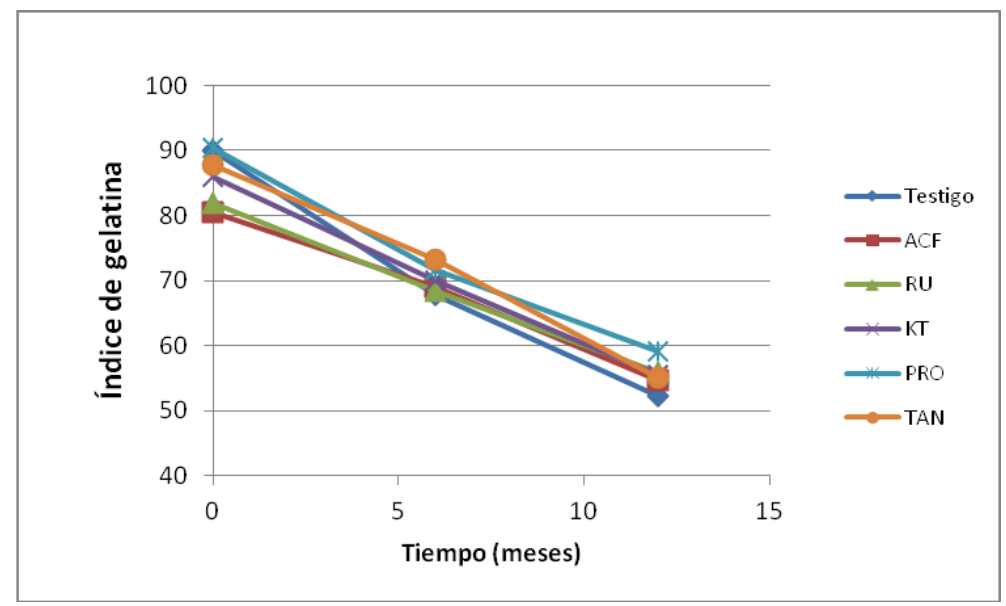

Gráfico 6.37. Evolución del índice de gelatina durante el periodo de conservación de los vinos en función de los distintos copigmentos adicionados.

Por el contrario, al final del proceso de conservación no se observan diferencias significativas en la astringencia de los vinos (tabla 6.16), salvo para el copigmento proantocianidina de hollejos de uva blanca, que da lugar a una mayor astringencia.

Las diferentes técnicas de vinificación ensayadas influyen sobre la astringencia de los vinos. El gráfico 6.38 muestra la evolución de este parámetro durante la conservación, observándose que posteriormente al embotellado son los vinos macerados prefermentativamente en frío los que muestran los menores valores (tabla 6.3). La aplicación de esta técnica podría ser adecuada para disminuir la astringencia en aquellos vinos procedentes de consumo rápido procedentes de vendimias no completamente maduras. 
A los 6 meses de conservación no se observan diferencias en la astringencia de los vinos, y en cambio, al final del periodo de conservación, son los vinos elaborados de forma tradicional los que presentan los menores valores para este parámetro, con diferencias significativas (tabla 6.17).

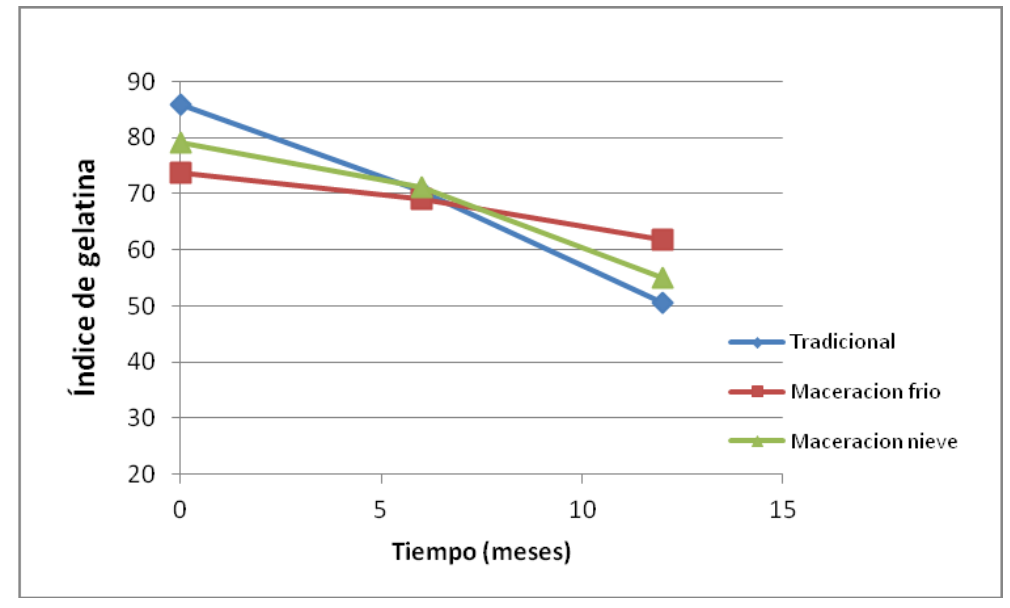

Gráfico 6.38. Evolución del índice de gelatina durante el periodo de conservación de los vinos en función de las diferentes técnicas de vinificación ensayadas.

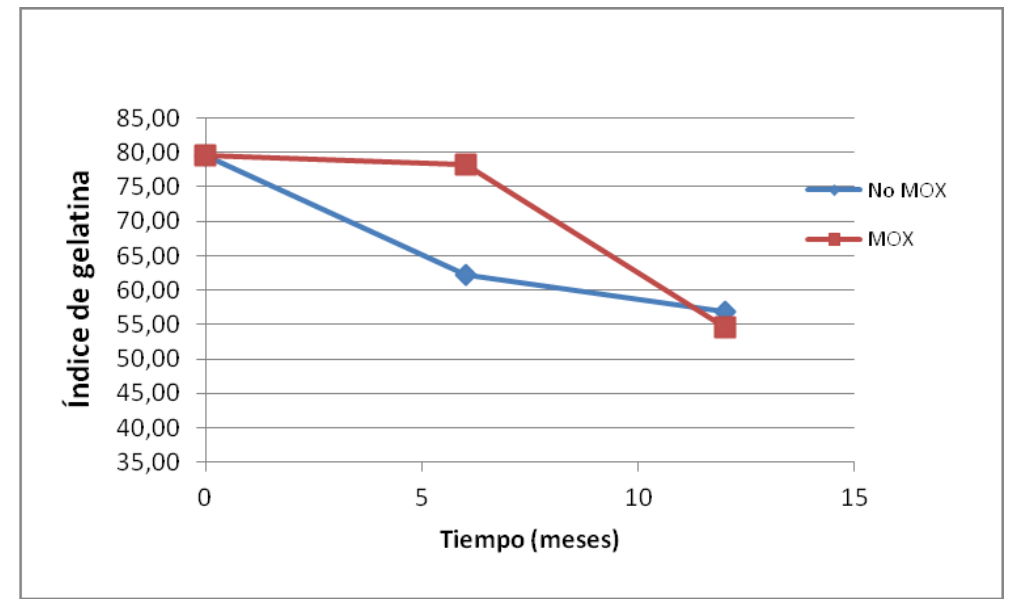

Gráfico 6.39. Evolución del índice de gelatina durante el periodo de conservación de los vinos en función de la aplicación de la microoxigenación.

El efecto de la microoxigenación sobre el índice de gelatina aparece en el gráfico 6.39. Podemos observar que el comportamiento de este índice es muy similar al observado para los polifenoles totales, valorados en el índice de Folin. La microoxigenación no da lugar a un descenso de la astringencia durante los primeros seis meses, debido al incremento de la masa molecular de los taninos, ocasionado por su mayor polimerización, hasta el tamaño en el que son capaces de causar la máxima reacción con las proteínas. Una vez superado este tamaño probablemente las precipitaciones han provocado el descenso observado.

Los vinos no microoxigenados, en cambio, dan lugar a un importante descenso inicial de la astringencia, que puede ser atribuido al descenso de polifenoles por 
precipitación, ya comentado en el índice de Folin. A partir de los seis meses se mantiene la concentración de polifenoles, así como la astringencia, presentando a los 12 meses valores similares a los de los vinos microoxigenados.

\subsection{EFECTO DE LAS PRÁCTICAS ENOLÓGICAS ENSAYADAS SOBRE LA COMPOSICIÓN POLIFENÓLICA DE LOS VINOS ELABORADOS EN 2007.}

La añada 2007 se caracterizó por una pluviometría suficiente en otoño e invierno, una primavera suaves sin heladas relevantes que favoreció una brotación media alta y con buen vigor, un verano seco, con días calurosos y noches con temperaturas bastantes suaves, lo que provocó una buena maduración de la uva. Fue calificada como Muy Buena.

\subsubsection{ANÁLISIS DE LOS VINOS POSTERIORMENTE A LA FERMENTACIÓN MALOLÁCTICA.}

La composición fenólica de los vinos se determinó una vez concluida la fermentación maloláctica, procediéndose con los resultados a realizar análisis comparativo en función de las distintas prácticas enológicas ensayadas.

\subsubsection{ANÁLISIS MULTIFACTORIAL DE LA VARIANZA DE LOS FACTORES CONSIDERADOS}

Con la finalidad de establecer si las distintas técnicas enológicas estudiadas tienen efecto sobre la composición polifenólica de los vinos, se realizó un análisis multifactorial de la varianza (ANOVA) para los factores adición de copigmentos y técnicas de maceración, así como para la interacción entre ambos.

En la tabla 6.23 podemos observar que prácticamente la totalidad de los parámetros polifenólicos estudiados se ven afectados por la adición de copigmentos y por las técnicas de maceración, así como por la interacción entre ambas, lo que pone de manifiesto que la composición fenólica de los vinos adicionados de los distintos copigmentos es distinta en función de la técnica de maceración empleada, tal como observamos en la cosecha de 2006.

En los vinos elaborados con la uva procedente de la vendimia del año 2007 se ha determinado también la concentración de los ácidos fenólicos, 3-flavanoles, flavonoles, delfinidina, cianidina, petunidina, peonidina, malvidina, la suma de los cinco monómeros identificados, los derivados de antocianos, que corresponden a la suma de los antocianos acetilados y cumaroilados y el total de antocianos (suma de las antocianidinas más los derivados de antocianos), utilizando cromatografía líquida de alta resolución. Con ello se pretende realizar una mejor interpretación de los fenómenos que ocurren en el vino a lo largo del proceso de conservación, así como de la influencia de las diferentes prácticas enológicas ensayadas. 
Tabla 6.23. Análisis multifactorial de la varianza (F-ratio) de los factores adición de copigmentos y técnica de maceración, así como de la interacción entre ambos

\begin{tabular}{lccc}
\hline & A & B & \\
& Copigmentos & Técnica & AB \\
\hline I.C. & $7,89^{* * *}$ & $6,01^{* *}$ & $3,66^{* * *}$ \\
Tono & $10,65^{* * *}$ & $5,06^{* *}$ & $3,38^{* *}$ \\
Ant. Totales (mg/L) & $3,22^{*}$ & $7,93^{* *}$ & $2,38^{*}$ \\
\hline Petunidina (mg/L) & 1,54 & $5,59 * *$ & 1,61 \\
Peonidina (mg/L) & $3,38^{*}$ & 2,58 & $3,13^{* *}$ \\
Malvidina (mg/L) & $21,8^{* * *}$ & $131,91^{* * *}$ & $99,74^{* * *}$ \\
\hline Antocianidinas (mg/L) & $18,66^{* * *}$ & $171,31^{* * *}$ & $74,25^{* * *}$ \\
Derivados de ant. (mg/L) & $40,52^{* * *}$ & $28,85^{* * *}$ & $13,2^{* * *}$ \\
Total antocianos (mg/L) & $81,05^{* * *}$ & $337,54^{* * *}$ & $134,51^{* * *}$ \\
\hline \% Ant. Copigmentados & $6,52^{* * *}$ & $3,21^{*}$ & $5,42^{* * *}$ \\
\% Ant. Libres & $18,1^{* * *}$ & $30,43^{* * *}$ & $9,33^{* * *}$ \\
\% Ant. Polimerizados & $10^{* * *}$ & $28,06^{* * *}$ & $3,73^{* * *}$ \\
I. PVPP & $7,8^{* * *}$ & $3,25^{*}$ & $4,97^{* * *}$ \\
\hline I. Folin & $10,28^{* * *}$ & 0,13 & $3,62^{* *}$ \\
Ac. Fenolicos (mg/L) & $188,68^{* * *}$ & 1,49 & $6,8^{* * *}$ \\
Flavonoles (mg/L) & $12,06^{* * *}$ & $5,39 * *$ & $13,75^{* * *}$ \\
3-flavanoles (mg/L) & $12,52^{* * *}$ & 0,5 & 1,49 \\
Catequinas (mg/L) & $3,18^{*}$ & 3,08 & 1,88 \\
Taninos (g/L) & 2,37 & 2,44 & $7,75^{* * *}$ \\
\hline I. DMACH & $10,14^{* * *}$ & 0,59 & 1,62 \\
I. Etanol & $3,84^{* *}$ & $15,96^{* * *}$ & 1,95 \\
I. Gelatina & $4,37^{* *}$ & $3,43^{*}$ & $2,14^{*}$ \\
\hline
\end{tabular}

$* p<0.05 ; * * p<0.01 . * * * p<0.001$

El análisis multifactorial de la varianza muestra como para el factor adición de copigmentos los ácidos fenólicos, la concentración total de antocianos, los derivados de antocianos, la malvidina y porcentaje del color que corresponde a los antocianos libres, por este orden, son los que presentan mayores valores del F-ratio. Los valores del Fratio pueden ser comparados entre sí en cada columna, debido a que el número de comparaciones fue el mismo en todos los casos, indicando un alto valor del F-ratio un efecto más marcado del factor sobre la variable.

El elevado valor del F-ratio encontrado para los ácidos fenólicos puede ser debido a la suplementación realizada con el ácido cafeico, que puede incrementar la concentración de este ácido fenólico, siendo la causa del importante efecto de los copigmentos sobre la concentración de estos ácidos. Es de destacar el hecho de que numerosos investigadores han identificado a estos compuestos como buenos copigmentos (Gris et al., 2005; Eiro y Heinonen, 2002; Malien-Aubert et al., 2001; Schwarz et al., 2005; Darías-Martin et al., 2001, 2002; Kunsági-Máté et al., 2009). 
Los elevados valores del F-ratio de los parámetros relacionados con la concentración y estado de los antocianos indican la influencia que tiene la adición de copigmentos en la composición antociánica de los vinos (Robinson y Robinson, 1931; Boutaric et al., 1937; Osawa, 1982; Mazza y Brouillard, 1987; Boulton, 2001).

El porcentaje de color debido a los antocianos copigmentados también muestra diferencias en función de la adición o no de copigmentos, tal como observaron otros autores (Boulton, 2001; Rivas-Gonzalo et al., 2003; Sacchi et al., 2005). También los polifenoles totales, los flavonoles, los 3-flavanoles y su estado de polimerización, muestran diferencias significativas al nivel de confianza del 99,9\%, sugiriendo la participación de estos compuestos en las reacciones con los copigmentos (RivasGonzalo, 1995; Francia-Aricha, 1998).

La concentración total de antocianos, la de antocianidinas, malvidina, derivados de antocianos y porcentaje de color correspondiente a los antocianos libres y polimerizados, son los parámetros que más están influidos por el factor técnica de vinificación. Este comportamiento indica la influencia de las diferentes técnicas de maceración prefermentativa en la composición y estado de los antocianos, favoreciéndose una mayor extracción de estos compuestos (Reynolds, 2001; Parenti et al., 2004; Álvarez et al., 2005; Heatherbell et al., 1997; Manchón et al., 2005; GilMuñoz et al., 2009; Gómez-Míguez et al., 2006; Gordillo et al., 2010; Koyama et al., 2007), así como una mayor interacción con los diferentes compuestos fenólicos que forman parte del vino (Kovac et al., 1992; Gordillo et al., 2010; Heredia et al., 2010). Es de destacar la escasa influencia de las técnicas de vinificación en la astringencia de los vinos, a diferencia de lo observado en la cosecha de 2006.

La interacción de ambos factores presenta diferencias estadísticas para la mayoría de los parámetros polifenólicos. La concentración de antocianos, de malvidina, antocianidinas, flavonoles y derivados de antocianos, son las variables que presentan un mayor efecto sobre la interacción de ambas técnicas. Una vez más se observa el importante efecto de estas técnicas en la concentración y el estado de los antocianos, afectando también al color, y en menor medida a la composición y al estado de los taninos en los vinos.

\subsubsection{2. $\quad$ EFECTO DE LA ADICIÓN DE COPIGMENTOS}

En la tabla 6.24 aparece el ANOVA simple realizado para el factor adición de copigmentos, donde se recogen los valores medios de los parámetros polifenólicos estudiados, en función de la adición de los distintos copigmentos utilizados.

Todos los copigmentos ensayados, a excepción de la catequina, muestran diferencias en la intensidad colorante de los vinos con respecto al vino testigo, destacando como la adición de copigmentos presenta un incremento del color con respecto a los vinos no adicionados, que aunque no es muy importante, si resulta significativo. Este comportamiento también fue observado en la cosecha anterior, así como por otros autores (González-Manzano et al., 2008; Boulton, 2001). Los copigmentos proantocianidna de hollejo y de pepita presentan una mayor protección frente a la oxidación, minimizando el incremento de la componente amarilla que presentan estos compuestos, tal y como ha sido observado numerosos autores (Crespy, 2003 a, b; Crespy y Urban, 2002; Zamora, 2003; Bautista-Ortín et al., 2007). 
En cuanto a la concentración de antocianos, son los copigmentos de carácter tánico (KT, PRO y TAN) los que presentan los valores más elevados para este parámetro, con diferencias significativas para el copigmento catequina. Por el contrario, los vinos adicionados de ácido cafeico muestran valores similares a los encontrados para los vinos no adicionados de copigmentos, comportamiento similar al observado en la cosecha del año anterior.

El copigmento rutina presenta diferencias significativas para el porcentaje del color que corresponde a la copigmentación, mientras que los otros copigmentos adicionados muestran valores similares $(\mathrm{KT})$ o ligeramente superiores al testigo (ACF, PRO, TAN). Es de destacar el menor efecto observado sobre la copigmentación en esta cosecha, con relación a la adición de copigmentos en la cosecha anterior, a excepción de la rutina, que incrementa su efecto coigmentante. Fang et al. (2008), estudiando la composición de flavonoles en vinos de Cabernet Sauvignon y Merlot, observan como la rutina se comporta de forma diferente en función de la madurez de la uva, lo que sugiere que esta pueda ser la causa de este distinto comportamiento, propiciado por una vendimia más madura que la del año anterior.

Kunsági-Máté et al. (2006), estudiando los parámetros termodinámicos que caracterizan las reacciones de copigmentación entre malvidina-3-glucosido y distintos compuestos fenólicos, observan que, tanto la configuración estérica, como el tamaño del copigmento, juegan un papel importante en la estabilización de catión flavílium. Concretamente destacan como los polifenoles con estructura completamente plana, como la rutina, son los mejores copigmentos debido a la completa superposición de los enlaces covalentes entre la malvidina y el copigmento. Por el contrario copigmentos con estructura no plana, como la catequina o la proantocianidina B2, a pesar de su gran tamaño no son capaces de estabilizar la carga positiva de la forma flavilium en la misma magnitud que la rutina, debido a su inconveniente estérico. En el caso de pequeños polifenoles con estructura plana, como el ácido cafeico, el tamaño del copigmento juega un papel crucial. Debido a su pequeño tamaño, el ácido cafeico no puede estabilizar completamente la carga positiva del catión flavilium, mostrando una más débil copigmentación que la rutina o la catequina, aunque su efecto copigmentante es destacado por numerosos autores (Gómez-Cordovés et al., 1995; Lambert et al., 2010; Malien-Aubert et al., 2007; Schwarz et al., 2005; Davies y Mazza, 1993; Baranac et al., 1996; Baranac et al., 1997; Gómez-Míguez et al., 2006).

El porcentaje del color que corresponde a los antocianos libres presenta un comportamiento opuesto al observado para la copigmentación, siendo las uvas adicionadas del copigmento catequina y el testigo no adicionado los que muestran los mayores porcentajes. Por el contrario aquellos vinos con mayores valores de copigmentación muestran valores inferiores de antocianos libres, al estar un porcentaje alto de los antocianos formando parte de estos complejos. 
0
0
0
0
0
0
0
0
0
0
0
0
0
0
0
0
0
0
0
0
0
0
0
0
0
0
0
0
0
0
0
0
0
0
0
00
0
0
0
0
0
00
0
0
0
0
0
0
0
0
01
0
0
0
0
0
0
0
0

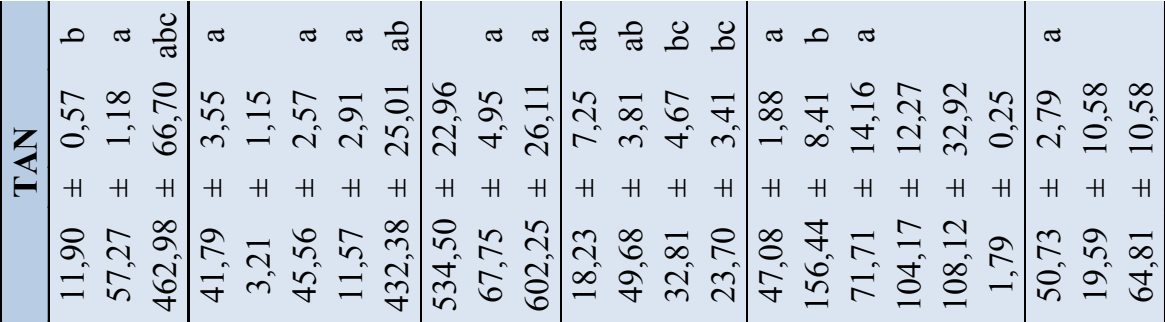

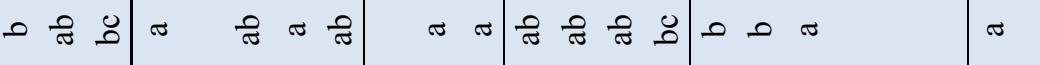

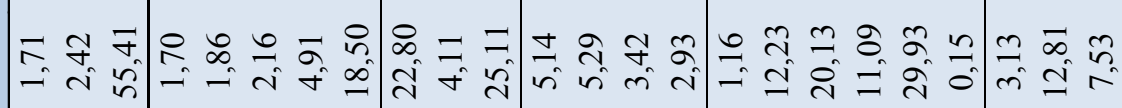
$\stackrel{\varpi}{\exists} \stackrel{0}{\circ}$ $+\mathrm{H}$

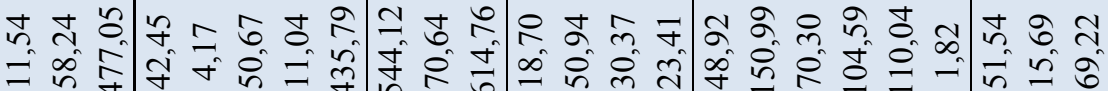

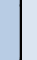

$\approx$ ठ

ก 0

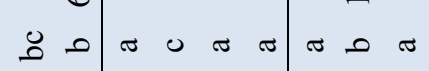

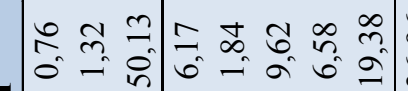

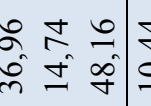

는

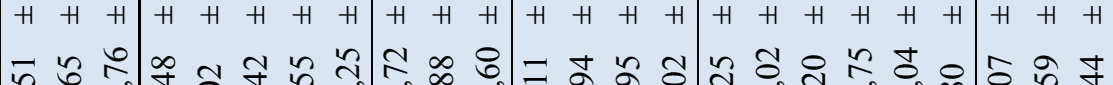

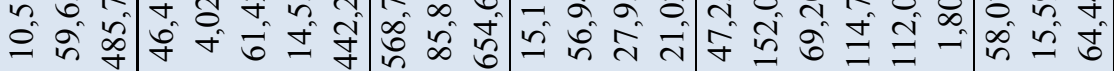

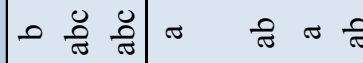

a ब

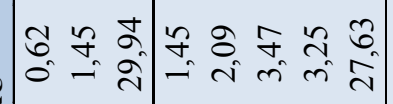

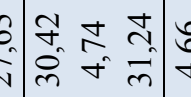

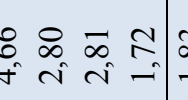

กิ

$\simeq$

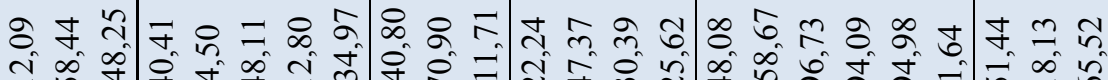

ป

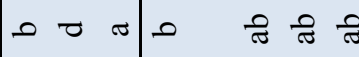

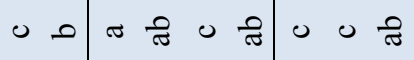

\&

约

$+$

$\infty \begin{array}{lll}\infty & \infty & \bar{n}\end{array}$

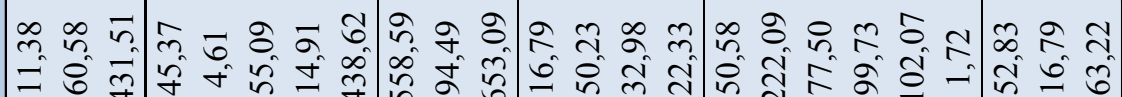

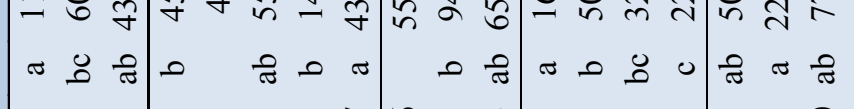

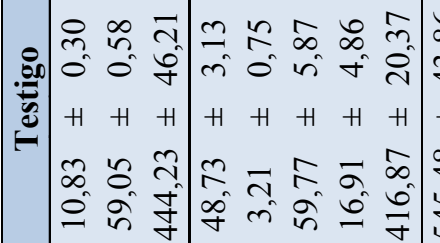

(2)

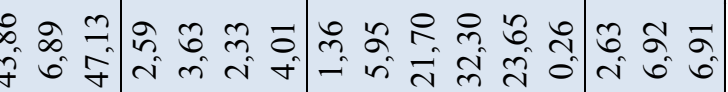

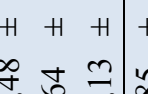

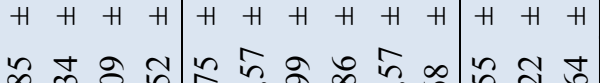

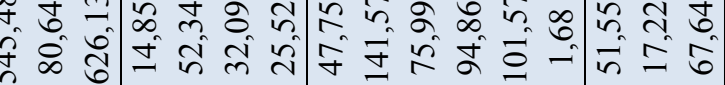

:

艺

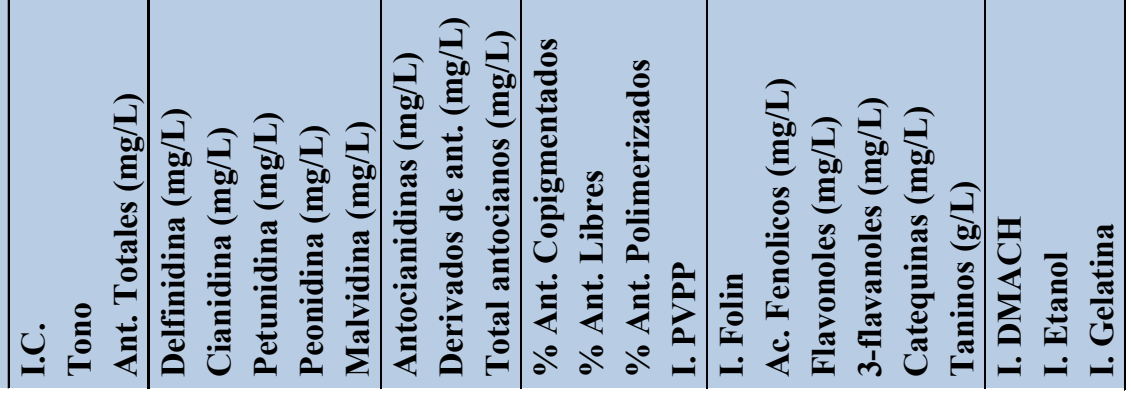

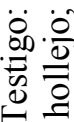


El vino adicionado con el copigmento ácido cafeico es el que presenta un mayor porcentaje del color debido a las reacciones de polimerización. La participación de este compuesto en reacciones de esterificación con los antocianos habrá facilitado la formación de pigmentos poliméricos, incrementando el porcentaje de color debido a estos antocianos, resultados que concuerdan plenamente con los observados el año anterior Las diferencias significativas que presenta el parámetro, "derivados de antocianos", refuerza este hecho en los vinos adicionados de ácido cafeico. También Darías-Martin et al. (2001) observan como aquellos vinos adicionados de ácido cafeico presentan un mayor color debido a las polimerizaciones tanto a los 30 días, como a los 7 meses de envejecimiento.

En cuanto al grado de polimerización de los taninos, es el vino adicionado del copigmento catequina el que muestra el menor grado de polimerización de estos compuestos, con diferencias estadísticamente significativas con respecto a los otros vinos analizados. Como los taninos del vino son polímeros condensados de 3flavonoles, es posible que la adición de catequina monómera contribuya a mantener parte de ellos en formas poco polimerizadas, que irán reaccionando con el paso del tiempo dando lugar a polímeros o moléculas más grandes.

La concentración de ácidos fenólicos se incrementa significativamente cuando se adiciona el ácido cafeico, que es el ácido fenólico más abundante en los vinos. Además todos ellos muestran estas diferencias frente a los vinos testigo no adicionados. Esta importante diferencia con respecto al testigo y a los otros copigmentos, puede ser la causa del elevado F-ratio encontrado en el análisis inicial.

El copigmento rutina adicionado a los vinos provoca diferencias significativas para la concentración de flavonoles, tal como era de esperar por ser la rutina un integrante de esta familia de compuestos.

Los vinos adicionados de catequina son los que presentan los valores superiores para la concentración de 3-flavanoles y de catequinas, al igual que sucedió el año anterior, aunque este año las diferencias no llegan a ser significativas debido a la variabilidad existente entre los datos. También los vinos suplementados con el copigmento catequina son los que muestran las mayores concentraciones de malvidina, presentando los vinos testigo los valores más bajos para este parámetro. Parece que la adición de catequina ha favorecido la interacción de las catequinas y la malvidina, contribuyendo a su extracción y/o estabilidad. Por el contrario no se observa este comportamiento para el resto de las antocianidinas presentes en los vinos, ni para la suma de todos ellos.

La concentración de los derivados de antocianos, calculados como la suma de los antocianos esterificados con el ácido cumárico, cafeico o acético, es superior en los vinos adicionados de ácido cafeico, y en menor medida de catequina; lógicamente en estos vinos se ha favorecido la esterificación de los antocianos con el cafeico, incrementándose su concentración. Bloomfield et al. (2003) demuestran como la adición de ácido $p$-cumárico presenta un efecto significativo sobre el color en vinos de Pinot Noir, variedad que carece de antocianos acilados, atribuyendo este efecto a la capacidad de los antocianos esterificados para participar en reacciones de copigmentación intramolecular, afectando decisivamente al color de los vinos (Eiro y Heinonen, 2002). 
Por último, para la suma de las antocianidinas y los derivados de antocianos, se observa como los vinos adicionados de ácido cafeico y los adicionados de catequina presentan diferencias significativas, mostrándose como los mejores copigmentos en cuanto a la extracción y/o conservación de estos compuestos.

A diferencia de lo observado el año anterior, no se observan diferencias en el índice de etanol ni de gelatina, en función de los copigmentos adicionados, lo que pone de manifiesto la importancia de la composición de la uva en las distintas reacciones que tienen lugar entre los polifenoles.

\subsubsection{EFECTO DE LAS TÉCNICAS DE VINIFICACIÓN}

En la tabla 6.25, se recogen el ANOVA simple de los valores medios de los parámetros polifenólicos analizados en los vinos, considerando conjuntamente los distintos tipos de copigmentos utilizados, según que la vinificación se realice de forma tradicional sin maceración prefermentativa, con maceración prefermentativa en frío a 6-8 ${ }^{\circ} \mathrm{C}$, o bien con una maceración prefermentativa con nieve carbónica.

Los vinos macerados prefermentativamente presentan un color ligeramente superior a los elaborados por vinificación tradicional, no encontrándose diferencias entre la maceración en frío o con nieve carbónica. Sacchi et al. (2005) destacan que el objetivo esperado de la maceración prefermentativa es que la extracción acuosa mejora la extracción del color. Este objetivo se cumple en estos vinos, pero en cambio no ha sido observado en los elaborados en la cosecha anterior, lo que pone de manifiesto la influencia de la materia prima en el comportamiento de la tecnología de vinificación.

Para la concentración de antocinaos totales son, de nuevo, las técnicas de maceración prefermentativa las que presentan los mayores valores, ambas con diferencias estadísticamente significativas con respecto a la vinificación tradicional. Al igual que ocurre para los vinos elaborados durante la vendimia 2006, la mayor presencia del mosto con los hollejos durante la fase prefermentativa ha favorecida el incremento de la concentración de antocianos, pudiendo también deberse esta situación a una mayor estabilidad de los antocianos extraídos, propiciados por la reacción de éstos con otros compuestos. Numerosos autores postulan que la aplicación de frío de forma prefermentativa incrementa la concentración antociánica de los vinos (Heatherbell et al., 1997; Reynolds, 2001; Parenti et al., 2004; Álvarez et al., 2005; Manchón et al., 2005; Gómez-Míguez et al., 2006; Koyama et al., 2007; Gil-Muñoz et al., 2009, Gordillo et al., 2010), mientras que otros observan un efecto negativo o nulo de esta técnica frente a la extracción de antocianos (Heatherbell et al., 1996; Okubo et al., 2003; Marais, 2003; Zini et al., 2003; Watson et al., 1995).

La malvidina tiene un comportamiento similar al observado en los antocianos totales, así como la suma de antocianidinas, sus derivados y el conjunto de todas ellas, no apreciándose diferencias en la concentración de las otras antocianidinas, en función de la técnica aplicada. 
Tabla 6.25. Efecto de las técnicas de vinificación sobre los valores medios de los parámetros determinados.

\begin{tabular}{|c|c|c|c|c|c|c|c|c|c|}
\hline & \multicolumn{3}{|c|}{ Tradicional } & \multicolumn{3}{|c|}{ Frio } & \multicolumn{3}{|c|}{ Nieve } \\
\hline I.C. & 11,16 & $\pm 0,98$ & $\mathrm{a}$ & 11,76 & $\pm 0,96$ & $\mathrm{~b}$ & 11,82 & $\pm 1,06$ & $\mathrm{~b}$ \\
\hline Tono & 59,52 & $\pm 1,75$ & $\mathrm{~b}$ & 58,60 & $\pm 1,45$ & $a b$ & 58,50 & $\pm 2,03$ & $\mathrm{a}$ \\
\hline Ant. Totales (mg/L) & 446,91 & $\pm 48,67$ & $\mathrm{a}$ & 478,23 & $\pm 42,69$ & $\mathrm{~b}$ & 484,75 & $\pm 48,30$ & $\mathrm{~b}$ \\
\hline Delfinidina (mg/L) & 45,74 & $\pm 3,27$ & & 48,39 & $\pm 4,50$ & & 48,91 & $\pm 5,92$ & \\
\hline Cianidina (mg/L) & 3,97 & $\pm 1,76$ & & 3,97 & $\pm 1,81$ & & 3,93 & $\pm 1,87$ & \\
\hline Petunidina (mg/L) & 50,42 & $\pm 3,27$ & & 53,07 & $\pm 4,50$ & & 56,34 & $\pm 5,92$ & \\
\hline Peonidina (mg/L) & 12,18 & $\pm 5,35$ & & 14,34 & $\pm 4,49$ & & 14,22 & $\pm 5,08$ & \\
\hline Malvidina (mg/L) & 416,30 & $\pm 25,43$ & $\mathrm{a}$ & 438,39 & $\pm 30,82$ & $\mathrm{~b}$ & 445,75 & $\pm 23,63$ & $\mathrm{~b}$ \\
\hline Antocianidinas (mg/L) & 528,61 & $\pm 21,17$ & $\bar{a}$ & 558,16 & $\pm 32,97$ & $\mathrm{~b}$ & 569,15 & $\pm 36,82$ & $\bar{b}$ \\
\hline ant. (mg/L) & 71,16 & $\pm 5,17$ & $\mathrm{a}$ & 81,82 & $\pm 15,71$ & $\mathrm{~b}$ & 82,18 & $\pm 16,64$ & $\mathrm{~b}$ \\
\hline Total antocianos $(\mathrm{mg} / \mathrm{L})$ & 599,77 & $\pm 21,58$ & $\mathrm{a}$ & 639,98 & $\pm 42,65$ & $\mathrm{~b}$ & 651,33 & $\pm 50,01$ & $\mathrm{~b}$ \\
\hline \% Ant. Copigmentados & 18,08 & $\pm 5,78$ & & 17,31 & $\pm 5,45$ & & 17,56 & $\pm 4,63$ & \\
\hline$\%$ Ant & 53,44 & $\pm 3,20$ & $\mathrm{~b}$ & 50,19 & $\pm 4,92$ & $\mathrm{a}$ & 50,12 & $\pm 6,09$ & $\mathrm{a}$ \\
\hline$\%$ Ant. Polimerizados & 28,48 & $\pm 3,01$ & $\mathrm{a}$ & 32,50 & $\pm 3,35$ & $\mathrm{~b}$ & 32,32 & $\pm 2,63$ & $b$ \\
\hline I. PVPP & 24,54 & $\pm 2,76$ & & 23,10 & $\pm 2,51$ & & 23,16 & $\pm 4,09$ & \\
\hline I. Folin & 48,17 & $\pm 2,39$ & & 48,29 & $\pm 1,85$ & & 48,38 & $\pm 1,76$ & \\
\hline Ac. Fenolicos (mg/L) & 165,24 & $\pm 30,61$ & & 164,02 & $\pm 29,29$ & & 161,63 & $\pm 26,91$ & \\
\hline Flavonoles (mg/L) & 82,94 & $\pm 18,36$ & & 85,03 & $\pm 26,70$ & & 85,24 & $\pm 30,98$ & \\
\hline 3-flavanoles (mg/L) & 98,41 & $\pm 28,16$ & & 105,28 & $\pm 38,25$ & & 102,40 & $\pm 31,33$ & \\
\hline Catequinas (mg/L) & 118,35 & $\pm 10,36$ & & 122,44 & $\pm 14,12$ & & 121,55 & $\pm 14,69$ & \\
\hline $\operatorname{Taninos}(\mathrm{g} / \mathrm{L})$ & 1,85 & $\pm 0,21$ & & 1,74 & $\pm 0,26$ & & 1,63 & $\pm 0,30$ & \\
\hline I. DMACH & 52,44 & $\pm 4,31$ & & 53,23 & $\pm 3,65$ & & 52,41 & $\pm 3,76$ & \\
\hline I. Etanol & 14,54 & $\pm 8,81$ & $\mathrm{a}$ & 21,33 & $\pm 11,42$ & $\mathrm{~b}$ & 22,53 & $\pm 10,20$ & \\
\hline I. Gelatina & 66,71 & $\pm 7,67$ & & 68,51 & $\pm 10,74$ & & 67,93 & $\pm 11,75$ & \\
\hline
\end{tabular}

Tradicional: elaboración sin maceración en frío previamente a la fermentación; Frío: aplicación de bajas temperaturas de forma prefermentativa; Nieve: uso de nieve carbónica prefermentativamente. Letras diferentes en la misma fila indican diferencias significativas al $95 \%$.

A diferencia de lo observado después de la fermentación maloláctica en los vinos de la cosecha anterior, no se observan diferencias en el porcentaje del color que corresponde a los antocianos copigmentados. En el porcentaje del color que corresponde a los antocianos libres y a los antocianos polimerizados se observa un efecto opuesto, ya que mientras las técnicas de maceración prefermentativa dan lugar a un mayor color debido a los antocianos polimerizados, es la vinificación tradicional la que presenta mayor color debido a los antocianos libres. También Gil-Muñoz et al. (2009) observan una mayor polimerización de sus antocianos en vinos de Carbernet Sauvignon y Syrah sometidos a criomacerión.

Los vinos macerados prefermentativamente muestran diferencias significativas para el índice de etanol, con respecto a la vinificación tradicional. La mayor extracción de polisacáridos durante la maceración prefermentativa puede ser la causa del 
incremento de las combinaciones polisacárido-tanino. A diferencia de lo observado el año anterior, las técnicas de vinificación no afectan a la extracción de catequinas y taninos, ni a los polifenoles totales ni a la astringencia de los vinos.

En la añada 2007, la vinificación con maceración prefermentativa se muestra como la técnica más favorable para los parámetros relacionados con el color y la concentración antociánica, no observándose diferencias entre la maceración en frío y la realizada con nieve carbónica. En cambio, no se observan diferencias en los parámetros relacionados con los flavanoles y taninos, debido a la distinta composición de la uva y la distinta extractibilidad de sus compuestos polifenólicos, ocasionados por un estado de maduración diferente.

\subsubsection{CORRELACIÓN ENTRE LOS PARÁMETROS POLIFENÓLICOS DE LOS VINOS, LA ADICIÓN DE COPIGMENTOS Y LAS TÉCNICAS DE VINIFICACIÓN}

A continuación se recoge el Análisis de Componentes Principales (ACP) para los vinos elaborados, en función de las distintas prácticas enológicas ensayadas. Para realizarlo es preciso construir primero la matriz de covarianzas o matriz de correlación.

En la tabla 6.26 aparece representada la matriz de correlaciones de las variables utilizadas en el análisis, donde una coloración más intensa indica una correlación más importante entre las variables consideradas; correspondiendo las coloraciones rojas a las relaciones negativas, las verdes a las positivas y, por último, las amarillas a las correlaciones débiles entre las variables relacionadas (próxima a cero).

El parámetro intensidad colorante muestra una correlación positiva con el porcentaje del color debido a los antocianos polimerizados y una negativa con el tono. El incremento de las uniones entre antocianos y taninos favorece el color de los vinos, además de protegerlos frente a la oxidación.

El porcentaje del color debido a los antocianos libres presenta correlaciones negativas con los parámetros taninos, índice de PVPP y porcentaje del color que corresponde a reacciones de copigmentación. La mayor presencia de antocianos en su forma libre indica que aún no son muy intensas las uniones antociano-tanino y que por lo tanto los taninos son susceptibles de precipitar en el medio y de aportar astringencia.

En cuanto a las correlaciones positivas, el incremento de la concentración de taninos daría lugar a un incremento de la astringencia de los vinos, medida mediante el índice de gelatina. Además una mayor concentración de 3-flavanoles provocaría un incremento de la tonalidad amarilla (Bautista-Ortín et al., 2005).

Los ácidos fenólicos están directamente correlacionados con el índice de Folin, incrementándose su concentración a medida que se incrementa este. También existe una correlación positiva entre los flavonoles y los 3-flavanoles, indicando como la concentración de estos polifenoles se produce de forma paralela durante la maduración en las uvas de la añada 2007, correlación que no fue tan evidente la añada anterior. 


\begin{tabular}{|c|c|c|c|c|c|c|c|c|c|c|c|c|c|c|c|c|c|c|c|c|c|c|c|}
\hline 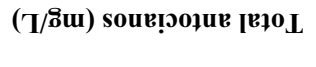 & $\begin{array}{l}\overline{0} \\
0 \\
0\end{array}$ & $\begin{array}{l}\text { ô } \\
0\end{array}$ & $\frac{n}{0}$ & $\begin{array}{l}0 \\
2 \\
1 \\
1\end{array}$ & $\bar{n}$ & ¿̂. & సै. & $\frac{\infty}{1}$ & $\mid \begin{array}{l}\text { in } \\
0 \\
\mathbf{1}\end{array}$ & $\begin{array}{c}\tilde{1} \\
\hat{1}\end{array}$ & $\mid \begin{array}{c}\text { ? } \\
0\end{array}$ & तु. & $\mid \begin{array}{l}0 \\
0 \\
0\end{array}$ & ন্ & f. & $\begin{array}{l}? \\
0 \\
0\end{array}$ & $\stackrel{1}{9}$ & के & f. & . & t. & $\begin{array}{l}\hat{t} \\
0\end{array}$ & \\
\hline ( ( T/8̊ & ô. & $\frac{a}{i}$ & $\begin{array}{c}3 \\
0\end{array}$ & $\begin{array}{c}\hat{n} \\
\hat{i}\end{array}$ & ?. & m. & $\frac{ \pm}{0}$ & $\begin{array}{c}\hat{y} \\
0 \\
1\end{array}$ & $\begin{array}{c}n \\
0 \\
i \\
1\end{array}$ & $\begin{array}{c}\hat{0} \\
\hat{i} \\
1\end{array}$ & के & $\frac{2}{0}$ & 尚? & ले & $\begin{array}{l}\infty \\
n \\
0\end{array}$ & $\stackrel{8}{:}$ & $\frac{m}{i}$ & m. & $\bar{z}$ & fa & 0 & & 응 \\
\hline 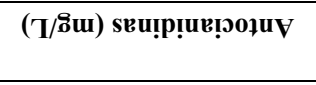 & $\overline{0}$ & $\begin{array}{l}0 \\
0 \\
\end{array}$ & ¿. & $\begin{array}{l} \\
\\
m \\
\end{array}$ & ก & I্ & $\begin{array}{l}\infty \\
\text { ஸे }\end{array}$ & 웅 & \begin{tabular}{|l}
$\vec{a}$ \\
0 \\
\end{tabular} & $\begin{array}{l}\hat{y} \\
0 \\
i\end{array}$ & \begin{tabular}{|c|} 
\\
ते
\end{tabular} & $\frac{2}{0}$ & $\frac{0}{0}$ & $=$ & J & $\stackrel{n}{0}$ & 8 & $\stackrel{\infty}{0}$ & ले & s. & & & $\begin{array}{l} \pm \\
0 \\
0\end{array}$ \\
\hline 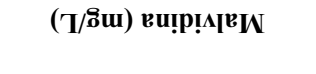 & 8 & 8 & $\begin{array}{l}n \\
0 \\
0\end{array}$ & $\begin{array}{l}\text { त̂ } \\
\vdots \\
\end{array}$ & J & 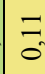 & ते & $\begin{array}{l}\delta \\
0 \\
0\end{array}$ & $\left|\begin{array}{l}n \\
0 \\
0 \\
1\end{array}\right|$ & ? & $\left|\begin{array}{l}1 \\
0 \\
0\end{array}\right|$ & $\begin{array}{l}\exists \\
0\end{array}$ & $\frac{m}{0}$ & $\overline{0}$ & तี & $\begin{array}{l}n \\
n \\
0\end{array}$ & ô & $\stackrel{2}{0}$ & ב. & & $\bar{a}$ & & $\mid \begin{array}{c}\infty \\
\infty \\
0\end{array}$ \\
\hline ( т/8̂u) вu!p!̣оoәd & $\bar{c}$ & $\stackrel{a}{0}$ & 8 & $\begin{array}{c}\text { ते } \\
\text { ç }\end{array}$ & तु & $\overline{0}$ & 하. & $\begin{array}{l}0 \\
0 \\
0 \\
1\end{array}$ & $\begin{array}{l}n \\
0 \\
\end{array}$ & $\begin{array}{l}\text { ते } \\
\text { î. }\end{array}$ & $\begin{array}{c}\text { ते } \\
0\end{array}$ & $\frac{2}{0}$ & 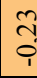 & 8 & I & $\begin{array}{l}0 \\
\text { in } \\
0\end{array}$ & $\begin{array}{c}m \\
\hat{i} \\
\hat{1}\end{array}$ & oे & & $\begin{array}{l}\text { है } \\
\text { ó }\end{array}$ & t. & & f \\
\hline 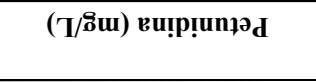 & $?$ & o. & $\begin{array}{l}\infty \\
0 \\
i\end{array}$ & $\begin{array}{l}\text { శ̂. } \\
\text { ?. }\end{array}$ & co & o & $\begin{array}{l}\text { s. } \\
0\end{array}$ & \begin{tabular}{|l|} 
\\
0 \\
0 \\
1
\end{tabular} & 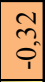 & \begin{tabular}{|l}
$\bar{n}$ \\
0 \\
1
\end{tabular} & f & 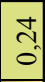 & $\frac{n}{9}$ & $\begin{array}{l}3 \\
0 \\
i\end{array}$ & ते & $\begin{array}{l}\stackrel{J}{3} \\
\text { O }\end{array}$ & $\begin{array}{l}\text { ते } \\
\text { ஸे }\end{array}$ & & : & $\frac{n}{0}$ & $\begin{array}{l}\infty \\
\stackrel{\infty}{3} \\
0\end{array}$ & & ? \\
\hline 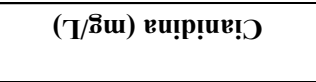 & $\begin{array}{l}\infty \\
0 \\
0\end{array}$ & $\begin{array}{l}\overline{0} \\
\bar{i}\end{array}$ & $\frac{\infty}{0}$ & s. & ô & $\tilde{O}$ & $\frac{n}{0}$ & $\frac{12}{0}$ & $\begin{array}{l}0 \\
0 \\
0\end{array}$ & $\frac{ \pm}{0}$ & 웅 & 웅 & $\tilde{O}$ & $\frac{7}{0}$ & $\frac{0}{9}$ & $\begin{array}{l}\text { กิ } \\
\text { ?े }\end{array}$ & & $\begin{array}{l}\text { ते } \\
\text { î }\end{array}$ & ?. & $\begin{array}{l}8 \\
0 \\
1\end{array}$ & $\stackrel{0}{\circ}$ & & $\stackrel{9}{0}$ \\
\hline 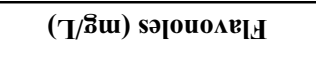 & $\begin{array}{l}8 \\
0\end{array}$ & $\frac{0}{1}$ & 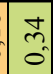 & $\frac{7}{0}$ & 文 & F & $\begin{array}{l}8 \\
0\end{array}$ & \begin{tabular}{|l|l}
$\infty$ \\
0 \\
1
\end{tabular} & \begin{tabular}{|c} 
\\
$\vdots$ \\
$c$
\end{tabular} & $\begin{array}{l} \\
0 \\
\end{array}$ & $\begin{array}{l}2 \\
0 \\
0\end{array}$ & $\begin{array}{l}7 \\
\\
\end{array}$ & $\frac{7}{9}$ & $\frac{n}{0}$ & $\begin{array}{l}\infty \\
n \\
0\end{array}$ & & $\begin{array}{l}\text { กิ } \\
\text { în }\end{array}$ & $\underset{t}{\stackrel{t}{0}}$ & : & ถู & 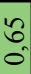 & & $\begin{array}{l}\stackrel{2}{0} \\
0\end{array}$ \\
\hline 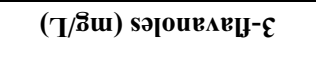 & $\begin{array}{l}n \\
0 \\
0\end{array}$ & $\begin{array}{l}0 \\
0 \\
1 \\
1 \\
1\end{array}$ & $\bar{n}$ & $\begin{array}{l}0 \\
0 \\
0\end{array}$ & $\frac{m}{0}$ & m. & $\begin{array}{l}0 \\
0 \\
0 \\
\end{array}$ & \begin{tabular}{|c|} 
\\
$m$ \\
0 \\
$i$
\end{tabular} & $\begin{array}{l}m \\
\\
\end{array}$ & $\begin{array}{l} \\
\\
\end{array}$ & हैं & $\begin{array}{l}\because \\
0 \\
\end{array}$ & $\frac{ \pm}{0}$ & तี & & $\begin{array}{l}\infty \\
n \\
0\end{array}$ & $\frac{0}{i}$ & ते & f̊ & तె & Fُ & & f. \\
\hline 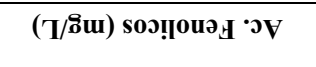 & กิ & $\div$ & $\begin{array}{l}7 \\
0\end{array}$ & $\frac{n}{0}$ & t: & mo & $\frac{\infty}{0}$ & 여 & $\frac{0}{0}$ & \begin{tabular}{|c|} 
\\
\end{tabular} & $\div$ & $\frac{0}{0}$ & $\stackrel{m}{m}$ & & สี & $\frac{n}{0}$ & 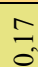 & ô & 8 & ने & $\bar{z}$ & के & సี. \\
\hline 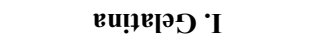 & ?ֶ. & $\begin{array}{l}n \\
0 \\
0\end{array}$ & $\frac{\infty}{0}$ & त) & $\hat{0}$ & $\frac{0}{0}$ & \pm & $\approx$ & $\vec{n}$ & f. & \begin{tabular}{|c|}
$\infty$ \\
0 \\
0
\end{tabular} & 오 & & $\tilde{m}$ & $\frac{7}{0}$ & $\frac{1}{0}$ & $\delta$ & $\frac{n}{0}$ & 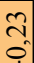 & $\stackrel{9}{\circ}$ & 응. & & 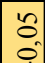 \\
\hline 'w!!Od १UV \% & $\delta$ & 8 & $\stackrel{\infty}{1}$ & 2 & $\vec{m}$. & ì & $\stackrel{\infty}{\sim}$ & . & ㄱ. & के & t. & & $\stackrel{乛}{\simeq}$ & 0 & $\frac{n}{8}$ & $\frac{7}{8}$ & $\stackrel{0}{=}$ & $\stackrel{\text { I }}{\text { S }}$ & $\stackrel{2}{=}$ & $=$ & $\stackrel{9}{9}$ & & $\vec{\sim}$ \\
\hline sə.xq!T جuv \% & 8 & \pm & $=$ & \pm & a & $\infty$ & $=$ & in & 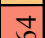 & थी & & & $\infty$ & 0 & 8 & $=$ & 은 & $=$ & $m$ & $=$ & 8 & & \\
\hline & i & i & i & 8 & 0 & - & î & 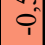 & $\left.\mid \begin{array}{l}0 \\
0\end{array}\right]$ & $\left|\begin{array}{c}0 \\
0\end{array}\right|$ & & $0^{\circ}$ & i & i & 3. & 8 & í & 0 & ?. & $\circ$ & of & 0 & 0 \\
\hline 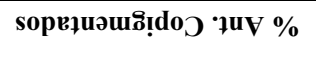 & $\frac{ \pm}{0}$ & \begin{tabular}{l} 
in \\
0 \\
\hdashline
\end{tabular} & $\frac{2}{0}$ & $\vec{f}$ & $\vec{f}$ & $\stackrel{8}{8}$ & $\begin{array}{l}1 \\
0 \\
0 \\
1\end{array}$ & fa & $\begin{array}{l}3 \\
0\end{array}$ & & $\begin{array}{l}m \\
0 \\
0 \\
i\end{array}$ & \begin{tabular}{|l|} 
\\
$n$ \\
0 \\
$i$
\end{tabular} & f & $\begin{array}{l}0 \\
0 \\
i\end{array}$ & $\frac{0}{0}$ & $\overrightarrow{0}$ & $\frac{\Delta}{0}$ & $\begin{array}{l}\bar{n} \\
0 \\
i\end{array}$ & ते & $\frac{7}{9}$ & $\begin{array}{c}\widehat{n} \\
\text { ç }\end{array}$ & & $\begin{array}{c}\tilde{c} \\
\hat{i} \\
i\end{array}$ \\
\hline$(\mathrm{T} / \mathbf{8}) \operatorname{sou}_{\mathbf{1}}$ & $\frac{\infty}{0}$ & : & $\frac{0}{0}$ & స్. & हे & s. & $\frac{n}{0}$ & f & & $\begin{array}{l}0 \\
0 \\
0\end{array}$ & 苟 & 요 & $\overline{3}$ & $\frac{0}{0}$ & $\frac{m}{0}$ & $\begin{array}{l}\text { Ũ } \\
\text { s. }\end{array}$ & : & कै & $\frac{n}{0}$ & $\stackrel{n}{0}$ & ָָ & & 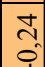 \\
\hline dd $\Lambda d^{\circ} I$ & $?$ & $\simeq$ & 8 & $\delta$ & $\stackrel{\sim}{\sim}$ & $\stackrel{2}{2}$ & $\because$ & & \pm & f & $\mid \begin{array}{l}n \\
0 \\
0\end{array}$ & $\begin{array}{l} \\
0\end{array}$ & $\tilde{\pi}$ & î & $\begin{array}{c}n \\
m \\
0\end{array}$ & $\begin{array}{l}\infty \\
0 \\
0\end{array}$ & $\stackrel{2}{2}$ & $\begin{array}{l}0 \\
\tilde{3} \\
0\end{array}$ & $\stackrel{8}{\circ}$ & ฮี & $\frac{0}{0}$ & & $\frac{\infty}{0}$ \\
\hline [оü子马 $\cdot I$ & 5. & $\widehat{\widehat{N}}$ & $\Xi$ & I & 于 & $\stackrel{1}{2}$ & & ㅇ․ & $\because$ & S. & $=$ & $\underset{\sim}{\infty}$ & \pm & $\infty$ & 8 & 8 & $\cong$ & $\delta$ & 0 & तิ & $\stackrel{\text { ๙ }}{\infty}$ & & 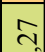 \\
\hline $28 \mathrm{NAO}$ & $\curvearrowleft$ & 0 & $n$ & a & N & & 이 & $n$ & A & 6 & $\infty$ & a & 0 & $m$ & $m$ & - & $m$ & $a$ & - & - & $\checkmark$ & & \\
\hline & g & i & $0^{3}$ & $0^{\circ}$ & 0 & & ?. & $\left|\begin{array}{lll}0 & 1 \\
0\end{array}\right|$ & $\left.\mid \begin{array}{lll}0 & 1 \\
i & 0\end{array}\right]$ & $\mid \begin{array}{l}0 \\
0 \\
1\end{array}$ & हैं & है: & i & i & 3 & $0_{0}^{+}$ & : & 0 & 8 & $0^{\circ}$ & ¿ & m & है: \\
\hline (T/8̂u) seu!̣bəңe & $\frac{ \pm}{0}$ & ป̂. & $\begin{array}{c}0 \\
\text { ? } \\
1\end{array}$ & $\begin{array}{c}\vec{c} \\
0 \\
1\end{array}$ & & $\frac{1}{0}$ & f. & $\begin{array}{l}0 \\
\hat{c} \\
1\end{array}$ & 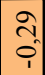 & $\begin{array}{c}\vec{f} \\
0 \\
i\end{array}$ & है. & $\vec{m}$ & $\begin{array}{l}3 \\
0 \\
i\end{array}$ & $\begin{array}{l} \pm \\
0 \\
0\end{array}$ & $\frac{m}{0}$ & त्र & $\begin{array}{l}0 \\
\text { ô } \\
\text { in }\end{array}$ & $\stackrel{n}{\tilde{c}}$ & ปี & $\stackrel{f}{8}$ & हี & & 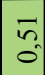 \\
\hline 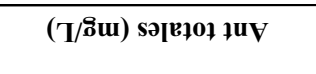 & กิ & $\begin{array}{l}\text { fo } \\
0 \\
0\end{array}$ & : & & $\begin{array}{l}\overline{\text { N̦}} \\
\text { in }\end{array}$ & 8 & $\begin{array}{l}\text { İ } \\
\text { on } \\
1\end{array}$ & $\begin{array}{l} \\
0 \\
0 \\
i\end{array}$ & \begin{tabular}{|c|} 
오 \\
\end{tabular} & F. & \begin{tabular}{|l|} 
\\
\\
0
\end{tabular} & $\begin{array}{l}2 \\
0 \\
0\end{array}$ & 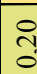 & $\frac{n}{9}$ & 웅 & $\frac{1}{9}$ & Oี & ก̂ & సి & สี & cit & & \begin{tabular}{|c} 
\\
?. \\
\end{tabular} \\
\hline Oü $\mathbf{L}$ & ? & $\begin{array}{l}n \\
0 \\
0\end{array}$ & & ${ }_{0}$ & $\begin{array}{l}\text { in } \\
\text { in }\end{array}$ & $\begin{array}{c}n \\
\tilde{c} \\
0\end{array}$ & $\frac{7}{1}$ & \begin{tabular}{|l} 
\\
0 \\
0
\end{tabular} & 웅 & $\frac{9}{0}$ & $=$ & \begin{tabular}{|l|}
$\infty$ \\
\\
\end{tabular} & \begin{tabular}{|l|}
$\infty$ \\
\end{tabular} & $\stackrel{f}{0}$ & 5 & ma & $\frac{\infty}{0}$ & $\stackrel{\infty}{0}$ & $\stackrel{8}{0}$ & $\hat{o}$ & $\stackrel{n}{0}$ & & $\because$ \\
\hline :D:I & $\because$ & & $\begin{array}{l}n \\
\vdots \\
\vdots\end{array}$ & 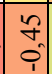 & $\stackrel{J}{\Xi}$ & $\begin{array}{l}0 \\
0 \\
0 \\
0\end{array}$ & ํ. & $\because$ & $\begin{array}{l}8 \\
0 \\
\end{array}$ & 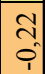 & $\begin{array}{l} \pm \\
\\
i\end{array}$ & $\begin{array}{l} \\
0 \\
0\end{array}$ & $\begin{array}{l}4 \\
0 \\
\end{array}$ & $\frac{0}{9}$ & $\begin{array}{l}0 \\
\text { ? } \\
\text { ? }\end{array}$ & $\frac{0}{1}$ & $\bar{c}$ & so & $\frac{\pi}{0}$ & a & $\stackrel{0}{\circ}$ & & $\begin{array}{l}0 \\
0 \\
i \\
1\end{array}$ \\
\hline U!! & & $\frac{0}{0}$ & 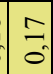 & حู. & $\frac{\Delta}{0}$ & 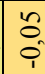 & : & $\frac{0}{0}$ & $\stackrel{\infty}{0}$ & $\frac{ \pm}{0}$ & î̀ & : & Oे & n? & $\stackrel{0}{0}$ & 8 & $\stackrel{\infty}{0}$ & $\frac{n}{i}$ & $\overline{0}$ & 8 & ㅎ․ㅇ. & & 하. \\
\hline & & & & 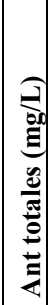 & & $\sum_{z}^{z}$ & & $\mid \begin{array}{l}\overrightarrow{\hat{z}} \\
\mathrm{z} \\
\end{array}$ & 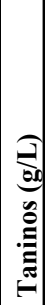 & 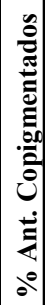 & 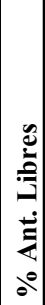 & 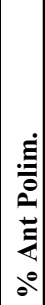 & ثَ & 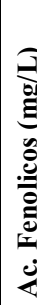 & 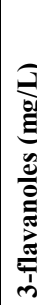 & 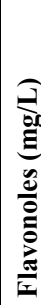 & كَّ & 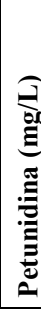 & & & & & 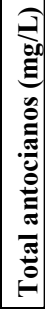 \\
\hline
\end{tabular}


Los parámetros concentración de malvidina, antocianidinas, derivados de antocianos y total de antocianos presentan lógicamente elevadas correlaciones entre ellos. Esto es debido a que la malvidina es el principal antociano monómero presente en la uva como en el vino, teniendo un gran peso tanto en la suma de antocianidinas como del total de antocianos. Además, respecto a los derivados de antocianos, aquellos unidos a la malvidina son los que presentan las mayores concentraciones, justificándose la elevada correlación encontrada para estos parámetros (Baldi et al., 1995).

Tabla 6.27. Autovalor, varianza explicada y acumulada para las componentes consideradas en el análisis.

\begin{tabular}{cccc}
\hline Componente & Autovalor & \% Varianza & \% Acumulado \\
\hline $\mathbf{1}$ & 6,234 & 25,974 & 25,974 \\
$\mathbf{2}$ & 3,617 & 15,073 & 41,047 \\
$\mathbf{3}$ & 3,128 & 13,033 & 54,080 \\
$\mathbf{4}$ & 2,206 & 9,191 & 63,271 \\
$\mathbf{5}$ & 1,629 & 6,789 & 70,060 \\
$\mathbf{6}$ & 1,345 & 5,605 & 75,664 \\
$\mathbf{7}$ & 0,933 & 3,888 & 79,553 \\
$\mathbf{8}$ & 0,924 & 3,850 & 83,402 \\
$\mathbf{9}$ & 0,761 & 3,170 & 86,573 \\
$\mathbf{1 0}$ & 0,668 & 2,782 & 89,355 \\
$\mathbf{1 1}$ & 0,525 & 2,186 & 91,540 \\
$\mathbf{1 2}$ & 0,454 & 1,890 & 93,431 \\
$\mathbf{1 3}$ & 0,370 & 1,542 & 94,973 \\
$\mathbf{1 4}$ & 0,320 & 1,333 & 96,305 \\
$\mathbf{1 5}$ & 0,229 & 0,954 & 97,259 \\
$\mathbf{1 6}$ & 0,175 & 0,729 & 97,989 \\
$\mathbf{1 7}$ & 0,136 & 0,567 & 98,556 \\
$\mathbf{1 8}$ & 0,118 & 0,492 & 99,047 \\
$\mathbf{1 9}$ & 0,091 & 0,380 & 99,428 \\
$\mathbf{2 0}$ & 0,073 & 0,302 & 99,730 \\
$\mathbf{2 1}$ & 0,035 & 0,145 & 99,875 \\
$\mathbf{2 2}$ & 0,018 & 0,076 & 99,952 \\
$\mathbf{2 3}$ & 0,012 & 0,048 & 100,000 \\
\hline
\end{tabular}

También los parámetros relacionados con los antocianos, muestran una correlación positiva importante con la concentración de flavonoles, compuestos con gran afinidad por los antocianos, que son mencionados por muchos autores como los compuestos con mejor poder copigmentante (Kunsági-Máté et al., 2006; Lambert et al., 2010; Malien-Aubert et al., 2007; Schwarz et al., 2005; Davies y Mazza, 1993; Baranac et al., 1996; Baranac et al., 1997; Gómez-Míguez et al., 2006).

Por último, también aparecen correlaciones positivas entre el total de antocianidinas y antocianos y la concentración de catequinas, y entre los derivados de antocianos y la concentración de 3-flavanoles, lo que puede favorecer la formación de complejos antociano-tanino. García-Marino et al. (2010), estudiando el efecto de la 
incorporación de la variedad Graciano en el color y la composición fenólica de los vinos de Tempranillo, identifican la formación del compuesto malvidina-3-O-(6'-p-cumaril) glucósido-8-etil-(epi) catequina, que aporta mayor estabilidad al color de los vinos.

Tabla 6.28. Tabla de pesos de los componentes

\begin{tabular}{lcccccc}
\hline & \multicolumn{6}{c}{ Componentes } \\
& $\mathbf{1}$ & $\mathbf{2}$ & $\mathbf{3}$ & $\mathbf{4}$ & $\mathbf{5}$ & $\mathbf{6}$ \\
\hline I. Folin & $-0,01$ & 0,17 & 0,17 & $-0,34$ & $-0,23$ & $-0,49$ \\
I.C. & $-0,01$ & $-0,34$ & 0,31 & $-0,09$ & 0,09 & $-0,16$ \\
Tono & $-0,07$ & 0,38 & $-0,12$ & $-0,21$ & 0,07 & 0,27 \\
Ant totales (mg/L) & $-0,18$ & 0,20 & 0,21 & 0,17 & $-0,20$ & $-0,43$ \\
Catequinas (mg/L) & $-0,23$ & $-0,14$ & $-0,14$ & 0,09 & $-0,33$ & $-0,22$ \\
I. DMACH & $-0,13$ & 0,19 & $-0,27$ & 0,12 & $-0,16$ & 0,16 \\
I. Etanol & $-0,08$ & $-0,13$ & 0,29 & 0,08 & $-0,29$ & 0,05 \\
I. PVPP & 0,15 & 0,07 & 0,30 & 0,13 & 0,22 & 0,27 \\
Taninos (g/L) & 0,20 & 0,21 & 0,24 & 0,05 & 0,20 & $-0,15$ \\
\%o Ant. Copigmentados & 0,23 & 0,33 & 0,17 & 0,15 & 0,09 & $-0,04$ \\
\% Ant. Libres & $-0,20$ & $-0,20$ & $-0,37$ & 0,01 & $-0,18$ & $-0,07$ \\
\% Ant Polim. & $-0,14$ & $-0,30$ & 0,23 & $-0,28$ & 0,09 & 0,17 \\
I. Gelatina & 0,13 & 0,07 & 0,19 & 0,40 & $-0,08$ & $-0,13$ \\
Ac. Fenolicos (mg/L) & $-0,10$ & 0,23 & 0,07 & $-0,49$ & $-0,03$ & $-0,06$ \\
3-flavanoles (mg/L) & $-0,23$ & 0,23 & $-0,17$ & 0,01 & 0,12 & $-0,09$ \\
Flavonoles (mg/L) & $-0,28$ & 0,23 & 0,01 & 0,16 & 0,18 & 0,01 \\
Cianidina (mg/L) & 0,07 & 0,09 & 0,06 & $-0,11$ & $-0,41$ & 0,37 \\
Petunidina (mg/L) & $-0,22$ & $-0,17$ & $-0,13$ & 0,05 & 0,22 & $-0,21$ \\
Peonidina (mg/L) & $-0,24$ & $-0,06$ & 0,00 & 0,06 & 0,48 & $-0,18$ \\
Malvidina (mg/L) & $-0,26$ & 0,09 & 0,22 & 0,26 & $-0,12$ & 0,04 \\
Antocianidinas (mg/L) & $-0,32$ & 0,07 & 0,18 & 0,23 & $-0,13$ & 0,07 \\
Derivados de ant. (mg/L) & $-0,34$ & 0,12 & $-0,01$ & $-0,09$ & 0,06 & 0,07 \\
Total antocianos (mg/L) & $-0,36$ & 0,10 & 0,14 & 0,15 & $-0,06$ & 0,05 \\
\hline
\end{tabular}

En la tabla 6.27 aparece el autovalor y el porcentaje de varianza acumulada por los sucesivos factores, observándose que son necesarios seis factores para que este valor descienda por debajo de la unidad. Incluso con seis factores, el porcentaje de varianza acumulada no supera el $75,66 \%$. Se han identificado seis patrones de comportamiento que aglutinan toda la variabilidad observada en las variables originales.

En la tabla 6.28 aparecen los valores de los coeficientes de las ecuaciones que forman cada uno de los seis componentes principales identificados. Como norma general en la interpretación de estos valores se tiende a prescindir de aquellas variables cuyo coeficiente con el factor sea inferior a $0,25-0,3$.

El primer componente principal identificado está directamente relacionado con el porcentaje del color que corresponde a los antocianos copigmentados y en menor medida con los taninos, por lo tanto, los vinos situados en la parte positiva del primer 
eje principal podrían corresponder a vinos con elevados niveles de copigmentación, y una concentración tánica superior.

Por otra parte este componente está relacionado indirectamente con los parámetros catequinas, 3-flavanoles, flavonoles, petunidina, peonidina, malvidina, antocianidinas, derivados de antocianos y total de antocianos. Correspondiendo a vinos con una importante concentración de compuestos monómeros, de carácter antociánico y tánico, y con una importante presencia de flavonoles. Compuestos que ya han demostrado anteriormente su alta capacidad de copigmentación. TambiénLambert et al. (2010), estudiando la interacción entre malvidina-3-glucosido y algunos de los constituyentes del vino, observan como el compuesto quercetina, correspondiente a la familia de los flavonoles, es el que presenta un mayor efecto copigmentante en las soluciones estudiadas, situando a estos compuestos entre los mejores copigmentos presentes en los vinos.

El segundo componente principal está relacionado positivamente con el tono, los antocianos totales, taninos, antocianos copigmentados, ácidos fenólicos, flavonoles y 3flavanoles, compuestos que intervienen todos ellos en las reacciones de copigmentación. También se correlaciona de forma inversa con la intensidad colorante y con los antocianos libres y polimerizados, correspondiendo a vinos con buenas características cromáticas siendo los antocianos libres y los polimerizados los responsables principales del color.

Los parámetros intensidad colorante, índice de etanol, índice de PVPP, taninos totales, antocianos polimerizados y malvidina son los que caracterizan de forma directa al tercer componente principal identificado. Correspondiendo, probablemente, a vinos donde tanto los antocianos como los taninos están formando parte de complejos que influyen decisivamente en el color y en las características sensoriales. Además presenta correlaciones negativas con los antocianos totales, índice de DMACH y porcentaje del color que corresponde a los antocianos libres.

El cuarto componente principal se asocia directamente con los parámetros índice de gelatina, malvidina y antocianidinas e indirectamente con el índice de Folin, tono, antocianos polimerizados y ácidos fenólicos. El quinto tiene una relación indirecta muy significativa con la concentración de peonidina, mientras que el sexto lo hace con la cianidina, los antocianos totales y el índice de Folin.

En el gráfico 6.40 aparecen representadas las dos primeras componentes principales identificadas, en función de los distintos copigmentos adicionados. Los vinos aparecen aleatoriamente distribuidos a lo lago tanto del primer, como del segundo eje principal. Sin embargo, se observa como la mayoría de los vinos están situados en la parte positiva del primer eje principal que corresponde a vinos donde las reacciones de copigmentación son importantes, además de presentar una importante presencia tanto de antocianos como de taninos, pudiendo concluirse que la adición de copigmentos afecta a estos parámetros polifenólicos, sin que se ponga en evidencia una tendencia concreta para ninguno de los copigmentos. 


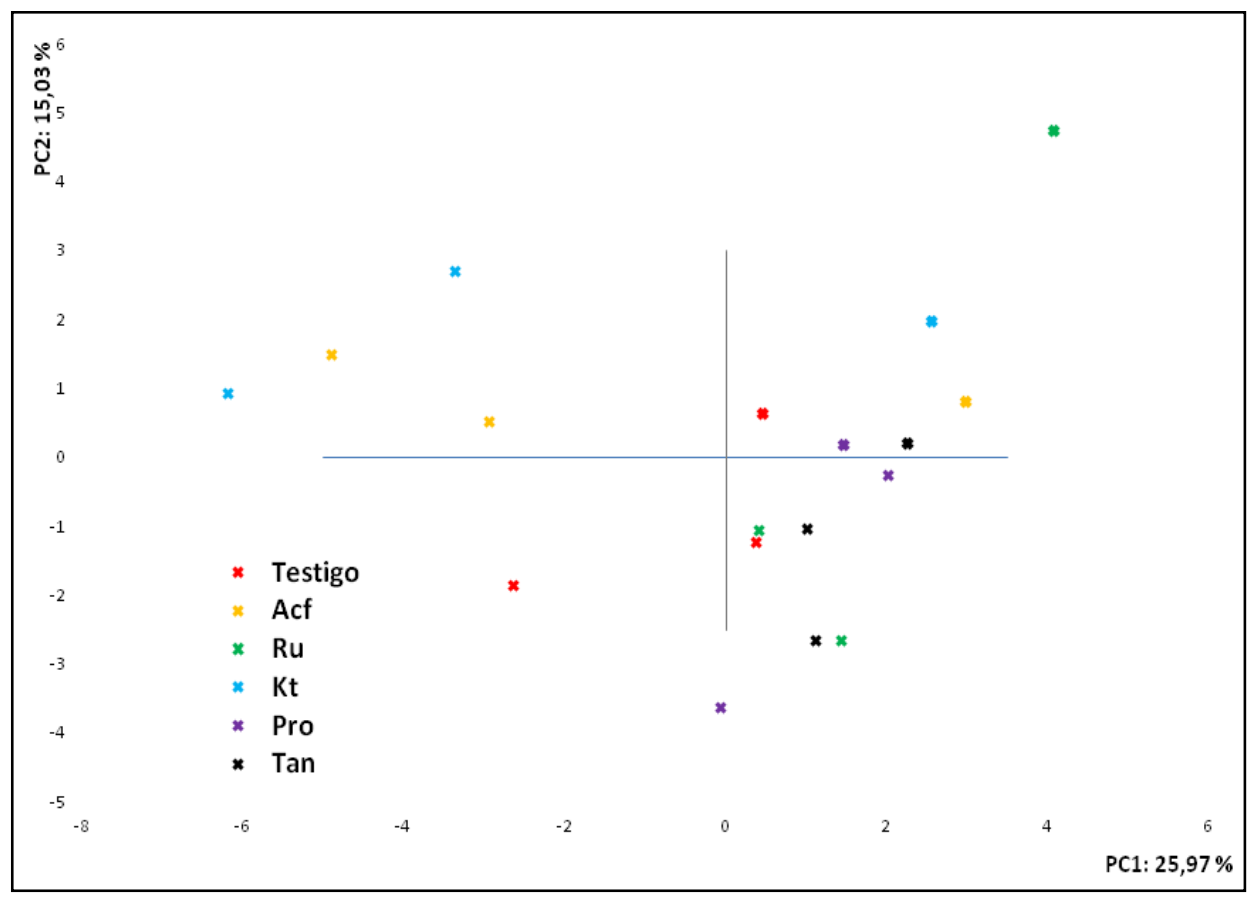

Gráfico 6.40. Primera componente frente a la segunda, en función de los copigmentos ensayados.

Con el objetivo de profundizar en el análisis se representó la segunda componente frente a la tercera y la primera frente a la tercera (datos no mostrados) observándose un comportamiento aleatorio de los vinos elaborados, no permitiendo establecer conclusiones sobre el efecto de la adición de copigmentos en la composición fenólica de los vinos analizados.

En el gráfico 6.41 aparecen representadas las dos primeras componentes en función de las diferentes técnicas de vinificación ensayadas. Podemos observar como aparecen entremezclados los vinos elaborados con maceración prefermentativa en frío y con nieve carbónica, y distribuidos aleatoriamente a lo largo de ambos ejes, lo que pone de manifiesto que en esta añada no se pueden diferenciar los vinos en función de la técnica de maceración aplicada, tal como vimos en los apartados anteriores.

Los vinos elaborados de forma tradicional, es decir, sin aplicación de ninguna técnica de maceración prefermentativa, se sitúan agrupados en la zona positiva del primer eje principal de la primera componente así como en la zona positiva de la segunda. Las variables con más peso en estas dos componentes son aquellos relacionados con el tono, y con el color que corresponde a la copigmentacion, siendo estos parámetros los responsables de la diferenciación entre los vinos sometidos a maceración tradicional, y el resto de los vinos, correspondientes a las dos técnicas de maceración prefermentativa aplicadas.

La representación de la segunda componente frente a la tercera (datos no mostrados) no ha aportado ningún nuevo criterio diferenciador, no permitiendo tampoco la diferenciación de los vinos sometidos a maceración prefermentativa en frío de los sometidos a la acción de la nieve carbónica. 


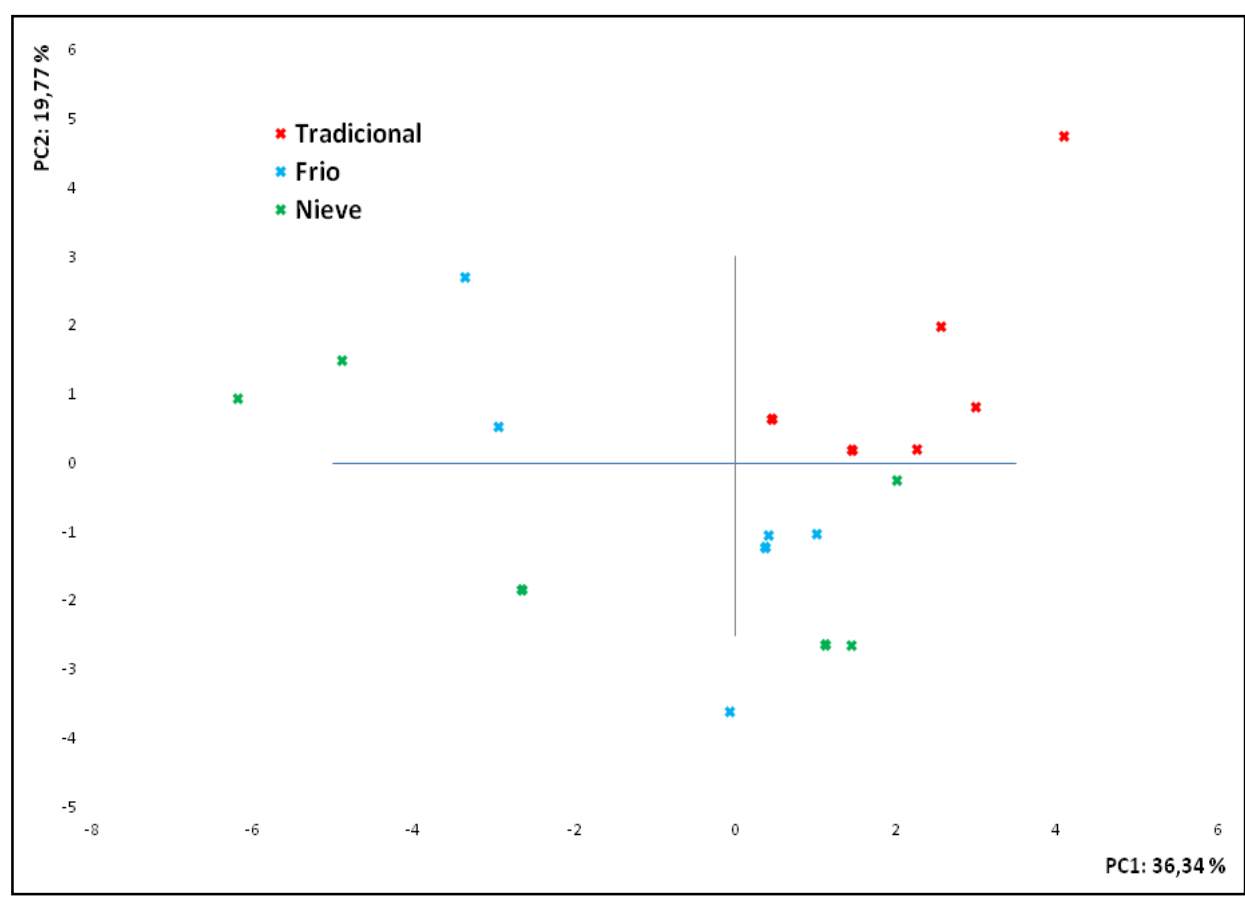

Gráfico 6.41. Primera componente frente a la segunda, en función de las técnicas de vinificación ensayadas.

En la añada 2006 fue posible diferenciar los vinos elaborados con las tres técnicas de vinificación mediante el Análisis de Componentes Principales. En la añada 2007, en cambio, es posible diferenciar los vinos elaborados con maceración tradicional y los elaborados con maceración prefermentativa, pero no es posible distinguir entre los elaborados con maceración en frío y los macerados con nieve carbónica. Las distintas condiciones climatológicas han modificado la concentración y el estado de los compuestos polifenólicos, encontrándose vinos con más color y mayor concentración antociánica que en la añada 2006, que responden de forma similar a las distintas técnicas de maceración prefermentativa ensayadas.

\subsubsection{ANÁLISIS DE LOS VINOS A LOS 6 MESES DE CONSERVACIÓN}

A los seis meses de conservación, se determinó la composición fenólica de los vinos, procediéndose con los resultados a realizar un análisis comparativo en función de las distintas prácticas enológicas ensayadas.

\subsubsection{ANÁLSIS MULTIFACTORIAL DE LA VARIANZA (ANOVA) DE LOS FACTORES CONSIDERADOS}

En la tabla 6.29 aparecen los datos del análisis multifactorial de la varianza (ANOVA) para los factores considerados, así como para las interacciones entre ellos. En este caso se ha estudiado el efecto de cuatro factores. Concretamente, el efecto de la adición de copigmentos, de las diferentes técnicas de vinificación ensayadas, de la aplicación de la microoxigenación y, por último, de la adición pre- o postfermentativa de copigmentos. 


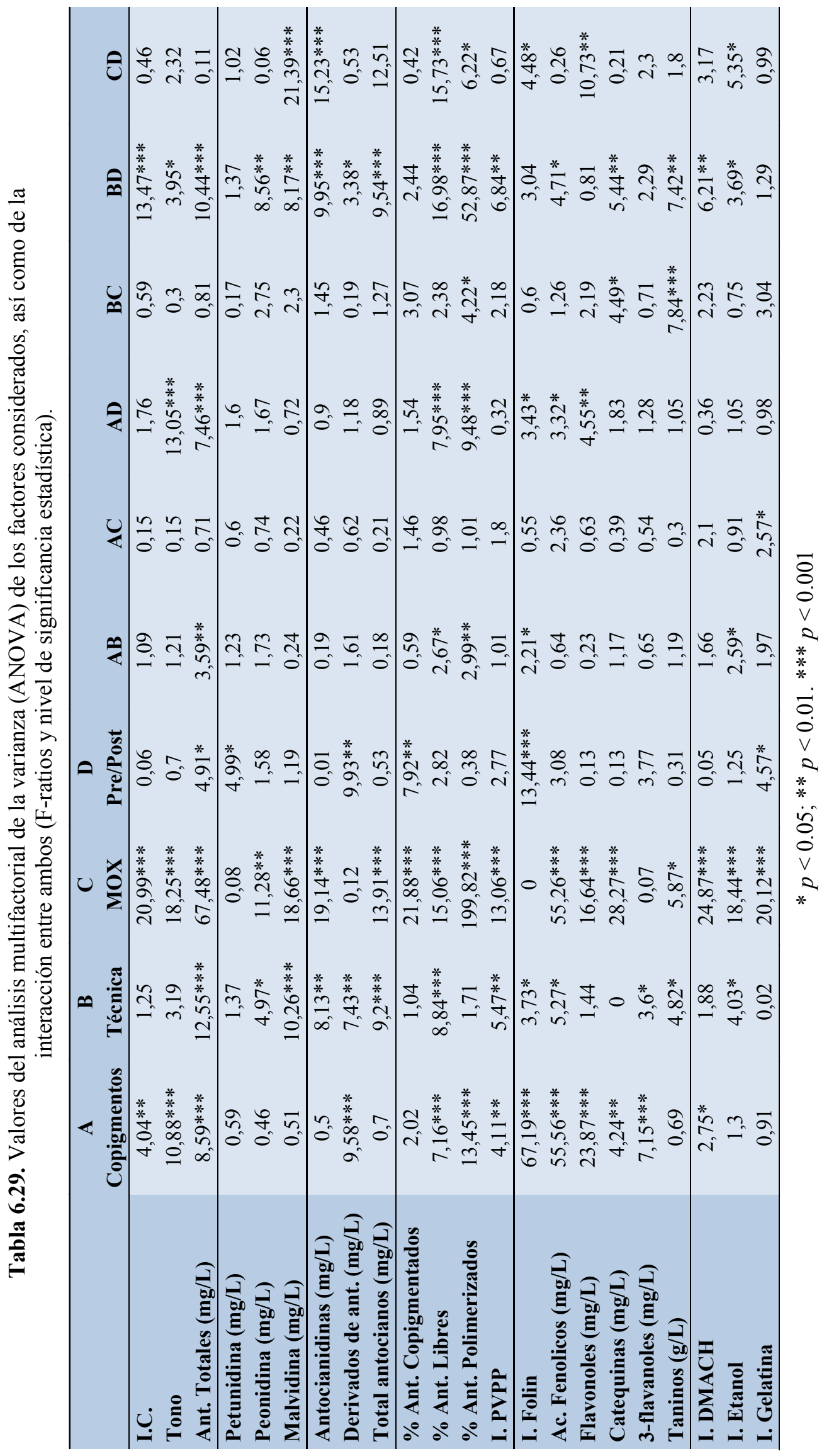


La aplicación controlada de oxígeno (factor $\mathrm{C}$ ) aparece como la técnica que mayores diferencias ocasiona en la mayoría de parámetros polifenólicos determinados, indicando un efecto marcado de esta práctica enológica sobre los parámetros polifenólicos estudiados en los vinos elaborados. Además, el análisis multifactorial de la varianza muestra como la técnica de la adición de copigmentos (factor A) y la aplicación de diferentes técnicas de maceración prefermentativa (factor $\mathrm{B}$ ), también afectan significativamente a la composición fenólica de los vinos, observándose diferencias significativas para algunos de los parámetros considerados. Por el contrario el factor momento de adición de copigmentos (factor D) parece tener un muy bajo o nulo efecto sobre la composición y estado de los compuestos fenólicos en los vinos objeto de estudio, tal como hemos observado en la cosecha del año anterior.

Los parámetros índice de Folin, ácidos fenólicos, flavonoles, porcentaje de color debido a los antocianos polimerizados y tono, por este orden son los que muestran el efecto más marcado sobre la variable adición de copigmentos. Además los parámetros antocianos totales decolorables, porcentaje del color que corresponde a los antocianos libres, 3-flavanoles y derivados de antocianos también presentan diferencias significativas al nivel de confianza del 99,9\%. Este comportamiento pone de manifiesto que la adición de copigmentos influye sobre la mayoría de los compuestos fenólicos identificados, así como sobre la concentración total de polifenoles, destacando como las reacciones de estos copigmentos con los polifenoles pueden contribuir al mantenimiento de la concentración fenólica en el vino (Rivas-Gonzalo, 1995; Francia-Aricha, 1998), contribuyendo a que polimericen haciéndose más estables (Cheynier et al., 1999, 2006).

Para el factor técnica de vinificación aquellos parámetros que presentan los valores más elevados del F-ratio son los antocianos totales decolorables, malvidina, porcentaje de color debido a los antocianos copigmentados, total de antocianos y porcentaje del color de los antocianos libres. Estos resultados indican el elevado efecto que presentan las diferentes técnicas de vinificación ensayadas con respecto a la concentración y el estado de los antocianos en los vinos.

La microoxigenación muestra un efecto muy marcado sobre los polifenoles a los seis meses de conservación, tal como observamos en la añada anterior. Los parámetros índice de Folin, 3-flavanoles, petunidina y derivados de antocianos son los únicos que no presentan diferencias significativas frente al factor aplicación de la microoxigenación. El porcentaje del color que corresponde a los antocianos polimerizados, los antocianos totales decolorables, los ácidos fenólicos, catequinas, índice de DMACH, intensidad colorante e índice de gelatina son las variables que presentan un efecto más marcado sobre la microoxigenación. El incremento de la estabilidad y de la coloración roja, así como la mejora de las características organolépticas y estructurales de los vinos tintos son algunos de los efectos observados cuando se aplica esta técnica (Gómez-Plaza y Cano-López, 2011).

Al igual que observamos en la cosecha anterior, la adición de copigmentos antes o después de la fermentación, no modifica prácticamente la composición de los vinos, afectando ligeramente a alguna fracción antociánica y a los polifenoles totales.

El efecto de la interacción entre los factores adición de copigmentos y técnicas de vinificación $(\mathrm{AB})$ se ha minimizado al cabo de seis meses, con respecto a lo observado después de la fermentación maloláctica, ya que de presentar importantes diferencias para la familia antociánica, pasa o mostrar solo unas mínimas diferencias en 
la concentración de antocianos totales decolorables, en la fracción de color polimerizada y en la libre.

La interacción entre la adición de copigmentos y la microoxigenación (AC) tampoco parece tener un efecto muy marcado sobre los parámetros polifenólicos al cabo de seis meses de conservación. La adición de copigmentos y el momento de adición de los mismos (interacción AD) muestran un ligero efecto sobre el tono, los antocianos totales decolorables y la fracción libre y polimerizada. La interacción entre las técnicas de vinificación con el momento de adición de copigmentos (interacción $\mathrm{BC}$ ) muestra únicamente una cierta influencia en la concentración de taninos. Para la interacción CD (microoxigenación $\mathrm{x}$ momento de adición de copigmentos) encontramos diferencias para los parámetros concentración de malvidina y petunidina y antocianos libres. La combinación de estas técnicas, en cada caso, podría influir sobre la concentración antocianica de los vinos considerados.

La interacción más importante la encontramos entre los factores técnicas de vinificación y momento de adición de copigmentos (BD), tal como se observó en la cosecha 2006, encontrando valores elevados del F-ratio para los parámetros antocianos polimerizados, libres, intensidad colorante y antocianos totales decolorables, indicando un marcado efecto de ambas técnicas sobre la concentración y el estado de los antocianos, actuando decisivamente en el color rojo de los vinos tintos (Monagas et al., 2005).

\subsubsection{EFECTO DE LA ADICIÓN DE COPIGMENTOS}

En la tabla 6.30 se recogen los valores medios de los parámetros polifenólicos a los seis meses de conservación, en función de la adición de los distintos copigmentos. El tratamiento estadístico se ha realizando considerando conjuntamente todos los vinos, independientemente de la técnica de vinificación utilizada, del momento de adición de los copigmentos o de la microoxigenación, valorando así exclusivamente el efecto de la adición de copigmentos en los vinos de Tempranillo.

Únicamente el copigmento rutina muestra diferencias significativas para la intensidad colorante a los seis meses de conservación, encontrando en los vinos adicionados de ácido cafeico y proantocianidinas valores iguales o inferiores a los testigos sin adicionar. La adición de copigmentos produce un incremento del tono en los vinos, a excepción del ácido cafeico que da lugar a valores similares a los testigos. La participación del ácido cafeico en la formación de piranoantocianos podría ser la causa de este comportamiento observado. Gauche et al. (2010) indican como el ácido cafeico favorece la formación de piranoantocianos, disminuyendo el color rojo de los vinos, pero incrementando su estabilidad, protegiéndolos frente al incremento de la tonalidad amarilla. 


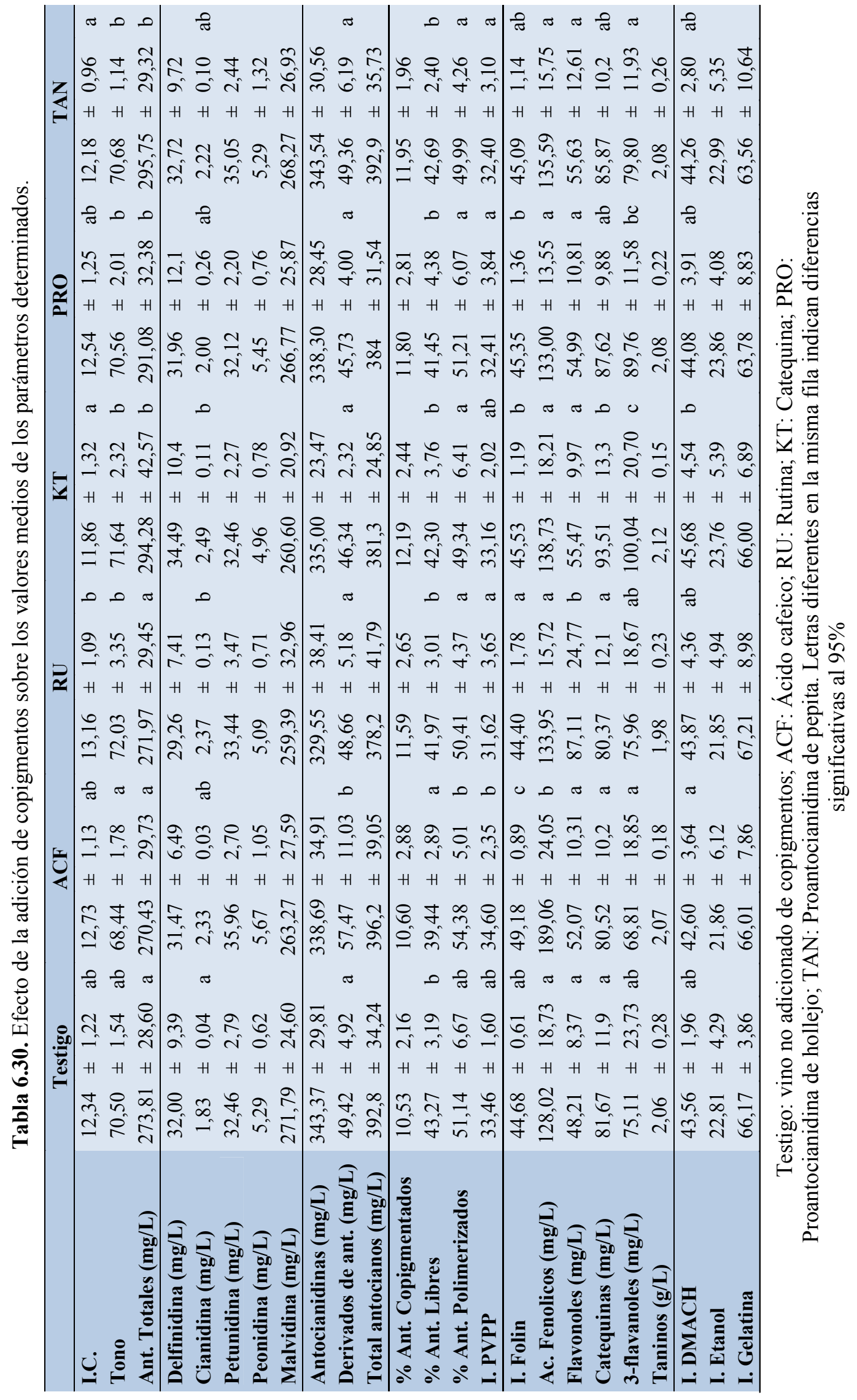


Para la concentración de antocianos totales decolorables por el sulfuroso, se observa como son aquellos copigmentos de carácter tánico (KT, PRO, TAN) los que presentan los mayores valores, tal como apreciamos en los vinos recién fermentados. Por el contrario los copigmentos ácido cafeico y rutina muestran el mismo nivel de significancia estadística que los vinos testigo. Estos resultados ponen de manifiesto las buenas propiedades protectoras frente a los antocianos que presentan este grupo de copigmentos, en las dosis adicionadas al vino (Crespy, 2003 a y b; Crespy y Urban, 2002; Zamora, 2003; Bautista-Ortín et al., 2007).

De las cinco antocianidinas identificadas, únicamente la cianidina muestra diferencias significativas en función de la adición de copigmentos, mostrando los vinos adicionados de los copigmentos rutina y catequina diferencias frente al testigo no adicionado. Posiblemente la participación de la cianidina en reacciones de copigmentación permita que se mantenga una mayor concentración de ésta en los vinos. Sun et al. (2010) estudiando las reacciones de copigmentación entre al cianidina-3glucosido y cinco ácidos fenólicos, mostraron que los ácidos ferúlico y sinápico son los mejores copigmentos para esta antocianidina.

La participación del ácido cafeico en las reacciones de esterificación de los antocianos podría ser la causa de las diferencias significativas observadas para la concentración de los derivados de antocianos en los vinos (Baldi et al., 1995; Favretto y Flamini, 2000; Mazza y Miniati, 1993, Monagas et al., 2003; Nuñez et al., 2004; Cheynier et al., 2000).

El vino adicionado con el copigmento ácido cafeico es el que presenta un mayor porcentaje del color debido a las reacciones de polimerización y el menor color debido a los antocianos libres, tal como se observó en los vinos de 2007 después de la maloláctica, y en los vinos de la cosecha anterior. También son los vinos adicionados con ácido cafeico los que muestran los valores superiores del índice de PVPP, indicando un mayor grado de polimerización de sus antocianos con los taninos.

Para el índice de Folin es, de nuevo, el copigmento ácido cafeico el que presenta una mayor concentración de compuestos fenólicos en el medio, con diferencias significativas, mostrando los vinos testigo y el copigmento rutina los valores más bajos para este parámetro. La inclusión, como ya se ha mencionado, de estos compuestos en reacciones de formación de pigmentos poliméricos podría ser la causa de la mayor concentración polifenólica mostrada por estos vinos.

Tanto para la concentración de catequinas como para la concentración de 3flavanoles son los vinos adicionados de catequina los que muestran diferencias estadísticamente significativas, mostrando también valores elevados los copigmentos proantociandínicos, polímeros formados por catequinas. Además estos vinos, adicionados de catequina, son los que muestran un menor grado de polimerización de taninos, medido mediante el índice de $\mathrm{DMACH}$, con diferencias significativas, tal como se observó en los en los vinos después de la fermentación maloláctica.

Para la concentración de ácidos fenólicos y de flavonoles son los vinos adicionados de ácido cafeico y rutina, respectivamente, los que presentan diferencias significativas frente a los otros copigmentos y frente al testigo no adicionado, tal como era de esperar. 


\subsubsection{EFECTO DE LAS TÉCNICAS DE VINIFICACIÓN}

En la tabla 6.31 se recogen los valores medios de los parámetros polifenólicos analizados en los vinos considerando conjuntamente los distintos vinos elaborados según que la vinificación se realice de forma tradicional, con maceración prefermentativa en frío a $6-8{ }^{\circ} \mathrm{C}$ o bien con una maceración prefermentativa usando nieve carbónica.

Tabla 6.31. Efecto de las técnicas de vinificación sobre los valores medios de los parámetros determinados.

\begin{tabular}{|c|c|c|c|c|c|c|c|c|c|}
\hline & \multicolumn{3}{|c|}{ Tradicional } & \multicolumn{3}{|c|}{ Frio } & \multicolumn{3}{|c|}{ Nieve } \\
\hline I.C. & 12,71 & $\pm 1,55$ & & 12,52 & $\pm 0,88$ & & 12,21 & $\pm 1,06$ & \\
\hline Tono & 71,20 & $\pm 2,63$ & & 69,93 & $\pm 2,28$ & & 70,84 & $\pm 2,28$ & \\
\hline Ant. Totales (mg/L) & 271,85 & $\pm 27,83$ & $\mathrm{a}$ & 287,27 & $\pm 30,64$ & $\mathrm{~b}$ & 297,55 & $\pm 38,96$ & $\mathrm{~b}$ \\
\hline Delfinidina (mg/L) & 33,10 & $\pm 2,84$ & & 32,21 & $\pm 1,85$ & & 33,58 & $\pm 1,73$ & \\
\hline Cianidina (mg/L) & 2,17 & $\pm 0,29$ & & 2,15 & $\pm 0,25$ & & 2,33 & $\pm 0,03$ & \\
\hline Petunidina (mg/L) & 30,67 & $\pm 2,90$ & $\mathrm{a}$ & 31,93 & $\pm 1,90$ & $a b$ & 32,61 & $\pm 2,42$ & $\mathrm{~b}$ \\
\hline Peonidina (mg/L) & 5,13 & $\pm 1,01$ & & 5,20 & $\pm 0,87$ & & 5,49 & $\pm 0,90$ & \\
\hline Malvidina (mg/L) & 257,42 & $\pm 18,40$ & $\mathrm{a}$ & 255,34 & $\pm 26,61$ & $\mathrm{a}$ & 280,43 & $\pm 25,88$ & $\mathrm{~b}$ \\
\hline Antocianidinas (mg/L) & 328,49 & $\pm 24,64$ & $\mathrm{a}$ & 326,83 & $\pm 30,30$ & $\mathrm{a}$ & 354,45 & $\pm 29,36$ & $\mathrm{~b}$ \\
\hline int. (mg/L) & 46,84 & $\pm 3,69$ & $\mathrm{a}$ & 48,33 & $\pm 7,28$ & $\mathrm{a}$ & 53,34 & $\pm 8,63$ & $\mathrm{~b}$ \\
\hline Total antocianos $(\mathrm{mg} / \mathrm{L})$ & 375,32 & $\pm 25,24$ & $\mathrm{a}$ & 375,16 & $\pm 34,48$ & $\mathrm{a}$ & 407,78 & $\pm 32,23$ & $\mathrm{~b}$ \\
\hline \% Ant. Copigmentados & 10,48 & $\pm 2,65$ & & 10,61 & $\pm 2,39$ & & 10,48 & $\pm 2,25$ & \\
\hline \% Ant. Libres & 39,49 & $\pm 4,21$ & a & 40,72 & $\pm 2,91$ & $a b$ & 41,98 & $\pm 2,76$ & $\mathrm{~b}$ \\
\hline$\%$ Ant. Polimerizados & 50,03 & $\pm 7,62$ & & 48,67 & $\pm 3,84$ & & 47,54 & $\pm 4,70$ & \\
\hline I. PVPP & 32,02 & $\pm 3,07$ & $\mathrm{a}$ & 32,79 & $\pm 2,90$ & $\mathrm{ab}$ & 33,92 & $\pm 2,98$ & $\mathrm{~b}$ \\
\hline I. Folin & 46,22 & $\pm 2,23$ & & 45,65 & $\pm 1,95$ & & 45,56 & $\pm 1,95$ & \\
\hline Ac. Fenolicos (mg/L) & 146,74 & $\pm 29,40$ & & 148,56 & $\pm 26,35$ & & 137,98 & $\pm 26,56$ & \\
\hline Flavonoles (mg/L) & 61,27 & $\pm 20,59$ & & 57,19 & $\pm 20,87$ & & 63,38 & $\pm 19,34$ & \\
\hline Catequinas (mg/L) & 85,49 & $\pm 17,59$ & & 84,93 & $\pm 15,05$ & & 85,49 & $\pm 13,88$ & \\
\hline 3-flavanoles (mg/L) & 65,45 & $\pm 19,01$ & $\mathrm{a}$ & 70,16 & $\pm 20,00$ & $a b$ & 80,89 & $\pm 18,34$ & $\mathrm{~b}$ \\
\hline Taninos $(\mathrm{g} / \mathrm{L})$ & 2,15 & $\pm 0,25$ & & 2,01 & $\pm 0,20$ & & 2,03 & $\pm 0,23$ & \\
\hline I. DMACH & 43,41 & $\pm 4,23$ & & 43,76 & $\pm 3,21$ & & 44,82 & $\pm 3,99$ & \\
\hline I. Etanol & 21,75 & $\pm 5,89$ & $\mathrm{a}$ & 23,96 & $\pm 4,39$ & $\mathrm{~b}$ & 22,78 & $\pm 4,83$ & $a b$ \\
\hline I. Gelatina & 64,97 & $\pm 5,96$ & & 65,45 & $\pm 10,12$ & & 65,53 & $\pm 8,65$ & \\
\hline
\end{tabular}

Tradicional: elaboración sin maceración en frío previamente a la fermentación; Frío: aplicación de bajas temperaturas de forma prefermentativa; Nieve: uso de nieve carbónica prefermentativamente. Letras diferentes en la misma fila indican diferencias significativas al 95\%.

No se observan diferencias en el color de los vinos, a diferencia de lo observado después de la fermentación, pero la concentración de antocianos totales decolorables sigue mostrando diferencias significativas entre la maceración prefermentativa, con aplicación de frío o de nieve carbónica y la vinificación tradicional.

Las antocianidinas petunidina y malvidina muestran diferencias significativas para la maceración con nieve carbónica, mostrando esta los valores más elevados para 
este parámetro. Además, tanto la concentración de antocianidinas como la concentración total de antocianos muestran un efecto positivo de la maceración prefermentativa con nieve carbónica (Gil-Muñoz et al., 2009, Álvarez et al., 2006).

Las diferencias estadísticas mostradas para la concentración de derivados de antocianos con la aplicación de nieve carbónica podría reforzar la teoría de que esta técnica favorece, además de la extracción antociánica, la extracción de otros componentes de la uva que pueden reaccionar con los antocianos, dando lugar a estructuras más complejas y, en ocasiones, más estables durante el envejecimiento de los vinos, manteniendo por lo tanto una mayor concentración de estos compuestos en solución.

Es de destacar la evolución de los vinos macerados con frío durante los seis meses de conservación, que después de la fermentación mostraban concentraciones de antocianos y derivados similares a los vinos macerados con nieve carbónica y en cambio a los seis meses han sufrido una caída superior, no apareciendo diferencias significativas entre ellos y los vinos de maceración tradicional.

El porcentaje de color debido a los antocianos libres, el grado de polimerización tanino-antociano (índice de PVPP) y la concentración de 3-flavanoles, también es superior en los vinos macerados con nieve carbónica, mientras que los complejos de los taninos con polisacáridos, sales y péptidos, medidas mediante el índice de etanol, muestran valores superiores a los 6 meses en los vinos macerados por frío.

\subsubsection{EFECTO DE LA MICROOXIGENACIÓN}

La tabla 6.32 muestra los valores medios de los parámetros polifenólicos, considerando conjuntamente a todos aquellos vinos que han sido microoxigenados frente a aquellos vinos a los que no se les ha realizado adición de acetaldehído.

Tanto la intensidad colorante como el tono muestran diferencias estadísticamente significativas, mostrando los vinos microoxigenados los mayores valores para estos parámetros relacionados con el color de los vinos. Es de sobra conocido el efecto de esta técnica, incrementando el color de los vinos (Cano-López et al., 2006, 2007, 2008, 2010; Wirth et al., 2010; Rayne et al., 2008), aunque las diferencias encontradas para la tonalidad amarilla indican que estos vinos podrían estar sufriendo un proceso oxidativo, actuando de forma negativa frente a la composición fenólica. Cano-López et al. (2010) observan un incremento de la tonalidad amarilla a los 6 meses de conservación de los vinos en botella en los vinos micooxigenados frente a aquellos vinos no adicionados de oxígeno. Probablemente la reacción del acetaldehído con el sulfuroso haya podido influir de forma decisiva en el tono de los vinos, al verse disminuido el efecto protector del sulfuroso por estar participando en reacciones estables con el acetaldehído adicionado durante la microoxigenación. 
Tabla 6.32. Efecto de la microoxigenación sobre los valores medios de los parámetros determinados.

\begin{tabular}{lccccccc}
\hline & \multicolumn{3}{c}{ No MOX } & \multicolumn{4}{c}{ MOX } \\
\hline I.C. & 11,95 & $\pm 0,89$ & $\mathrm{a}$ & 13,02 & $\pm 1,24$ & $\mathrm{~b}$ \\
Tono & 69,93 & $\pm 2,17$ & $\mathrm{a}$ & 71,37 & $\pm 2,48$ & $\mathrm{~b}$ \\
Ant. Totales (mg/L) & 301,94 & $\pm 25,32$ & $\mathrm{~b}$ & 269,21 & $\pm 34,35$ & $\mathrm{a}$ \\
\hline Delfinidina (mg/L) & 33,10 & $\pm 1,53$ & & 32,87 & $\pm 2,80$ & \\
Cianidina (mg/L) & 2,25 & $\pm 0,24$ & & 2,04 & $\pm 0,19$ & \\
Petunidina (mg/L) & 32,46 & $\pm 2,45$ & $\mathrm{~b}$ & 30,98 & $\pm 2,29$ & $\mathrm{a}$ \\
Peonidina (mg/L) & 5,54 & $\pm 0,82$ & & 5,04 & $\pm 0,93$ & \\
Malvidina (mg/L) & 273,16 & $\pm 25,34$ & $\mathrm{~b}$ & 255,63 & $\pm 24,34$ & $\mathrm{a}$ \\
\hline Antocianidinas (mg/L) & 346,5 & $\pm 26,65$ & $\mathrm{~b}$ & 326,6 & $\pm 30,42$ & $\mathrm{a}$ \\
Derivados de ant. (mg/L) & 49,25 & $\pm 5,85$ & & 49,75 & $\pm 8,61$ & \\
Total antocianos (mg/L) & 395,8 & $\pm 30,10$ & $\mathrm{~b}$ & 376,3 & $\pm 34,85$ & $\mathrm{a}$ \\
\hline \% Ant. Copigmentados & 12,45 & $\pm 1,75$ & $\mathrm{~b}$ & 10,60 & $\pm 2,89$ & $\mathrm{a}$ \\
\% Ant. Libres & 42,59 & $\pm 2,70$ & $\mathrm{~b}$ & 40,87 & $\pm 3,96$ & $\mathrm{a}$ \\
\% Ant. Polimerizados & 47,61 & $\pm 3,14$ & $\mathrm{a}$ & 54,64 & $\pm 5,32$ & $\mathrm{~b}$ \\
I. PVPP & 33,73 & $\pm 1,86$ & & 33,09 & $\pm 3,75$ & \\
\hline I. Folin & 46,81 & $\pm 2,16$ & & 45,81 & $\pm 1,95$ & \\
Ac. Fenolicos (mg/L) & 154,97 & $\pm 29,09$ & $\mathrm{~b}$ & 133,88 & $\pm 21,32$ & $\mathrm{a}$ \\
Flavonoles (mg/L) & 66,03 & $\pm 20,21$ & $\mathrm{~b}$ & 55,20 & $\pm 18,83$ & $\mathrm{a}$ \\
Catequinas (mg/L) & 79,39 & $\pm 13,69$ & $\mathrm{a}$ & 91,21 & $\pm 14,96$ & $\mathrm{~b}$ \\
3-flavanoles (mg/L) & 83,01 & $\pm 20,50$ & & 81,33 & $\pm 19,61$ & \\
Taninos (g/L) & 2,02 & $\pm 0,20$ & $\mathrm{a}$ & 2,11 & $\pm 0,25$ & $\mathrm{~b}$ \\
\hline I. DMACH & 45,41 & $\pm 3,81$ & $\mathrm{~b}$ & 42,57 & $\pm 3,36$ & $\mathrm{a}$ \\
I. Etanol & 24,40 & $\pm 4,68$ & $\mathrm{~b}$ & 21,25 & $\pm 5,09$ & $\mathrm{a}$ \\
I. Gelatina & 68,14 & $\pm 5,12$ & $\mathrm{~b}$ & 62,49 & $\pm 9,92$ & $\mathrm{a}$ \\
\hline
\end{tabular}

No MOX: vinos no adicionados de acetaldehído; MOX: vinos adicionados de acetaldehído. Letras diferentes en la misma fila indican diferencias significativas al 95\%

Los parámetros que miden la concentración antociánica de los vinos (antocianos totales decolorables, petunidina, malvidina, antociandinas y total de antocianos) muestran diferencias significativas favorables a los vinos no adicionados de acetaldehído. La participación de estos compuestos en las reacciones de polimerización mediadas por el acetaldehído podría ser la causa del comportamiento observado (González-del Pozo et al., 2010), reforzándose este resultado con los elevados valores encontrados tanto para la intensidad colorante como para el porcentaje del color que corresponde a la polimerización de los antocianos, tal como se observó también en los vinos elaborados en 2006.

El porcentaje del color que corresponde a la copigmentación muestra diferencias significativas, mostrando los vinos microoxigenados los mayores valores, siendo este resultado inverso al observado para los antocianos libres.

Para los parámetros ácidos fenólicos y flavonoles los vinos adicionados de acetaldehído son los que muestran las menores concentraciones, mientras que para la concentración de catequinas y taninos, así como para su grado de polimerización, son 
los vinos microoxigenados los que presentan valores significativamente superiores con respecto a los vinos no adicionados. Estos compuestos también forman parte de complejos de polimerización con antocianos (Cejudo-Bastante et al., 2010), favoreciendo la microoxigenación su presencia al cabo de seis meses, tal como observamos anteriormente. Por el contrario esta técnica no ha favorecido las uniones entre taninos y polisacáridos.

Tao et al. (2007), estudiando el efecto de la microoxigenación en función de la presencia de diferentes concentraciones de sulfuroso, observan un importante descenso de los antocianos monómeros y de los flavan-3-oles en los vinos con menores concentraciones de $\mathrm{SO}_{2}$, junto con un incremento en la concentración de pigmentos poliméricos no decolorables, además de un incremento de la concentración de taninos.

\subsubsection{EFECTO DEL MOMENTO DE ADICIÓN DE LOS COPIGMENTOS}

En la tabla 6.33 se recogen los valores medios de los parámetros polifenólicos analizados en los vinos considerando conjuntamente a todos aquellos que han sido adicionados de copigmentos previamente o posteriormente a la fermentación de los vinos.

Tal como observamos en la cosecha anterior, el momento de adición de los copigmentos tiene un mínimo efecto sobre la composición de los vinos al cabo de seis meses de conservación, observándose solamente diferencias en la concentración de los derivados acetilados y cumaroilados y en el porcentaje de color debido a los antocianos copigmentados, que es ligeramente superior cuando los copigmentos se adicionan antes de la fermentación, sugiriendo una mejor conservación de los complejos de copigmentación cuando la adición de los copigmentos se realiza en las uvas recién exprimidas. 
Tabla 6.33. Efecto del momento de adición de copigmentos sobre los valores medios de los parámetros determinados.

\begin{tabular}{|c|c|c|c|c|c|c|}
\hline & \multicolumn{3}{|c|}{ PRE } & \multicolumn{3}{|c|}{ POST } \\
\hline I.C. & 12,47 & $\pm 1,23$ & & 12,52 & $\pm 1,20$ & \\
\hline Tono & 65,55 & $\pm 2,20$ & & 66,30 & $\pm 1,97$ & \\
\hline Ant. Totales (mg/L) & 279,98 & $\pm 39,46$ & & 288,72 & $\pm 28,69$ & \\
\hline Delfinidina (mg/L) & 32,48 & $\pm 2,24$ & & 33,52 & $\pm 2,23$ & \\
\hline Cianidina (mg/L) & 2,18 & $\pm 0,28$ & & 2,24 & $\pm 0,21$ & \\
\hline Petunidina (mg/L) & 32,07 & $\pm 2,03$ & & 31,59 & $\pm 2,94$ & \\
\hline Peonidina (mg/L) & 5,31 & $\pm 0,99$ & & 5,28 & $\pm 0,85$ & \\
\hline Malvidina (mg/L) & 261,05 & $\pm 25,22$ & & 266,26 & $\pm 27,75$ & \\
\hline Antocianidinas (mg/L) & 333,09 & $\pm 29,70$ & & 338,89 & $\pm 32,31$ & \\
\hline Derivados de ant. $(\mathrm{mg} / \mathrm{L})$ & 47,37 & $\pm 5,88$ & $\mathrm{a}$ & 51,65 & $\pm 8,46$ & $\mathrm{~b}$ \\
\hline Total antocianos (mg/L) & 380,5 & $\pm 31,30$ & & 390,5 & $\pm 37,53$ & \\
\hline \% Ant. Copigmentados & 12,17 & $\pm 2,35$ & b & 11,08 & $\pm 2,69$ & $\mathrm{a}$ \\
\hline \% Ant. Libres & 41,22 & $\pm 2,32$ & & 41,93 & $\pm 4,35$ & \\
\hline \% Ant. Polimerizados & 50,98 & $\pm 5,07$ & & 51,27 & $\pm 5,97$ & \\
\hline I. PVPP & 32,45 & $\pm 3,45$ & & 33,26 & $\pm 2,83$ & \\
\hline I. Folin & 45,55 & $\pm 2,20$ & & 46,30 & $\pm 1,97$ & \\
\hline Ac. Fenolicos (mg/L) & 148,61 & $\pm 30,25$ & & 143,53 & $\pm 25,27$ & \\
\hline Flavonoles (mg/L) & 62,39 & $\pm 17,46$ & & 61,32 & $\pm 23,58$ & \\
\hline Catequinas (mg/L) & 85,24 & $\pm 15,26$ & & 86,09 & $\pm 15,77$ & \\
\hline 3-flavanoles (mg/L) & 78,90 & $\pm 11,36$ & & 86,84 & $\pm 24,90$ & \\
\hline $\operatorname{Taninos}(\mathrm{g} / \mathrm{L})$ & 2,05 & $\pm 0,24$ & & 2,07 & $\pm 0,23$ & \\
\hline I. DMACH & 44,11 & $\pm 3,79$ & & 43,97 & $\pm 4,22$ & \\
\hline I. Etanol & 23,28 & $\pm 5,45$ & & 22,38 & $\pm 4,96$ & \\
\hline I. Gelatina & 66,70 & $\pm 7,60$ & & 63,76 & $\pm 9,49$ & \\
\hline
\end{tabular}

PRE: adición de copigmentos previamente al inicio de la fermentación alcohólica; POST: adición de copigmentos en el embotellado. Letras diferentes en la misma fila indican diferencias significativas al $95 \%$

\subsubsection{CORRELACIÓN ENTRE LOS PARÁMETROS POLIFENÓLICOS DE LOS VINOS, LA ADICIÓN DE COPIGMENTOS Y LAS TÉCNICAS DE VINIFICACIÓN}

A continuación se expone la matriz de covarianzas o matriz de correlaciones entre los parámetros polifenólicos analizados, como paso previo a la realización del Análisis de Componentes Principales (ACP).

En la tabla 6.34 se representa la matriz de correlaciones de las variables utilizadas en el análisis, indicando una coloración más intensa una mayor correlación entre las variables consideradas; correspondiendo las coloraciones rojas a las relaciones negativas, las verdes a las positivas y, por último, las amarillas a las correlaciones débiles entre las variables relacionadas (próxima a cero). 


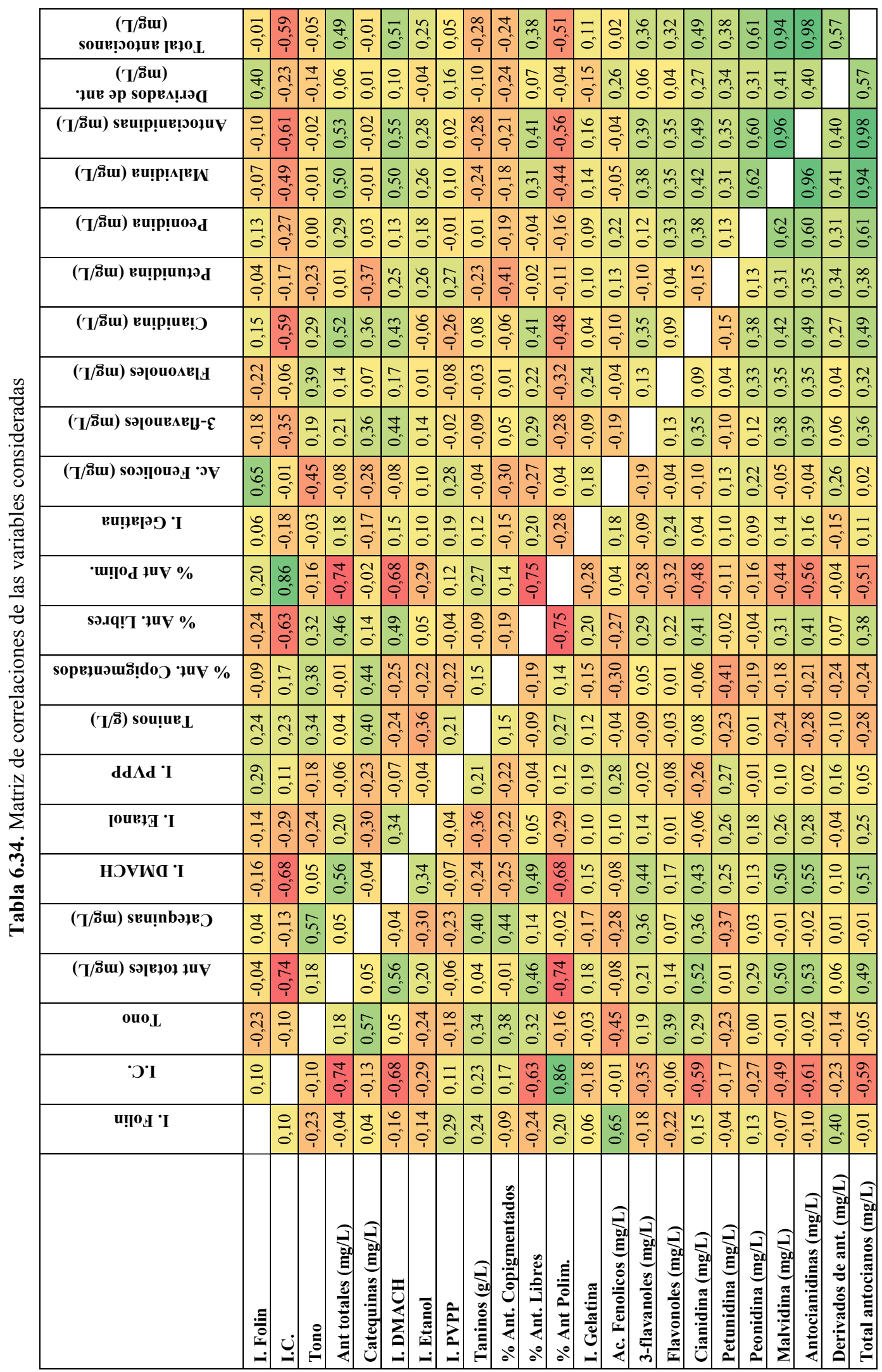


El índice de Folin y la concentración de ácidos fenólicos presentan una correlación positiva indicando, como era de esperar, que el incremento en la concentración de estos compuestos aumenta la concentración total de los compuestos con grupos fenol presentes en el vino. También se observa una correlación positiva entre la concentración de catequinas y el tono, indicando la facilidad de oxidación que presentan estos compuestos incrementando la componente amarilla de los vinos.

El porcentaje del color que corresponde a los antocianos polimerizados presenta un coeficiente positivo con la intensidad colorante. Este resultado confirma como en los vinos envejecidos una parte importante del color es debido a los pigmentos poliméricos (Castañeda-Ovando et al., 2009, Cheynier et al., 2006, Malien-Aubert et al., 2002), a diferencia de los vinos jóvenes, en los cuales los antocianos libres representan el 50$70 \%$ del color.

Tabla 6.35. Autovalor, varianza explicada y acumulada para las componentes consideradas en el análisis

\begin{tabular}{cccc}
\hline Componente & Autovalor & \% Varianza & \% Acumulado \\
\hline $\mathbf{1}$ & 6,713 & 27,972 & 27,972 \\
$\mathbf{2}$ & 3,477 & 14,487 & 42,458 \\
$\mathbf{3}$ & 2,285 & 9,520 & 51,978 \\
$\mathbf{4}$ & 1,830 & 7,625 & 59,603 \\
$\mathbf{5}$ & 1,510 & 6,291 & 65,894 \\
$\mathbf{6}$ & 1,432 & 5,965 & 71,859 \\
$\mathbf{7}$ & 0,987 & 4,112 & 75,971 \\
$\mathbf{8}$ & 0,851 & 3,545 & 79,517 \\
$\mathbf{9}$ & 0,757 & 3,155 & 82,672 \\
$\mathbf{1 0}$ & 0,732 & 3,052 & 85,724 \\
$\mathbf{1 1}$ & 0,671 & 2,796 & 88,521 \\
$\mathbf{1 2}$ & 0,537 & 2,239 & 90,759 \\
$\mathbf{1 3}$ & 0,457 & 1,906 & 92,665 \\
$\mathbf{1 4}$ & 0,401 & 1,671 & 94,336 \\
$\mathbf{1 5}$ & 0,279 & 1,161 & 95,496 \\
$\mathbf{1 6}$ & 0,263 & 1,097 & 96,594 \\
$\mathbf{1 7}$ & 0,215 & 0,895 & 97,489 \\
$\mathbf{1 8}$ & 0,190 & 0,793 & 98,282 \\
$\mathbf{1 9}$ & 0,156 & 0,651 & 98,933 \\
$\mathbf{2 0}$ & 0,140 & 0,585 & 99,517 \\
$\mathbf{2 1}$ & 0,060 & 0,251 & 99,768 \\
$\mathbf{2 2}$ & 0,029 & 0,120 & 99,888 \\
$\mathbf{2 3}$ & 0,027 & 0,112 & 100,000 \\
\hline
\end{tabular}

Tanto los antocianos totales como el índice de DMACH se correlacionan directamente entre sí, y muestran coeficientes positivos para la cianidina, malvidina, antocianidinas y total de antocianos. Destacando como un menor grado de polimerización de los taninos entre sí en el vino, favorece el mantenimiento de los antocianos formando parte de complejos con estos últimos y no en complejos de polimerización entre ellos mismos. 
Por último destacar como muchos de los parámetros que determinan el perfil antociánico de los vinos presentan coeficientes positivos al estar altamente relacionados entre sí. Un ejemplo de esto son los elevados coeficientes encontrados para la malvidina con las antocianidinas o el total de antocianos.

En cuanto a las correlaciones negativas, los parámetros antocianos totales decolorables, índice de DMACH, porcentaje de antocianos libres, cianidina, antocianidinas y total de antocianos presentan coeficientes negativos para la intensidad colorante. Este comportamiento indica la facilidad de los antocianos libres para sufrir oxidaciones, actuando de forma negativa frente al color, apareciendo los tonos característicos de los vinos envejecidos, junto con una menor intensidad colorante provocada por la precipitación de materia colorante (Castañedo-Ovando et al., 2009). Este razonamiento se ve reforzado por las correlaciones negativas que presentan la mayoría de estos parámetros frente al porcentaje del color que corresponde a polimerizaciones, índice relacionado positivamente con la intensidad colorante.

Tabla 6.36. Tabla de pesos de los componentes

\begin{tabular}{lcccccc}
\hline & \multicolumn{6}{c}{ Componentes } \\
& $\mathbf{1}$ & $\mathbf{2}$ & $\mathbf{3}$ & $\mathbf{4}$ & $\mathbf{5}$ & $\mathbf{6}$ \\
\hline I. Folin & $-0,04$ & $-0,22$ & 0,43 & $-0,31$ & 0,09 & 0,13 \\
I.C. & $-0,32$ & $-0,06$ & 0,07 & 0,21 & $-0,10$ & $-0,19$ \\
Tono & 0,03 & 0,42 & 0,12 & 0,07 & $-0,25$ & $-0,05$ \\
Ant totales (mg/L) & 0,28 & 0,11 & $-0,01$ & $-0,26$ & $-0,01$ & 0,03 \\
Catequinas (mg/L) & 0,01 & 0,37 & 0,31 & $-0,03$ & 0,13 & 0,00 \\
I. DMACH & 0,29 & 0,03 & $-0,18$ & $-0,09$ & 0,03 & 0,14 \\
I. Etanol & 0,14 & $-0,17$ & $-0,30$ & 0,00 & 0,16 & $-0,15$ \\
I. PVPP & $-0,02$ & $-0,23$ & 0,15 & $-0,01$ & $-0,45$ & 0,26 \\
Taninos (g/L) & $-0,11$ & 0,16 & 0,34 & $-0,22$ & $-0,30$ & 0,01 \\
\%o Ant. Copigmentados & $-0,10$ & 0,31 & 0,09 & 0,05 & 0,13 & $-0,19$ \\
\% Ant. Libres & 0,23 & 0,19 & $-0,14$ & $-0,09$ & $-0,23$ & 0,32 \\
\% Ant Polim. & $-0,31$ & $-0,10$ & 0,19 & 0,25 & 0,06 & $-0,06$ \\
I. Gelatina & 0,09 & $-0,08$ & $-0,06$ & $-0,34$ & $-0,45$ & $-0,25$ \\
Ac. Fenolicos (mg/L) & $-0,01$ & $-0,36$ & 0,20 & $-0,33$ & 0,06 & $-0,08$ \\
3-flavanoles (mg/L) & 0,18 & 0,17 & 0,03 & 0,11 & 0,18 & 0,07 \\
Flavonoles (mg/L) & 0,14 & 0,09 & 0,04 & 0,13 & $-0,34$ & $-0,48$ \\
Cianidina (mg/L) & 0,24 & 0,18 & 0,24 & $-0,14$ & 0,18 & 0,12 \\
Petunidina (mg/L) & 0,11 & $-0,30$ & $-0,10$ & 0,21 & $-0,19$ & 0,12 \\
Peonidina (mg/L) & 0,20 & $-0,11$ & 0,30 & 0,11 & 0,04 & $-0,37$ \\
Malvidina (mg/L) & 0,32 & $-0,08$ & 0,13 & 0,25 & $-0,04$ & $-0,11$ \\
Antocianidinas (mg/L) & 0,35 & $-0,07$ & 0,08 & 0,20 & $-0,02$ & $-0,08$ \\
Derivados de ant. (mg/L) & 0,14 & $-0,20$ & 0,35 & 0,18 & 0,10 & 0,25 \\
Total antocianos (mg/L) & 0,34 & $-0,10$ & 0,15 & 0,22 & 0,01 & $-0,02$ \\
\hline & & & & & & \\
\hline & & & & &
\end{tabular}


En la tabla 6.35 aparece tanto el autovalor como el porcentaje de varianza acumulada por los sucesivos factores, observándose como son necesarios seis factores para que el autovalor descienda por debajo de la unidad. Estos seis patrones de comportamiento asociado explican entre ellos más del $70 \%$ de la variabilidad total observada en las variables originales, consiguiéndose con esto una reducción de las variables iniciales.

La tabla 6.36 muestra los valores de los coeficientes de las ecuaciones que forman cada uno de las seis componentes principales identificados. Como norma general en la interpretación de estos valores se tiende a prescindir de aquellas variables cuyo coeficiente con el factor es inferior a 0.25-0.3.

El primer componente principal identificado presenta asociaciones directas (coeficientes positivos) para los parámetros antocianos totales decolorables, índice de DMACH, malvidina, antocianidinas y total de antocianos. Por el contrario presenta asociaciones indirectas frente a la intensidad colorante y los antocianos polimerizados. Estos resultados relacionan al primer componente en su parte positiva con vinos que presentan una elevada concentración de antocianos, principalmente en su forma libre, es decir poco estable, y que además los taninos están formando parte de procesos de polimerización con ellos mismos y no con los antocianos. En su parte negativa este componente correspondería a vinos que presenten una composición antociánica formada en su mayoría por polímeros de antocianos, que afectan decisivamente al color de los vinos manteniendo sus características cromáticas durante el envejecimiento.

Los parámetros tono, catequinas y porcentaje del color que corresponde a copigmentación presentan coeficientes positivos para el segundo componente principal considerado. Además, los parámetros ácidos fenólicos y petunidina, junto con el índice de Folin y el de PVPP, en menor medida, presentan una asociación indirecta frente a este componente. Correspondiendo en su parte positiva a vinos con elevadas concentraciones de compuestos monómeros, fácilmente oxidables, que pueden contribuir al incremento del tono de los vinos, en los que además podrían estar todavía presentes, en gran medida, las reacciones de copigmentación. En su parte negativa correspondería a vinos con elevadas concentraciones de ácidos fenólicos, los cuales incrementan considerablemente la concentración fenólica.

El tercer componente principal está relacionado de forma directa con los parámetros índice de Folin, catequinas, taninos, peonidina y derivados de antocianos, correspondiendo a vinos con una elevada concentración de polifenoles, concretamente de taninos, tanto en su forma monómera como polimerizada, y con derivados de antocianos. Presentando coeficientes negativos únicamente para el índice de etanol.

El cuarto componente principal se relaciona de forma positiva con los antocianos polimerizados y la malvidina y de forma negativa con índice de Folin, antocianos totales, índice de gelatina y ácidos fenólicos. El quinto con la concentración de taninos, los taninos polimerizados con antocianos y la astingencia de los taninos, y el sexto con loa antocianos libres, peonidina y flavonoles.

Una vez comprobadas que variables están más correlacionadas con las componentes principales, se calcularon los coeficientes de las combinaciones lineales y se representan estos coeficientes en el espacio definido por los distintos componentes principales. 


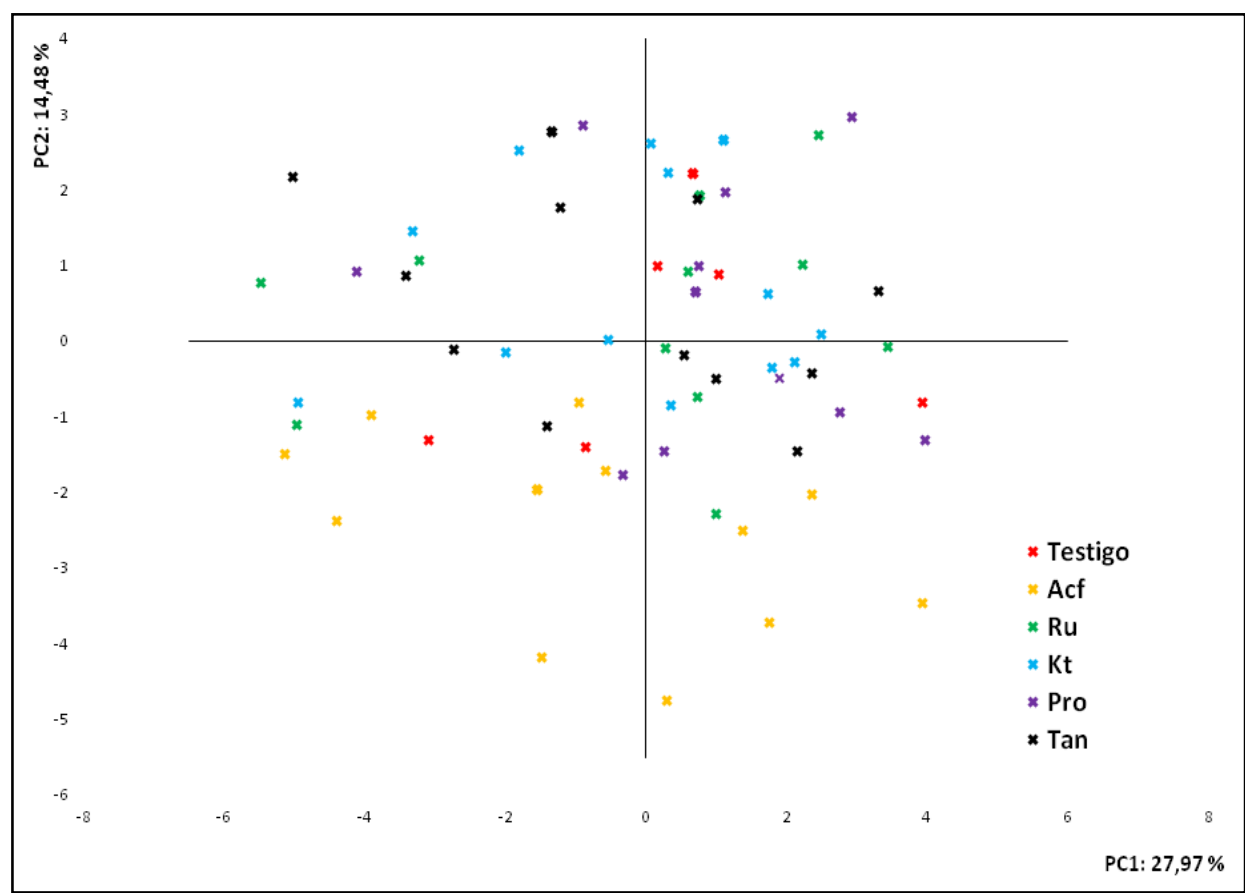

Gráfico 6.42. Primera componente frente a la segunda, en función de los copigmentos ensayados.

En el gráfico $\mathbf{6 . 4 2}$ aparecen las dos primeras componentes de los vinos elaborados, en función de los copigmentos utilizados, observándose como los vinos se presentan aleatoriamente distribuidos a lo largo del primer componente y como únicamente los vinos adicionados de copigmento ácido cafeico parecen diferenciarse del resto, situándose en la zona negativa del segundo componente principal considerado.

A continuación aparece la representación de la segunda componente frente a la tercera (gráfico 6.43) en función de los copigmentos adicionados. Donde podemos comprobar cómo los vinos adicionados de ácido cafeico se diferencian del resto situándose en la parte positiva del tercer eje principal y en la negativa del segundo eje como ya se había observado en el gráfico $\mathbf{6 . 4 2}$.

La elevada concentración de ácidos fenólicos, de derivados de antocianos, y en general de compuestos polifenólicos, junto con una mayor polimerización de sus antocianos, que presentan los vinos suplementados con ácido cafeico, permite diferenciar claramente mediante la técnica APC los vinos elaborados con este copigmento a los seis meses de conservación. Es interesante destacar que ya existían estas diferencias de los vinos elaborados con el ácido cafeico con respecto al testigo en los vinos recién terminada la fermentación maloláctica, pero en ese momento no eran tan evidentes con respecto a los vinos adicionados de otros copigmentos, lo que no nos permitía una diferenciación mediante el análisis de componentes principales. Lo mismo sucedió en la cosecha de 2006, que aunque el ácido cafeico mostró un comportamiento similar, no fue posible establecer mediante esta técnica diferencias con los vinos adicionados de otros copigmentos, ni con los testigos. 


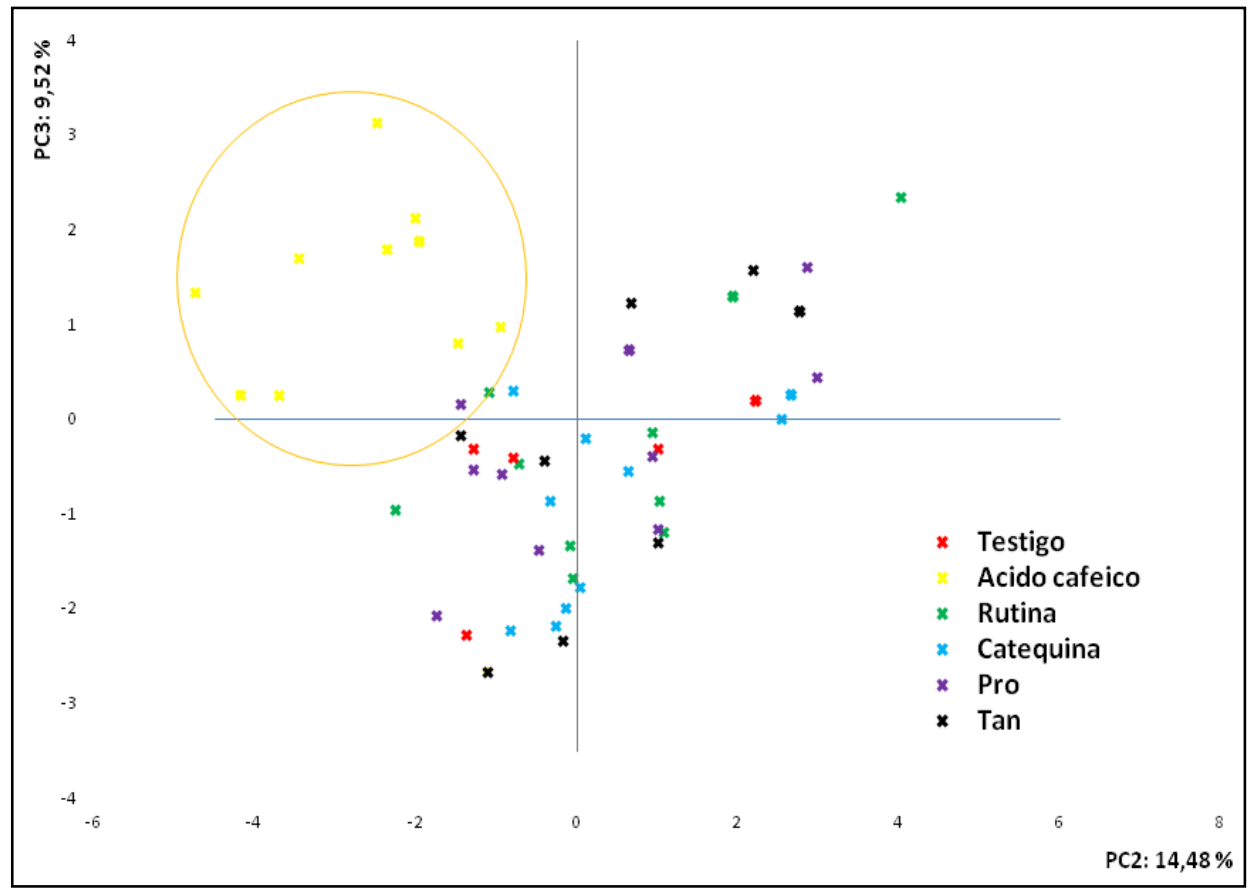

Gráfico 6.43. Segunda componente frente a la tercera, en función de los copigmentos ensayados.

A pesar de que al ácido cafeico no ha demostrado a lo largo del estudio incrementar el color debido a los antocianos copigmentados, si ha tenido un efecto positivo sobre los vinos, facilitando las reacciones de esterificación de los antocianos con formación de derivados de antocianos y pigmentos poliméricos, contribuyendo a mantener el color y la concentración fenólica de los vinos, tal como observaron DaríasMartin et al. (2001). Schwarz et al. (2005) estudiando el efecto de la adición prefermentativa de copigmentos en vinos de Tempranillo y Cabernet Sauvignon indican como los ácidos hidroxicinámicos (cumárico, cafeico, ferúlico o sinápico) o sus productos de descarboxilación (4-vinilfenoles) pueden reaccionar de forma covalente con los antocianos dando lugar a la formación de piranoantocianos (Fulcrand et al., 1996; Hayasaka y Asenstorfer, 2002, Schwarz et al., 2003), compuestos caracterizados por su elevada estabilidad; además observan también como en aquellos vinos adicionados de cafeico y cumárico se produce un incremento del color debido a polimerizaciones, lo cual pone de manifiensto la influencia de estos compuestos en la formación de polímeros de antocianos, responsables del color de vinos envejecidos.

El análisis de componentes principales no permite diferenciar a los vinos elaborados mediante las diferentes técnicas de vinificación ensayadas, apareciendo distribuidos aleatoriamente a lo largo de los dos primeros componentes (gráfico 6.44), no presentando ninguna tendencia que permita la caracterización de los vinos. Tampoco la representación de los otros componentes ha permitido establecer conclusiones sobre el efecto de las técnicas de vinificación sobre la composición de los vinos. 


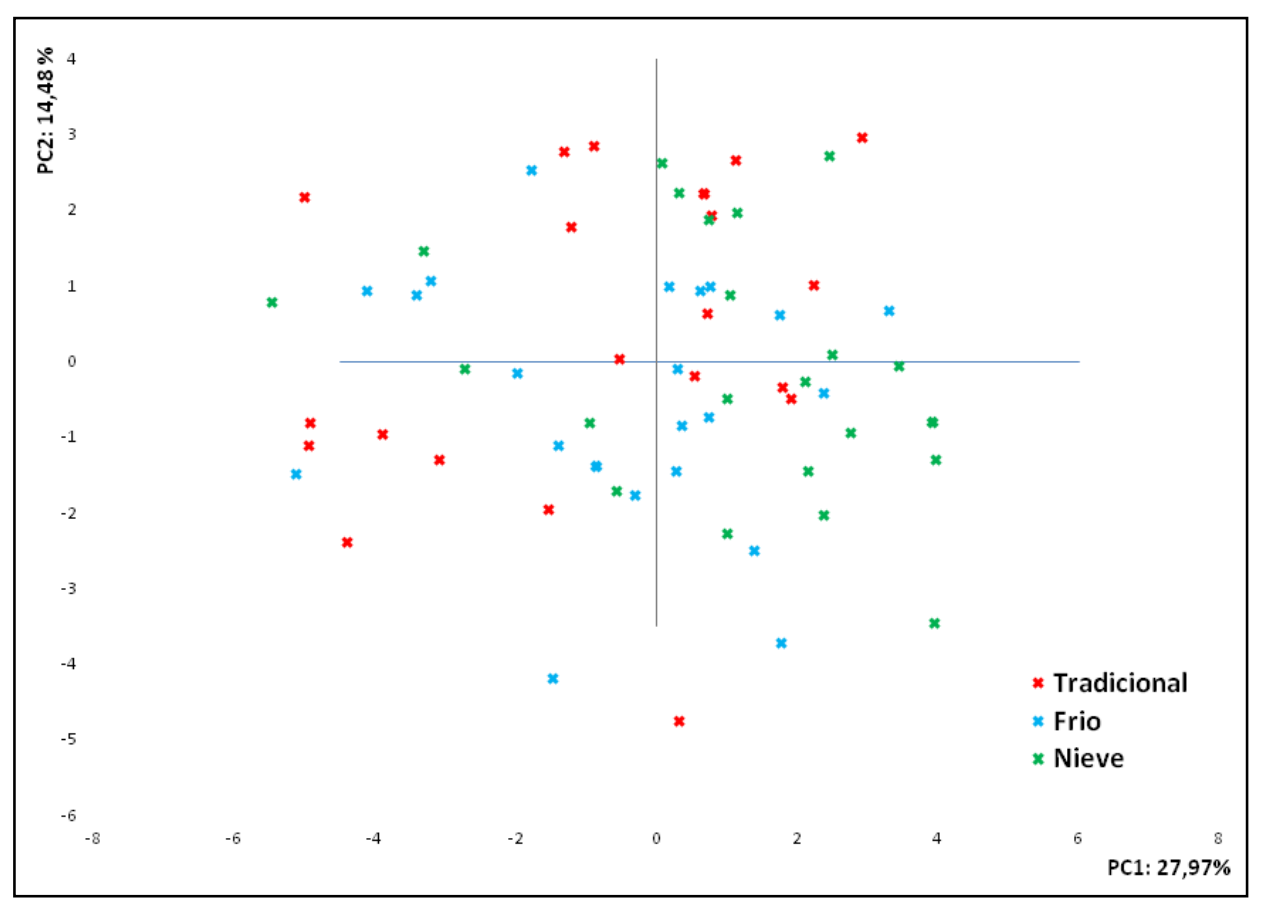

Gráfico 6.44. Primera componente frente a la segunda, en función de las técnicas de vinificación ensayadas.

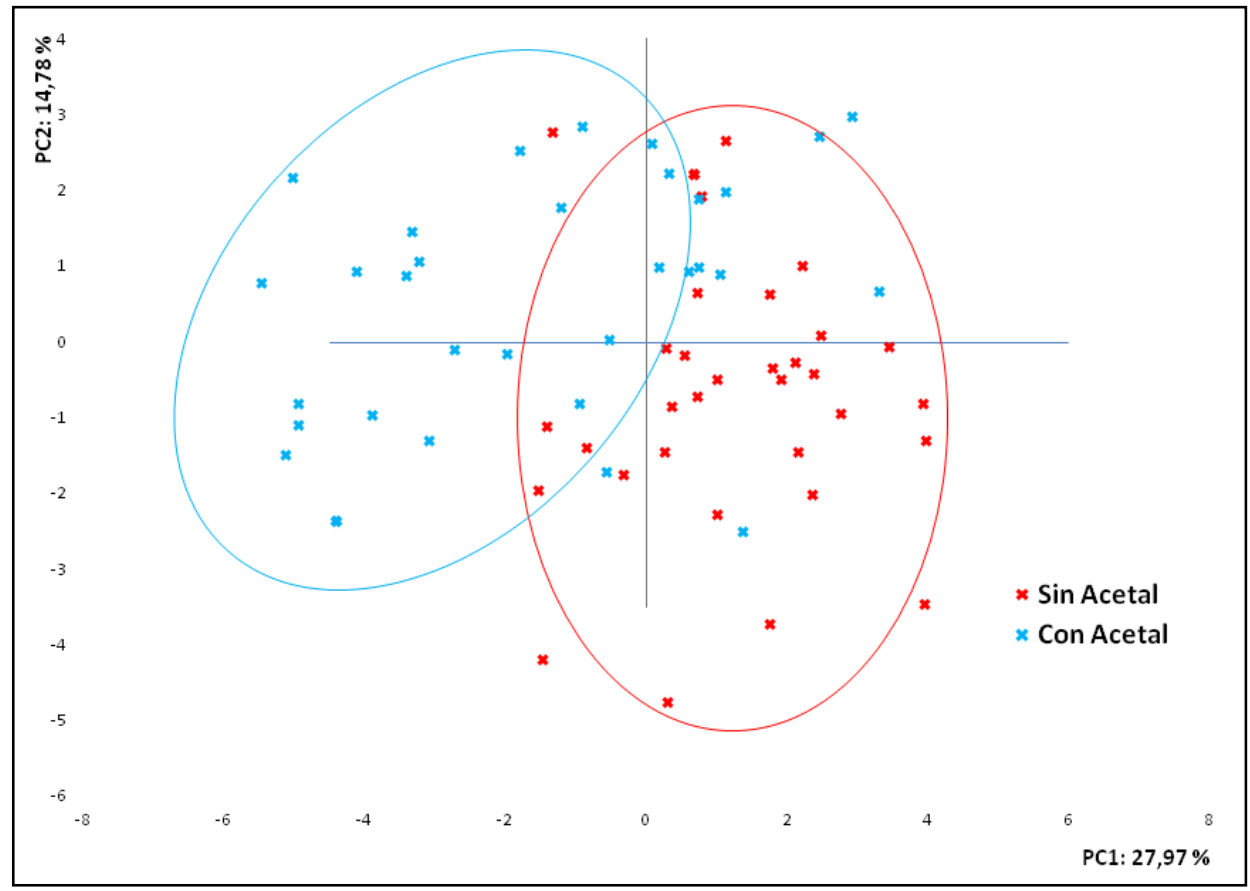

Gráfico 6.45. Primera componente frente a la segunda, en función de la aplicación de la microoxigenación

En el gráfico 6.45 aparecen representados en función de los dos primeros ejes principales identificados los vinos elaborados según si se realizó o no la adición de acetaldehído. Se observa como los vinos no microoxigenados aparecen situados, en su mayoría, en la zona positiva del primer componente, correspondiendo a vinos que 
presentan una elevada concentración de antocianos decolorables pricipalmente en su forma libre, y en los que los taninos están formando parte de los procesos de polimerización entre ellos y no con los antocianos.

Por el contrario aquellos vinos microoxigenados por adición controlada de acetaldehído aparecen situados en la zona negativa del primer eje principal, se caracterizan por presentar una composición antociánica formada en su mayoría por polímeros de antocianos, que afectan decisivamente al color de los vinos manteniendo sus características cromáticas durante el envejecimiento, consiguiéndose, por lo tanto, uno de los principales objetivos de la aplicación de esta técnica.

Por último se ha representado el efecto de la adición pre- o postfermentativa de copigmentos. En la gráfico $\mathbf{6 . 4 6}$ aparece la representación de los vinos elaborados en función de la primera componente frente a la segunda, donde los vinos aparecen aleatoriamente distribuidos a lo largo de los componentes principales representados. Este comportamiento nos indica como el momento de adición de los copigmentos no presenta ningún efecto según se hayan adicionado previamente o posteriormente a la fermentación, mostrando los vinos elaborados características similares. Esta distribución aleatoria no permite caracterizar los vinos en función de los coeficientes que definen a los componentes principales identificados.

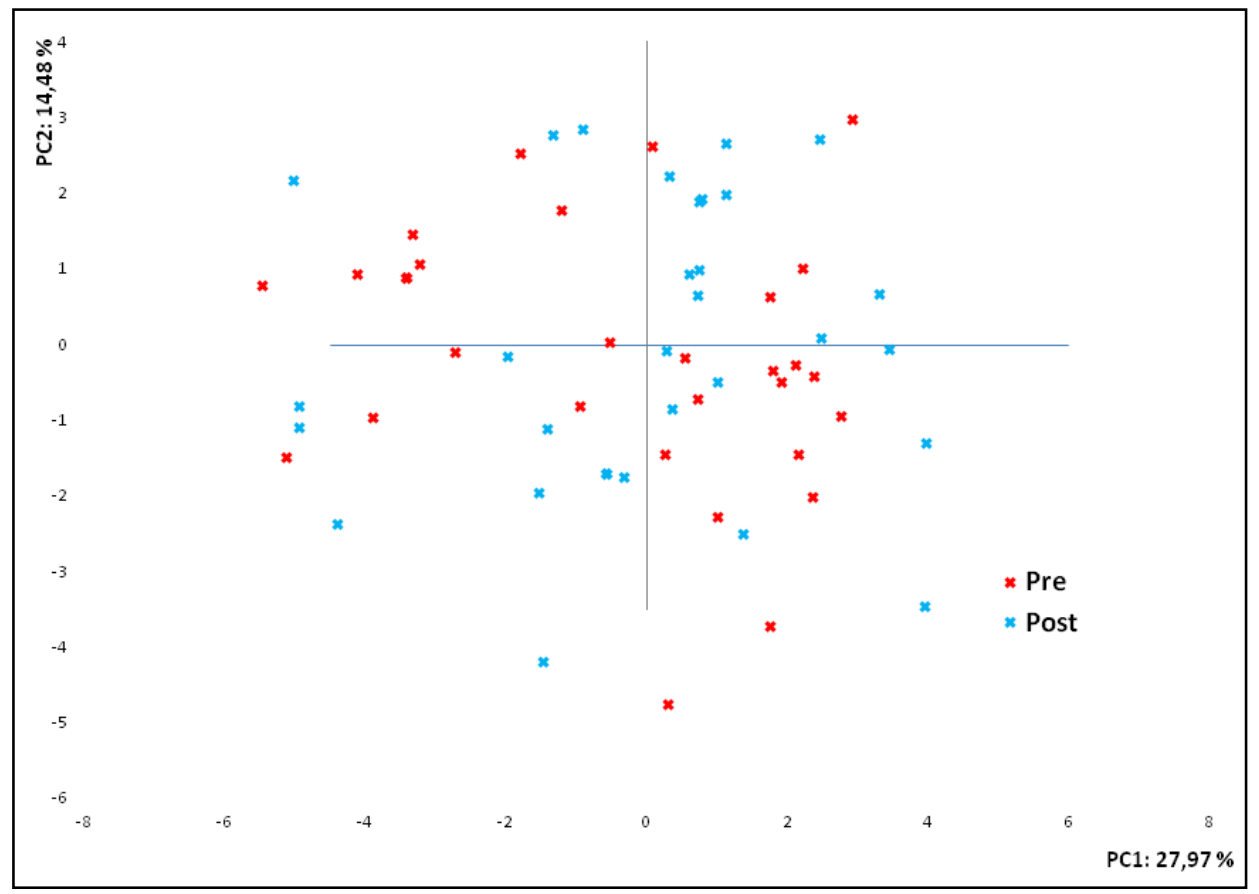

Gráfico 6.46. Primera componente frente a la segunda, en función del momento de adición de los copigmentos.

\subsubsection{ANÁLISIS DE LOS VINOS A LOS 12 MESES DE CONSERVACIÓN}

Una vez transcurridos los doce meses de conservación, se determinó la composición fenólica de los vinos, procediéndose con los resultados a realizar un análisis comparativo en función de las distintas prácticas enológicas ensayadas. 


\subsubsection{ANÁLSIS MULTIFACTORIAL DE LA VARIANZA (ANOVA) DE LOS FACTORES CONSIDERADOS}

En la tabla 6.37 se recoge el análisis multifactorial de la varianza (ANOVA) para los factores adición de copigmentos, técnicas de maceración prefermentativa, microoxigenación y adición pre- o postfermentativa de copigmentos, así como para las interacciones entre ellos.

El análisis multifactorial de la varianza muestra como todos los factores considerados presentan diferencias significativas para la gran mayoría de los parámetros polifenólicos determinados. Los factores aplicación de la microoxigenación (factor $\mathrm{C}$ ), técnicas de vinificación empleadas (factor B) y adición de copigmentos (factor A) son los que presentan, por este orden, la mayor influencia sobre la composición fenólica de los vinos elaborados. Por el contrario para el factor momento de adición de los copigmentos (factor D) se observan diferencias significativas solo en un pequeño número de los parámetros determinados, mostrando un ligero efecto sobre la composición de los vinos a los 12 meses de permanencia en botella.

La interacción entre los factores técnicas de vinificación y momento de adición de copigmentos (interacción BD) presenta el efecto más marcado sobre los vinos elaborados, observándose diferencias significativamente estadísticas para la mayoría de parámetros que caracterizan a la composición fenólica de los vinos considerados. Además las interacciones $\mathrm{AB}$ (adición de copigmentos $\mathrm{x}$ técnica de vinificación), $\mathrm{AD}$ (adición de copigmentos $\mathrm{x}$ momento de adición) y $\mathrm{BC}$ (técnicas de vinificación $\mathrm{x}$ microoxigenación) muestran un ligero efecto sobre los parámetros analizados.

Para el factor adición de copigmentos se observa un comportamiento similar al encontrado a los seis meses de conservación, siendo los ácidos fénolicos, índice de Folin, porcentaje de color debido a los antocianos polimerizados y libres, tono, derivados de antocianos e índice de PVPP, los que muestran un efecto más marcado sobre esta variable, presentando todos ellos diferencias estadísticas al nivel de confianza del 99,9\%. Según estos resultados, la adición de copigmentos afecta decisivamente al estado de los antocianos en los vinos, provocando un efecto significativo sobre la composición total de polifenoles y actuando de forma decisiva sobre el tono de los vinos (Brouillard y Dangles, 1994; Schwarz et al., 2005), efecto que aparecen durante la vinificación y que se mantienen a lo largo de la conservación.

Los parámetros malvidina, antocianidinas, total antocianos, antocianos totales decolorables, 3-flavanoles, catequinas, derivados de antocianos, peonidina, flavonoles, petunidina, son los que presentan mayores valores del F-ratio para el factor técnicas de vinificación, mostrando un mayor efecto del factor sobre la variable. Estos resultados indican la elevada influencia de las técnicas de vinificación empleadas sobre la composición antociánica y en general polifenólica de los vinos, favoreciéndose la extracción de estos durante la vinificación (Koyama et al., 2007), y su posterior conservación, manteniéndose en el medio, incluso a los 12 meses de envejecimiento en botella. Este efecto es más evidente para las formas monómeras de antocianos y flavanoles, ya que no se observa influencia sobre las interacciones entre estos monómeros (antocianos polimerizados, índice de PVPP, índice de DMACH o índice de etanol), que son al final los responsables de su estabilización. Gómez-Plaza et al. (2001), estudiando el efecto de la duración de la fase prefermentativa observan como a 
medida que se incrementa el periodo de contacto entre hollejos y mostos se incrementa la concentración fenólica, pero también el tono y las reacciones de degradación de los principales compuestos fenólicos presentes en el vino, sugiriendo que la extracción no fue acompañada de estabilización.

La aplicación de microoxigenación afecta prácticamente a la totalidad de compuestos polifenólicos, especialmente al índice de PVPP, antocianos polimerizados, porcentaje de color de los antocianos libres, índice de Folin, antocianos totales decolorables, 3-flavanoles, derivados de antocianos, flavonoles e índice de gelatina. Estos resultados ponen de manifiesto que el efecto de la microoxigenación favorece las reacciones antociano-tanino mediadas por el acetaldehído, manteniéndose una importante concentración fenólica en los vinos envejecidos, junto con una disminución de la astringencia, medida por el índice de gelatina. Llaudy et al. (2006) estudiando la aplicación de oxígeno en vinos muy astringentes, previamente a la crianza en barricas, observa cómo se produce una disminución de la astringencia, acompañada de un incremento en la concentración de pigmentos poliméricos, atribuyendo, principalmente, a estas uniones el efecto de disminución de la astringencia observado (Peleg et al., 1999; Vidal et al., 2003; Remy et al., 2000; Brossaud et al., 2001).

Además en estudios realizados por Cheynier et al. (2005) indican como la astringencia está relacionada con el estado de los taninos y con su concentración, incrementándose a medida que aumenta su tamaño molecular. Por lo tanto, la pérdida de la astringencia durante el envejecimiento puede ser debida a la condensación de los taninos con los antocianos y otros compuestos, pero también a la formación de polímeros más grandes, que precipitan.

Por último para el factor momento de adición de copigmentos se observan únicamente diferencias significativas para algunos parámetros relacionados con los compuestos fenólicos en su forma simple (3-flavanoles, malvidina, flavonoles, ácido fenólicos); sugiriendo que quizás la adición de copigmentos posteriormente a la fermentación haya contribuido a mantener mejor estos monómeros en el vino al cabo del periodo de conservación al que han sido sometidos.

La interacción entre los factores técnica de vinificación con el momento de adición de copigmentos (BD) presenta elevados valores del F-ratio para los parámetros índice de PVPP, malvidina, antocianidinas, total de antocianos, catequinas, petunidina, antocianos libres y polimerizados. Se observa una elevada influencia para los principales compuestos fenólicos en su forma libre, aunque también sobre parámetros relaciones con las reacciones entre antocianos, mostrando no solo un mayor efecto de extracción de la composición fenólica, sino también una estabilización de la materia colorante en los vinos estudiados. La combinación de ambas técnicas podría dar lugar a una metodología de vinificación favorable tanto para el incremento como para la estabilidad del color de vinos sometidos a envejecimiento en botella.

Las interacciones entre los otros factores son prácticamente inexistentes, mostrando solo una ligera acción sobre los porcentajes de color debido a las distintas fracciones de antocianos. 


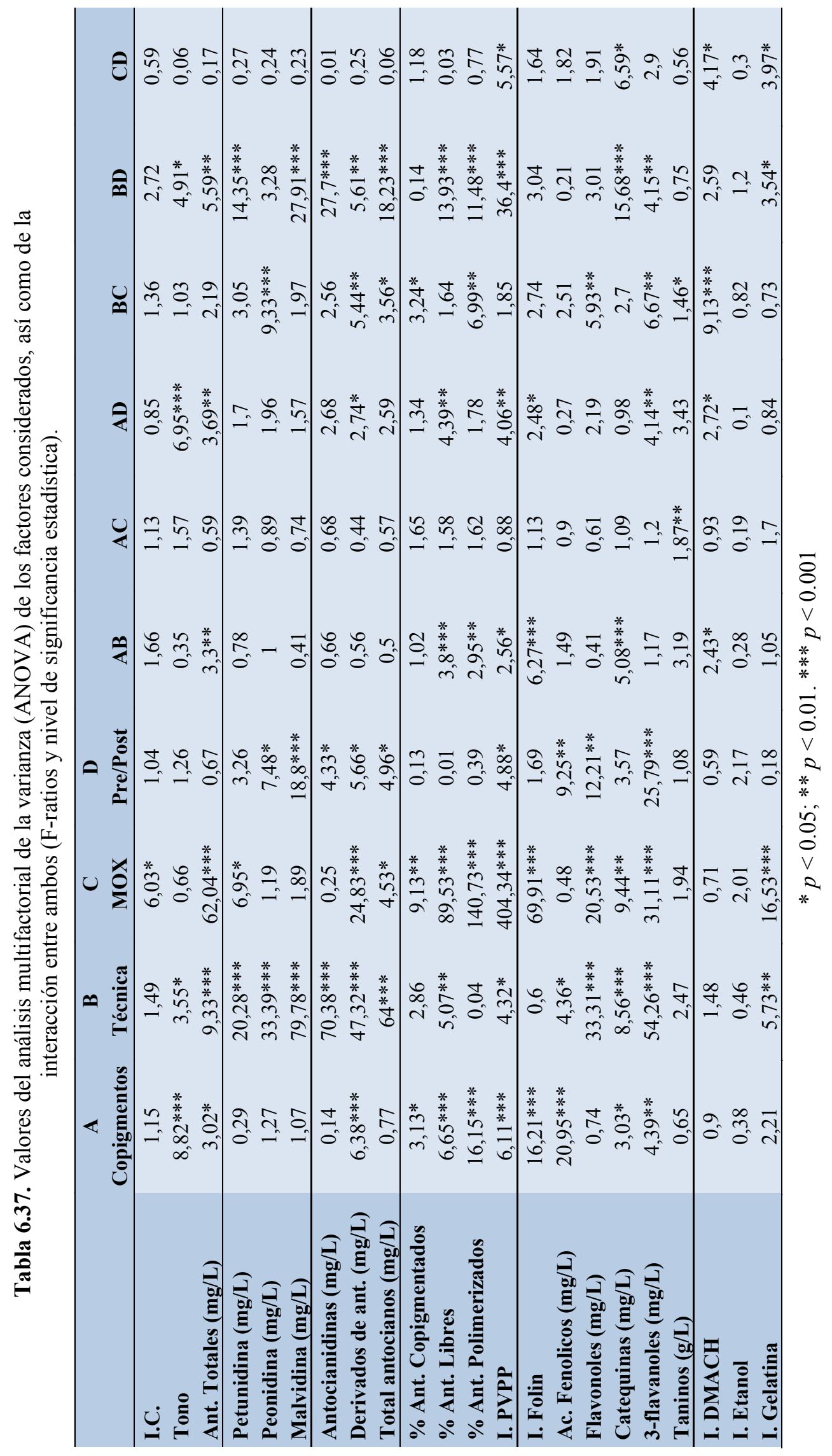




\subsubsection{EFECTO DE LA ADICIÓN DE COPIGMENTOS}

En la tabla 6.38 se muestran los valores medios de los parámetros polifenólicos estudiados, en función de la adición de los distintos copigmentos. El tratamiento estadístico se ha realizando considerando conjuntamente todos los vinos, independientemente de la técnica de vinificación utilizada, del momento de adición de los copigmentos o de la microoxigenación, valorando así exclusivamente el efecto de la adición de copigmentos en los vinos de Tempranillo.

La adición de copigmentos provoca que los vinos presenten una mayor intensidad del color en los vinos envejecidos durante 12 meses en botella., siendo la adición de ácido cafeico la que da lugar a los mayores valores para la intensidad colorante. Por otra parte es de nuevo este copigmento el que presenta los menores valores para el tono, como sucedía a los seis meses de conservación.

Para la concentración de los antocianos totales decolorables, son los copigmentos proantocianidínicos los que presentan las mayores concentraciones de estos compuestos, con diferencias estadísticas frente a los vinos adicionados de ácido cafeico, vinos que presentan las menores concentraciones para este parámetro. Este comportamiento inverso observado para la intensidad colorante con la concentración de antocianos es debido a que en los vinos envejecidos el color es debido a la presencia de pigmentos poliméricos (polímeros antociano-tanino o piranoantocianos), compuestos más estables en el tiempo, verdaderamente responsables del color en estos vinos que han sido sometidos a un periodo prolongado de envejecimiento en botella (CastañedaOvando et al., 2009; Cheynier et al., 2006; Malien-Aubert et al., 2002).

Para el parámetro derivados de antocianos los vinos adicionados de ácido cafeico presentan diferencias significativas frente al copigmento rutina. La esterificación de los antocianos con el acido acético, $p$-cumárico y cafeico da lugar a la formación de estos compuestos, viéndose incrementada su concentración en los vinos cuando este copigmento fue adicionado.

El porcentaje de antocianos copigmentados muestra como son los vinos testigo, no adicionados de copigmentos, los que presentan los mayores valores para este porcentaje, con diferencias significativas, únicamente, respecto a los vinos adicionados de ácido cafeico; mostrándose un comportamiento similar para el porcentaje del color que corresponde a los antocianos libres, aunque para este parámetro el vino que presenta los mayores valores es el adicionado del copigmento catequina.

En cuanto al color que corresponde a polimerizaciones los vinos adicionados de ácido cafeico presentan diferencias significativas frente a los otros vinos analizados. Probablemente la mayor presencia de los derivados acilados con este ácido fenólico en los vinos haya permitido que estos participen en las reacciones de polimerización con los taninos, justificando el comportamiento observado en el análisis realizado (AlcaldeEon et al., 2006); observándose un comportamiento similar para el índice de PVPP. 


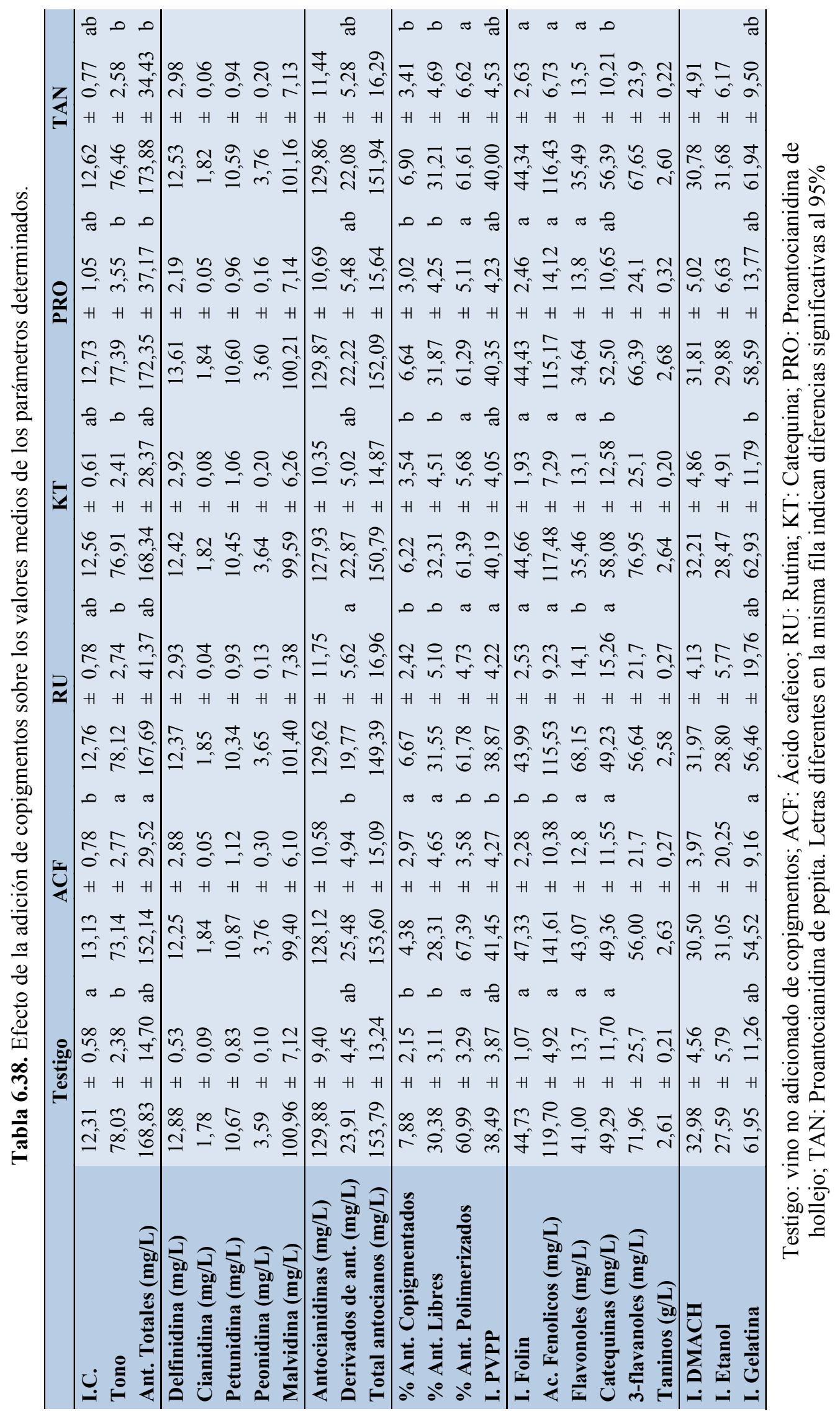


Tanto el índice de Folin como la concentración de ácidos fenólicos presentan diferencias estadísticas, mostrándose los vinos adicionados de ácido cafeico los mayores valores para estos parámetros. Ya ha sido mencionada en este trabajo la importante relación entre la concentración de estos ácidos y la concentración total de polifenoles, medida mediante el índice de Folin, destacando como aquellos vinos que presentan un elevada concentración de estos compuestos son capaces de mantener una mayor concentración fenólica.

Rein, (2005) estudiando la participación de los antocianos en distintas reacciones, así como su influencia en el color de los vinos, cita la mayor estabilidad que poseen los antocianos acilados o esterificados frente a los antocianos en su forma simple o monómera, presentando el ácido cafeico buenas propiedades en cuanto a la protección del color, cuando está formando parte de estas reacciones, manteniéndose a su vez una mayor estabilidad del contenido polifenólico de los vinos.

Los vinos adicionados de rutina son los que presentan los valores más elevados para la concentración de flavonoles, con diferencias estadísticamente significativas. Por otra parte aquellos vinos adicionados de catequina y proantocianidinas de pepita son los que muestran diferencias significativas para la concentración de 3-flavanoles, mostrando también valores elevados aquellos vinos adicionados de proantocianidinas de hollejo. La fragilidad de las uniones mediadas por el acetaldehído, tanto entre antocianos y taninos, como únicamente entre taninos (polimerización lineal) ha podido dar lugar en estos vinos al incremento de los polifenoles monómeros (Cheynier et al., 2006; Escribano-Bailón et al., 2001; Atanasova et al., 2002a).

A diferencia de lo observado a los seis meses, son los vinos adicionados de ácido cafeico los que presentan diferencias estadísticas para la astringencia de los vinos, mostrando los menores valores para este índice. Este comportamiento junto con el mostrado para los parámetros porcentaje del color que corresponde a polimerizaciones, índice de PVPP, derivados de antocianos, índice de Folin e intensidad colorante nos lleva a la conclusión de que la adición de ácido cafeico a los vinos favorece las reacciones de unión entre antocianos y taninos durante la conservación, quizás por la participación de los antocianos esterificados con este ácido en estas uniones, provocando un incremento de la intensidad colorante (Cheynier et al., 1999, 2006; Vidal et al., 2002; Koyama et al., 2007), manteniendo una importante concentración fenólica, y disminuyendo la astringencia de los vinos (Llaudy et al., 2006; Peleg et al., 1999; Vidal et al., 2003; Remy et al., 2000; Brossaud et al., 2001).

\subsubsection{EFECTO DE LAS TÉCNICAS DE VINIFICACIÓN}

En la tabla 6.39 se recogen los valores medios de los parámetros polifenólicos analizados considerando conjuntamente los distintos vinos elaborados según que la vinificación se realice de forma tradicional, con maceración prefermentativa en frío a 6$8{ }^{\circ} \mathrm{C}$ o bien con una maceración prefermentativa usando nieve carbónica.

La maceración prefermentativa con aplicación de nieve carbónica presenta diferencias significativas para la mayoría de los parámetros que determinan la composición antociánica de los vinos elaborados, tal como ya observamos a los seis meses. Concretamente los parámetros antocianos totales decolorables, delfinidina, cianidina, petunidina, malvidina, antocianidinas, derivados de antocianos y total de 
antocianos son los que presentan las mayores concentraciones cuando esta técnica ha sido aplicada. Además, todos ellos, a excepción de la concentración de antocianos totales presentan diferencias estadísticas de la maceración con aplicación de bajas temperaturas con respecto a la vinificación tradicional.

Tabla 6.39. Efecto de las técnicas de vinificación sobre los valores medios de los parámetros determinados.

\begin{tabular}{|c|c|c|c|c|c|c|c|c|c|}
\hline & \multicolumn{3}{|c|}{ Tradicional } & \multicolumn{3}{|c|}{ Frio } & \multicolumn{3}{|c|}{ Nieve } \\
\hline I.C. & 11,79 & $\pm 0,88$ & & 11,89 & $\pm 0,62$ & & 11,47 & $\pm 0,84$ & \\
\hline Tono & 77,67 & $\pm 3,00$ & $\mathrm{~b}$ & 75,62 & $\pm 2,69$ & a & 76,36 & $\pm 3,61$ & $a b$ \\
\hline Ant. Totales (mg/L) & 160,05 & $\pm 33,77$ & $\mathrm{a}$ & 162,52 & $\pm 28,14$ & $\mathrm{a}$ & 181,07 & $\pm 35,15$ & $\mathrm{~b}$ \\
\hline Delfinidina (mg/L) & 8,99 & $\pm 3,48$ & $\mathrm{a}$ & 14,59 & $\pm 0,26$ & $\mathrm{~b}$ & 14,95 & $\pm 1,74$ & $\mathrm{c}$ \\
\hline Cianidina (mg/L) & 1,76 & $\pm 0,05$ & $\mathrm{a}$ & 1,82 & $\pm 0,07$ & $\mathrm{~b}$ & 1,86 & $\pm 0,04$ & $\mathrm{c}$ \\
\hline Petunidina (mg/L) & 9,81 & $\pm 0,44$ & $\mathrm{a}$ & 10,57 & $\pm 0,63$ & $\mathrm{~b}$ & 11,37 & $\pm 1,01$ & $\mathrm{c}$ \\
\hline Peonidina (m & 3,74 & $\pm 0,34$ & & 3,68 & $\pm 0,15$ & & 3,62 & $\pm 0,13$ & \\
\hline Malvidina (mg/L) & 94,64 & $\pm 2,88$ & $\mathrm{a}$ & 99,68 & $\pm 2,69$ & $\mathrm{~b}$ & 106,91 & $\pm 6,37$ & $\mathrm{c}$ \\
\hline Antocianidinas (mg/L) & 118,93 & $\pm 6,89$ & $\mathrm{a}$ & 130,33 & $\pm 4,65$ & $\mathrm{~b}$ & 138,70 & $\pm 8,66$ & $\mathrm{c}$ \\
\hline nt. (mg/L) & 18,17 & $\pm 3,61$ & $\mathrm{a}$ & 22,91 & $\pm 4,32$ & $\mathrm{~b}$ & 26,76 & $\pm 4,14$ & $\mathrm{c}$ \\
\hline Total antocianos $(\mathrm{mg} / \mathrm{L})$ & 137,11 & $\pm 9,38$ & $\mathrm{a}$ & 153,24 & $\pm 8,10$ & $\mathrm{~b}$ & 165,46 & $\pm 12,12$ & $\mathrm{c}$ \\
\hline$\%$ Ant. Copigmentados & 7,26 & $\pm 2,91$ & & 7,03 & $\pm 3,40$ & & 6,66 & $\pm 2,85$ & \\
\hline \% Ant. Libres & 30,62 & $\pm 5,21$ & $\mathrm{a}$ & 30,75 & $\pm 3,87$ & $\mathrm{ab}$ & 32,68 & $\pm 4,89$ & $\mathrm{~b}$ \\
\hline$\%$ Ant. Polimerizados & 62,12 & $\pm 6,89$ & & 62,21 & $\pm 4,23$ & & 60,67 & $\pm 5,87$ & \\
\hline I. PVPP & 39,92 & $\pm 4,01$ & & 39,41 & $\pm 4,27$ & & 40,72 & $\pm 4,45$ & \\
\hline I. Folin & 44,91 & $\pm 2,60$ & & 45,08 & $\pm 2,27$ & & 44,79 & $\pm 2,75$ & \\
\hline Ac. Fenolicos (mg/L) & 116,37 & $\pm 18,00$ & & 123,17 & $\pm 11,49$ & & 123,76 & $\pm 8,36$ & \\
\hline Flavonoles (mg/L) & 27,00 & $\pm 15,71$ & $\mathfrak{a}$ & 39,68 & $\pm 25,60$ & $\mathrm{~b}$ & 48,22 & $\pm 22,17$ & $\mathrm{c}$ \\
\hline Catequinas (mg/L) & 47,71 & $\pm 14,32$ & $\mathrm{a}$ & 53,59 & $\pm 9,49$ & $\mathrm{~b}$ & 54,60 & $\pm 11,67$ & $\mathrm{~b}$ \\
\hline 3-flavanoles (mg/L) & 54,10 & $\pm 12,40$ & $\mathrm{a}$ & 62,82 & $\pm 27,35$ & $\mathrm{~b}$ & 70,14 & $\pm 24,48$ & $\mathrm{c}$ \\
\hline $\operatorname{Taninos}(\mathrm{g} / \mathrm{L})$ & 2,63 & $\pm 0,25$ & & 2,68 & $\pm 0,28$ & & 2,57 & $\pm 0,22$ & \\
\hline I. DMACH & 32,18 & $\pm 4,99$ & & 30,70 & $\pm 4,61$ & & 31,90 & $\pm 4,05$ & \\
\hline I. Etanol & 31,03 & $\pm 5,93$ & & 29,03 & $\pm 6,02$ & & 29,21 & $\pm 15,31$ & \\
\hline I. Gelatina & 63,88 & $\pm 10,91$ & $\mathrm{~b}$ & 60,77 & $\pm 11,80$ & $\mathrm{a}$ & 58,84 & $\pm 15,71$ & $\mathrm{a}$ \\
\hline
\end{tabular}

Tradicional: elaboración sin maceración en frío previamente a la fermentación; Frío: aplicación de bajas temperaturas de forma prefermentativa; Nieve: uso de nieve carbónica prefermentativamente. Letras diferentes en la misma fila indican diferencias significativas al 95\%.

A los 12 meses de conservación de los vinos en botella todavía se mantiene el efecto de la maceración prefermentativa, de forma similar al encontrado después de la fermentación maloláctica y a los seis meses de conservación, siendo la aplicación de nieve carbónica la que mayor concentración de compuestos polifenólicos proporciona a los vinos, seguido de la maceración en frío, lo que sitúa a estas prácticas enológicas como las más adecuadas si se quiere incrementar la composición antociánica de los vinos. Álvarez et al. (2006) estudiando el efecto de ambas técnicas sobre la composición antociánica de vinos de Monastrell, observan también que a los 6 meses 
del embotellado todavía existe una mayor concentración antociánica en los vinos objeto de estudio.

La maceración prefermentativa en frío también favorece la presencia de otros compuestos diferentes de los antocianos en los vinos, ya que muestra diferencias significativas tanto para la concentración de flavonoles como para la de 3-flavanoles y catequinas, siendo la aplicación de nieve carbónica la técnica más efectiva para la extracción de estos compuestos.

Por último la astringencia de los vinos, medida por el índice de gelatina, muestra como es la vinificación tradicional la técnica que presenta los mayores valores, con diferencias significativas, quizás debido a la formación de compuestos más complejos con un menor poder reactivo frente a la astringencia.

El análisis de la varianza muestra como al cabo de un prolongado periodo de envejecimiento en botella los vinos elaborados no presentan diferencias estadísticas en cuanto a aquellos parámetros relacionados con las reacciones entre los diferentes compuesto fenólicos (índice de PVPP, \% del color debido a polimerizaciones, índice de DMACH o índice de etanol), mientras que después de la maloláctica y a los seis meses, se encontraban diferencias en el grado de polimerización de antocianos con taninos, y de éstos con polisacáridos y péptidos, lo que puede indicar que la evolución de estos vinos ya ha tenido lugar, minimizándose a partir de este momento las reacciones de estabilización, pudiendo tener lugar otras de degradación.

\subsubsection{EFECTO DE LA MICROOXIGENACIÓN}

En la tabla 6.40 se exponen los valores medios de los parámetros polifenólicos analizados considerando conjuntamente a todos aquellos vinos que han sido microoxigenados frente a aquellos vinos a los que no se les ha realizado adición de acetaldehído.

La técnica de la microoxigenación provoca una menor intensidad colorante junto con una menor concentración de antocianos totales decolorables, con diferencias significativas al final del periodo de conservación de los vinos. Además únicamente existen diferencias estadísticas para la antocianidina peonidina, mostrando, de nuevo, los vinos adicionados de oxígeno las menores concentraciones. Por el contrario para la concentración de derivados de antocianos esta técnica parece provocar un efecto protector frente a estos compuestos. Quizás la interacción con los taninos podría ser la causa de la elevada concentración observada para este parámetro.

Contrariamente a lo observado para los antocianos, la adición controlada de acetaldehído favorece la conservación de de los de 3-flavanoles y flavonoles. En cuanto al porcentaje del color que corresponde a copigmentación, la técnica de la microoxigenación muestra los menores valores para estos compuestos y los mayores para los antocianos libres. Estos resultados, junto con los observados para el índice de PVPP y para el porcentaje del color que corresponde a polimerización, demuestran como la microoxigenación favorece la polimerización de antocianos, propiciando que la mayor parte de los antocianos presentes estén formando parte de complejos con los taninos y no participando en reacciones de copigmentación. Demostrándose la poca estabilidad de las reacciones de los antocianos con cofactores o copigmentos, alcanzándose porcentajes del color inferiores al $10 \%$ en estos vinos envejecidos en 
botella.

Tabla 6.40. Efecto de la microoxigenación sobre los valores medios de los parámetros determinados.

\begin{tabular}{lcllcllll}
\hline & \multicolumn{3}{c}{ No MOX } & \multicolumn{3}{c}{ MOX } \\
\hline I.C. & 11,94 & $\pm 0,71$ & $\mathrm{~b}$ & 11,50 & $\pm 0,83$ & $\mathrm{a}$ \\
Tono & 76,80 & $\pm 3,07$ & & 76,31 & $\pm 3,34$ & \\
Ant. Totales (mg/L) & 184,00 & $\pm 22,45$ & $\mathrm{~b}$ & 151,76 & $\pm 35,25$ & $\mathrm{a}$ \\
\hline Delfinidina (mg/L) & 11,72 & $\pm 3,12$ & & 13,97 & $\pm 1,85$ & \\
Cianidina (mg/L) & 1,84 & $\pm 0,09$ & & 1,82 & $\pm 0,05$ & \\
Petunidina (mg/L) & 10,66 & $\pm 1,26$ & & 10,50 & $\pm 0,57$ & \\
Peonidina (mg/L) & 3,73 & $\pm 0,20$ & $\mathrm{~b}$ & 3,60 & $\pm 0,20$ & $\mathrm{a}$ \\
Malvidina (mg/L) & 100,87 & $\pm 7,09$ & & 99,94 & $\pm 6,20$ & \\
\hline Antocianidinas (mg/L) & 128,82 & $\pm 11,99$ & & 129,83 & $\pm 8,85$ & \\
Derivados de ant. (mg/L) & 20,82 & $\pm 5,87$ & $\mathrm{a}$ & 24,41 & $\pm 4,04$ & $\mathrm{~b}$ \\
Total antocianos (mg/L) & 149,64 & $\pm 17,52$ & & 154,25 & $\pm 12,16$ & \\
\hline \% Ant. Copigmentados & 7,01 & $\pm 2,88$ & & 5,63 & $\pm 3,24$ & \\
\% Ant. Libres & 33,73 & $\pm 4,31$ & $\mathrm{~b}$ & 28,97 & $\pm 3,93$ & $\mathrm{a}$ \\
\% Ant. Polimerizados & 58,95 & $\pm 4,00$ & $\mathrm{a}$ & 65,40 & $\pm 5,39$ & $\mathrm{~b}$ \\
I. PVPP & 36,70 & $\pm 2,51$ & $\mathrm{a}$ & 43,34 & $\pm 2,78$ & $\mathrm{~b}$ \\
\hline I. Folin & 46,10 & $\pm 1,88$ & $\mathrm{~b}$ & 43,76 & $\pm 2,57$ & $\mathrm{a}$ \\
Ac. Fenolicos (mg/L) & 121,69 & $\pm 13,30$ & & 120,51 & $\pm 13,82$ & \\
Flavonoles (mg/L) & 36,53 & $\pm 18,52$ & $\mathrm{a}$ & 46,67 & $\pm 12,79$ & $\mathrm{~b}$ \\
Catequinas (mg/L) & 53,64 & $\pm 11,19$ & & 50,30 & $\pm 13,16$ & \\
3-flavanoles (mg/L) & 68,97 & $\pm 16,92$ & & 79,07 & $\pm 18,21$ & \\
Taninos (g/L) & 2,64 & $\pm 0,28$ & & 2,62 & $\pm 0,22$ & \\
\hline I. DMACH & 31,17 & $\pm 4,67$ & & 32,02 & $\pm 4,47$ & \\
I. Etanol & 28,43 & $\pm 12,90$ & & 31,09 & $\pm 5,83$ & \\
I. Gelatina & 63,74 & $\pm 10,05$ & $\mathrm{~b}$ & 54,59 & $\pm 14,64$ & $\mathrm{a}$ \\
\hline
\end{tabular}

No MOX: vinos no adicionados de acetaldehído; MOX: vinos adicionados de acetaldehído. Letras diferentes en la misma fila indican diferencias significativas al 95\%

Por último, se observan diferencias estadísticamente significativas para el parámetro que mide la astringencia de los vinos, mostrando los valores más elevados aquellos vinos elaborados sin microoxigenación, tal como se había observado a los seis meses de conservación. Ya se ha comentando a lo largo del presente trabajo la participación de las reacciones mediadas por el acetaldehído en la astringencia de los vinos, confirmándose de nuevo como la polimerización entre los antocianos y los taninos, que hemos observado que potencia la microoxigenación, también es la responsable de la diminución de la astringencia de los vinos, que tiene lugar en los vinos sometidos a este proceso (Llaudy et al., 2006; Peleg et al., 1999; Vidal et al., 2003; Remy et al., 2000; Brossaud et al., 2001). 


\subsubsection{EFECTO DEL MOMENTO DE ADICIÓN DE LOS COPIGMENTOS}

En la tabla 6.41 se recogen los valores medios de los parámetros polifenólicos analizados en los vinos considerando conjuntamente todos aquellos que han sido adicionados de copigmentos previamente o posteriormente a la fermentación.

Tabla 6.41. Efecto del momento de adición de copigmentos sobre los valores medios de los parámetros determinados.

\begin{tabular}{|c|c|c|c|c|c|c|}
\hline & \multicolumn{3}{|c|}{ PRE } & \multicolumn{3}{|c|}{ POST } \\
\hline I.C. & 12,85 & $\pm 0,66$ & & 12,66 & $\pm 0,93$ & \\
\hline Tono & 76,08 & $\pm 2,55$ & & 76,73 & $\pm 3,83$ & \\
\hline Ant. Totales (mg/L) & 165,06 & $\pm 32,25$ & & 168,71 & $\pm 37,37$ & \\
\hline Delfinidina (mg/L) & 13,47 & $\pm 1,85$ & & 11,80 & $\pm 3,34$ & \\
\hline Cianidina (mg/L) & 1,82 & $\pm 0,07$ & & 1,84 & $\pm 0,05$ & \\
\hline Petunidina (mg/L) & 10,36 & $\pm 0,86$ & & 10,78 & $\pm 1,07$ & \\
\hline Peonidina (mg/L) & 3,72 & $\pm 0,26$ & & 3,63 & $\pm 0,12$ & \\
\hline Malvidina (mg/L) & 98,67 & $\pm 3,06$ & $\mathrm{a}$ & 102,04 & $\pm 8,62$ & $\mathrm{~b}$ \\
\hline Antocianidinas (mg/L) & 128,04 & $\pm 5,79$ & & 130,09 & $\pm 13,84$ & \\
\hline Derivados de ant. (mg/L) & 21,62 & $\pm 4,81$ & & 23,35 & $\pm 5,91$ & \\
\hline Total antocianos $(\mathrm{mg} / \mathrm{L})$ & 149,67 & $\pm 10,02$ & & 153,43 & $\pm 19,20$ & \\
\hline \% Ant. Copigmentados & 6,25 & $\pm 3,20$ & & 6,07 & $\pm 3,18$ & \\
\hline$\%$ Ant. Libres & 31,07 & $\pm 4,66$ & & 31,02 & $\pm 4,95$ & \\
\hline \% Ant. Polimerizados & 62,51 & $\pm 5,32$ & & 62,87 & $\pm 6,04$ & \\
\hline I. PVPP & 39,80 & $\pm 4,05$ & & 40,54 & $\pm 4,49$ & \\
\hline I. Folin & 44,75 & $\pm 2,54$ & & 45,14 & $\pm 2,74$ & \\
\hline Ac. Fenolicos (mg/L) & 117,85 & $\pm 13,69$ & & 124,64 & $\pm 13,81$ & \\
\hline Flavonoles (mg/L) & 38,71 & $\pm 12,33$ & $\mathrm{a}$ & 48,61 & $\pm 10,87$ & $\mathrm{~b}$ \\
\hline Catequinas (mg/L) & 49,83 & $\pm 12,55$ & & 52,88 & $\pm 11,61$ & \\
\hline 3-flavanoles (mg/L) & 58,97 & $\pm 25,42$ & $\mathrm{a}$ & 79,07 & $\pm 30,26$ & $\mathrm{~b}$ \\
\hline $\operatorname{Taninos}(\mathrm{g} / \mathrm{L})$ & 2,60 & $\pm 0,24$ & & 2,65 & $\pm 0,28$ & \\
\hline I. DMACH & 31,18 & $\pm 3,82$ & & 31,73 & $\pm 5,24$ & \\
\hline I. Etanol & 31,47 & $\pm 13,43$ & & 28,48 & $\pm 5,70$ & \\
\hline I. Gelatina & 58,44 & $\pm 15,36$ & & 59,34 & $\pm 11,51$ & \\
\hline
\end{tabular}

PRE: adición de copigmentos previamente al inicio de la fermentación alcohólica; POST: adición de copigmentos en el embotellado. Letras diferentes en la misma fila indican diferencias significativas al $95 \%$

Únicamente se observan diferencias estadísticas para los parámetros polifenólicos flavonoles, 3-flavanoles y malvidina, mostrándose los vinos adicionados de copigmentos posteriormente a la fermentación los que presentan las mayores concentraciones de estos compuestos a los 12 meses de conservación de los vinos en botella. Probablemente la adición de rutina y catequina después de la fermentación haya provocado una mayor presencia de estos compuestos en los vinos, siendo de difícil explicación la mayor concentración de malvidina observada. 
Los resultados indican que la aplicación de los copigmentos previamente o posteriormente a la fermentación no presenta influencia estadística frente a la mayor parte de los parámetros polifenólicos determinados en este estudio.

\subsubsection{CORRELACIÓN ENTRE LOS PARÁMETROS POLIFENÓLICOS DE LOS VINOS, LA ADICIÓN DE COPIGMENTOS Y LAS TÉCNICAS DE VINIFICACIÓN}

En la tabla 6.42 aparece representada la matriz de correlaciones de las variables utilizadas en el análisis, donde una coloración más intensa indica una correlación más importante entre las variables consideradas; correspondiendo las coloraciones rojas a las relaciones negativas, las verdes a las positivas $\mathrm{y}$, por último, las amarillas a las correlaciones débiles entre las variables.

La intensidad colorante presenta una correlación positiva con el índice de Folin, indicando como una mayor concentración fenólica en los vinos después de su envejecimiento, va acompañada de un color más elevado, quizás debido a una mayor reactividad de ellos formándose nuevas moléculas responsables del color de los vinos envejecidos. Lorenzo et al., (2005) estudiando el efecto de la co-vinificación, de Monastrell con Cabernet Sauvignon, y Merlot sobre la composición fenólica y el color de los vinos, observan como aquellos vinos que muestran una mayor concentración fenólica, también presentan una mayor intensidad colorante.

Es interesante la interacción positiva entre los antocianos totales decolorables con la concentración de catequinas y con los antocianos libres, y la de las catequinas con el porcentaje del color debido a los antocianos libres. Probablemente en estos vinos la estabilidad de las reacciones entre antocianos y taninos se esté viendo comprometida, incrementándose la concentración de estos compuestos a medida que se van rompiendo los enlaces etílicos, siempre y cuando no actúen sobre ellos otros fenómenos como oxidaciones y/o precipitaciones.

La interacción positiva entre los antocianos libres y las uniones entre taninos y polisacáridos (índice de etanol), podría indicar que el incremento de antocianos libres va acompañado de liberación de taninos de las moléculas antociano-tanino, permitiendo a estos últimos reaccionar con los polisacáridos, péptidos o sales, incrementándose estas uniones responsables de la disminución de la astringencia (Zamora, 2003). La interacción negativa encontrada para la concentración de catequinas y el índice de etanol podría justificar el razonamiento citado en este párrafo. 


\begin{tabular}{|c|c|c|c|c|c|c|c|c|c|c|c|c|c|c|c|c|c|c|c|c|c|c|c|c|}
\hline 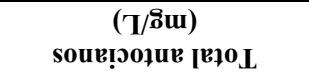 & & in & $\hat{o}$ & $\vec{m}$ & in & $\int_{0}^{3}$ & तี & $a_{0}^{\infty}$ & $b_{0}^{2}$ & $\int_{0}^{n}$ & $a$ & $\begin{array}{lll}n \\
c \\
c\end{array}$ & 3 & ç & & & & & & & & & & \\
\hline 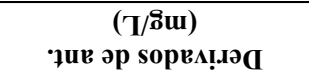 & & के & $\frac{1}{1}$ & $\stackrel{ \pm}{0}$ & ְై & $\begin{array}{l}0 \\
0 \\
i\end{array}$ & $\frac{9}{9}$ & $\hat{a}$ & $\begin{array}{l}8 \\
1 \\
1\end{array}$ & $\begin{array}{l}7 \\
\text { 7 } \\
1\end{array}$ & $\bar{c}$ & $\frac{6}{c}$ & ç & & & 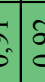 & $\begin{array}{l}y_{1} \\
5\end{array}$ & $\begin{array}{l}0 \\
0 \\
0\end{array}$ & $\begin{array}{l}y \\
0 \\
0\end{array}$ & & g & & & ถู \\
\hline 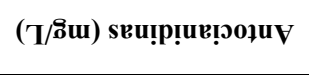 & & $\begin{array}{l}n \\
m \\
i\end{array}$ & $\frac{0}{0}$ & $\hat{3}$ & f & $\begin{array}{l}0 \\
i\end{array}$ & a & $\mid \begin{array}{l}8 \\
0 \\
1 \\
1\end{array}$ & i & î & $\frac{0}{2}$ & $\frac{6}{9}$ & ì & $\vdots$ & $\frac{n}{2}$ & 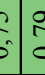 & s. & $c$ & $\begin{array}{l}0 \\
0 \\
0\end{array}$ & i & & & & $\stackrel{\infty}{2}$ \\
\hline (Т/శిயu) вu!p! & & ma & $\frac{7}{0}$ & ริ & I & $\stackrel{\infty}{\infty}$ & ç & $\begin{array}{l}8 \\
1 \\
1\end{array}$ & $\frac{0}{9}$ & $\frac{7}{9}$ & 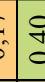 & $\hat{i}$ & i & 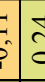 & 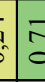 & 5 & 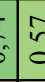 & 6 & 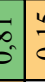 & $\frac{6}{i}$ & y & & & aे \\
\hline 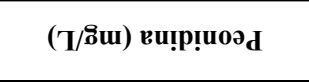 & & $\frac{9}{0}$ & $\begin{array}{l}1 \\
0 \\
0\end{array}$ & ô & $\begin{array}{l} \\
\\
\end{array}$ & in & $\stackrel{\alpha}{c}$ & है & $\begin{array}{l}n \\
0 \\
i\end{array}$ & 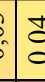 & $\tilde{c}$ & $\int_{1}^{1}$ & 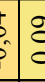 & $\hat{z}$ & & & 5 & 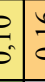 & ?: & & 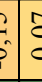 & & & $\frac{m}{i}$ \\
\hline 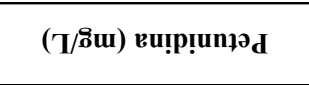 & & 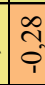 & ô & F & 咅 & io & $\hat{\tilde{i}}$ & i & $\frac{0}{9}$ & $\bar{c}_{i}$ & I & $\frac{4}{9}$ & $\hat{i}$ & בְ & 2 & 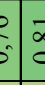 & $\begin{array}{l}0 \\
b \\
5\end{array}$ & & & 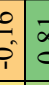 & g & & & क) \\
\hline 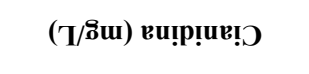 & & ڤ̂̀ & ô. & $\stackrel{7}{0}$ & $\hat{n}$ & î̀ & $\frac{5}{c}$ & 0 & 8 & है & ปิ & $a^{a}$ & $\bar{c}$ & $\frac{7}{c}$ & in & $\begin{array}{lll}4 & 4 \\
c & 4\end{array}$ & & & & 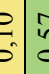 & ty & & & $\frac{0}{\pi}$ \\
\hline 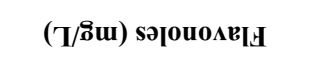 & $\frac{m}{0}$ & F & $\begin{array}{lll}0 & 0 \\
0 & 1\end{array}$ & $\stackrel{\infty}{0}$ & $\bar{c}$ & D & $\frac{\infty}{c}$ & $\begin{array}{l}0 \\
5 \\
5\end{array}$ & $\begin{array}{l}n \\
0 \\
i\end{array}$ & $\hat{c}_{0}^{n}$ & $\frac{n}{c}$ & $\frac{c}{c}$ & ci & 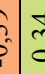 & $\delta$ & & & 6 & 6 & $?$ & ì & & & $\begin{array}{c}\infty \\
\infty \\
0\end{array}$ \\
\hline 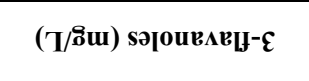 & $\frac{m}{i}$ & $\begin{array}{c}n \\
\tilde{i} \\
\hat{i}\end{array}$ & $\begin{array}{l}t \\
0 \\
c\end{array}$ & $\frac{\square}{0}$ & $\hat{c}$ & $\stackrel{8}{0}$ & $\frac{9}{9}$ & $\tilde{c}$ & $\begin{array}{l}0 \\
0\end{array}$ & $\hat{c}_{0}^{n}$ & 0 & $\exists$ & 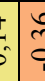 & 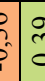 & & & 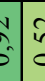 & $\begin{array}{ll}4 \\
6 \\
6\end{array}$ & $\begin{array}{l}0 \\
0 \\
0\end{array}$ & $\begin{array}{l}3 \\
2 \\
1\end{array}$ & s & & & $\begin{array}{l} \pm \\
\infty \\
0 \\
0\end{array}$ \\
\hline ( ( $/ / \mathbf{s} \mathbf{u}) \operatorname{sos}^{\prime}$ & ? & $\frac{9}{0}$ & $\varlimsup_{\substack{\infty \\
i}}^{2}$ & $\stackrel{t}{i}$ & $\underset{d}{1}$ & $\frac{ \pm}{\rho}$ & $\mid \begin{array}{l}\infty \\
c\end{array}$ & $\frac{7}{0}$ & 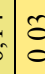 & $\hat{c}$ & ç & $\begin{array}{c}0 \\
c\end{array}$ & $\hat{l}_{2}$ & & ¿̇ & a & $\begin{array}{l}f \\
2 \\
0\end{array}$ & $\begin{array}{l}0 \\
0 \\
0\end{array}$ & $\overrightarrow{3}$ & s. & 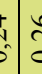 & & & m్ \\
\hline 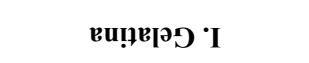 & तु & $\begin{array}{l}n \\
0 \\
0\end{array}$ & ֻ̇ & הี & 方 & 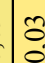 & $\frac{4}{c}$ & 3 & 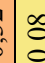 & $\bar{z}$ & $a^{\infty}$ & and & $?$ & $\hat{\imath}$ & ç & cic & ?. & 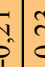 & $?$ & s. & $£$ & รู & & הุ \\
\hline ·w!! & ? & $\stackrel{8}{\circ}$ & กี & $\begin{array}{l}0 \\
\infty \\
i\end{array}$ & $\begin{array}{l}0 \\
\text { in } \\
\text { in }\end{array}$ & $\begin{array}{l}n \\
? \\
?\end{array}$ & $\tilde{z}$ & 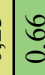 & $\frac{8}{8}$ & $\left\{\begin{array}{l}\infty \\
n \\
c\end{array}\right.$ & \{ & & cr & 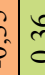 & col & $\stackrel{5}{c}$ & 0 & $\begin{array}{l}0 \\
0 \\
0 \\
1 \\
1\end{array}$ & $\begin{array}{c}c \\
\vdots \\
\end{array}$ & is & 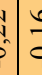 & & & $\begin{array}{l}\text { ro } \\
\text { in }\end{array}$ \\
\hline 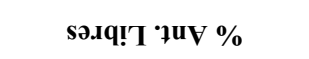 & तે & 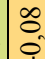 & q & $\begin{array}{l}1 \\
\infty \\
0 \\
0\end{array}$ & 2 & 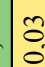 & and & $\int_{0}^{2}$ & $\frac{1}{0}$ & $a$ & & $\infty$ & $\begin{array}{lll}\infty & \infty \\
0 & 0 & 0\end{array}$ & 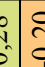 & $\stackrel{5}{c}$ & $\frac{4}{c}$ & $c$ & ?. & $\begin{array}{l}y \\
\dot{b} \\
\dot{y}\end{array}$ & 6 & s & & & तె \\
\hline 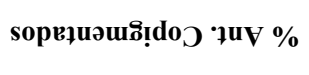 & $\frac{2}{0}$ & o. & $\stackrel{m}{?}$ & 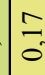 & $\frac{9}{9}$ & in & $\left(\check{c}_{c}^{\infty}\right.$ & 文 & 0 & & $a$ & 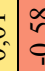 & $\bar{a}$ & $\tilde{c}$ & $c^{2}$ & 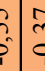 & 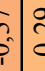 & 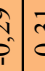 & $\vec{c}$ & 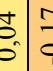 & ริ & 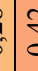 & & $\begin{array}{l}\text { mे } \\
\text { ?े }\end{array}$ \\
\hline (T/8) sou!ur $\mathbf{L}$ & \begin{tabular}{c}
$\infty$ \\
\multirow{3}{3}{} \\
0
\end{tabular} & ָู & 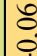 & $\frac{\infty}{2}$ & हి & $\frac{9}{0}$ & $\frac{\infty}{c}$ & $\frac{5}{c}$ & & 을 & $\frac{1}{c}$ & 8 & $b_{c}^{\infty}$ & : & 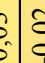 & ca & 8 & 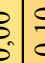 & 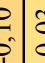 & 8 & $\gtreqless$ & 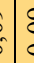 & & 8. \\
\hline $\operatorname{dd} \boldsymbol{\Lambda} \mathrm{d} \cdot \mathrm{I}$ & is & ?ֶ. & $\frac{6}{9}$ & $\bar{n}$ & ¿ุ̀ & : & $\dddot{u}$ & & $\frac{0}{i}$ & 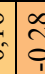 & 8 & 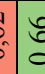 & 8 & $\bar{c}$ & ç & ?̧ & 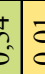 & 5 & $\begin{array}{l}0 \\
i \\
i\end{array}$ & 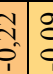 & 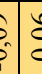 & $£$ & & $\begin{array}{l}\infty \\
0 \\
0\end{array}$ \\
\hline [OUв;日 $\cdot I$ & $\frac{0}{i}$ & î & $\ddot{c}$ & $\begin{array}{l}n \\
\text { in }\end{array}$ & $\begin{array}{l}\mathbf{q} \\
\mathbf{1}\end{array}$ & $\frac{0}{0}$ & & ă & $\frac{\infty}{9}$ & $\sum_{0}^{\infty}$ & ? & כֶ & $\frac{4}{9}$ & $c$ & $\begin{array}{c}0 \\
\vdots\end{array}$ & $\begin{array}{c}c \\
\vdots \\
i\end{array}$ & 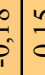 & $c$ & 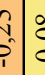 & $\begin{array}{c}\infty \\
0 \\
0\end{array}$ & ริ & ¿ & & $\begin{array}{l}\text { กิ } \\
\text { के }\end{array}$ \\
\hline HOVINA 'I & ֻู & : & $\frac{9}{0}$ & $\frac{7}{0}$ & $\stackrel{8}{8}$ & & 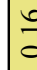 & $a$ & $\frac{9}{9}$ & $i_{0}^{n}$ & $\overbrace{0}^{2}$ & $a_{0}^{n}$ & $\check{c}$ & 8 & 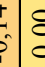 & $b$ & b. & $\begin{array}{l}0 \\
\vdots \\
0 \\
\vdots\end{array}$ & b. & ît. & 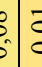 & 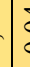 & & $\begin{array}{ll}\text { ô } \\
0 \\
i\end{array}$ \\
\hline ( ( & 然 & 8 & $\frac{m}{0}$ & i & & : & i & 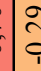 & हे & $\frac{7}{9}$ & 2 & 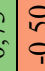 & 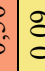 & 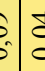 & ç & $=$ & $\dot{c}$ & 6 & $\begin{array}{l}7 \\
0 \\
0\end{array}$ & î & 8 & 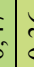 & & is \\
\hline 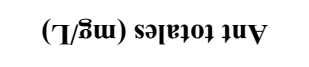 & 요 & $\stackrel{0}{0}$ & $\dddot{1}$ & & b & $\frac{5}{0}$ & $\operatorname{lin}^{1}$ & $\overline{4}$ & $\frac{\infty}{0}$ & $\frac{7}{0}$ & $\sum_{c}^{\infty}$ & $b$ & לְ & $\frac{5}{a}$ & $\frac{5}{a}$ & 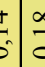 & 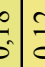 & 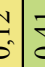 & f & e. & ปู & & & $\bar{m}$ \\
\hline OuoL & i & 亲 & & $\tilde{c}$ & $\frac{m}{0}$ & $\frac{2}{0}$ & 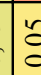 & 5 & o & $\hat{c}$ & $\int_{0}^{2}$ & 5 & $\lesssim$ & $\underset{c}{\infty}$ & $\begin{array}{l}0 \\
? \\
1 \\
1\end{array}$ & $\bar{a}$ & $\begin{array}{l}0 \\
\vdots \\
\vdots\end{array}$ & S. & 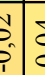 & $\begin{array}{l} \pm \\
0 \\
0\end{array}$ & & & & $\tilde{o}_{0}$ \\
\hline$\cdot \mathrm{r} \cdot \mathrm{I}$ & हैं & & $\begin{array}{l}\text { J } \\
\text { c }\end{array}$ & $\tilde{o}$ & 8 & o. & E & תִ & $\hat{z}$ & $\tilde{c}$ & 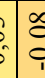 & 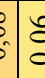 & $b^{2}$ & $\frac{9}{c}$ & $\begin{array}{l}2 \\
0\end{array}$ & 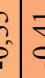 & $\begin{array}{l}\overrightarrow{7} \\
\vdots \\
\end{array}$ & i. & $\begin{array}{l}0 \\
\vdots \\
1 \\
1\end{array}$ & 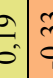 & "ू & & & 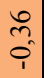 \\
\hline u! & & हो & तె & g & 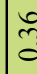 & ָָ & $\frac{\square}{c}$ & 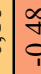 & {$\left[\begin{array}{l}\infty \\
\tilde{c}\end{array}\right.$} & $\frac{9}{0}$ & $c^{2}$ & $\overbrace{0}^{7}$ & $\bar{a}$ & 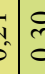 & $c^{2}$ & 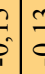 & $\begin{array}{l}n \\
1 \\
1\end{array}$ & $\begin{array}{c}3 \\
c\end{array}$ & 2 & $=$ & 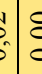 & & & $\begin{array}{l}\overline{0} \\
\vdots\end{array}$ \\
\hline & & & & $\begin{array}{l}3 \\
0\end{array}$ & U. & 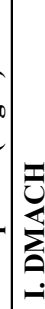 & 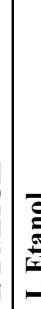 & 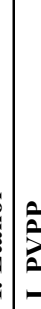 & 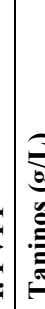 & o & 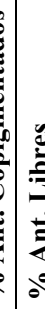 & 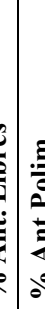 & 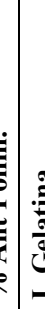 & 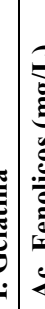 & 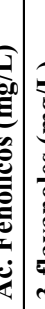 & 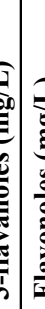 & 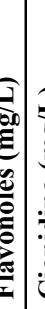 & 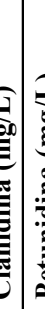 & 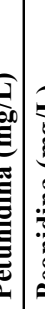 & 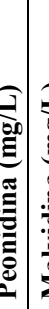 & & & & 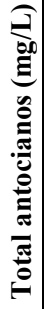 \\
\hline
\end{tabular}


El color debido a las polimerizaciones alcanza en estos vinos valores próximos al $60 \%$, correspondiendo el $30 \%$ a los antocianos libres, siendo el $10 \%$ restante debido a copigmentación. Este comportamiento indica como en estos vinos el color se debe en su mayoría a pigmentos poliméricos, justificándose la correlación positiva encontrada para el índice de PVPP con el porcentaje del color que corresponde a polimerizaciones. La correlación negativa de ambos índices con el color que corresponde a los antocianos libres indican, de nuevo, como el incremento de estas uniones disminuye a los antocianos en su forma libre. Reforzando la correlación negativa encontrada para los antocianos polimerizados con el tono, y la de los antocianos totales con el índice de PVPP y el color debido a polimerizaciones, la influencia de estos sobre el color de los vinos al final del periodo de conservación.

Para el color encontramos dos correlaciones negativas, que corresponde a las reacciones de copigmentación, una con el índice de DMACH y otra con el color que corresponde a polimerizaciones. La participación de los antocianos en reacciones de polimerización puede ser a expensas de los antocianos cedidos por las moléculas de copigmentación, justificándose el comportamiento observado.

Tabla 6.43. Autovalor, varianza explicada y acumulada para las componentes consideradas en el análisis

\begin{tabular}{cccc}
\hline Componente & Autovalor & \% Varianza & \% Acumulado \\
\hline $\mathbf{1}$ & 7,666 & 31,942 & 31,942 \\
$\mathbf{2}$ & 5,234 & 21,810 & 53,752 \\
$\mathbf{3}$ & 2,634 & 10,974 & 64,727 \\
$\mathbf{4}$ & 1,800 & 7,499 & 72,225 \\
$\mathbf{5}$ & 1,453 & 6,054 & 78,280 \\
$\mathbf{6}$ & 0,934 & 3,893 & 82,173 \\
$\mathbf{7}$ & 0,799 & 3,327 & 85,500 \\
$\mathbf{8}$ & 0,695 & 2,897 & 88,397 \\
$\mathbf{9}$ & 0,613 & 2,554 & 90,952 \\
$\mathbf{1 0}$ & 0,431 & 1,795 & 92,747 \\
$\mathbf{1 1}$ & 0,391 & 1,631 & 94,378 \\
$\mathbf{1 2}$ & 0,331 & 1,379 & 95,757 \\
$\mathbf{1 3}$ & 0,205 & 0,856 & 96,612 \\
$\mathbf{1 4}$ & 0,201 & 0,836 & 97,449 \\
$\mathbf{1 5}$ & 0,175 & 0,729 & 98,178 \\
$\mathbf{1 6}$ & 0,140 & 0,585 & 98,763 \\
$\mathbf{1 7}$ & 0,081 & 0,339 & 99,102 \\
$\mathbf{1 8}$ & 0,078 & 0,326 & 99,428 \\
$\mathbf{1 9}$ & 0,050 & 0,208 & 99,637 \\
$\mathbf{2 0}$ & 0,042 & 0,175 & 99,811 \\
$\mathbf{2 1}$ & 0,035 & 0,145 & 99,956 \\
$\mathbf{2 2}$ & 0,007 & 0,028 & 99,984 \\
$\mathbf{2 3}$ & 0,004 & 0,016 & 100,000 \\
\hline
\end{tabular}


En cuanto a la correlación negativa con el índice de DMACH, si los antocianos están formando parte de complejos de copigmentación, los taninos encuentran en el medio una mayor dificultad para unirse con estos antocianos, favoreciéndose las reacciones entre ellos, con lo que se incrementa la formación de polímeros coloidales.

Por último, se han identificado un gran número de correlaciones positivas para los parámetros 3-flavanoles, flavonoles, cianidina, petunidina, malvidina, antocianidinas, derivados de antocianos, total de antocianos. Este resultado indica como aquellos vinos que presenten una elevada concentración antociánica en su composición, presentaran también una elevada concentración de los principales compuestos fenólicos que caracterizan a los vinos, siendo este efecto más marcado al final del periodo de conservación de los vinos en botella.

En la tabla 6.43 aparece el autovalor y el porcentaje de varianza acumulada por los sucesivos factores, observándose como son necesarios cinco factores para que el autovalor descienda por debajo de la unidad. Estas cinco componentes son responsables del $80 \%$ de la variabilidad total.

Tabla 6.44. Tabla de pesos de los componentes

\begin{tabular}{lccccc}
\hline & \multicolumn{5}{c}{ Componentes } \\
& $\mathbf{1}$ & $\mathbf{2}$ & $\mathbf{3}$ & $\mathbf{4}$ & $\mathbf{5}$ \\
\hline I. Folin & $-0,01$ & 0,26 & $-0,35$ & $-0,28$ & $-0,06$ \\
I.C. & $-0,14$ & 0,11 & $-0,42$ & $-0,15$ & $-0,11$ \\
Tono & 0,02 & 0,14 & 0,44 & 0,08 & 0,17 \\
Ant totales (mg/L) & 0,14 & 0,35 & 0,04 & 0,06 & $-0,13$ \\
Catequinas (mg/L) & 0,20 & 0,26 & $-0,09$ & 0,15 & $-0,24$ \\
I. DMACH & $-0,02$ & 0,11 & 0,20 & $-0,52$ & $-0,28$ \\
I. Etanol & $-0,12$ & $-0,18$ & 0,16 & $-0,41$ & 0,24 \\
I. PVPP & 0,03 & $-0,35$ & 0,09 & $-0,02$ & $-0,23$ \\
Taninos (g/L) & $-0,02$ & 0,12 & $-0,23$ & 0,15 & $-0,24$ \\
\% Ant. Copigmentados & $-0,14$ & 0,18 & 0,26 & $-0,42$ & 0,01 \\
\% Ant. Libres & 0,14 & 0,35 & 0,08 & 0,22 & 0,01 \\
\% Ant Polim. & $-0,03$ & $-0,39$ & $-0,23$ & 0,06 & $-0,02$ \\
I. Gelatina & $-0,10$ & 0,20 & 0,08 & 0,16 & 0,06 \\
Ac. Fenolicos (mg/L) & 0,12 & $-0,10$ & $-0,39$ & $-0,19$ & 0,14 \\
3-flavanoles (mg/L) & 0,32 & $-0,11$ & 0,00 & $-0,11$ & $-0,14$ \\
Flavonoles (mg/L) & 0,33 & $-0,10$ & 0,03 & $-0,06$ & $-0,13$ \\
Cianidina (mg/L) & 0,25 & $-0,02$ & $-0,01$ & 0,07 & 0,30 \\
Petunidina (mg/L) & 0,33 & 0,03 & $-0,03$ & $-0,08$ & 0,05 \\
Peonidina (mg/L) & $-0,07$ & 0,06 & $-0,17$ & 0,02 & 0,65 \\
Malvidina (mg/L) & 0,32 & 0,06 & 0,07 & $-0,11$ & 0,11 \\
Antocianidinas (mg/L) & 0,34 & 0,04 & 0,03 & $-0,06$ & 0,17 \\
Derivados de ant. (mg/L) & 0,33 & $-0,11$ & $-0,05$ & $-0,11$ & $-0,04$ \\
Total antocianos (mg/L) & 0,35 & $-0,01$ & 0,00 & $-0,08$ & 0,10 \\
\hline & & & & &
\end{tabular}

En la tabla 6.44 aparecen los valores de los coeficientes de las ecuaciones que forman cada uno de los cinco componentes principales identificados. El primer 
componente principal presenta asociaciones directas con los parámetros 3-flavanoles, flavonoles, cianidina, petunidina, malvidina, antocianidinas, derivados de antocianos y total de antocianos; correspondiendo a vinos que se caracterizan por presentar una elevada concentración antociánica y fenólica en su forma simple o monómera.

Para el segundo eje principal los parámetros índice de Folin, antocianos totales, catequinas y porcentaje del color de los antocianos libres presentan coeficientes positivos, mientras que por el contrario el índice de PVPP y los antocianos polimerizados muestran coeficientes negativos importantes. Este eje podría corresponder a vinos donde existe una elevada concentración de compuestos fenólicos en su forma libre. Mientras que está correlacionado de forma negativa con los vinos en los que predominan las reacciones de unión entre antocianos y taninos siendo estos compuestos, en gran parte, responsables del color.

El tercer eje considerado está relacionado indirectamente con el índice de Folin, intensidad colorante y ácidos fenólicos; caracterizándose estos vinos por presentar una importante concentración fenólica, siendo importante también la concentración de ácidos fenólicos y presentando además unas buenas propiedades cromáticas. Por el contrario, está asociado directamente con el tono y el porcentaje de antocianos copigmentados. Estos vinos se caracterizarían por presentar, todavía, un gran porcentaje de antocianos copigmentados, en detrimento de los polimerizados.

Por último el cuarto componente se correlaciona de forma negativa con el índice de Folin, índice de DMACH, índice de etanol y con el color que corresponde a los antocianos copigmentados, y el quinto con la cianidina y peonidina.

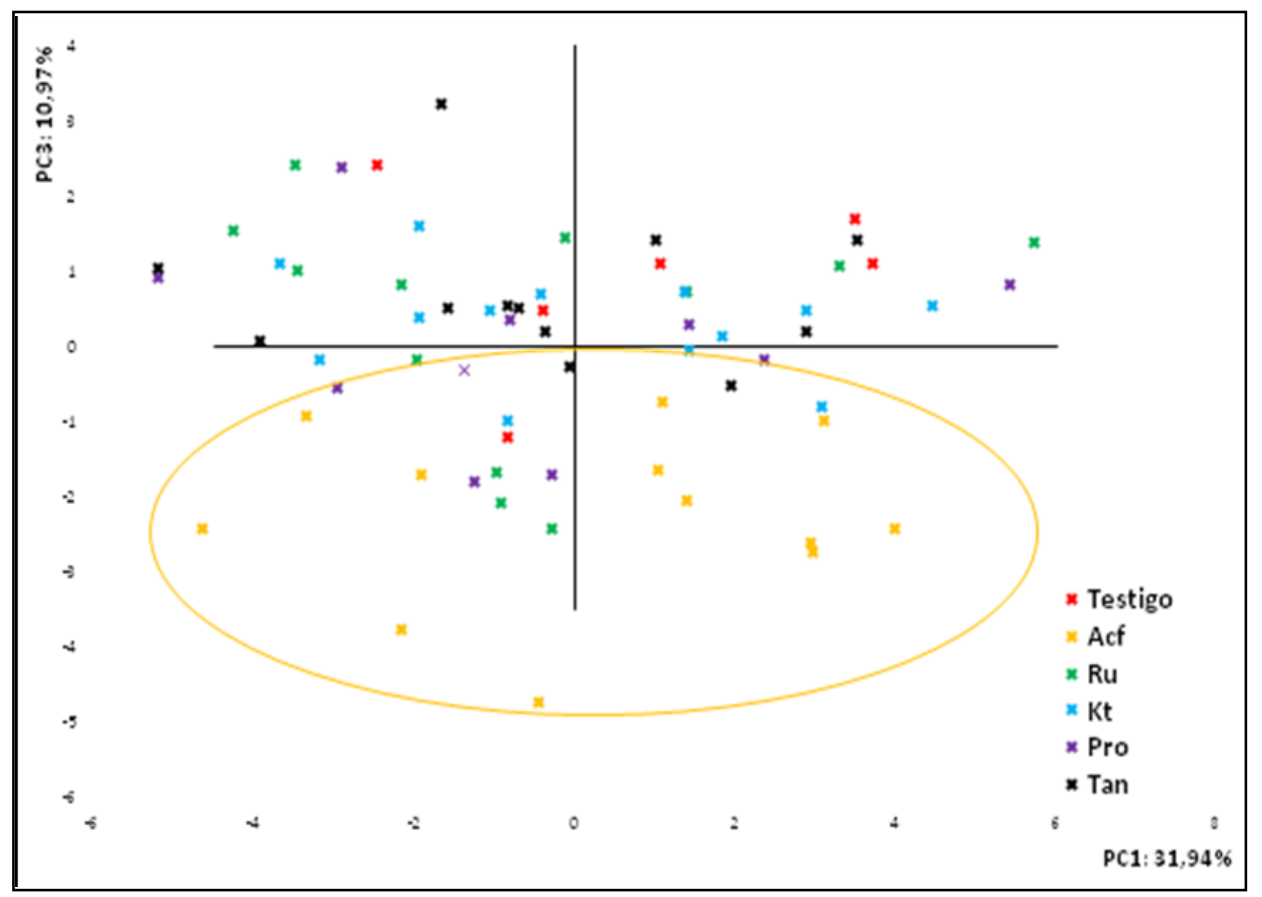

Gráfico 6.47. Primera componente frente a la segunda, en función de los copigmentos ensayados. 
Una vez comprobadas que variables están más correlacionadas con las componentes principales, se calcularon los coeficientes de las combinaciones lineales sobre las variables antiguas, para poder calcular a partir de ellos las nuevas coordenadas de los objetos en las componentes. Obtenidos los coeficientes de las componentes principales se representó la primera componente frente a la tercera.

La representación de los vinos elaborados en función del primer y del tercer eje principal aparece en el gráfico 6.47, observándose como los vinos se distribuyen a lo largo del primer componente principal, no pudiéndose identificar ningún patrón de comportamiento asociado. El tercer eje principal es capaz de situar a los vinos adicionados del copigmento ácido cafeico en la zona negativa del eje. Estos vinos se caracterizan por presentar una importante concentración fenólica, influyendo de forma decisiva la presencia de ácidos fenólicos, presentando además unas buenas propiedades cromáticas. El segundo componente principal no permite diferenciar a los diferentes copigmentos utilizados en el estudio (datos no mostrados) no pudiendo establecerse un comportamiento específico del APC para la adición de los otros copigmentos, tal como observamos en los vinos después de seis meses de conservación.

En el gráfico 6.48 aparece representada la primera componente frente a la segunda en función de las técnicas de vinificación. Se observa una distribución de los vinos a lo largo del primer eje principal, mostrándose aquellos vinos macerados con aplicación de nieve carbónica en la zona positiva del primer componente, aquellos macerados únicamente con aplicación de bajas temperaturas en la zona central del eje y por último los vinos elaborados de forma tradicional en la zona negativa del gráfico.

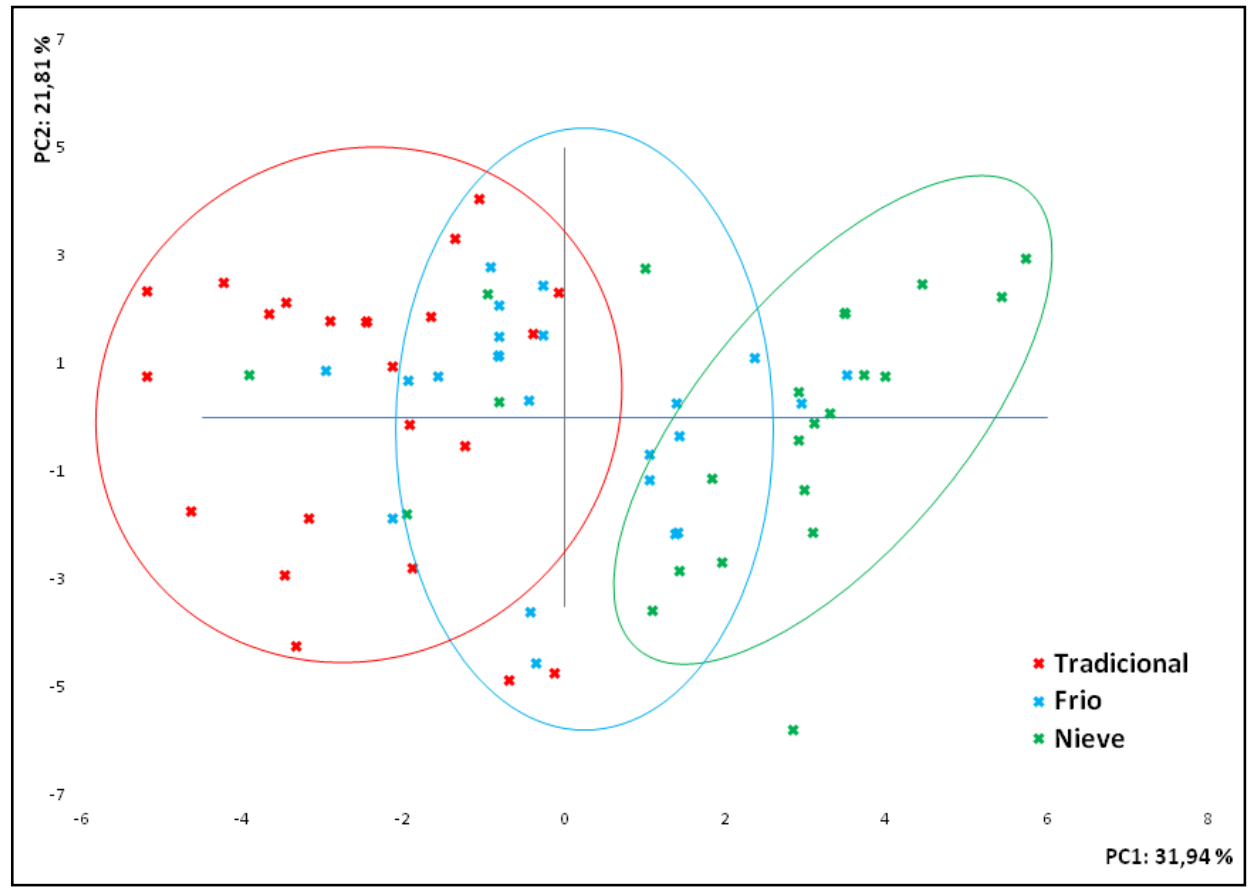

Gráfico 6.48. Primera componente frente a la segunda, en función de las técnicas de vinificación ensayadas.

La maceración con aplicación de nieve carbónica de lugar a vinos que presentan una elevada concentración antociánica y fenólica en su forma simple, sugiriéndose que en estos vinos, a pesar de las polimerizaciones y condensaciones entre los distintos 
compuestos fenólicos, todavía se encuentrar muchos compuestos en forma de monómeros. Los vinos elaborados de forma tradicional presentan una menor concentración de polifenoles, y la maceración en frío una concentración intermedia.

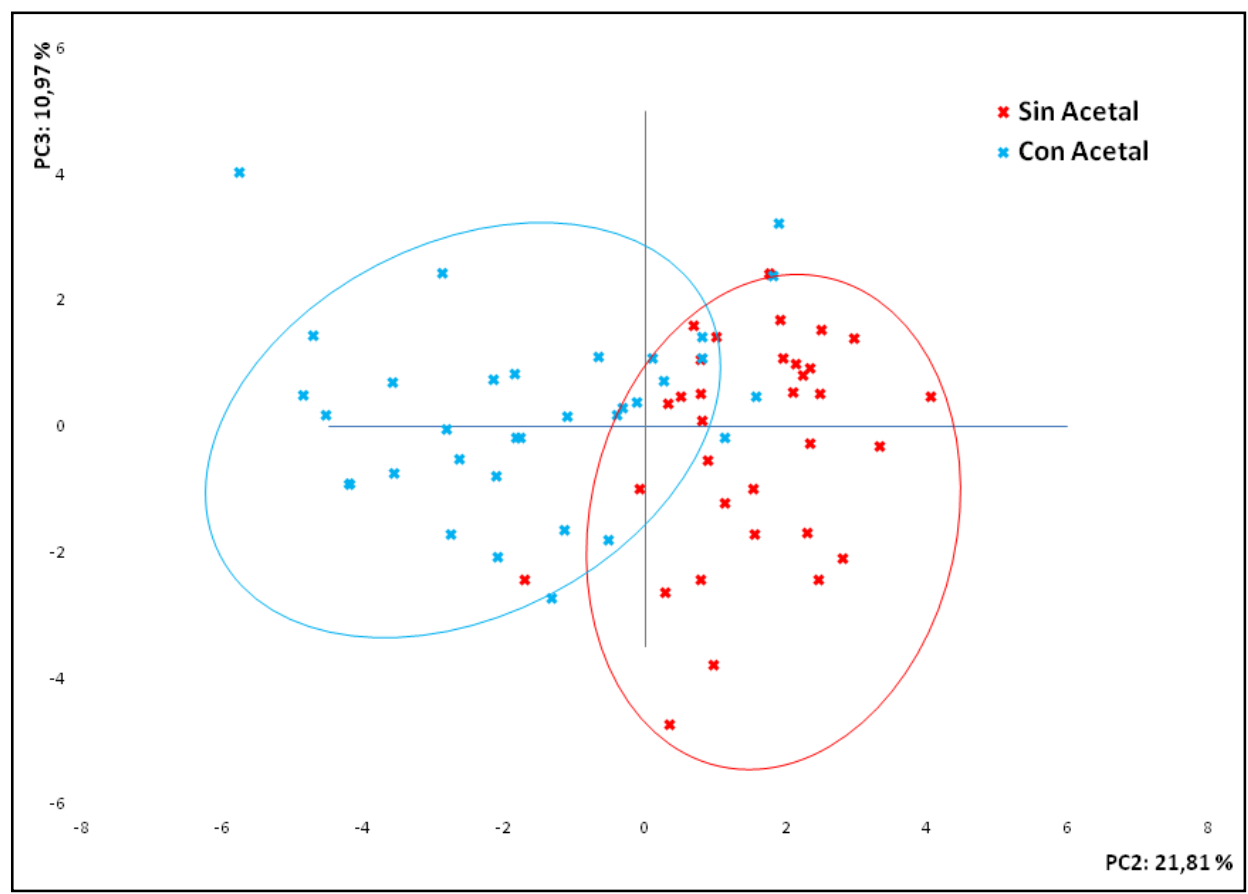

Gráfico 6.49. Segunda componente frente a la tercera, en función de la aplicación de la microoxigenación.

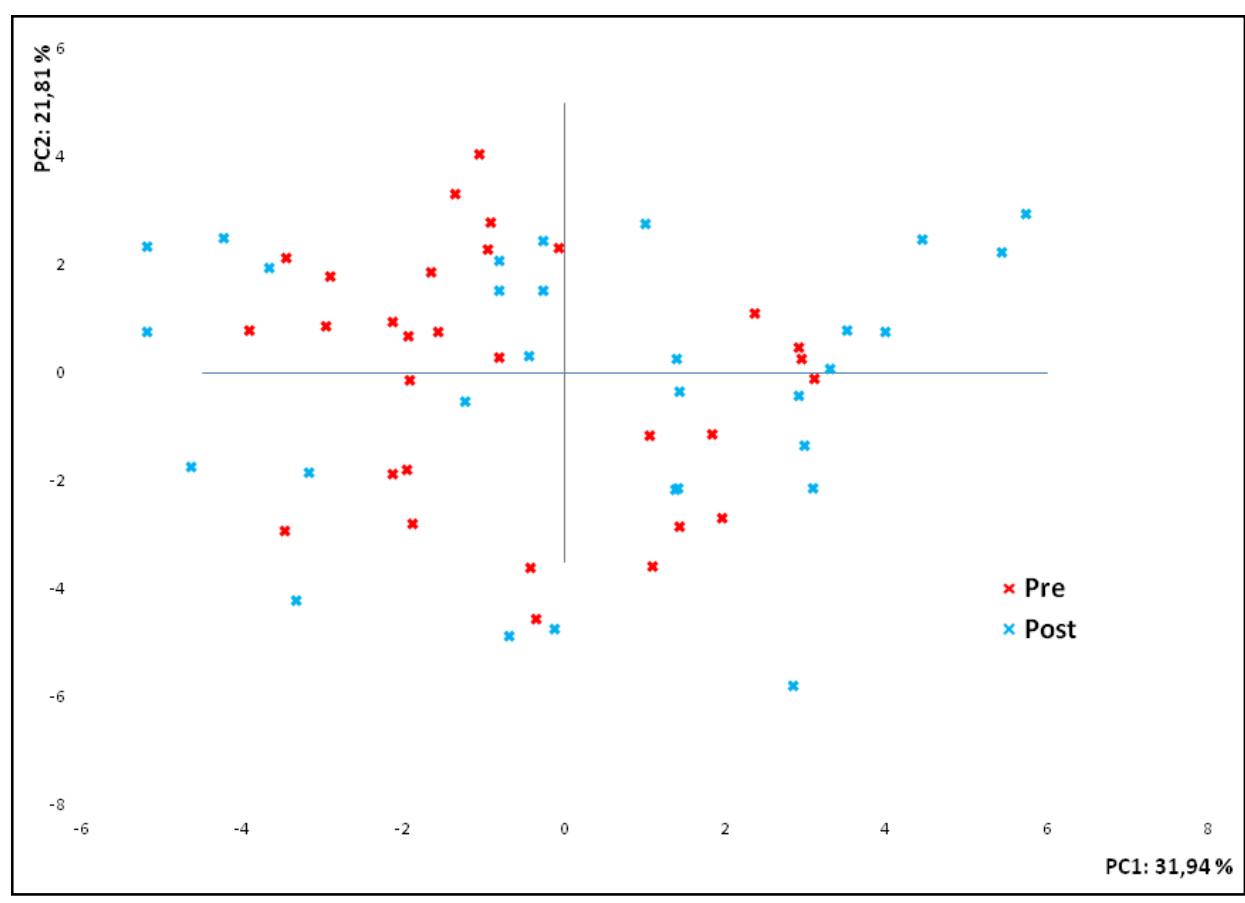

Gráfico 6.50. Primera componente frente a la segunda, en función del momento de adición de los copigmentos. 
En el gráfico 6.49 aparecen representados tanto los vinos microxigenados, como aquellos no adicionados de acetaldehído, en función de la segunda componente frente a la tercera, observándose como, en este caso, es la segunda componente la que permite diferenciar a los vinos sometidos a esta práctica enológica. Los vinos adicionados de acetaldehído se sitúan principalmente en la zona negativa del segundo componente, mientras que aquellos no microoxigenados se sitúan en la parte positiva.

En el gráfico 6.50 se ha representado el efecto de la adición pre- o postfermentativa de copigmentos en función de la primera y segunda componente, encontrándose que los vinos aparecen aleatoriamente distribuidos a lo largo de espacio representado por las dos componentes. Este comportamiento no permite diferenciar los vinos en función del momento de adición de los copigmentos, mostrando los vinos elaborados características similares. Tampoco permite caracterizar los vinos en función de los coeficientes que definen a los componentes principales identificados, tal como sucedía en los vinos después de la maloláctica y a los seis meses de conservación.

\subsubsection{EVOLUCIÓN DE LOS VINOS ELABORADOS DURANTE 12 MESES DE CONSERVACIÓN EN BOTELLA}

Con el propósito de valorar la eficacia de las distintas técnicas aplicadas en la elaboración de los vinos, así como de definir con más claridad las modificaciones que tienen lugar durante los doce meses de conservación, se va a estudiar cada uno de los parámetros polifenólicos por separado en función de los distintos factores ensayados.

Los análisis multifactorial de la varianza (tablas 6.23, 6.29 y 6.37) muestran como los factores adición de copigmentos, aplicación de las diferentes técnicas de vinificación ensayadas y aplicación de la microoxigenación, afectan significativamente a la composición fenólica de los vinos tanto después de su elaboración como durante su conservación; correspondiendo al factor momento de adición de copigmentos la menor influencia en la composición polifenólica de los vinos sometidos a estas prácticas.

La interacción adición de copigmentos x técnicas de vinificación presenta un marcado efecto sobre los polifenoles de los vinos analizados después de la fermentación maloláctica, despareciendo este efecto durante el envejecimiento de los vinos en botella. Por el contrario el factor técnicas de vinificación x momento de adición de copigmentos presenta un marcado efecto sobre la composición de los vinos a lo largo de todo el proceso de conservación. Las interacciones adición de copigmentos $\mathrm{x}$ momento de adición, y microoxigenación $\mathrm{x}$ momento de adición presentan un efecto moderado sobre la composición fenólica de los vinos a los 6 meses del embotellado, manteniéndose este efecto y desapareciendo, respectivamente, a los 12 meses de envejecimiento. Por último, la interacción técnicas de vinificación x microoxigenación presenta un efecto débil sobre la composición fenólica al final del proceso de conservación de los vinos. La complejidad de estas interacciones nos indica la complejidad de la composición polifenólica de los vinos, y la gran influencia de todas aquellas técnicas que afecten a la extracción y/o a la interacción de los distintos compuestos polifenólicos del vino.

El análisis de componentes principales no ha permitido diferenciar el efecto de los diferentes copigmentos utilizados al concluir la fermentación maloláctica de los vinos, aunque si observamos un efecto positivo de la adición de ácido cafeico en la composición fenólica de los vinos (gráfico 6.40). A medida que los vinos van 
evolucionando, los adicionados con ácido cafeico van presentando características específicas que conducen a una clara diferenciación mediante la técnica del APC (gráficos 6.42, 6.43, 6.47); caracterizándose por una mayor esterificación y polimerización de sus antocianos, y un mayor contenido en ácidos fenólicos y polifenoles totales. Este resultado concuerda con lo observado en el ANOVA (tablas 6.24, 6.30 y 6.38). En el año 2006 el APC también permitió establecer diferencias entre los vinos copigmentados y los testigos, sin que destacase el comportamiento individual de ningún copigmento (gráficos 6.1, 6.3 y 6.8).

Para la caracterización de las diferentes metodologias de vinificación ensayadas, la técnica del Análisis de Componentes Principales aplicada a los vinos una vez concluida la fermentación maloláctica, permite diferenciar aquellos elaborados de forma tradicional de los que han sido sometidos a maceración prefermentativa (gráfico 6.41). A los 6 meses del periodo de envejecimiento la diferenciación de estos vinos se dificulta (gráfico 6.44); pero en cambio, al final del periodo de conservación, vuelve a ser posible diferenciar los vinos elaborados por maceración tradicional de aquellos macerados prefermentativamente, confundiendo algunos vinos elaborados con maceración en frío con otros elaborados con nieve carbónica (gráfico 6.48).

Es curioso destacar como en el ANOVA realizado (tablas 6.25, 6.31 y 6.39), a medida que transcurre la conservación, los vinos elaborados con aplicación de nieve carbónica van incrementando sus diferencias con los elaborados con maceración en frío, de forma que a los 12 meses de conservación presentan una concentración significativamente mayor de estos compuestos. Esta situación también se aprecia en los APC realizados, donde observamos que a los 12 meses una parte importante de los vinos elaborados con nieve carbónica se diferencia perfectamente de los elaborados con frío, pero esta separación no es tan clara como sucedía con el análisis de la varianza; una situación similar también fue observada en los vinos de la cosecha 2006 (tablas 6.3, 6.9, 6.18 y gráficos 6.2, 6.4 y 6.7). La mayor concentración de antocianos y sus derivados, de ácidos fenólicos, catequinas y flavanoles encontrada en los vinos elaborados con maceración prefermentativa, es la causante de esta diferenciación, apreciándose a los 12 meses de conservación una situación en la que los menores valores de estos compuestos corresponden a la vinificación tradicional, los intermedios a la maceración con frío y los superiores a los elaborados con nieve carbónica.

El Análisis de Componentes Principales permite la diferenciación de los vinos no adicionados de acetaldehído de aquellos microoxigenados, a lo largo de todo el proceso de envejecimiento en botella (gráficos 6.45, 6.49); caracterizándose los vinos microoxigenados por presentar una composición antociánica formada en su mayoría por polímeros de antocianos, afectando estos decisivamente al color de los vinos, manteniendo sus características cromáticas durante el envejecimiento. Estos resultados concuerdan con los observados en el ANOVA (Tablas 6.32 y 6.40), y con los encontrados en los vinos de 2006 (tablas 6.10, 6.10 y gráficos 6.5 y 6.11).

Por último, únicamente destacar que la adición pre- o postfermentativa de compigmentos no presentó diferencias cuando los parámetros polifenólicos fueron sometidos al Análisis de Componentes Principales, tal como sucedía en los ANOVA, concluyendo que la adición de copigmentos en un determinado momento del proceso de elaboración tiene una mínima influencia sobre la composición fenólica de los vinos. 
Para una mejor interpretación de la evolución de los parámetros polifenólicos a lo largo de la conservación, que nos permita comparar los resultados de forma más gráfica, se va a representar la evolución de cada uno de los parámetros por separado, con cada una de las técnicas ensayadas.

\subsubsection{EVOLUCIÓN DE LA INTENSIDAD COLORANTE}

En el gráfico 6.51 aparece representada la evolución de la intensidad colorante para los vinos elaborados, adicionados de los distintos copigmentos ensayados.

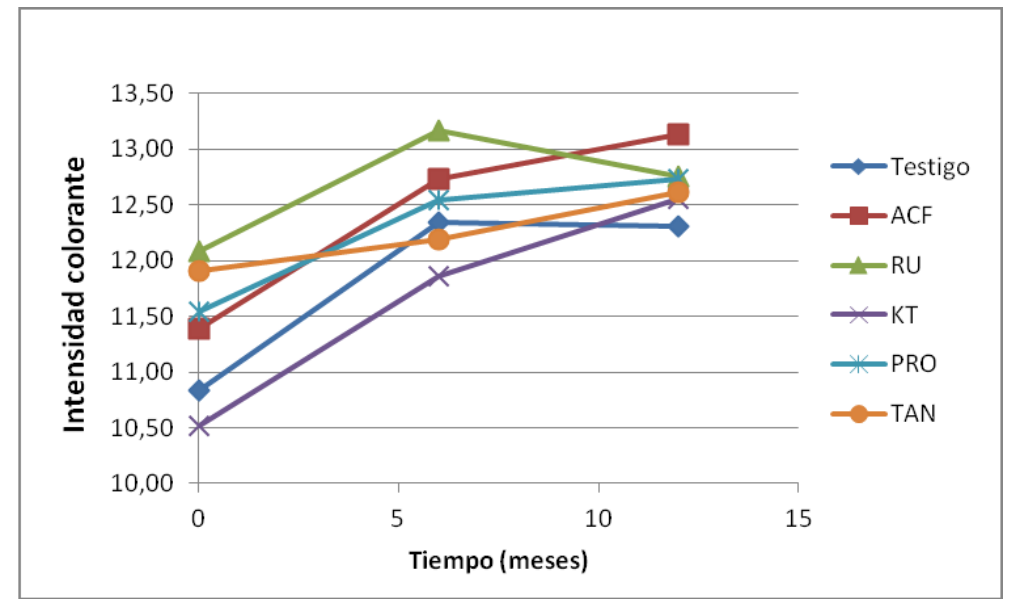

Gráfico 6.51. Evolución de la intensidad colorante durante el periodo de conservación de los vinos en función de los distintos copigmentos adicionados

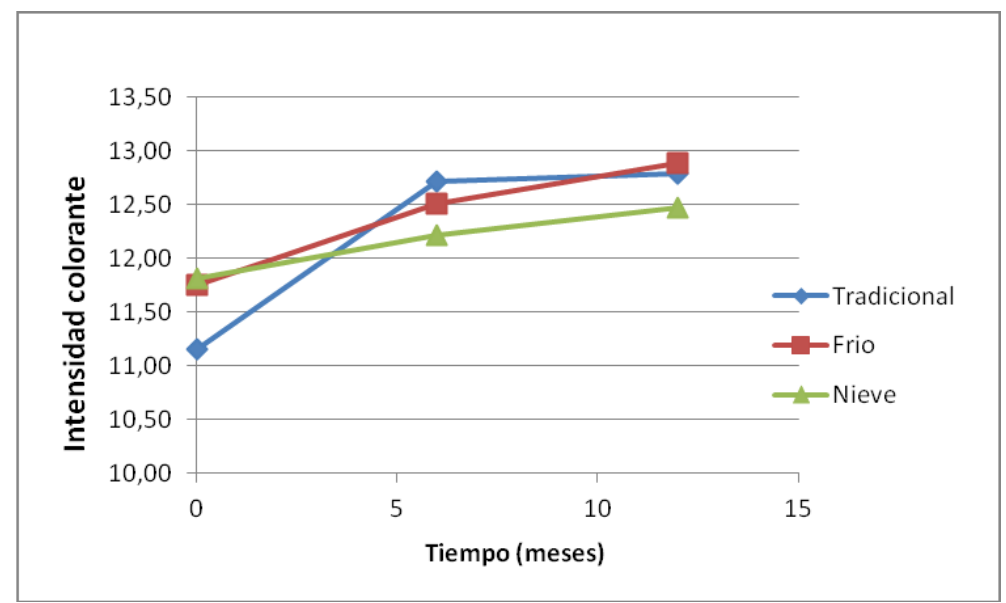

Gráfico 6.52. Evolución de la intensidad colorante durante el periodo de conservación de los vinos en función de las distintas técnicas de vinificación ensayadas.

La adición de copigmentos incrementa significativamente el color de los vinos posteriormente al embotellado (tabla 6.24). Es de destacar el importante efecto sobre el color del copigmento rutina, también observado en la cosecha de 2006, que da lugar al mayor incremento de color en los vinos en postmaloláctica y durante los primeros seis meses de conservación, para después caer a niveles similares a los de los otros copigmentos, a los 12 meses de conservación (tablas 6.2, 6.8 y 6.16). En cambio, duranre la conservación se observa un importante incremento del color debido al 
copigmento ácido cafeico (tablas 6.30 y 6.38), alcanzando los vinos adicionados con este copigmento a los 12 meses la mayor intensidad colorante, siendo los vinos testigo sin adicionar los que tienen el menor color, lo que pone de manifiesto el efecto positivo de la adición de copigmentos sobre el color de los vinos.

El gráfico 6.52 muestra la evolución del color de los vinos, en función de las técnicas de vinificación. Se observa un incremento de la intensidad colorante que indica que los compuestos formados afectan positivamente al color de los vinos.

Posteriormente a la fermentación, las técnicas de maceración prefermentativa en frío presentan diferencias significativas con respecto a la vinificación tradicional (tabla 6.25), favoreciendo éstas técnicas un mayor color en los vinos recién elaborados, por lo que la maceración prefermentativa podría ser interesante para los vinos de consumo rápido (Reynolds et al., 2001; Parenti et al., 2004; Gómez-Plaza et al., 2001; Koyama et al., 2007; Gil-Muñoz et al., 2009). En cambio, estas diferencias se minimizan durante la conservación (tablas 6.30 y 6.38), no apareciendo diferencias significativas con la vinificación tradicional ni a los 6 ni a los 12 meses de conservación. Una situación similar se observó en los vinos de 2006 (tablas 6.3, 6.9 y 6.17), no pudiendo establecerse en esta añada diferencias significativas en el color de los vinos en función de la técnica de vinificación.

En el gráfico 6.53 se recoge la evolución de la intensidad colorante durante la conservación de los vinos, en función de la microoxigenación, observándose a los 6 meses de la evolución un incremento significativo de este parámetro con respecto a aquellos vinos no adicionados (tabla 6.32). Este efecto de la microoxigenación, que se manifiesta en numerosos estudios (Cano-López et al., 2006, 2007, 2008, 2010; Wirth et al., 2010, Rayne et al., 2008), disminuye progresivamente hasta desaparecer cuando los vinos fueron analizados a los 12 meses de permanencia en botella (tabla 6.40). Este mismo comportamiento fue observado en los vinos de la cosecha anterior (gráfico 6.13).

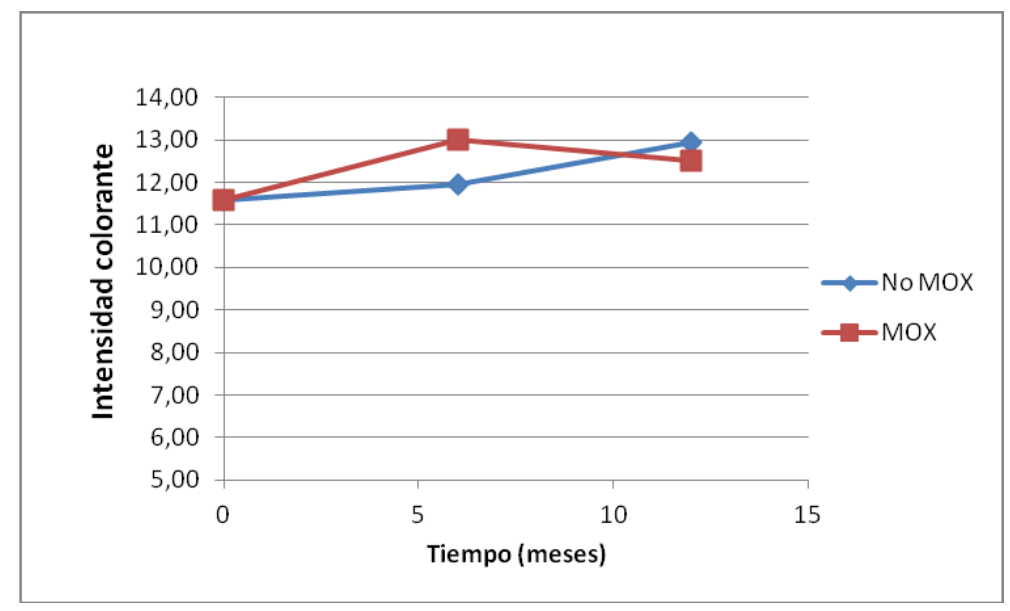

Gráfico 6.53. Evolución de la intensidad colorante durante el periodo de conservación de los vinos en función de la aplicación de la microoxigenación.

Factores como la composición fenólica, las condiciones de conservación o la dosis, duración y frecuencia de la microoxigenación, van a condicionar el efecto de esta 
técnica. La microoxigenación puede incrementar el color de los vinos, pero es necesaria una correcta aplicación de la misma, dimensionando su intensidad y duración en función de las características fenólicas del vino a tratar.

El comportamiento observado indica que en nuestras condiciones de trabajo, la microoxigenación únicamente presentará un efecto positivo en los primeros meses de conservación, disminuyendo este efecto a medida que transcurre la conservación. Ya se ha comentado anteriormente la poca estabilidad que presentan los enlaces etílicos, pudiendo romperse las moléculas formadas, dando lugar a la disminución del color (Cheynier et al., 2006; Escribano-Bailón et al., 2001; Atanasova et al., 2002a).

De las técnicas ensayadas, solo la adición de rutina antes o después de la fermentación, permite obtener vinos con una intensidad colorante superior independientemente del momento de consumo de los vinos. En aquellos vinos que van a ser consumidos jóvenes, también resulta interesante la realización de maceración prefermentativa y la microoxigenación. En cambio, en vinos que han sido envejecidos, también el copigmento ácido cafeico presenta un efecto positivo sobre la conservación del color.

\subsubsection{EVOLUCIÓN DEL TONO}

En el gráfico 6.54 se representa la evolución de la tonalidad amarilla de los vinos durante el periodo de conservación, observándose como a medida que avanza ésta, los vinos adicionados con el ácido cafeico son los que presentan el mejor comportamiento, ya que mantienen la tonalidad roja en detrimento de la amarilla (tablas 6.30, 6.38). La adición de ácido cafeico podría ser una técnica adecuada para proteger el color de aquellos vinos que por sus características fenólicas sean propensos a la oxidación.

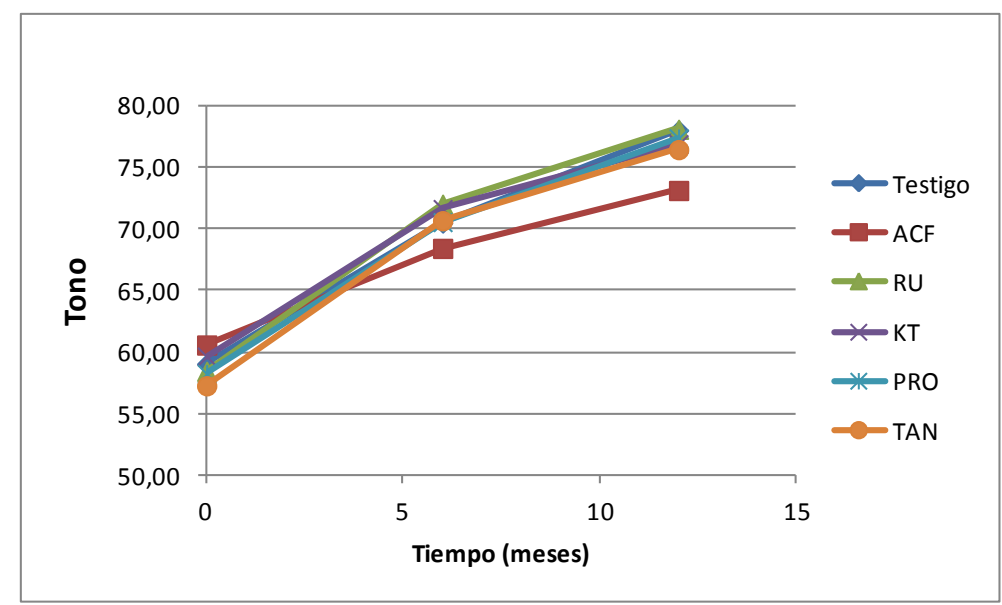

Gráfico 6.54. Evolución del tono durante el periodo de conservación de los vinos en función de los distintos copigmentos adicionados.

En el gráfico 6.55 aparece representada la evolución del tono para los vinos elaborados mediante las distintas técnicas de vinificación, observándose como la tonalidad amarilla de los vinos se incrementa gradualmente a lo largo de la conservación. La maceración prefermentativa permite una ligera protección del color, tanto después de la fermentación (tabla 6.25) como a lo largo de la conservación 
(tablas 6.31 y 6.39), incluso la maceración prefermentativa en frío da lugar a un tono inferior al de los vinos de maceración tradicional, a diferencia de lo observado en la añada anterior. La microoxigenación, en cambio, no da lugar a modificaciones en el tono.

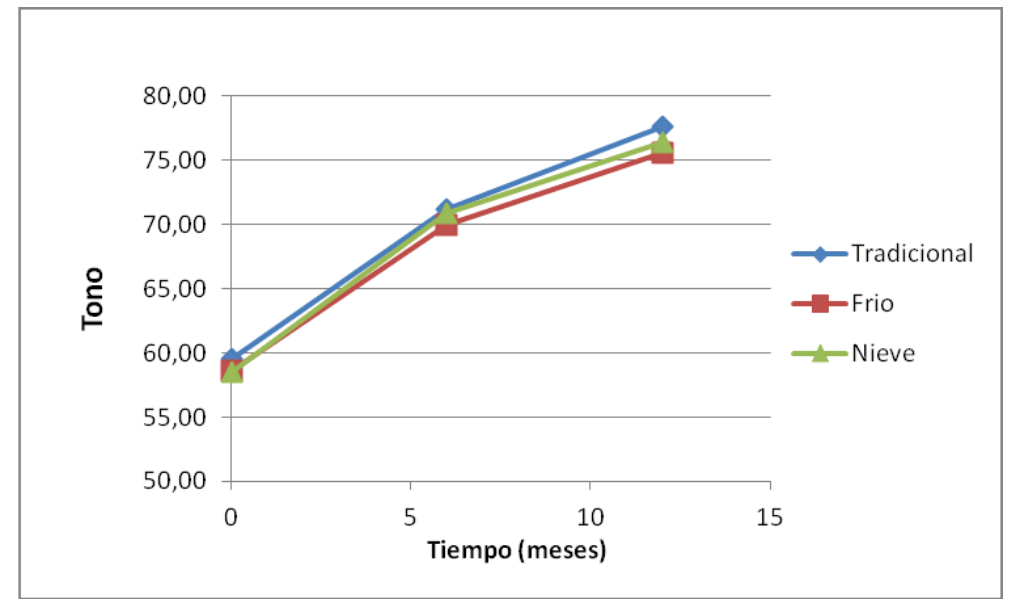

Gráfico 6.55. Evolución del tono durante el periodo de conservación de los vinos en función de las distintas técnicas de vinificación ensayadas.

\subsubsection{EVOLUCIÓN DE LA CONCENTRACIÓN DE ANTOCIANOS \\ TOTALES}

En el gráfico 6.56 aparece la evolución de la concentración de antocianos totales coloreados en los vinos adicionados de los distintos copigmentos ensayados. Los copigmentos catequina, proantocianidina de hollejo y de pepita de uva blanca son los que presentan una mayor capacidad para mantener la concentración de antocianos en solución a lo largo del periodo de conservación (tablas 6.24, 6.30 y 6.38).

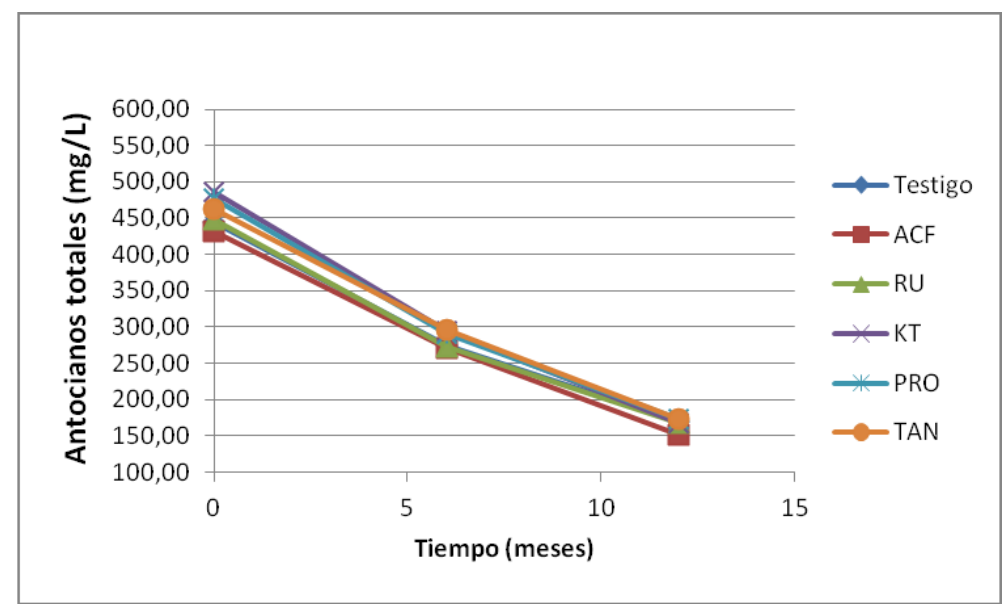

Gráfico 6.56. Evolución de los antocianos totales durante el periodo de conservación de los vinos en función de los distintos copigmentos adicionados.

Este comportamiento es similar al observado en la cosecha anterior (gráfico 6.17), aunque las diferencias en 2006 son más acentuadas. Estos compuestos, al ser 
suplementados en los vinos, ejercen una acción protectora sobre los antocianos decolorables, tal como observaron otros autores (Crespy y Urban, 2002; Zamora, 2003; Bautista-Ortín et al., 2007).

Por el contrario, los copigmentos ácido cafeico y rutina presentan a lo largo de la conservación valores similares a los vinos no adicionados de copigmentos, tal como observamos en la cosecha anterior. Hay que destacar, en cambio, que son estos copigmentos los que dan lugar a los vinos más coloreados, tal como observamos en el gráfico 6.51.

Las técnicas de maceración prefermentativa tanto mediante la aplicación de bajas temperaturas como mediante la adición de nieve carbónica, contribuyen a minimizar las pérdidas de antocianos decolorables a lo largo de la conservación, tal y como se observa en el gráfico 6.57, con diferencias significativas a lo largo de la evolución (tablas 6.25, 6.30, 6.38). Aunque al final del proceso de conservación únicamente la aplicación de nieve carbónica mantiene diferencias significativas con respecto a las otras dos técnicas de vinificación.

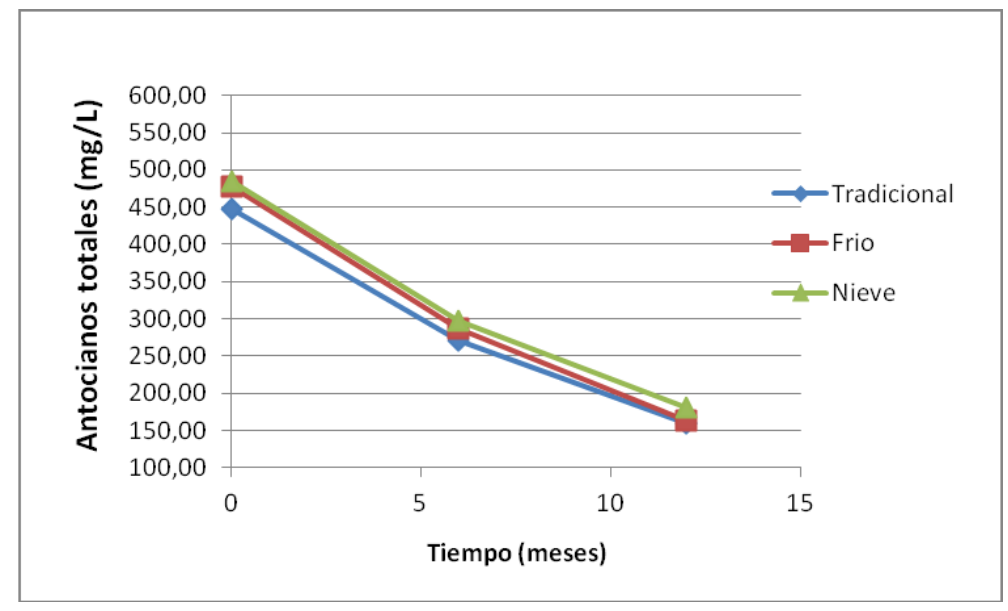

Gráfico 6.57. Evolución de los antocianos totales durante el periodo de conservación de los vinos en función de las técnicas de vinificación ensayadas.

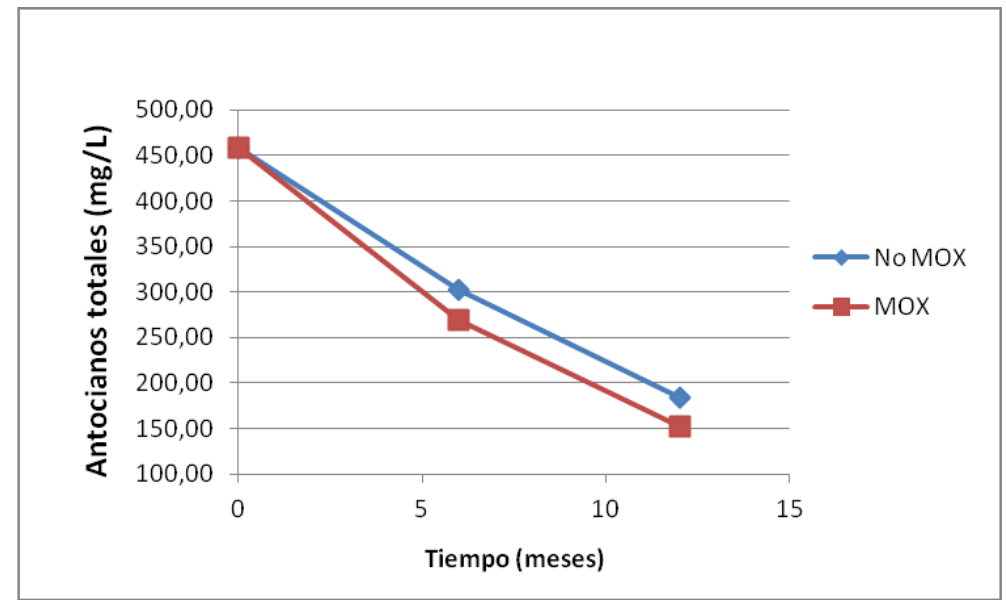

Gráfico 6.58. Evolución de los antocianos totales durante el periodo de conservación de los vinos en función de la microoxigenación. 
En el gráfico 6.58 aparece representada la evolución de la concentración de antocianos totales en función de la aplicación de la microoxigenación. La aplicación controlada de acetaldehído ha provocado una disminución en la concentración de antocianos decolorables a partir del momento de su aplicación, con diferencias significativas, tanto a los 6 como a los 12 meses (tablas 6.31, 6.39), tal como observamos la cosecha anterior. La participación de los antocianos libres en reacciones mediadas por acetaldehído ha sido probablemente la causa del resultado observado. El comportamiento observado durante los primeros meses es contrario al observado para la intensidad colorante, que le incremento inicialmente en los vinos micrrooxigenados, lo que nos pone de manifiesto que no son los antocianos decolorables los únicos responsables del color de los vinos en el envejecimiento, sino otras fracciones de antocianos que se encuentran formando parte de complejos de polimerización.

\subsubsection{EVOLUCIÓN DE LA CONCENTRACIÓN TOTAL DE MALVIDINA.}

La evolución de la concentración de malvidina durante la conservación de los vinos, en función de los distintos copigmentos adicionados, aparece representada en el gráfico 6.59. Se observa una disminución progresiva a lo largo de la conservación, ocasionada por reacciones de oxidación, polimerización y/o precipitación. Los vinos adicionados de copigmentos, especialmente catequina, presentan una mayor concentración de malvidina en el análisis realizado al concluir la fermentación (Tabla 6.44), pero a medida que transcurre la conservación, estas diferencias se van reduciendo, no encontrándose ni a los 6 ni a los 12 meses (tablas 6.29, 6.37).

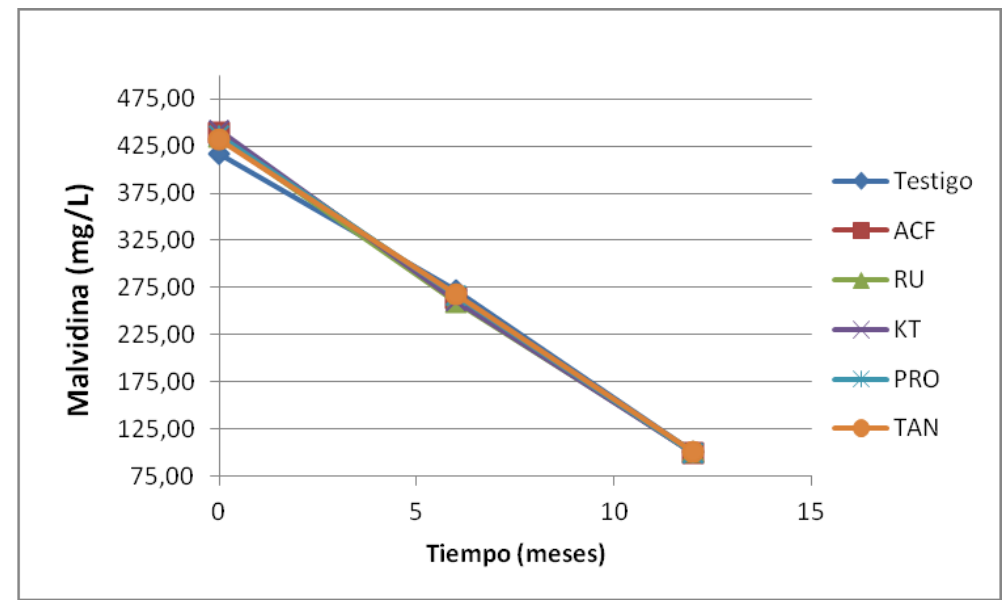

Gráfico 6.59. Evolución de los antocianos totales durante el periodo de conservación de los vinos en función de los distintos copigmentos adicionados.

El gráfico 6.60 representa la concentración total de malvidina en función de las diferentes prácticas de vinificación. Las técnicas de maceración prefermentativa presentan diferencias significativas a lo largo del proceso de conservación de los vinos (tablas 6.25, 6.30, 6.38); siendo la maceración con aplicación de nieve carbónica la técnica que mas contribuye a favorecer la presencia de este compuesto. 
El monoglucósido de malvidina es el antociano con mayor presencia en los vinos, por tanto la aplicación de estas prácticas prefermentativas se muestran adecuadas para favorecer la concentración antocianica de los vinos (Reynolds, 2001; Parenti et al., 2004; Álvarez et al., 2005; Manchon et al., 2005; Gil-Muñoz et al., 2009; GómezMíguez et al., 2006; Gordillo et al., 2010; Koyama et al., 2007), manteniéndose su efecto durante todo el periodo de conservación de los vinos en botella. Este mismo comportamiento lo observamos en la concentración de los antocianos decolorables, tanto en esta cosecha (gráfico 6.57), como en la del año anterior (gráfico 6.17).

La microoxigenación da lugar inicialmente a valores inferiores de malvidina (tabla 6.32), pero a los 12 meses no se observan diferencias significativas con respecto a los vinos no microoxigenados.

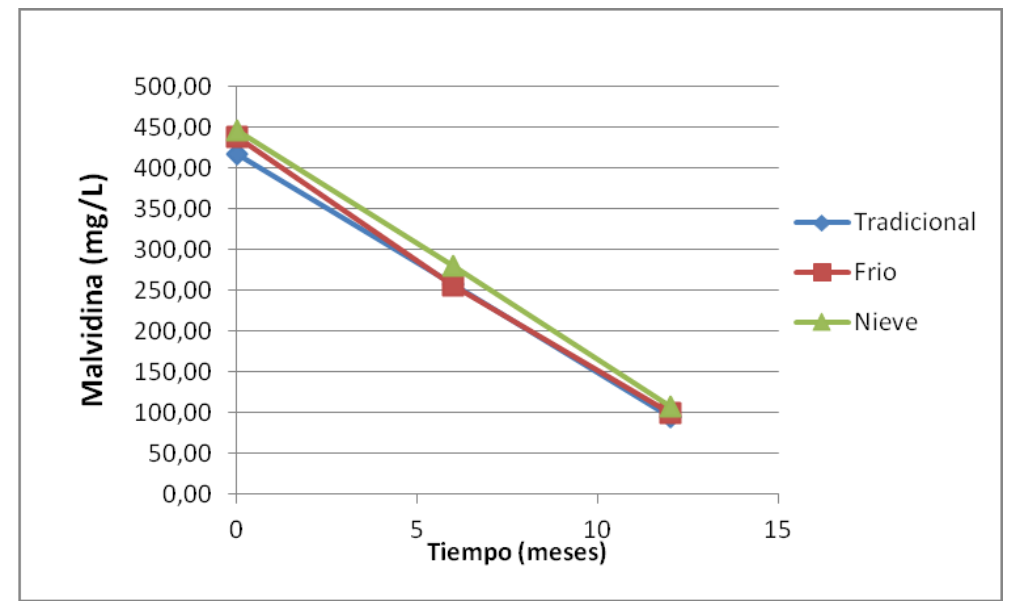

Gráfico 6.60. Evolución de la concentración de malvidina durante el periodo de conservación de los vinos en función de las distintas técnicas de vinificación ensayadas.

\subsubsection{EVOLUCIÓN DE LA SUMA DE ANTOCIANIDINAS}

Los monoglucósidos de delfinidina, cianidina, petunidina y peonidina tienen un comportamiento similar al observado para la malvidina, pudiendo observarse el mismo comportamiento para la suma de las concentraciones de estas antocianidinas.

La adición de copigmentos no parece influir en la concentración total de antocianidinas de los vinos. En cambio, la maceración prefermentativa en frío se presenta como la técnica con mayor impacto sobre la concentración de estos compuestos (gráfico 6.61), con diferencias estadísticamente significativas a lo largo de todo el proceso de conservación de los vinos (tablas 6.25, 6.30, 6.38). Este comportamiento es similar al observado para la concentración de malvidina, ya que al tratarse de la antocianinina más abundante, que representa aproximadamente el $75 \%$ de la totalidad de antocianidinas presentes en estos vinos, es la que tiene una repercusión mayor en la concentración global de estos compuestos. 


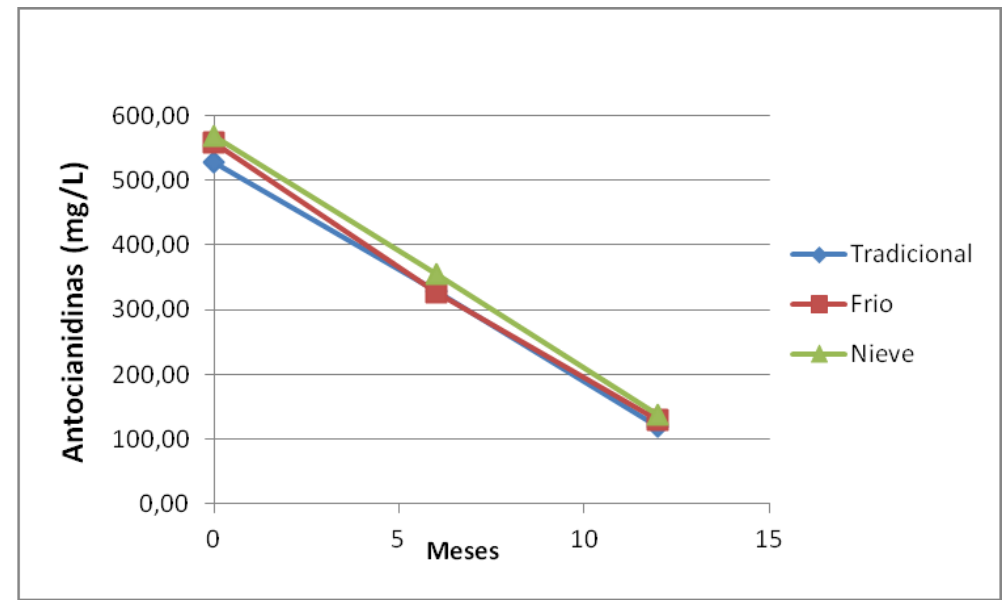

Gráfico 6.61. Evolución de la suma de las antocianidinas durante el periodo de conservación de los vinos en función de las distintas técnicas de vinificación ensayadas.

En el gráfico 6.62 aparece representada la evolución de la suma de las antocianidinas en función de la microoxigenación, observándose como a los 6 meses de conservación de los vinos la aplicación de acetaldehído ha provocado una mayor disminución en la concentración de estos compuestos (tabla 6.31), pero al finalizar el periodo de conservación, estas diferencias han desaparecido (tabla 6.39), tal como observamos para la concentración de malvidina.

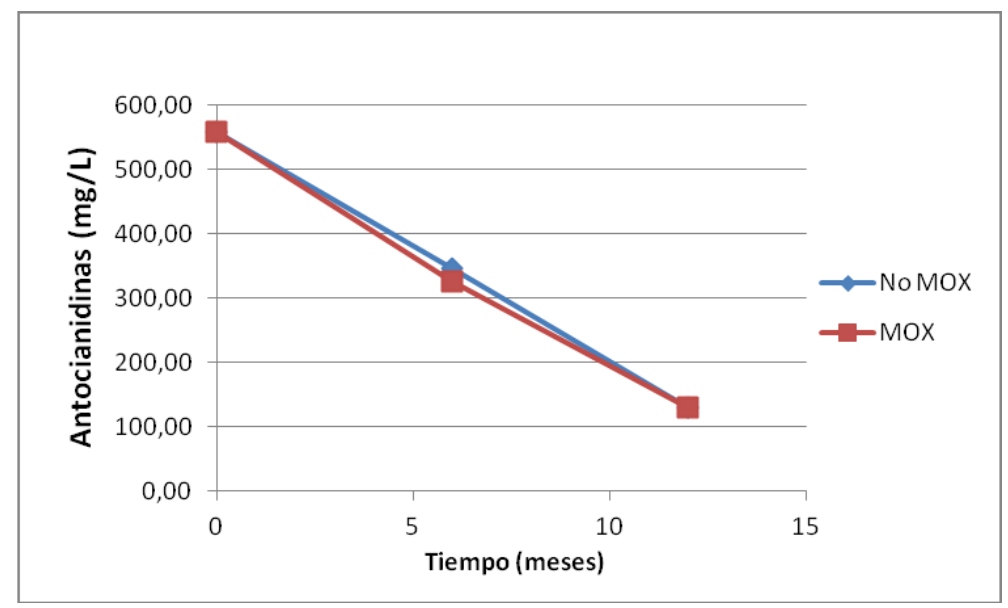

Gráfico 6.62. Evolución de la concentración de la suma de antocianidinas durante el periodo de conservación de los vinos en función de la microoxigenación

\subsubsection{EVOLUCIÓN DE LA CONCENTRACIÓN DE LOS DERIVADOS DE ANTOCIANOS}

La evolución de la concentración de los derivados de antocianos en función de los distintos copigmentos adicionados aparece representada en el gráfico 6.63, observándose una disminución progresiva en la concentración de estos compuestos. 


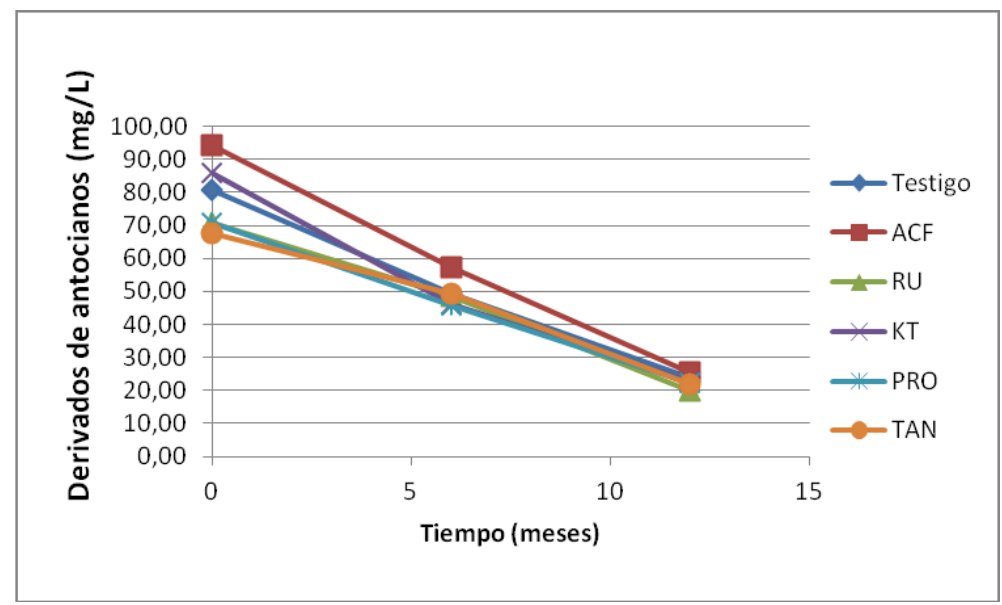

Gráfico 6.63. Evolución de los derivados de antocianos durante el periodo de conservación de los vinos en función de los distintos copigmentos adicionados.

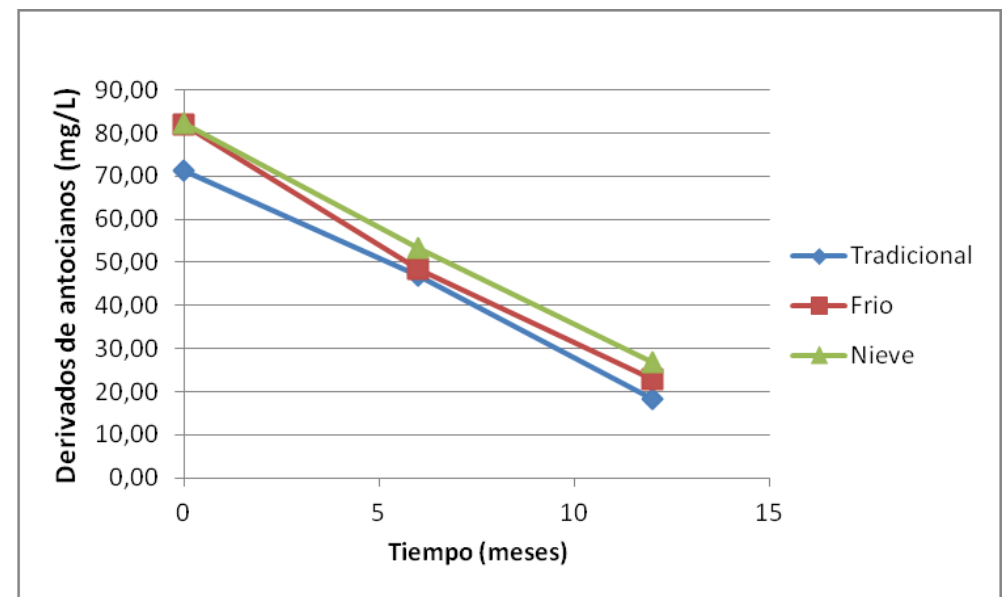

Gráfico 6.64. Evolución de la concentración de los derivados de antocianos durante la conservación en función de las diferentes técnicas de vinificación ensayadas.

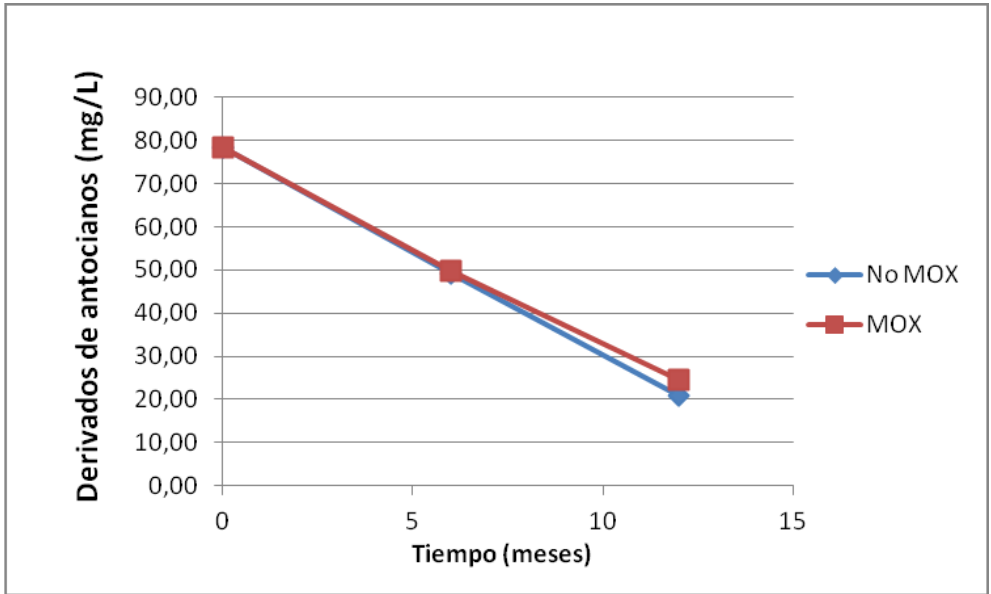

Gráfico 6.65. Evolución de la concentración de los derivados de antocianos durante la conservación de los vinos en función de la microoxigenación. 
Los vinos adicionados del copigmento ácido cafeico son los que presenta las mayores concentraciones con diferencias significativas a lo largo de la conservación de los vinos (tablas 6.24, 6.29, 6.37). La participación de este ácido fenólico en las reacciones de esterificación con los antocianos habrá sido probablemente la responsable del comportamiento observado (Bloomfield et al., 2003; Eiro y Heinonen, 2002)

En el gráfico 6.64 aparece representada la evolución de la concentración de los derivados de antocianos en función de las distintas técnicas de vinificación ensayadas, observándose como las técnicas prefermentativas presentan las mayores concentraciones para estos compuestos con diferencias significativas durante toda la evolución de los vinos (tablas 6.25, 6.30, 6.38), siendo la nieve carbónica la técnica que presenta los mejores resultados.

En el gráfico 6.65 podemos apreciar como la microoxigenación ha dado lugar a una mayor concentración de derivados de antocianos, con diferencias significativas al final del periodo de conservación de los vinos (tabla 6.39), al contrario de lo observado para los antocianos totales decolorables y para la malvidina y las otras antocianinas. Esto podría indicar que la esterificación de las antocianidinas las protege contra la decoloración y las pérdidas por oxidación y precipitación.

\subsubsection{EVOLUCIÓN DE LA CONCENTRACIÓN TOTAL DE ANTOCIANOS}

El gráfico 6.66 muestra la concentración total de antocianos en función de los distintos copigmentos adicionados. Podemos observar como una vez concluida la fermentación, son los vinos adicionados de los copigmentos ácido cafeico y catequina los que presentan las mayores concentraciones de antocianos (tabla 6.24), probablemente debido a una mayor reactividad de estos copigmentos con los antocianos extraídos durante la fermentación, pero a medida que se produce la disminución de los antocianos durante la conservación, estas diferencias van desapareciendo (tablas 6.30 y 6.38). Este comportamiento es semejante al observado para las distintas fracciones antociánicas determinadas.

En la gráfica 6.67 se observa la evolución de la concentración total de antocianos en función de las técnicas de vinificación aplicadas, observándose que una vez concluida la fermentación alcohólica es superior en los vinos que se han sometido a maceración prefermentativa, independientemente de que sea en frío o con nieve carbónica (tabla 6.25), pero en el transcurso de la conservación, los vinos sometidos a maceración en frío tienen una mayor un caída de antocianos (tabla 6.31), correspondiendo a los vinos macerados con nieve carbónica la concentración superior de antocianos, a los elaborados con maceración en frío la intermedia, y a los de vinificación tradicional la más baja (tabla 6.39). 


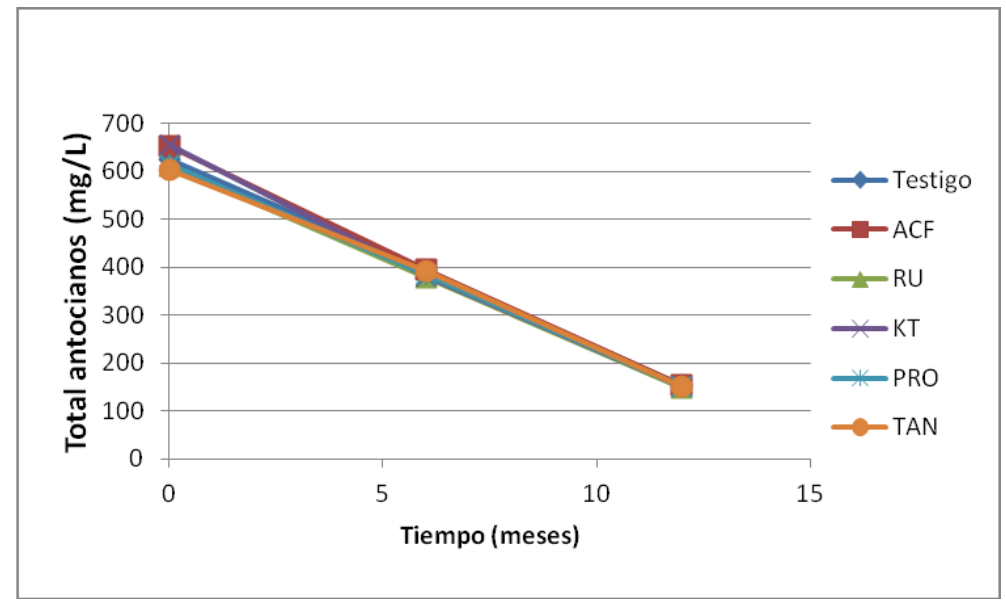

Gráfico 6.66. Evolución de la concentración total de antocianos durante la conservación de los vinos en función de los copigmentos adicionados

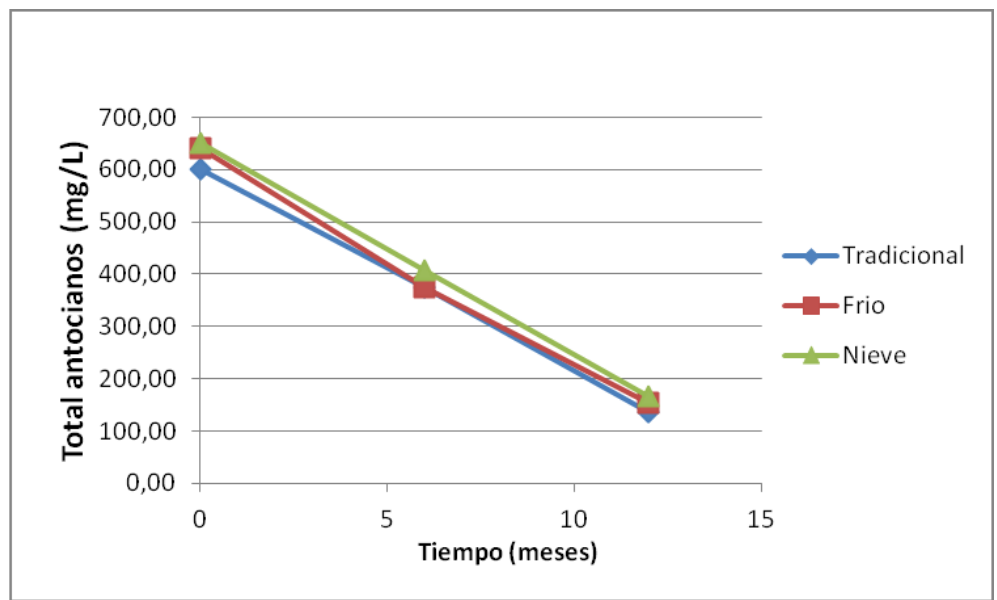

Gráfico 6.67. Evolución de la concentración total de antocianos durante la conservación en función de las diferentes técnicas de vinificación ensayadas.

La microoxigenación da lugar a una pérdida superior de antocianos en los primeros meses (tabla 6.32), no observándose diferencias a los 12 meses entre los vinos microoxigenados y los no microoxigenados (tabla 6.40).

De todas las técnicas ensayadas, la maceración prefermentativa se presenta como la más adecuada para mantener los antocianos en los vinos, tanto los decolorables, como las distintas antocianidinas, la concentración de los derivados de antocianos y en conclusión, la concentración total de antocianos; siendo la maceración prefermentativa con nieve carbónica la que da lugar a los valores superiores. Este efecto ha sido observado con anterioridad en otros estudios, atribuyéndose a la mayor extracción de polifenoles que tiene lugar en fase prefermentaiva (Gil-Muñoz et al., 2009; Koyama et al., 2007; Gordillo et al., 2010), a la mayor reactividad de los compuestos extraídos (Álvarez et al., 2008; Boulton, 2001), y a la desestructuración celular causado por la nieve carbónica, que potencian la extracción de estos compuestos (Heredia et al., 2010). 


\subsubsection{EVOLUCIÓN DEL PORCENTAJE DEL COLOR QUE CORRESPONDE A LAS REACCIONES DE COPIGMENTACIÓN}

En el gráfico 6.68 se recoge la evolución del color debido a los antocianos copigmentados, en función de los copigmentos adicionados. Los vinos adicionados de rutina muestran posteriormente a la fermentación, los mayores porcentajes de copigmentación (tabla 6.24), pero a lo largo de la conservación, se van rompiendo estas uniones, de tal forma que al cabo de 12 meses solo se encuentran diferencias significativas para el copigmento ácido cafeico, cuyos vinos muestran los menores porcentajes de color debido a la copigmentación (tablas 6.30, 6.38).

La adición de rutina se presenta como una técnica adecuada para favorecer la copigmentación en estos vinos (Davies y Mazza, 1993; Baranac et al., 1996 y 1997; Malien-Aubert, 2001; Boulton, 2001; Schwarz et al., 2005, Gómez-Míguez et al., 2006; Kunsági-Máté et al., 2006; Lambert et al., 2010), aunque en nuestro estudio su efecto está limitado a unos pocos meses posteriores al embotellado. Por el contrario la adición de ácido cafeico tiene un efecto copigmentante bajo, ya que debido a su pequeño tamaño, no puede estabilizar completamente la carga positiva del catión flavilium, mostrando un efecto copigmentante más debil que la rutina o la catequina (Schwarz et al., 2005; Gómez-Míguez et al., 2006; Malien-Aubert et al., 2007; Lambert et al., 2010). La rotura de estos copigmentos, con la posterior pérdida de estos antocianos, puede justificar la caída de color observada a partir de los seis meses de conservación.

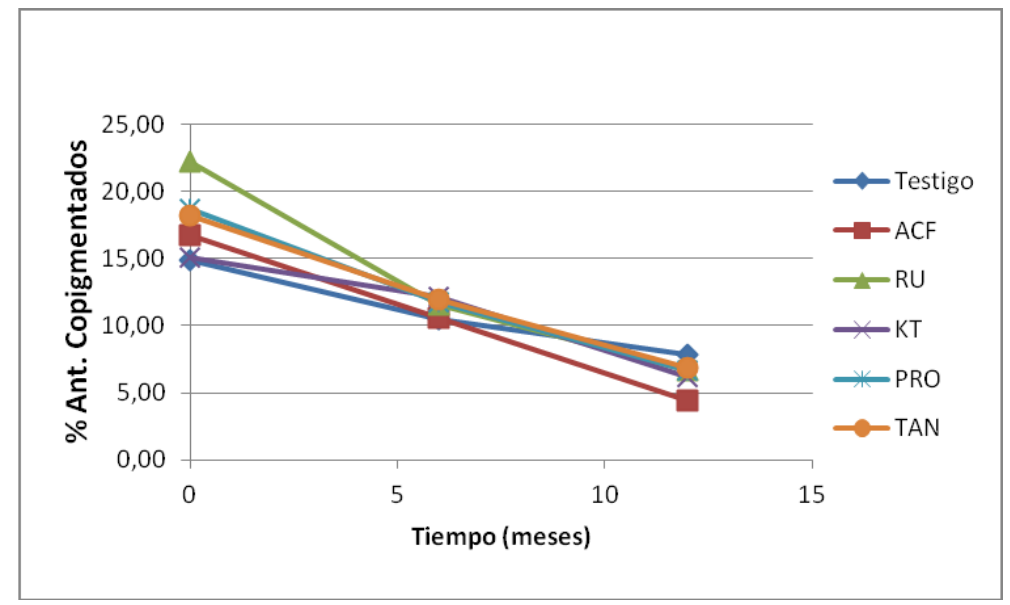

Gráfico 6.68. Evolución del color debido a los antocianos copigmentados durante la conservación de los vinos en función de los distintos copigmentos adicionados

Las técnicas de vinificación no influyen en el porcentaje del color que corresponde a los antocianos copigmentados (tablas 6.25, 6.31 y 6.39), a diferencia de lo observado la cosecha de 2006, cuyos vinos muestran a lo largo del proceso de conservación la influencia de las técnicas de maceración prefermentativa, que presentan valores significativamente superiores a la vinificacion tradicional (gráfico 6.20).

La microoxigenación mantiene el color de los antocianos copigmentados durante los primeros meses (tabla 6.32), pero al final de la conservación no se observan diferencias entte los distintos vinos elaborados (tabla 6.40). 


\subsubsection{EVOLUCIÓN DEL PORCENTAJE DEL COLOR QUE CORRESPONDE A LOS ANTOCIANOS LIBRES}

El gráfico 6.69 muestra la evolución del porcentaje del color que corresponde a los antocianos en su forma libre o no polimerizada, observándose una disminución a lo largo de la conservación hasta alcanzarse valores próximos al 30\% transcurridos 12 meses desde el embotellado.

Los vinos adicionados del copigmento ácido cafeico presentan a los 6 y 12 meses de la evolución valores significativamente más bajos de color debido a los antocianos libres (tablas 6.30, 6.38). Este comportamiento también se observa en el color debido a los antocianos copigmentados, lo que implica que durante la conservación de los vinos el ácido cafeico está incrementando notablemente el color debido a la polimerización de sus antocianos.

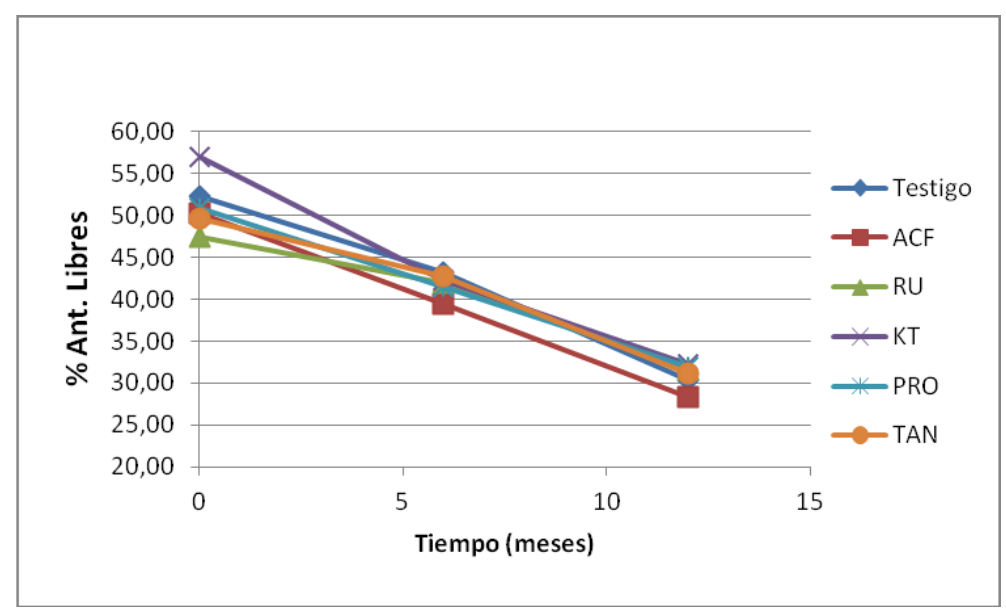

Gráfico 6.69. Evolución del color debido a los antocianos libres durante la conservación de los vinos en función de los distintos copigmentos adicionados.

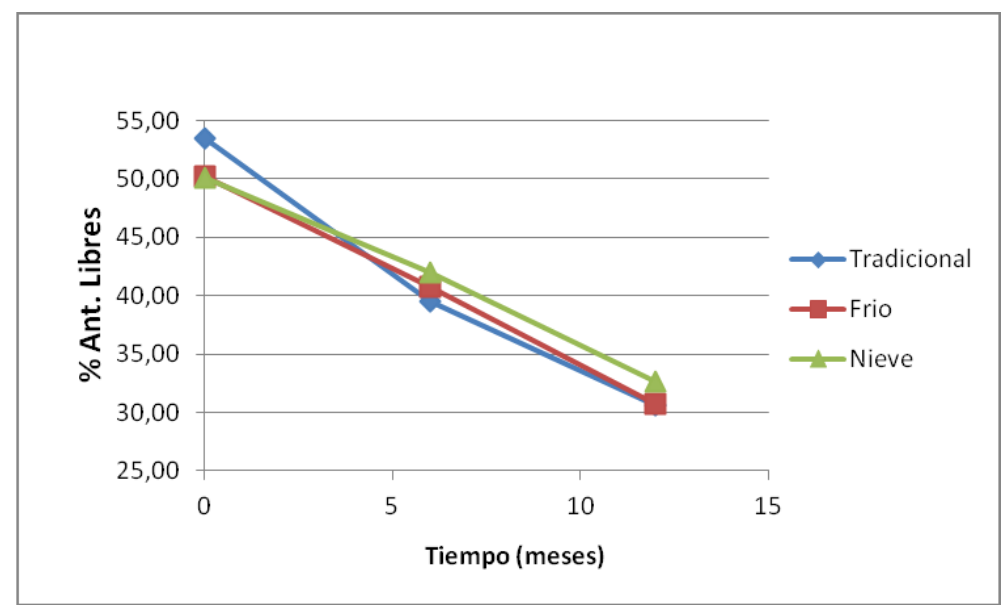

Gráfico 6.70. Evolución del color debido a los antocianos libres durante la conservación de los vinos en función de las técnicas de vinificación ensayadas.

La maceración prefermentativa con aplicación de nieve carbónica aparece como la técnica que presenta un mayor porcentaje del color debido a los antocianos en su forma libre (gráfico 6.70), mostrando diferencias significativas a los 6 y 12 meses de la conservación de los vinos (tablas 6.31 y 6.39). Sin embargo, posteriormente a la 
fermentación, es la vinificación tradicional la técnica que presenta el mayor porcentaje de antocianos libres, que aún no han intervenido en otras reacciones (Gordillo et al., 2010; Heredia et al., 2010).

En el gráfico 6.71 se observa representada la evolución del color que corresponde a los antocianos en su forma libre a lo largo de la conservación de los vinos. El hecho de no microoxigenar ha mantenido un mayor porcentaje del color debido a los antocianos en su forma libre, incrementándose las diferencias a medida que transcurre la evolución de los vinos en las botellas (tablas 6.32 y 6.40), en detrimento de la otras posibles reacciones de estabilización de estos antocianos.

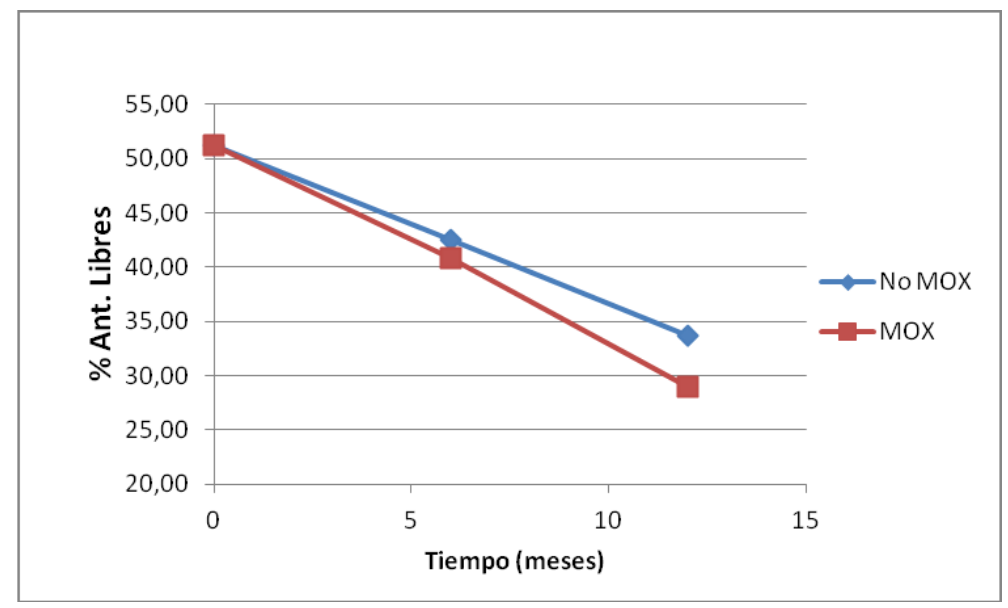

Gráfico 6.71. Evolución del color debido a los antocianos libres durante el periodo de conservación de los vinos en función de la aplicación de la microoxigenación.

\subsubsection{EVOLUCIÓN DEL PORCENTAJE DEL COLOR QUE CORRESPONDE A LOS ANTOCIANOS POLIMERIZADOS}

Los vinos adicionados de ácido cafeico muestran durante la conservación un mayor porcentaje del color debido a polimerizaciones (gráfico 6.72), con diferencias significativas a lo largo del proceso (tablas 6.24, 6.30, 6.38), incrementándose estas diferencias con el tiempo; tal como observamos en la cosecha 2006.

La aplicación de ácido cafeico podría ser una técnica adecuada para favorecer la polimerización entre antocianos y taninos, incrementándose, por lo tanto la estabilidad del color en el tiempo. Hemos observado anteriormente su capacidad de esterificación con los derivados de antocianos, que junto con su facilidad para polimerizar a éstos con los taninos, va a contribuir a mantener los antocianos en el vino, y por tanto a mantener su color, tal como observamos en la intensidad colorante (tabla 6.51).

En el gráfico 6.73 aparece representada la evolución del porcentaje del color debido a las reacciones de polimerización en función de las técnica de vinificación ensayadas, puediendo observarse como a medida que transcurre el tiempo, el color debido a estas reacciones se incrementa, alcanzando valores al finalizar el proceso superiores al 60\%, lo cual pone de manifiesto la importancia de estas reacciones en el color de los vinos sometidos a un proceso de envejecimiento (Castañeda-Ovando et al., 2009; Cheynier et al., 2006, Malien-Aubert et al., 2002). 


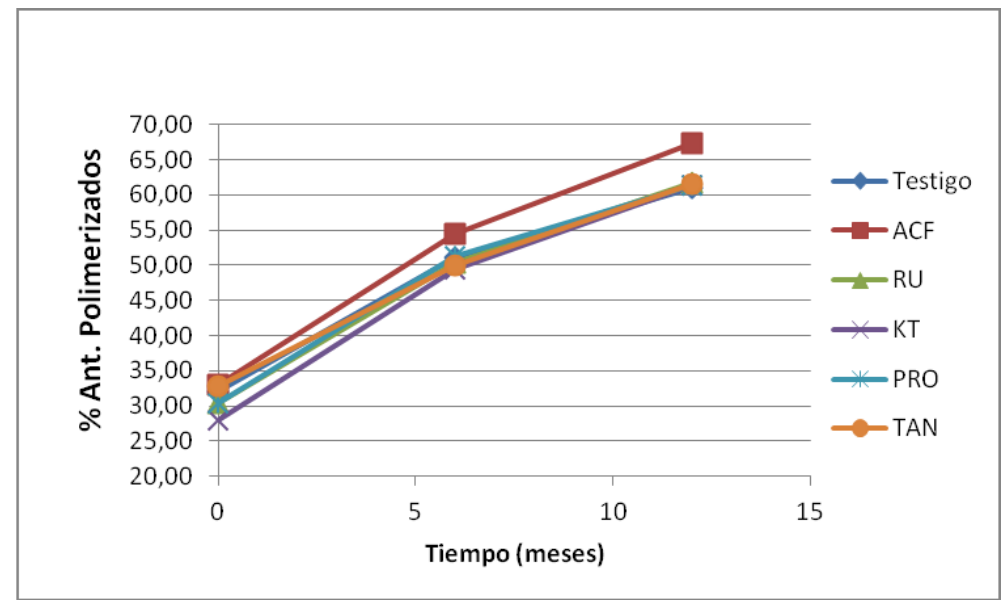

Gráfico 6.72. Evolución del color debido a los antocianos polimerizados durante el periodo de conservación de los vinos en función de los copigmentos adicionados.

Únicamente, en el análisis realizado posteriormente al embotellado se han encontrado diferencias significativas a favor de las técnicas de maceración prefermentativa (tabla 6.25), aunque posteriormente estas diferencias desaparecen (tablas 6.31, 6.39). La mayor extracción fenólica durante la fase prefermentativa podría contribuir a que las reacciones de polimerización fuesen más precoces e intensas, presentándose como una técnica adecuada para incrementar de forma rápida la estabilidad del color de los vinos jóvenes.

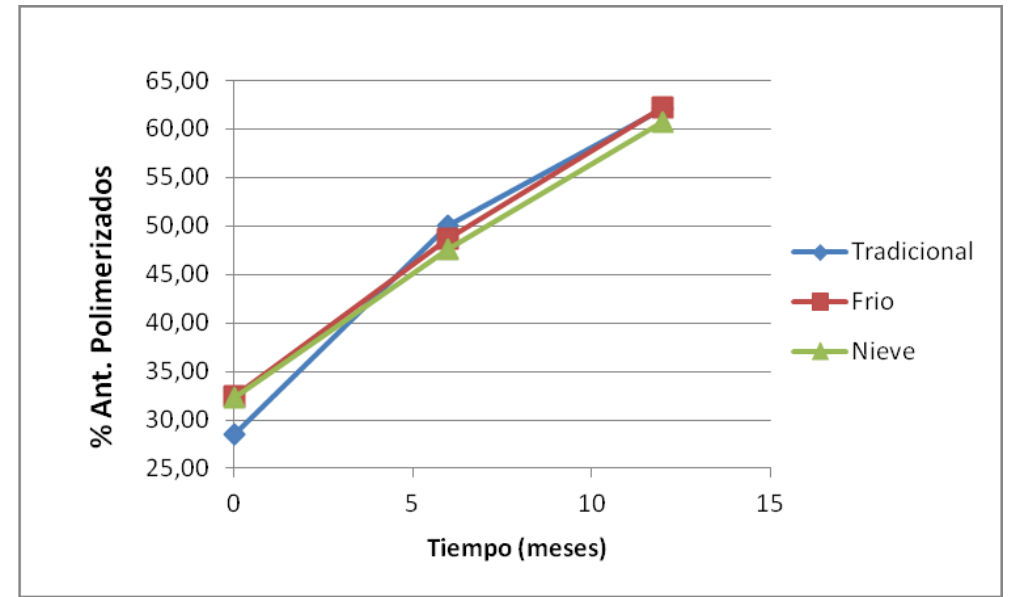

Gráfico 6.73. Evolución del color debido a los antocianos polimerizados durante el periodo de conservación de los vinos en función las técnicas de vinificación ensayadas.

La aplicación controlada de acetaldehído ha provocado un incremento en el porcentaje del color debido a las reacciones de polimerización (gráfico 6.74), con diferencias significativas durante la conservación de los vinos en botella (tablas 6.31, 6.39).

Este comportamiento indica como la aplicación de esta técnica afecta a la concentración y al estado de los antocianos en el vino, influyendo decisivamente sobre el color (Wirth et al., 2010; Cano-López et al., 2006, 2007, 2010; Rayne et al., 2008; González-del Pozo et al., 2010; Pérez-Magariño et al., 2007; Tao et al., 2007; Cejudo- 
Bastante et al., 2010, 2011; Sartini et al., 2007), y ha sido observado también en los vinos de 2006.

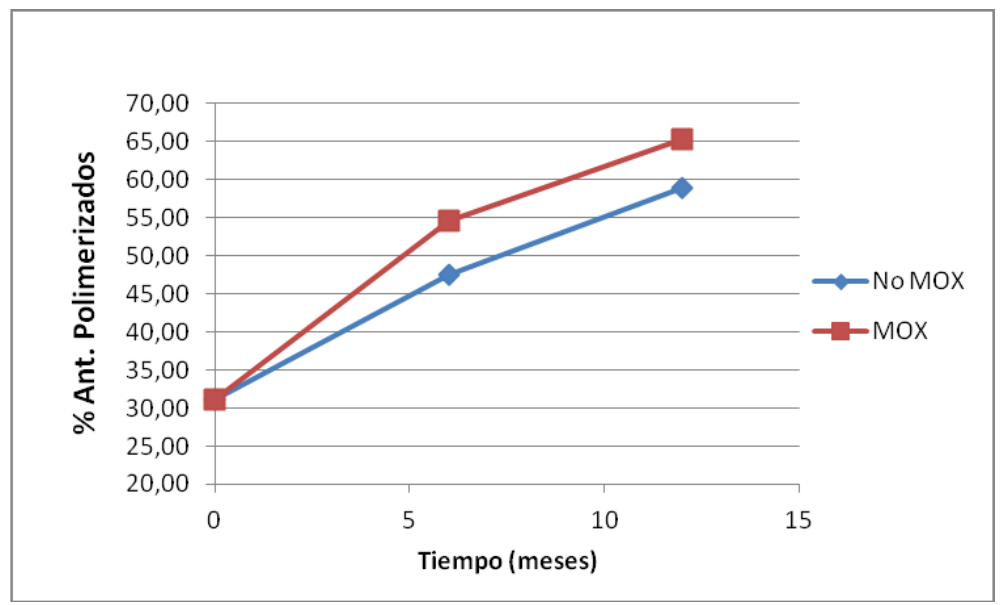

Gráfico 6.74. Evolución del color debido a los antocianos polimerizados durante el periodo de conservación de los vinos en función la aplicación de la microoxigenación.

\subsubsection{EVOLUCIÓN DEL ÍNDICE DE PVPP}

En el gráfico 6.75 aparece representada la evolución del índice de PVPP, que mide las uniones entre antocianos y taninos, durante la conservación de los vinos.

Tal como era de esperar, son los vinos adicionados de ácido cafeico los que presentan el mayor grado de polimerización de los antocianos con los taninos a los $6 \mathrm{y}$ 12 meses de permanencia de los vinos en botella (tablas 6.30, 6.38), que va acompañado de un aumento significativo de la intensidad colorante (gráfica 6.51). Además, el gráfico muestra un incremento muy elevado de estas reacciones durante los primeros meses de conservación, de forma similar a lo observado en la cosecha de 2006.

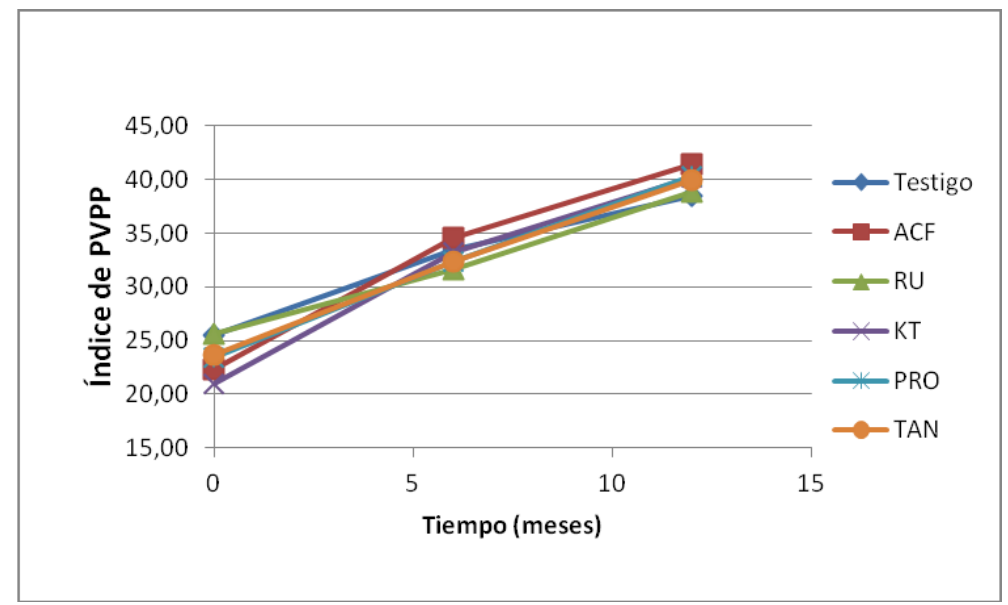

Gráfico 6.75. Evolución del índice de PVPP durante el periodo de conservación de los vinos en función de los distintos copigmentos adicionados. 
La adición de rutina produce un incremento de las reacciones de polimerización entre antocianos y taninos durante la vinificación y los primeros meses de la conservación, pudiendo ser la causa del incremento de intensidad colorante observado en estos vinos durante ese período, pero en los meses siguientes su efecto se minimiza y va acompañado de una caída progresiva de la intensidad colorante, hasta valores similares a los observados para los otros copigmentos al cabo de 12 meses de conservación (tabla 6.38). Esta caída no ha sido observada en los vinos de la cosecha 2006, en los cuales la adición de rutina es la técnica que más contribuye a mantener el color tanto en vino jóvenes como envejecidos, mientras que en 2007 esta técnica solo parece adecuada para incrementar el color de los vinos jóvenes, siendo la adición de ácido cafeico la recomendada para los vinos que van a ser sometidos a envejecimiento.

Las técnicas de vinificación no influyen en el grado de polimerización de antocianos y taninos, como tampoco afectó al color debido a los antocianos polimerizados, a lo largo de la conservación. Esta situación también fue observada en la cosecha anterior.

La microoxigenación provoca un incremento de las uniones entre antocianos y taninos (gráfico 6.76), con respecto a los vinos no adicionados de acetaldehído; aunque con diferencias significativas únicamente cuando los vinos fueron analizados al final de su periodo de conservación (tabla 6.40). Este comportamiento es similar al observado para el color debido a los antocianos polimrizados en las dos añadas estudiadas, pero difiere del observado en el índice de PVPP en 2006, ya que en estos vinos las diferencias fueron minimizándose durante la conservación (gráfico 6.27).

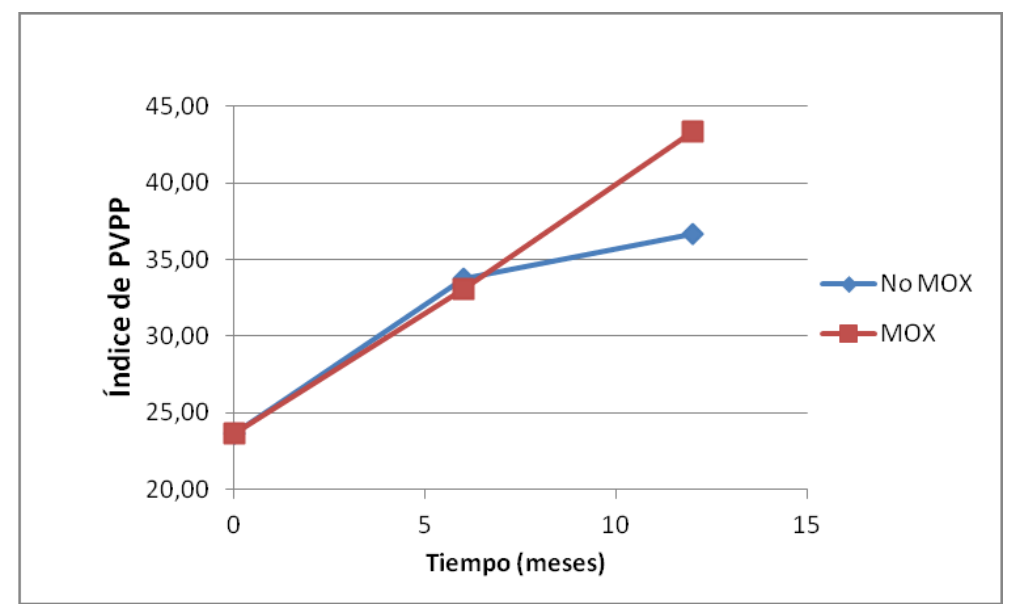

Gráfico 6.76. Evolución del índice de PVPP durante el periodo de conservación de los vinos en función de la aplicación de la microoxigenación.

\subsubsection{EVOLUCIÓN DEL ÍNDICE DE FOLIN}

La representación de la evolución del índice de Folin a lo largo de la conservación de los vinos aparece en el gráfico 6.77, mostrando una ligera disminución de este parámetro a lo largo del envejecimiento debido a la precipitación de material fenólico causado por la pérdida de parte de la materia colorante y tánica. 


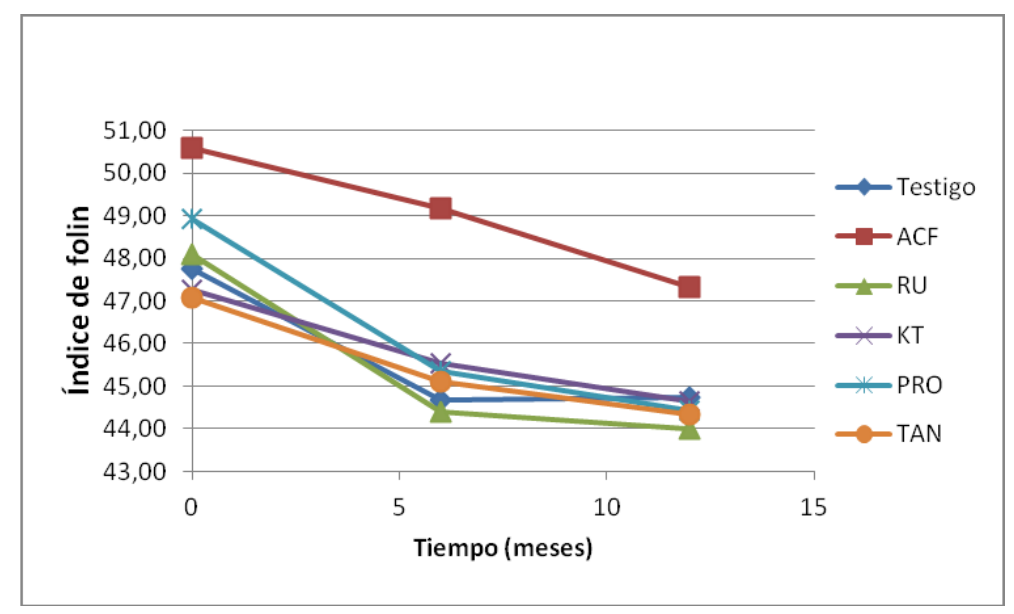

Gráfico 6.77. Evolución del índice de Folin durante el periodo de conservación de los vinos en función de los distintos copigmentos adicionados.

A lo largo del proceso de conservación los vinos adicionados de ácido cafeico presentan las mayores concentraciones de polifenoles totales (tablas 6.24, 6.30, 6.38), mostrándose como el mejor copigmento frente a este parámetro. La adición de ácido cafeico podría ser una técnica adecuada para incrementar y mantener la concentración fenólica de los vinos. Este comportamiento también se observó en 2006.

No se observa influencia de las técnicas de vinificación en la concentración de polifenoles totales, en cambio la aplicación de acetaldehído ha ocasionado una mayor pérdida de éstos en el transcurso de la conservación (tablas 6.32 y 6.40), tal y como se observa en el gráfico 6.78. La participación del acetaldehído en la formación de polimeros de gran tamaño molecular, y su posterior preciptación, pueden ser la causa de este comportamiento, que no ha sido observado en la cosecha anterior.

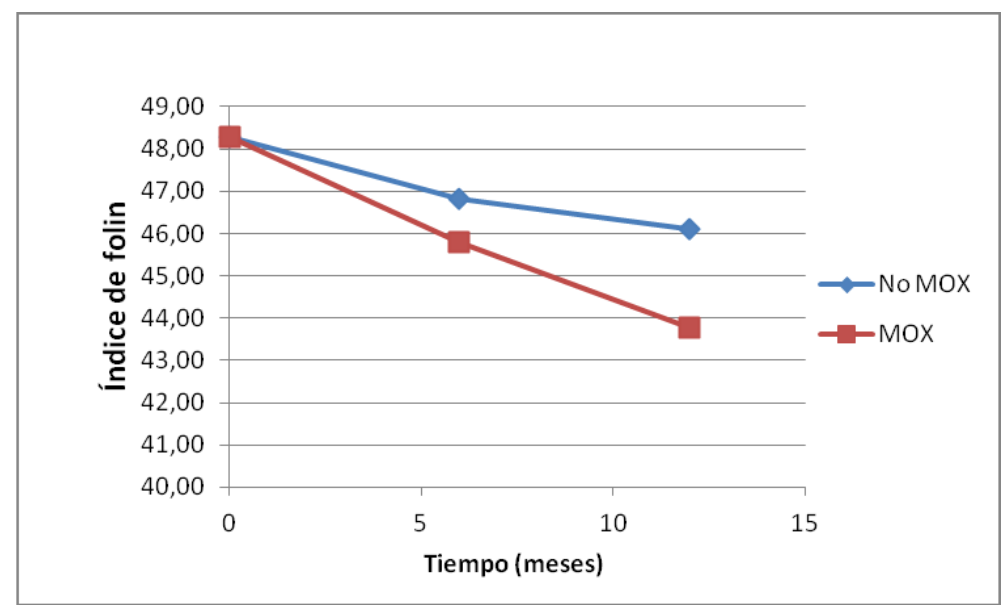

Gráfico 6.78. Evolución del índice de Folin durante el periodo de conservación de los vinos en función de la aplicación de la microoxigenación. 


\subsubsection{EVOLUCIÓN DE LA CONCENTRACIÓN DE LOS ÁCIDOS FENÓLICOS}

La evolución de los ácidos fenólicos a lo largo de la conservación (gráfico 6.79) muestra como estos compuestos disminuyen de forma progresiva, observándose el mismo comportamiento que para los principales compuestos fenólicos presentes en los vinos. Además se observa, tal como era de esperar, que los vinos adicionados del copigmento ácido cafeico son los que presentan una concentración significativamente superior a lo largo de todo el proceso, aunque las diferencias van disminuyendo a medida que transcurre la conservación (tablas 6.24, 6.30 y 6.38).

En función de los resultados observados es necesario destacar como la elevada concentracion de ácidos fenólicos, suponemos que mayoritariamente de acido cafeico, ha provocado, en primer lugar, un incremento en la concentración de antocianos esterificados (derivados de antocianos), favoreciéndose, en segundo lugar, las reacciones de los antocianos con los taninos y el porcentaje de color debido a polimerizaciones, y presentando, finalmente, estos vinos una mayor intensidad colorante, así como una mejor concentracion fenólica. El copigmento ácido cafeico no ha favorecido las reacciones de copigmentación, pero ha influido decisivamente tanto sobre el color, como sobre la composicion fenólica de los vinos objeto de estudio (Gauche et al., 2010; Gómez-Miguez et al., 2006, Rein, 2005).

Ni las técnicas de vinificación ni la microoxigenación afectan a la concentración de ácidos fenólicos en los vinos (tablas 6.25, 6.31, 6.39, 6.32 y 6.40).

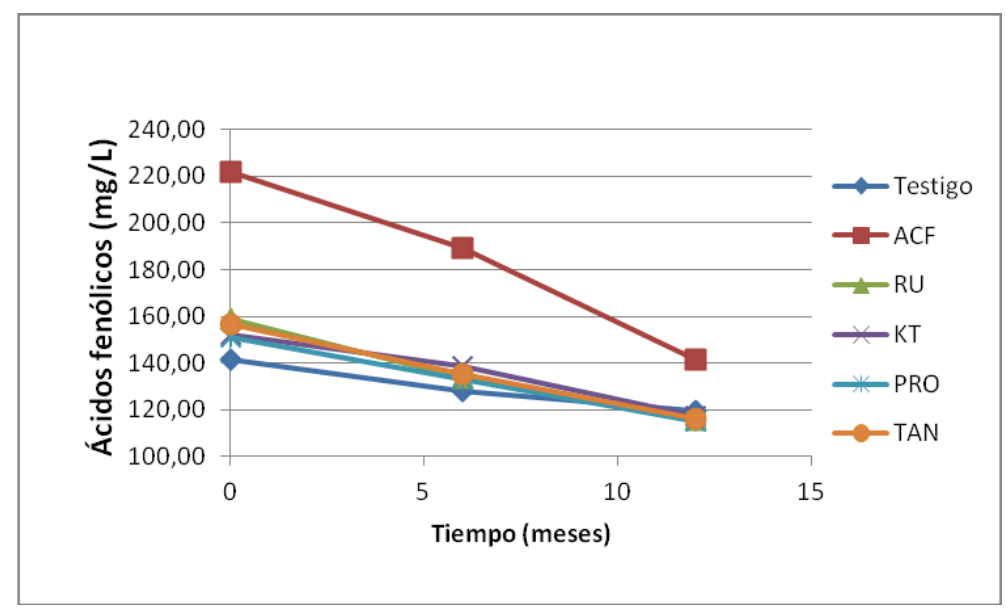

Gráfico 6.79. Evolución de la concentración de ácidos fenólicos durante la conservación de los vinos en función de los distintos copigmentos adicionados

\subsubsection{EVOLUCIÓN DE LA CONCENTRACIÓN DE FLAVONOLES}

Los vinos adicionados del copigmento rutina son los que presentan una mayor concentración de estos compuestos durante todo el proceso de conservación (tablas $6.24,6.31,6.39$ ). A lo largo de la evolución se observa una disminución progresiva en la concentración de estos compuestos (gráfico 6.80). Dado su elevada capacidad para actuar como copigmentos, que quedó patente en el incremento del color debido a la 
copigmentación, los vinosadicionados de rutina mantienen muy bien el color de los vinos, tal como observamos en los de la cosecha 2006 y 2007.

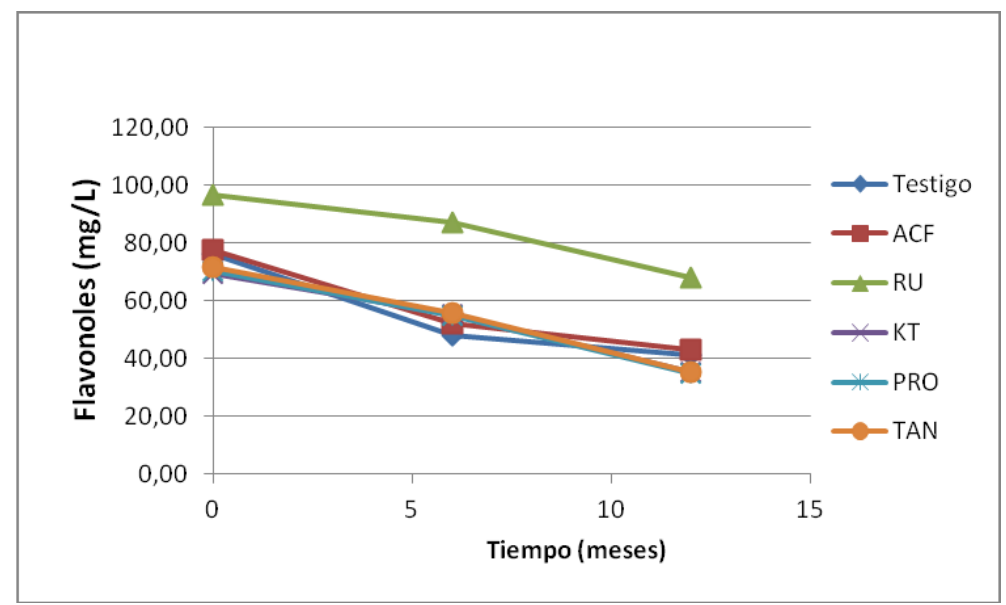

Gráfico 6.80. Evolución de la concentración de flavonoles durante el periodo de conservación de los vinos en función de los distintos copigmentos adicionados.

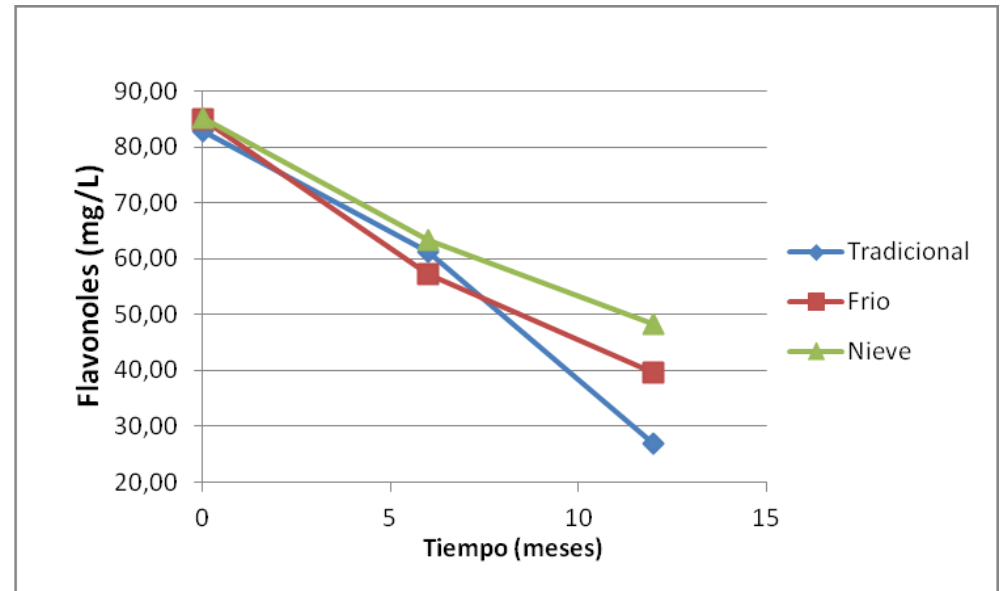

Gráfico 6.81. Evolución de la concentración de flavonoles durante el periodo de conservación de los vinos en función de las técnicas de vinificación ensayada.

El gráfico 6.81 muestra la evolución de la concentración de flavonoles, en función de las técnicas de vinificación ensayadas. Únicamente al final de la evolución los vinos macerados prefermentativamente en frío muestran diferencias significativas (tabla 6.39), siendo los adicionados de nieve carbónica de forma prefermentativa los que muestran las mayores concentraciones de flavanoles. Posiblemente la participación de parte de ellos en reacciones de copigmentación con los antocianos haya permitido una mayor presencia en los vinos al final de los 12 meses de permanencia en botella.

\subsubsection{EVOLUCIÓN DE LA CONCENTRACIÓN DE 3-FLAVANOLES}

Se observa un descenso de la concentración de 3-flavanoles durante la conservación de los vinos en botella (gráfico 6.82). Los vinos adicionados de catequina son los que presentan la mayor concentración de 3-flavanoles, tal como era de esperar, pero esta diferencia deja de ser significativa a los 12 meses (tabla 6.38). 


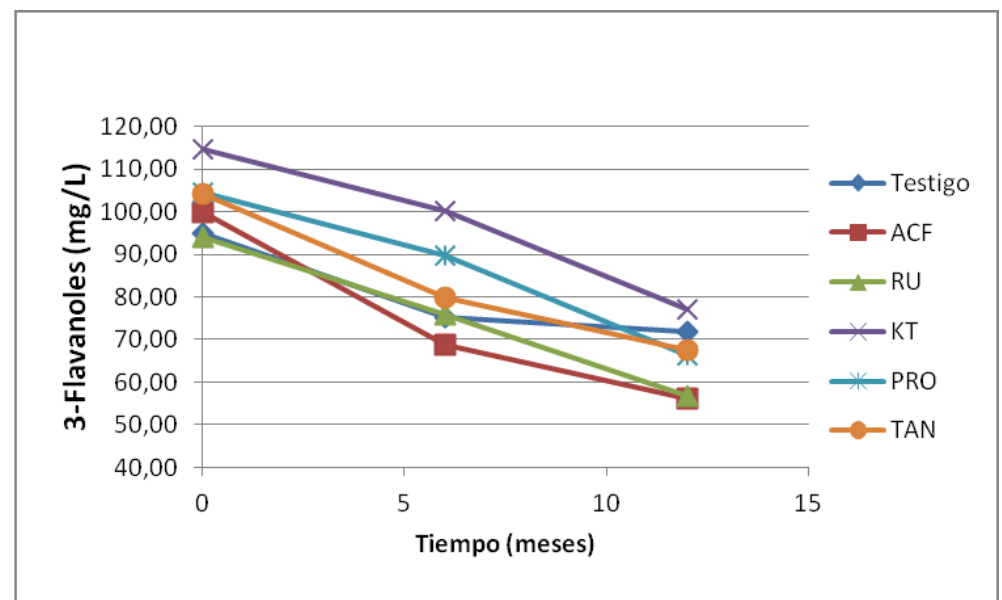

Gráfico 6.82. Evolución de la concentración de 3-flavanoles durante el periodo de conservación de los vinos en función de los distintos copigmentos adicionados.

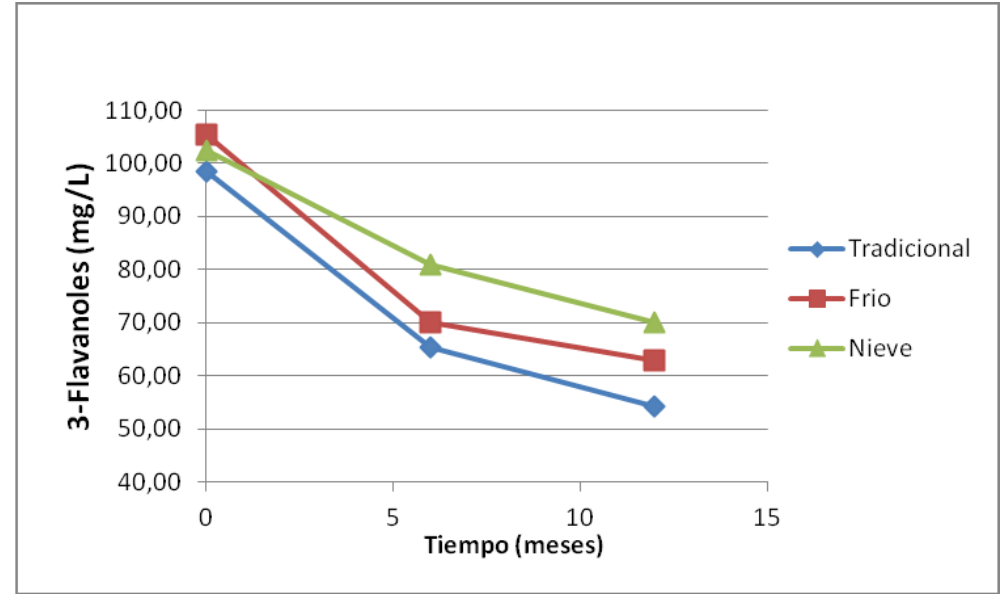

Gráfico 6.83. Evolución de la concentración de 3-flavanoles durante la conservación de los vinos en función de las distintas técnicas de vinificación ensayadas.

La maceración prefermentativa en frío permite una mejor conservación de los flavanoles a lo largo del periodo de conservación de los vinos. En el gráfico $\mathbf{6 . 8 3}$ podemos observar como la aplicación de nieve carbónica da lugar a los mejores resultados, con diferencias significativas a los 6 y 12 meses (tablas 6.31 y 6.39) con respecto a la vinificación tradicional; además, al finalizar la conservación de los vinos, la maceración con a bajas temperaturas muestra también diferencias significativas respecto a la vinificación tradicional. La maceración prefermentativa parece no influir en la extracción de estos compuestos durante la fermentación, pero contribuye a mantener los 3-flavanoles en estado monómero durante un tiempo más prolongado, afectando a las propiedades sensoriales de los vinos (Zini et al., 2003; Soto-Vázquez et al., 2010).

La microxigenación, en cambio, no afecta significativamente al contenido de 3flavanoles en los vinos (tablas 6.32 y 6.40). 


\subsubsection{EVOLUCIÓN DE LA CONCENTRACIÓN CATEQUINAS}

El gráfico 6.84 muestra la evolución de la concentración de catequinas durante los 12 meses de conservación de los vinos en botella, observándose como aquellos vinos adicionados del copigmento catequina muestran valores superiores a lo largo del proceso de conservación (tablas 6.30 y 6.38), sin que se encuentren diferencias en función del momento de adición de este copigmento (tabla 6.29). Es de destacar que las proantocianidinas adicionadas también contribuyen a mantener más elevada la concentración de catequinas, pero solo con diferencias significativas para la proantocianidina de pepitas a los 12 meses de conservación. La rotura de los polímeros de catequinas que forman las proantocianidinas podría ser la causa de este incremento.

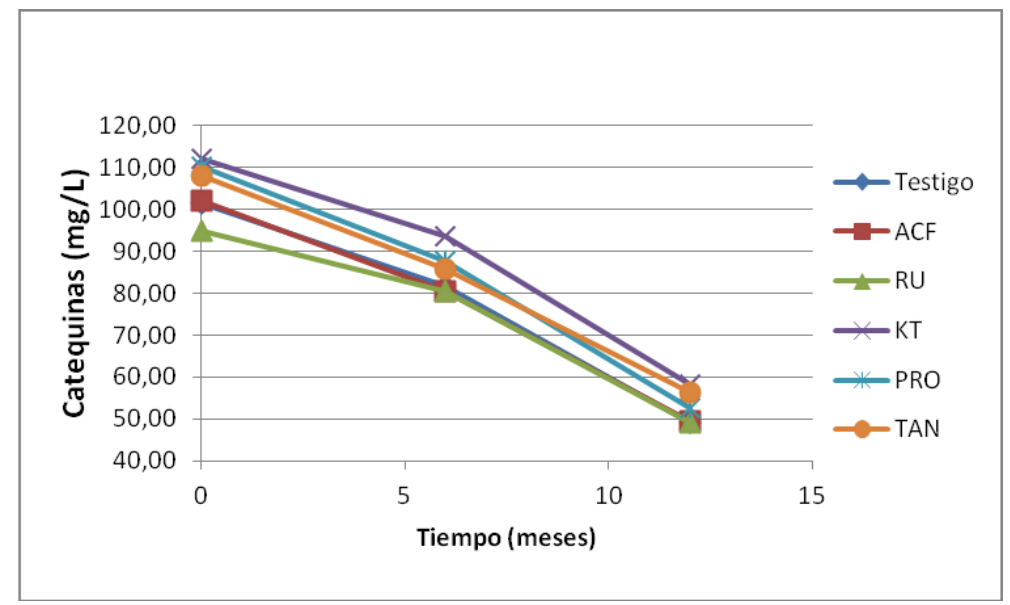

Gráfico 6.84. Evolución de la concentración de catequinas durante el periodo de conservación de los vinos en función de los distintos copigmentos adicionados.

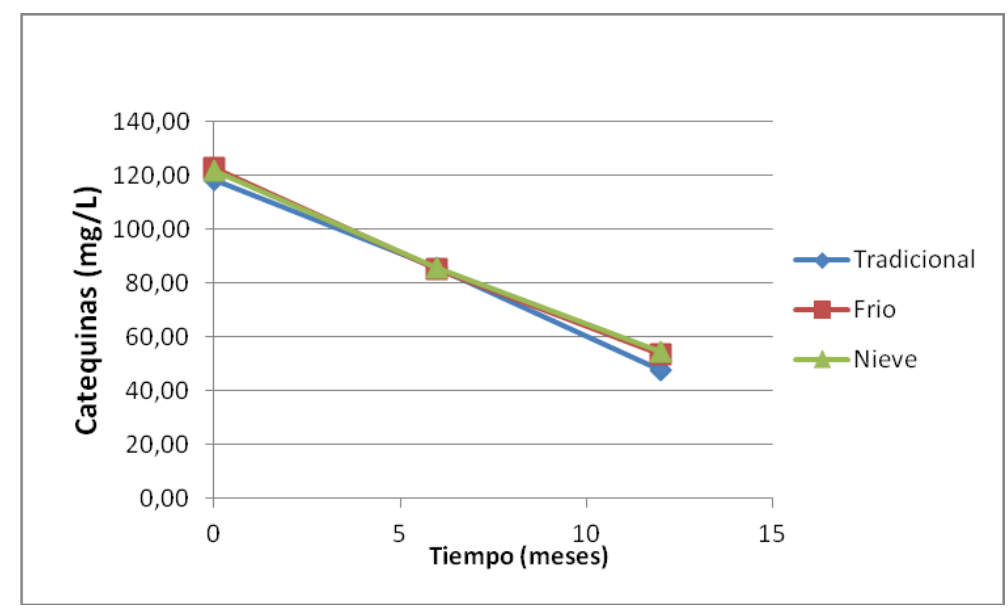

Gráfico 6.85. Evolución de la concentración de catequinas durante el periodo de conservación de los vinos en función de las distintas técnicas de vinificación ensayadas.

En el gráfico 8.85 se observa como al final de la conservación son los vinos sometidos a la maceración prefermentativa en frío, tanto con aplicación de bajas temperaturas como de nieve carbónica, los que presentan una concentración 
significativamente superior de catequinas (tabla 6.39). El efecto de la nieve carbónica también fue observado en los 3-flavanoles, y en la añada 2006 (gráfico 6.31)

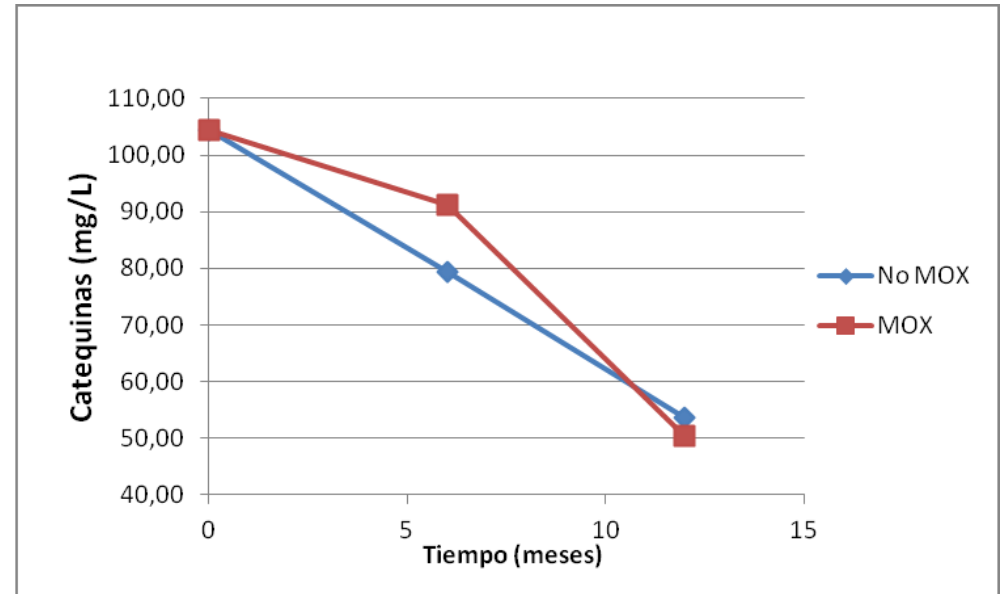

Gráfico 6.86. Evolución de la concentración de catequinas durante el periodo de conservación de los vinos en función de la aplicación de la microoxigenación.

La maceración prefermentativa, tanto en frío como mediante adición de nieve carbónica ha provocado un efecto favorable en estos vinos, ya que contribuye a mantener la concentración de los compuestos antociánicos (antocianos totales decolorables, malvidina, antocianidinas, derivados de antocianos y total de antocianos), la de 3-flavanoles y catequinas, asi como a disminuir el tono de los vinos.

En el gráfico 6.86 aparece representada la evolución de la concentración de catequinas en los vinos elaborados en función de la adición de acetaldehído. La microoxigenación mantiene una mayor concentración de estos compuestos durante los 6 meses de permanencia del vino en botella (tabla 6.32), despareciendo su efecto al final de la conservación (tabla 6.40), debido al incremento de las reacciones de polimerización de estos compuestos monómeros.

\subsubsection{EVOLUCIÓN DEL ÍNDICE DE DMACH}

La evolución del índice de DMACH aparece representada en el gráfico 6.87, donde se observa que después de la fermentación maloláctica son los vinos adicionados del copigmento catequina los que presentan los mayores valores, lo que corresponde a un menor grado de polimerización de taninos. La suplementación de estos compuestos monómeros en los vinos provoca un descenso del grado de polimerización, que se va incrementando durante la conservación hasta valores similares a los observados para los otros copigmentos (tablas 6.24, 6.30 y 6.38). 


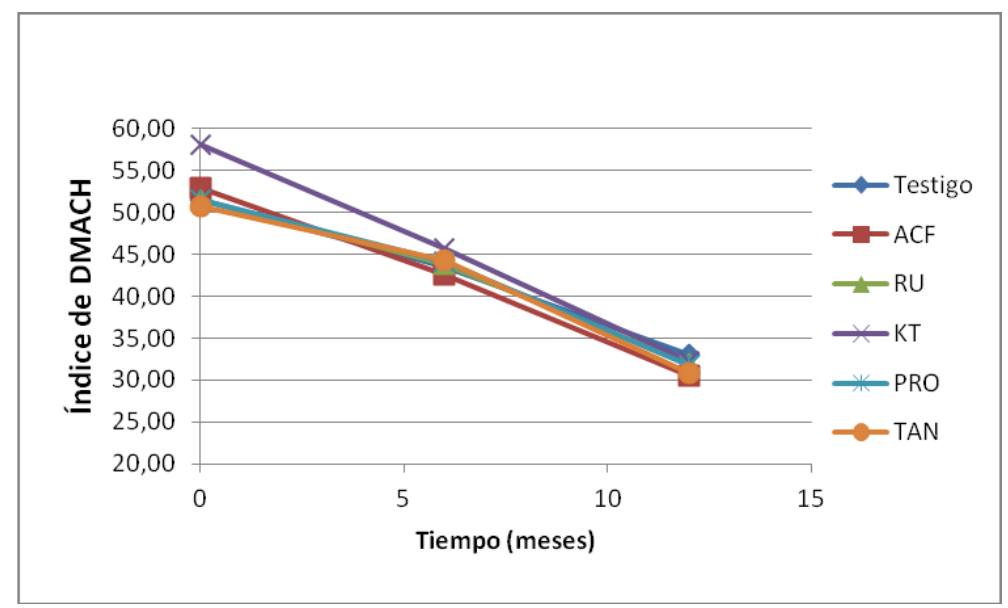

Gráfico 6.87. Evolución del índice de DMACH durante el periodo de conservación de los vinos en función de los distintos copigmentos adicionados.

Los vinos adicionados de acetaldehído muestran inicialmente un valor del índice de DMACH inferior, tal como se observa en el gráfico 6.88, pero a medida que transcurre la conservación, los vinos microoxigenados incrementan sus reacciones de polimerización, no observándose diferencias entre ellos a los 12 meses de conservación (tablas 6.32 y 6.40). La aplicación de esta técnica favorece de forma más evidente las reacciones de polimerización entre antocianos y taninos (gráfico 6.76).

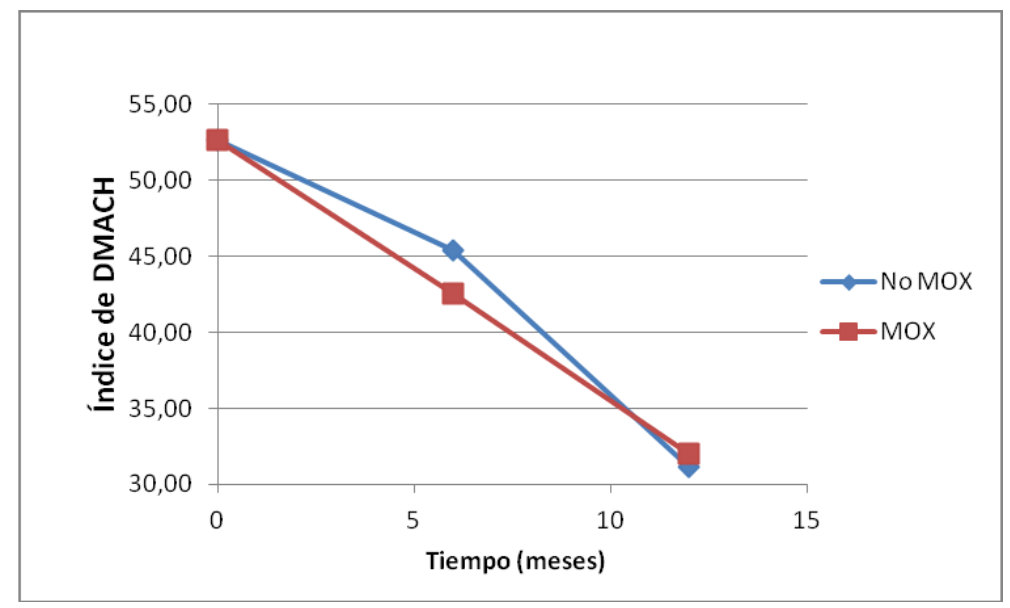

Gráfico 6.88. Evolución del índice de DMACH durante el periodo de conservación de los vinos en función de la aplicación de la microoxigenación.

\subsubsection{EVOLUCIÓN DEL ÍNDICE DE ETANOL}

La evolución del índice de etanol durante la conservación de los vinos, en función de las técnicas de vinificación, aparece representada en el gráfico 6.89. 


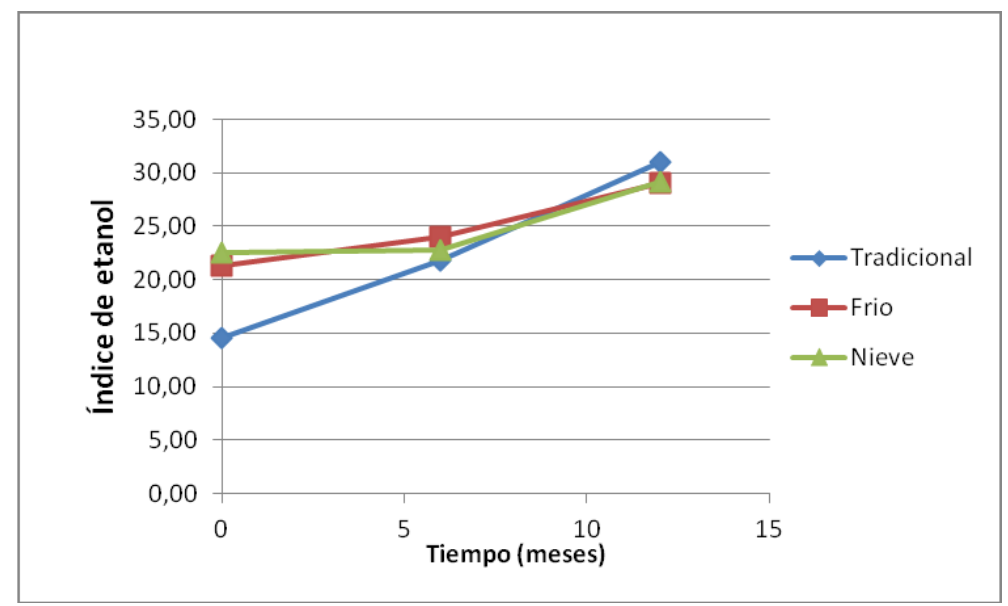

Gráfico 6.89. Evolución del índice de etanol durante el periodo de conservación de los vinos en función de las distintas técnicas de vinificación ensayadas.

Podemos observar un incremento de las uniones de taninos con polisacárido, péptidos y sales a medida que los vinos permanecen en botella. Posteriormente a la fermentación, son las técnicas de maceración prefermentativa las que dan lugar a los valores significativamente más elevados (tabla 6.25), desapareciendo las diferencias a los 6 y 12 meses de evolución de los vinos (tablas 6.31 y 6.39). La mayor extracción de polisacáridos, proteínas o péptidos durante la fase prefermenativa habrá sido probablemente la causa del incremento observado, mostrándose como técnicas adecuadas para mejorar las sensaciones en boca de los vinos jóvenes.

\subsubsection{EVOLUCIÓN DE LA CONCENTRACIÓN DE TANINOS TOTALES}

Ni la adición de copigmentos (tablas 6.24, 6.30 y 6.38), ni las distintas técnicas de maceración (tablas 6.25, 6.31 y 6.39), han mostrado una influencia significativa en la concentración de taninos condensados de los vinos elaborados en la cosecha de 2007 (tablas 6.24, 6.30 y 6.38), a diferencia de lo observado en la cosecha 2006 (gráfico 6.32), en la que se aprecia un efecto marcado de la maceración prefermentativa con nieve carbónica en la concentración de taninos, a los 12 meses de almacenamiento.

La técnica de la microoxigenación ha provocado inicialmente un incremento significativo en la concentración de los taninos (tabla 6.32). El gráfico 6.90 muestra la evolución a lo largo de la conservación de la concentración de estos compuestos, observándose que al final de la conservación no hay diferencias en función de la microoxigenación (tabla 6.40). El aporte de acetaldehído se presenta como una técnica válida para incrementar las reacciones de polimerización entre las catequinas dando lugar a taninos condensados, pero el tiempo de aplicación ha sido insuficiente para que estas reacciones se sigan produciendo al final del periodo de conservación, tal como hemos apreciado para el índice de DMACH en el gráfico 6.88. 


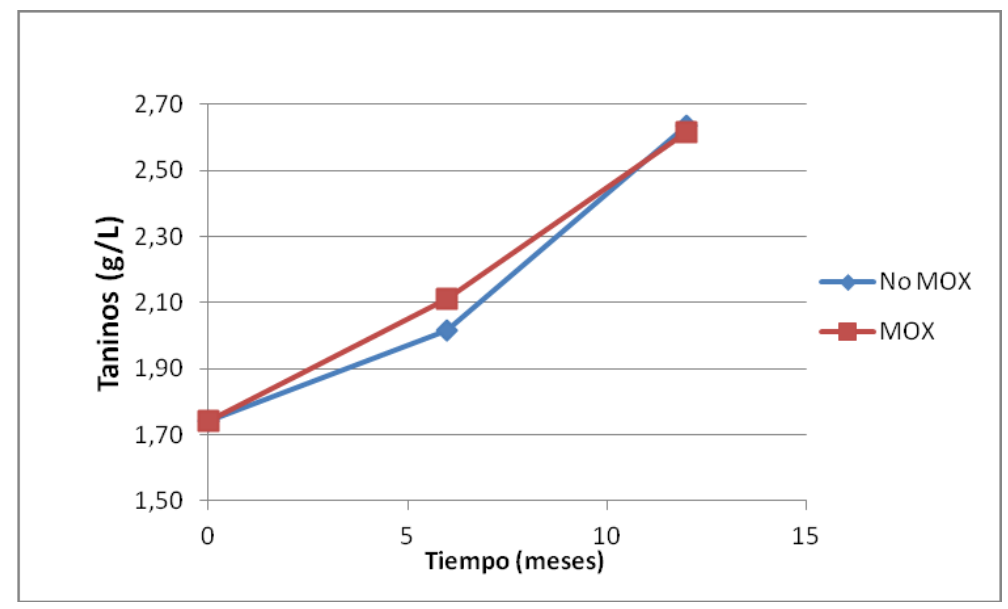

Gráfico 6.90. Evolución de la concentración de taninos totales durante el periodo de conservación de los vinos en función de la aplicación de la microoxigenación.

\subsubsection{EVOLUCIÓN DEL ÍNDICE DE GELATINA}

La adición de copigmentos no muestra una influencia significativa en la astringencia de los vinos elaborados en la cosecha de 2007 (tablas 6.24, 6.30 y 6.38), a diferencia de lo observado en los vinos de la cosecha 2006 (gráfico 6.37), en los que pudimos observar como la adición de los copigmentos ácido cáfeico y rutina contribuían a disminuir su astringencia.

Aunque inicialmente los vinos elaborados con maceración prefermentativa presentan un valor superior del índice de gelatina (tabla 6.25), estas técnicas dan lugar a un descenso de la astringencia de los vinos a partir del sexto mes de conservación, tal como se muestra en la gráfico 6.91.

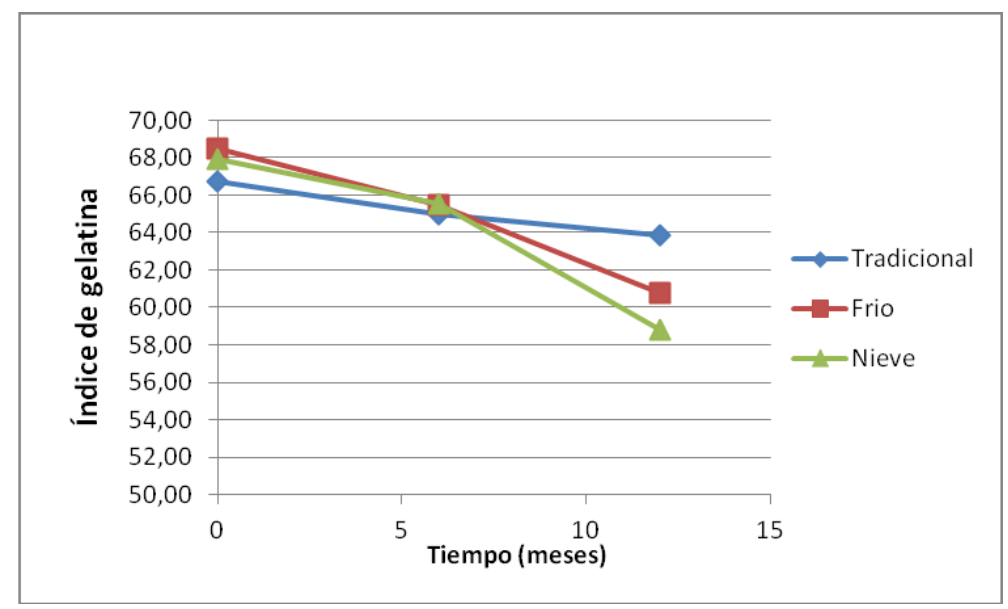

Gráfico 6.91. Evolución del índice de gelatina durante el periodo de conservación de los vinos en función de las distintas técnicas de vinificación ensayadas.

Podemos observar como al final del periodo de evolución tanto los vinos macerados con frío como los sometidos a maceración prefermentativa con nieve carbónica, presentan valores inferiores a los elaborados con maceración tradicional, sin 
que se observen diferencias significativas entre los dos tipos de maceración prefermentativa (tabla 6.39).

Probablemente la mayor presencia de compuestos fenólicos extraídos durante la fase prefermentativa habrá provocado el resultado inicial observado, pero la mayor combinación de los compuestos fenólicos a lo largo de la conservación, a dado lugar a la disminución de la astringencia de los vinos (Koyama et al., 2007).

La evolución del índice de gelatina durante el periodo de conservación de los vinos de 12 meses en botella en función de la aplicación de la microoxigenación aparece representada en el gráfico 6.92.

Los vinos microoxigenados presentan una disminución de la astringencia medida mediante el ídice de gelatina, con diferencias significativas a lo largo de todo el proceso de envejecimiento (tablas 6.32, 6.40). Esto podría justificarse por la formación de polimeros entre antocianos y taninos, que da lugar a una disminución del índice de gelatina al perder los compuestos de partida parte de los grupos $\mathrm{OH}$ disponibles para reaccionar con las proteínas. En el caso de los vinos, la reacción de los taninos poco polimerizados con las proteínas de la saliva, ocasiona la precipitación de la mucina, responsable de la lubricación, con la consiguiente aparición de la sensación de astringencia (Llaudy et al., 2006; Peleg et al., 1999; Vidal et al., 2003; Remy et al., 2000; Brossaud et al., 2001).

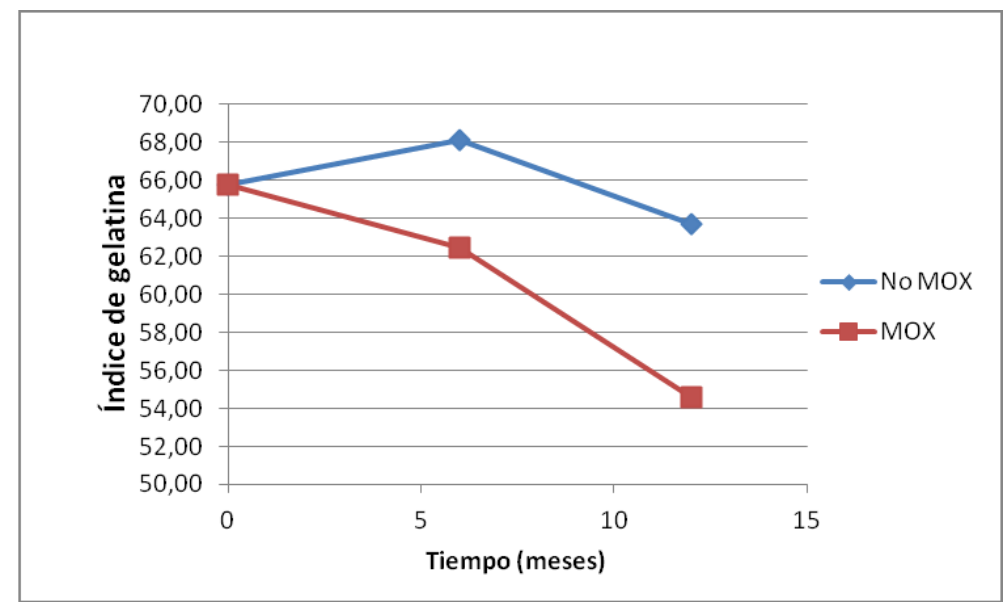

Gráfico 6.92. Evolución del índice de gelatina durante el periodo de conservación de los vinos en función de la aplicación de la microoxigenación.

La aplicación controlada de oxígeno ha provocado en los vinos elaborados en la vendimia 2007 una mayor intensidad colorante, aunque este efecto ha desaparecido al final de la conservación de los vinos, un incremento del color correspondiente a los antocianos polimerizados, así como del índice de PVPP, junto con la disminución de la astringencia de los vinos, confirmándose el efecto positivo de esta técnica sobre la estabilidad del color y sobre la astringencia. 


\subsection{EFECTO DE LAS DIFERENTES PRÁCTICAS ENOLÓGICAS ENSAYADAS SOBRE LA COMPOSICIÓN POLIFENÓLICA DE LOS VINOS ELABORADOS EN EL AÑO 2008.}

La añada 2008 se caracterizó por una pluviometría escasa durante la primavera, por un verano seco y caluroso, con altas temperaturas diurnas y nocturnas, que dificultó la madurez polifenólica, y por la aparición de lluvias previas a la vendimia, que propició la aparición de Botrytis cinerea. La añada fue calificada como Buena.

\subsubsection{ANÁLSIS DE LOS VINOS POSTERIORMENTE A FERMENTACIÓN MALOLÁCTICA}

Una vez terminada la fermentación maloláctica se determinó la composición fenólica de los vinos, utilizándose los resultados para realizar un análisis comparativo en función de las distintas prácticas enológicas ensayadas.

\subsubsection{ANÁLISIS MULTIFACTORIAL DE LA VARIANZA DE LOS FACTORES CONSIDERADOS}

Con objeto de conocer el efecto de los factores objeto de estudio sobre la composición fenólica de los vinos se emplea la herramienta estadística denominada análisis multifactorial de la varianza.

En la tabla 6.45 aparecen los datos del análisis multifactorial de la varianza (ANOVA) para los factores considerados, así como para la interacción entre ambos, estudiándose el efecto de la adición de copigmentos y de las diferentes técnicas de vinificación, tal como se ha realizado para las cosechas 2006 y 2007.

Mediante la herramienta estadística de ANOVA multifactorial, se establecen los valores de F-ratio, los cuales pueden ser comparados entre sí en cada columna, debido a que el número de comparaciones fue el mismo en todos los casos. De acuerdo con esto, las variables son afectadas ligeramente por la adición de los distintos copigmentos y en mayor medida por las técnicas de vinificación empleadas; se observa también un ligero efecto de la interacción entre ambos factores.

Es importante destacar que el año 2008, resultó ser climatológicamente algo distinto a las cosechas previas 2006 y 2007 incluidas en el presente estudio. En septiembre de 2008, unos días antes de la vendimia, se produjeron unas ligeras lluvias, que junto con las altas $\mathrm{T}^{\mathrm{a}}$ propias de esas fechas, propiciaron el desarrollo de Botrytis cinerea afectando al grado sanitario de la uva. El efecto de la podredumbre fue minimizado al máximo durante la vendimia manual, descartando la recolección de los racimos afectados.

El análisis multifactorial de la varianza muestra como los parámetros ácidos fenólicos y porcentaje del color que corresponde a las polimerizaciones muestran los mayores valores del F-ratio con diferencias significativas al nivel de confianza del 99,9\%, indicando un elevado de la adición de copigmentos sobre ambas determinaciones. Además para la concentración de 3-flavanoles, índice de DMACH, catequinas e índice de etanol se observan diferencias al nivel de confianza del 99\%, 
comportamiento que resulta diferente al observado en las cosechas anteriores. Por último el índice de Folin muestra diferencias al 95\%, mostrando un ligero efecto sobre esta variable, mientras que en las cosechas anteriores mostró un efecto más destacado.

Tabla 6.45. Análisis multifactorial de la varianza (F-ratio) de los factores adición de copigmentos y técnicas de maceración, así como de la interacción entre ambos.

\begin{tabular}{lccc}
\hline & $\begin{array}{c}\text { A } \\
\text { Copigmentos }\end{array}$ & $\begin{array}{c}\text { B } \\
\text { Técnica }\end{array}$ & AB \\
\hline I.C. & 0,29 & 1,32 & 0,76 \\
Tono & $5,57^{* *}$ & 0,06 & 0,19 \\
Ant. Totales (mg/L) & $2,93^{*}$ & $50,92^{* * *}$ & $3,62^{* *}$ \\
\hline Delfinidina (mg/L) & 1,89 & 3,09 & 0,75 \\
Petunidina (mg/L) & 1,71 & $5,17^{*}$ & 0,66 \\
Peonidina (mg/L) & $8,56^{* *}$ & $6,03^{*}$ & 2,91 \\
Malvidina (mg/L) & $3,44^{*}$ & $31,1^{* *}$ & $4,63^{* *}$ \\
Antocianidinas (mg/L) & $7,53^{* *}$ & $38,11^{* * *}$ & $6,65^{* * *}$ \\
Derivados de ant. (mg/L) & 1,04 & $42,14^{* * *}$ & 0,41 \\
Total antocianos (mg/L) & $3,45^{*}$ & $36,26^{* * *}$ & $4,59^{* *}$ \\
\hline \% Ant. Copigmentados & 1,98 & 0,26 & $3,93 * *$ \\
\% Ant. Libres & 0,66 & $13,61^{* *}$ & $6,93^{* * *}$ \\
\% Ant. Polimerizados & $6,19^{* * *}$ & 1,81 & 0,89 \\
I. PVPP & 0,58 & $15^{* * *}$ & $3,13^{*}$ \\
\hline I. Folin & $2,85^{*}$ & $4,31^{*}$ & $3,17^{*}$ \\
Ac. Fenolicos (mg/L) & $14,5^{* * *}$ & 0,11 & 2,93 \\
Flavonoles (mg/L) & 0,49 & 0,27 & 0,45 \\
Catequinas (mg/L) & $3,69^{* *}$ & $11,55^{* *}$ & $5,15^{* *}$ \\
3-flavanoles (mg/L) & $5,42^{* *}$ & 0,2 & 2,36 \\
Taninos (g/L) & 1,41 & $52^{* * *}$ & $11,76^{* * *}$ \\
\hline I. DMACH & $4,51^{* *}$ & $11,7 * *$ & $7,57^{* * *}$ \\
I. Etanol & $3,66^{* *}$ & 1,51 & $5,54^{* * *}$ \\
I. Gelatina & 1,86 & 1,19 & $2,72^{*}$ \\
\hline
\end{tabular}

$* p<0.05 ; * * p<0.01$. *** $p<0.001$

En los vinos elaborados en la cosecha 2008, la adición de copigmentos ha provocado un ligero efecto sobre la concentración de antocianos totales decolorables, y por ello de sus derivados y monómeros presentes en la uva; apareciendo diferencias significativas para los parámetros peonidina, malvidina, antocianidinas y total de antocianos. Además, se observan también diferencias para algunos de los parámetros relacionados con el estado de los antocianos (porcentaje del color de los antocianos polimerizados) así como en el estado de los taninos definido por las variables índice de DMACH e índice de etanol, así como para la concentración de catequinas y de 3flavanoles. Este comportamiento muestra diferencias con los hallados en las cosechas 2006 y 2007, en las cuales la adición de copigmentos provocó un elevado efecto sobre los antocianos, e incluso sobre el color del vino, pudiendo estar provocadas estas diferencias por el estado sanitario de la uva. El marcado efecto de la adición de copigmentos en la variable ácidos fenólicos también fue observado en la cosecha 2007, 
pudiendo atribuirse a la adición del ácido cafeico un efecto importante en la estabilidad de la materia colorante en las añadas anteriores, obteniéndose vinos con mejores características cromáticas durante la conservación (Gauche et al., 2010; Gómez-Miguez et al., 2006; Rein, 2005).

Observamos también en la tabla 6.45 el efecto de las técnicas de vinificación sobre los parámetros antocianos totales decolorables, malvidina, antocianidinas, derivados de antocianos y total de antocianos, que muestran diferencias significativas al nivel de confianza del $99,9 \%$, mientras que las antocianidinas petunidina y peonidina muestran diferencias significativas aunque en este caso con un nivel de confianza del 95\%. Esto parece indicar que la aplicación de prácticas prefermentativas ha provocado un efecto considerable sobre la fracción antociánica en su forma simple o monómera, así como sobre los antocianos decolorables y sobre la concentración total de antocianos, tal como se observó en las cosechas anteriores. Las diferentes técnicas de maceración prefermentativa tienen influencia en la composición y estado de los antocianos, favoreciéndose una mayor extracción de estos compuestos (Reynolds, 2001; Parenti et al., 2004; Álvarez et al., 2005; Heatherbell et al., 1997; Manchón et al., 2005; GilMuñoz et al., 2009; Gómez-Míguez et al., 2006; Gordillo et al., 2010; Koyama et al., 2007). Por el contrario, las técnicas de vinificación muestran un efecto mínimo sobre los parámetros relacionados con el estado de los antocianos en sus formas copigmentadas, polimerizadas o libres, ya que únicamente estos últimos presentan un valor significativo del F-ratio. Este comportamiento con respecto a los antocianos libres también fue observado en añadas anteriores, aunque en 2006 también hay un efecto significativo sobre el color debido a antocianos copigmentados, y en 2007 sobre los polimerizados.

Las técnicas de maceración prefermentativa, parecen propiciar una mayor interacción con los diferentes compuestos fenólicos que se encuentran en el vino (Kovac et al., 1992; Gordillo et al., 2010; Heredia et al., 2010). La concentración de taninos totales, de catequinas, el índice de PVPP y el índice de DMACH presentan diferencias al 99\%. Para el índice de Folin, en cambio, se observa un ligero efecto de las técnicas de vinificación ensayadas, efectos que difieren considerablemente de los encontrados en las cosechas anteriores.

El ANOVA multifactorial pone de manifiesto la influencia de la maceración prefermentativa sobre la extracción de los antocianos, junto con un ligero efecto sobre el estado y la concentración de los taninos en los vinos; afectando tanto a su forma monómera como a su forma simple, reaccionando estos compuestos con los antocianos o con ellos mismos, incrementando así su grado de polimerización, dando lugar a vinos con una importante concentración fenólica.

Los parámetros polifenólicos taninos totales, índice de $\mathrm{DMACH}$, antocianidinas, porcentaje del color que corresponde a los antocianos libres e índice de etanol, por este orden, son los que muestran un efecto más marcado sobre la interacción entre la adición de copigmentos y las técnicas de vinificación. Además los parámetros antocianos totales decolorables, malvidina, concentración total de antocianos, catequinas y porcentaje del color debido a la copigmentación presentan diferencias al 99\%, mostrando un notable efecto sobre la variable. Por último, parámetros como el índice de Folin, índice de PVPP e índice de gelatina muestran diferencias al 95\% sobre la variable considerada, al 
igual que sucedía en los vinos elaborados en 2006 y a diferencia de lo observado en la cosecha de 2007.

La combinación de ambas técnicas podría dar lugar a una metodología de vinificación que permita obtener vinos donde predominaran las principales reacciones entre compuestos fenólicos, afectando decisivamente tanto al color, como a la estructura de los vinos. Es necesario realizar un análisis de los vinos durante su conservación para establecer el efecto que a largo plazo tiene la combinación de técnicas y adición de copigmentos sobre las reacciones de estabilización de la materia colorante, así como sobre la reducción de la astringencia.

\subsubsection{2. $\quad$ EFECTO DE LA ADICIÓN DE COPIGMENTOS}

En la tabla 6.46 se recogen los valores medios de los parámetros polifenólicos estudiados, en función de la adición de los distintos copigmentos, así como el ANOVA simple realizado.

Los vinos adicionados de ácido cafeico presentan diferencias estadísticamente significativas, presentando los valores más bajos para la variable tono y para la concentración de antocianos decolorables. Estos ácidos fenólicos participan en reacciones de esterificación con los antocianos contribuyendo a una mayor estabilidad de éstos frente a la decoloración y la oxidación, incrementando en menor proporción la tonalidad amarilla, que da lugar al incremento del tono (Rein, 2005). Sin embargo, no se observa ningún efecto en la concentración de los derivados de antocianos para este copigmento en este momento, aunque es probable que durante la conservación se incrementen estas reacciones de esterificación.

Un efecto similar fue observado en los vinos de las añadas 2006 y 2007, en los cuales los valores más bajos de antocianos decolorables son los vinos testigo y los suplementados con ácido cafeico. La adición de copigmentos de naturaleza tánica (KT, PRO y TAN) propician una mayor concentración de antocianos decolorables, tal y como sucedía en las dos cosechas anteriores, pero en este caso sólo presentan diferencias significativas los vino suplementados con proantocianidinas.

Nuevamente, de todos los compuestos ensayados, el que presenta un menor porcentaje de color debido a la copigmentación es el ácido cafeico, en relación a los otros copigmentos ensayados. Como ya se comentó previamente, el ácido cafeico, debido a su pequeño tamaño, no puede estabilizar completamente la carga positiva del catión flavilium, mostrando un efecto copigmentante más débil que la rutina o la catequina (Gómez-Cordovés et al., 1995; Lambert et al., 2010; Malien-Aubert et al., 2007; Schwarz et al., 2005; Davies y Mazza, 1993; Baranac et al., 1996; Baranac et al., 1997; Gómez-Míguez et al., 2006). La capacidad de copigmentación de la rutina es también destacada (Boulton, 2001; Schwarz et al., 2005; Gómez-Míguez et al., 2006) gracias a la completa superposición de los enlaces covalentes entre la malvidina. Sin embargo, en los resultados obtenidos en la cosecha 2008, no se observan diferencias significativas en el porcentaje de copigmentación debido a la rutina y a los copigmentos de naturaleza tánica, de los cuales la catequina también tiene un importante efecto copigmentante (Darías et al., 2001).

Para el porcentaje del color que corresponde a los antocianos polimeizados, es el copigmento ácido cafeico es el que presenta los valores más elevados, con diferencias 
significativas respecto a los otros copigmentos ensayados. Las reacciones de esterificación que facilita el ácido cafeico con los antocianos, permite el incremento de pigmentos poliméricos que a su vez incrementan la estabilidad del color. Estos resultados también se observaron en los vinos de las cosechas 2006 y 2007, en los que se encontraron diferencias significativas con todos los copigmentos ensayados, y además se observa también en ellos, que el menor porcentaje de color debido a la copigmentación corresponde a la adición del copigmento ácido cafeico. También Darías-Martín et al. (2001) observan como aquellos vinos adicionados de ácido cafeico presentan un mayor color debido a las polimerizaciones tanto a los 30 días, como a los 7 meses de envejecimiento.

Los vinos adicionados del copigmento rutina son los que presentan los valores más elevados para la concentración total de polifenoles, determinada mediante el índice de Folin, observándose también un comportamiento positivo de los copigmentos ácido cafeico, catequina y proantocianidina de pepita, en la concentración de los polifenoles.

Para los ácidos fenólicos, 3-flavanoles y flavonoles, los vinos adicionados de ácido cafeico, catequina y rutina, respectivamente, son los que muestran las mayores concentraciones de estos compuestos. La concentración de catequina se ve incrementada por la adición de copigmento catequina, como era de esperar, pero también por la adición de proantocianidinas, indicando como estos preparados comerciales también aportan catequinas monómeras al vino.

El índice de DMACH está relacionado con la polimerización de taninos, correspondiendo a los vinos adicionados de los copigmentos de carácter tánico los menores grados de polimerización, y a los adicionados con ácido cafeico los más altos. El bajo grado de polimerización observado en los vinos suplementados con copigmentos de origen tánico concuerda con lo observado para la concentración de catequina en esta cosecha, pero también con lo observado en la cosecha 2006. En la cosecha 2007, en cambio, la adición de proantocianidinas dio lugar a mayor grado de polimerización que la adición de catequina, en concordancia con los resultados obtenidos por Bautista-Ortín et al. (2007), que observaron que los vinos adicionados de tanino proantocianidínico incrementaban el grado de polimerización de sus taninos.

El mayor grado de polimerización de los taninos encontrado para los vinos adicionados de ácido cafeico, puede estar relacionado con el elevado porcentaje del color debido a la polimerización de los antocianos, ya que la mayor presencia de moléculas antociano-etil-tanino en estos vinos pudo haber servido de reservorio de taninos, polimerizándose los antocianos monómeros en su forma libre, con la parte tánica de la molécula, incrementando el tamaño molecular medio de estos compuestos en los vinos elaborados (Jurd, 1969; Somers, 1971).

Al igual que ocurría en los ensayos realizados en la cosecha 2006, se observan una relación entre los índices de etanol y de gelatina. Los valores más altos del índice de etanol corresponden a los vinos adicionados con el copigmento rutina, no mostrando diferencias significativas con el ácido cafeico, siendo estos vinos los que presentan un mayor número de uniones tanino-polisacáridos, las cuales provocan una reducción de la astringencia (Llaudy et al., 2006; Vidal et al., 2003; Remy et al., 2000). 


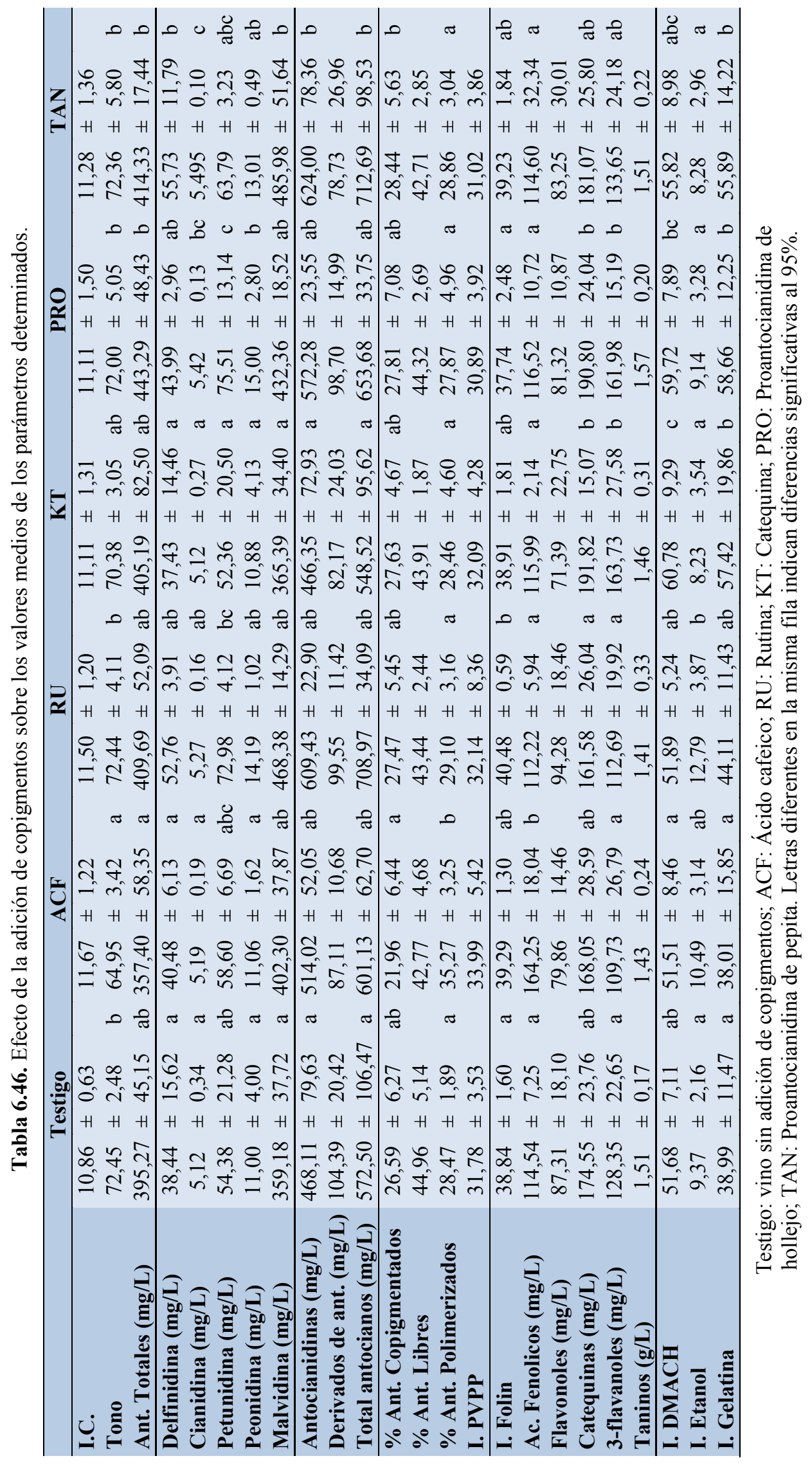


En cuanto a la astringencia, se pueden establecer dos grupos en base a las diferencias significativas encontradas; estando uno de ellos formado por los vinos adicionados de ácido cafeico, rutina y testigo y el otro por los vinos adicionados de copigmentos de carácter tánico, teniendo estos últimos una mayor astringencia.

\subsubsection{EFECTO DE LAS TÉCNICAS DE VINIFICACIÓN}

En la tabla 6.47 se recogen los valores medios de los parámetros polifenólicos analizados considerando conjuntamente los distintos tipos de copigmentos utilizados según que la vinificación se realice de forma tradicional, con maceración prefermentativa en frío a $6-8{ }^{\circ} \mathrm{C}$ durante 4 días o con maceración prefermentativa con adición de nieve carbónica.

La aplicación de la maceración prefermentativa en frío muestra diferencias significativas para los parámetros relacionados con la composición antocianica: antocianos totales decolorables, cianidina, malvidina, antocianidinas, derivados de antocianos y total de antocianos.

La concentración fenólica de los vinos de la cosecha 2008 es inferior a la de los vinos elaborados en las cosechas 2006 y 2007, debido a las circunstancias climatológicas acaecidas, que afectaron por una parte a la maduración de la uva, y por otra a su estado sanitario, por la presencia de polifenoloxidasa aportado por Botrytis cinera (Sotomayor, 1982). A pesar de ello, las técnicas de maceración prefermentativa han resultado eficaces, tal y como confirmaron Álvarez et al. (2006) en un trabajo llevado a cabo con distintas técnicas de maceración en frío aplicadas a uva de la variedad Monastrell con distinto grado de madurez.

Tal como se observó en los vinos de 2006 y 2007, la aplicación de prácticas prefermentativas, bien con aplicación de bajas temperaturas o bien mediante nieve carbónica, ha favorecido la concentración de los principales compuestos que forman la fracción antocianica de los vinos (Parenti et al., 2004; Álvarez et al., 2005; Manchon et al., 2005; Gil-Muñoz et al., 2009; Gómez-Míguez et al., 2006; Gordillo et al., 2010; Koyama et al., 2007), aunque no se apreciaron diferencias significativas entre la maceración en frío y la aplicación de nieve carbónica.

Sin embargo, esto no dio lugar a diferencias en la intensidad colorante, para las tres técnicas ensayadas, al contrario de lo observado en la cosecha 2007, debido a que el efecto de la tecnología está supeditado a las características de la materia prima, no resultando efectiva en este caso (Sacchi et al., 2005). El color de los vinos está relacionado con la concentración de antocianos, pero no de una manera directamente proporcional, ya que afectan el estado en que se encuentren esos antocianos y las reacciones entre ellos y con los taninos (Cheynier et al., 2006).

Además, la maceración prefermentativa incrementa la extracción de compuestos correspondientes a la fracción tánica. La concentración de catequinas y taninos totales es significativamente superior en los vinos macerados prefermentativamente, encontrándose el mismo efecto para las catequinas en 2006 y para los taninos en 2007. Sin embargo, comparando las tres cosechas realizadas, en la de 2008 el hecho de que los valores de catequinas y taninos sean superiores podría indicar también un mayor aporte 
de taninos de pepitas poco maduros (Busse-Valverde et al., 2010), dando lugar a un incremento de la astringencia, tal como observamos en estos vinos.

Tabla 6.47. Efecto de las técnicas de vinificación sobre los valores medios de los parámetros determinados.

\begin{tabular}{|c|c|c|c|c|c|c|c|c|c|}
\hline & \multicolumn{3}{|c|}{ Tradicional } & \multicolumn{3}{|c|}{ Frio } & \multicolumn{3}{|c|}{ Nieve } \\
\hline I.C. & 11,50 & $\pm 1,04$ & & 10,95 & $\pm 1,16$ & & 11,13 & $\pm 0,89$ & \\
\hline Tono & 70,68 & $\pm 4,50$ & & 70,99 & $\pm 4,76$ & & 71,26 & $\pm 3,98$ & \\
\hline Ant. Totales (m & 390,79 & $\pm 27,12$ & $\mathrm{a}$ & 419,57 & $\pm 25,49$ & $\mathrm{~b}$ & 425,61 & $\pm 22,37$ & \\
\hline Delfinid & 43,96 & $\pm 8,63$ & & 46,43 & $\pm 14,56$ & & 47,52 & $\pm 12,65$ & \\
\hline Cianidina & 5,20 & $\pm 0,25$ & $\mathrm{a}$ & 5,35 & $\pm 0,20$ & $\mathrm{~b}$ & 5,41 & $\pm 0,23$ & \\
\hline Petunidina (mg/L) & 61,50 & $\pm 11,40$ & & 65,22 & $\pm 18,29$ & & 62,34 & $\pm 21,14$ & \\
\hline & 12,17 & $\pm 2,34$ & & 13,03 & $\pm 3,52$ & & 12,85 & $\pm 4,03$ & \\
\hline Malv & 412,66 & $\pm 34,93$ & $\mathrm{a}$ & 429,88 & $\pm 30,55$ & $\mathrm{~b}$ & 431,26 & $\pm 25,65$ & \\
\hline Antoc & 531,47 & $\pm 36,88$ & $\mathrm{a}$ & 556,06 & $\pm 27,41$ & $\mathrm{~b}$ & 559,38 & $\pm 25,49$ & \\
\hline Der & 85,52 & $\pm 14,01$ & $\mathrm{a}$ & 98,52 & $\pm 12,60$ & $\mathrm{~b}$ & 101,26 & $\pm 9,46$ & \\
\hline Tota & 616,98 & $\pm 58,67$ & $\mathrm{a}$ & 654,58 & $\pm 53,67$ & $\mathrm{~b}$ & 660,64 & $\pm 44,53$ & \\
\hline$\% \mathrm{An}$ & 26,43 & $\pm 6,11$ & & 26,99 & $\pm 6,15$ & & 25,48 & $\pm 7,95$ & \\
\hline$\% \mathrm{~A}$ & 44,51 & $\pm 3,17$ & & 43,57 & $\pm 3,85$ & & 42,16 & $\pm 2,98$ & \\
\hline$\% \mathrm{Ar}$ & 28,50 & $\pm 4,41$ & & 30,00 & $\pm 4,36$ & & 32,36 & $\pm 5,64$ & \\
\hline I. PVPP & 18,02 & $\pm 6,71$ & & 14,76 & $\pm 5,22$ & & 16,45 & $\pm 7,24$ & \\
\hline I. Folin & 38,67 & $\pm 2,08$ & & 39,51 & $\pm 1,34$ & & 39,64 & $\pm 3,25$ & \\
\hline Ac. $\mathbf{F}$ & 118,01 & $\pm 15,39$ & & 116,73 & $\pm 36,27$ & & 120,59 & $\pm 24,56$ & \\
\hline Flave & 81,05 & $\pm 20,95$ & & 85,27 & $\pm 17,54$ & & 86,97 & $\pm 23,21$ & \\
\hline Catequinas (mg/L) & 169,38 & $\pm 24,88$ & & 187,56 & $\pm 23,24$ & $\mathrm{~b}$ & 184,39 & $\pm 20,46$ & \\
\hline les $(\mathrm{mg} / \mathrm{L})$ & 122,86 & $\pm 31,85$ & & 136,80 & $\pm 28,35$ & & 135,28 & $\pm 30,02$ & \\
\hline $\operatorname{Taninos}(\mathrm{g} / \mathrm{L})$ & 1,26 & $\pm 0,21$ & $a$ & 1,42 & $\pm 0,20$ & $\mathrm{~b}$ & 1,44 & $\pm 0,27$ & \\
\hline I. DN & 57,63 & $\pm 7,68$ & b & 52,68 & $\pm 8,70$ & $\mathrm{a}$ & 51,64 & $\pm 6,49$ & \\
\hline I. Et & 10,14 & $\pm 2,30$ & & 9,24 & $\pm 4,25$ & & 8,69 & $\pm 4,32$ & \\
\hline I. Gelatina & 43,19 & $\pm 12,97$ & & 47,49 & $\pm 16,44$ & & 48,79 & $\pm 18,46$ & \\
\hline
\end{tabular}

Tradicional: elaboración sin maceración en frío previamente a la fermentación; Frío: aplicación de bajas temperaturas de forma prefermentativa; Nieve: uso de nieve carbónica prefermentativamente. Letras diferentes en la misma fila indican diferencias significativas al 95\%.

Por otra parte, este incremento de la concentración de catequinas y taninos viene acompañado del incremento de su grado de polimerización, y esto no siempre se corresponde con una reducción de astringencia, a no ser que la molécula esté formada por más de 10 monómeros de taninos (Nagel y Glories, 1991; Vivas et al., 1994). La aplicación de bajas temperaturas en la maceración prefermentativa no siempre provoca un incremento en la extracción de taninos, siendo más acusado el efecto del tiempo de maceración fermentativa. La extracción de taninos puede ser superior cuando la maceración prefermentativa se realiza con nieve carbónica, por su efecto desestructurante sobre las membranas celulares (Álvarez, et al., 2005). 
En la añada 2008, la aplicación de la maceración prefermentativa puede ser una buena técnica aplicable al procesado de uva con una madurez deficiente y/o con una ligera afección de podedumbre, al favorecer la extracción de las fracciones antociánica y tánica que permitirán probablemente una buena evolución de los vinos en botella.

\subsubsection{CORRELACIÓN ENTRE LOS PARÁMETROS POLIFENÓLICOS DE LOS VINOS, LA ADICIÓN DE COPIGMENTOS Y LAS TÉCNICAS DE VINIFICACIÓN}

A continuación se recoge el Análisis de Componentes Principales para los vinos elaborados en 2008, en función de las distintas prácticas enológicas ensayadas. Para ello es preciso generar inicialmente la matriz de covarianzas o matriz de correlaciones.

En la tabla 6.48 aparece representada la matriz de correlaciones de las variables utilizadas en el análisis, donde una coloración más intensa indica una correlación más importante entre las variables consideradas; correspondiendo las coloraciones rojas a las relaciones negativas, las verdes a las positivas y las amarillas a las correlaciones débiles entre las variables relacionadas (próxima a cero).

El índice de Folin, que está relacionado con la concentración tánica de los vinos, presenta correlaciones positivas para la concentración de catequinas, y de taninos y con el índice de gelatina (Zamora, 2003; Bautista-Ortín et al., 2007).

En cuanto a la intensidad colorante, se encuentra una correlación positiva entre la fracción de antocianos polimerizados $(0,67)$ y libres $(0,47)$, y negativa con el tono $(-0,76)$. Aquellos vinos que presenten un mayor porcentaje del color debido a polimerizaciones presentarán un mejor color, ya que mediante la unión antociano tanino se protegen los antocianos frente a la oxidación, y en consecuencia el color de los vinos. Ya se ha comentado en numerosas ocasiones la importancia de los pigmentos poliméricos en el color de los vinos (Castañedo-Ovando., 2009; Cheynier et al., 2006; Malien-Aubert et al., 2002). En estos vinos analizados posteriormente a la fermentación maloláctica, el color debido a estos pigmentos todavía no representa valores elevados (próximos al 30\%), aunque observando los resultados de la matriz de correlaciones parece que afectan decisivamente tanto al color como al tono de los vinos.

Otras correlaciones interesantes han sido observadas entre el índice de DMACH y el de PVPP, indicando como el incremento de las uniones de los taninos con los antocianos disminuye las polimerizaciones entre taninos, reduciendo el su grado de polimerización. Además, el aumento de la concentración de taninos en el medio llevará a una mayor polimerización y a un aumento inicial de la astringencia, estimada por el índice de gelatina, la cual tiene también una correlación positiva con las catequinas.

El resultado más destacado en la tabla es la alta correlación entre las variables antociánicas, teniendo unos coeficientes de correlación próximos a 1 . Un ejemplo de esto son los coeficientes encontrados para la malvidina con las antocianidinas o con el total de antocianos, correlación esperada, ya que la malvidina es el monómero antociánico más abundante en los vinos (Baldi et al., 1995). 


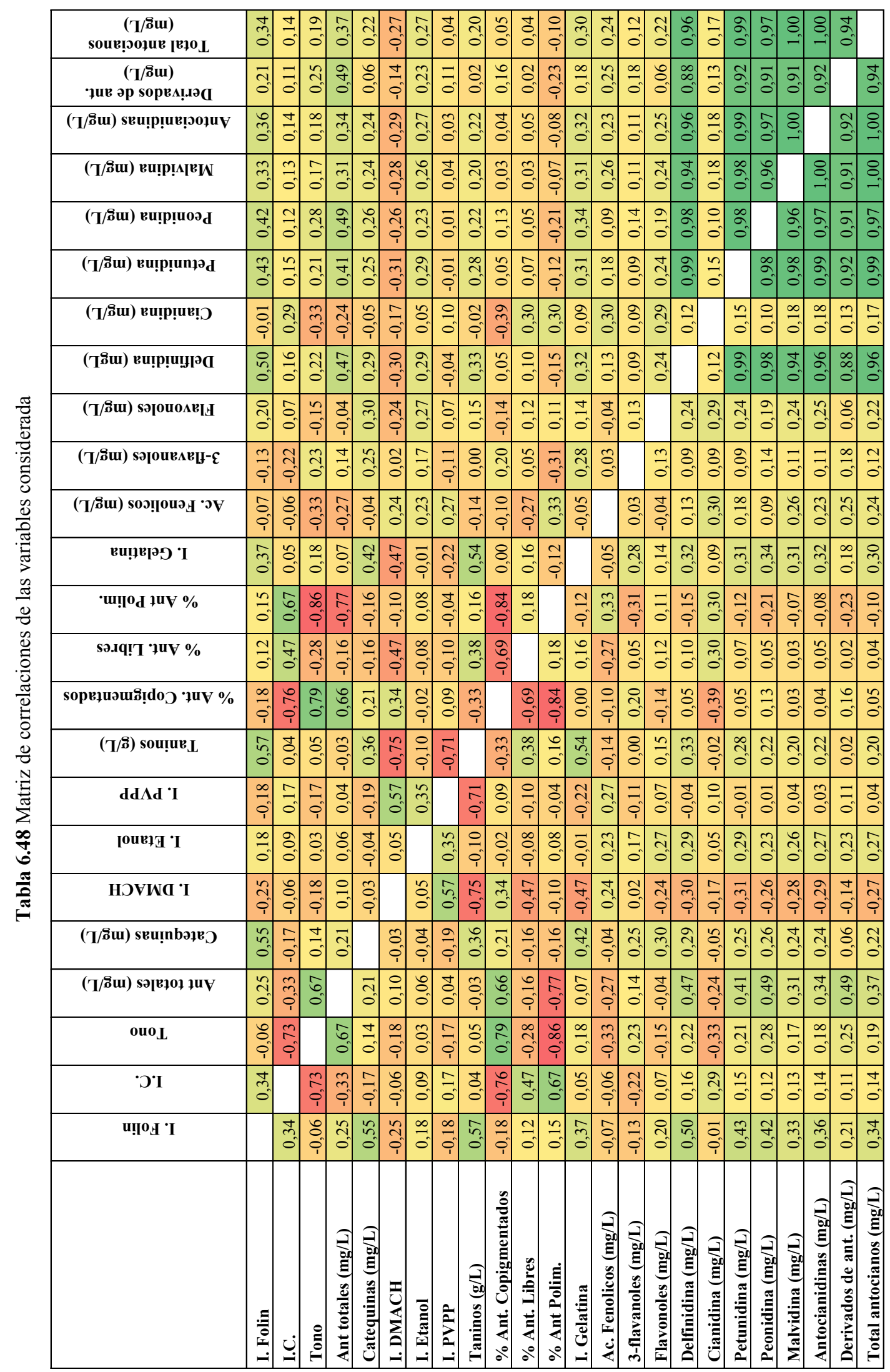


En la tabla 6.49 se recoge tanto el autovalor como el porcentaje de varianza acumulada por los sucesivos factores, observándose como son necesarios seis factores para que el autovalor descienda por debajo de la unidad. Se han identificado seis patrones de comportamiento que consigen aglutinar toda la variabilidad observada en las variables originales, y que representan el $82,87 \%$ de la varianza acumulada.

En la tabla 6.50 aparecen los valores de los coeficientes de las ecuaciones que forman cada uno de los seis componentes principales identificados. El primer componente principal está directamente relacionado con los parámetros que definen la composición antociánica, es decir, la delfinidina, peonidina, petunidina, malvidina, antocianidinas, derivados de antocianos y antocianos totales decolorables. Hay que destacar que este eje no presenta coeficientes importantes negativos y que además los parámetros relacionados con la composición tánica no superan 0,25 en valor absoluto, al contrario de los resultados hallados en la cosecha 2007, donde los flavonoles, 3flavonoles y ácidos fenólicos tienen un peso importante en la clasificación de los vinos, confirmando la alta capacidad de copigmentación de estos compuestos (Lambert et al., 2010). El resultado obtenido en esta cosecha puede estar relacionado con el estado sanitario de la uva y con la presencia de polifenoloxidasa (Sotomayor, 1982).

Tabla 6.49. Autovalor, varianza explicada y acumulada para las componentes consideradas en el análisis

\begin{tabular}{|c|ccc}
\hline Componente & Autovalor & \% Varianza & \% Acumulado \\
\hline $\mathbf{1}$ & 7,993 & 31,976 & 31,976 \\
$\mathbf{2}$ & 4,613 & 18,456 & 50,432 \\
$\mathbf{3}$ & 3,481 & 13,925 & 64,357 \\
$\mathbf{4}$ & 1,836 & 7,345 & 71,702 \\
$\mathbf{5}$ & 1,472 & 5,89 & 77,593 \\
$\mathbf{6}$ & 1,320 & 5,282 & 82,874 \\
$\mathbf{7}$ & 0,956 & 3,826 & 86,7 \\
$\mathbf{8}$ & 0,848 & 3,394 & 90,094 \\
$\mathbf{9}$ & 0,669 & 2,677 & 92,77 \\
$\mathbf{1 0}$ & 0,613 & 2,455 & 95,225 \\
$\mathbf{1 1}$ & 0,464 & 1,856 & 97,081 \\
$\mathbf{1 2}$ & 0,288 & 1,153 & 98,234 \\
$\mathbf{1 3}$ & 0,141 & 0,566 & 98,801 \\
$\mathbf{1 4}$ & 0,127 & 0,509 & 99,309 \\
$\mathbf{1 5}$ & 0,065 & 0,261 & 99,57 \\
$\mathbf{1 6}$ & 0,042 & 0,171 & 99,741 \\
$\mathbf{1 7}$ & 0,021 & 0,084 & 99,825 \\
$\mathbf{1 8}$ & 0,019 & 0,078 & 99,903 \\
$\mathbf{1 9}$ & 0,011 & 0,047 & 99,95 \\
$\mathbf{2 0}$ & 0,009 & 0,037 & 99,987 \\
$\mathbf{2 1}$ & 0,002 & 0,009 & 99,996 \\
$\mathbf{2 2}$ & 0,001 & 0,004 & 100 \\
\hline & & & \\
\hline
\end{tabular}


El segundo eje principal identificado está relacionado positivamente con la intensidad colorante y con el porcentaje del color que corresponde a los antocianos libres y a los polimerizados. Por el contrario, presenta asociaciones indirectas con los parámetros polifenólicos tono, antocianos totales y porcentaje del color que corresponde a los antocianos copigmentados.

Los vinos se caracterizarían, en función del segundo eje principal en su parte positiva, por los parámetros intensidad colorante, antocianos polimerizados y libres, es decir, presentan una gran influencia sobre el color de los vinos aquellos antocianos que están formando parte de polimerizaciones o que se encuentren en el medio en su forma libre, siendo ambos parámetros los responsables principales de las importantes características cromáticas mostradas por estos vinos.

Tabla 6.50. Tabla de pesos de los componentes

\begin{tabular}{lcccccc}
\hline & \multicolumn{7}{c}{ Componentes } \\
& $\mathbf{1}$ & $\mathbf{2}$ & $\mathbf{3}$ & $\mathbf{4}$ & $\mathbf{5}$ & $\mathbf{6}$ \\
\hline I. Folin & 0,18 & 0,15 & $-0,18$ & 0,25 & $-0,30$ & 0,32 \\
I.C. & 0,03 & 0,34 & 0,19 & $-0,11$ & $-0,20$ & 0,29 \\
Tono & 0,10 & $-0,37$ & $-0,20$ & $-0,16$ & 0,06 & $-0,03$ \\
Ant totales (mg/L) & 0,16 & $-0,31$ & $-0,06$ & $-0,10$ & $-0,15$ & 0,28 \\
Catequinas (mg/L) & 0,14 & $-0,02$ & $-0,26$ & 0,43 & 0,05 & 0,19 \\
I. DMACH & $-0,14$ & $-0,19$ & 0,27 & 0,32 & $-0,14$ & 0,15 \\
I. Etanol & 0,10 & 0,00 & 0,18 & 0,21 & 0,17 & 0,26 \\
I. PVPP & $-0,03$ & $-0,08$ & 0,40 & 0,13 & 0,03 & 0,34 \\
Taninos (g/L) & 0,14 & 0,21 & $-0,40$ & $-0,03$ & $-0,04$ & $-0,12$ \\
\% Ant. Copigmentados & 0,03 & $-0,45$ & $-0,06$ & 0,12 & 0,00 & $-0,03$ \\
\%o Ant. Libres & 0,03 & 0,27 & $-0,06$ & $-0,42$ & 0,15 & 0,24 \\
\% Ant Polim. & $-0,07$ & 0,40 & 0,13 & 0,16 & $-0,11$ & $-0,14$ \\
I. Gelatina & 0,16 & 0,07 & $-0,24$ & 0,03 & 0,24 & 0,03 \\
Ac. Fenolicos (mg/L) & 0,04 & 0,06 & 0,25 & 0,38 & 0,12 & $-0,48$ \\
3-flavanoles (mg/L) & 0,06 & $-0,10$ & $-0,07$ & 0,04 & 0,59 & 0,05 \\
Flavonoles (mg/L) & 0,10 & 0,11 & $-0,01$ & 0,17 & 0,37 & 0,35 \\
Delfinidina (mg/L) & 0,35 & 0,01 & 0,06 & $-0,03$ & $-0,09$ & 0,02 \\
Cianidina (mg/L) & 0,05 & 0,20 & 0,16 & $-0,04$ & 0,42 & $-0,05$ \\
Petunidina (mg/L) & 0,34 & 0,01 & 0,09 & $-0,04$ & $-0,06$ & $-0,04$ \\
Peonidina (mg/L) & 0,34 & $-0,04$ & 0,08 & $-0,06$ & $-0,06$ & 0,01 \\
Malvidina (mg/L) & 0,33 & 0,01 & 0,13 & $-0,01$ & 0,00 & $-0,11$ \\
Antocianidinas (mg/L) & 0,34 & 0,01 & 0,12 & $-0,02$ & $-0,02$ & $-0,09$ \\
Derivados de ant. (mg/L) & 0,31 & $-0,08$ & 0,19 & $-0,13$ & $-0,03$ & $-0,10$ \\
Total antocianos (mg/L) & 0,34 & 0,00 & 0,13 & $-0,04$ & $-0,02$ & $-0,09$ \\
\hline
\end{tabular}

La parte negativa del eje principal permite caracterizar estos vinos por la presencia de un mayor color debido a copigmentaciones, aunque también a antocianos libres coloreados, siendo estos compuestos susceptibles a las reacciones de oxidación. Este eje podría ser un marcador de las reacciones de copigmentación, aunque en estos vinos estas reacciones no van acompañadas del incremento del color esperado. En los 
vinos obtenidos en la cosecha 2007, se obtuvo la misma relación entre los antocianos totales decolorables y la IC, siendo de signo opuesto.

El tercer eje principal esta caracterizado por los parámetros catequinas, taninos e índice de gelatina (-0.24) en su zona negativa, y con el índice de DMACH, el de PVPP y la concentración de ácidos fenólicos en su parte positiva. La parte negativa del eje permite caracterizar los vinos por su elevada concentración de los principales compuestos de carácter tánico, afectando estos de forma decisiva sobre la astringencia, y por supuesto al índice de gelatina. Por el contrario, en su parte positiva corresponderán a vinos donde predominan las reacciones de unión entre antocianos y taninos, siendo los taninos un reservorio para llevar a cabo estas reacciones en detrimento del incremento del grado de polimerización de taninos, al estar participando estos en las reacciones con los antocianos y no con ellos mismos. Además estos vinos presentaran una importante concentración de ácidos fenólicos en su composición.

El cuarto eje principal se asocia directemente con el índice de Folin, las catequinas, el índice de DMACH y los ácidos fenólicos con asociación directa, mientras que se asocia de forma negativa con el parámetro porcentaje del color correspondiente a los antocianos libres.

El quinto eje se asocia con los 3-flavanoles, flavonoles e índice de Folin, mientras que el sexto con el índice de Folin, la intensidad colorante, antocianos totales, índice de etanol, índice de PVPP y flavonoles.

Una vez comprobadas qué variables están más correlacionadas con las componentes principales, se calcularon los coeficientes de las combinaciones lineales sobre las variables antiguas que definen las variables nuevas, para poder calcular a partir de ellos las nuevas coordenadas de los objetos en las componentes. Obtenidos los coeficientes de las componentes principales se procedió a representar las componentes.

En el gráfico 6.93 aparecen representados los vinos elaborados con los distintos copigmentos en función de las dos primeras componentes principales identificadas.

Se puede observar como los vinos aparecen distribuidos aleatoriamente a lo largo tanto del primer como del segundo eje principal, no pudiéndose caracterizar el efecto de ninguno de los copigmentos adicionados, como tampoco diferenciar a los vinos copigmentados de aquellos testigos no adicionados de copigmentos. Sin embargo, los vinos se encuentran más concentrados en la parte positiva del primer eje, eje que se encuentra directamente relacionado con la composición antociánica de los vinos, por lo que la representación gráfica parece indicar la influencia de la adición de copigmentos en la concentración antociánica, mostrando como la aplicación de copigmentos puede incrementar la concentración de antocianos de los vinos, aunque no se haya podido establecer en este gráfico las diferencias que ocasionan la adición de los diferentes copigmentos.

Con el objetivo de profundizar en el análisis, se representó la segunda componente frente a la tercera y la primera frente a la tercera (datos no mostrados), observándose un comportamiento aleatorio de los vinos elaborados, no aportando estas representaciones ningún criterio diferenciador. 


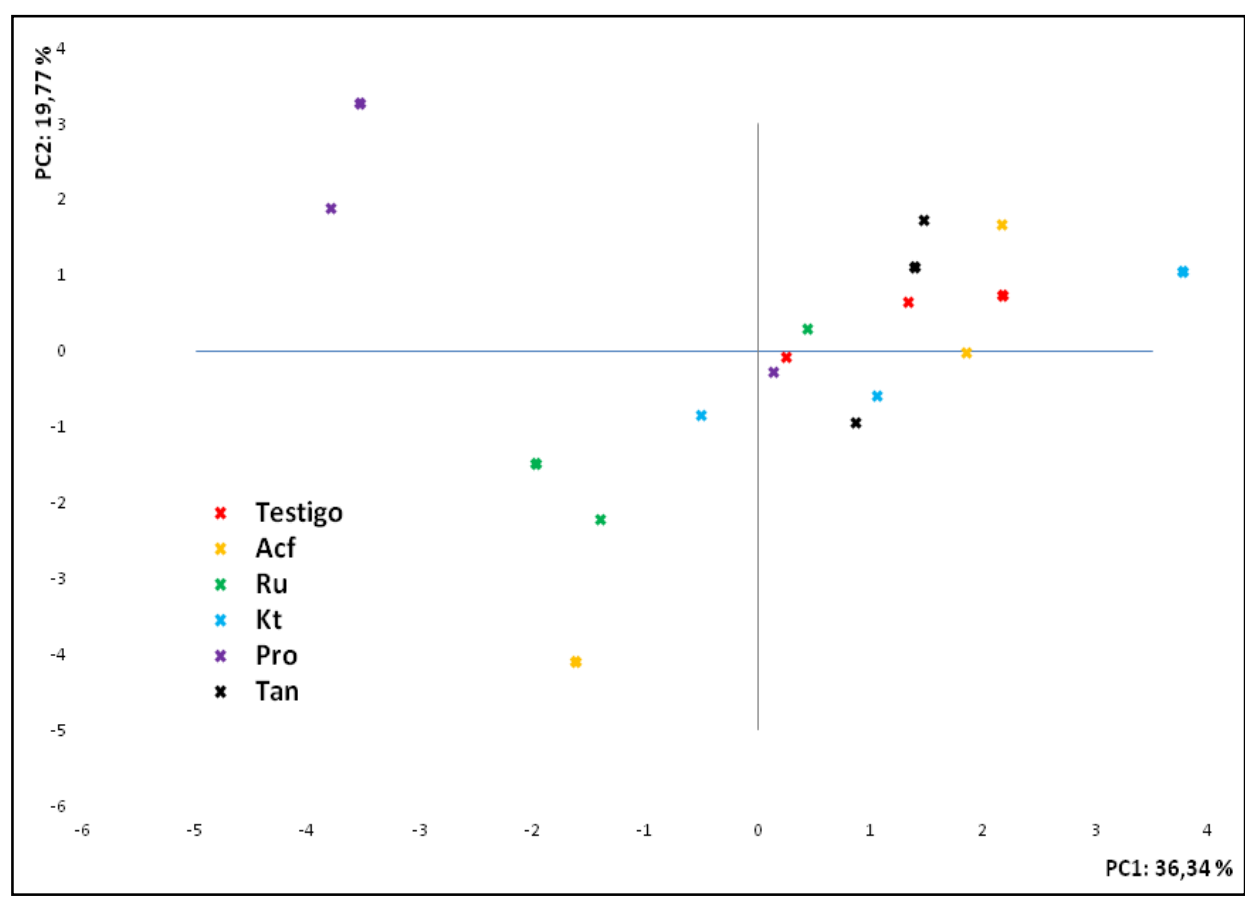

Gráfico 6.93. Primera componente frente a la segunda, en función de los copigmentos ensayados.

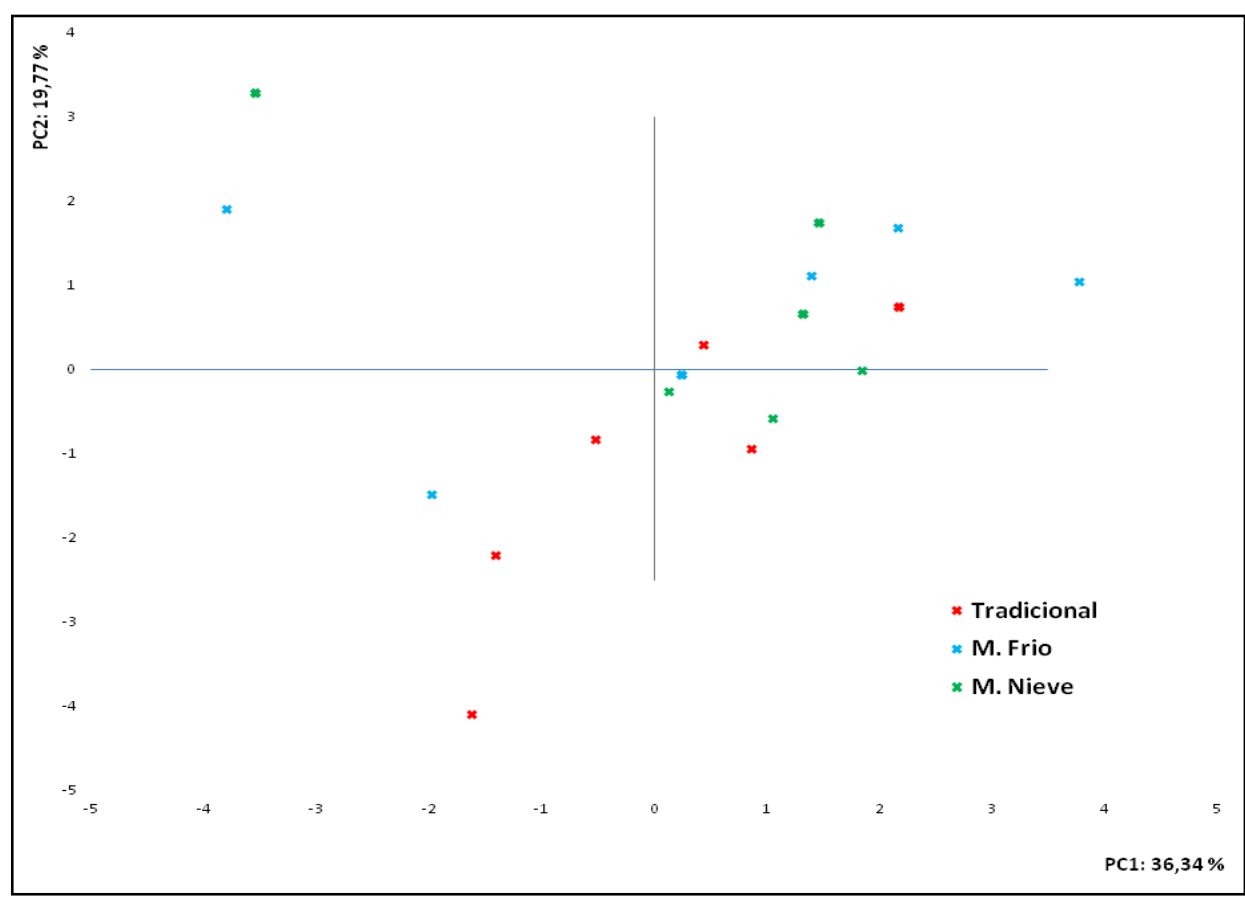

Gráfico 6.94. Primera componente frente a la segunda, en función de las técnicas de vinificación ensayadas.

En el gráfico 6.94 aparece representada la primera componente frente a la segunda en función de las técnicas de vinificación. Los vinos obtenidos por vinificación tradicional se sitúan aleatoriamente a lo largo del primer eje, mientras que los obtenidos por maceración prefermentativa se encuentran más concentrados en la zona positiva de este eje, aunque sin diferenciarse aquellos vinos macerados en frío de aquellos adicionados de nieve carbónica. Las variables que más peso tienen en la parte positiva 
del primer eje están relacionadas con la concentración y composición antociánica de los vinos.

La representación de la segunda componente frente a la tercera, la primera frente a la tercera (datos no mostrados), no permiten una mejor clasificación de los vinos en función de las técnicas de vinificación ensayadas.

\subsubsection{ANÁLISIS DE LOS VINOS A LOS 6 MESES DE CONSERVACIÓN}

A los 6 meses de conservación de los vinos en botella, se determinó la composición fenolica de los vinos y se procedió a realizar un análisis comparativo de los resultados, en función de las distintas prácticas enológicas ensayadas.

\subsubsection{ANÁLSIS MULTIFACTORIAL DE LA VARIANZA (ANOVA) DE LOS FACTORES CONSIDERADOS}

En la tabla 6.51 aparecen los datos del análisis multifactorial de la varianza (ANOVA) para los factores considerados, así como para las interacciones entre ellos. En este caso se ha estudiado el efecto de cuatro factores. Concretamente, el efecto de la adición de copigmentos, de la maceración prefermentativa, de la aplicación de la microoxigenación y, por último, de la adición pre- o postfermentativa de copigmentos.

El análisis multifactorial de la varianza muestra como todos los factores considerados (adición de copigmentos, técnicas de vinificación, aplicación de la microoxigenación y momento de adición de copigmentos) presentan diferencias estadísticamente significativas para un gran número de parámetros polifenólicos; lo que pone de manifiesto el marcado efecto de estas técnicas sobre la composición fenólica de los vinos elaborados, influyendo tanto en el color, como en la concentración y estado de los principales compuestos fenólicos identificados.

Las interacciones entre los factores $\mathrm{AD}$ (copigmentos $\mathrm{x}$ momento de adición de copigmentos), $\mathrm{BC}$ (técnica de vinificación $\mathrm{x}$ microoxigenación) y $\mathrm{CD}$ (microoxigenación $\mathrm{x}$ momento de adición) muestran un ligero efecto sobre la composición fenólica de los vinos, por el contrario la interacción BD (técnica de vinificación x momento de adición de copigmentos), presenta diferencias significativas para un mayor número de parámetros polifenólicos, indicando como la combinación de ambas técnicas podría tener una influencia positiva sobre la composición de los vinos.

La adición de copigmentos presenta un efecto mucho más marcado sobre los compuestos polifenólicos que el observado después de la fermentación maloláctica, lo que nos indica que la adición de copigmentos no solo influye en la composición de los vinos, sino también en su evolución. Los parámetros más influidos por la adición de copigmentos son la concentración de ácidos fenólicos, tono, flavonoles, antocianos totales decolorables, porcentaje del color debido a los antocianos polimerizados, porcentaje del color debido a los antocianos libres e índice de Folin, por este orden. Además, parámetros como la concentración de 3-flavanoles, derivados de antocianos o peonidina presentan también diferencias, con un nivel de significancia del 99,9\%. 


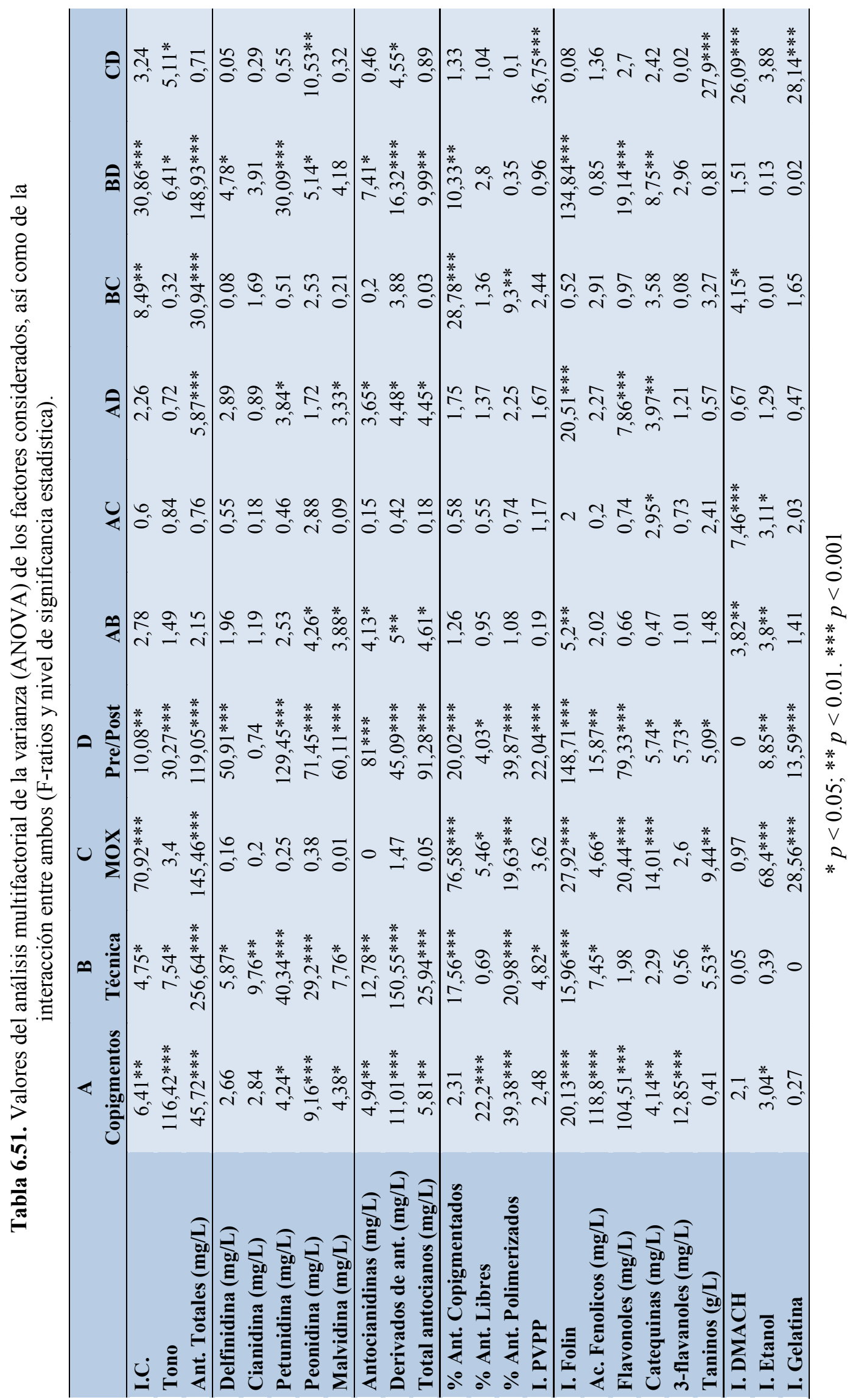


Tal como observamos en los vinos analizados después de la fermentación maloláctica, la adición de copigmentos va a actuar sobre la concentración total de polifenoles, y especialmente sobre los compuestos fenólicos en su forma simple, tales como flavonoles, y flavanoles o catequinas. Además, los elevados F-ratio mostrados por los parámetros antocianos totales, porcentaje del color que corresponde a polimerizaciones y a los antocianos en su forma libre, indican la influencia de estas técnicas en el estado de los antocianos, en el color y en el tono de los vinos (Cheynier et al., 2006), situación solo observada para el color debido a los antocianos polimerizados en los vinos recién elaborados.

Las técnicas de vinificación tienen un efecto importante sobre la concentración de antocianos totales decolorables, derivados de antocianos, petunidina, peonidina, porcentaje del color que corresponde a los antocianos polimerizados, color que corresponde a las reacciones de copigmentación e índice de Folin. Este comportamiento nos muestra la gran influencia de la maceración prefermentativa sobre la composición antociánica de los vinos y sobre el estado de estos compuestos en los vinos (Kovac et al., 1992; Gordillo et al., 2010; Heredia et al., 2010), tal como pudimos observar en estos vinos después de la fermentación maloláctica. En cambio, a lo largo de la conservación se ha minimizado el efecto de las técnicas de maceración sobre el estado y la concentración de los taninos, a diferencia de lo observado en la cosecha de 2006, en la cual, a los seis meses de conservación aún se apreciaba la elevada influencia de las técnicas de maceración en los polifenóles no antociánicos de los vinos.

El hecho de microoxigenar o no los vinos da lugar a un importante efecto sobre los antocianos totales decolorables, porcentaje del color debido a copigmentación, intensidad colorante, índice de etanol, índice de gelatina, índice de Folin, flavonoles, porcentaje del color debido a polimerizaciones y catequinas, parámetros relacionados con el color y el estado de los antocianos en el vino, pero también con el estado de los taninos. El efecto de la microoxigenación sobre el estado de los antocianos y sobre su estabilidad también fue observado en las añadas anteriores, así como por otros investigadores (Pérez-Magariño et al., 2007; Wirth et al., 2010), apreciándose también el efecto de esta técnica en las reacciones entre antociano y taninos, y en las de estos últimos entre sí o con otros compuestos, especialmente en aquellas reacciones mediadas por el oxígeno (Rayne et al., 2008; Cano-López et al., 2006, 2007, 2008, 2010).

Es interesante destacar el efecto de la microoxigenación sobre los antocianos copigmentados, efecto también observado en la cosecha 2007, lo que nos indicaría que a pesar de tratarse de vinos en proceso de envejecimiento, todavía tienen una importancia elevada las reacciones de copigmentación entre antocianos.

El factor momento de adición de copigmentos, bien previamente $\mathrm{o}$ posteriormente a la fermentación, presenta, por primera vez a lo largo de este estudio, diferencias significativas para la mayoría de parámetros considerados. Siendo el índice de Folin, el tono, los parámetros relacionados con la concentración antociánica en su forma simple (antocianos totales, antocianidinas, derivados de antocianos, etc.) y los parámetros que dan información sobre el estado de estos antocianos en los vinos (copigmentados, polimerizados e índice de PVPP), los que presentan un mayor efecto sobre la variable considerada. La baja concentración polifenólica observada en esta 
cosecha, junto con la inestabilidad de sus antocianos ocasionado por la presencia de enzimas oxidantes, pudo ser la causa de las diferencias encontradas.

La interacción entre las variables técnicas de vinificación y adición pre- o postfermentativa de copigmentos presenta diferencias significativas importantes para los parámetros antocianos totales decolorables, índice de Folin, intensidad colorante, petunidina, flavonoles y derivados de antocianos (nivel de confianza del 99,9\%). La importancia de esta interacción ha sido mostrada también en las cosechas anteriores, y pone de manifiesto que el efecto de la maceración prefermentativa es diferente en función de que la adición de copigmentos se realice en el momento de máxima concentración polifenólica en los vinos, cuando abundan las moléculas polifenólicas simples, o cuando parte de estas moléculas se encuentran formando parte de compuestos más complejos (Gómez-Míguez y Heredia, 2004; Darías-Martin et al., 2001).

\subsubsection{2. $\quad$ EFECTO DE LA ADICIÓN DE COPIGMENTOS}

En la tabla 6.52 se recogen los valores medios de los parámetros polifenólicos estudiados, en función de la adición de los distintos copigmentos. El tratamiento estadístico se ha realizando considerando conjuntamente todos los vinos, independientemente de la técnica de vinificación utilizada, del momento de adición de los copigmentos o de la microoxigenación, valorando así exclusivamente el efecto de la adición de copigmentos en los vinos de Tempranillo.

Los vinos adicionados del copigmento ácido cafeico son los que presentan los mayores valores para la intensidad colorante, aunque únicamente con diferencias estadísticas frente a los vinos adicionados de catequinas. Tanto para el parámetro tono, como para la concentración de antocianos totales decolorables, es de nuevo este copigmento el que presenta los valores más bajos, con diferencias significativas con respecto a los otros vinos, tal como observamos en los vinos después de la fermentación maloláctica. El hecho de que los vinos presente una mayor intensidad colorante y una menor concentración de antocianos decolorables fue observada repetidamente en este trabajo en los vinos que están en proceso de conservación, y puede ser debido a que en estos vinos su color no es únicamente debido a la presencia de antocianos libres fácilmente decolorables, sino a otros derivados de antocianos más estables, responsables del color de los vinos envejecidos (Cheynier et al., 2006).

Las antocianidinas monómeras cianidina y peonidina muestran el mismo comportamiento, observándose como son los vinos adicionados de proantocianidina de hollejo de uva blanca los que presentan las mayores concentraciones.

Los vinos adicionados con ácido cafeico presentan la mayor concentración de derivados de antocianos. Este comportamiento puede justificarse por los fenómenos de esterificación que sufren los antocianos monómeros con los ácidos acético, $p$-cumárico y cafeico, incrementándose finalmente su concentración en los vinos (Baldi et al., 1995; Favretto y Flamini, 2000; Monagas et al., 2003; Nuñez et al., 2004). 


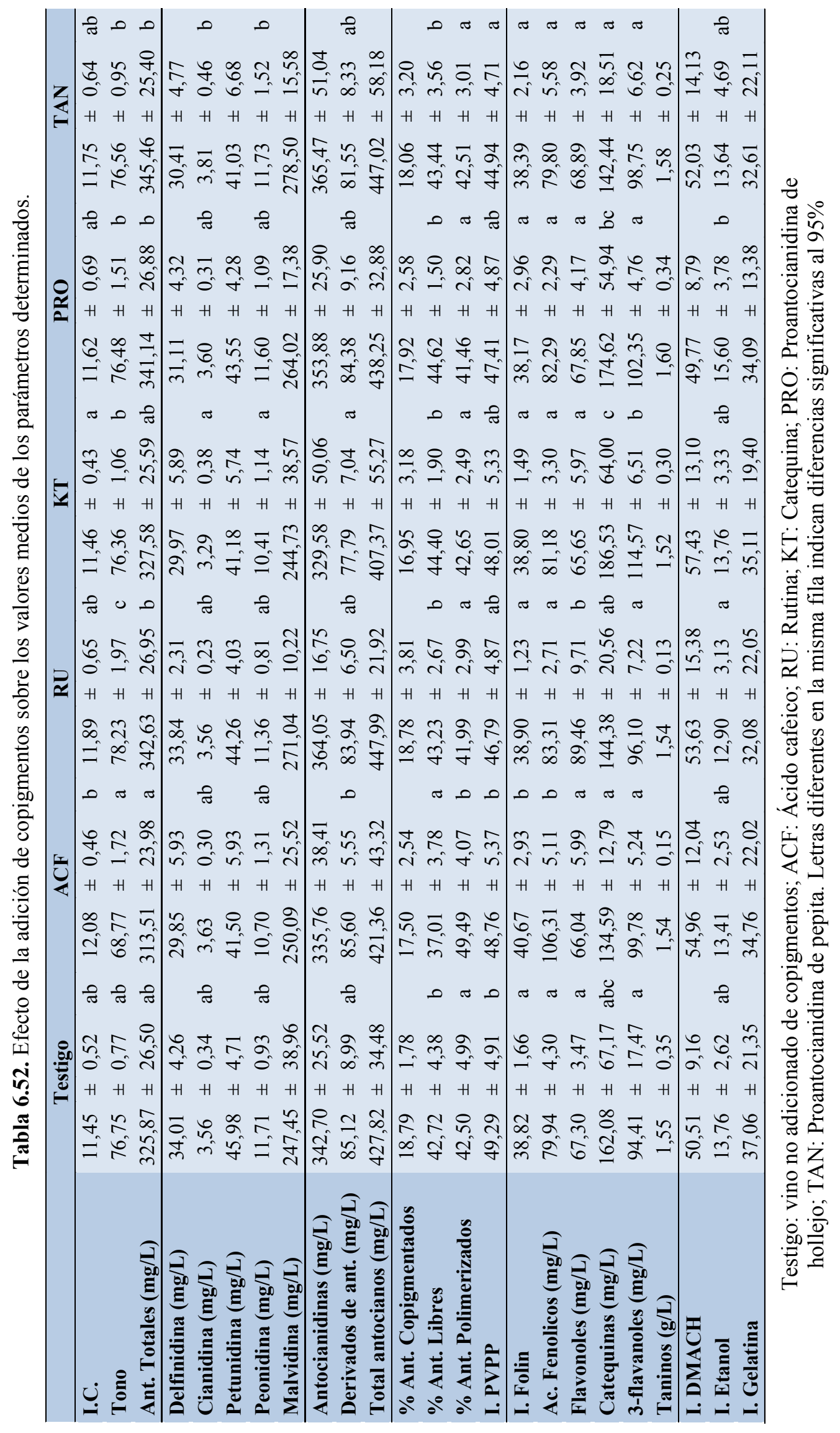


Los parámetros, porcentaje del color que corresponde a los antocianos libres, porcentaje que corresponde a los antocianos polimerizados e índice de PVPP, justifican con su comportamiento lo mencionado anteriormente sobre la relación inversa de la intensidad colorante frente a la concentración de antocianos totales decolorables. Observándose como los vinos adicionados de ácido cafeico presenta diferencias estadísticamente significativas frente al color debido a los antocianos libres y a los polimerizados, mostrando los menores y mayores valores, respectivamente. También el índice de Folin es superior en los vinos adicionados con ácido cafeico, tal como observamos en la conservación de los vinos de las añadas anteriores 2006 y 2007.

Los vinos donde predominan las reacciones de polimerización entre antocianos y taninos presentan una mayor intensidad colorante y un menor tono, a pesar de mostrar una menor concentración de antocianos en su forma libre o coloreada, y presentan un significativo incremento del color y de la estabilidad de la materia colorante a los 6 meses de conservación de los vinos en botella, en relación a lo observado al concluir la fermentación (Cheynier et al., 1999, 2006; Vidal et al., 2002; Koyama et al., 2007).

La ausencia de diferencias significativas para el porcentaje de color debido a los antocianos copigmentados, así como el descenso de este porcentaje, indica un rápido desdoblamiento de estos complejos, despareciendo las diferencias observadas en los vinos analizados posteriormente al embotellado (tabla 6.45).

Tanto para la concentración de los ácidos fenólicos (ácido cafeico), como para la de flavonoles (rutina) y catequinas o 3-flavanoles (catequina) son los vinos adicionados de los respectivos copigmentos los que muestran los mayores valores con diferencias significativas frente a los otros vinos estudiados.

Los vinos adicionados de proantocianidina de pepita son los que muestran los mayores valores para el índice de etanol, quizás debido a la gran reactividad de estas proantocianidinas para reaccionar con polisacáridos, péptidos y sales.

\subsubsection{EFECTO DE LAS TÉCNICAS DE VINIFICACIÓN}

En la tabla 6.53 se recogen los valores medios de los parámetros polifenólicos analizados considerando conjuntamente los distintos vinos elaborados según que la vinificación se realice de forma tradicional o bien con maceración prefermentativa.

Las técnicas de maceración prefermentativa aplicadas incrementan de forma significativa la concentración de antocianos totales decolorables, la concentración de cianidina, petunidina y peonidina, la concentración total de antocianidinas, los derivados de antocianos y la concentración total de antocianos, en los vinos elaborados. No observándose diferencias significativas entre la maceración prefermentativa realizada con frío y la efectuada con nieve carbónica.

Similar comportamiento lo hemos observado en los vinos de 2008 después de la fermentación maloláctica, manteniéndose estas diferencias a lo largo de los seis meses de conservación. El efecto de la maceración prefermentativa sobre la concentración y estado de los antocianos en los vinos, también ha sido observado en los vinos elaborados en las añadas 2006 y 2007, observándose en estos vinos un efecto más significativo de la maceración prefermentativa con nieve carbónica. En vista de los resultados obtenidos a lo largo de este estudio, se confirma que la maceración prefermentativa es una técnica favorable para favorecer la presencia de estos 
compuestos durante la fermentación, manteniéndose su efecto con el paso del tiempo, tal como observaron otros autores (Parenti et al., 2004; Álvarez et al., 2005; Manchon et al., 2005; Gil-Muñoz et al., 2009; Gómez-Míguez et al., 2006; Gordillo et al., 2010).

Se observa también que los vinos elaborados con maceración prefermentativa tienen un porcentaje ligeramente superior de color debido a los antocianos copigmentados, diferencia que no se encontró en los vinos después de la fermentación maloláctica. Esta mejor conservación de los antocianos copigmentados también fue observado a lo largo de la vendimia 2006.

La maceración prefermentativa ha provocado también un incremento en la extracción de taninos de las partes sólidas de la uva, mostrando significancia estadística para este parámetro tanto en postmaloláctica como a los seis meses de conservación.

Tabla 6.53. Efecto de las técnicas de vinificación sobre los valores medios de los parámetros determinados.

\begin{tabular}{|c|c|c|c|c|c|c|c|c|}
\hline & \multicolumn{2}{|c|}{ Tradicional } & \multicolumn{3}{|c|}{ Frio } & \multicolumn{3}{|c|}{ Nieve } \\
\hline I.C. & 11,85 & $\pm 0,38$ & 11,62 & $\pm 0,73$ & & 11,58 & $\pm 0,54$ & \\
\hline Tono & 75,81 & $\pm 3,24$ & 75,02 & $\pm 3,79$ & & 75,46 & $\pm 4,03$ & \\
\hline Ant. Totales (mg/L) & 320,17 & $\pm 21,99$ & a 350,11 & $\pm 24,95$ & $\mathrm{~b}$ & 355,13 & $\pm 28,41$ & $\mathrm{~b}$ \\
\hline Delfinidina (mg/L) & 29,98 & $\pm 3,62$ & 32,63 & $\pm 5,50$ & & 31,21 & $\pm 6,38$ & \\
\hline Cianidina (mg/L) & 3,41 & $\pm 0,26$ & 3,74 & $\pm 0,37$ & $\mathrm{~b}$ & 3,75 & $\pm 0,29$ & $\mathrm{~b}$ \\
\hline Petunidina (mg/L) & 40,42 & $\pm 2,90$ & 44,86 & $\pm 6,26$ & $\mathrm{~b}$ & 45,31 & $\pm 3,69$ & $\mathrm{~b}$ \\
\hline Peonidina (mg/L) & 10,72 & $\pm 0,83$ & 11,70 & $\pm 1,37$ & $\mathrm{~b}$ & 11,5 & $\pm 1,06$ & $\mathrm{~b}$ \\
\hline Malvidina (mg/L) & 250,15 & $\pm 22,93$ & 264,96 & $\pm 32,25$ & & 261,94 & $\pm 29,46$ & \\
\hline Antocianidinas (mg/L) & 334,67 & $\pm 28,80$ & a 357,89 & $\pm 44,51$ & $\mathrm{~b}$ & 353,71 & $\pm 32,15$ & $\mathrm{~b}$ \\
\hline Derivados de ant. (mg/L) & 77,54 & $\pm 3,84$ & a 88,22 & $\pm 6,68$ & $\mathrm{~b}$ & 92,46 & $\pm 5,24$ & $\mathrm{~b}$ \\
\hline Total antocianos (mg/L) & 412,21 & $\pm 30,24$ & a 446,11 & $\pm 50,50$ & $\mathrm{~b}$ & 446,17 & $\pm 48,95$ & $\mathrm{~b}$ \\
\hline \% Ant. Copigmentados & 13,09 & $\pm 3,22$ & a 14,77 & $\pm 2,50$ & $\mathrm{~b}$ & 15,42 & $\pm 2,86$ & $\bar{b}$ \\
\hline$\%$ Ant. Libres & 42,60 & $\pm 3,90$ & 42,51 & $\pm 4,07$ & & 42,38 & $\pm 4,12$ & \\
\hline$\%$ Ant. Polimerizados & 42,63 & $\pm 4,20$ & 44,41 & $\pm 4,29$ & & 42,2 & $\pm 4,65$ & \\
\hline I. PVPP & 48,09 & $\pm 4,74$ & 46,66 & $\pm 5,34$ & & 48,36 & $\pm 6,54$ & \\
\hline I. Folin & 39,45 & $\pm 2,82$ & 38,49 & $\pm 1,58$ & & 40,12 & $\pm 1,98$ & \\
\hline Ac. Fenolicos (mg/L) & 84,82 & $\pm 8,98$ & 87,13 & $\pm 11,91$ & & 88,46 & $\pm 9,23$ & \\
\hline Flavonoles (mg/L) & 70,78 & $\pm 11,55$ & 71,60 & $\pm 9,60$ & & 72,64 & $\pm 12,46$ & \\
\hline Catequinas (mg/L) & 162,17 & $\pm 62,41$ & 167,42 & $\pm 17,61$ & & 168,35 & $\pm 35,46$ & \\
\hline 3-flavanoles (mg/L) & 102,97 & $\pm 8,48$ & 100,22 & $\pm 10,99$ & & 103,29 & $\pm 11,49$ & \\
\hline $\operatorname{Taninos}(\mathrm{g} / \mathrm{L})$ & 1,36 & $\pm 0,26$ & 1,48 & $\pm 0,22$ & $\mathrm{~b}$ & 1,5 & $\pm 0,16$ & $\mathrm{~b}$ \\
\hline I. DMACH & 52,65 & $\pm 17,96$ & 52,10 & $\pm 18,18$ & & 51,62 & $\pm 15,46$ & \\
\hline I. Etanol & 14,06 & $\pm 3,45$ & 13,65 & $\pm 3,59$ & & 15,49 & $\pm 4,02$ & \\
\hline I. Gelatina & 32,25 & $\pm 20,13$ & 32,90 & $\pm 19,64$ & & 30,91 & $\pm 16,4$ & \\
\hline
\end{tabular}

Tradicional: elaboración sin maceración en frío previamente a la fermentación; Frío: aplicación de bajas temperaturas de forma prefermentativa; Nieve: uso de nieve carbónica prefermentativamente. Letras diferentes en la misma fila indican diferencias significativas al $95 \%$. 
En resumen, podemos establecer que los vinos elaborados de forma tradicional tienen una menor concentración antociánica, sobre todo de compuestos monómeros, no afectando esta situación de forma decisiva a las características cromáticas y estructurales de los vinos, ni tampoco al estado de los otros compuestos fenólicos presentes en los vinos.

\subsubsection{EFECTO DE LA MICROOXIGENACIÓN}

En la tabla 6.54 se recogen los valores medios de los parámetros polifenólicos analizados considerando conjuntamente a todos aquellos vinos que han sido microoxigenados frente a aquellos vinos a los que no se les ha realizado adición de acetaldehído.

Tabla 6.54. Efecto de la microoxigenación sobre los valores medios de los parámetros determinados.

\begin{tabular}{|c|c|c|c|c|c|c|}
\hline & \multicolumn{3}{|c|}{ No MOX } & \multicolumn{3}{|c|}{ MOX } \\
\hline I.C. & 11,38 & $\pm 0,57$ & a & 12,08 & $\pm 0,36$ & \\
\hline Tono & 75,11 & $\pm 3,81$ & & 75,72 & $\pm 3,25$ & \\
\hline Ant. Totales (mg/L) & 345,5 & $\pm 21,34$ & $\mathrm{~b}$ & 324,74 & $\pm 29,80$ & a \\
\hline Delfinidina (mg/L) & 31,14 & $\pm 5,08$ & & 31,48 & $\pm 4,61$ & \\
\hline Cianidina (mg/L) & 3,60 & $\pm 0,38$ & & 3,55 & $\pm 0,35$ & \\
\hline Petunidina (mg/L) & 42,36 & $\pm 5,71$ & & 42,91 & $\pm 5,02$ & \\
\hline Peonidina (mg/L) & 11,16 & $\pm 1,36$ & & 11,26 & $\pm 1,10$ & \\
\hline Malvidina (mg/L) & 257,70 & $\pm 29,74$ & & 257,42 & $\pm 28,22$ & \\
\hline Antocianidinas (mg/L) & 345,95 & $\pm 41,05$ & & 346,61 & $\pm 37,53$ & \\
\hline Derivados de & 82,30 & $\pm 7,65$ & & 83,46 & $\pm 7,74$ & \\
\hline Total antocis & 428,25 & $\pm 47,30$ & & 430,07 & $\pm 42,76$ & \\
\hline \% Ant. Copigmentados & 15,55 & $\pm 1,77$ & $\mathrm{~b}$ & 12,30 & $\pm 3,08$ & \\
\hline$\%$ Ant. & 42,13 & $\pm 4,00$ & & 42,98 & $\pm 3,93$ & \\
\hline$\%$ Ant. & 42,31 & $\pm 4,11$ & $\mathrm{a}$ & 44,72 & $\pm 4,21$ & 0 \\
\hline I. PVPP & 48,49 & $\pm 6,35$ & & 48,26 & $\pm 3,03$ & \\
\hline I. Folin & 38,50 & $\pm 2,15$ & & 39,44 & $\pm 2,41$ & \\
\hline Ac. Fenolicos (mg/L) & 87,20 & $\pm 10,49$ & & 84,75 & $\pm 10,59$ & \\
\hline Flavonoles (mg/L) & 69,39 & $\pm 11,11$ & & 72,99 & $\pm 9,79$ & \\
\hline Catequinas (mg/L) & 148,4 & $\pm 18,42$ & $\mathrm{a}$ & 161,2 & $\pm 27,73$ & \\
\hline 3-flavanoles (mg/L) & 103,6 & $\pm 8,18$ & & 99,54 & $\pm 10,99$ & \\
\hline $\operatorname{Taninos}(\mathrm{g} / \mathrm{L})$ & 1,37 & $\pm 0,26$ & & 1,47 & $\pm 0,24$ & \\
\hline I. DMACH & 49,84 & $\pm 15,57$ & & 52,91 & $\pm 19,93$ & \\
\hline I. Etanol & 11,86 & $\pm 3,12$ & $\mathrm{a}$ & 15,84 & $\pm 2,65$ & \\
\hline I. Gelatina & 42,04 & $\pm 7,25$ & $\mathrm{~b}$ & 23,12 & $\pm 8,21$ & \\
\hline
\end{tabular}

No MOX: vinos no adicionados de acetaldehído; MOX: vinos adicionados de acetaldehído. Letras diferentes en la misma fila indican diferencias significativas al 95\%

La adición controlada de acetaldehído ha provocado un incremento significativo de la intensidad colorante de los vinos, junto con un incremento del porcentaje del color que corresponde a los antocianos polimerizados con los taninos. Este comportamiento 
justifica el razonamiento realizado, en varias ocasiones en este trabajo, de la importancia tanto de los polímeros de antocianos, como de compuestos antociánicos más complejos (piranoantocianos) en el color de los vinos envejecidos. Además, el hecho de que la concentración de antocianos totales decolorables sea superior en los vinos no microoxigenados, justifica este mecanismo. Este mismo comportamiento lo observamos en los vinos de las cosechas anteriores.

El porcentaje del color que corresponde a los antocianos copigmentados muestra diferencias significativas, con porcentajes más elevados para la vinificación tradicional. Seguramente la participación de los antocianos en las reacciones con los taninos, favorecidas por la adición de oxígeno, sea la responsable de la disminución del número de estas uniones en los vinos microoxigenados. Cejudo-Bastante et al. (2011), estudiando el efecto de la micooxigenación y de la adición de chips sobre la composición fenólica y las características sensoriales de vinos de Petit Verdot, observaron como el color debido a la copigmentación presenta valores superiores en los vinos no microoxigenados, después de la aplicación de oxígeno, una vez finalizada la fermentación maloláctica y posteriormente al contacto del vino con los chips. Además observa como aquellos vinos microoxigenados presentan valores más elevados del color que corresponde a polimerizaciones. Este mismo comportamiento lo hemos encontrado en los vinos de 2007 después de 12 meses de conservación.

Al cabo de seis meses de conservación, la técnica de la microoxigenación afectó más a la estabilidad de los antocianos que a su concentración, pero trajo consigo un incremento de la intensidad colorante de los vinos microoxigenados, un mayor número de uniones entre antocianos y taninos mediadas por el acetaldehído, y una disminución de la astringencia por la participación de compuestos monómeros en reacciones mediadas por el oxígeno (Cano-López et al., 2006, 2007, 2008, 2010; Pérez-Magariño et al., 2007; Wirth et al., 2010; Rayne et al., 2008 ).

Pérez-Magariño et al. (2007), estudiando el efecto de la microoxigenación durante tres vendimias consecutivas observaron como esta técnica provoca una disminución del contenido fenólico de los vinos, aunque reduciendo parcialmente la habitual caída del color que ocurre después de la fermentación maloláctica.

La menor astringencia observada en los vinos microoxigenados puede ser debida al mayor número de uniones entre taninos y polisacáridos, que afectan a las características organolépticas de los vinos, disminuyendo la sensación de astringencia (Zamora, 2003). Esta disminución de la astringencia ocasionada por la microoxigenación, también fue observada en los vinos elaborados en la añada 2007.

\subsubsection{EFECTO DEL MOMENTO DE ADICIÓN DE LOS COPIGMENTOS}

En la tabla 6.55 se recogen los valores medios de los parámetros polifenólicos analizados considerando conjuntamente a todos aquellos que han sido adicionados de copigmentos previamente o posteriormente a la fermentación de los vinos.

La adición de copigmentos posteriormente a la fermentación ha provocado un efecto favorable sobre la presencia de los principales compuestos antociánicos que 
forman parte de la componente cromática de los vinos. Los parámetros antocianos totales, las antocianidinas: delfinidina, peonidina, petunidina y malvidina, la suma de antocianidinas, los derivados de antocianos y el total de antocianos presentan diferencias significativas con valores superiores a la adición prefermentativa.

Estos resultados, junto con los observados para el porcentaje del color debido a los antocianos copigmentados y para el índice de PVPP, ponen de manifiesto un efecto favorable de la adición postfermentativa frente a la protección de los antocianos. La elevada concentración de flavonoles, también puede haber contribuído a favorecer las reacciones de copigmentación. También la adición postfermentativa de copigmentos contribuye a mantener una mayor concentración de compuestos fenólicos en los vinos.

Tabla 6.55. Efecto del momento de adición de copigmentos sobre los valores medios de los parámetros determinados.

\begin{tabular}{lcccccccc}
\hline & \multicolumn{3}{c}{ PRE } & \multicolumn{4}{c}{ POST } \\
\hline I.C. & 11,90 & \pm & 0,48 & & 11,63 & \pm & 0,68 & \\
Tono & 74,43 & \pm & 3,61 & 76,13 & \pm & 3,59 & \\
Ant. Totales (mg/L) & 324,40 & \pm & 19,90 & a & 343,73 & \pm & 31,39 & b \\
\hline Delfinidina (mg/L) & 27,82 & \pm & 4,16 & a & 34,25 & \pm & 2,91 & b \\
Cianidina (mg/L) & 3,54 & \pm & 0,41 & & 3,62 & \pm & 0,32 & \\
Petunidina (mg/L) & 38,62 & \pm & 3,43 & a & 45,99 & \pm & 4,20 & b \\
Peonidina (mg/L) & 10,44 & \pm & 1,07 & a & 11,88 & \pm & 0,97 & b \\
Malvidina (mg/L) & 236,49 & \pm & 28,28 & a & 274,44 & \pm & 12,67 & b \\
\hline Antocianidinas (mg/L) & 316,90 & \pm & 35,47 & a & 370,17 & \pm & 19,75 & b \\
Derivados de ant. (mg/L) & 79,86 & \pm & 6,75 & a & 85,45 & \pm & 7,46 & b \\
Total antocianos (mg/L) & 396,76 & \pm & 39,55 & a & 455,62 & \pm & 26,75 & b \\
\hline \% Ant. Copigmentados & 12,95 & \pm & 2,63 & a & 14,73 & \pm & 3,27 & b \\
\% Ant. Libres & 41,94 & \pm & 3,91 & & 43,14 & \pm & 3,95 & \\
\% Ant. Polimerizados & 45,11 & \pm & 3,76 & & 42,13 & \pm & 4,25 & \\
I. PVPP & 45,25 & \pm & 4,41 & a & 49,12 & \pm & 5,01 & b \\
\hline I. Folin & 37,78 & \pm & 1,57 & a & 40,19 & \pm & 2,46 & b \\
Ac. Fenolicos (mg/L) & 84,76 & \pm & 11,30 & & 88,39 & \pm & 10,14 & \\
Flavonoles (mg/L) & 67,65 & \pm & 8,48 & a & 75,51 & \pm & 11,83 & b \\
Catequinas (mg/L) & 153,03 & \pm & 24,88 & & 170,21 & \pm & 54,04 & \\
3-flavanoles (mg/L) & 100,16 & \pm & 8,65 & & 104,46 & \pm & 8,51 & \\
Taninos (g/L) & 1,38 & \pm & 0,31 & & 1,47 & \pm & 0,12 & \\
\hline I. DMACH & 52,49 & \pm & 14,08 & & 52,63 & \pm & 21,33 & \\
I. Etanol & 13,08 & \pm & 3,54 & & 14,65 & \pm & 3,52 & \\
I. Gelatina & 25,97 & \pm & 10,35 & a & 37,89 & \pm & 24,51 & b \\
\hline
\end{tabular}

PRE: adición de copigmentos previamente al inicio de la fermentación alcohólica; POST: adición de copigmentos en el embotellado. Letras diferentes en la misma fila indican diferencias significativas al $95 \%$ 


\subsubsection{CORRELACIÓN ENTRE LOS PARÁMETROS POLIFENÓLICOS DE LOS VINOS, LA ADICIÓN DE COPIGMENTOS, LAS TÉCNICAS DE VINIFICACIÓN Y EL MOMENTO DE ADICIÓN DE LOS COPIGMENTOS}

En la tabla 6.56 se observa la matriz de correlaciones de las variables utilizadas en el análisis, pudiendo observarse como el índice de Folin muestra correlaciones positivas importantes con los parámetros antociánicos delfinidina, petunidina, antocianidinas y total de antocianos, lo que indica que el incremento de la composición antociánica conducirá a una mayor concentración fenólica.

La concentración de antocianos totales decolorables por el sulfuroso presenta coeficientes positivos con los parámetros delfinidina, petunidina, peonidina, antocianidinas, derivados de antocianos y total de antocianos, además de para el porcentaje del color que corresponde a copigmentación. Lo cual pone de manifiesto la importancia de la presencia de una importante concentración de antocianos en su forma libre para poder actuar en este tipo de uniones con cofactores o copigmentos.

Versari et al. (2008) estudiando diferentes métodos para la determinación de antocianos en los vinos observan como los niveles de copigmentacion pueden ser casi totalmente descritos por los niveles de monómeros de antocianos, citando como existe una correlación directa importante $\left(\mathrm{R}^{2}=0.9464\right)$ entre la copigmentación y los antocianos monómeros determinados mediante HPLC.

La correlación positiva entre el tono y el porcentaje del color que corresponde a los antocianos libres está relacionada con las correlaciones negativas entre el tono y entre el color que corresponde a los antocianos libres frente al porcentaje del color que corresponde a polimerizaciones y con la concentración de ácidos fenólicos. La inestabilidad de los antocianos libres frente a la oxidación es la responsable del incremento del tono observado, relacionado, a su vez, con la protección frente al color que ofrecen las polimerizaciones. Además, la participación de los ácidos fenólicos en reacciones de esterificación de los antocianos monómeros parece que favorece las reacciones posteriores con los taninos, incrementándose las polimerizaciones. GómezMíguez et al. (2006) indican que tienen lugar reacciones distintas a las de copigmentación cuando se añaden al vino los copigmentos ácido cafeico y catequina. Este razonamiento podría justificarse la relación positiva entre el color debido a polimerización y los ácidos fenólicos

Se observa una correlación positiva entre los antocianos totales decolorables y el color debido a la copigmentación, siendo negativa la correlación entre estos antocianos y el color debido a las polimerizaciones; lo que pone de manifiesto que si los antocianos están formando parte de complejos con los taninos, no están disponibles para participar en reacciones de copigmentación, y viceversa (Somers, 1971; Boulton, 2001).

El índice de PVPP muestra una correlación negativa frente al índice de $\mathrm{DMACH}$, indicando que las polimerizaciones entre antociano-etil-tanino se producen paralelamente a la polimerización entre taninos. A pesar de que los taninos estén unidos con los antocianos, la parte tánica de la molécula puede seguir reaccionando, incrementándose el peso molecular medio de los taninos en el vino (Remy et al., 2000). 


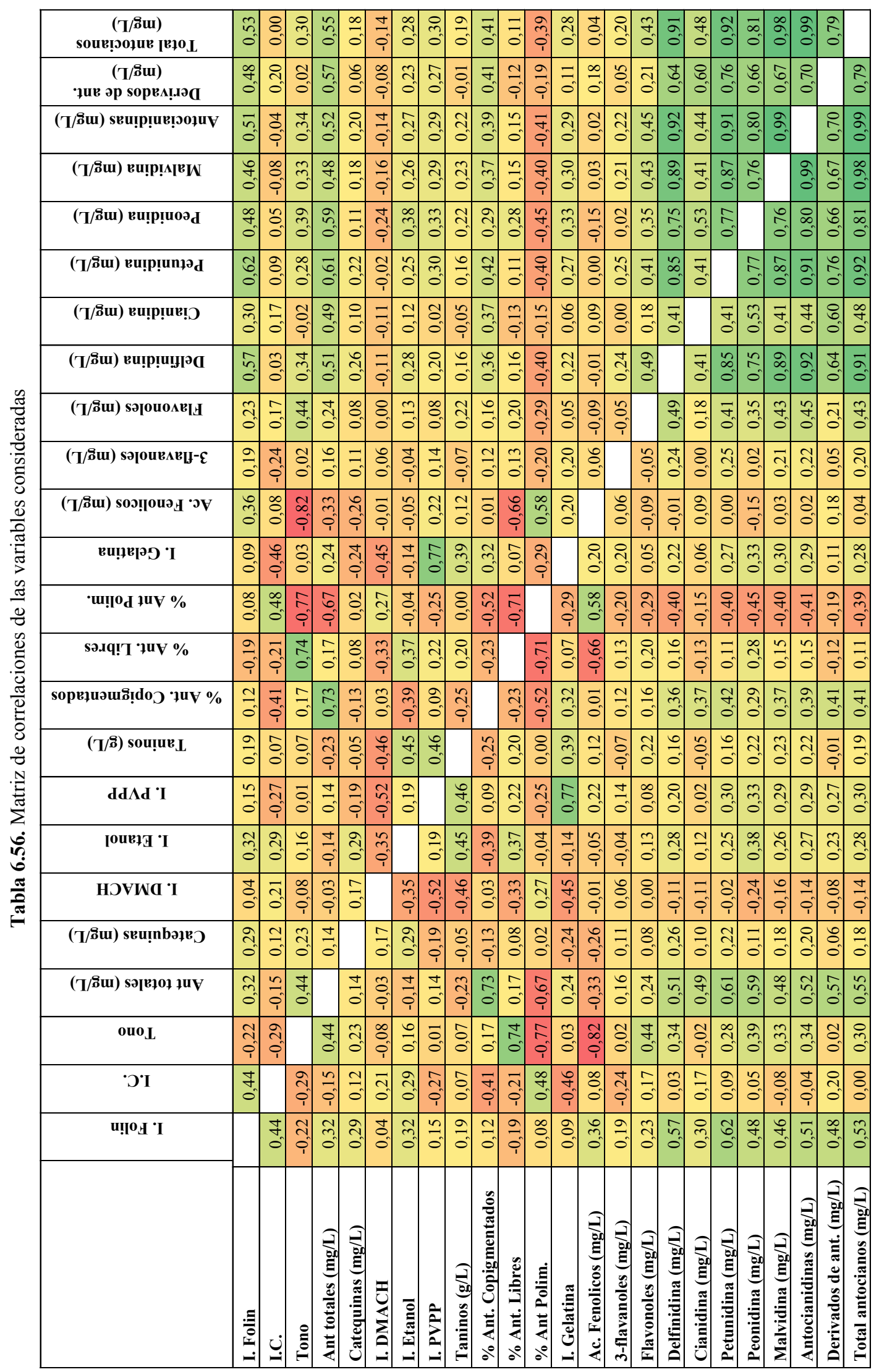


En la tabla 6.57 aparece tanto el autovalor como el porcentaje de varianza acumulada por los sucesivos factores, observándose como son necesarios seis factores para que el autovalor descienda por debajo de la unidad. Además comprobamos como el porcentaje de varianza acumulada corresponde al $81.27 \%$.

En la tabla 6.58 aparecen los valores de los coeficientes de las ecuaciones que forman cada uno de las seis componentes principales identificados. El primer componente principal identificado muestra coeficientes negativos para los parámetros delfinidina, petunidina, peonidina, malvidina, antociandinas, derivados de antocianos y total de antocianos, caracterizándose los vinos situados en la parte negativa por presentar una elevada concentración antociánica en su forma monómer

Tabla 6.57. Autovalor, varianza explicada y acumulada para las componentes consideradas en el análisis

\begin{tabular}{cccc}
\hline Componente & Autovalor & \% Varianza & \% Acumulado \\
\hline $\mathbf{1}$ & 8,299 & 33,196 & 33,196 \\
$\mathbf{2}$ & 3,516 & 14,063 & 47,258 \\
$\mathbf{3}$ & 3,369 & 13,475 & 60,733 \\
$\mathbf{4}$ & 2,683 & 10,731 & 71,465 \\
$\mathbf{5}$ & 1,368 & 5,471 & 76,936 \\
$\mathbf{6}$ & 1,084 & 4,337 & 81,272 \\
$\mathbf{7}$ & 0,784 & 3,137 & 84,409 \\
$\mathbf{8}$ & 0,738 & 2,953 & 87,362 \\
$\mathbf{9}$ & 0,701 & 2,804 & 90,166 \\
$\mathbf{1 0}$ & 0,509 & 2,037 & 92,204 \\
$\mathbf{1 1}$ & 0,457 & 1,827 & 94,031 \\
$\mathbf{1 2}$ & 0,376 & 1,503 & 95,534 \\
$\mathbf{1 3}$ & 0,326 & 1,304 & 96,838 \\
$\mathbf{1 4}$ & 0,212 & 0,847 & 97,686 \\
$\mathbf{1 5}$ & 0,130 & 0,521 & 98,207 \\
$\mathbf{1 6}$ & 0,114 & 0,457 & 98,664 \\
$\mathbf{1 7}$ & 0,087 & 0,349 & 99,012 \\
$\mathbf{1 8}$ & 0,078 & 0,311 & 99,324 \\
$\mathbf{1 9}$ & 0,063 & 0,251 & 99,575 \\
$\mathbf{2 0}$ & 0,051 & 0,204 & 99,779 \\
$\mathbf{2 1}$ & 0,038 & 0,153 & 99,932 \\
$\mathbf{2 2}$ & 0,017 & 0,068 & 100,000 \\
\hline
\end{tabular}

Los parámetros polifenólicos índice de Folin, intensidad colorante, color de los antocianos polimerizados y ácidos fenólicos presentan asociaciones directas respecto al segundo eje principal considerado. Por el contrario, el tono y el porcentaje del color debido a los antocianos libres, presentan asociación indirecta sobre este componente.

Los vinos situados en la zona positiva del segundo componente presentan un gran número de uniones entre antocianos y taninos, dando lugar a un incremento del color de los vinos, así como favoreciéndose la presencia de una adecuada concentración 
fenólica. Además, en estos vinos las elevadas concentraciones de ácidos fenólicos afectan decisivamente sobre las características cromáticas y estructurales.

En cuanto a los vinos situados en la zona negativa, la componente amarilla del color será la responsable de una parte importante de este, debido a la elevada importancia de los antocianos libres inestables, fácilmente oxidables sobre las características cromáticas.

El tercer componente principal esta relacionado positivamente con parámetros como el índice de etanol, índice de PVPP, taninos, sugiriendo vinos con una elevada concentración tánica, viéndose favorecidas tanto las uniones con los antocianos, como con polisacáridos, péptidos o sales, afectando estas reacciones a las propiedades sensoriales de los vinos. En su parte negativa está relacionado con los antocianos totales, el índice de DMACH y con el color que corresponde a copigmentaciones. Dando lugar a vinos con una elevada concentración antociánica, favoreciéndose las reacciones de copigmentación, donde los taninos están formando parte de polimerizaciones con ellos mismos y no con los antocianos.

Tabla 6.58. Tabla de pesos de los componentes

\begin{tabular}{lcccccc}
\hline & \multicolumn{7}{c}{ Componentes } \\
& $\mathbf{1}$ & $\mathbf{2}$ & $\mathbf{3}$ & $\mathbf{4}$ & $\mathbf{5}$ & $\mathbf{6}$ \\
\hline I. Folin & $-0,18$ & 0,32 & 0,01 & 0,08 & 0,19 & $-0,07$ \\
I.C. & 0,02 & 0,31 & 0,09 & 0,35 & $-0,19$ & 0,03 \\
Tono & $-0,15$ & $-0,42$ & 0,02 & 0,21 & $-0,02$ & 0,15 \\
Ant totales (mg/L) & $-0,24$ & $-0,13$ & $-0,26$ & $-0,02$ & $-0,17$ & $-0,20$ \\
Catequinas (mg/L) & $-0,07$ & 0,02 & $-0,02$ & 0,34 & 0,33 & $-0,25$ \\
I. DMACH & 0,08 & 0,11 & $-0,30$ & 0,24 & 0,18 & 0,27 \\
I. Etanol & $-0,11$ & 0,06 & 0,37 & 0,24 & 0,03 & $-0,28$ \\
I. PVPP & $-0,13$ & $-0,03$ & 0,28 & $-0,38$ & 0,03 & $-0,07$ \\
Taninos (g/L) & $-0,08$ & 0,03 & 0,41 & $-0,10$ & 0,04 & 0,21 \\
\% Ant. Copigmentados & $-0,17$ & $-0,07$ & $-0,35$ & $-0,24$ & $-0,17$ & 0,04 \\
\%o Ant. Libres & $-0,09$ & $-0,40$ & 0,21 & 0,15 & 0,09 & $-0,10$ \\
\% Ant Polim. & 0,20 & 0,40 & 0,07 & 0,04 & 0,04 & 0,06 \\
I. Gelatina & $-0,13$ & $-0,07$ & 0,12 & $-0,48$ & 0,07 & 0,05 \\
Ac. Fenolicos (mg/L) & 0,03 & 0,41 & 0,02 & $-0,30$ & 0,09 & 0,10 \\
3-flavanoles (mg/L) & $-0,08$ & $-0,03$ & $-0,10$ & $-0,11$ & 0,65 & $-0,21$ \\
Flavonoles (mg/L) & $-0,17$ & $-0,03$ & 0,04 & 0,15 & $-0,08$ & 0,63 \\
Delfinidina (mg/L) & $-0,31$ & 0,07 & $-0,02$ & 0,07 & 0,14 & 0,12 \\
Cianidina (mg/L) & $-0,18$ & 0,14 & $-0,13$ & 0,02 & $-0,35$ & $-0,31$ \\
Petunidina (mg/L) & $-0,32$ & 0,10 & $-0,04$ & 0,04 & 0,09 & 0,05 \\
Peonidina (mg/L) & $-0,30$ & 0,01 & 0,07 & 0,04 & $-0,17$ & $-0,10$ \\
Malvidina (mg/L) & $-0,32$ & 0,06 & 0,00 & 0,00 & 0,10 & 0,14 \\
Antocianidinas (mg/L) & $-0,33$ & 0,07 & 0,00 & 0,02 & 0,09 & 0,12 \\
Derivados de ant. (mg/L) & $-0,26$ & 0,20 & $-0,06$ & 0,00 & $-0,23$ & $-0,19$ \\
Total antocianos (mg/L) & $-0,33$ & 0,09 & $-0,01$ & 0,01 & 0,04 & 0,07 \\
\hline
\end{tabular}


Por último, el cuarto componente principal se correlaciona de forma directa con la intensidad colorante y con las catequinas y de forma negativa con índice de PVPP, índice de gelatina y con la concentración de ácidos fenólicos. El quinto presenta correlaciones importantes con las catequinas, 3-flavanoles y la cianidina, y el sexto con catequinas, índice de etanol, flavonoles y cianidina.

Obtenidos los coeficientes de las componentes principales, se calcularon los coeficientes de las combinaciones lineales sobre las variables antiguas que definen las variables nuevas, para poder calcular a partir de ellos las nuevas coordenadas de los objetos en las componentes.

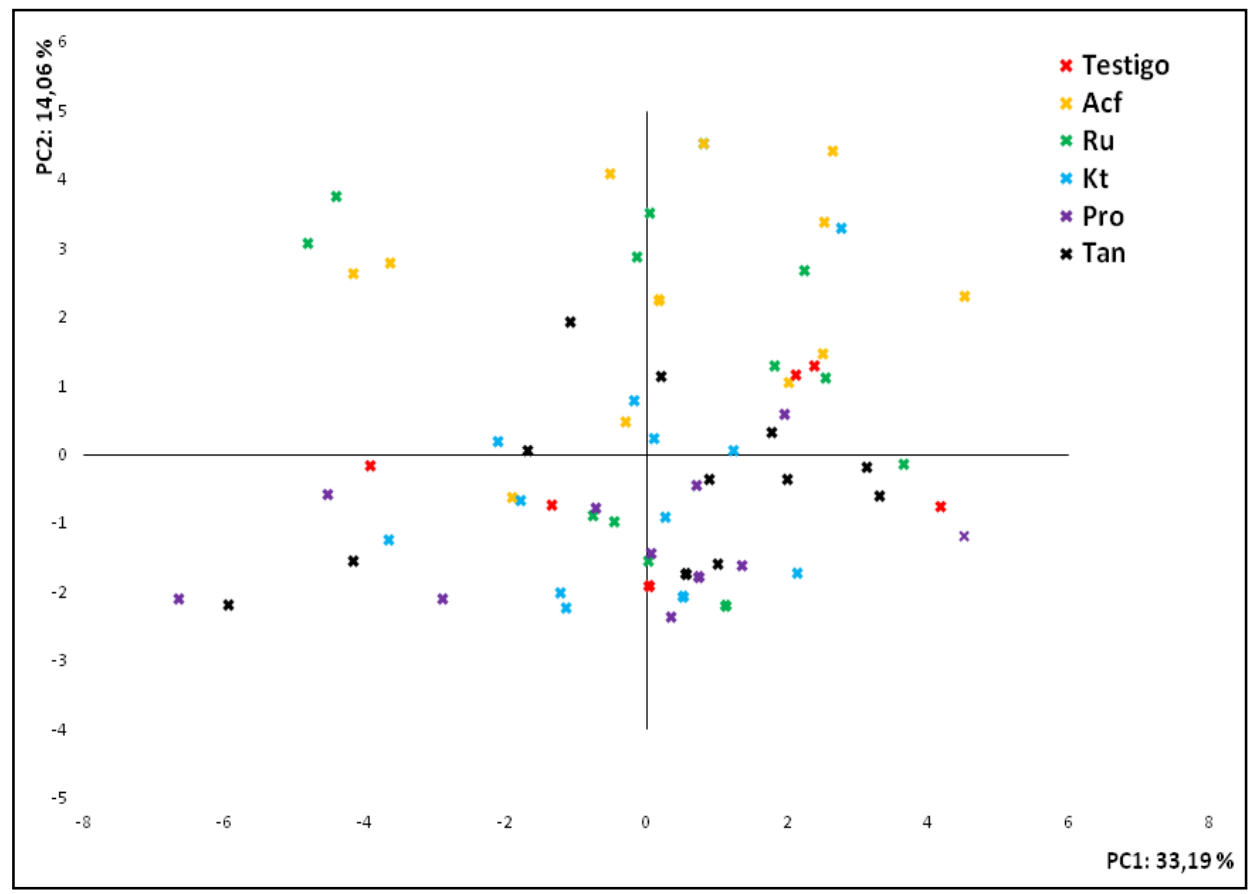

Gráfico 6.95. Primera componente frente a la segunda, en función de los copigmentos ensayados

En el gráfico 6.95 aparecen representados los diferentes vinos elaborados en función de los diferentes copigmentos adicionados, para la primera componente frente a la segunda, observando una diferenciación clara de los vinos adicionados del copigmento ácido cafeico, situándose todos ellos en la zona positiva del segundo eje principal. Por el contrario el análisis no permite diferenciar a los vinos en función de su distribución a lo largo del primer componente, observándose los mismos resultados para el tercer componente considerado (datos no mostrados).

Los componentes que definen la parte positiva del segundo eje están directamente relacionados con el efecto que la adición de ácido cafeico produce en los vinos, ya que se caracterizan por presentar un gran número de uniones entre antocianos y taninos, dando lugar a un incremento del color, así como favoreciendo la presencia de una adecuada concentración fenólica. También nos encontramos con elevados niveles de ácidos fenólicos debido a haber sido adicionados de ácido cafeico. 
La representación de la primera componente frente a la segunda (gráfico 6.96) muestra como tanto los vinos macerados prefermentativamente como los elaborados de forma tradicional se situan distribuidos aleatoriamente en el gráfico, no viéndose afectados por los parámetros que caracterizan al primer y segundo componente principal identificados.

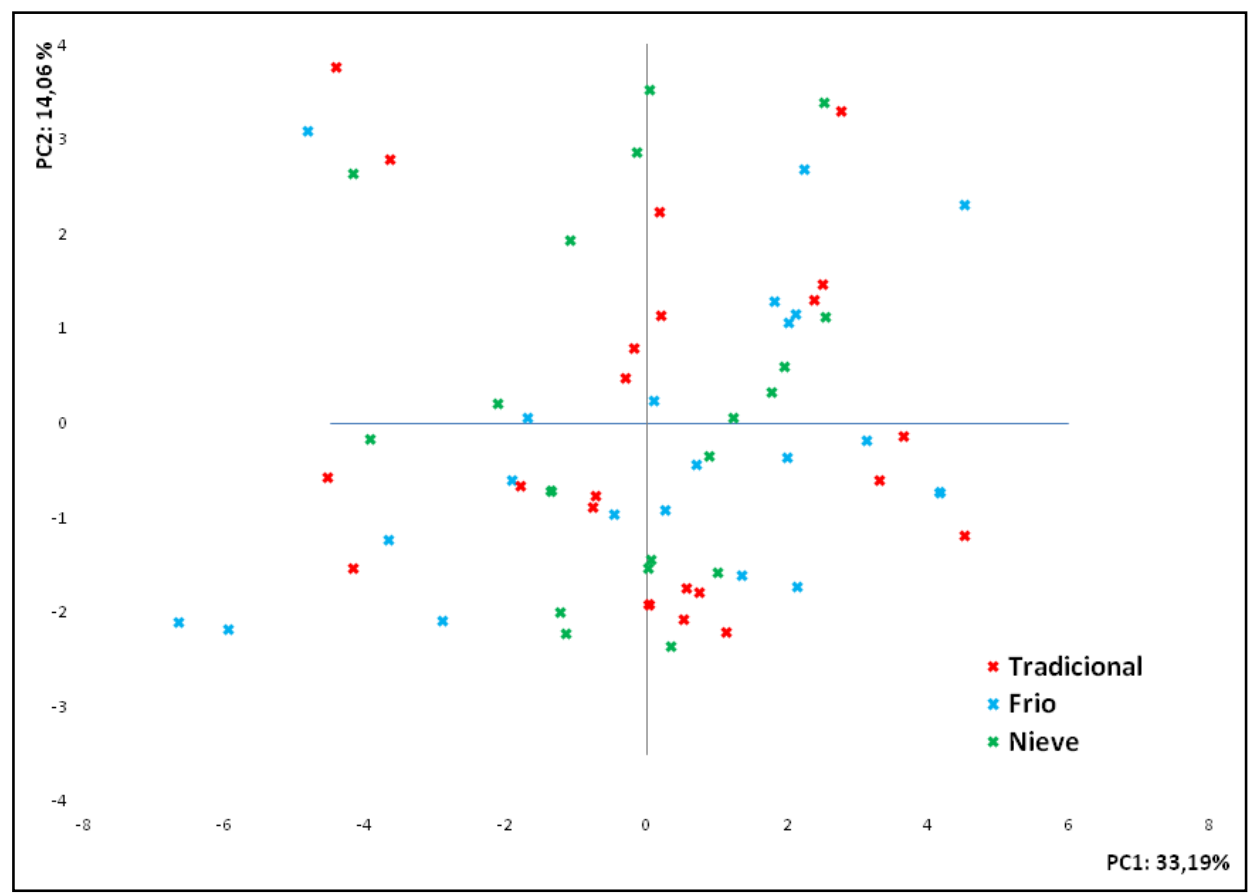

Gráfico 6.96. Primera componente frente a la segunda, en función de las técnicas de vinificación ensayadas.

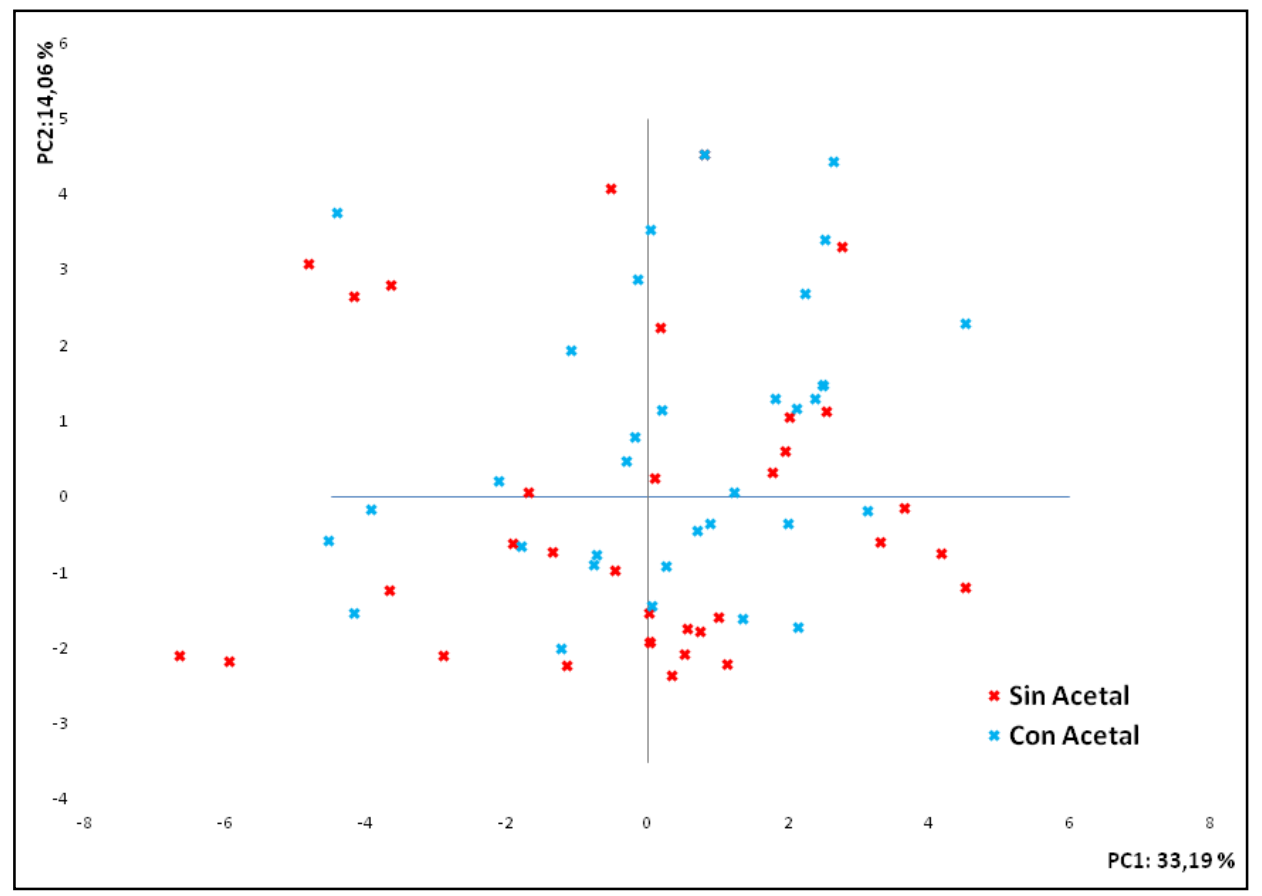

Gráfico 6.97. Primera componente frente a la segunda, en función de la aplicación de la microoxigenación. 
El gráfico 6.97 representa a los vinos sometidos a la técnica de la microoxigenación en función de los dos primeros ejes principales considerados; observándose como el Análisis de Componentes Principales no permite diferenciar a los vinos en función de esta técnica, distribuyéndose los vinos aleatoriamente a lo largo de los componentes principales representados.

Por último, se han representado los vinos en función del momento de adición de los copigmentos (gráfico 6.98). Podemos observar la distribución de los vinos en el espacio formado por las dos primeras componentes, destacando como el primer componente principal marca las diferencias entre los vinos, situándose en su parte positiva los vinos adicionados de copigmentos antes del inicio de la fermentación, y en su parte negativa los vinos adicionados de copigmentos después de la fermentación.

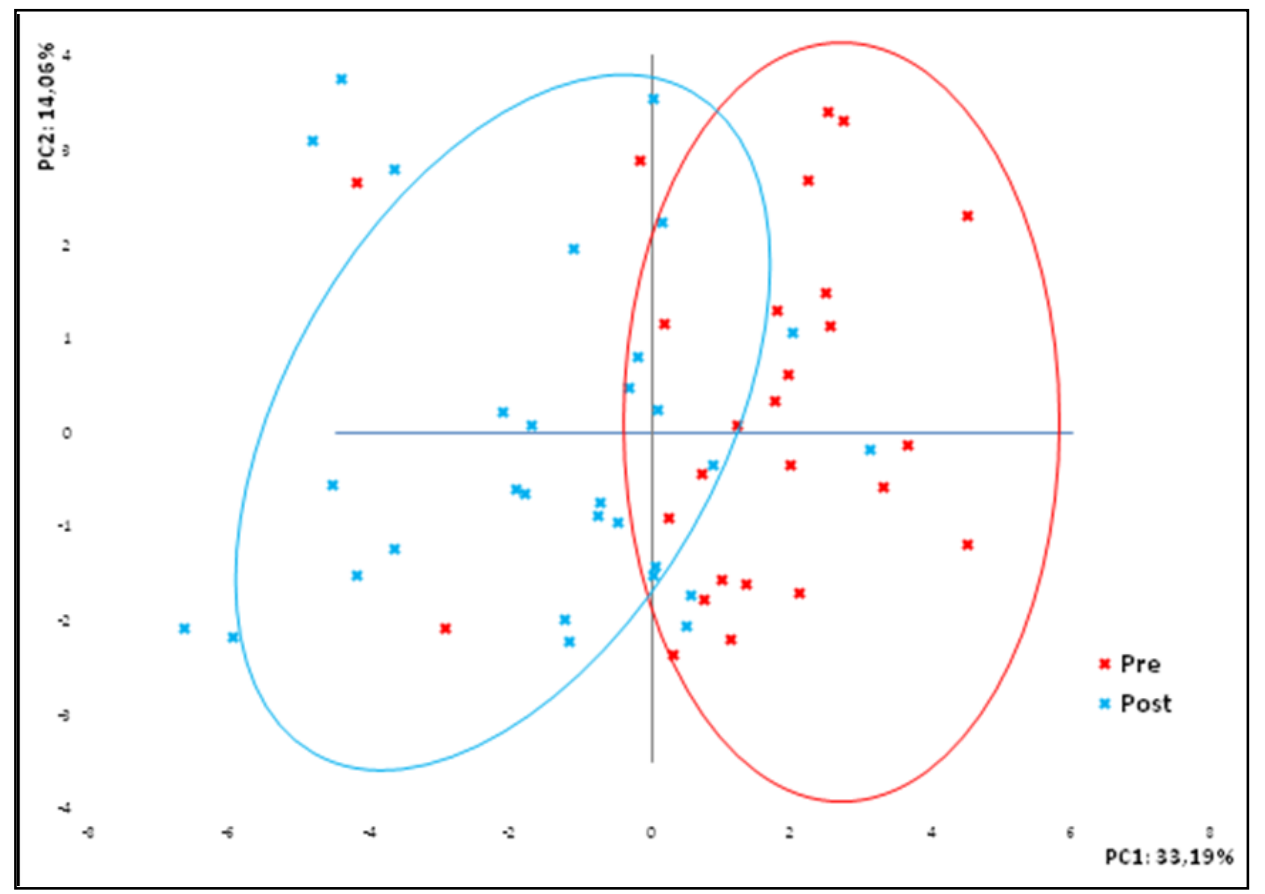

Gráfico 6.98. Primera componente frente a la segunda, en función del momento de adición de los copigmentos.

Los vinos adicionados postfermentativamente de copigmentos vienen definidos por los parámetros correlacionados negativamente con el primer componente, caracterizándose por presentar una elevada concentración de antocianos monómeros, tales como delfinidina, petunidina, peonidina, malvidina y derivados de antocianos. No observándose en este análisis los efectos favorables frente a la copigmentación y a las polimerizaciones de los antocianos identificadas en el análisis de varianza (tabla 6.55).

\subsubsection{ANÁLISIS DE LOS VINOS A LOS 12 MESES DE CONSERVACIÓN}

Una vez transcurridos los doce meses de conservación, se determinó la composición fenólica de los vinos, procediéndose con los resultados a realizar un análisis comparativo en función de las distintas prácticas enológicas ensayadas. 


\subsubsection{ANÁLSIS MULTIFACTORIAL DE LA VARIANZA (ANOVA) DE LOS FACTORES CONSIDERADOS}

En la tabla 6.59 aparecen los datos del análisis multifactorial de la varianza (ANOVA) para los factores considerados, así como para las interacciones entre ellos; estudiándose concretamente, el efecto de la adición de copigmentos, de las diferentes técnicas de vinificación ensayadas, de la aplicación de la microoxigenación y, por último, de la adición pre- o postfermentativa de copigmentos.

El análisis multifactorial de la varianza muestra como todos los factores adición de copigmentos, técnicas de vinificación, aplicación de la microoxigenación y momento de adición de copigmentos, presentan diferencias estadísticamente significativas para un gran número de parámetros polifenólicos; influyendo tanto en el color, como en la concentración y estado de los compuestos polifenólicos en general, y en la familia antociánica en particular. A su vez, se observan una importante interacción entre los factores técnicas de vinificación x momento de adición de copigmentos (BD), las otras interacciones observadas tienen una repercusión mucho menor en los parámetros polifenólicos de los vinos.

Los parámetros ácidos fenólicos, porcentaje del color debido a las polimerizaciones, 3-flavanoles, porcentaje que corresponde a los antocianos libres y derivados de antocianos son los que presentan un efecto más marcado sobre la variable adicion de copigmentos (elevados F-ratio). Además, el tono, índice de DMACH, petunidina, malvidina, índice de PVPP, catequinas e índice de Folin afectan decisivamente a la concentración fenólica de los vinos elaborados.

Estos resultados indican como la adición de copigmentos afecta de forma determinante, a la mayoría de parámetros fenólicos presentes en el vino. Efecto observado durante los primeros meses de conservación, que se mantiene presente al cabo de 12 meses de envejecimiento. Darías-Martín et al. (2002), estudiando la adición de copigmentos sobre los compuestos polifenólicos de las principales variedades cultivadas en las Islas Canarias, observan también como este efecto se mantiene a los 8 meses de conservación de los vinos en botella.

Para el factor técnicas de vinificación los parámetros que presentan un mayor efecto sobre la variable son los antocianos totales decolorables, los derivados de antocianos, la concentración total de antocianos, porcentaje del color que corresponde a los antocianos polimerizados, catequinas, antocianidinas, ácidos fenólicos, malvidina e índice de etanol. La maceración prefermentativa provoca un efecto destacado sobre la concentración y el estado de los antocianos, así como sobre la concentración de los principales compuestos fenólicos presentes (Álvarez et al., 2006).

La microoxigenación da lugar a un destacado efecto sobre el índice de PVPP, índice de gelatina, intensidad colorante, índice de etanol, ácidos fenólicos, 3-flavanoles e índice de Folin. Los resultados demuestran el efecto de esta técnica sobre el color, la concentración fenólica y las propiedades sensoriales de los vinos (Wirth et al., 2010; Cano-López et al., 2006, 2007, 2010; Rayne et al., 2008; González-del Pozo et al., 2010; Pérez-Magariño et al., 2007; Tao et al., 2007; Cejudo-Bastante et al., 2010, 2011; Sartini et al., 2007). 


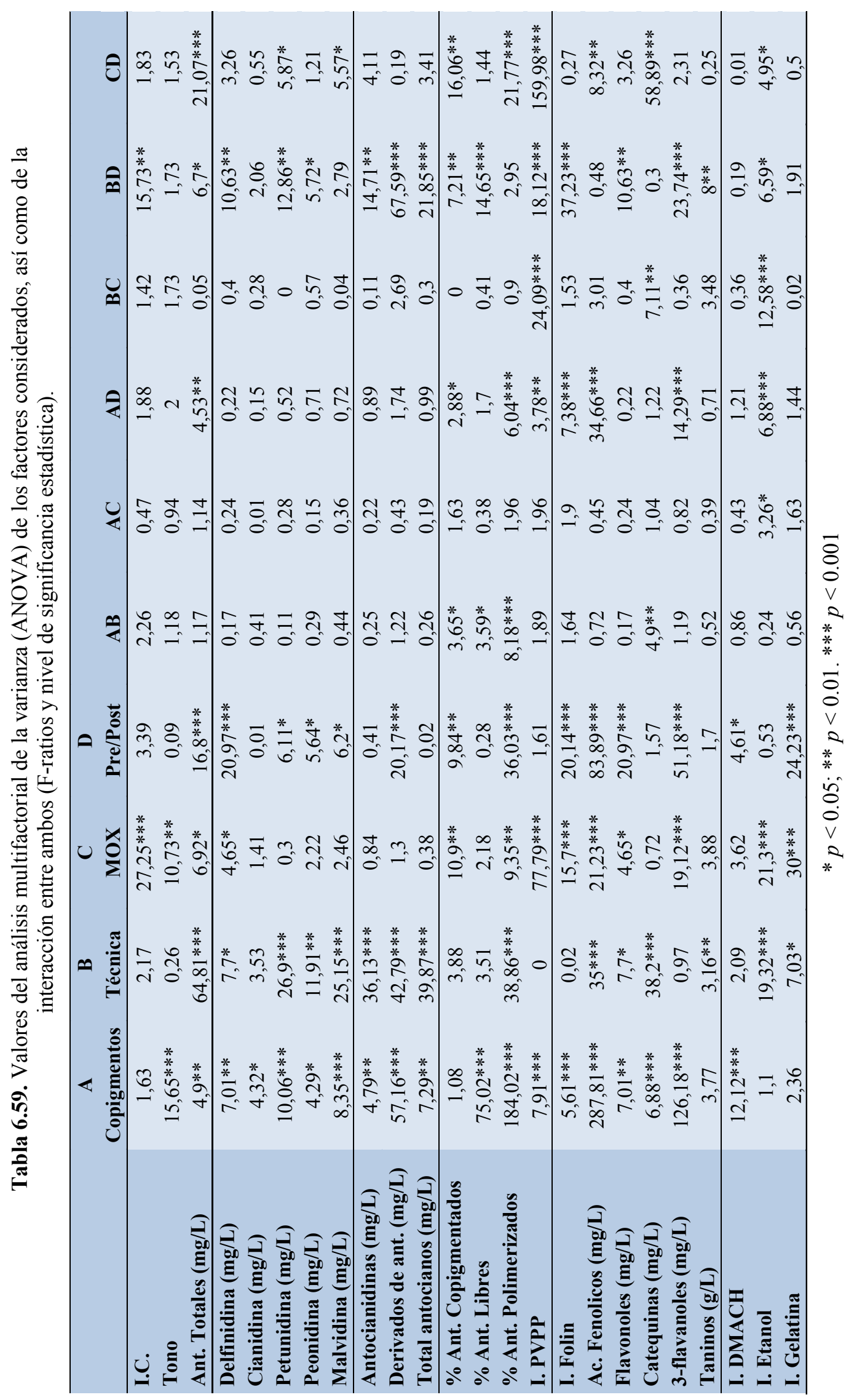


El momento de adición de los copigmentos también presenta un efecto significativo en los vinos a los 12 meses de envejecimiento, tal como se observó a los seis meses, con significación estadística al nivel de confianza del 99,9\% para la concentración de ácido fenólicos, 3-flavanoles, porcentaje del color que corresponde a polimerizaciones, índice de gelatina, flavonoles, delfinidina, derivados de antocianos, índice de Folin y antocianos totales; presentando este factor un elevado efecto sobre la composición de los vinos.

En cuanto a la interacción entre las técnicas de vinificación y la adición pre- o postfermentativa de copigmentos (interacción $\mathrm{BD}$ ), los parámetros derivados de antocianos, índice de Folin, 3-flavanoles, total de antocianos, índice de PVPP y color que corresponde a los antocianos libres presentan diferencias significativas al nivel de confianza del 99,9\%. La combinación de ambas técnicas podría dar lugar a una metodología de vinificación, caracterizándose los vinos por presentar una elevada concentración de los principales compuestos fenólicos, favoreciéndose las uniones entre ellos y siendo todavía importante la presencia de grandes concentraciones de antocianos en su forma libre.

La interacción $\mathrm{AD}$ (adición de copigmentos $\mathrm{x}$ momento de adición de copigmentos) muestra diferencias significativas, con elevados valores del F-ratio, para los ácidos fenólicos, 3-flavanoles, índice de Folin, índice de etanol y porcentaje del color debido a la polimerización. Indicando como a los 12 meses de envejecimiento de los vinos en botella, la adición de copigmentos no provoca ningún efecto sobre la concentración antocianica de los vinos, aunque si frente a la concentración fenólica (Darías-Martín et al., 2002).

\subsubsection{2. $\quad$ EFECTO DE LA ADICIÓN DE COPIGMENTOS}

En la tabla 6.60 se muestran los valores medios de los parámetros polifenólicos estudiados, en función de la adición de los distintos copigmentos. El tratamiento estadístico se ha realizando considerando conjuntamente todos los vinos, independientemente de la técnica de vinificación utilizada, del momento de adición de los copigmentos o de la microoxigenación, valorando así exclusivamente el efecto de la adición de copigmentos sobre los vinos de Tempranillo.

Los vinos adicionados de ácido cafeico presentan los valores más bajos del tono con diferencias significativas frente a los otros copigmentos, así como frente al vino testigo. Este efecto protector sobre la componente amarilla ha sido ya identificado en numerosas ocasiones a lo largo de este trabajo, tanto para los vinos de este año, como para los vinos elaborados en la vendimia 2007, mostrándose como el mejor copigmento en cuanto a la protección del color de los vinos. 


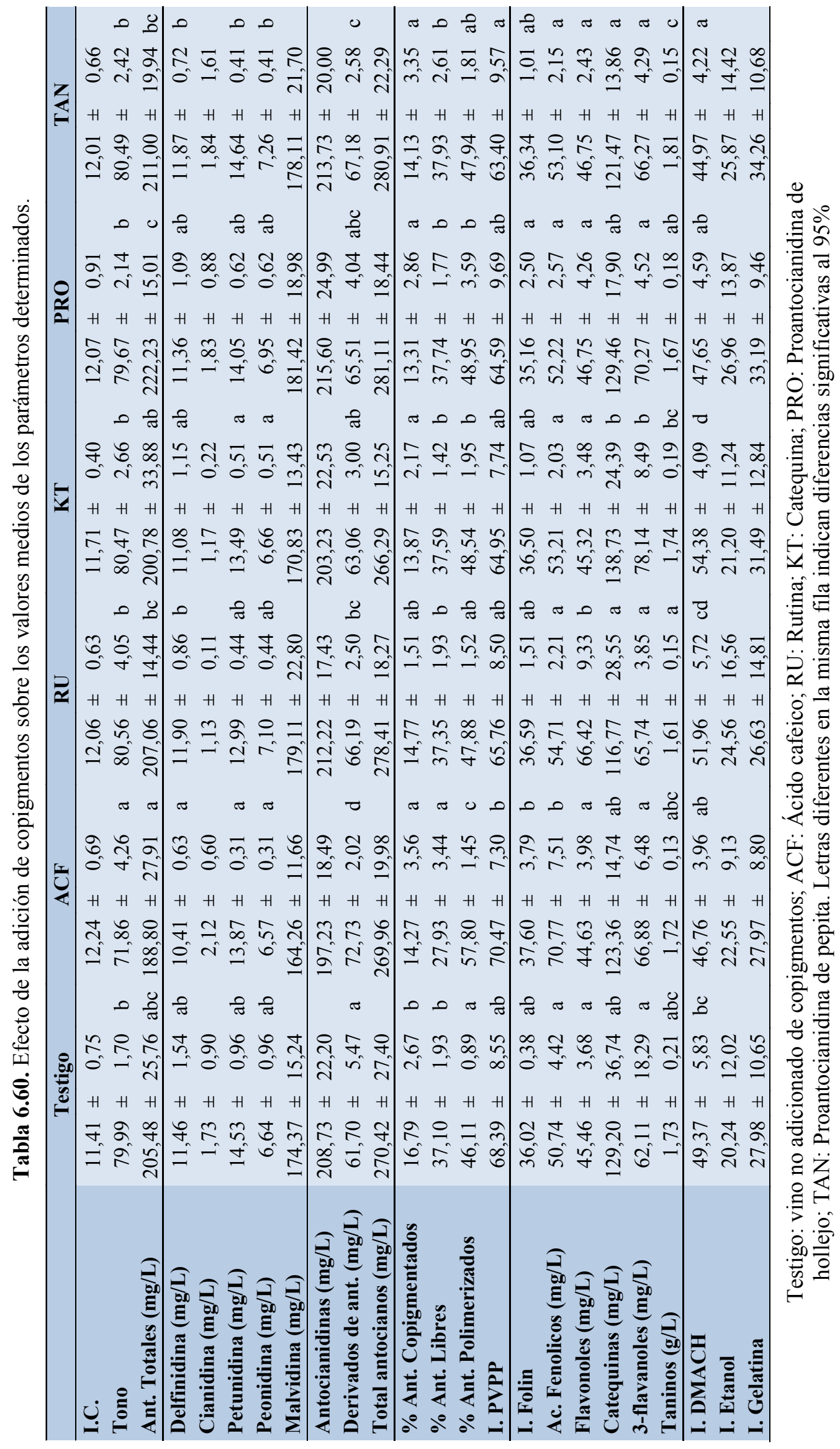


Además, estos vinos son los que presentan las menores concentraciones para los parámetros antocianos totales decolorables, delfinidina, petunidina, peonidina, malvidina, con diferencias significativas frente a algunos de los copigmentos ensayados. Para la suma de las antocianidinas son los copigmentos rutina y proantocianidina de pepita los que presentan un mayor nivel de significanción, en cambio, para la concentración de derivados de antocianos, son los vinos adicionados de ácido cafeico los que muestran los valores más elevados, con diferencias estadísticamente significativas, explicándose probablemente este comportamiento por la participación de estos ácidos en la esterificación de los antocianos monómeros. Estos resultados concuerdan en líneas generales con los observados en los vinos después de la maloláctica y a los seis meses de conservación.

Los vinos adicionados de ácido cafeico, proantocianidina de pepita y rutina muestran las mayores concentraciones de derivados de antocianos, aunque está concentración es significativamente superior en los vinos adicionados de ácido cafeico.

El comportamiento mostrado para el porcentaje del color que corresponde a las reacciones de copigmentación y de polimerización, y para los antocianos en su forma libre, justifica la afirmación realizada anteriormente con respecto a la estabilidad de los antocianos en los vinos elaborados de ácido cafeico; siendo estos vinos los que presentan los menores y mayores valores para los antocianos libres y polimerizados, respectivamente; mostrándose estos últimos como los compuestos responsables de la protección frente a la componente amarilla del color observada. Las diferencias observadas en el porcentaje de color debido a la copigmentación no son muy evidentes, pero hay que destacar el efecto negativo del cafeico sobre estas reacciones.

Tanto para el índice de PVPP, como para la concentración total de polifenoles (índice de Folin), son los vinos adicionados de ácido cafeico los que presentan los mayores valores, con diferencias significativas frente a la proantocianidina de pepita (índice de PVPP) o frente a la proantocianidina de hollejo (índice de Folin); observándose como la mayor presencia en los vinos de estas uniones es la responsable de los mayores valores de la concentración fenólica encontrada (Castañeda-Ovando et al., 2009; Cheynier et al., 2006; Malien-Aubert et al., 2002).

Tanto para la concentración de los ácidos fenólicos (ácido cafeico), como para la de flavonoles (rutina) y catequinas o 3-flavanoles (catequina) son los vinos adicionados de los respectivos copigmentos los que muestran los mayores valores, con diferencias significativas frente a los otros vinos considerados. Por último, para el índice de $\mathrm{DMACH}$, son los vinos adicionados del copigmento catequina los que presentan un menor grado de polimerización, mientras que los adicionados de proantocianidina de pepita presentan el mayor grado.

Tal como observamos a lo largo de la vinificación y conservación de los vinos de 2008, es el copigmento ácido cafeico el que ejerce la mayor influencia sobre los compuestos polifenólicos de los vinos, contribuyendo a la mayor estabilidad de los antocianos, a un menor tono y a un incremento de la concentración polifenólica de los vinos. Este mismo efecto fue observado también en los vinos de las cosechas anteriores.

\subsubsection{EFECTO DE LAS TÉCNICAS DE VINIFICACIÓN}

En la tabla 6.61 se recogen los valores medios de los parámetros polifenólicos 
analizados, considerando conjuntamente los distintos vinos elaborados, según que la vinificación se realice de forma tradicional o con maceración prefermentativa en frío a mediante adición de nieve carbónica.

La maceración prefermentativa en frío ha provocado que los vinos elaborados, a los 12 meses de conservación en botella, presenten mayores concentraciones de la mayoría de compuestos que caracterizan a la composición antociánica de los vinos, tal como se observó en estos vinos después de la maloláctica y a los seis meses de conservación.

Tabla 6.61. Efecto de las técnicas de vinificación sobre los valores medios de los parámetros determinados.

\begin{tabular}{|c|c|c|c|c|c|c|c|c|c|}
\hline & \multicolumn{3}{|c|}{ Tradicional } & \multicolumn{3}{|c|}{ Frio } & \multicolumn{3}{|c|}{ Nieve } \\
\hline I.C. & 12,11 & $\pm 0,52$ & & 11,82 & $\pm 0,80$ & & 11,52 & $\pm 0,83$ & \\
\hline Tono & 78,89 & $\pm 4,30$ & & 78,58 & $\pm 4,63$ & & 80,21 & $\pm 5,64$ & \\
\hline Ant. Totales (mg/L) & 191,29 & $\pm 20,38$ & $a$ & 217,52 & $\pm 23,63$ & $\mathrm{~b}$ & 221,36 & $\pm 23,61$ & $\mathrm{~b}$ \\
\hline Delfinidina (mg/L) & 10,96 & $\pm 0,90$ & $\mathrm{a}$ & 11,71 & $\pm 1,10$ & b & 11,56 & $\pm 1,12$ & $\mathrm{~b}$ \\
\hline Cianidina (mg/L) & 1,40 & $\pm 0,72$ & & 1,95 & $\pm 0,92$ & & 2,09 & $\pm 1,04$ & \\
\hline Petunidina (mg/L) & 13,31 & $\pm 0,53$ & $\mathrm{a}$ & 14,55 & $\pm 0,47$ & b & 14,65 & $\pm 0,32$ & $\mathrm{~b}$ \\
\hline Peonidina (mg/L) & 6,62 & $\pm 0,53$ & $\mathrm{a}$ & 7,14 & $\pm 0,47$ & $\mathrm{~b}$ & 7,56 & $\pm 0,52$ & $b$ \\
\hline Malvidina (mg/L) & 168,77 & $\pm 8,46$ & $\mathrm{a}$ & 179,37 & $\pm 8,54$ & $\mathrm{~b}$ & 178,45 & $\pm 6,89$ & $\mathrm{~b}$ \\
\hline Antocianidinas (mg/L) & 201,06 & $\pm 10,78$ & $\mathrm{a}$ & 214,73 & $\pm 8,40$ & $\mathrm{~b}$ & 214,31 & $\pm 8,64$ & $\mathrm{~b}$ \\
\hline Derivados de ant. (mg/L) & 64,80 & $\pm 5,20$ & $\mathrm{a}$ & 68,11 & $\pm 3,14$ & $\mathrm{~b}$ & 70,42 & $\pm 4,56$ & $\mathrm{~b}$ \\
\hline Total antocianos $(\mathrm{mg} / \mathrm{L})$ & 265,86 & $\pm 14,67$ & $\mathrm{a}$ & 282,84 & $\pm 9,77$ & $\mathrm{~b}$ & 284,73 & $\pm 8,46$ & $\mathrm{~b}$ \\
\hline$\%$ Ant. Copigmentados & 13,99 & $\pm 2,93$ & & 14,64 & $\pm 2,76$ & & 14,87 & $\pm 2,46$ & \\
\hline$\%$ Ant. Libres & 36,27 & $\pm 3,99$ & & 35,40 & $\pm 4,74$ & & 37,49 & $\pm 4,44$ & \\
\hline$\%$ Ant. Polimerizados & 49,09 & $\pm 4,10$ & & 50,61 & $\pm 4,53$ & & 47,64 & $\pm 5,64$ & \\
\hline I. PVPP & 81,00 & $\pm 9,18$ & & 81,13 & $\pm 8,32$ & & 81,35 & $\pm 10,26$ & \\
\hline I. Folin & 36,39 & $\pm 2,61$ & & 36,41 & $\pm 1,76$ & & 35,78 & $\pm 3,63$ & \\
\hline Ac. Fenolicos (mg/L) & 55,25 & $\pm 7,61$ & & 57,26 & $\pm 8,29$ & & 57,03 & $\pm 9,63$ & \\
\hline Flavonoles (mg/L) & 49,42 & $\pm 10,27$ & & 49,71 & $\pm 8,74$ & & 50,21 & $\pm 15,46$ & \\
\hline Catequinas (mg/L) & 116,03 & $\pm 21,92$ & $a$ & 136,47 & $\pm 19,50$ & $\mathrm{~b}$ & 134,52 & $\pm 24,56$ & $\mathrm{~b}$ \\
\hline 3-flavanoles (mg/L) & 70,50 & $\pm 7,84$ & & 67,09 & $\pm 9,29$ & & 72,46 & $\pm 11,32$ & \\
\hline Taninos $(\mathrm{g} / \mathrm{L})$ & 1,68 & $\pm 0,16$ & & 1,75 & $\pm 0,18$ & & 1,77 & $\pm 0,22$ & \\
\hline I. DMACH & 48,51 & $\pm 5,51$ & & 49,82 & $\pm 5,76$ & & 48,67 & $\pm 7,94$ & \\
\hline I. Etanol & 19,00 & $\pm 9,98$ & & 28,73 & $\pm 13,96$ & 0 & 26,81 & $\pm 10,09$ & $\mathrm{~b}$ \\
\hline I. Gelatina & 28,32 & $\pm 10,80$ & & 32,19 & $\pm 11,88$ & & 31,62 & $\pm 14,54$ & \\
\hline
\end{tabular}

Tradicional: elaboración sin maceración en frío previamente a la fermentación; Frío: aplicación de bajas temperaturas de forma prefermentativa; Nieve: uso de nieve carbónica prefermentativamente. Letras diferentes en la misma fila indican diferencias significativas al $95 \%$.

Se observan diferencias significativas para los parámetros antocianos totales, delfinidina, petunidina, peonidina, malvidina, antocianidinas, derivados de antocianos y total de antocianos, mostrando diferencias estadísticamente significativas la maceración 
prefermentativa respecto a la vinificación tradicional. En cuanto al resto de parámetros polifenólicos, la maceración prefermentativa presenta diferencias significativas respecto a la vinificación tradicional únicamente para la concentración de catequinas y el índice de etanol. No se observan diferencias en el efecto de la maceración prefermentativa en frío y la maceración con nieve carbónica, para ninguno de los parámetros estudiados.

Este efecto de la maceración prefermentativa sobre la concentración y el estado de los diferentes compuestos antociánicos, ha sido observado en los vinos de las tres cosechas estudiadas, tanto inmediatamente después de la fermentación maloláctica, como a lo largo y al final del envejecimiento. También se ha encontrado una influencia positiva de la maceración prefermentativa sobre la extracción y conservación de catequinas y taninos, pero este efecto no se presenta en todos los vinos ni en todas las añadas, sino que va a depender de la composición polifenólica de la uva.

\subsubsection{EFECTO DE LA MICROOXIGENACIÓN}

En la tabla 6.62 se recogen los valores medios de los parámetros analizados, considerando conjuntamente a todos aquellos vinos que han sido microoxigenados frente a aquellos vinos a los que no se les ha realizado adición de oxígeno.

La aplicación de la microoxigenación ha provocado un incremento del color de los vinos (intensidad colorante), manteniéndose el efecto hasta el final de la conservación. Al mismo tiempo, ha dado lugar a un incremento significativo del tono de los vinos, a los 12 meses de conservación (Cano-López et al., 2010).

El porcentaje del color que corresponde a las reacciones de copigmentación presenta diferencias significativas siendo los vinos elaborados sin adición de oxígeno los que presentan los mayores porcentajes para este parámetro, tal como observamos a los seis meses de conservación. Por el contrario, el índice de PVPP es superior en los vinos microoxigenados, debido al efecto polimerizador de esta técnica. La participación de los antocianos en las reacciones de polimerización hace que no estén disponibles para participar en las de copigmentación (Somers, 1971; Boulton, 2001).

La concentración de polifenoles totales y de taninos en inferior en los vinos microoxigenados al cabo de 12 meses, en cambio, a los seis meses estos parámetros no mostraban diferencias. Esto pone de manifiesto que durante los últimos meses de conservación, se ha producido una mayor pérdida de estos compuestos, como consecuencia indirecta de la microoxigenación; pérdida que no puede achacarse al incremento de la polimerización de los taninos, ya que no se observan diferencias para el índice de DMACH.

Los parámetros índice de etanol e índice de gelatina diferencian significativamente a los vinos microoxigenados de aquellos no adicionados de acetaldehido, siendo los microoxigenados los que presentan una menor astringencia, así como una mayor presencia de taninos unidos a polisacárido. La disminución de la astringencia puede ser debida a la pérdida de reactividad de los taninos al intervenir en estas reacciones (Zamora, 2003), tal como observamos a los seis meses de conservación. 
Tabla 6.62. Efecto de la microoxigenación sobre los valores medios de los parámetros determinados.

\begin{tabular}{lcccccc}
\hline & \multicolumn{2}{c}{ No MOX } & \multicolumn{3}{c}{ MOX } \\
\hline I.C. & 11,61 & $\pm 0,61$ & a & 12,31 & $\pm 0,59$ & b \\
Tono & 77,38 & $\pm 4,13$ & a & 80,09 & $\pm 4,37$ & b \\
Ant. Totales (mg/L) & 208,66 & $\pm 27,2$ & & 200,16 & $\pm 23,4$ & \\
\hline Delfinidina (mg/L) & 11,56 & $\pm 1,12$ & & 11,11 & $\pm 0,97$ & \\
Cianidina (mg/L) & 1,71 & $\pm 0,19$ & & 1,68 & $\pm 0,28$ & \\
Petunidina (mg/L) & 14,19 & $\pm 0,59$ & & 13,61 & $\pm 0,53$ & \\
Peonidina (mg/L) & 6,979 & $\pm 0,59$ & & 6,787 & $\pm 0,53$ & \\
Malvidina (mg/L) & 100,73 & $\pm 10,5$ & & 97,41 & $\pm 9,31$ & \\
\hline Antocianidinas (mg/L) & 210,97 & $\pm 12,00$ & 208,70 & $\pm 13,2$ & \\
Derivados de ant. (mg/L) & 66,14 & $\pm 4,49$ & & 66,77 & $\pm 4,72$ & \\
Total antocianos (mg/L) & 277,11 & $\pm 14,8$ & & 275,47 & $\pm 17,00$ & \\
\hline \% Ant. Copigmentados & 15,14 & $\pm 3,00$ & $\mathrm{~b}$ & 13,49 & $\pm 2,47$ & $\mathrm{a}$ \\
\%o Ant. Libres & 35,44 & $\pm 4,63$ & & 36,23 & $\pm 4,13$ & \\
\%o Ant. Polimerizados & 49,42 & $\pm 4,23$ & & 50,27 & $\pm 4,49$ & \\
I. PVPP & 77,96 & $\pm 8,64$ & $\mathrm{a}$ & 84,17 & $\pm 7,69$ & $\mathrm{~b}$ \\
\hline I. Folin & 36,98 & $\pm 1,79$ & $\mathrm{~b}$ & 35,82 & $\pm 2,46$ & $\mathrm{a}$ \\
Ac. Fenolicos (mg/L) & 57,42 & $\pm 8,09$ & & 55,09 & $\pm 7,79$ & \\
Flavonoles (mg/L) & 48,13 & $\pm 10,2$ & & 50,99 & $\pm 8,57$ & \\
Catequinas (mg/L) & 128,71 & $\pm 20,4$ & & 123,80 & $\pm 25,4$ & \\
3-flavanoles (mg/L) & 70,40 & $\pm 6,18$ & & 67,18 & $\pm 10,5$ & \\
Taninos (g/L) & 1,75 & $\pm 0,19$ & $\mathrm{~b}$ & 1,67 & $\pm 0,14$ & $\mathrm{a}$ \\
\hline I. DMACH & 49,94 & $\pm 5,89$ & & 48,38 & $\pm 5,34$ & \\
I. Etanol & 19,28 & $\pm 6,55$ & $\mathrm{a}$ & 28,45 & $\pm 16,00$ & $\mathrm{~b}$ \\
I. Gelatina & 35,01 & $\pm 10,4$ & $\mathrm{~b}$ & 25,5 & $\pm 10,6$ & $\mathrm{a}$ \\
\hline
\end{tabular}

No MOX: vinos no adicionados de acetaldehído; MOX: vinos adicionados de acetaldehído. Letras diferentes en la misma fila indican diferencias significativas al 95\%

\subsubsection{EFECTO DEL MOMENTO DE ADICIÓN DE LOS COPIGMENTOS}

En la tabla 6.63 se recogen los valores medios de los parámetros polifenólicos analizados, considerando conjuntamente a todos aquellos que han sido adicionados de copigmentos previamente o posteriormente a la fermentación de los vinos.

La adición postfermentativa de copigmentos muestra diferencias significativas, propiciando concentraciones superiores de antocianos totales decolorables, delfinidina, porcentaje del color que corresponde a los antocianos copigmentados y 3 -flavanoles, y dando lugar a una disminución de la astringenca valorada mediante el índice de gelatina.

A los 12 meses de conservación de los vinos en botella se ha minimizado el efecto del momento de adición de copigmentos sobre los parámetros que definen la 
composición antociánica de los vinos (tabla 6.55), destacando como posible efecto de la adición postfermentativa una mayor permanencia del color debido a las reacciones de copigmentación, así como el mantenimiento de una mayor concentración fenólica al final del proceso de envejecimiento.

Tabla 6.63. Efecto del momento de adición de copigmentos sobre los valores medios de los parámetros determinados.

\begin{tabular}{|c|c|c|c|c|c|}
\hline & \multicolumn{3}{|c|}{ PRE } & \multicolumn{2}{|c|}{ POST } \\
\hline I.C. & 12,14 & $\pm 0,51$ & & 11,89 & $\pm 0,78$ \\
\hline Tono & 78,49 & $\pm 4,93$ & & 78,74 & $\pm 4,37$ \\
\hline Ant. Totales (mg/L) & 195,54 & $\pm 21,2$ & $\mathrm{a}$ & 209,71 & $\pm 28,2 \mathrm{~b}$ \\
\hline Delfinidina (mg/L) & 10,85 & $\pm 0,65$ & $\mathfrak{a}$ & 11,8 & $\pm 1,13 \mathrm{~b}$ \\
\hline Cianidina (mg/L) & 5,29 & $\pm 0,17$ & & 5,30 & $\pm 0,27$ \\
\hline Petunidina $(\mathrm{mg} / \mathrm{L})$ & 13,61 & $\pm 0,31$ & & 14,23 & $\pm 0,63$ \\
\hline Peonidina (mg/L) & 6,759 & $\pm 0,31$ & & 7,057 & $\pm 0,63$ \\
\hline Malvidina ( & 96,01 & $\pm 7,83$ & & 100,66 & $\pm 10,4$ \\
\hline Antocianidinas (mg/L) & 209,14 & $\pm 7,98$ & & 210,63 & $\pm 14,6$ \\
\hline Derivados de ant. (mg/L) & 67,88 & $\pm 3,37$ & & 65,98 & $\pm 4,89$ \\
\hline Total antocianos $(\mathrm{mg} / \mathrm{L})$ & 277,03 & $\pm 9,76$ & & 276,62 & $\pm 18,5$ \\
\hline \% Ant. Copigmentados & 13,35 & $\pm 2,35$ & $\mathfrak{a}$ & 14,79 & $\pm 2,98 \mathrm{~b}$ \\
\hline$\%$ Ant. Libres & 35,59 & $\pm \quad 4,4$ & & 35,83 & $\pm 4,72$ \\
\hline$\%$ Ant. Polimerizados & 51,06 & $\pm 4,08$ & & 49,38 & $\pm 4,59$ \\
\hline I. PVPP & 80,28 & $\pm 10,8$ & & 81,38 & $\pm 6,22$ \\
\hline I. Folin & 35,70 & $\pm 2,14$ & & 37,17 & $\pm 2,27 \mathrm{~b}$ \\
\hline Ac. Fenolicos (mg/L) & 54,91 & $\pm 5,23$ & & 58,7 & $\pm 9,87$ \\
\hline Flavonoles (mg/L) & 47,34 & $\pm 6,75$ & & 52,61 & $\pm 11,6$ \\
\hline Catequinas (mg/L) & 124,15 & $\pm 21,8$ & & 127,76 & $\pm 21,4$ \\
\hline 3-flavanoles (mg/L) & 66,82 & $\pm 5,09$ & $\mathrm{a}$ & 72,10 & $\pm 8,13 b$ \\
\hline $\operatorname{Taninos}(\mathrm{g} / \mathrm{L})$ & 1,69 & $\pm 0,19$ & & 1,73 & $\pm 0,14$ \\
\hline I. DMACH & 48,07 & $\pm 5,64$ & & 50,22 & $\pm 5,55$ \\
\hline I. Etanol & 24,96 & $\pm 12,8$ & & 23,49 & $\pm 13,6$ \\
\hline I. Gelatina & 35,44 & $\pm 10,6$ & $\mathrm{~b}$ & 25,98 & $\pm 10,8 \mathrm{a}$ \\
\hline
\end{tabular}

PRE: adición de copigmentos previamente al inicio de la fermentación alcohólica; POST: adición de copigmentos en el embotellado. Letras diferentes en la misma fila indican diferencias significativas al $95 \%$

\subsubsection{CORRELACIÓN ENTRE LOS PARÁMETROS POLIFENÓLICOS DE LOS VINOS, LA ADICIÓN DE COPIGMENTOS, LAS TÉCNICAS DE VINIFICACIÓN Y EL MOMENTO DE ADICIÓN DE COPIGMENTOS}

La tabla 6.64 muestra la matriz de correlaciones realizada con el conjunto de los datos obtenidos de los vinos a los 12 meses de conservación. Podemos observar dos correlaciones positivas importantes para la suma de antocianidinas, una de ellas frente a la intensidad colorante, y la otra frente al color que corresponde a los antocianos polimerizados. Este comportamiento indica como en estos vinos el color está altamente relacionado con la suma de la concentración de antocianidinas monómeras; 
justificándose esta afirmación con la relación encontrada para este parámetro con el color que corresponde a polimerizaciones, parámetro realmente importante del color de los vinos envejecidos (Castañeda-Ovando et al., 2009; Cheynier et al., 2006; MalienAubert et al., 2002).

El tono presenta un coeficiente positivo sobre el porcentaje del color debido a los antocianos en su forma libre, observándose como a medida que se incrementa el color debido a estos antocianos inestables, fácilmente oxidables, aumenta el tono de los vinos (Brouillard, 1982; Furtado et al., 1993). Además, las correlaciones negativas del tono con el color debido a polimerización y con el total de antocianidinas, y la correlación negativa entre el color que corresponde a los antocianos libres, la concentración de antocianidinas y el color debido a las reacciones de polimerización, podría justificar el comportamiento antes mencionado.

Los antocianos totales muestran correlaciones positivas con los parámetros polifenólicos flavonoles, cianidina, petunidina, peonidina, malvidina y derivados de antocianos, indicando que un aumento de la concentración de antocianos totales decolorables por el sulfuroso en su forma simple, provocaría un incremento de la mayoría de los compuestos que caracterizan a la composición antociánica de los vinos; sumándose a este hecho las correlaciones negativas encontradas entre el color debido a la polimerización de los antocianos y la concentración de antocianos totales decolorables, de flavonoles, cianidina, peonidina y malvidina; indicando también que el incremento de esta fracción de los antocianos no provocará un incremento en la calidad del color de los vinos.

Por último, destacar como muchos de los parámetros que determinan el perfil antociánico de los vinos presentan coeficientes positivos al estar altamente relacionados entre sí. Un ejemplo de esto son los elevados coeficientes encontrados para las cinco antocianidinas presentes en el vino o para el total de antocianos. Además parece ser que en estos vinos una elevada concentración de estos compuestos esta también relacionada con una presencia importante de flavonoles.

En la tabla 6.65 aparece tanto el autovalor como el porcentaje de varianza acumulada por los sucesivos factores, observándose como son necesarios siete factores para que el autovalor descienda por debajo de la unidad. Además comprobamos como el porcentaje de varianza acumulada corresponde al 83,86\%.

Se han identificado siete patrones de comportamiento asociado, explicando entre ellos casi el $80 \%$ de la variabilidad total observada en las variables originales, consiguiéndose con esto una reducción de las variables iniciales.

En la tabla 6.66 aparecen los valores de los coeficientes de las ecuaciones que forman cada uno de los siete componentes principales identificados. El primer componente principal está relacionado de forma positiva con los parámetros antocianos totales, cianidina, petunidina, peonidina, malvidina $y$ total de antocianos, no observándose coeficientes negativos importantes. Los vinos situados en la zona positiva de este componente estarán caracterizados por presentar una elevada concentración de los principales compuestos antociánicos presentes en su forma libre, junto con concentraciones importantes de flavonoles. 


\begin{tabular}{|c|c|c|c|c|c|c|c|c|c|c|c|c|c|c|c|c|c|c|c|c|c|c|c|c|}
\hline 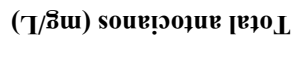 & $\begin{array}{l}\infty \\
\stackrel{\infty}{\infty}\end{array}$ & ?. & $\frac{\infty}{i}$ & gे & ?.. & ô? & $\begin{array}{l}\text { त̂ } \\
\text { in }\end{array}$ & $\stackrel{5}{0}$ & $\begin{array}{l}: \\
\text { i }\end{array}$ & $\bar{m}$ & $\frac{2}{i}$ & 8 & 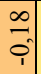 & $\begin{array}{l}n \\
0 \\
0 \\
0\end{array}$ & $\overrightarrow{\mathrm{N}}$ & $e_{0}^{\circ}$ & 管。 & $\begin{array}{c}0 \\
0 \\
0\end{array}$ & 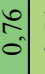 & $\stackrel{4}{*}$ & 恶 & $=$ & b. & \\
\hline 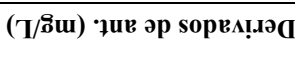 & ?n. & $\begin{array}{l}\text { İ } \\
\text { o. }\end{array}$ & $\begin{array}{l}\text { t) } \\
\text { i }\end{array}$ & $\begin{array}{l}8 \\
: \\
0\end{array}$ & $\begin{array}{l}\bar{r} \\
\vdots \\
\vdots\end{array}$ & $\frac{n}{i}$ & i & $\begin{array}{l}8 \\
0\end{array}$ & $\begin{array}{l}t \\
0 \\
\text { i }\end{array}$ & $\begin{array}{l}\infty \\
\overbrace{}^{\infty}\end{array}$ & $\begin{array}{l}2 \\
0 \\
0\end{array}$ & $\begin{array}{l}\text { तิ } \\
\text { i. }\end{array}$ & 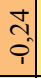 & $\begin{array}{l}8 \\
: \\
:\end{array}$ & 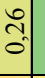 & $\begin{array}{l}\stackrel{ \pm}{t} \\
0\end{array}$ & $\tilde{n}$ & $\begin{array}{l}\infty \\
\vdots \\
\vdots\end{array}$ & & & & : & & ठ́. \\
\hline 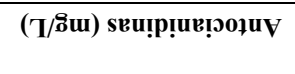 & $\tilde{m}$ & $\begin{array}{l}n \\
\vdots \\
0\end{array}$ & $\begin{array}{l}\text { n. } \\
\text { ?. }\end{array}$ & $\stackrel{t}{0}$ & $\begin{array}{l}0 \\
\text { ?. } \\
\text { ?. }\end{array}$ & @্ & & $\stackrel{0}{0}$ & : & $\stackrel{0}{0}$ & $\begin{array}{l}\overrightarrow{0} \\
\end{array}$ & in & $\stackrel{0}{0}$ & $\begin{array}{l}{ }_{0} \\
0_{1}\end{array}$ & E. & $\stackrel{\circ}{\circ}$ & ल. & $\frac{n}{0}$ & $\bar{c}_{0}$ & $\frac{0}{i}$ & : & & & $\begin{array}{c}\hat{A} \\
0\end{array}$ \\
\hline 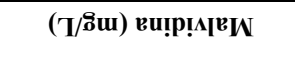 & $\stackrel{7}{0}$ & $\begin{array}{l}8 \\
0\end{array}$ & $\overbrace{0}^{2}$ & है & $\begin{array}{l}\hat{m} \\
\hat{i}\end{array}$ & $\stackrel{\Delta}{0}_{0}^{t}$ & $\frac{7}{c^{2}}$ & $\stackrel{\Omega}{0}$ & 8 & fo & $\begin{array}{l}f \\
0\end{array}$ & $\begin{array}{l}\hat{0} \\
i\end{array}$ & $\begin{array}{l}\overrightarrow{3} \\
\text { ?े. }\end{array}$ & o. & $\begin{array}{ll}T \\
m \\
0\end{array}$ & $\begin{array}{c}\infty \\
0_{0}^{0}\end{array}$ & $\begin{array}{c}\infty \\
0 \\
c\end{array}$ & s. & $\begin{array}{c}0 \\
0^{0}\end{array}$ & $\begin{array}{l}\infty \\
0 \\
0\end{array}$ & & & & : \\
\hline 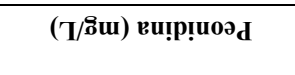 & : & $\stackrel{?}{i}$ & $\begin{array}{l}\tilde{m} \\
\tilde{c}\end{array}$ & $\frac{\pi}{0}$ & $\begin{array}{l}\text { no } \\
\text { in }\end{array}$ & $\stackrel{8}{\circ}$ & $\begin{array}{l}\text { ?} \\
\text { i }\end{array}$ & : & $\begin{array}{l}8 \\
\text { i }\end{array}$ & I & fo & $\begin{array}{l}R \\
i \\
i\end{array}$ & $\begin{array}{l}\text { के } \\
\text { ?ै. }\end{array}$ & $\begin{array}{l}\Delta \\
: \\
:\end{array}$ & $\begin{array}{l}\text { cे. } \\
\text { o. }\end{array}$ & $\begin{array}{l}0 \\
0 \\
0 \\
0\end{array}$ & $\begin{array}{l}\text { of } \\
0\end{array}$ & $\stackrel{\delta}{\delta}$ & f. & & & 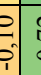 & & $\begin{array}{l}\mathbf{4} \\
\text { s? } \\
0\end{array}$ \\
\hline 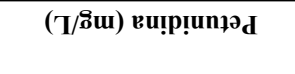 & ঙ্రু & $\tilde{\delta}_{0}^{\prime}$ & $\frac{l}{0}$ & nิ & $\begin{array}{l}\infty \\
0 \\
0 \\
\end{array}$ & $\stackrel{\square}{0}$ & $\frac{m}{i}$ & : & ठ̊. & $\overbrace{0}^{m}$ & त̂. & fo & ते & $\begin{array}{l}\infty \\
0 \\
0 \\
0\end{array}$ & ?. & $\begin{array}{c}8 \\
:\end{array}$ & $b_{0}^{\circ}$ & $\begin{array}{c}\infty \\
\vdots \\
0 \\
0\end{array}$ & & & $\begin{array}{c}0 \\
0 \\
0\end{array}$ & $\overrightarrow{3}$ & & $\begin{array}{l}0 \\
\vdots \\
0\end{array}$ \\
\hline 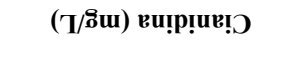 & तิ & : & ?ె & $\begin{array}{l}\infty \\
\stackrel{0}{0}\end{array}$ & $\begin{array}{l}5 \\
0\end{array}$ & $\stackrel{0}{\circ}$ & $\frac{ \pm}{i}$ & $\tilde{D}_{0}$ & 8 & ${ }_{0}^{g}$ & $\begin{array}{l}\infty \\
m_{2}^{2}\end{array}$ & $\begin{array}{l}0 \\
: \\
\end{array}$ & $\begin{array}{c}\overline{2} \\
\bar{i}\end{array}$ & $\frac{0}{0}$ & $\begin{array}{c}\exists \\
0\end{array}$ & ס̊. & $\begin{array}{l}\infty \\
\vdots \\
c \\
0\end{array}$ & & $\begin{array}{c}\infty \\
\infty \\
0\end{array}$ & ¿. & & $?$ & & $\hat{0}$ \\
\hline 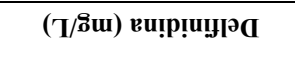 & : & 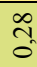 & $0_{0}^{\infty}$ & ํ. & $\begin{array}{l}\infty \\
0 \\
0\end{array}$ & of & ț & ठ & $\stackrel{0}{\circ}$ & $\stackrel{\Delta}{\circ}$ & $\frac{?}{0}$ & $\begin{array}{l}\overrightarrow{7} \\
\text { ?े }\end{array}$ & $\begin{array}{l}\stackrel{n}{0} \\
0\end{array}$ & : & $\begin{array}{l}n \\
0 \\
0\end{array}$ & $\begin{array}{l}\tilde{n} \\
\text { ? }\end{array}$ & & $\stackrel{\infty}{\infty}$ & ¿ & $\begin{array}{l}\text { o } \\
\text { fos }\end{array}$ & $\begin{array}{l}\infty \\
0 \\
0 \\
0\end{array}$ & $\overrightarrow{3}$ & & $\begin{array}{l}\dot{t} \\
\text { s? } \\
0\end{array}$ \\
\hline (T/8̈ & लु. & $\begin{array}{l}\infty \\
0\end{array}$ & $\begin{array}{l}\text { ते } \\
\text { o }\end{array}$ & $\begin{array}{l}\bar{b} \\
0\end{array}$ & $\begin{array}{l}8 \\
0^{\circ}\end{array}$ & $\stackrel{7}{0}$ & $\frac{\infty}{0}$ & $=$ & $\stackrel{0}{\circ}$ & J & $\begin{array}{l}0 \\
\text { ही. }\end{array}$ & $\stackrel{0}{0}$ & $\begin{array}{l}\vec{m} \\
?\end{array}$ & $\begin{array}{l}\vec{c} \\
\mathrm{c}\end{array}$ & $\begin{array}{c}\text { fo } \\
0\end{array}$ & & กิ? & ס. & \&̊. & $\begin{array}{c}0 \\
0 \\
0 \\
0\end{array}$ & $\begin{array}{l}0 \\
0 \\
0\end{array}$ & s. & & $\begin{array}{l}8 \\
0 \\
0\end{array}$ \\
\hline 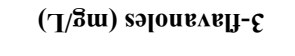 & $\frac{n}{0}$ & ֶి & $\begin{array}{l}0 \\
0\end{array}$ & $\begin{array}{l}= \\
0\end{array}$ & $\begin{array}{l}\text { of } \\
0\end{array}$ & $\frac{a}{0}$ & $\stackrel{5}{0}$ & $\stackrel{2}{2}{ }_{0}^{\circ}$ & స్ & $\begin{array}{l}8 \\
:\end{array}$ & $\begin{array}{l}\overline{1} \\
0\end{array}$ & $\begin{array}{l}\text { ปे } \\
\text { है }\end{array}$ & $\stackrel{2}{0}$ & $\begin{array}{l} \pm \\
0 \\
0\end{array}$ & & fo & $\frac{n}{0}$ & F. & ?. & $\begin{array}{c}\text { en } \\
\text { ce }\end{array}$ & $\begin{array}{c}m^{2} \\
0^{2}\end{array}$ & 5 & & $\begin{array}{l}\bar{y} \\
\text {. }\end{array}$ \\
\hline 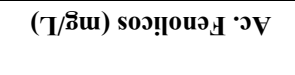 & $\stackrel{7}{\circ}$ & Oे & $\overrightarrow{\bar{c}}$ & $\begin{array}{l}m \\
0\end{array}$ & $\begin{array}{l}n \\
0 \\
0\end{array}$ & $\frac{9}{\circ}$ & $\begin{array}{l}\text { f } \\
\text { si }\end{array}$ & $\frac{\pi}{i}$ & సิ & $\begin{array}{l}0 \\
0 \\
0\end{array}$ & $\begin{array}{l}n \\
0 \\
0 \\
1\end{array}$ & $\begin{array}{l}8 \\
:\end{array}$ & $\begin{array}{l}\infty \\
0 \\
0 \\
\end{array}$ & & $\begin{array}{l} \\
\vdots \\
i \\
1\end{array}$ & $\vec{c}$ & oे & $\begin{array}{l}0 \\
\circ \\
\end{array}$ & $\begin{array}{l}\infty \\
\vdots\end{array}$ & to & $\begin{array}{l}0 \\
0 \\
0\end{array}$ & 8 & & $\begin{array}{l}n \\
\vdots \\
0\end{array}$ \\
\hline 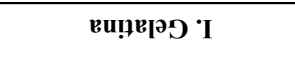 & $\begin{array}{l}\text { N. } \\
\text { i }\end{array}$ & రి & तె. & के & ? & $\begin{array}{l}\text { J } \\
\text { i }\end{array}$ & $\stackrel{8}{0}$ & $\begin{array}{l}8 \\
0\end{array}$ & స్ & $\begin{array}{l}\tilde{m} \\
? \\
i\end{array}$ & $\begin{array}{l}\infty \\
0 \\
0\end{array}$ & $\stackrel{m}{0^{\circ}}$ & & $\begin{array}{l}8 \\
8 \\
0 \\
i\end{array}$ & $\begin{array}{l}n \\
\vdots \\
i\end{array}$ & $\begin{array}{c}\vec{m} \\
c^{2}\end{array}$ & $\frac{1}{0}$ & $\overline{\bar{n}} \bar{i}$ & ָे & $\begin{array}{l}\text { ले } \\
\text { ? }\end{array}$ & $\begin{array}{l}\overrightarrow{3} \\
\text { ?. }\end{array}$ & 8 & & $\frac{\infty}{c}$ \\
\hline ·U!!od +UV \% & $\div$ & fo & o. & $\begin{array}{l}n \\
\text { ? }\end{array}$ & $\frac{0}{10}$ & 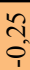 & $\stackrel{\square}{0}$ & $\frac{0}{0}$ & ¿. & $\begin{array}{c}m \\
\stackrel{m}{1}\end{array}$ & $\begin{array}{c}\tilde{\infty} \\
0\end{array}$ & & $\frac{m}{0}$ & $\begin{array}{l}8 \\
8 \\
0\end{array}$ & \begin{tabular}{c}
\multirow{2}{*}{} \\
ch
\end{tabular} & $\begin{array}{l}8 \\
: \\
\vdots \\
\end{array}$ & ה్. & : & fo & $\begin{array}{l}\text { R} \\
\mathbf{i}\end{array}$ & ب. & $?$ & & $\begin{array}{l}8 \\
8\end{array}$ \\
\hline sə.xq!T ๆUV \% & $\widehat{3}$ & $\begin{array}{l}\bar{~} \\
0\end{array}$ & ?. & กิ & $\begin{array}{l} \pm \\
0 \\
0\end{array}$ & ?ี & $\stackrel{\infty}{0}$ & กิ & $\frac{0}{0}$ & $\tilde{\tilde{S}}$ & & $\begin{array}{c}\tilde{0} \\
0 \\
0\end{array}$ & $\begin{array}{l}0 \\
0 \\
0\end{array}$ & $\begin{array}{l}2 \\
0 \\
0\end{array}$ & ç. & $\begin{array}{c}0 \\
c \\
0\end{array}$ & $\frac{2}{0}$ & 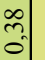 & 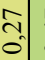 & fo & $\begin{array}{l}7 \\
0\end{array}$ & 0 & & $\frac{0}{0}$ \\
\hline 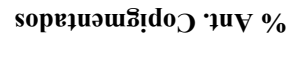 & $\underset{0}{F}$ & $\begin{array}{l}f \\
0 \\
i\end{array}$ & ô & ธี & $\begin{array}{l}n \\
\tilde{c} \\
\vdots\end{array}$ & กิ & $\stackrel{\circ}{i}$ & $\stackrel{0}{\circ}$ & $\frac{\infty}{0}$ & & $\begin{array}{l}\text { त̂. } \\
\text { ch }\end{array}$ & $\begin{array}{c}\text { m. } \\
\text { ?he }\end{array}$ & $\begin{array}{c}\text { m. } \\
?\end{array}$ & $\begin{array}{l}8 \\
0 \\
0\end{array}$ & 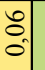 & $\begin{array}{c}f \\
0 \\
0\end{array}$ & $\begin{array}{l} \pm \\
0 \\
0\end{array}$ & $\frac{9}{9}$ & ç & fo & $\begin{array}{l}0 \\
0 \\
0 \\
0\end{array}$ & 8 & & $\bar{c}$ \\
\hline ( $\mathbf{T} / \mathbf{8})$ sou!ug $_{\mathbf{L}}$ & 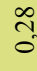 & $\begin{array}{l}\tilde{z} \\
\hat{1}\end{array}$ & $\frac{m}{i}$ & $\begin{array}{l}\bar{\sigma} \\
0\end{array}$ & $\begin{array}{l}\text { त̂ } \\
\text { of }\end{array}$ & $\begin{array}{l}\text { @. } \\
\text { î }\end{array}$ & $\begin{array}{l}\tilde{y} \\
\text { îs }\end{array}$ & $\begin{array}{c}\text { ô. } \\
i\end{array}$ & & $\frac{\infty}{0}$ & $\frac{0}{i}$ & $\begin{array}{l}\overrightarrow{0} \\
\end{array}$ & సે. & ç. & $\begin{array}{c}0 \\
\vdots \\
\vdots\end{array}$ & $\stackrel{0}{\circ}$ & $\frac{0}{0}$ & $\begin{array}{c}8 \\
8\end{array}$ & : & : & $\stackrel{8}{8}$ & : & & $\begin{array}{l}8 \\
\end{array}$ \\
\hline $\operatorname{dd} \Lambda \mathrm{d}{ }^{\top} I$ & $\frac{7}{0}$ & $\overline{0}$ & : & $\frac{6}{0}$ & f. & $\stackrel{\circ}{\circ}$ & $\begin{array}{l}9 \\
0 \\
0\end{array}$ & & ़ְ: & $\because$ & సి & $\stackrel{0}{0}$ & 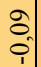 & $\begin{array}{c}7 \\
0\end{array}$ & $\begin{array}{l}{ }_{0}^{2} \\
0 \\
0\end{array}$ & $\begin{array}{c}\bar{c} \\
\end{array}$ & : 0 & $\stackrel{0}{\circ}$ & $\begin{array}{l}0 \\
0 \\
0\end{array}$ & $\begin{array}{c}0 \\
0 \\
0\end{array}$ & $\begin{array}{l}0 \\
0 \\
0\end{array}$ & 8 & & :. \\
\hline IOUB?⿴囗十⺝ 'I & : & $\frac{7}{0}$ & of & సิ & స̂. & $\bar{\circ}$ & & gi & ñ & $\frac{0}{0}$ & $\begin{array}{l}\infty \\
0 \\
0\end{array}$ & $\begin{array}{l}\overline{0} \\
0^{\circ}\end{array}$ & $\begin{array}{l}\because \\
0 \\
0\end{array}$ & 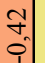 & $\begin{array}{c}\overline{0} \\
0\end{array}$ & $\frac{\infty}{0}$ & $\begin{array}{l} \pm \\
0 \\
0\end{array}$ & $\frac{7}{0}$ & $\frac{7}{0}$ & $\frac{0}{0}$ & $\frac{7}{0}$ & $\frac{6}{6}$ & & $\begin{array}{c}\text { กิ } \\
\text { ? }\end{array}$ \\
\hline HOVWA II & స్ & $\begin{array}{l}\text { กิ } \\
\text { : }\end{array}$ & $\begin{array}{l}\overline{\text { N}} \\
0\end{array}$ & $\stackrel{?}{0}$ & $\begin{array}{l}n \\
f \\
0\end{array}$ & & $\stackrel{\square}{\circ}$ & 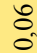 & m. & กิ & $\begin{array}{l}7 \\
0\end{array}$ & $\begin{array}{l}\text { ? } \\
\text { s. }\end{array}$ & $\begin{array}{l}7 \\
0 \\
0\end{array}$ & $\frac{2}{0}$ & $\stackrel{0}{0}$ & $\frac{7}{0}$ & $\begin{array}{l}f \\
0 \\
0\end{array}$ & : & $\begin{array}{l}{ }_{0} \\
0\end{array}$ & $\begin{array}{l}0 \\
0 \\
0\end{array}$ & ${ }_{0}^{0}$ & $\begin{array}{c}0 \\
0 \\
0\end{array}$ & & $\begin{array}{l}\bar{\imath} \\
\text { : }\end{array}$ \\
\hline 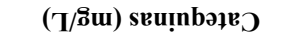 & $\overline{0}$ & ले & กิ & $\begin{array}{l}\infty \\
0 \\
0\end{array}$ & & ?for & ָิ & $\stackrel{m}{g}$ & त̂ & $\begin{array}{c}m \\
? \\
0\end{array}$ & $\begin{array}{l}\text { to } \\
0\end{array}$ & $\begin{array}{l}0 \\
\text { ?" }\end{array}$ & $\stackrel{0}{\circ}$ & $\begin{array}{l}2 \\
0 \\
0\end{array}$ & $\stackrel{0}{0}$ & $\stackrel{8}{\circ}$ & 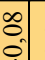 & $\stackrel{0}{0}$ & 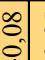 & $\begin{array}{l}8 \\
0 \\
0\end{array}$ & $\begin{array}{l}0 \\
0 \\
0\end{array}$ & ? & & $\begin{array}{l}\text { ?े } \\
0\end{array}$ \\
\hline 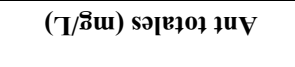 & $\frac{7}{0}$ & $\frac{7}{9}$ & \begin{tabular}{l}
$\infty$ \\
\multirow{3}{0}{}
\end{tabular} & & $\begin{array}{ll}\infty \\
0 \\
0\end{array}$ & & $\begin{array}{l}\text { त̂ } \\
\stackrel{9}{2}\end{array}$ & $\stackrel{0}{0}$ & $\overline{0}$ & $\vec{n}$ & ते & $\begin{array}{l}\text { n } \\
\text { ? }\end{array}$ & $\begin{array}{l}\text { के } \\
\text { ?े }\end{array}$ & $\begin{array}{l}0 \\
: \\
i\end{array}$ & $\begin{array}{l}\overline{0} \\
0\end{array}$ & $\vec{\square} \cdot \overrightarrow{0}$ & ते & $\stackrel{0}{: 0}$ & గn. & $\begin{array}{l}\text { E. } \\
0\end{array}$ & స. & 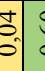 & & ơ \\
\hline $0^{040}{ }_{L}$ & $\begin{array}{l}\hat{3} \\
\text { ? }\end{array}$ & $\frac{9}{1}$ & & 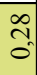 & तु. & ֶָ. & $\stackrel{0}{\circ}$ & हे & $\frac{m}{i}$ & $\tilde{0}$ & $\begin{array}{l}? \\
\text { ?f }\end{array}$ & $\begin{array}{l}\text { bे } \\
\text { i }\end{array}$ & กี. & $\begin{array}{l}\bar{Z} \\
\text { i. }\end{array}$ & $\begin{array}{l}0 \\
0^{\circ}\end{array}$ & $\begin{array}{c}n \\
\vdots \\
0\end{array}$ & $\begin{array}{l}0 \\
0 \\
0\end{array}$ & $\stackrel{2}{3}$ & $\frac{0}{\circ}$ & ?. & 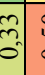 & $\begin{array}{l}0 \\
0 \\
0 \\
1\end{array}$ & & $\begin{array}{l}\infty \\
0 \\
\end{array}$ \\
\hline 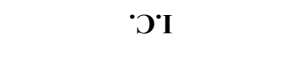 & $\stackrel{0}{0}$ & & $\frac{9}{0}$ & ? & ç. & ธิ & $\stackrel{7}{0}$ & $\begin{array}{l}\overline{0} \\
\end{array}$ & กี & g & $\overline{\widetilde{\sigma}}$ & of & ?ి. & $\begin{array}{l}\text { so } \\
0\end{array}$ & ֻ̊. & $\begin{array}{l}\infty \\
0 \\
0\end{array}$ & $\begin{array}{c}0 \\
c \\
c\end{array}$ & : & $\begin{array}{l}\tilde{\delta} \\
0\end{array}$ & $\frac{7}{0}$ & $\begin{array}{l}\text { oे } \\
0\end{array}$ & ?. & & $\begin{array}{l}0 \\
\text { ?? } \\
0\end{array}$ \\
\hline U!ा & & : & $\hat{\tilde{3}}$ & ? & $\Rightarrow$ & స్ & 8 & $\frac{7}{i}$ & న్రి & $\vec{J}_{0}$ & ?. & $\frac{\simeq}{0}$ & 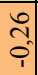 & $\begin{array}{ll}\simeq \\
0\end{array}$ & $\begin{array}{l}n \\
0 \\
0\end{array}$ & $\overrightarrow{c^{2}}$ & $\begin{array}{c}0 \\
0 \\
0 \\
0\end{array}$ & $\begin{array}{c}\text { ते } \\
\text {. }\end{array}$ & $\begin{array}{l}\text { c. } \\
\text { o. }\end{array}$ & 8 & & & & $\begin{array}{l}\infty \\
c_{0}^{2}\end{array}$ \\
\hline & 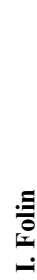 & & $\bar{\theta}$ & 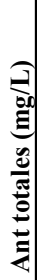 & 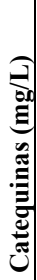 & J & & : & 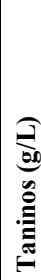 & 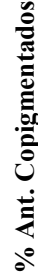 & $\frac{3}{3}$ & $\begin{array}{l}\dot{0} \\
0 \\
0 \\
0 \\
0 \\
0\end{array}$ & 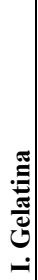 & 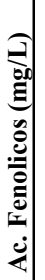 & 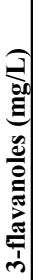 & 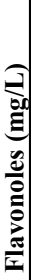 & 窝 & 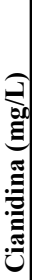 & 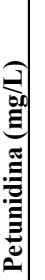 & 兽 & 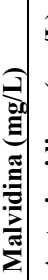 & 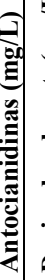 & 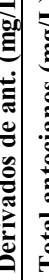 & 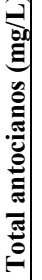 \\
\hline
\end{tabular}


En cuanto al segundo eje principal identificado, se correlaciona de forma positiva con la intensidad colorante, porcentaje del color que corresponde a las reacciones de polimerización, antocianidinas y total de antocianos, dando lugar a vinos capaces de mantener una notable intensidad colorante, debida principalmente a la mayor presencia de los antocianos en su forma polimerizada, aunque siendo necesario para ello la presencia de una importante concentración antociánica. Por el contrario, esta relacionado de forma negativa con el tono y el porcentaje del color que corresponde a los antocianos libres, correspondiendo a vinos que presentan las características opuestas a los situados en la parte positiva del segundo eje considerado.

Tabla 6.65. Autovalor, varianza explicada y acumulada para las componentes consideradas en el análisis

\begin{tabular}{cccc}
\hline Componente & Autovalor & \% Varianza & \% Acumulado \\
\hline $\mathbf{1}$ & 7,837 & 31,350 & 31,350 \\
$\mathbf{2}$ & 4,079 & 16,314 & 47,664 \\
$\mathbf{3}$ & 2,603 & 10,411 & 58,075 \\
$\mathbf{4}$ & 2,212 & 8,849 & 66,924 \\
$\mathbf{5}$ & 1,816 & 7,263 & 74,187 \\
$\mathbf{6}$ & 1,323 & 5,292 & 79,479 \\
$\mathbf{7}$ & 1,096 & 4,384 & 83,863 \\
$\mathbf{8}$ & 0,899 & 3,597 & 87,460 \\
$\mathbf{9}$ & 0,663 & 2,650 & 90,110 \\
$\mathbf{1 0}$ & 0,561 & 2,243 & 92,353 \\
$\mathbf{1 1}$ & 0,498 & 1,991 & 94,344 \\
$\mathbf{1 2}$ & 0,360 & 1,442 & 95,785 \\
$\mathbf{1 3}$ & 0,308 & 1,234 & 97,019 \\
$\mathbf{1 4}$ & 0,189 & 0,758 & 97,776 \\
$\mathbf{1 5}$ & 0,173 & 0,693 & 98,469 \\
$\mathbf{1 6}$ & 0,144 & 0,575 & 99,044 \\
$\mathbf{1 7}$ & 0,092 & 0,368 & 99,412 \\
$\mathbf{1 8}$ & 0,080 & 0,318 & 99,730 \\
$\mathbf{1 9}$ & 0,043 & 0,170 & 99,901 \\
$\mathbf{2 0}$ & 0,019 & 0,076 & 99,977 \\
$\mathbf{2 1}$ & 0,005 & 0,021 & 99,997 \\
$\mathbf{2 2}$ & 0,001 & 0,003 & 100,000 \\
\hline
\end{tabular}

Los parámetros índice de Folin, concentración de catequinas, índice de DMACH y porcentaje del color debido a la copigmentación, caracterizan de forma positiva al tercer eje principal identificado. Por el contrario la intensidad colorante, el porcentaje del color debido a los antocianos libres, el índice de gelatina y la concentración de delfinidinas lo caracterizan de forma negativa.

Los vinos situados en la zona positiva del tercer eje principal se caracterizan por presentar una elevada concentración de catequinas, afectando al grado de polimerización de taninos y manteniendo una importante concentración fenólica. 
Además en estos vinos parece que las reacciones de copigmentación se ven intensificadas. Por otra parte, los situados en la zona negativa presentaran un color importante debido a los antocianos libres, con concentraciones elevadas de definidinas, afectando decisivamente a la intensidad colorante de los vinos, así como a la astringencia de los mismos.

Tabla 6.66. Tabla de pesos de los componentes

\begin{tabular}{lccccccc}
\hline & \multicolumn{7}{c}{ Componentes } \\
& $\mathbf{1}$ & $\mathbf{2}$ & $\mathbf{3}$ & $\mathbf{4}$ & $\mathbf{5}$ & $\mathbf{6}$ & $\mathbf{7}$ \\
\hline I. Folin & 0,09 & 0,19 & 0,35 & 0,07 & 0,07 & 0,29 & $-0,24$ \\
I.C. & $-0,01$ & 0,30 & $-0,28$ & $-0,15$ & 0,21 & 0,23 & 0,16 \\
Tono & 0,10 & $-0,35$ & $-0,21$ & $-0,03$ & $-0,01$ & 0,06 & 0,07 \\
Ant totales (mg/L) & 0,27 & $-0,06$ & 0,11 & $-0,04$ & $-0,06$ & $-0,24$ & $-0,04$ \\
Catequinas (mg/L) & $-0,01$ & $-0,20$ & 0,33 & $-0,19$ & $-0,24$ & 0,39 & 0,11 \\
I. DMACH & 0,02 & $-0,21$ & 0,34 & $-0,08$ & 0,41 & 0,14 & 0,23 \\
I. Etanol & $-0,06$ & $-0,08$ & $-0,10$ & $-0,46$ & $-0,04$ & 0,32 & $-0,26$ \\
I. PVPP & 0,01 & $-0,02$ & 0,07 & $-0,55$ & $-0,22$ & $-0,02$ & 0,25 \\
Taninos (g/L) & 0,01 & 0,03 & 0,12 & 0,42 & $-0,39$ & 0,34 & $-0,18$ \\
\%o Ant. Copigmentados & 0,18 & $-0,03$ & 0,40 & $-0,05$ & $-0,18$ & $-0,07$ & $-0,22$ \\
\%o Ant. Libres & 0,13 & $-0,35$ & $-0,31$ & 0,10 & 0,10 & 0,02 & 0,02 \\
\%o Ant Polim. & $-0,22$ & 0,36 & 0,07 & $-0,07$ & 0,02 & 0,02 & 0,11 \\
I. Gelatina & $-0,12$ & 0,03 & $-0,36$ & 0,12 & $-0,28$ & 0,28 & $-0,05$ \\
Ac. Fenolicos (mg/L) & 0,03 & 0,04 & 0,14 & 0,32 & $-0,03$ & 0,15 & 0,74 \\
3-flavanoles (mg/L) & 0,13 & $-0,03$ & $-0,06$ & $-0,17$ & 0,32 & 0,40 & $-0,01$ \\
Flavonoles (mg/L) & 0,33 & $-0,03$ & 0,04 & 0,10 & 0,03 & 0,18 & 0,02 \\
Delfinidina (mg/L) & 0,20 & 0,13 & $-0,26$ & 0,00 & $-0,25$ & 0,21 & 0,10 \\
Cianidina (mg/L) & 0,35 & 0,01 & $-0,07$ & 0,00 & 0,02 & 0,06 & 0,03 \\
Petunidina (mg/L) & 0,32 & 0,07 & $-0,03$ & 0,03 & 0,04 & 0,07 & $-0,03$ \\
Peonidina (mg/L) & 0,33 & $-0,10$ & $-0,04$ & $-0,03$ & $-0,01$ & $-0,12$ & 0,00 \\
Malvidina (mg/L) & 0,35 & $-0,06$ & $-0,03$ & 0,00 & $-0,01$ & $-0,05$ & $-0,01$ \\
Antocianidinas (mg/L) & 0,06 & 0,46 & 0,00 & $-0,08$ & 0,02 & $-0,04$ & 0,01 \\
Derivados de ant. (mg/L) & 0,31 & 0,23 & $-0,02$ & $-0,05$ & 0,00 & $-0,06$ & 0,00 \\
Total antocianos (mg/L) & 0,26 & 0,32 & $-0,02$ & $-0,06$ & 0,01 & $-0,06$ & 0,00 \\
\hline
\end{tabular}

El cuarto componente está altamente relacionado con el índice de etanol, el de PVPP y la concentración de ácidos fenólicos; el quinto con el índice de DMACH, taninos totales, índice de gelatina y 3-flavanoles; el sexto con el índice de Folin, catequinas, taninos y la concentración de 3-flavanoles; y por último el séptimo con el índice de etanol, el de PVPP y la concentración de ácidos fenólicos.

Una vez comprobadas que variables están más correlacionadas con las componentes principales, se calcularon los coeficientes de las componentes principales y se representan estas componentes.

En el gráfico 6.99 aparecen representados los vinos adicionados de los diferentes copigmentos ensayados en función de los dos primeros ejes principales identificados, observándose como únicamente los vinos adicionados del copigmento 
ácido cafeico presentan un marcado efecto, diferenciándose su localización frente al resto de vinos elaborados, y situándose prácticamente todos ellos en la zona positiva del segundo eje principal considerado.

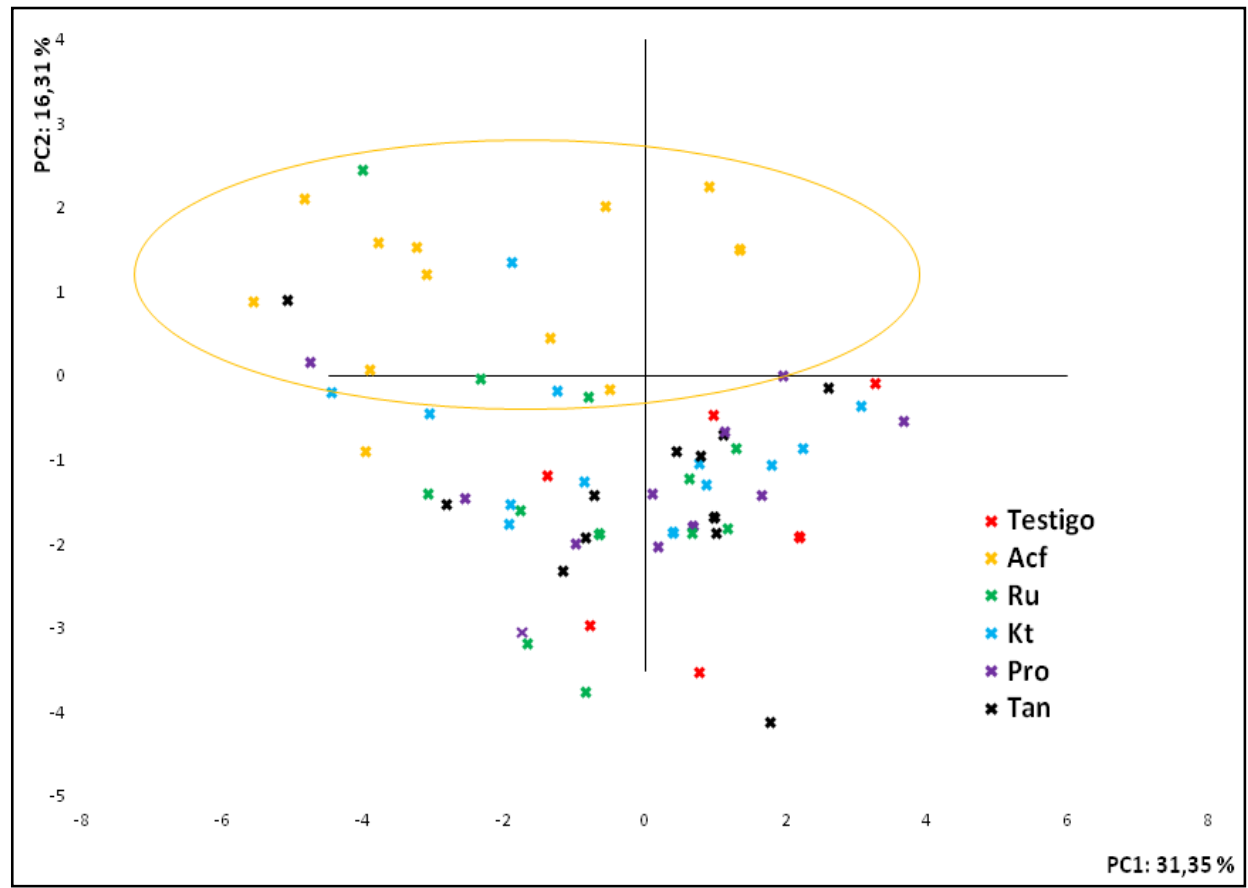

Gráfico 6.99. Primera componente frente a la segunda, en función de los copigmentos ensayados

Las variables correlacionadas con la zona positiva del segundo componente ponen de manifiesto que los vinos adicionados de ácido cafeico se caracterizan por ser capaces de mantener una notable intensidad colorante, debida principalmente a la mayor presencia de los antocianos en su forma polimerizada, aunque siendo necesario para ello la presencia de una importante concentración antociánica.

La representación de la primera componente frente a la segunda en función de las diferentes técnicas de vinificación ensayadas aparece representada en el gráfico 6.100; pudiéndo observar que los vinos macerados con aplicación de bajas temperaturas aparecen situados hacia la parte positiva del primer componente, mientras que los elaborados de forma tradicional se sitúan, prácticamente, en la zona negativa.

La maceración prefermentativa en frío ha permitido la elaboración de vinos caracterizados por presentar una elevada concentración de los principales compuestos antociánicos presentes en su forma libre, junto con concentraciones importantes de flavonoles; observándose en estos vinos el efecto favorable de extracción de la composición antociánica, atribuido a la maceración prefermentativa por numerosos autores incluso al final de la conservación de los vinos.

Únicamente el tercer eje principal considerado es capaz de separar de una forma medianamente clara los vinos microoxigenados de aquellos no adicionados de acetaldehído (gráfico 6.101); situándose los vinos microoxigenados en la zona negativa del tercer eje. 


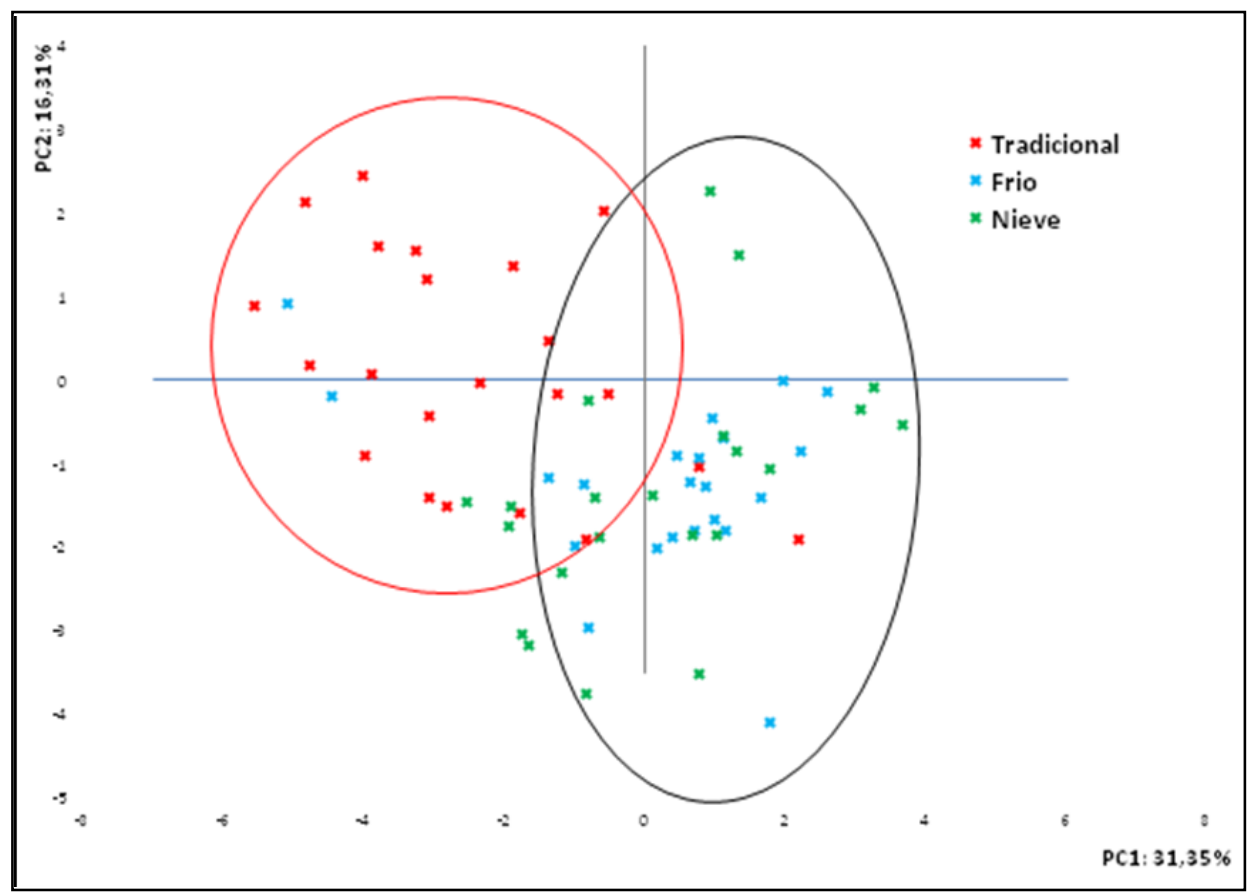

Gráfico 6.100. Primera componente frente a la segunda, en función de las técnicas de vinificación ensayadas.

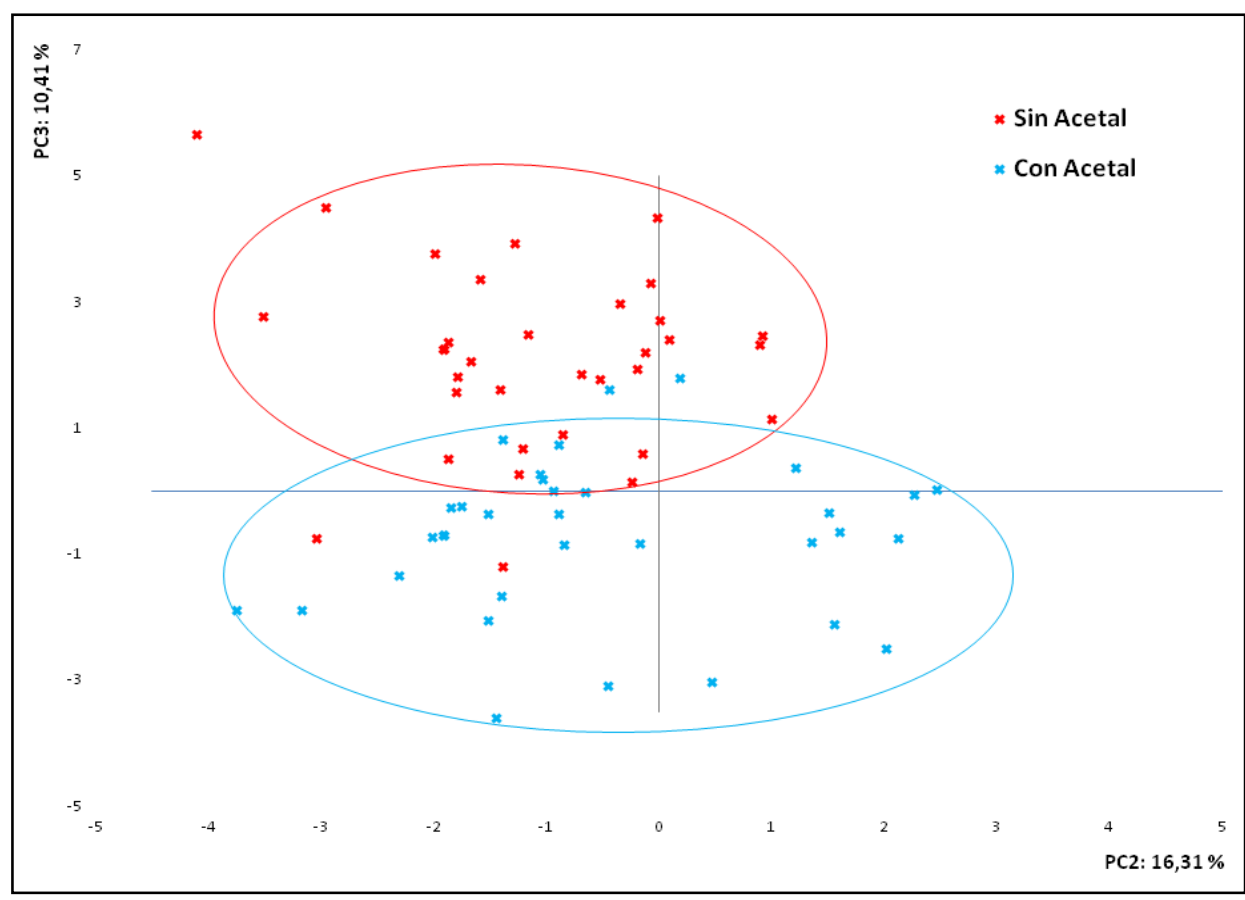

Gráfico 6.101. Primera componente frente a la tercera, en función de la aplicación de la microoxigenación.

Estos vinos presentaran un importante color debido a los antocianos libres, con concentraciones elevadas de definidinas, afectando decisivamente a la intensidad colorante de los vinos, así como a la astringencia de los mismos. Por el contrario los vinos no microoxigenados situados en la parte positiva se caracterizaran por presentar 
una elevada concentración de catequinas, afectando al grado de polimerización de taninos y manteniendo una importante concentración fenólica.

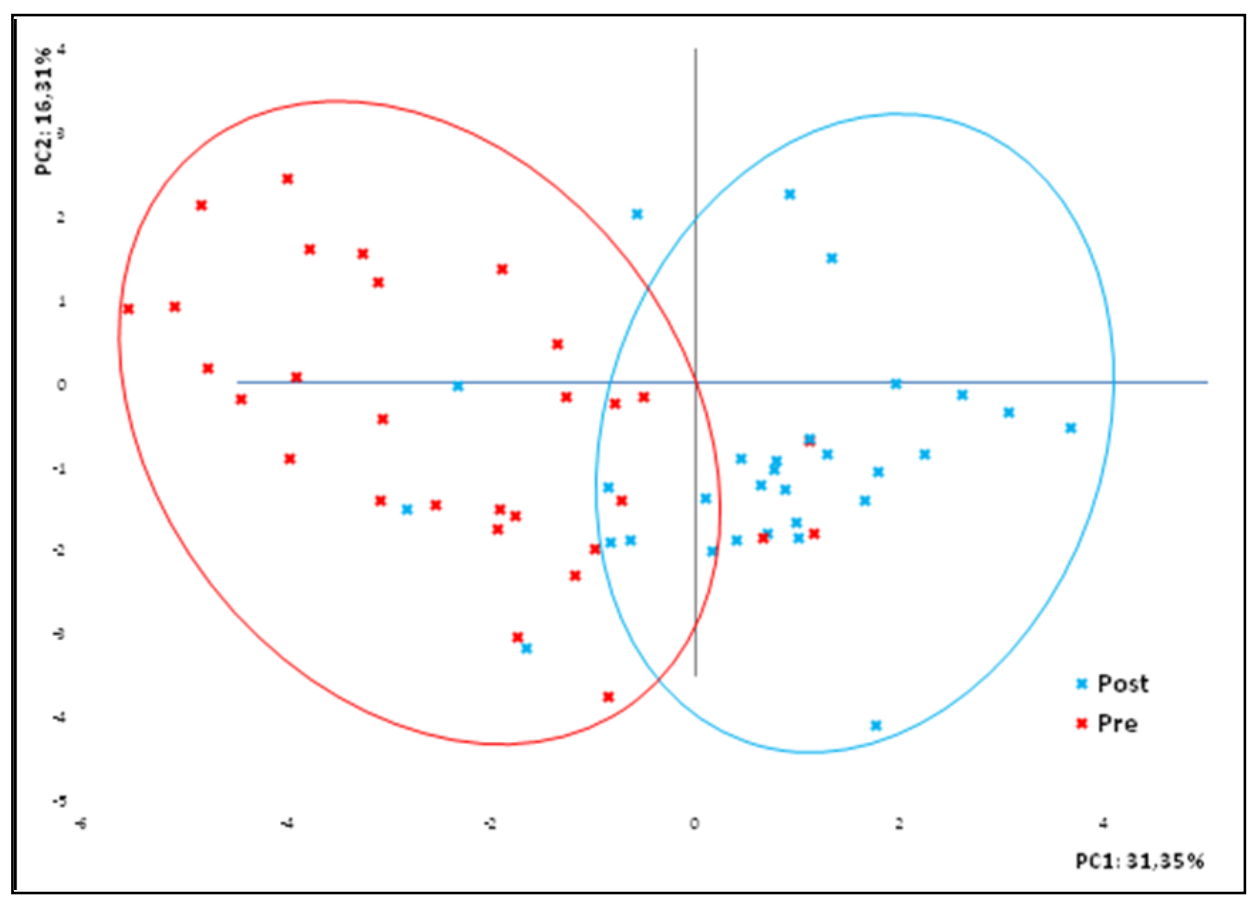

Gráfico 6.102. Primera componente frente a la segunda, en función del momento de adición de los copigmentos.

En el gráfico 6.102, que muestra la representación de los vinos elaborados en función de la adición pre- o portfermentativa de copigmentos, se observa como el análisis de componentes principales permite la diferenciación de los vinos en función del momento de adición de los copigmentos. Los vinos adicionados posteriormente a la fermentación se sitúan, principalmente en la zona positiva del primer componente principal que corresponde a vinos que presentan una elevada concentración de los principales compuestos antociánicos en su forma libre, junto con concentraciones importantes de flavonoles, manteniéndose estas diferencias hasta el final del periodo de conservación de los vinos, de 12 meses en botella.

\subsubsection{EVOLUCIÓN DE LOS VINOS ELABORADOS DURANTE 12 MESES DE CONSERVACIÓN EN BOTELLA}

Con el fin de estimar la eficacia de las distintas técnicas aplicadas en el presente trabajo, así como de establecer los mecanismos que tienen lugar durante los doce meses de seguimiento, se estudiará cada uno de los parámetros polifenólicos por separado en función de los distintos factores ensayados.

El análisis multifactorial de la varianza (tablas 6.44, 6.50 y 6.58) muestra como los factores adición de copigmentos, aplicación de las diferentes técnicas de vinificación ensayadas, aplicación de la microoxigenación y adición de copigmentos previamente o posteriormente a la fermentación, afectan significativamente a la composición fenólica de los vinos elaborados a lo largo del periodo de conservación de 12 meses en botella. 
La interacción entre la adición de copigmentos y las técnicas de vinificación presenta un efecto moderado sobre la composición fenólica de los vinos analizados después de la fermentación maloláctica, despareciendo este efecto durante el envejecimiento de los vinos en botella. Por el contrario la interacción entre el factor técnicas de vinificación y momento de adición de copigmentos presenta un marcado efecto sobre la composición de los vinos a lo largo del proceso de conservación.

Las interacciones adición de copigmentos con momento de adición, microoxigenación con momento de adición y técnicas de vinifinación con microoxigenación presentan un efecto moderado sobre la composición fenólica de los vinos a los 6 meses de conservación. Por el contrario únicamente se mantiene este efecto moderado para las dos primeras interacciones al final del proceso de conservación de los vinos en botella.

El Análisis de Componentes Principales no ha permitido clasificar a los diferentes copigmentos utilizados en el estudio, en función de su poder copigmentante. Únicamente el copigmento ácido cafeico ha sido capaz de diferenciarse frente al resto de copigmentos adicionados $\mathrm{y}$ frente al vino testigo (gráficos 6.94, 6.98); caracterizándose estos vinos por presentar un gran número de uniones entre antocianos y taninos, dando lugar a un incremento del color, así como favoreciendo la presencia de una adecuada concentración fenólica; evolucionando hacia vinos capaces de mantener una notable intensidad colorante, debida principalmente a la mayor presencia de los antocianos en su forma polimerizada, aunque siendo necesario para ello mantener una importante concentración antociánica al final de la conservación.

Para la caracterización de las diferentes metodologías de vinificación ensayadas la técnica estadística del APC permite diferenciar posteriormente al embotellado a los vinos elaborados de forma tradicional de aquellos sometidos a técnicas prefermentativas mediante aplicación de bajas temperaturas. La maceración prefermentativa, tanto en frío como con adición nieve carbónica, permite obtener vinos enevejecidos donde predominan las reacciones de unión entre antocianos y taninos mediadas por el acetaldehído, viéndose reducido el grado de polimerización de los taninos, al estar participando estos en las reacciones con los antocianos (gráfico 6.93).

Por el contrario, a los 6 y 12 meses de conservación en botella, los vinos criomacerados se caracterizan por presentar una elevada concentración de la fracción antociánica en su forma simple (gráficos 6.95, 6.99), no encontrándose este efecto en el análisis realizado posteriormente a la fermentación.

En cuanto a la aplicación de la microoxigenacion, no es posible caracterizar a los vinos a los 6 meses del embotellado, aunque al final de la conservación los vinos microoxigenados presentan un importante color debido a los antocianos libres, con concentraciones elevadas de definidinas, afectando decisivamente a la intensidad colorante de los vinos, así como a la astringencia de los mismos. Por el contrario, los vinos no microoxigenados se caracterizaran por presentar una elevada concentración de catequinas, afectando al grado de polimerización de taninos (gráfico 6.56).

Por último, los vinos adicionados de copigmentos posteriormente a la fermentación, son caracterizados por el ACP como vinos que presentan una elevada concentración antociánica en sus formas simples o monómeras, manteniéndose estas diferencias durante todo el proceso de conservación en botella (gráficos 6.97, 6.101). 
Para poder resumir la evolución de los parámetros polifenólicos a lo largo de la conservación, y poder establecer la mejor metodología en función del objetivo deseado, se va a representar la evolución de cada uno de los parámetros por separado, con cada una de las técnicas ensayadas.

\subsubsection{1. $\quad$ EVOLUCIÓN DE LA INTENSIDAD COLORANTE}

A lo largo del proceso de conservación se observa que la adición de los distintos copigmentos ensayados afecta significativamente al color de los vinos elaborados.

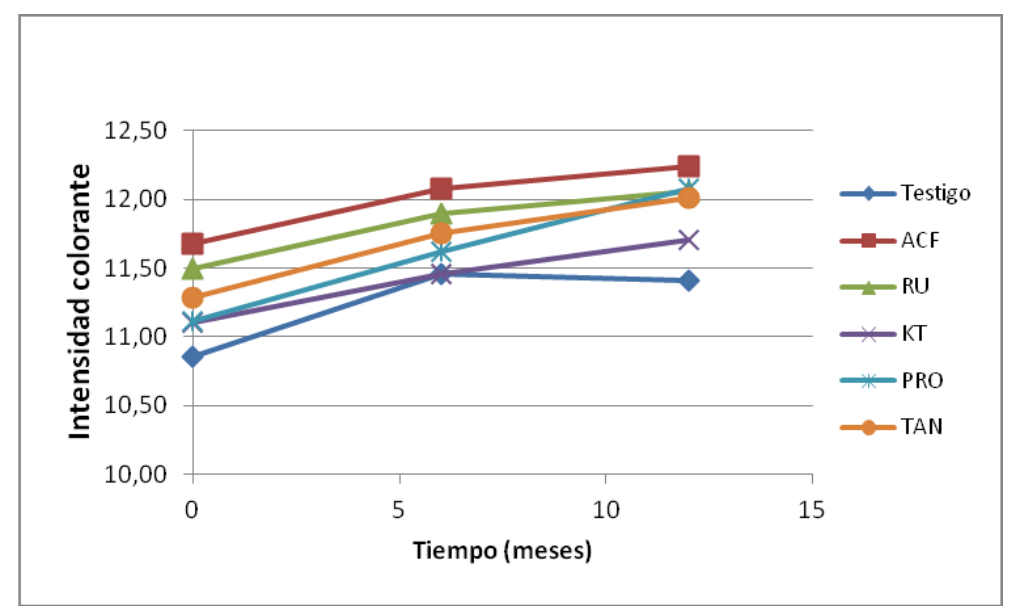

Gráfico 6.103. Evolución de la intensidad colorante durante el periodo de conservación de los vinos en función de los distintos copigmentos adicionados

En el gráfico 6.103 aparece la evolución de la intensidad colorante en función de los distintos copigmentos adicionados. La adición de copigmentos ha provocado un incremento del color de los vinos elaborados, aunque sin diferencias significativas tanto al principio como al final del proceso de conservación (tablas 6.45, 6.51, 6.59). El comportamiento de los copigmentos a lo largo de la conservación es similar al observado después de la fermentación maloláctica, siendo el ácido cafeico el copigmento más adecuado para incrementar el color de los vinos, tal como hemos observado en los vinos de la cosecha 2007.

En el gráfico 6.104 aparece representada la evolución de la intensidad colorante en función de la adición controlada de acetaldehído. Se observa como los vinos microoxigenados presentan una intensidad colorante estadísticamente superior a la observada en los vinos no microoxigenados, manteniéndose estos efectos hasta el final de la conservación (gráficos 6.54, 6.62). Ya se ha comentado a lo largo del presente trabajo el efecto de esta técnica frente al color, mostrándose como una técnica adecuada para incrementar las características cromáticas, incluso en los vinos envejecidos.

Este efecto ha sido observado en todos los vinos elaborados, independientemente de la añada (gráficos 6.13 y 6.51), y puede justificarse por el hecho de que parte de los antocianos incoloros se conviertan en coloreados al entrar a formar parte de combinaciones antociano-tanino o tanino-antociano, y por la formación de 
piranoantocianos, tal como también observaron otros autores (Rayne et al., 2008; Cano-López et al. 2006, 2007, 2008, 2010; Wirth et al., 2010).

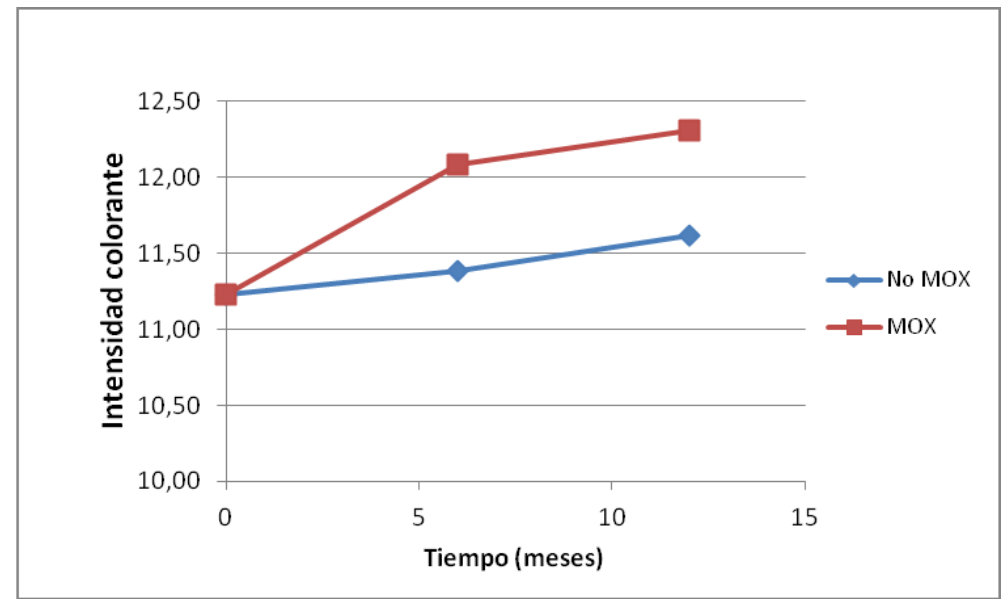

Gráfico 6.104. Evolución de la intensidad colorante durante el periodo de conservación de los vinos en función de la aplicación de la microoxigenación.

\subsubsection{2. $\quad$ EVOLUCIÓN DEL TONO}

En el gráfico 6.105 aparece la evolución del tono en los diferentes vinos elaborados en función de los copigmentos adicionados. Podemos observar el incremento de la componente amarilla de los vinos a lo largo de la conservación, debido, principlamente, a la oxidación de compuestos fenólicos, pero también a la formación de piranoantocianos, compuestos antocianídicos estables cuyo color presenta tonalidades más teja, características de los vinos envejecidos.

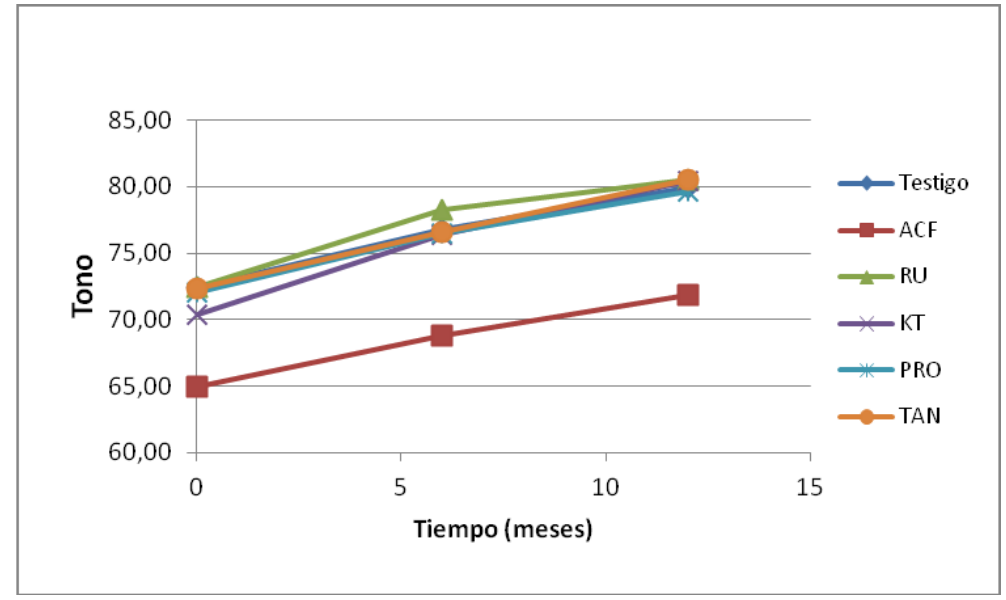

Gráfico 6.105. Evolución del tono durante el periodo de conservación de los vinos en función de los distintos copigmentos adicionados

Los vinos adicionados del copigmento ácido cafeico presentan a lo largo de la conservación de los vinos los menores valores del tono, con diferencias significativas con el resto de los vinos (tablas 6.46, 6.52, 6.60). En función de los resultados observados también en las vendimias anteriores, podemos afirmar que el ácido cafeico 
protege a los polifenoles de la oxidación, y contribuye a estabilizar a los antocianos, haciéndolos menos sensibles a la acción del oxígeno (Darías-Martín et al., 2001).

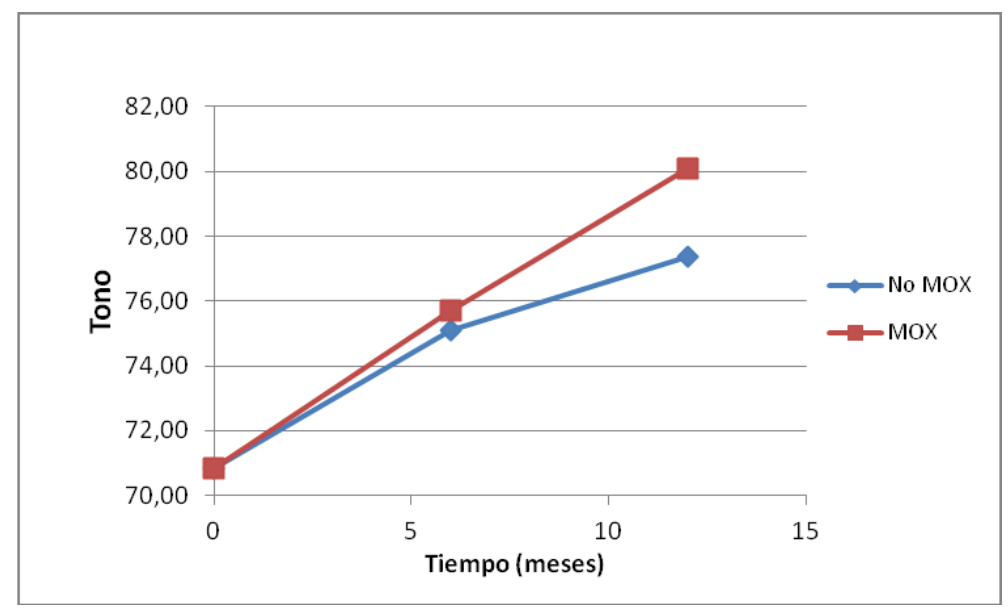

Gráfico 6.106. Evolución del tono durante el periodo de conservación de los vinos en función de la aplicación de la microoxigenación.

Tal y como se ha observado para la intensidad colorante y para el tono, la adición de ácido cafeico se presenta como una técnica que permite mejorar el color de los vinos, aumentando la intensidad colorante y disminuyendo el tono; mostrándose estos compuestos como los mejores copigmentos en cuanto a la protección del color (Rein, 2005), en los vinos de las tres añadas estudiadas.

En el gráfico 6.106 se representa la evolución del tono durante la conservación de los vinos en función de la adición de acetaldehído. Tal como podemos observar, a partir del sexto mes la microoigenación contribuye a incrementar el tono de los vinos, siendo significativa esta diferencia a los 12 meses de envejecimiento (tabla 6.62).

La mayor concentración de antocianos propiciada por la microoxigenación, que no va acompañada de un incremento en la concentración de taninos, podría ser la causa de este comportamiento. Los bajos niveles de taninos encontrados pueden no ser suficientes para polimerizarse con los antocianos, y así protegerlos a éstos de la oxidación (Zamora, 2003). El aleatorio comportamiento de esta técnica observado en las distintas añadas, puede ser debido a la distinta composición fenólica de los vinos.

La microoxigenación es de por sí una técnica con elevado riesgo de producir oxidaciones, ya que es muy complicado incorporar al vino la cantidad suficiente de oxígeno para las polimerizaciones, sin correr el riesgo de un exceso. Es importante determinar con exactitud la cantidad de oxígeno a incorporar, en función de las características de la vendimia, para evitar posibles fenómenos de oxidación del material fenólico presente (Gómez-Plaza y Cano-López, 2011). Pero en nuestro caso el proceso de microoxigenación se simuló añadiendo directamente acetaldehído, con lo cual no hubo un contacto directo con el oxígeno, que pueda justificar este comportamiento. 


\subsubsection{EVOLUCIÓN DE LA CONCENTRACIÓN DE ANTOCIANOS TOTALES}

La evolución de los antocianos totales decolorables, en función de los distintos copigmentos adicionados, aparece representada en el gráfico 6.107. Tal como podemos observar, la concentración de antocianos decolorables sufre una cinética de degradación gradual durante los 12 meses de permanencia de los vinos en botella.

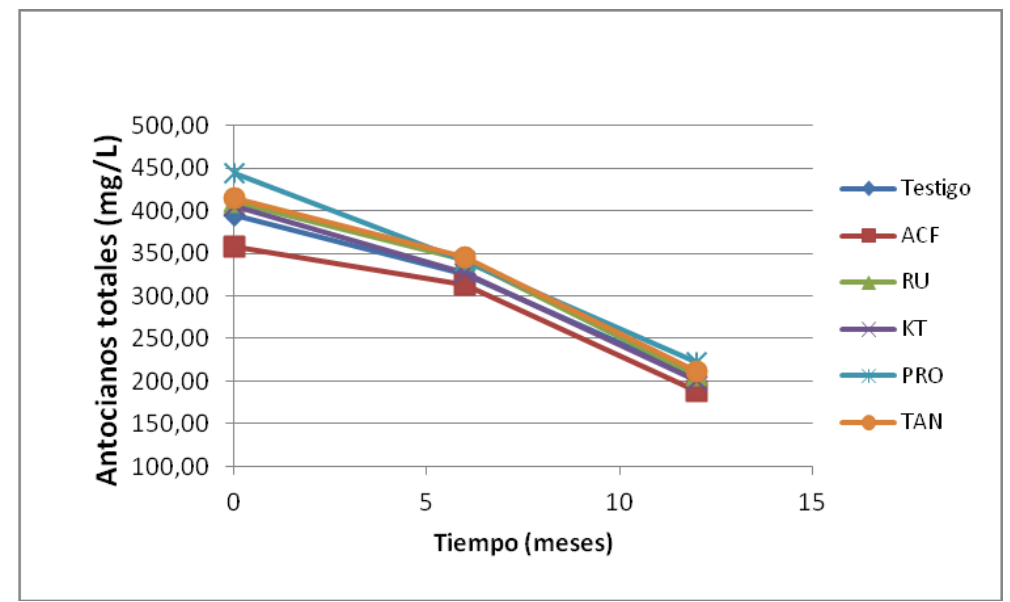

Gráfico 6.107. Evolución de los antocianos totales durante el periodo de conservación de los vinos en función de los distintos copigmentos adicionados.

Durante todo el periodo de conservación, son los vinos adicionados de las proantocianidinas los que presentan las menores pérdidas de antocianos decolorables, con diferencias significativas con respecto a los otros vinos (tablas 6.46, 6.52, 6.60), tal como se observó en los vinos elaborados en las vendimias 2006 y 2007, aunque en ellas los vinos adicionados del copigmento catequina presentaba valores similares a los de las proantocianidinas.

Los vinos adicionados del copigmento ácido cafeico presentan concentraciones significativamente inferiores a las de la mayoría de los vinos estudiados (tablas 6.46, 6.52, 6.60), observándose un comportamiento inverso al observado para la intensidad colorante (gráfico 6.102), tal como sucede en los vinos de las cosechas anteriores.

Este comportamiento ha sido discutido en numerosas ocasiones a lo largo de este trabajo, y se justifica por el hecho de que los antocianos decolorables son mayoritariamente monómeros, y la adición de ácido cafeico contribuye a su esterificación y polimerización, perdiendo con ello su capacidad de decolorarse.

En el gráfico 6.108 aparece representada la evolución de la concentración de antocianos totales decolorables por el sulfuroso en función de las distintas prácticas de vinificación ensayadas. Podemos observar como ambas técnicas de maceración prefermentativa favorecen la concentración de antocianos decolorables durante todo el periodo de conservación de los vinos (tablas $6.47,6.53,6.61$ ), aunque sin diferencias entre ellas.

El mayor tiempo de contacto entre hollejos y mosto durante la fase prefermentativa habría favorecido la mayor extracción de antocianos, y potenciado sus reacciones de estabilidad con otros polifenoles, manteniéndose estas diferencias durante los 12 meses de evolución de los vinos en botella. 


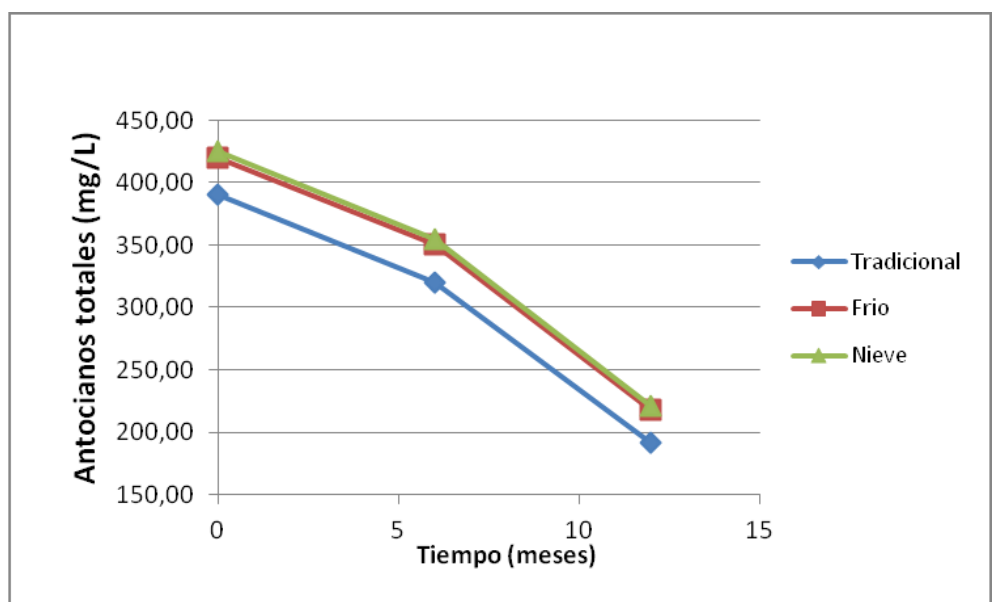

Gráfico 6.108. Evolución de los antocianos totales durante el periodo de conservación de los vinos en función de las distintas técnicas de vinificación ensayadas.

La concordancia de estos resultados durante las tres vendimias realizadas, pone de manifiesto la aptitud de esta técnica para favorecer la presencia de antocianos decolorables en los vinos.

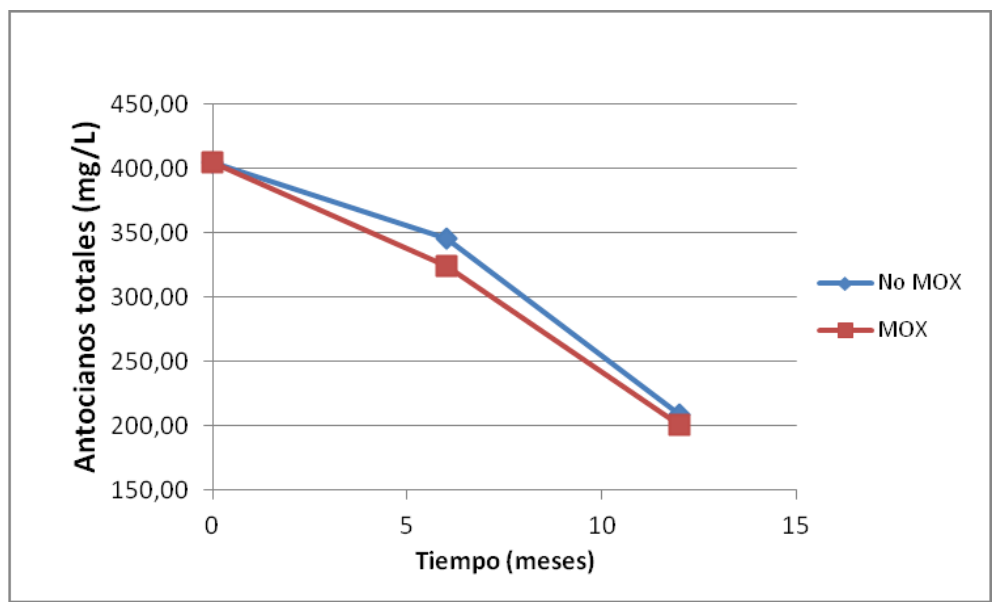

Gráfico 6.109. Evolución de los antocianos totales durante el periodo de conservación de los vinos en función de la aplicación de la microoxigenación.

A los 6 meses de conservación de los vinos en botella, tal y como se observa en el gráfico 6.109, la aplicación de acetaldehído da lugar a un descenso significativo de la concentración de antocianos decolorables (tabla 6.54). Probablemente la mayor participación de los taninos en reacciones con los antocianos, en los vinos microoxigenados, haya sido la causa de la disminución de los antocianos más inestables; aunque al final de la conservación, cuando las polimerizaciones están minimizadas, esta diferencia ya no es significativa.

En el gráfico 6.110 aparece representada la evolución de la concentración de antocianos totales decolorables en función del momento de aplicación de los 
copigmentos. Se observa como la adición de copigmentos posteriormente a la fermentación da lugar a una menor pérdida de estos compuestos (tablas 6.55, 6.63).

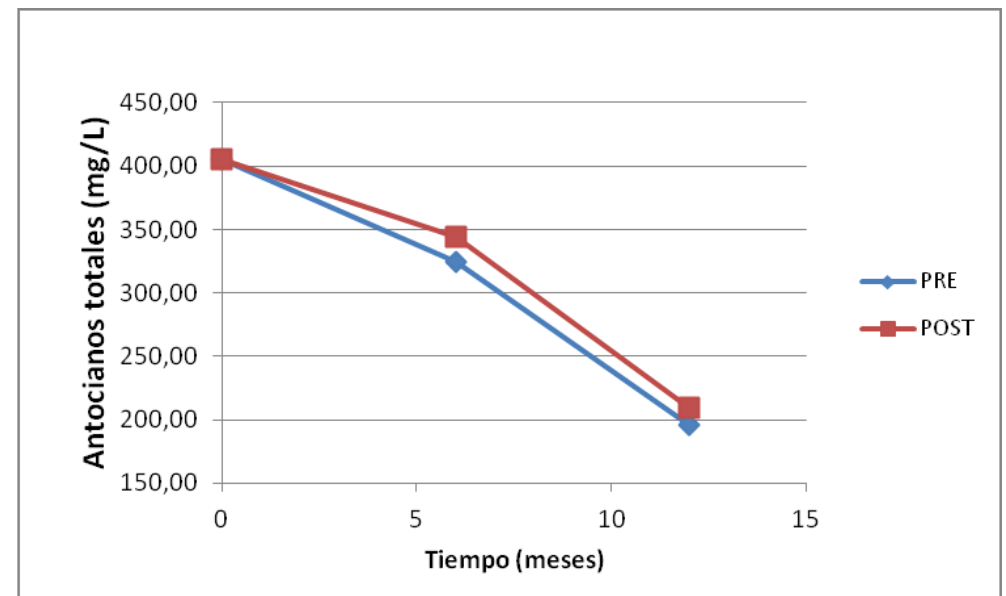

Gráfico 6.110. Evolución de los antocianos totales durante el periodo de conservación de los vinos en función del momento de adición de copigmentos.

\subsubsection{EVOLUCIÓN DE LA CONCENTRACIÓN TOTAL DE MALVIDINA}

En el gráfico 6.111 aparece representada la evolución de la concentración de malvidina en función de los distintos copigmentos adicionados. Podemos observar que son los adicionados de proantocianidinas de pepitas los que presentan un incremento significativo después de la fermentación maloláctica (tabla 6.46), desapareciando estas diferencias durante la evolución de los vinos (tablas 6.52, 6.61). En vista de estos resultados, podríamos intuir que la adición de copigmentos ha favorecido la extracción de antocianos en la vinificación (Rivas-Gonzalo et al., 1995, 2003; Boulton 1996, 2001; Sacchi et al., 2005), pero no ha permitido una mejor conservación de éstos.

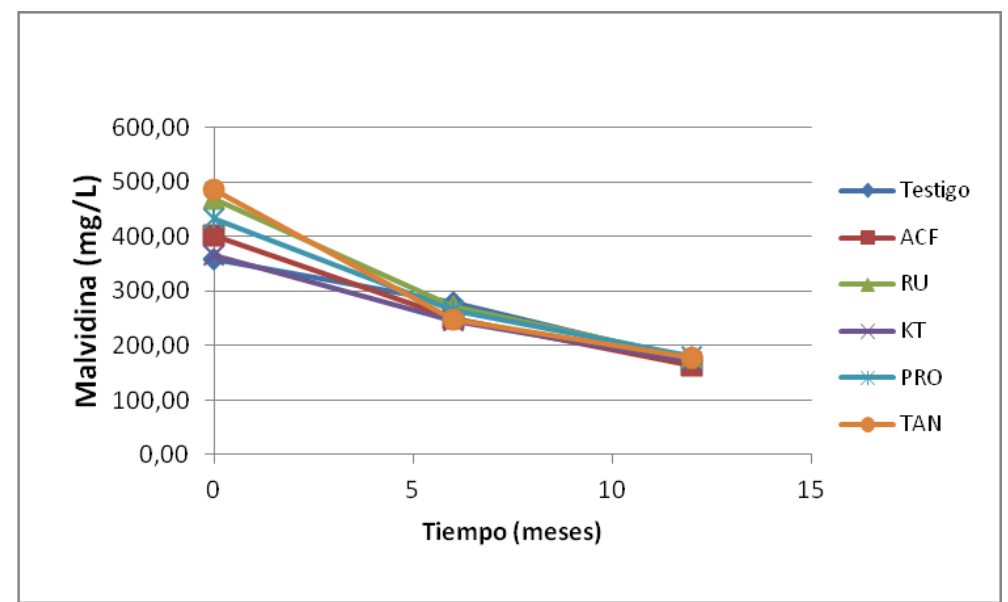

Gráfico 6.111. Evolución de la concentración de malvidinas durante el periodo de conservación de los vinos en función de los distintos copigmentos adicionados. 


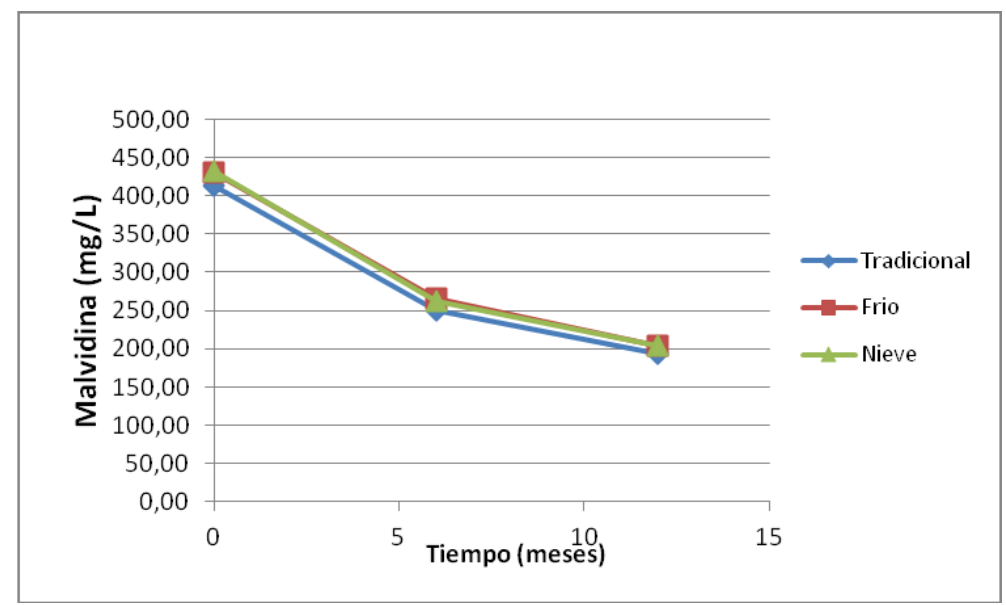

Gráfico 6.111. Evolución de la concentración de malvidinas durante el periodo de conservación de los vinos en función de las distintas técnicas de vinificación ensayadas.

En el gráfico 6.112 aparece representada la evolución de la malvidina a lo largo de la conservación de los vinos, en función de las técnicas de vinificación. Se observa que la maceración prefermentativa ha ocasionado un incremento de la concentración de malvidinas durante la vinificación, pero también a contribuído a minimizar las pérdidas durante la conservación de los vinos en botella (tablas 6.47, 6.61), tal como se observó en la cosecha anterior.

La evolución de la concentración de malvidina en función del momento de adición de copigmentos se recoge en el gráfico 6.113, y muestra como a los 6 meses de conservación de los vinos en botella, aquellos vinos adicionados postfermentativamente presentan mayor concentración de malvidina, observándose el mismo efecto que para la concentración de antocianos totales decolorables, indicando probablemente una mayor protección de los antocianos monómeros cuando la adición se realiza tardíamente.

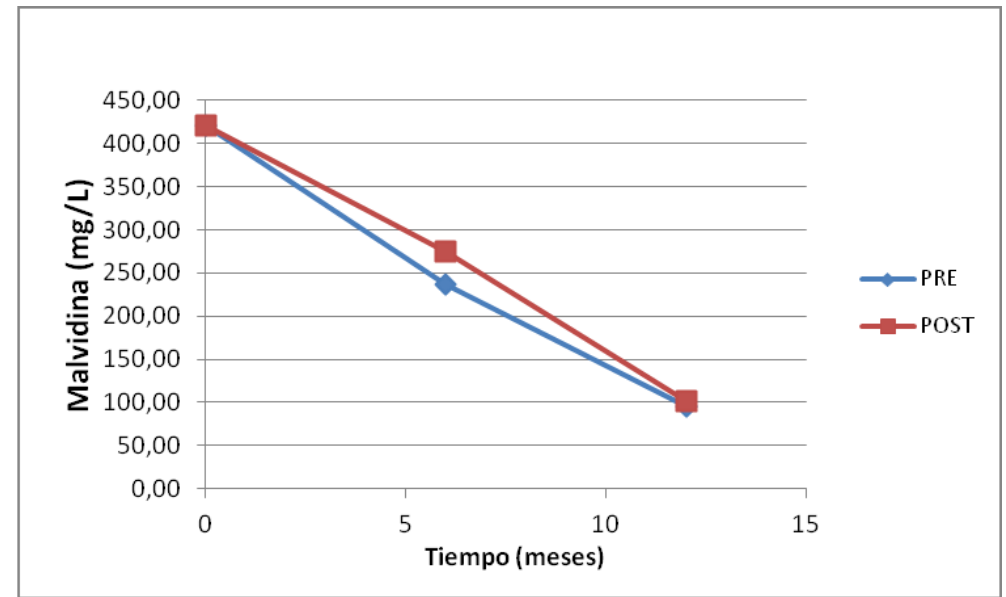

Gráfico 6.113. Evolución de la concentración de malvidinas durante el periodo de conservación de los vinos en función del momento de aplicación de los copigmentos. 


\subsubsection{EVOLUCIÓN DE LA CONCENTRACIÓN DE LAS SUMA DE LAS ANTOCIANIDINAS}

Los monoglucósidos de delfinidina, cianidina, petunidina y peonidina muestran un comportamiento similar al observado para la malvidina, por lo que se va a comentar solamente el comportamiento de la concentración total de estas antocianidinas.

La representación de la evolución de la concentración total de antocianidinas en función de los distintos copigmentos añadidos, las técnicas de vinificación ensayadas y el momento de adición de los copigmentos aparece en los gráficos 6.114, 6.115 y 6.116.

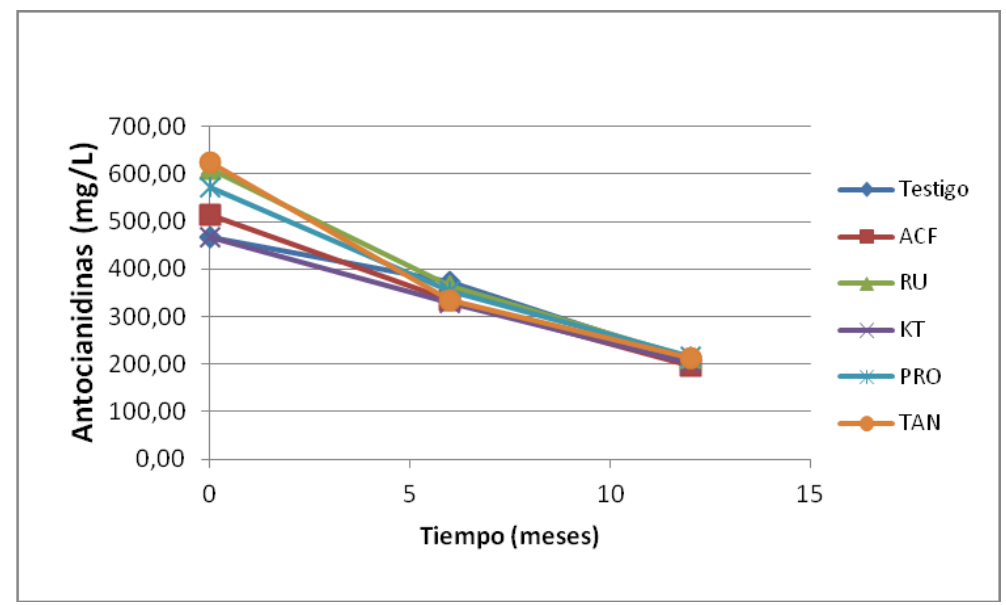

Gráfico 6.114. Evolución de la concentración de antocianidinas durante la conservación de los vinos en función de los distintos copigmentos adicionados.

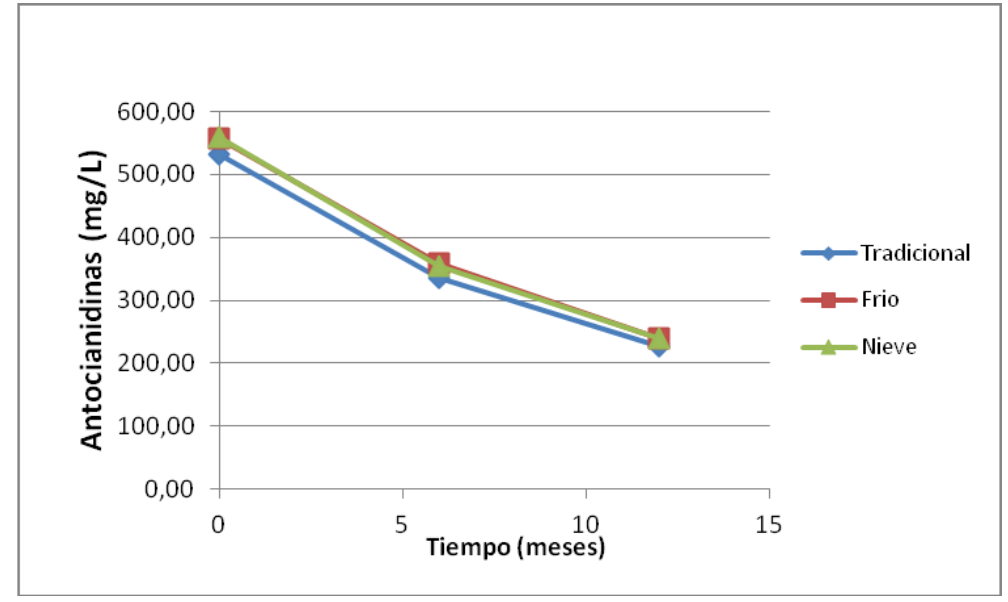

Gráfico 6.115. Evolución de la concentración de antocianidinas durante la conservación de los vinos en función de las distintas técnicas de vinificación ensayadas.

La malvidina es la antocianidina mayoritaria de los vinos, ya que tiene un peso de un $70-75 \%$ en la suma de las antocianidinas analizadas; por tanto, su comportamiento es idéntico al observado para la concentración de malvidina, tanto en los vinos elaborados en la añada 2007 como en los de 2008. 


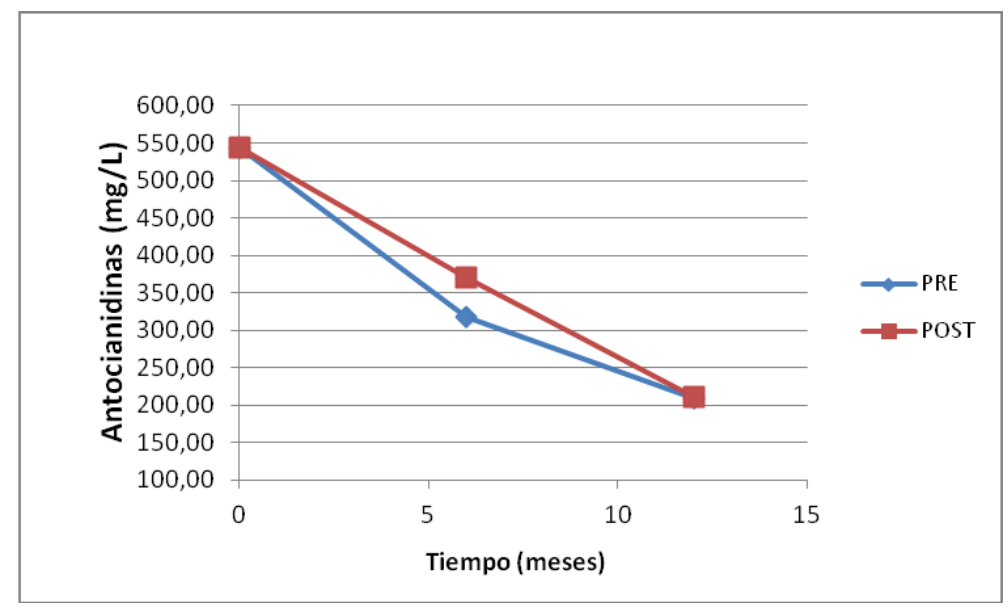

Gráfico 6.116. Evolución de la concentración de antocianidinas durante el periodo de conservación de los vinos en función del momento de aplicación de los copigmentos.

\subsubsection{EVOLUCIÓN DE LA CONCENTRACIÓN DE LOS DERIVADOS DE ANTOCIANOS}

En la gráfico 6.117 se representa la evolución de la concentración de derivados de antocianos en función de los distintos copigmentos adicionados; podemos observar como la concentración de estos derivados desciende durante la conservación, siendo los vinos adicionados con el copigmento ácido cafeico los que presentan a los 6 y 12 meses de evolución la mayor concentración de estos compuestos (tabla 6.60). Tal y como se observó para la vendimia 2007, la participación de este ácido fenólico en las reacciones de esterificación con los antocianos habrá sido probablemente la responsable del comportamiento observado (Bloomfield et al., 2003; Eiro y Heinonen, 2002).

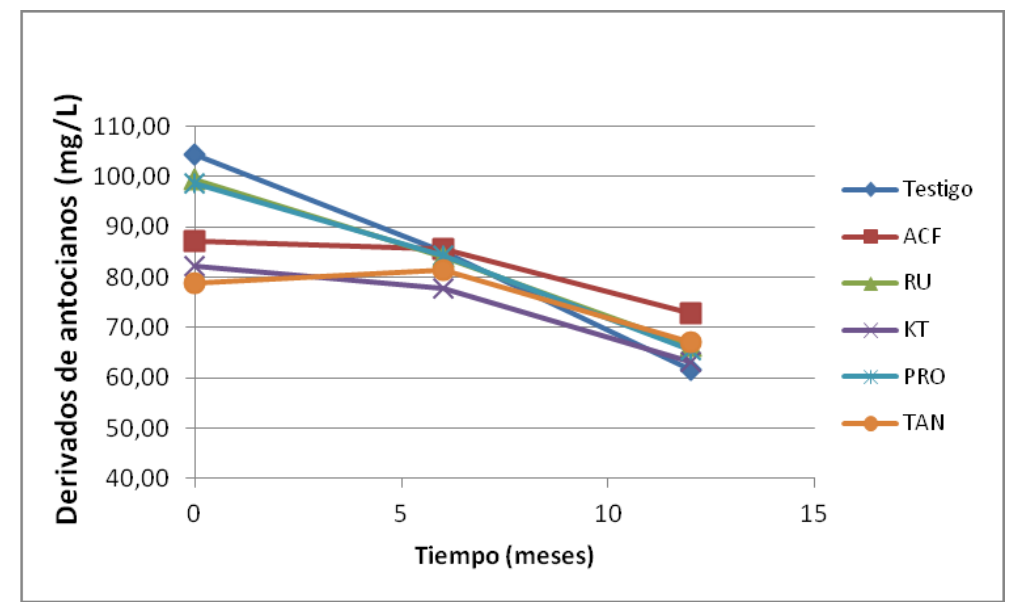

Gráfico 6.117. Evolución de la concentración de derivados de antocianos durante la conservación de los vinos en función de los distintos copigmentos adicionados.

Las técnicas de maceración prefermentativa muestran diferencias significativas respecto a la concentración de estos compuestos durante la conservación de los vinos 
(tablas 6.47, 6.53, 6.61), tal como muestra el gráfico 6.118. Al igual que para la concentración de malvidina y para las antocianidinas, esta fracción de los antocianos, acilados con el ácido cafeico, cumárico y acético, tiene descenso significativamente inferior en los vinos macerados prefermentativamente. No encontrándose tampoco diferencias en este caso entre la maceración a bajas temperaturas y la adición de nieve carbónica.

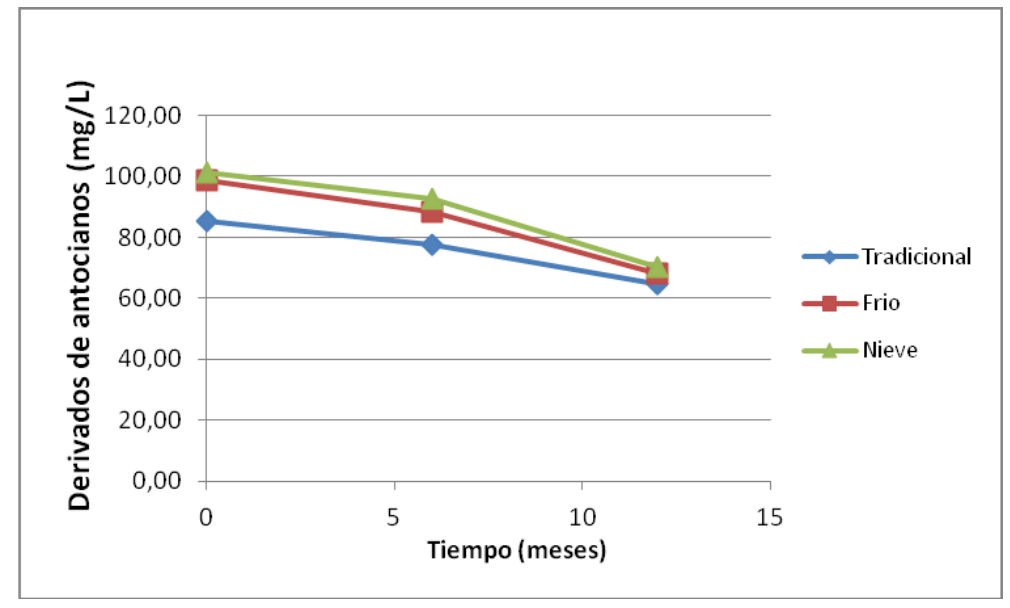

Gráfico 6.118. Evolución de la concentración de derivados de antocianos durante la conservación de los vinos en función de las distintas técnicas de vinificación ensayadas.

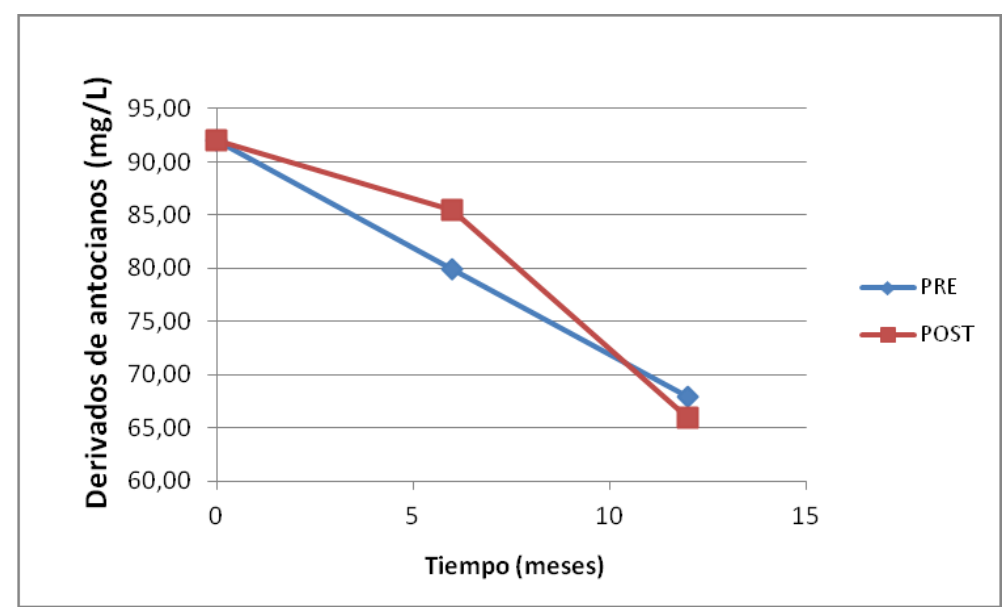

Gráfico 6.119. Evolución de la concentración de antocianidinas durante el periodo de conservación de los vinos en función del momento de aplicación de los copigmentos.

En el gráfico 6.119 aparece representada la evolución de la concentración de derivados de antocianos en función del momento de adición de los copigmentos. La adición postfermentativa ha dado lugar a menores pérdidas de derivados de antocianos, tal como se observó para toda la familia polifenólica (tabla 6.55), aunque estas diferencias desaparecen al final del periodo de permanencia en botella (tabla 6.63). 


\subsubsection{EVOLUCIÓN DE LA CONCENTRACIÓN TOTAL DE ANTOCIANOS}

La evolución durante la conservación de los vinos de la concentración total de antocianos para los distintos copigmentos ensayados, aparece en el gráfico 6.120.

Durante la evolución de los vinos, se observa una disminución gradual de la concentración de los compuestos antocianidínicos, así como de la concentración total de éstos. Los vinos adicionados de los copigmentos proantocianidínicos son los que muestran un menor descenso, especialmente con proantocianidina de pepita (tabla 6.46), desapareciendo estas diferencias a lo largo de la conservación de los vinos (tablas 6.52, 6.60). Este mismo comportamiento ha sido observado para la malvidina, antocianidinas, y antocianos decolorables, destacando finalmente como la adición de copigmentos ha mantenido más elevada la concentración de estos compuestos (gráficos 6.102, 6.104), tal y como se ha observado para las vendimias 2006 y 2007.

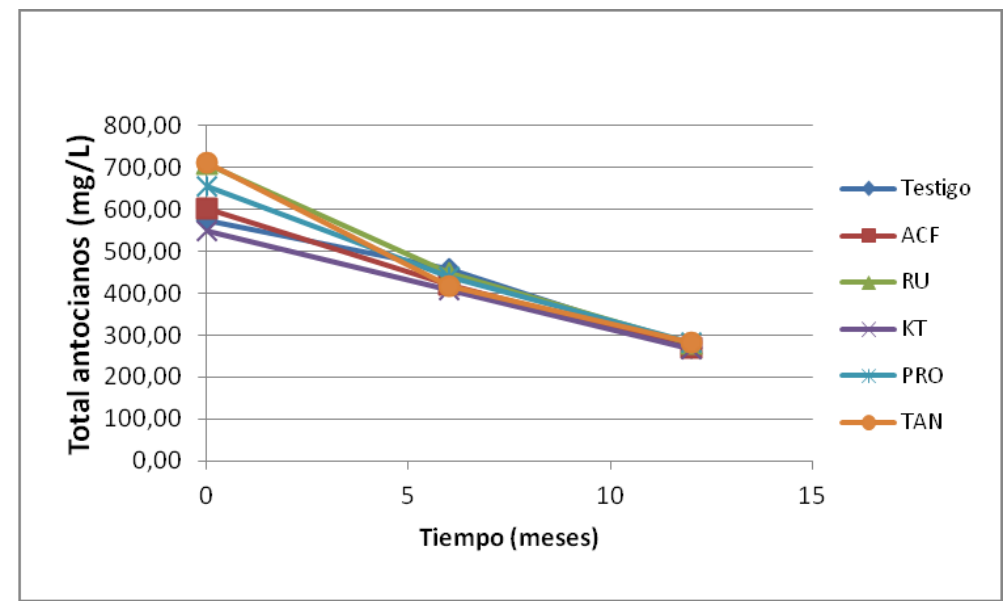

Gráfico 6.120. Evolución de la concentración del total de antocianos durante la conservación de los vinos en función de los distintos copigmentos adicionados.

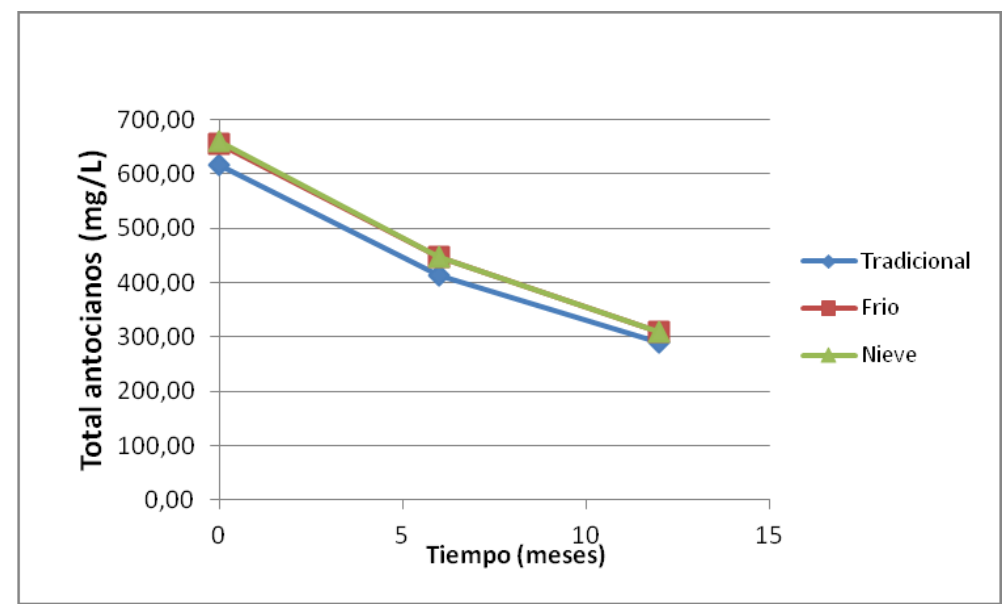

Gráfico 6.121. Evolución de la concentración del total de antocianos durante la conservación de los vinos en función de las distintas técnicas de vinificación ensayadas. 
En los gráficos 6.121 y 6.122 aparece representada la evolución de la concentración total de antocianos en función de las técnicas de vinificación ensayadas y del momento de adición de copigmentos. Se puede observar como la maceración prefermentativa da lugar a un incremento de antocianos en los vinos recién elaborados, ya que potencia su extracción y su estabilización. Ese comportamiento estabilizador se observa a lo largo de la conservación, sin que aparezcan diferencias entre los vinos macerados en frío o con adición de nieve carbónica.

Tal como observamos para los parámetros polifenólicos mostrados, la adición pstfermentativa de copigmentos protege a los vinos de su pérdida, indicando probablemente una mayor protección de los antocianos por parte de los copigmentos, aunque esta protección no se mantiene en el tiempo.

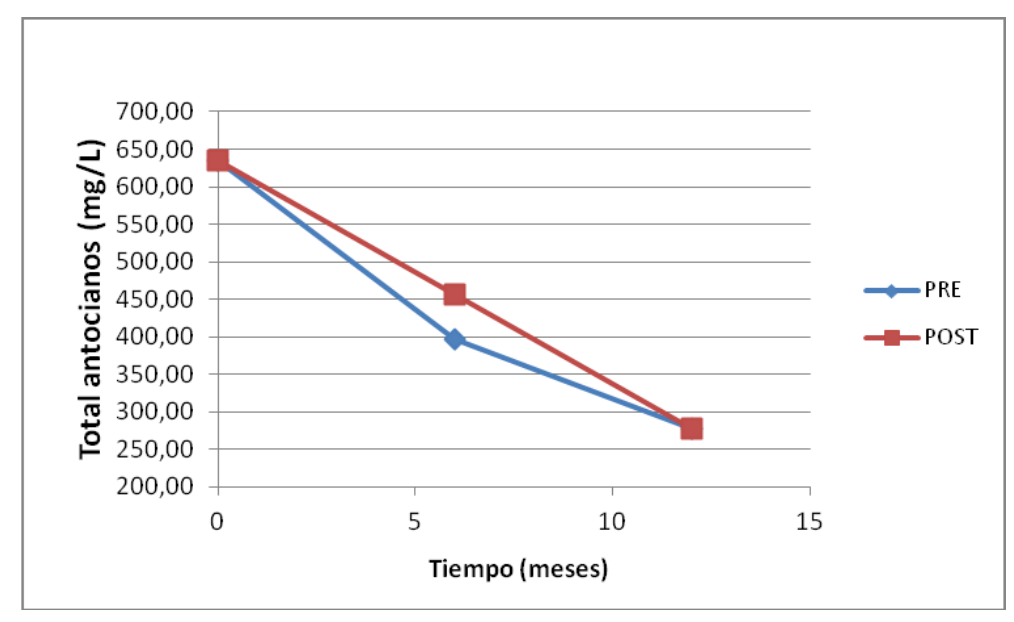

Gráfico 6.122. Evolución de la concentración del total de antocianos durante la conservación de los vinos en función del momento de aplicación de los copigmentos.

\subsubsection{EVOLUCIÓN DEL PORCENTAJE DEL COLOR QUE CORRESPONDE A LAS REACCIONES DE COPIGMENTACIÓN.}

No se observan diferencias en el porcentaje de color debido a la copigmentación, ni en función de los distintos copigmentos adicionados, ni con las distintas técnicas de vinificación. Este comportamienton difiere con el observado en las cosechas anteriores, ya que en los vinos de 2006, la adición de poantocianidinas y la maceración prefermentativa consiguieron incrementar las reacciones de copigmentación durante el proceso de vinificación, y en 2007 la adición de rutina tuvo este mismo efecto, aunque en ningún caso se observaron diferencias al final del período de conservación.

La influencia de la microoxigenación sobre el porcentaje del color que corresponde a la copigmentación, se muestra en el gráfico 6.123. Podemos observar como el color debido a la copigmentación desciende de forma brusca durante los primeros seis meses, alcanzando valores próximos al 15\%; a partir de ese momento se mantiene estable, o sufre una caída muy lenta. Los vinos adicionados de acetaldehído presentan una mayor caída del porcentaje de color debido a la copigmentación, muy importante a los 6 meses, pero significativa también a los 12 (tabla 6.54, 6.62). El incremento de las reacciones de polimerización inducido por la microoxigenación, podría ser la causa del comportamiento observado. 


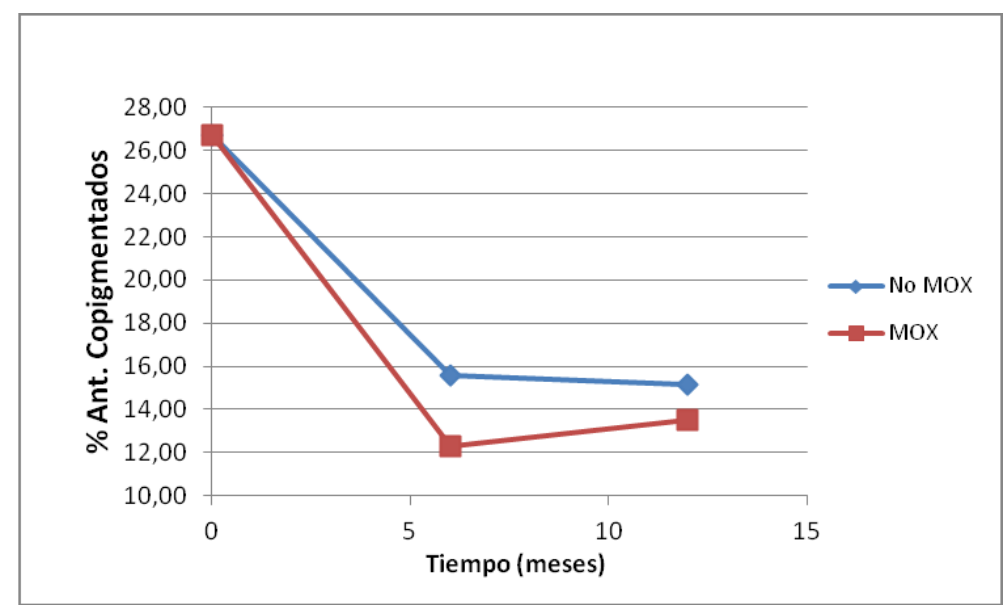

Gráfico 6.123. Evolución del \% de antocianos copigmentados durante el periodo de conservación de los vinos en función de la microoxigenación.

La aplicación postfermentativa de copigmentos ha provocado, tal y como se observa en el gráfico 6.124, un mayor color debido a las reacciones de copigmentación, con diferencias significativas durante todo el proceso de conservación de los vinos en botella (tablas 6.55, 6.63). La elevada concentración de antocianos extraída durante la vinificación, junto con la débil concentración tánica, podría ser la causa de que parte de estos antocianos, en lugar de participar en reacciones de polimerización con los taninos, reaccionen con los copigmentos, incrementando el porcentaje de color debido a la copigmentación en los vinos embotellados.

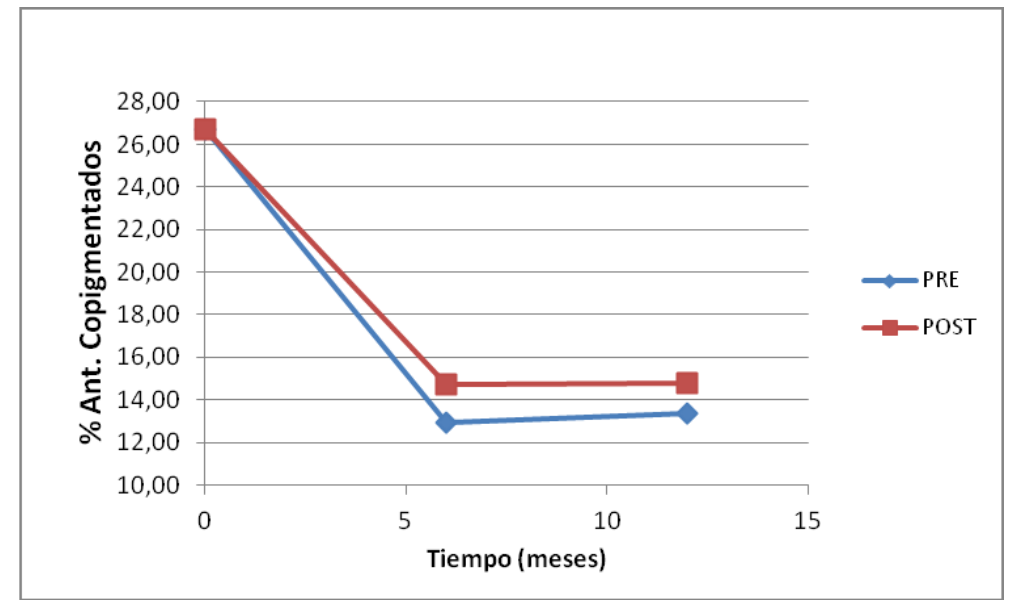

Gráfico 6.124. Evolución del \% de antocianos copigmentados durante el periodo de conservación de los vinos en función del momento de aplicación de los copigmentos. 


\subsubsection{EVOLUCIÓN DEL PORCENTAJE DEL COLOR QUE CORRESPONDE A LOS ANTOCIANOS LIBRES}

Los vinos adicionados del copigmento ácido cafeico presentan los menores porcentajes del color debido a los antocianos en su froma libre, con diferencias significativas a los 6 y 12 meses desde el embotellado (tablas 6.52, 6.60).

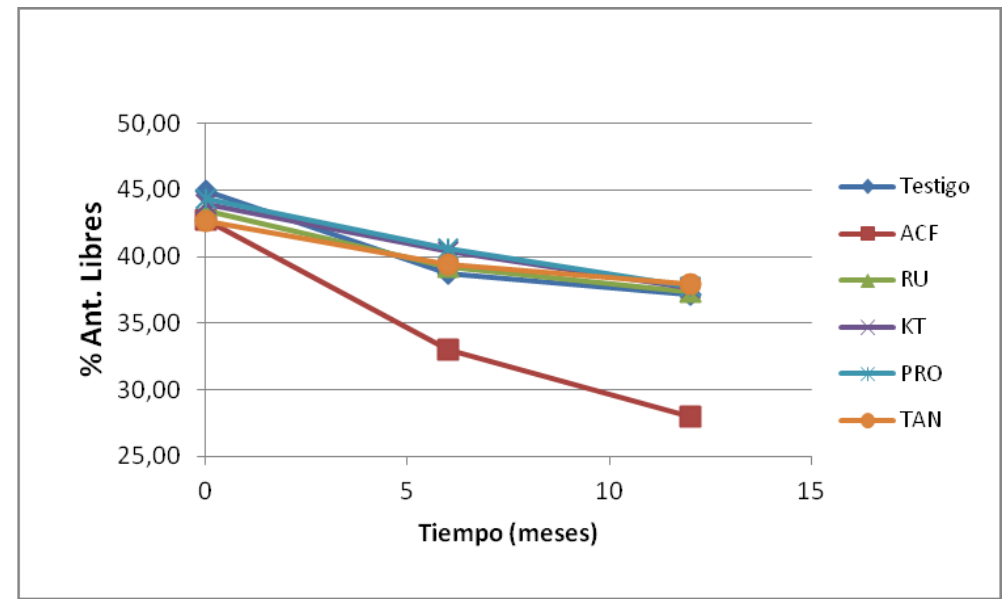

Gráfico 6.125. Evolución de la concentración del total de antocianos durante el periodo de conservación de los vinos en función de los distintos copigmentos adicionados.

En el gráfico 6.125, donde se representa la evolución de este porcentaje en función de los diferentes copigmentos adicionados, se observa cómo estos vinos sufren una caída muy intensa, muy inferior a la observada en los vinos adicionados de los otros copigmentos. Este comportamiento puede ser debido a la capacidad que tiene el ácido cafeico de propiciar reacciones de polimerización y esterificación con los antocianos monoméricos o libres, lo que ocasianó un descenso del color debido a estas estructuras (Bloomfield et al., 2003; Eiro y Heinonen, 2002).

\subsubsection{EVOLUCIÓN DEL PORCENTAJE DEL COLOR QUE CORRESPONDE A LOS ANTOCIANOS POLIMERIZADOS}

Lo comentado anteriormente se confirma cuando se representa la evolución del color debido a los antocianos polimerizados, con relación a la adición de copigmentos. En el gráfico 6.126 podemos apreciar el incremento del color debido a las reacciones de polimerización, que tienen lugar a lo largo de la conservación de los vinos, alcanzando valores próximos al 60\%, en aquellos vinos adicionados de ácido cafeico (tablas 6.46, 6.52 y 6.60).

El comportamiento que presentan los vinos adicionados de ácido cafeico podría ser una de las causas de la relación inversa encontrada para la concentración de antocianos decolorables y antocianos libres frente a la intensidad colorante (gráficos 6.107, 6.125 y 6.102). Es de sobra conocida la importancia de otras moléculas más complejas sobre el color de los vinos (Cheynier et al., 1999; 2006; Vidal et al., 2002; Koyama et al., 2007), probablemente la mayor presencia de antocianos formando parte de estas uniones sea la causante, no solamente del incremento del color, sino de su estabilidad a lo largo de la conservación, mejorando, por tanto, las características cromáticas de los vinos elaborados. 


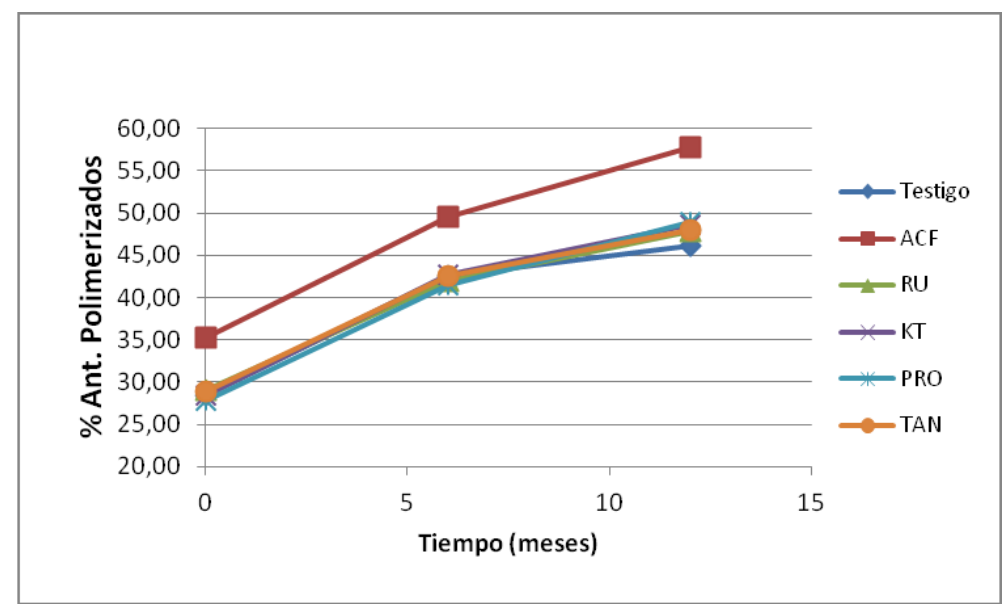

Gráfico 6.126. Evolución del color que corresponde a polimerizaciones durante la conservación de los vinos en función de los distintos copigmentos adicionados.

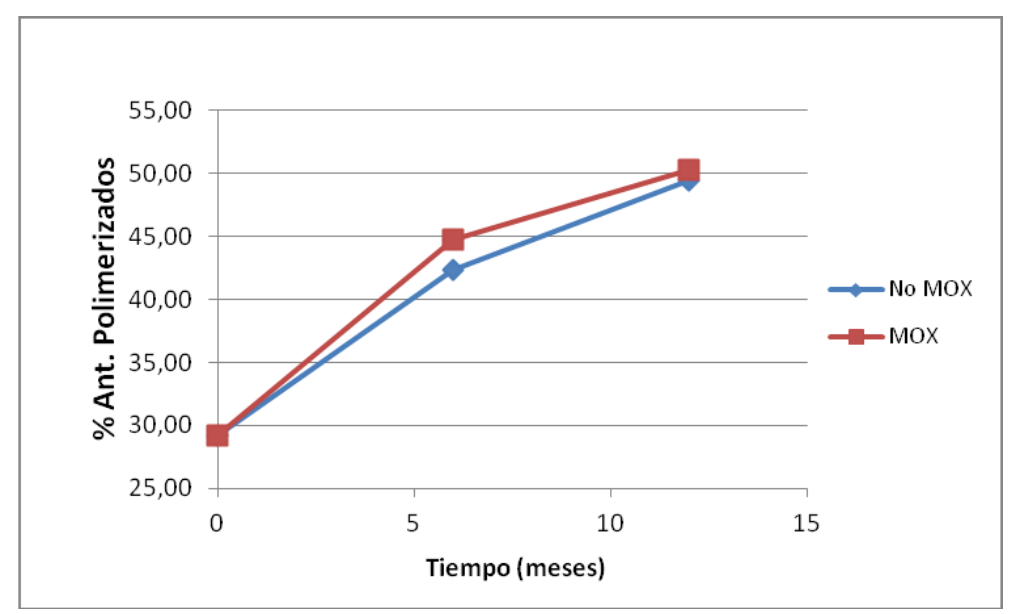

Gráfico 6.127. Evolución del color que corresponde a polimerizaciones durante la conservación de los vinos en función de la aplicación de la microoxigenación.

En el gráfico 6.127 aparece representada la evolución para el porcentaje del color que corresponde a los antocianos en su forma polimerizada, observándose como los vinos adicionados de acetaldehído presentan a los seis meses un significativo incremento del porcentaje de color debido a la polimerización (tabla 6.54). Al finalizar el proceso de conservación de los vinos, las diferencias ya no son significativas (tabla 6.62), lo que nos induce a pensar que para conseguir vinos de largo envejecimiento, es preciso aplicar las técnicas de microoxigenación durante un periodo más prolongado (Cheynier et al., 2006; Escribano-Bailón et al., 2001; Atanasova et al., 2002a).

\subsubsection{EVOLUCIÓN DEL ÍNDICE DE PVPP}

En el gráfico 6.128 aparece representada la evolución del índice de PVPP, que mide la formación de polímeros entre los antocianos y los taninos, Podemos apreciar como son de nuevo los vinos adicionados del copigmento ácido cafeico los que 
presentan los mayores valores del índice de PVPP, incrementándose las diferencias durante la conservación de los vinos (tablas 6.46, 6.52, 6.60).

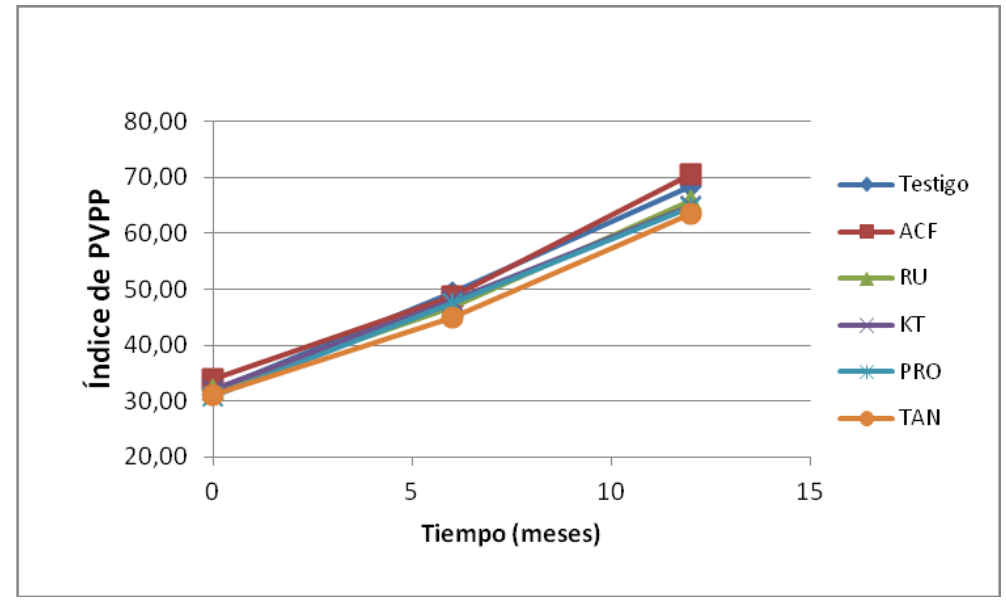

Gráfico 6.128. Evolución del índice de PVPP durante el periodo de conservación de los vinos en función de los distintos copigmentos adicionados.

El parámetro que mide estas uniones presenta un comportamiento similar al observado para el porcentaje del color que corresponde a los antocianos polimerizados, aunque en este caso las diferencias no son tan evidentes. Este comportamiento era predecible, ya que un porcentaje de los polímeros de antocianos se forman junto con los taninos.

La adición postfermentativa de copigmentos ha provocado un ligero incremento de la polimerización a los 6 meses de conservación de los vinos (gráfico 6.129); pero esas diferencias desaparecen a medida que transcurren los últimos meses de conservación (tablas 6.55, 6.63).

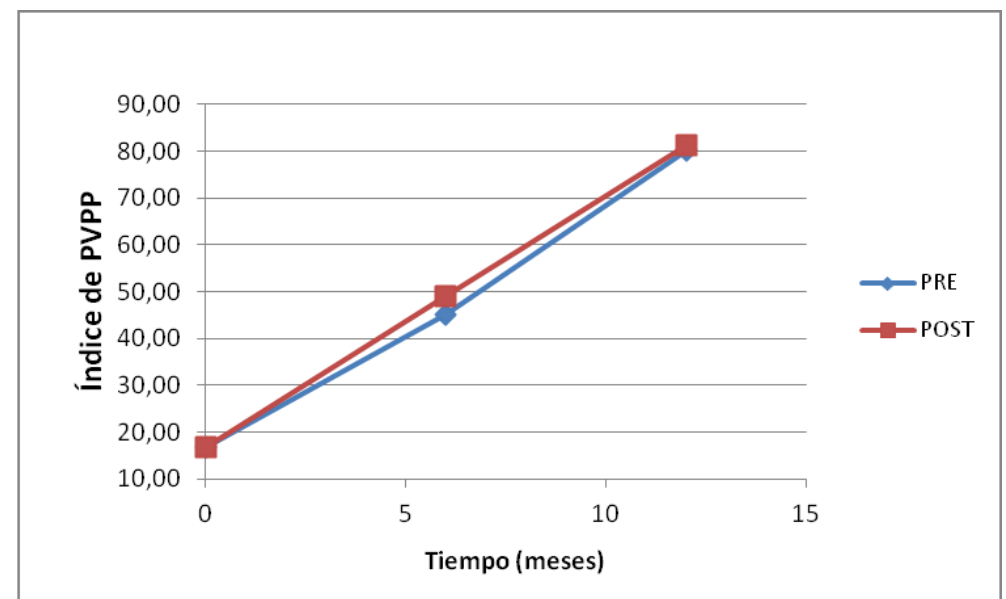

Gráfico 6.129. Evolución del índice de PVPP durante la conservación de los vinos en función del momento de aplicación de los distintos copigmentos adicionados.

\subsubsection{EVOLUCIÓN DEL ÍNDICE DE FOLIN}

Los vinos adicionados del copigmento ácido cafeico presentan diferencias significativas en la concentración total de polifenoles a los 6 y 12 meses del 
embotellado (tablas 6.52, 6.60), tal y como se observa en el gráfico 6.130. El razonamiento sugerido en este trabajo, por el cual una mayor presencia de antocianos formando parte de reacciones de polimerización y acilación permiter mantener el contenido polifenólico de los vinos, puede corroborarse con los resultados obtenidos para los vinos de las cosechas 2006, 2007 y 2008. Por lo tanto, la adición de ácido cafeico podría ser una técnica adecuada para favorecer la presencia del material fenólico en los vinos.

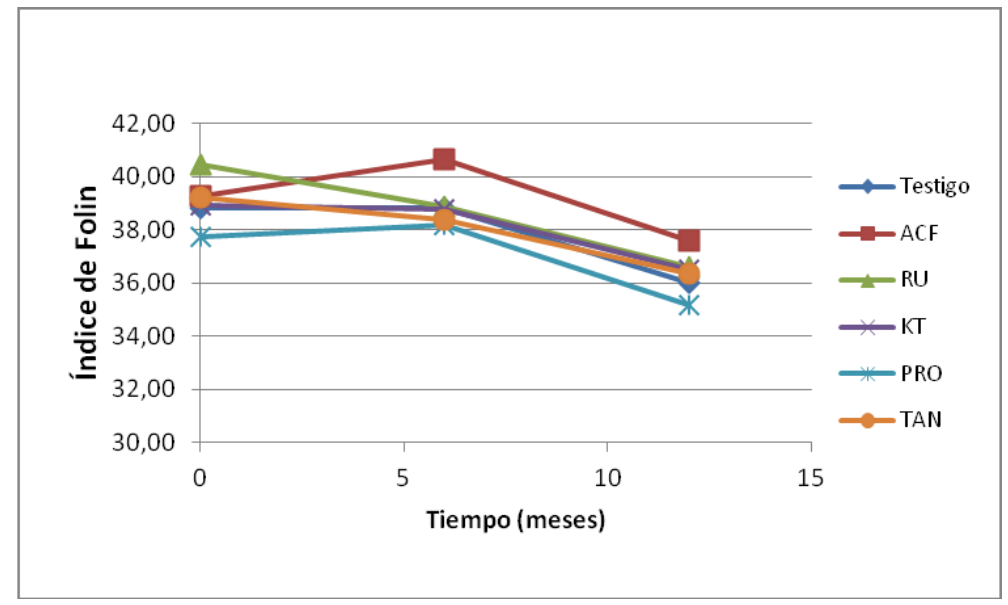

Gráfico 6.130. Evolución del índice de Folin durante el periodo de conservación de los vinos en función de los distintos copigmentos adicionados.

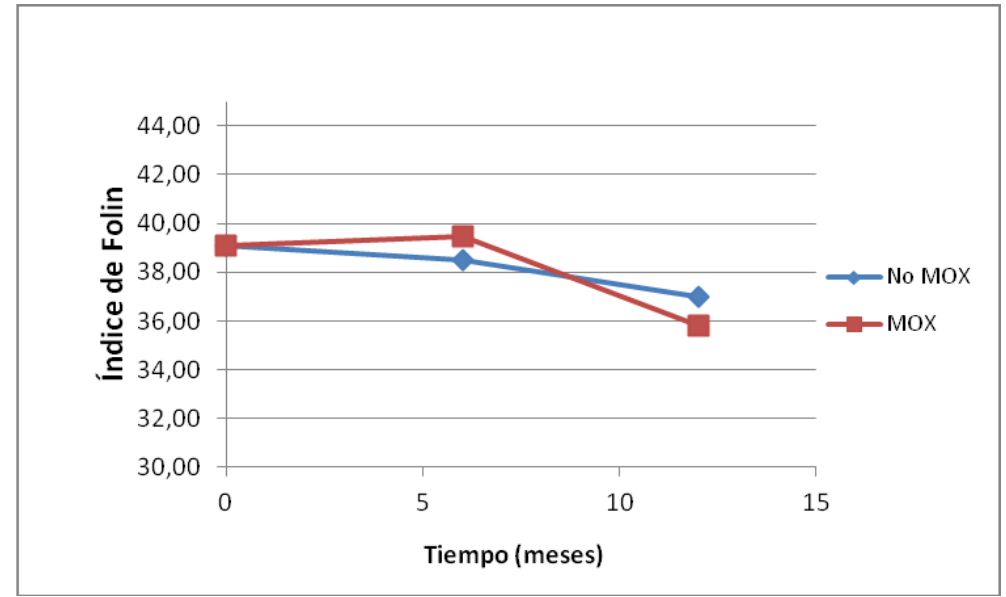

Gráfico 6.131. Evolución del índice de Folin durante el periodo de conservación de los vinos en función de la aplicación de la mocrooxigenacion.

En el gráfico 6.131 se representa el efecto de la microoxigenación sobre la concentración total de polifenoles, valorada mediante el índice de Folin, en los vinos recién elaborados y a lo largo de los 12 meses de conservación en botella.

Podemos observar como la adición de acetaldehído ha provocado el mantenimiento de la concentración total de polifenoles durante los primeros 6 meses del embotellado, desapareciendo su efecto en los últimos meses de conservación (tablas 6.54, 6.62). Esto apoya el comentario anterior, sobre la necesidad de prolongar la microoxigenación para obtener efectos más duraderos. Factores como las característica 
fenólicas de la vendimia, el momento de aplicación y la dosis de oxigeno a aplicar influyen decisivamente en la duración y el efecto de la microoxigenación (Cano-López et al., 2008).

En el gráfico 6.132 se representa la evolución del índice de Folin en función del momento de adición de los copigmentos, observándose como la adición postfermentativa incrementa la concentración de polifenoles, y ocasiona un menor descenso (tablas 6.54, 6.62). Una de las causas de este efecto podría ser que los propios copigmentos son de naturaleza fenólica, por tanto al añadirse al vino, incrementan de forma inmediata su concentración.

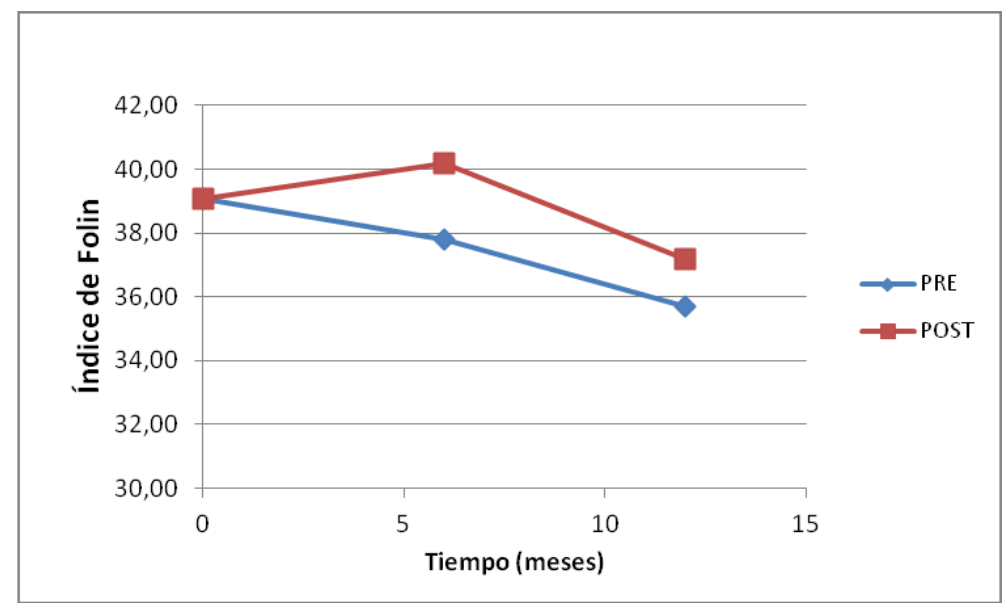

Gráfico 6.132. Evolución del índice de Folin durante el periodo de conservación de los vinos en función del momento de adición de copigmentos.

\subsubsection{EVOLUCIÓN DE LA CONCENTRACIÓN DE LOS ÁCIDOS FENÓLICOS}

La evolución de la concentración de los ácidos fenólicos durante la conservación de los vinos en botella aparece representada en el gráfico 6.133. Valorando el efecto que sobre estos vinos tiene la adición de copigmentos, observamos que cuando adicionamos ácido cafeico a los vinos, estos incrementan significativamente su concentración, e incluso la mantienen más elevada durante la conservación (tablas 6.46, 6.52, 6.60).

Al pertenecer este ácido a la familia de los ácidos fenólicos, era de esperar este comportamiento. No se observa la influencia de ninguno de los otros copigmentos en el mantenimiento de la concentración de ácidos fenólicos en los vinos. 


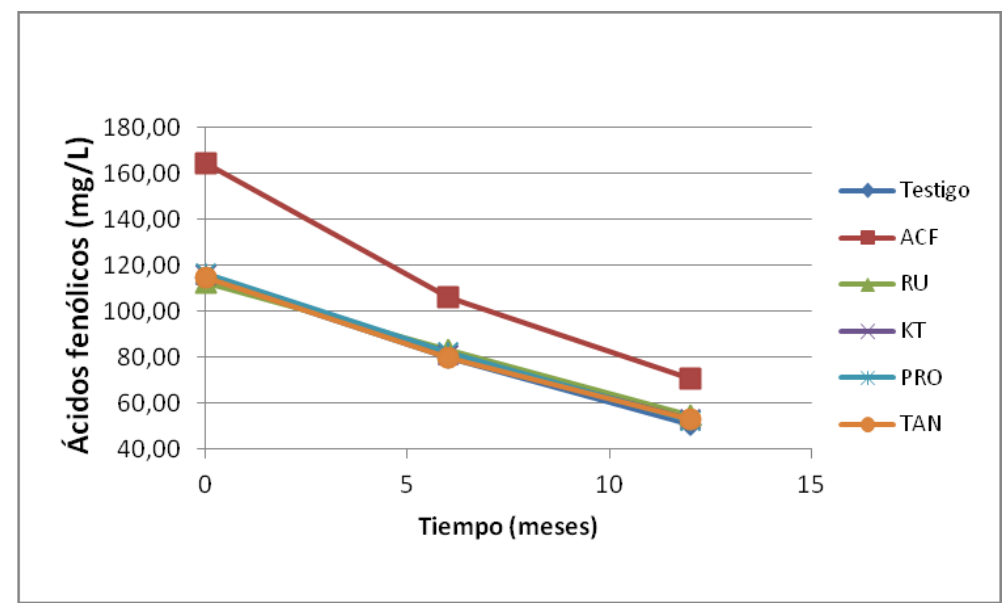

Gráfico 6.133. Evolución de la concentración de ácidos fenólicos durante la conservación de los vinos en función de la adición de los distintos copigmentos.

\subsubsection{EVOLUCIÓN DE LA CONCENTRACIÓN DE FLAVONOLES}

El Gráfico 6.134 muestra la evolución en la concentración de flavonoles durante la conservación de los vinos, observándose como los vinos adicionados de rutina presentan diferencias significativas tanto a los 6 como a los 12 meses del embotellado (tablas 6.52, 6.60), tal como era de esperar, al ser la rutina un flavanol. No se observan diferencias en el comportamiento de los otros copigmentos.

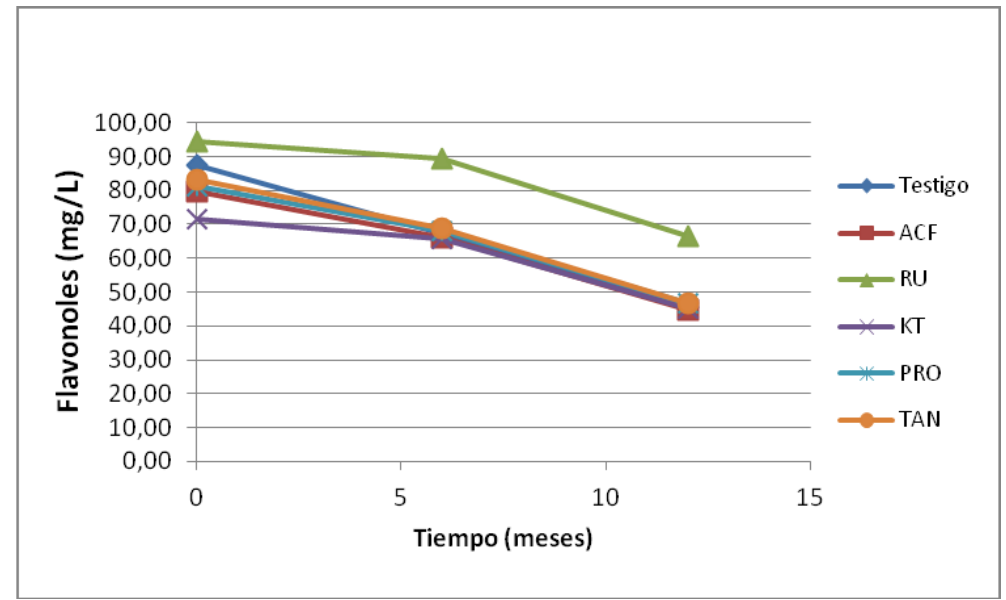

Gráfico 6.134. Evolución de la concentración de flavonoles durante la conservación de los vinos en función de la adición de los distintos copigmentos ensayados.

La adición de este copigmento ha provocado para las vendimias analizadas $(2006,2007,2008)$ un efecto favorable sobre la intensidad colorante de los vinos, presentando los vinos adicionados de rutina valores superiores frente a los otros copigmentos ensayados. La participación de estos compuestos en reacciones de copigmentación (Davies y Mazza, 1993; Baranac et al., 1996 y 1997; Malien-Aubert, 2001; Boulton, 2001; Schwarz et al., 2005, Gómez-Míguez et al., 2006; Kunsági-Máté et al., 2006; Lambert et al., 2010), podría ser la causa del comportamiento observado, 
aunque este resultado no ha podido ser identificado en el parámetro que mide el porcentaje del color debido a las reacciones de copigmentación.

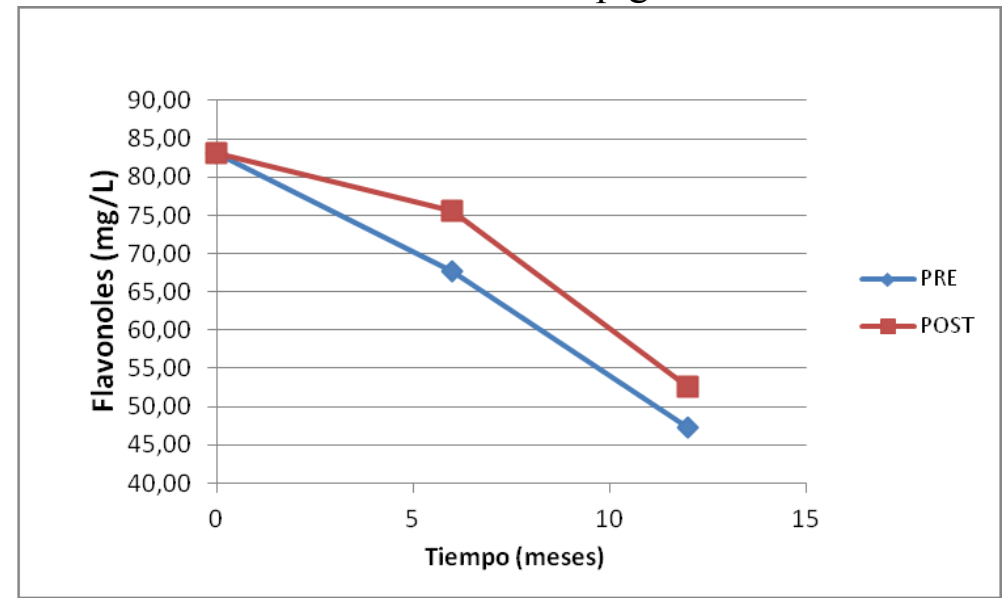

Gráfico 6.135. Evolución de la concentración de flavonoles durante la conservación de los vinos en función del momento de adición de los distintos copigmentos ensayados.

En el gráfico 6.135 aparece representada la evolución de la concentración de flavonoles cuando los copigmentos fueron adicionados previamente o posteriormente a la fermentación; observándose como a los 6 meses del embotellado, los vinos adicionados después de la fermentación presentan diferencias significativas (tabla 6.55), despareciendo estas diferencias al final de la conservación de los vinos (tabla 6.63). Un comportamiento similar lo observamos en los vinos de 2007.

\subsubsection{EVOLUCIÓN DE LA CONCENTRACIÓN DE 3-FLAVANOLES}

Tal como era de esperar, son los vinos adicionados del copigmento catequina los que muestran las mayores concentraciones para estos compuestos, con diferencias significativas durante la evolución de los vinos en botella (tablas 6.43, 6.52, 6.60). En la tabla 6.136 se observa que también los vinos adicionados de los copigmentos proantocianidina de hollejo y de pepita presentan concentraciones elevadas para estos compuestos, quizás debido al bajo grado de polimerización de estas antocianidinas, e incluso a la rotura de sus polímeros.

No se observan diferencias en la concentración de flavanoles de los vinos, ni en función de las técnicas de maceración, ni con la microoxigenación, ni con el momento de adición de copigmentos. 


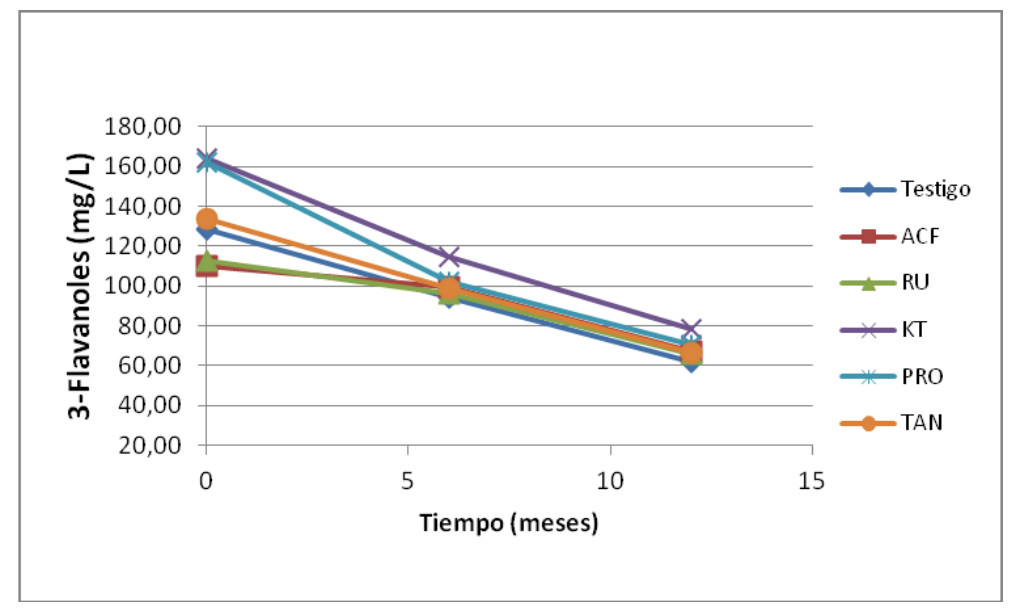

Gráfico 6.136. Evolución de la concentración de 3-flavanoles durante la conservación de los vinos en función de la adición de los distintos copigmentos ensayados.

\subsubsection{EVOLUCIÓN DE LA CONCENTRACIÓN DE CATEQUINAS}

En el gráfico 6.137 se recoge la evolución de la concetración de catequinas durante la conservación de los vinos, en función de las distintas técnicas de vinificación ensayadas. Observamos como los vinos macerados prefermentativamente tanto en frío como mediante adición de nieve carbónica presentan diferencias significativas en el embotellado (tabla 6.47), y al finalizar el periodo de permanencia de los vinos en botella

(tabla 6.60).

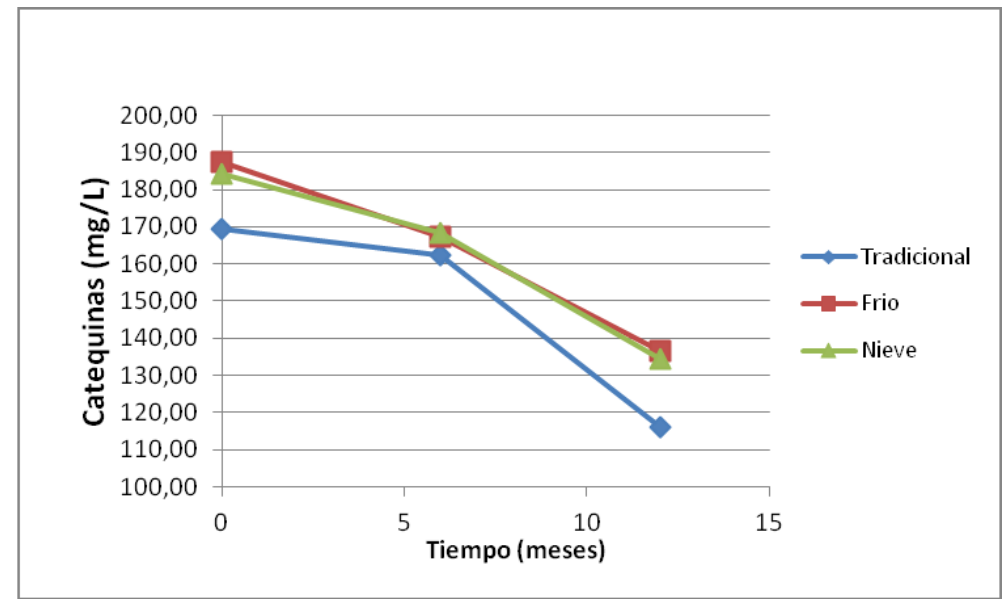

Gráfico 6.137. Evolución de la concentración de catequinas durante la conservación de los vinos en función de la adición de los distintos copigmentos ensayados.

El incremento del tiempo de contacto entre hollejos y mosto durante la fase prefermentativa ha permitido la extracción de material fenólico diferente de los antocianos (Busse-Valverde et al., 2010) en los vinos elaborados en la vendimia 2008. A pesar de la ausencia de alcohol la concentración de catequinas, compuestos monómeros de bajo peso molecular (Koyama et al., 2007), se ha visto incrementada 
manteniéndose sus efectos en el tiempo. Los altos valores alcanzados durante la vinificación parecen avalar esta hipótesis.

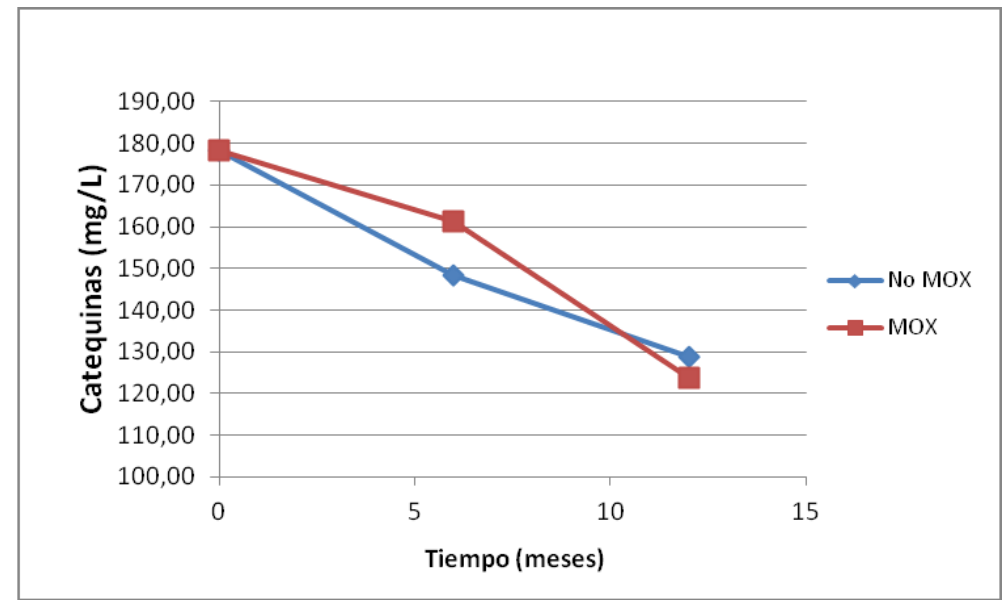

Gráfico 6.138. Evolución de la concentración de catequinas durante el periodo de conservación de los vinos en función de la aplicación de la microoxigenacion.

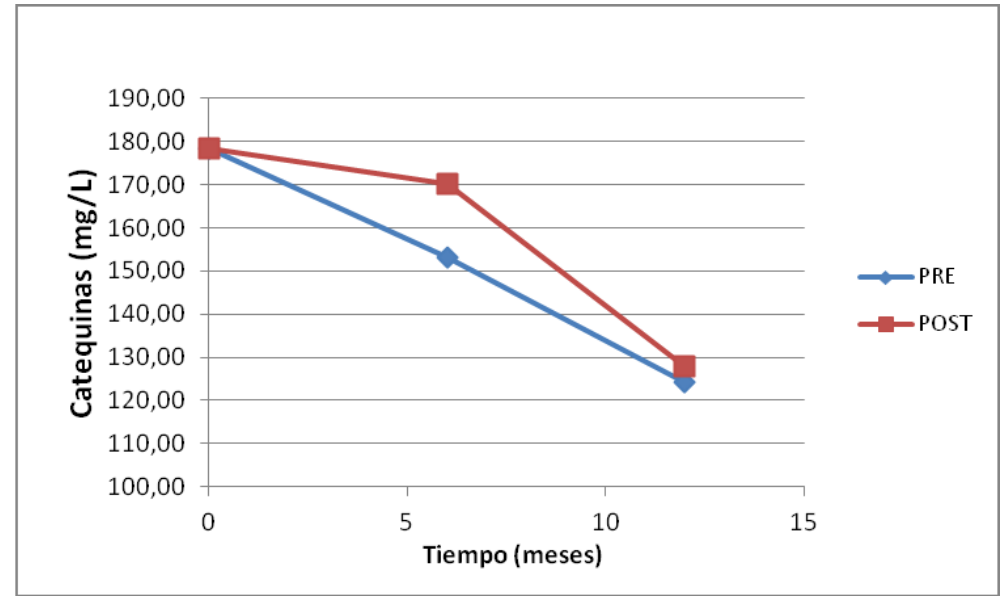

Gráfico 6.139. Evolución de la concentración de catequinas durante el periodo de conservación de los vinos en función del momento de adición de los copigmentos.

La microoxigenación ha permitido mantener una mayor concentración de catequinas durante los primeros seis meses, desapareciendo éstas al final del proceso de conservación (tablas 6.54, 6.62), tal como se observa en el gráfico 6.138. La participación de estos compuestos en las reacciones de unión con los taninos habrá sido probablemente la causa de este comportamiento. El comportamiento de las catequinas durante el año 2008 coincide con el observado en las añadas anteriores.

En el gráfico 6.139 aparece representada la evolución de la concentración de catequinas en función de la adición pre- o postfementativa de copigmentos. Los vinos adicionados de copigmentos posteriormente a la fermentación muestran concentraciones superiores de estos compuestos con diferencias significativas a los 6 meses de permanencia de los vinos en botella (tabla 6.55), despareciendo estas al final de la conservación (tabla 6.63).

Este resultado es similar al encontrado para la mayoría de los compuestos fenólicos cuando son suplementados de forma postfermentativa, así como para la concentración total de polifenoles, medida mediante el índice de Folin. La adición de 
estos copigmentos antes de la fermentación no incrementa significativamente su concentración en los vinos, ya que a lo largo de la fermentación participan en reaccioes con otros compuestos, que impiden que sean valorados como monómeros.

\subsubsection{EVOLUCIÓN DEL ÍNDICE DE DMACH}

El grado de polimerización de taninos medido por el índice de DMACH aparece representado en el gráfico 6.140. Se observa un descenso de este índice a lo largo de la conservación de los vinos, que indica un incremento en el grado de polimerización de sus taninos durante la conservación.

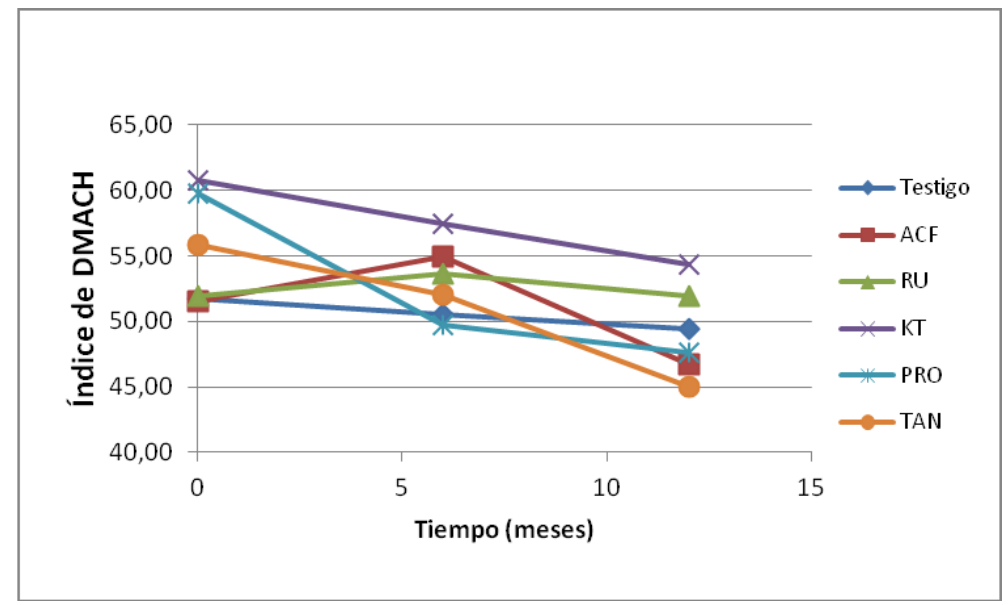

Gráfico 6.140. Evolución del índice de DMACH durante la conservación de los vinos en función de la adición de los distintos copigmentos ensayados.

La adición de copigmentos ha provocado en los vinos elaborados un incremento del grado de polimerización de los taninos, siendo la proantocianidina de pepitas de uvas blancas la que propicia un mayor grado de polimerización de los taninos al final de la conservación (tablas 6.46, 6.60). La adición de catequina, contribuye a mantener los monómeros de flavanoles en el vino, tal como observamos en el apartado anterior.

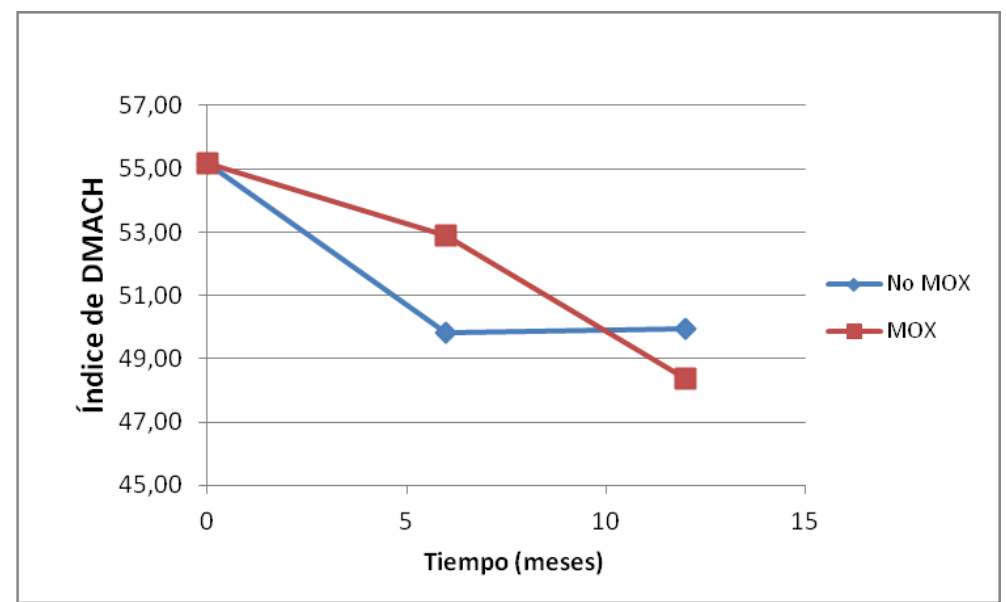

Gráfico 6.141. Evolución del índice de DMACH durante el periodo de conservación de los vinos en función de la aplicación de la microoxigenación. 
La presencia de estos compuestos monómeros en solución podría ser la causa del comportamiento observado, tal y como se ha comentado en varias ocasiones a lo largo del presente trabajo.

La evolución del índice de DMACH en función de la aplicación de la microoxigenación aparece representada en el gráfico 6.141. Es interesante destacar que no se observan diferencias significativas en el grado de polimerización de los taninos, para los vinos de la cosecha 2008 (tablas 6.54, 6.62), a diferencia de lo observado en los vinos elaborados en 2006 y 2007, en los cuales la microoxigenación incrementaba el grado de polimerización de los taninos, tal como sucede con el grado de polimerización de los antocianos. La escasa concentración de taninos, que participa activamente en las reacciones con los antocianos mediadas por la presencia de acetaldehído, podría ser la causa de que no quedasen taninos disponibles para reaccionar entre ellos.

\subsubsection{EVOLUCIÓN DEL ÍNDICE DE ETANOL}

La maceración prefermentativa en frío únicamente ha favorecido las uniones entre taninos y polisacáridos, medidas por el índice de etanol, al finalizar la conservación de los vinos. En el gráfico 6.142 se representa la evolución de este índice a lo largo de la conservación de los vinos.

Posteriormente a la fermentación maloláctica no se aprecian diferencias entre los vinos elaborados con maceración prefermentativa, pero a partir del sexto mes de conservación, los vinos macerados con aplicación de frío o adicionados de nieve carbónica, incrementan de forma exponencial el número de estos complejos taninopolisacárido (tabla 6.61). En los vinos elaborados en esta vendimia se ha necesitado un mayor periodo de tiempo para que la mayor extracción del material tánico propiciada por la maceración prefermentativa haya favorecido la presencia de estas uniones que participan en las sensaciones de estructura y cuerpo de los vinos (gráficos 6.137, 6.144).

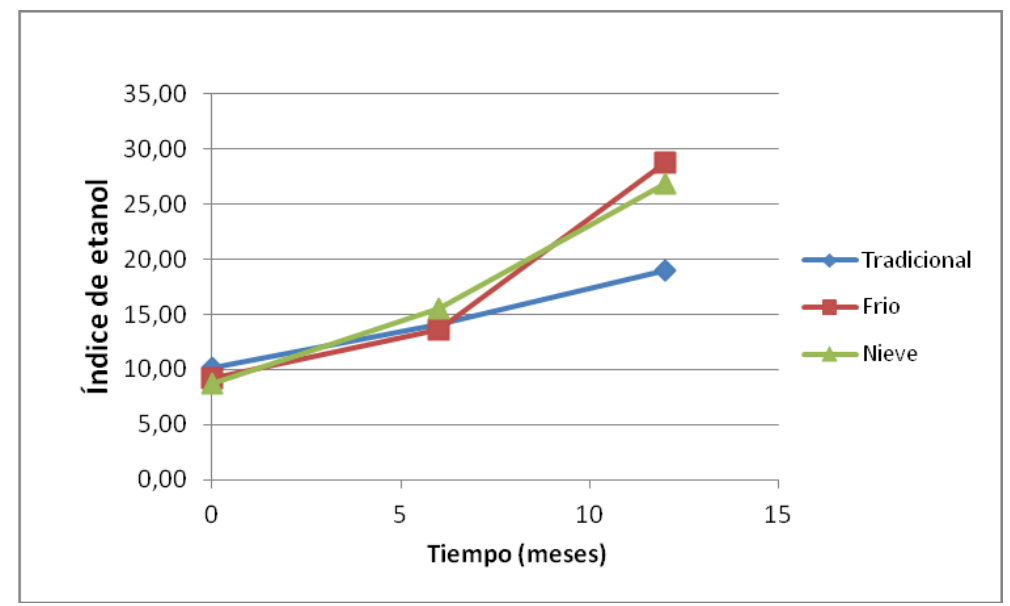

Gráfico 6.142. Evolución del índice de DMACH durante el periodo de conservación de los vinos en función de las distintas técnicas de vinificación ensayadas. 


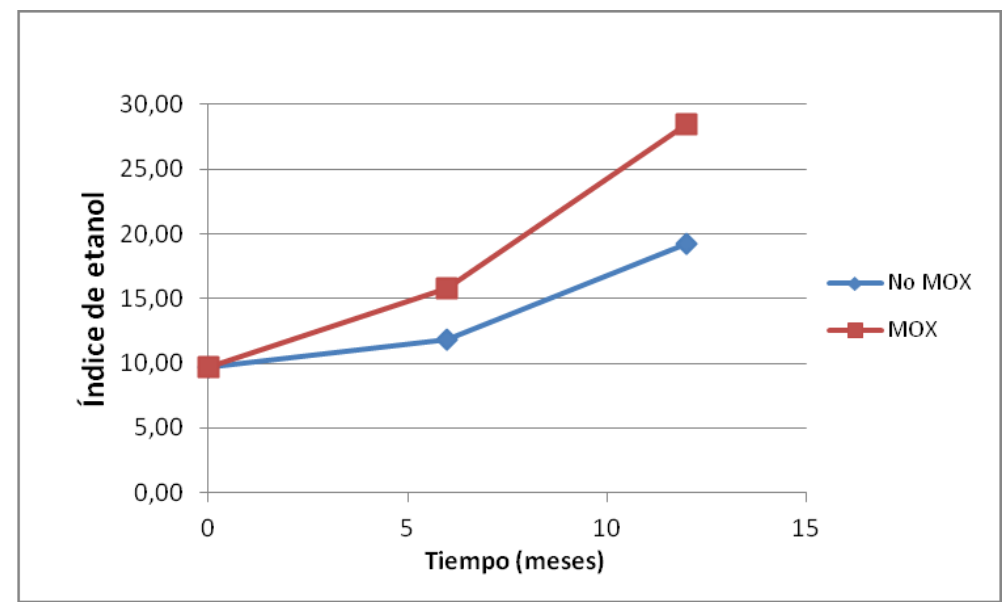

Gráfico 6.143. Evolución del índice de etanol durante el periodo de conservación de los vinos en función de la aplicación de la microoxigenación.

La evolución del índice de etanol durante el periodo de conservación de los vinos en función de la microoxigenación, aparece representada en el gráfico 6.143. Podemos observar un incremento de estas uniones en aquellos vinos sometidos a la acción del oxígeno, con diferencias significativas durante toda la conservación (tablas 6.53, 6.61). Esta técnica no debería afectar de forma directa al número de estas uniones en los vinos, aunque quizás el efecto del oxígeno sobre la polimerización lineal de taninos ha favorecido una mayor presencia de éstos en el medio, favoreciéndose a su vez este tipo de reacciones entre taninos y polisacáridos, en detrimento de la polimerización entre taninos, que no fue potenciada por la microoxigenación en estos vinos. Este comportamiento también fue observado en los vinos de 2006.

\subsubsection{EVOLUCIÓN DE LA CONCENTRACIÓN DE TANINOS TOTALES}

En el gráfico 6.144 aparece representada la evolución de la concentración de taninos totales durante la conservación de los vinos, en función de las técnicas de maceración aplicadas. Se observa como ambas prácticas de maceración prefermentativa presentan diferencias significativas tanto en el embotellado como a los 6 meses de permanencia en botella (tablas 6.47, 6.53), mientras que al final de la conservación estas diferencias se minimizan (tabla 6.60). Este resultado pone de manifiesto que en los vinos sometidos a técnicas de maceración prefermentativa, no únicamente se ha favorecido la extracción de la fracción antociánica (gráficos 6.108, 6.121) sino que además se ha favorecido la presencia de los compuestos que forman la fracción tánica tanto en su forma monómera como polimerizada (gráficos 6.137, 6.144), lo que contribuye al incremento observado en la concentración polifenólica de estos vinos. Este resultado también fue observado en los vinos de 2006, aunque en este caso la técnica de maceración que mostró diferencias con las otras fue la adición de nieve carbónica. 


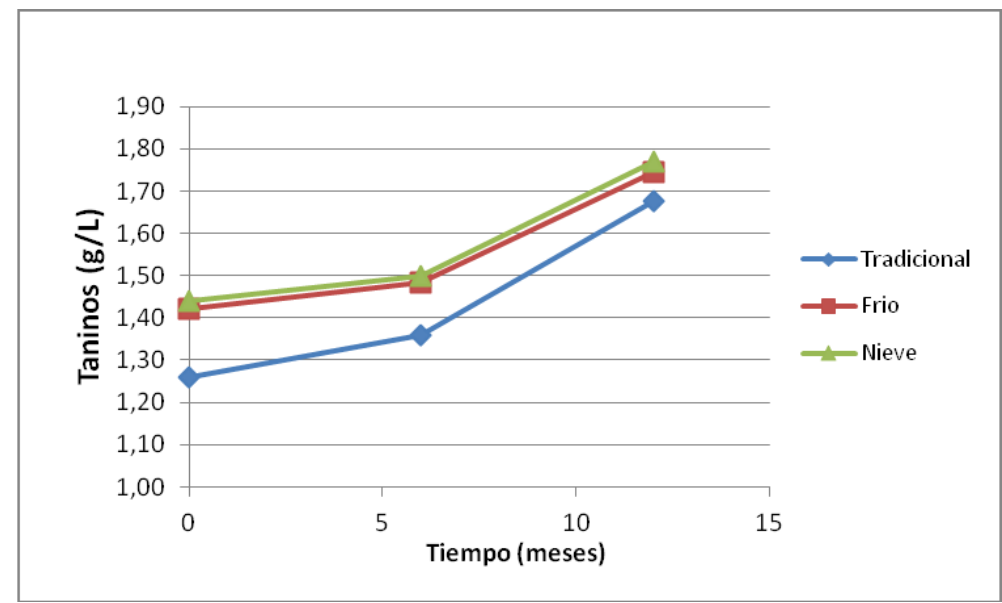

Gráfico 6.144. Evolución de la concentración de taninos totales durante la conservación de los vinos en función de las distintas técnicas de vinificación ensayadas.

La maceración prefermentativa ha provocado un incremento en la concentración de los principales compuestos que definen la composición antociánica de los vinos, en su forma simple o monómera, así como de las catequinas y los taninos, favoreciéndose por último las uniones de estos con los polisacáridos, y con los antocianos. Al igual que para las vendimias 2006 y 2007, la aplicación de la técnica de maceración prefermentativa ha favorecido la presencia de los compuestos polifenólicos en los vinos.

La aplicación de acetaldehído no ha ocasionado diferencias cuantificables en la concentración tánica de los vinos (gráfico 6.145), como tampoco modificó su grado de polimerización, tal como hemos observado (gráfico 6.141); a pesar de que el aporte de acetaldehído debería ser una técnica válida para incrementar las reacciones de polimerización entre las catequinas dando lugar a un incremento de los taninos condensados. Este reducido efecto de la adición de acetaldehído también se observó en los vinos de las añadas anteriores.

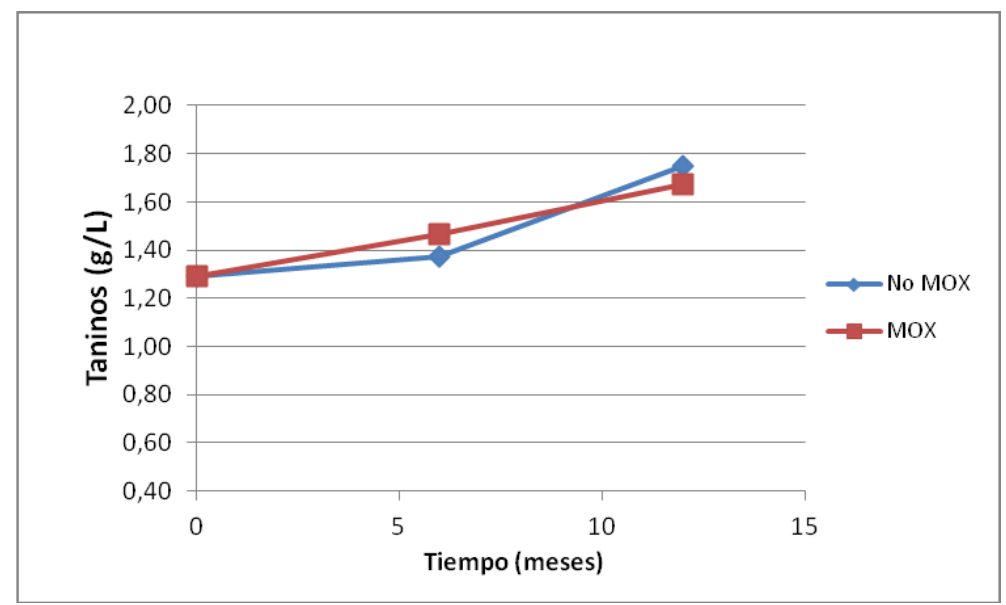

Gráfico 6.145. Evolución de la concentración de taninos totales durante la conservación de los vinos en función de la aplicación de la microoxigenación. 


\subsubsection{EVOLUCIÓN DEL ÍNDICE DE GELATINA}

En el gráfico 6.146 aparece representada la evolución del índice de gelatina para los vinos sometidos a la técnica de la microoxigenación. Aquellos vinos adicionados de acetaldehído muestran una disminución de la astringencia con respecto a los vinos no adicionados, con diferencias significativas a lo largo de los 12 meses de permanencia en botella (tablas 6.54, 6.62).

La participación del acetaldehído en la formación de moléculas antociano-etiltanino debería de ser la principal responsable de la modificación de la astringencia de los vinos (Llaudy et al., 2006); pero esta teoría no se confirma en estos vinos, ya que la microoxigenación no afecta al grado de polimerización de sus taninos. Esta disminución tendría que ser justificada por el incremento de la polimerización entre antocianos y taninos, cuya consecuencia es la disminución de la astringencia de estos últimos, y por la formación de complejos de los taninos con polisacáridos, que no solo disminuyen la astringencia de los taninos, sino que incrementan su suavidad y untuosidad. Este mismo comportamiento fue observado en los vinos elaborados en 2007.

A la vista de los resultados obtenidos, la microoxigenación podría dar lugar a un incremento de la intensidad colorante y del tono, así como a un descenso en la concentración de antocianos decolorables por el sulfuroso. Además, ha dado lugar a priorizado las reacciones de polimerización en detrimento de las de copigmentación. También ha contribuído a minimizar las pérdidas de catequinas, taninos y finalmente la concentración total de polifenoles. Finalmente también ha favorecido la formación de complejos tanino-polisacárido, y ha dado lugar a una importante disminución de la astringencia. Por tanto, representa una técnica que bien controlada, contribuye a mantener el potencial polifenólico de los vinos.

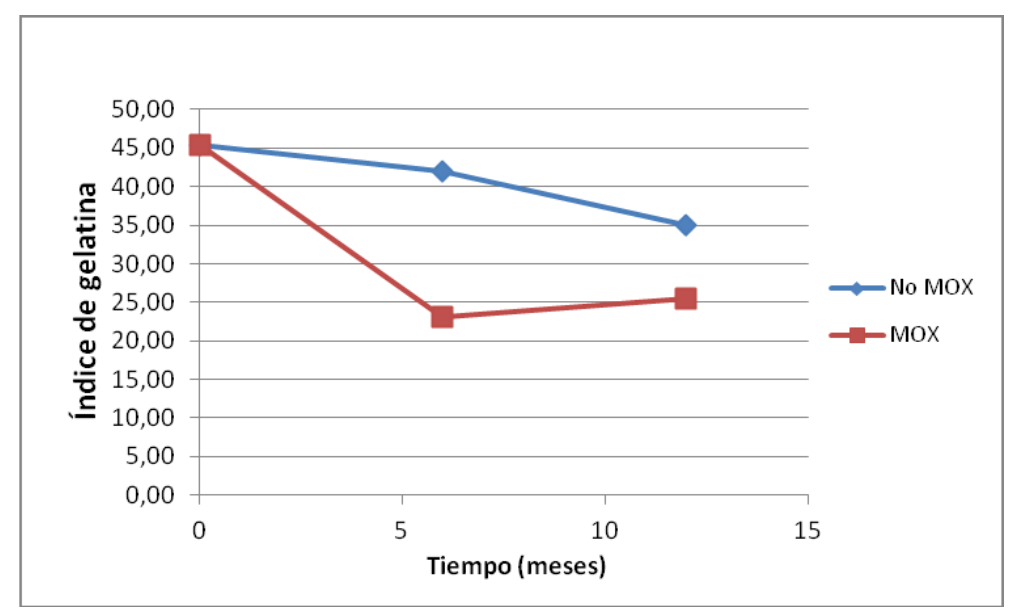

Gráfico 6.146. Evolución del índice de gelatina durante el periodo de conservación de los vinos en función de la aplicación de la microoxigenación.

La adición postfermentativa de copigmentos ha provocado una mayor astringencia de los vinos, medida con el índice de gelatina, tal como se observa en el gráfico 6.147, con diferencias significativas durante la conservación de los vinos en botella (tablas 6.55, 6.63). La adición de los copigmentos de naturaleza tánica directamente a los vinos en el momento del embotellado, ha incrementado significativamente la concentración de polifenoles (gráfico 6.132), pero también la 
astringencia de los vinos, al tratarse de taninos enológicos muy reactivos, con una gran capacidad de reacción con las proteínas. Además este efecto se mantiene a lo largo de la conservación, siendo necesario un largo período de microoxigenación para minimizar el efecto de esta adición tardía.

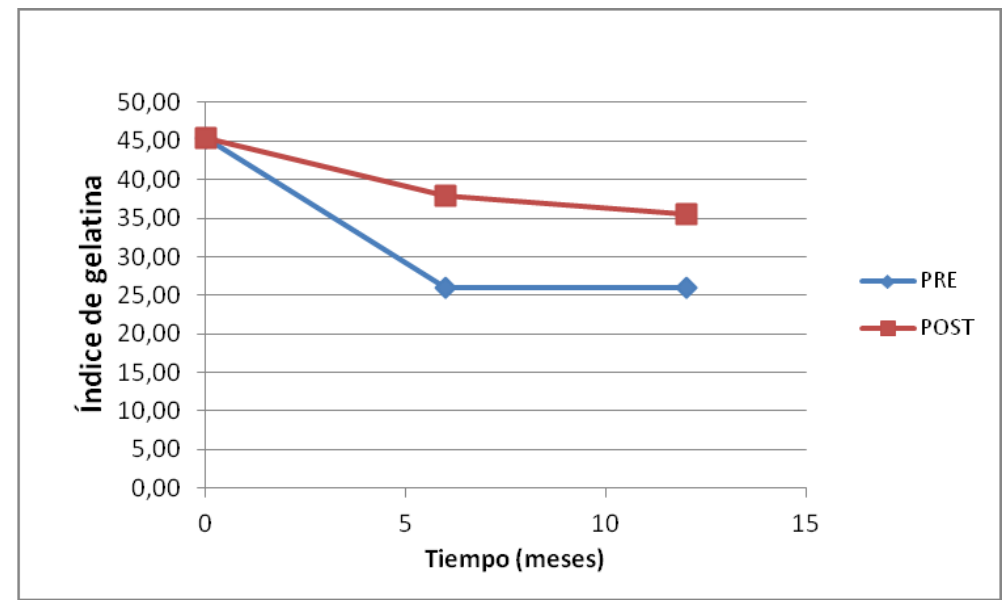

Gráfico 6.147. Evolución del índice de gelatina durante el periodo de conservación de los vinos en función del momento de adición de los copigmentos.

En la vendimia 2008, la adición postfermentativa de copigmentos ha provocado que los vinos elaborados presenten mayores concentraciones de antocianos decolorables, malvidina, antocianidinas, derivados de antocianos, antocianos totales y polifenoles totales. Debido a ello, la adición de copigmentos en el embotellado podría ser interesante para incrementar la presencia de compuestos fenólicos, pero también ha incrementado la astringencia de los vinos, con el consiguiente deterioro de su calidad organoléptica. 





\section{CONCLUSIONES}




\section{CONCULSIONES}

Las conclusiones a las que se llega tras analizar los resultados encontrados en este estudio, son las siguientes:

1. Los factores adición de copigmentos, aplicación de diferentes técnicas de vinificación y aplicación de la microoxigenación presentan un elevado efecto sobre la composición fenólica de los vinos elaborados, afectando a sus características organolépticas. Además, en la cosecha 2008, también se observa un importante efecto del momento de adición de copigmentos sobre la composición fenólica de los vinos.

2. La adición de copigmentos incrementó la intensidad colorante de los vinos elaborados, siendo el ácido cafeico y la rutina los copigmentos que tienen un efecto más acusado sobre el incremento de la intensidad colorante, aunque presentan un ligero o nulo efecto sobre la concentración total de antocianos.

3. La adición de rutina ha dado lugar al mayor porcentaje de color debido a los antocianos copigmentados en los vinos recién elaborados, pero a partir de los seis meses se produjo un descenso muy acusado del color debido a esta fracción, que se tradujo en una caída importante en la intensidad colorante.

4. La adición de ácido cafeico ha dado lugar a vinos con mayor color y menor tono, ya que facilitó la esterificación y polimerización de los antocianos, protegiéndolos de las reacciones de oxidación. Estos vinos presentan una mayor concentración de derivados acetilados y cumarínicos de antocianos, un mayor color debido a la fracción de antocianos polimerizados, una mayor concentración de polifenoles, y una mayor tendencia a reducir su astringencia.

5. Los copigmentos catequina, proantocianidina de hollejo y proantocianidina de pepita incrementan inicialmente el color debido a las reacciones de copigmentación, la concentración de antocianos decolorables, la concentración de malvidina y en general de la totalidad de antocianidinas pormenorizadas, así como la concentración global de antocianos; aunque a los 12 meses de conservación ya no se aprecian estas diferencias. En cambio, si mantienen al final de la conservación una mayor concentración de taninos, así como de su grado de polimerización.

6. La aplicación de las técnicas de maceración prefermentativa provocan una mayor extracción de aquellos compuestos que definen la composición antociánica de los vinos, en su forma simple o monómera, así como una mayor concentración de estos compuestos a lo largo de la conservación. Ocasionan también mayor extracción de catequinas y taninos, así como de polifenoles en general, favoreciendo las reacciones de polimerización entre ellos, junto con la disminución de la astringencia de los vinos. Así mismo, se observa una tendencia a incrementar las uniones entre taninos y polisacáridos, péptidos y sales, circunstancia que también contribuye a disminuir la astringencia.

7. La aplicación de nieve carbónica durante la fase prefermentativa permite una mayor presencia de la fracción antociánica a lo largo de la conservación de los vinos, excepto en los vinos elaborados durante la vendimia 2008, en los que no se observan diferencias entre los vinos macerados prefermentativamente en frío y los tratados con nieve carbónica. 
8. En algunos vinos, la utilización de nieve carbónica ha incrementado la tonalidad amarilla de los vinos, lo que pone de manifiesto el riesgo importante de oxidación que supone la aplicación de bajas temperaturas de forma prefermentativa, favorecido por la mayor disolución del oxígeno.

9. Los vinos microoxigenados presentan una mayor fracción antociánica, formada en su mayoría por polímeros de antocianos, que afecta positivamente al color y mantiene sus características cromáticas durante el envejecimiento.

10. La microoxigenación da lugar a vinos con mayor concentración de polifenoles totales, catequinas, y taninos, así como con mayor grado de polimerización de estos últimos entre sí, con polisacáridos, péptidos y sales, y menor astringencia; aunque a medida que transcurre la conservación, las diferencias entre los vinos tienden a acortarse, indicando la necesidad de hacer una microoxigenación más prolongada para que su efecto sobre estos compuestos sea más duradero.

11. En la vendimia 2008 se han detectado diferencias en función del momento de adición de los copigmentos. La adición postfermentativa ha provocado que los vinos elaborados presenten mayor concentración de antocianos decolorables, malvidina, antocianidinas, derivados de antocianos y antocianos totales; aunque a medida que transcurren los meses, su concentración va disminuyendo hasta valores similares a los que observamos en los vinos adicionados prefermentativamente de copigmentos.

12. La adición postferementativa de copigmentos da lugar a un significativo incremento de la concentración de polifenoles, así como de la astringencia de los vinos, y este efecto se mantiene a lo largo de la conservación, siendo necesario un largo período de microoxigenación para minimizar el efecto de esta adición tardía. Debido a ello, la adición de copigmentos después de la fermentación podría ser interesante para incrementar la presencia de compuestos fenólicos, pero el consiguiente incremento de la astringencia de los vinos, traería consigo un deterioro de su calidad organoléptica

13. Las interacciones entre los factores adición de copigmentos, momento de incorporación al vino y microoxigenación, han presentado una notable influencia sobre los parámetros polifenólicos determinados. Por otra parte, la interacción entre la aplicación de diferentes técnicas de vinificación con el momento de adición de los copigmentos ha presentado diferencias significativas para los vinos elaborados durante las tres vendimias realizadas.

14. La aplicación prefermentativa del copigmento ácido caféico, acompañada de maceración prefermentativa con nieve carbónica, seguida de un período de microoxigenación una vez concluida la fermentación maloláctica, podría establecerse como la metodología de vinificación que permitirá obtener vinos de Tempranillo con más color, menor tonalidad, mayor concentración polifenólica, polifenoles más polimerizados, y menor astringencia; contribuyendo también a la estabilidad de estos compuestos polifenólicos, ya que estos vinos mantienen mejor sus características cromáticas y su estructura polifenólica durante el envejecimiento. 


\section{BIBLIOGRAFÍA}





\section{BIBLIOGRAFÍA}

$>$ ABRIL, I.; CASP, A., (1999). Los compuestos fenólicos del vino. Alimentación. Equipos y tecnología 12: 97-103.

$>$ ALCALDE-EON, C.; BOIDO, E.; CARRAU, F.; DELLACASSA,E.; RIVASGONZALO, J. (2006). Pigment Profiles in Monovarietal Wines Produced in Uruguay.

> ALVAREZ, I.; ALEIXANDRE, J.; GARCÍA, M.J.; LIZAMA, V. (2005b). Impact of prefermentative maceration on the phenolic and volatile compounds in the Monastrell red wines. Analytica Chimica Acta.

$>$ ÁlVAREZ, I.; ALEIXANDRE, J.L. (2003). Tecnología Enológica. Ed. Síntesis. Madrid.

> ÁlVAREZ, I.; GARCÍA, M. A.; MARTÍN, P.; GONZÁLEZ, R. (2005a). Utilización de la criomaceración para mejorar la extracción de compuestos polifenólicos en uvas de Tempranillo procedentes de cultivo con altos niveles de fertilización. Jornadas Técnicas de los grupos de investigación enológica españoles. GIENOL.

> ÁlVAREZ, I.; GARCÍA, M. A.; MARTÍN, P.; GONZÁlEZ, R.; RODRÍGUEZ, M. (2004). Efecto de la maceración prefermentativa en frío en la composición de vinos tintos de Tempranillo. En "III Congreso Español de Ingeniería de Alimentos". Pamplona.

> ALVAREZ, I.; GARCÍA, M.A.; MARTIN, P.; GONZALEZ, M.R.; GARCÍA, M.J.; ALEIXANDRE, J.L. (2003). Influencia de la maceración prefermentativa en la composición polifenólica de vinos tintos de Tempranillo. En "VII Jornadas Científicas de los grupos de investigación enológica", 83-85. Am. J. Enol. Vitic. $57: 4,449-459$.

$>$ AMRANI JOUET, K. y GLORIES, Y. (1994). Etude en conditions models de l'extractibilite des composes phenoliques des pellicules et des pepins de raisins rouges. J. Int. Sci. Vigne Vin 28: 303-317.

> AMRANI JOUTEI, K.; GLORIES, Y. Y MERCIER M. (1994). Localisation des tanins dans la pellicule de baie de raisin. Vitis 33: 133-138.

$>$ ANOCIBAR, A. (2005). La microoxigenación en la elaboración de vino. Rev. Guía de oro de los vinos de España. 2, 32-39.

$>$ ARNOLD, R.A.; NOBLE, A.C. (1979). Effects of pomace contact on flavor of Chardonnay wine. Am. J. Enol. Vitic. 30, 179-181

> ASEN, S.; STEWART, R.N.; NORRIS, K.H. (1972). "Copigmentation of anthocyanins in plant tissues and its effect on color". Phytochemistry. 11, $1139-$ 11145. 
> ATANASOVA, V.; FULCRAND, H.; LE GUERNEVÉ, C.; CHEYNIER, V. ; MOUTOUNET, M. (2002a). Structure of a new dimeric acetaldehyde malvidin 3-glucoside condensation product. Tetrahedron Letters, 43: 6151-6153.

$>$ ATANASOVA, V.; FULCRAND, H.; CHEYNIER, V.; MOUTOUNET, M. (2002). Effect of oxigenation on polyphenol changes occurring in the course of winemaking. Anal. Chim. Acta. 458, 15-27.

$>$ AUW, J.M.; BLANCO, V.; O'KEEFE, S.F. y SIMS, C.A.; (1996). Effect of processing on the phenolics and colour of Cabernet Sauvignon, Chambourcin, and Noble wines and juices. Am. J. Enol. Vitic. 47: 279-286.

$>$ BAKKER, J.; TIMBERLAKE, C.F.; BRIDLE, P. (1993). Model wine solutions: colour and composition changes during ageing. Vitis. 32, 111-118.

$>$ BAKKER, J. y TIMBERLAKE, C.F. (1997). Isolation, identification and characterization of new color-stable anthocyanins occurring in some red wines. J. Agric. Food. Chem. 45, 35-43.

$>$ BAKKER, J. y TIMBERLAKE, C.F. (1985). The distribution and content of anthocyanins in young Port wines as determined by high performance liquid chromatography. J. Sci. Food Agric. 36: 1325-1333

$>$ BAKOWSKA, A.; KUCHARSCA, A.Z.; OSZMIANSKI, J. (2002). The effects of Heating, UV irradiation, and storage on stability of the anthocyaninpolyphenol copigment complex. Food Chemistry 81 (2003) 349 - 355.

$>$ BALDI, A.; ROMANI, A.; MULINACCI, N.; VINCIERI, F.F.; CASETTA, B., (1995). HPLC/MS application to anthocyanis of Vitis vinifera L. J Agric Food Chem, 43: 2104-2109.

> BARANAC, J.M., PETRANOVIV, N.A. and DIMITRIC-MARKOVIC, J.M., (1997a). Spectrophotometric study of anthocyan copigmentation reactíons. 2. J. Agrie. Food Chem. 45: 1694-1697.

$>$ BARANAC, J.M., PETRANOVIV, N.A. and DIMITRIC-MARKOVIC, J.M., (1997b). Spectrophotometric study of anthocyan copigmentation reactions. 3. J. Agrie. Food Chem. 45: 1698-1700.

$>$ BARANAC, J.M., PETRANOVIV, N.A. and DIMITRIC-MARKOVIC, J.M., (1996). Spectrophotometric study of anthocyan copigmentation reactions. Journal of Agricultural and Food Chemistry, 44, 1333-1336.

$>$ BARANAC, J.M., PETRANOVIV, N.A. and DIMITRIC-MARKOVIC, J.M., (1997). "Spectrophotometric study of anthocyan copigmentation reactions". Journal of Agricultural and Food Chemistry, 45, 1694-1703.

$>$ BARANAC, J.M.; N.A. PETRANOVIC AND J.M DIMITRIC-MARKOVIC. (1997c). Spectrophotometric study of anthocyan copigmentation reactions. 4. J. Agrie. Food Chem. 45: 1701-1703.

$>$ BARANOWSKI, E.S.; NAGEL, C.W. (1983). Kinetics of malvidin-3-glucoside condensation in wine model solutions. J. FoodSci. 38, 932-936.

> BAUTISTA-ORTIN, A.B.; FERNANDEZ-FERNANDEZ, J.; LOPEZ-ROCA, J.M.; GOMEZ-PLAZA, E. (2007). The effect of enological practices in 
anthocyanins phenolic compounds and wine color and their dependence on grape characteristics. Journal of Food Composition and Analysis. 20: 546-552.

$>$ BAUTISTA-ORTIN, A.B.; MARTINEZ-CUTILLAS, A.; ROS-GARCIA, J.M.; LOPEZ-ROCA, J.M.; GOMEZ-PLAZA, E. (2005). Improving color extraction and the stability in red wines: the use of maceration enzymes and enological tannins. International Journal of Food Science and Technology 40: 867-878.

$>$ BISHOP, P.D. y NAGEL, C.W. (1984). Characterization of the condensation product of Malvidin 3,5-diglucioside and catechin. Journal of Agricultural and Food Chemistry, 32, 1022-1026.

$>$ BLOOMFIELD, D.G.; HEATHERBELL, D.A.; NIKFARDJAM, M.S. (2003).Effect of $p$-coumaric acid on the color in red wine, 53, 195-198.

$>$ BLOOR, S.J.; FALSHAW, R. (2000). Covalently linked anthocyanin-flavonol pigments from blue Agapanthus flowers. Photochemistry, 53, 575-579.

$>$ BLOUIN, J. (1977). Manuel pratique d'analyse des moûts et des vins. Chambre d'Agriculture de la Gironde.

$>$ BOIDO, E.; ALCALDE-EON, C.; CARRAU, F.; DELLACASSA, E.; RIVAS GONZALO, J.C. 2006. Aging effect on the Pigment Composition and Color of Vitis vinífera L. Cv. Tannat Wines. Contribution of the Main Pigment Families to Wine Color. J. Agric. Food Chem., 54, 6692-6704.

$>$ BOSSO, A.; GUAITA, M.; VANDANO, E.; DI STEFANO, R. (2000). Influenza dell'ossigenao sull'evolucione dei composti fenolici durante la conservazione dei vini rossi. Industrie delle Bevande. 29, 630-640.

$>$ BOULTON, R. B., (1996). Methods for the assement of copigmentation in red wines. Presented at the $47^{\text {th }}$ Annual Meeting of the American Society for Enology and Viticulture, Reno, NV

$>$ BOULTON, R., (1997). Copigmentation in red wines. Some skin contact, a seedy side or is it just pulp fiction?. American Vineyard: UC Davis Viticulture and Enology Lab 05/97.

$>$ BOUlTON, R., (1999). Copigmentation in Pinot Noir Wines. $2^{\text {rd }}$ Joint Burgundy - California - Oregon Winemaking Symposium.

$>$ BOULTON, R., (2000). The variation in Skin Composition and Wine Color for Six Vineyard Sites. 3rd International. Burgundy. California. Oregon Colloquium.

$>$ BOULTON, R., (2001). The copigmentation of Anthocyanins and Its Role in the Color of Red Wine: A Critical Review. Am. J. Enol. Vitic. 52, 67-87.

$>$ BOULTON, R.B.; SINGLETON, V.L.; BISSON, L.F.y KUNKEE, R.E. (1996). Principles and Practices of Winemaking. Aspen, New York.

> BOURZEIX, M.; WEYLAND, D.; HEREDIA, N. (1986). Étude des catéchines et des procyanidols de la grape de raisin, du vin et d'autres dérivés de la vigne. Bull O.I.V., 669670: 1171-1253. 
$>$ BOUTARIC, A.; FERRE, L.; ROY, M. (1937). Reserches spectrophotometriques sur la couleur des vins. J. Annal. Falsific. 30: 196-209.

$>$ BROSSAUD, F.; CHEYNIER, V. Y NOBLE, A.C. (2001). Bitterness and astringency of grape and wine polyphenols. Australian Journal of Grape and Wine Research. 7 (1): 33-39.

$>$ BROUILLARD R.; G. MAZZA; Z. SAAD; A. CHEMINAT (1989). The copigmentation reactions of anthocyanins: a microprobe for the structural study of aqueous solutions. J.Ame.Chem.Soc. 11: 2604-2610.

$>$ BROUILLARD, R. y DANGLES, O. (1994). Anthocyanin molecular interacction : the first step of the formation of new pigments during wine aging? Food Chem., 51, 365-371.

$>$ BROUILLARD, R. (1982). Chemical structure of anthocyanidins. In: Anthocyanins as foodcolors. P. Markakis (Ed.). 1-40. Academic Press, N. York.

$>$ BROUILlARD, R., WIGAND, M. C., DANGLES, O., CHEMINAT, A. (1991). $\mathrm{PH}$ and solvent effects on the copigmentation reaction of malvin by polyphenols, purine and pyrimidme derivates. J. Chemical Society Perkin Trans. $2,1235-1241$.

$>$ BRUCHFELD, S.E.; BORDEU, E.S. y BOULTON, R.B. (1998).Effect of color and formed copigmentation complexes due to the addition of different cofactors to Pinot noir musts and wines. Presented at the Forty-ninth Annual Meeting of the American Society for Enology and Viticulture, Sacramento, CA.

$>$ BUSSE-VARVERDE, N.; GOMEZ-PLAZA, E.; LOPEZ-ROCA, J.M.; GILMUÑOZ, R.; FERNANDEZ-FERNANDEZ, J.I, BAUTISTA-ORTIN, A. (2010). Effect of different enological practices on skin and sees proanthicyanidins in three varietal wines. J. Agric. Food Chem. 58, 1133311339

$>$ C.I.E., (1986). Colorimetry" (2a edición). Publicación C.I.E. 15.2. Viena.

$>$ CABANILLAS, P.; CANALS, J.M.; ROZES, N.; AROLA, L.; ZAMORA, F. (2001). Influencia de la microoxigenacion en el color y las características organolépticas de los vinos tintos. Tecnología del vino. 51-55.

$>$ CACHO, J. (2003). El vino y su composición y nuestros sentidos. Real Academia de Ciencias Exactas, Físicas, Químicas y Naturales de Zaragoza (España) 47: 13

$>$ CANO-LOPEZ, M.; LOPEZ-ROCA, J.M.; PARDO-MINGUEZ, F.; GOMEZ PLAZA, E. (2010). Oak barrel maturation vs. micro-oxygenation: Effect on the formation of anthocyanin-derived pigments and wine colour. Food Chemistry 119: 191-195.

> CANO-LOPEZ, M.; PARDO-MINGUEZ, F.; LOPEZ-ROCA, J.M.; GOMEZPLAZA, (2006). Effect of Microoxygenation on Anthocyanin and Derived Pigment Content and Chromatic Characteristics of Red Wines. Am. J. Enol. Vitic. 57:3 325-331.

CANO-LOPEZ, M.; PARDO-MINGUEZ, F.; SCHMAUCH, G.; SAUCIER, C.; TEISSEDRE, P.L.; LÓPEZ-ROCA, J.M.; GÓMEZ-PLAZA, E. (2008). Effect of 
Micro-oxygenation on Color and Anthocyanin-Related Compounds of Wines with Different Phenolic Contents. J. Agric. Food Chem., 56, 5932-5941.

> CANO-LOPEZ, M.; PARDO-MINGUEZ, J.; LOPEZ-ROCA, J.M.; GOMEZPLAZA, E. (2007) Chromatic characteristics and anthocyanin profile of amicrooxygenated red wine after oak or bottle maturation. Eur. Food Res. Technol. 225: $127-132$.

$>$ CASTAÑEDA-OVANDO, A.; PACHECO-HERNANDEZ, M.; PAEZHERNANDEZ, M.E.; RODRIGUEZ, J.; GALAN-VIDAL, C. (2009). Chemical studies of anthocyanins: A review. Food Chemistry 113: 859-871.

$>$ CASTELLARI, M.; MATRICARDI, L.; ARFELLIS, G.; GALASSI, S.; AMATI, A., (1999). "Level of single phenolics in red wine as a function of the oxygen supplied during stotag". Food Chemistry 69: $61-67$.

> CASTILLO-SANCHEZ, J.X.; GARCIA-FALCON, M.S.; GARRIDO, J.; MARTINEZ-CARBALLO, E.; MARTINS-DIAS, L.R.; MEJUTO. X.C. (2008). Phenolic compuonds and color stability of Vinhao wines: Influence of winemaking protocol and finning agents. Food Chemistry 106, 18-26.

$>$ CEJUDO-BASTANTE, M.J.; HERMOSIN-GUTIERREZ, H.; PEREZCOELLO, M.S. (2011) Micro-oxygenation and oak chip treatments of red wines: Effects on colour-related phenolics, volatile composition and sensory characteristics. Part I: Petit Verdot wines. Food Chemistry 124: 727-737.

$>$ CEJUDO-BASTANTE, M.J.; PEREZ-COELLO, M.S.; HERMOSINGUTIERREZ, I. (2010). Effect of wine micro-oxygenation treatment and storage period on colour-related phenolics, volatile composition and sensory characteristics. Food Science and Technology. 44 (4): 866-874.

$>$ CHARPENTIER, C. y FEUILLANT, M. (1998). Métabolisme des levures cryotolerants : application a la maceration préfermentaire à friod du Pinot Noir en Bourgogne. Revue Française d'œnologie. 170, 36-37.

> CHEYNIER, V.; SOUQUET, J.M.; LE ROUX, E.; GUYOT, S.; RIGAUD, J. (1999). Size separation of condensed tannins by normal-phase-high-performance liquid chromatography. Methods in Enzimology. Vol. 299, 178-184.

$>$ CHEYNIER, V.; REMY, S.; FULCRAND, H. (2000). Mechanisms of anthocyanin and tannin changes during winemaking and aging. En: The ASEV 50th Anniversary Annual Meeting. Rautz, J. (Ed.), ASEV, Davis, CA, 337-344.

$>$ CHEYNIER, V.; MOUTOUNET, M.; SARNI-MANCHADO, P. (2003). Los compuestos fenolicos. Enologia: Fundamentos cientificos y tecnologicos, Flanzy, C. Ed.; Ediciones Mundi-Prensa, 2a edición Madrid, 114-136.

$>$ CHEYNIER, V. y DE SILVA, R. (1991). Oxydation of grape procyanidins in model solutions containing trans-caffeoyltartaric acido $\mathrm{n}$ polyphenol oxidase. J. Agric. Food. Chem., 39, 1047-1049.

$>$ CHEYNIER, V.; DUEÑAS-PATON, M.; SALAS, E.; MAURY, C.; SOUQUET, J.; SARNI-MANCHADO, P.; FULCRAND, H. (2006). Structure and properties of wine pigments and tannins. Am. J. Enol. Vitic. 57:3, 298-305. 
$>$ COMISIÓN EUROPEA, (1990). Reglamento (CEE) No 2676/90 de 17 de septiembre de 1990 por el que se determinan los métodos oficiales de análisis de vinos, zumos y mostos de uva. En: Diario Oficial de las Comunidades Europeas L272 (3 de octubre de 1990). Comisión Europea ed. Bruselas. Bélgica: 00010192.

$>$ COUASNON, M.B. (1999). Une nouvelle technique: La macération prefermentaire à froid. Extraction à la niege carbonique. $1^{\text {re }}$ partie : Resultats oenologiques. $2^{\mathrm{e}}$ partie : La technologie de la niege carbonique. Revue des Oenologues. $92: 26-30,93: 28-30$.

$>$ CRESPY, A. (2003a). Etude de l'elimination de composes soufre' s par tanisage avec des tannins de pe' pins de raisin. Revue des Oenologues 108, 38-39.

$>$ CRESPY, A. (2003b). Etude de la resistance a la decoloration des vins roses apre`s sulfitage par ajout de tannins de raisin (pepins et pellicules). Revue des Oenologues 108, 33-35.

$>$ CRESPY, A. y URBAN, N. (2002). Tanins de pepins de raisin: bilan de trios anne'es d'experimentation. Revue des Oenologues 105, 11-14.

$>$ DALlAS, C.; RICARDO DA SILVA, J. M. Y LAUREANO, O. (1996). Products formed in model wine solutions involving anthocyanins, procyanidin B2 and acetaldehyde. Journal of Agriculture and Food Chemistry, 44, 24022407.

$>$ DANGLES, O.; SAITO, N. Y BROUILLARD, R.; 1993: Anthocyanin intramolecular copigment effect. Phytochem. 34:119-124.

$>$ DANGLES, O. y BROUILLARD, R. (1992). A spectroscopic method based on the anthocyanin copigmentation interaction and applied to the quantitative study of molecular complexos. J. Chem. Soc. Perkin Trans. 2, 247-257.

$>$ DANGLES, O.; ELHABIRI, M.; BROUILLARD, R. (1994). Kinetic and thermodynamic investigation of the aluminium-anthocyanin complexation in aqueous solution. J. Chem. Soc., Perkin Trans. 2: 2587-2596.

> DARIAS-MARTÍN J.; V.GUTIÉRREZ; M.CARRILLO; E.DÍAZ AND R.B.BOULTON (1998). The enhancement of red wine color by using of copigment precursors. Future possibilities of color manipulations. Paper presented ai XXIII Congrés Mondial. 78 Assemblée General OIV 1998. Lisboa,Portugal. June.

> DARIAS-MARTÍN, J., B. MARTÍN, M. CARRILLO, R. LAMUELA, C. DÍAZ AND R. BOULTON (2002). The effect of caffeic acid on the color of red wine. Joumal of Agricultural and Food Chemistry. 50 (7): 2062-2067.

> DARIAS-MARTÍN, J.; CARRILLO, M.; DÍAZ, E.; BOULTON, R.B., (2001). "Enhancement of wine colour by prefermentation addiction of copigments". Food Chemistry 73 (2001) 217-220.

$>$ DAVIES, A.J. and MAZZA, G. (1993). Copigmentation of simple and acylated anthocyanins with colourless phenolic compounds. Journal of Agricultural and Food Chemistry, 41, 716-720. 
$>$ DE BEER, D.; JOUBERT, E.; MARAIS, J.; MANLEY, M. S. (2008) Effect of Oxygenation During Maturation on Phenolic Composition, Total Antioxidant Capacity, Colour and Sensory Quality of Pinotage Wine. S. Afr. J. Enol. Vitic., Vol. 29, No. 1, 13-25.

$>$ DI STEFANO, R. (1995). Extraction of phenolics from grape solids during fermentation. Acta Horticulturae, 388: 163-170.

$>$ DOCO, T.; WILliAMS, P.; MOUTOUNET, M. Y PELLERIN, P.; (2000). Les polisaccharides du vin. Bulletin de l'O.I.V. (837-838): 785-792.

$>$ DONNER, H.; KALT, W.; MAZZA, G. (1998). Simple and monoacylated cyanidin 3-glucosides copigmented with chlorogenic acid, protocatechuic acid and caffeine. 2nd International Electronic Conference on Synthetic Organic Chemistry.

$>$ DU TOIT, W.J.; PRETORIUS, I.S.; LONVAND-FUNEL, A. (2005). The effect of siphur dioxide and oxygen on the viability and culturability of a strain of Acetobacter pasterianus and a strain of Brettanomyces bruxellensis isolated from wines. J. Appl. Microbiol., 98, 862-871.

$>$ DUCOURNAU, P. Y LAPLACE, J. (1993). "Patente 93.11073”. República Francesa.

$>$ EIRO, M. y HEINONEN, M. (2002). Anthocyanin color behavior and stability during storage: effect of intermolecular copigmentation. J. Agric. Food. Chem. 50: 7461-7466.

$>$ ESCRIBANO-BAILON, T.; DANGLES, O.; BROUILLARD. (1996). Coupling reactions between flavilium ions and catechin. Phytochem., 41, 1583-1592.

$>$ ESCRIBANO-BAILON, T., M. ALVAREZ-GARCIA, J.C. RIVASGONZALO, F.J. HEREDIA, AND C. SANTOS-BUELGA. (2001). Color and stability of pigments derived from the acetaldehyde-mediated condensation between malvidin-3-O-glucoside and $(+)$-catechin. J. Agric. Food Chem. 49: 1213-1217.

$>$ ES-SAFI, N.; LE GUERNEVÉ, C.; FULCRAND, H.; CHEYNIER, V. Y MOUTOUNET, M. (1999). New polyphenolic compounds with xanthylium skeletons formed through reaction between $(+)$-catechin and glyoxylic acid. Journal of Agriculture and Food Chemistry, 47, 5211-5217.

> ES-SAFI, N.; LE GUERNEVÉ, C.; CHEYNIER, V. Y MOUTOUNET, M. (2000). New phenolic compounds formed by evolution of $(+)$-catechin and glyoxylic acid in hydroalcoholic solution and their implication in color changes of grape-derived foods. Journal of Agriculture and Food Chemistry, 48, 42334240 .

$>$ ETIÉVANT, P.X. (1991). Volatile compounds in foods and beverages. Ed. $H$. Maarse, Marcel Dekker, Nueva York.

$>$ FANG, F.; LI, J.M.; ZHANG, P.; TANG, K.; WANG, W.; PAN,Q.H.; HUANG, W.D. (2008). Effects of grape variety, harvest date, fermentation vessel and 
wine ageing on flavonoid concentration in red wines. Food Research International 41: 53-60

$>$ FAVRETTO, D. y FLAMINI, R. (2000). Application of Electro spray Ionization Mass Spectrometry to the Study of Grape Anthocyanins Am. J. Enol. Vitic., Vol. 51, No. 1

> FERNÁNDEZ, B.; HERNÁNDEZ, T.; CADAHÍA, E.; DUEÑAS, M. Y ESTRELLA, I. (2003). Phenolic compounds in a Spanish red wine aged in barrels made of Spanish, French and American oak Wood. Eur. Food Res. Technol., 216: 150-156.

> FERNÁNDEZ-LÓPEZ, J. A.; HIDALGO, V.; ALMELA, L. Y LOPEZ-ROCA, J. M. (1992). Quantitative changes in anthocyanin pigments of Vitis vinifera c.v.Monastrell during maturation. Journal of the Science of Food and Agriculture, 58, 153-155.

> FERNÁNDEZ-LÓPEZ, J.A.; ALMELA, L.; MUÑOZ, J.A.; HIDALGO V.; CARRERO, J. (1998). Dependence between colour and individual anthocyanin content in ripening grapes. Food Research International. 31(9): 667-672.

$>$ FISCHER, U.; BOULTON, R.B.; NOBLE, A.C. (1994). Physiological factors contributing to the variability of sensory assessments: Relationship between salivary flow rate and temporal perception of gustatory stimuli. Food Qual. Pref. 5: 55-64.

$>$ FISCHER, U. y STRASSER, M. (1999). Tannin management I. Body, fullness and ageing potential. Deutsche-Weinmagazine. 18, 36-39.

$>$ FLANZY, C., (1999). Vinification avec maceration prefermenteire a froid de Pinot Noir. Cap. 17.4 de Oenologie: fundaments scientifiques et technologiques. Ed Technique et Documentation, París.

$>$ RANCIA-ARICHA, E. M.; GUERRA, M.; RIVAS-GONZALO, J.C.; SANTOS-BUELGA, C. (1997). New anthocyanin pigment formed after condensation with flavanols. J. Agric. Food. Chem. 45, 2262-2266.

> FRANCIA-ARICHA, E.M.; RIVAS-GONZALO, J.C.; SANTOS-BUELGA, C. (1998). Effect of malvidin-3-monoglucoside on the browning of monomeric and dimeric flavanols. Z Lebensm. Unters. Forsch. 207(3), 223-228.

$>$ FULCRAND, H.; CHEYNIER, V.; OSZMIANSKI, J. Y MOUTOUNET, M. (1997a). An oxidized tartaric acid residue as a new bridge potentially competing with acetaldehyde in flavan-3-ol condensation. Phytochemistry, 46, 223-227.

$>$ FULCRAND, H.; BENABDELJALIL, C.; RIGAUD, J.; CHEYNIER, V. Y MOUTOUNET, M. (1998). A new class of wine pigments generated by reaction between piruvic acid and grape anthocyanins. Phytochem., 47, p. 1401-1407.

> FULCRAND, H.; DUEÑAS, M.; SALAS, E. Y CHEYNIER, V. (2006). Phenolic reactions during winemaking and aging. Am. J. Enol. Vitic., 57, 289297.

$>$ FULCRAND, H.; BENABDEIJALIL, C.; RIGAUD, J.; CHEYNIER, V.; MOUTOUNET, M. (1997). A new class of wine pigments generated by reaction between pyruvic acid and grape anthocyanins. Phytochemistry. 47, 1401-1407. 
> FULCRAND, H.; CAMENA-DOS SANTOS, P.J.; SARNI-MANCHADO, J.P.; CHEYNIER, V.; FAVRE-BONVIN, J. (1996). Structure of new anthocyaninderived wine pigments. J. Chem. Soc. Perkins Trans 1 (735-739)

$>$ FURTADO, P.; FIGUEREIDO, P.; CHAVES, H.; PINA, F. (1993). Photochemical and thermal degradation ofanthocyanidins. .7. Photochem. Photobiol. A. Chem. 75, 113-118.

> GAlleGO, J.I.; GONZÁleZ, M.R.; MARTíN, P.; AlONSO, A., 2005. Tratamientos con etanol favorecen la acumulación de materia colorante en la uva cv. Tempranillo durante la maduración" Viticultura/Enología Profesional (aceptado).

$>$ GALLEGO, C. (2005). El vino uva a uva: Enología de las variedades de uva y su madridaje. Everest (Ed.), León.

$>$ GARCÍA-ESCUDERO, E.; ZABALLA, O. (1997). Efecto asociado del riego y del aclareo de racimos sobre la expresión vegetativa de la vid. En: Reunión Anual del Grupo de Trabajo en Experimentación en Viticultura y Enología. Ministerio de Agricultura, Pesca y Alimentación (Ed.), Madrid, 1-10.

$>$ GARCIA-FALCON, M.S.; SOTO-GONZALEZ, B.; SIMAL-GANDARA, J. (2006). Evoluction of the concentration of polycyclic aromatic hidrocarbons in burnt Woodland soils. Environmental Science and technology. 40 (3), 759-763.

> GARCIA-MARINO, M.; HERNANDEZ-HIERRO, J.M.; RIVAS-GONZALEZ, J.; ESCRIBANO-BAILON, M: (2010). Color and pigment composition of red wines obrained from co-maceration of Tempranillo and Graciano varieties. Analytica Chimica Acta 660: 134-142.

$>$ GARCÍA-VIGUERA, C. Y BRIDLE, P. (1995). Análisis of non-coloured phenolic compounds in red wines. A comparison of high-performance liquid chromatography and capillary zone electrophoresis. Food Chem., 4, 349-352.

$>$ GARCÍA-VIGUERA, C.; BRIDLE, P.; BAKKER, J. (1994). The efifect ofpH on the formation of coloured compounds in model solutions containing anthocyanins, catechin and acetaldehyde. Vitis. 33, 37-40.

$>$ GAUCHE, C.; DA SILVA-MALAGOLI, E.; BORDIGUEN-LUIZ, M. (2010). Effect of $\mathrm{pH}$ on the copigmentation of anthocyanins from Cabernet Sauvignon grape extracts with organic acids. Sci. Agric. (Piracicaba, Brazil) V.67, n-1, p. 41-46.

$>$ GAWEL, R. (1998). Red wine astringency: a review. Australian Journal of Grape and Wine Research, 4, 74-95.

$>$ GAWEL, R.; ILAND, P. G.; LESKE, P. A. Y DUNN, C. G. (2001). Compositional and sensory differences in Syrah wines following juice run-off prior to fermentation. Journal of wine research, 12, 5-18.

$>$ GIL-MUÑOZ, R.; MORENO-PEREZ, A.; VILA-LOPEZ, R.; MARTINEZCUTILLAS, A.; FERNANDEZ-FERNANDEZ, J.I.; GOMEZ-PLAZA, E. (2009). Influence of low temperatura prefermentative techniques on chromatic 
and phenolic characteristics of Syrah and Cabernet sauvignon wines. Eur. Food Res. Technol. 228: 777-788.

$>$ GIUSTI, M.M. y WROLSTAD, R.E. (2003). Acylated anthocyanins from edible sources and their applications in food systems: A review. Biochem. Eng. J., 14: 217-225.

$>$ GLORIES, Y. (1984). La coleur des vins roges. 2ème partie. Mesure, origine et interpretation. Connaisance Vigne Vin, 18, 253-271.

$>$ GLORIES, Y. Y AGUSTIN, M. (1993). Actes du Colloque Jouneé Tecnique du CIVB, Burdeos, pp. 56- 61.

$>$ GLORIES, Y. GALVIN, C. (1990). Les complexes tanin-anthocyanes en présence d'éthanal. Conditions de leur formation. Actualités oenologiques. 89 : 408-413.

$>$ GLORIES, Y. (1999). La maturità fenolica delle uve: primo parametro da controllare per una corretta vinificazione in rosso. Vignevini, 3, 46-50.

$>$ GLORIES, Y. 2001. Caractérisation du potentiel phénolique: adaptation de la vinification. Progrès Agricole et Viticole, 118: 347-350.

$>$ GLORIES, Y. (1978) Recherches sur la matière colorante des vins rouges. Thèse a L'Université de Bordeaux II.

$>$ GLORIES, Y. (1984a) La coleur des vins rouges. Les equilibres des anthocyanes et des tannins. Conn. Vigne Vin, 18(3): 195-217.

$>$ GLORIES, Y. (1984b) La coleur des vins rouges. Mesure, origine et interpretation. Conn. Vigne Vin, 18(4): 253-271.

$>$ GLORIES, Y. La couleur des vins rouge. 1. Les equilibres des anthocyanes et des tanins. Conn. Vigne Vin 18:195-217 (1984).

$>$ GLORIES, Y., (1978). Characteristics of the various constitutive fractions of the phenolic compounds in red wine, and their oenological properties. Ann. Technol. Agric., 27: 253-255.

> GÓMEZ-CORDOVÉS, C.; GONZÁLEZ-SANJOSÉ, M.L.; JUNQUERA, B. Y ESTRELLA, I. (1995). Correlation between flavonoids and color in red wines aged in wood. Am. J. Enol. Vitic., 46, p. 295-298.

> GOMEZ-CORDOVÉS, M.C.; VARELA, F.; LARRIGAUDIERE, C.; VENDRELL, M.; (1996). Effect of ethephon and sephos treatments on the anthocyanin composition of starking apples. J.Agric.Food.Chem. 44: 3449-3452.

$>$ GOMEZ-MIGUEZ, M. y HEREDIA, F. (2004). Effect of maceration technique on the relationship between anthocyanin composition objective color of Syrah wines. J. Agric. Food Chem. 52, 5117-5123.

$>$ GOMEZ-MIGUEZ, M.; GONZALEZ-MANZANO, S.; ESCRIBANOBAILON, M.T.; HEREDIA, F.J.; SANTOS-BUELGA, C. (2006). Influence of different phenolic copigments on the color of malvidin-3-glucoside. J. Agric. Food Chem. 54, 5422-5429. 
> GOMEZ-MIGUEZ, M.; GONZALEZ-MIRET, M.; HEREDIA, F. (2007). Evolution of color and anthocyanin composition of Syrah wines elaborated with pre-fermentative cold maceration. Journal of Food Engineering. 79, 271-278.

> GÓMEZ-PLAZA, E.; GIL-MUÑOZ, R.; LÓPEZ-ROCA, J.M.; MARTÍNEZ, A. (2000). Color and phenolic compounds of a young red wine. Influence of winemaking techniques, storage temperature and length of storage time. Journal of Agricultural and Food Chemistry, 48: 736-741.

$>$ GOMEZ-PLAZA, E.; CANO-LOPEZ, M.A. (2011). A review on microoxygenation of red wines: Claims, benefits and the underlying chemistry. Food Chemistry 125: 1131-1140.

> GOMEZ-PLAZA, E.; GIL-MUÑOZ, R.; LOPEZ-ROCA, J.M.; MARTINEZCUTILLAS, A.; FERNANDEZ-FERNANDEZ, J.I. (2001). Phenolic compuonds and color stability of red wines: Effect of skin maceration time. Am. J. Enol. Vitic. 52:3, 266-270.

> GONZALES-MANZANO, S.; SANTOS-BUELGA, C.; DUEÑAS, M.; RIVASGONZALO, J.; ESCRIBANO-BAILON, T. (2008). Color implication of selfassociation processes of wine anthocyanins. Eur. Food Res. And Technol. 226: 483-490.

$>$ GONZÁlEZ-DEL POZO, A.; AROZARENA, I.; NORIEGA, M.J.; NAVARRO, M.; CASP, A. (2010). Short- and long-term effects of microoxygenation treatments on the colour and phenolic composition of a Cabernet Sauvignon wine aged in barrels and/or bottles. Eur Food Res Technol 231: 589601.

$>$ GONZÁLEZ-MANZANO, S.; DUEÑAS, M.; RIVAS-GONZALO, J.; ESCRIBANO-BAILÓN, M.T.; SANTOS-BUELGA, C. (2009). Studies on the copigmentation between anthocyanins and flavan-3-ols and their influence in the colour expression of red wine. Food Chemistry 114: 649-656.

> GONZALEZ-MANZANO, S.; MATEUS, N.; DE FREITAS, V.; SANTOSBUELGA, C., (2008). Influence of the degree of polymerisation in the ability of catechins to act as anthocyanins copigments. Eur. Food Res. Technol. 227: 8392.

> GONZÁLEZ-MANZANO, S.; RIVAS-GONZALO, J.C.; SANTOS BUELGA, C. (2004). Extraction of flavan-3-ols from grape seed and skin into wine using simulated maceration. Analytica Chimica Acta, 513: 283-289.

$>$ GONZALEZ-NEVES, G.; BARRERO, L., GIL, G.; FAVRE, G. (2010). Pigment profiles of red wines cv. Tannat made with alternative winemaking techniques. Journal of Food Composition and Analysis. 23: 447-454.

$>$ GONZALEZ-SAN JOSÉ, M. L.; SANTA- MARIA, G. Y DIEZ, C. (1990a). Anthocyanins as parameters for differentiating wines by grape variety, wine growing reaction and wine making methods. Journal of Food Composition and Analysis, 3, 54-56. 
> GONZALEZ-SAN JOSÉ, M. L.; BARRON, L. J. R. Y DIEZ, C. (1990B). Evolution of anthocyanins during maturation of Tempranillo grape variety (Vitis vinifera) using polynomial regression model. Journal of the Science of Food and Agriculture, 51, 337-343.

$>$ GONZÁLEZ-SANJOSÉ, M.L. (2005). Transferencia del color de la uva al vino. ACE Rev. Enología. www.acenología.com, Ciencia y Tecnología (29.09.05), 7.

$>$ GORDILLO, B.; LOPEZ-INFANTE, M.I.; RAMIREZ-PEREZ, P.; GONZALEZ-MIRET, M.; HEREDIA, F. (2010). Influence of prefermentative cold maceration on the color and anthocyanin copigmentation of organic tempranillo wines elaborated in warm climate. J. Agric. Food Chem. 58, 67976803.

$>$ GOTO, T. y KONDO, T. (1991) "Structures and molecular staking of anthocyanins flower color variation". Angew. Chem. Int. Ed. Engl, 30, 17-33.

> GRIS, E.F.; FERREIRA, E.A.; FALCAO, LD ; BORDIGNON-LUIZ, M.T., (2005). Caffeic acid copigmentation of anthocyanins from Cabernet Sauvignon grape extract in model system. Food Chemistry, en prensa.

$>$ GUERRA, C. y SAUCIER, C. (1997). Partial characterization of coloured polymers of flavanols-3/anthocyanins by mass spectrometry. In: Vino Analytica Scientia. Soc. FR. Chim. Anal. (Ed). 124-127.

$>$ GUINARD, J.X.; PANGBORN, R.M.; SHOEMAKER, C.F. (1985). The tiome course of astringency in wine upon repeated ingestions. Am. J. Enol. Vitic. 37, 184-189.

$>$ GUNATA, Y. Z.; SAPIS, J.C.; MOUTOUNET, M. (1987). Substrates and aromatic carboxylic acid inhibitors of grape phenol oxidases. Phytochemistry, $26,1573-1575$.

$>$ HAIBO WANG, H., RACE, E.J.; SHRIKHANDE, A.J. (2003). Anthocyanin Transformation in Cabernet Sauvignon Wine during Aging. J. Agric. Food Chem., 51, 7989-7994.

> HASLAM, E. (1998). In vino veritas: Oligomeric procyanidins and the aging of red wines. Phytochemistry 19:2577-2582 (1980). Haslam, E. Practical Polyphenolics: From Structure to Molecular Recognition and Physiological Action, 262-285. Cambridge University Press, Cambridge, UK.

$>$ HAYASAKA, Y. y ASENSTORFER, R.E. (2002) Screening for potential pigments derived from anthocyanins in red wine using nanoelectrospray tandem mass spectrometry, J. Ag. Food Chem. 50: 756-761.

$>$ HEATHERBELL, D.; DICEY, M.; GOLDSWORTHY, S.; VANHANEN, L. (1997). Effect of prefermentation cold maceration on the composition, colour and flavor of Pinot noir wine. Proceedings of the $4^{\text {th }}$ International Symposium on Cool Climate Viticulture and Enology. VI: 10-17. New York State Agricultural Experimental Station, Geneva, New York.

$>$ HEATHERBELL, D.; DICEY, M.; GOLDSWORTHY, S.; VANHANEN, L. (1997). Effect of prefermentation cold maceration on the composition, colour and flavor of Pinot noir wine. Proceedings of the New Zealand Grape \& Wine 
Symposium, G.F. Steans (Ed.), 30-42, New Zealand Society for Viticulture and Oenology, P.O. Box 90-276, Auckland Mail Centre, Auckland 1, New Zealand.

$>$ HEBRERO, E.; SANTOS-BUELGA, C.; RIVAS-GONZALO, J.C.; (1988). High performance liquid chromatography diode array spectroscopy identification of anthocyanins of Vitis vinifera variety Tempranillo. Am. J. Enol. Vitic., 39 (3): 227-233.

$>$ HEREDIA, F.J.; GUZMÁN, M. (1993). Compuestos fenólicos en vinos tintos. I. Características y propiedades. Alim. Eq. y Tecn. 12(8), 37-42.

$>$ HEREDIA, F, J.; ESCUDERO-GILETE, M.L.; HERNANZ, D.; GORDILLO, B.; MELENDEZ-MARTINEZ, A.J.; VICARIO, I.M.; GONZALEZ-MIRET, M.L. (2010). Influence of the refrigeration technique on the color and phenolic composition of Syrah wines obtained with pre-fermentative cold maceration. Food Chemistry. 118: 377-383.

$>$ HERMOSÍN, I.; BLANCO, F. J.; CASTRO, J. M. (2002). Evolución de la madurez fenólica en uvas tintas de las variedades Cencibel (Tempranillo) y Cabernet Sauvignon. Tecnología del Vino, 8: 37-47.

> HERMOSÍN GUTIÉRREZ, I. y GONZÁLEZ, P. (2003). Influence of etanol content on the extend of copigmentation in a Cencibel young red wine. J. Agric. Food Chem, 51, 4079-4083.

> HERMOSÍN GUTIÉRREZ, I. y SCHWARZ, M. (2005a). Efectos de la naturaleza del copigmento y de la variedad de uva en el color de vinos tintos elaborados con adicción prefermentativa de copigmentos. Actas de las VIII Jornadas de los Grupos de Investigation Enológica (GIENOL). Palencia. 80-82.

$>$ HERMOSÍN GUTIERREZ, I.; SANCHEZ-PALOMO LORENZO, E.; VICARIO ESPINOSA, A. (2005). Phenolic composition and magnitude of copigmentation in young and shortly aged red wines made from the cultivars, Cabernet Sauvignon, Cencibel, and Syrah. Food Chemistry 92: 269-283.

> HERMOSÍN GUTIÉRREZ, I.; SANCHEZ-PALOMO, E.; VICARIO, A. (2005b). Phenolic composition and magnitude of copigmentation in young and shortly aged red wines made from the cultivars Cabernet Sauvignon, Cencibel and Syrah. Food Chemistry, 92, 269-283.

$>$ HERMOSIN-GUTIERREZ, I.; SANCHEZ-PALOMO, E.; VICARIOESPINOSA, A.; (2005). Phenolic composition and magnitude of copigmentattion in Young and shortly aged red wines made from the cultivars Cabernet Sauvignon, Cencibel y Syrah. Food Chemistry 92, 269-283.

$>$ HOSHINO, T. (1991). An approximate estimate of self-association constants and self-stacking conformation of malvin quinoidal bases studied by $1 \mathrm{H}$ NMR. Phytochemistry 30:2049-2055.

$>$ HOSHINO, T. (1992).Self-association of flavylium cations of anthocyanidin 3,5- diglucosides studies by circular dichroism and 1H NMR. Phytochemistry 31: 647-653. 
> IBEM-GÓMEZ, M.; ANDRÉS-LACUEVA, C.; LAMUELA-RAVENTÓS, R. M.; BUXADERAS, S.; SINGLETON, V. L.; TORRE-BORONAT, M. C. (2000). Browning of cava (sparkiing wine) during aging m contact with lees due to the phenolic composition. American Joumal of Enologyand Vitículture. 51, 29-36.

$>$ IBERN-GÓMEZ, M.; ANDRÉS-LACUEVA, C.; LAMUELA-RAVENTÓS, R.M.; WATERHOUSE, A.L. (2002). Rapid HPLC analysis of phenolic compounds in red wines. Am. J. Enol. Vitic.,. 53, 218-221.

$>$ IZCARA, E. y GONZÁLEZ-SAN JOSÉ, M. L. (2001). Análisis de métodos rápidos de extracción para la maduración fenólica de la uva. Enólogos, 14, 1428.

$>$ JOSLYN, M. A. y GOLDSTEIN, J. L. (1964). Astringency of fruits and fruit products in relation to phenolic content. In C.O. Chichester, E. M. Mark, \& G. F. Stewart, Advances in food research (pp. 179-217). New York: Academic Press.

> JUNQUERA, B.; GONZÁLEZ-SANJOSÉ, M.L. Y DIEZ, C. (1992). El pardeamiento enzimático en uva y vino. Rev. Esp. Cien. Tecnol. Alim., 32, p. 481-491.

$>$ JURD, L. (1969). Review of polyphenol condensation reactions and their possible occurrence in the aging of wines. Am. J. Enol. Vitic., 20, 191-195.

$>$ JURD, L y ASEN, S. (1966). The formation of metal and "co-pigment" complexes of cyanidin 3-glucoside. Phytochemistry 5: 1263-1271.

> KALLITHRAKA, S.; BAKKER, J.; CLIFFORD, M.N. (1997). Effect of pH on astringency in model solutions and wines. Journal of Agricultural and Food Chemistry, 45(6): 2211-2216.

$>$ KENNEDY, J. A.; HAYASAKA, Y.; VIDAL, S.; WATERS, E. J. Y JONES, G. P. (2001). Composition of grape skin proanthocyanidins at different stages of berry development. Journal of Agricultural and Food Chemistry, 49, 5348-5355.

$>$ KING, G.A.; SWEENNEY, J.C. RADFORD, T. Y LACOBUCCI, G.A. (1980). The ascorbic/O2 degradation of anthocyanidins. Bull. Liaison Groupe Polyphenols., 9, p. 121-128.

> KOVAC, V.; BOURZEIX, M.; HEREDIA, A.; RAMOS, T. (1990). Étude des catéchines et proanthocyanidols de. raisins et vins blancs. Revue Française d'Oenologie, 30: 7-14.

$>$ KOVAC, V.; ALONSO, E.; BOURZEIX, M.; REVILLA, E. (1992). Effect of several enologcal practices on the content of catechins and proanthocyanidinas of red wines. J. Agric. Food Chem. 40, 1953-1957.

$>$ KOYAMA, K.; GOTO-YAMAMOTO, N.; HASHIZUME, K. (2007). Influence of maceration temperature in red wine vinification on extraction of phenolics from berry skins and seed of grape (Vitis Vinifera). Biosci. Biotechnol. Biochem. 71(4), 958-965.

$>$ KUNSAGI-MATE, S.; KUMAR, A.; SHARMA, P.; KOLLAR, L.; NIKFARDJAM, M. (2009). Effect of molecular environment on the formation 
kinetics of complexes of malvidin-3-o-glucoside with caffeic acid and catechin. J. Phys. Chem. B. 113: 7468-7473.

> S. KUNSÁGI-MÁTÉ, S.; STAMPEL, E.; KOLLÁR, K.; NIKFARDJAM, M. (2008). The effect of the oxidation state of iron ions on the competitive complexation of malvidin by caffeic or ellagic acid Food Research International 41, 693-696.

$>$ KUNSAGI-MATE, S.; SZABO, K.; NIKFARDJAM, M.; KOLLAR, K. (2006). Determination of the termodynamic parameters of the coplex formation between malvidin-3-O-glucoside and polyphenols. Copigmentation effect in red wines.J. Biochem. Biophys. Methods. 69: 113-119.

$>$ LAMADON, F. (1995). Protocole pour I'évaluation de la richesse polyphénolique des raisins. Revue des Oenologues, 76, 37-38.

$>$ LAMBERT, S.; ASENTORFER, R.; WILLIAMSON, N; ILAND, P.; JONES, G. (2011). Copigmentation between malvidin-3-glucoside and some wine constitutens nd its importance to color expression in red wine. Food Chemistry 125: 106-115.

$>$ LEA, A.G.H. Y ARNOLD, G.M. (1978). The phenolics of ciders: bitterness and astringency. J. Agric. Food Chem., 29, 478-483.

$>$ LECAS, M. Y BRILLOUET, J. M. (1994). Cell wall composition of grape berry skins. Phytochemistry, 35, 1241-1243.

$>$ LEMAIRE, T. (1995) "La micro-oxygénation des vins". Report for the requirements of the Diplôma National d'Oenologie (Ecole Nationale Superieure Agronomique: Montpellier, France).

$>$ LEVENGOOD, J., AND BOULTON, R. B. (1997). A study of copigmentation in 1995 Cabernet sauvignon wines. $48^{\text {th }}$ Annual Meeting of the American Society for Enology and Viticulture. San Diego. California.

$>$ LEVENGOOD, J. (1996). A study of copigmentation in 1995 Cabemet Sauvignon wines. M.S. Thesis, Univ. Of California. Davis, CA.

$>$ LIAO, H.; CAI, Y.; HASLAM, E. (1992). "Polyphenol interactions. Anthocyanins : Co-pigmentation and colour changes in red wines", J. Sci. Food. Agric., 1992; 59: 299-305.

$>$ LIU, S. Q. Y PILONE, G. J. (2000). An overview of formation and roles of acetaldehyde in winemaking with emphasis on microbiological implications. Intern. J. Food Sci. Technol., 35, 49-61.

$>$ LLAUDY, M.C.; CANALS, R.; GONZÁLEZ-MANZANO,S.; CANALS,J.M.; SANTOS-BUELGA,C.; ZAMORA, F. (2006). Influence of Micro-Oxygenation Treatment before Oak Aging on Phenolic Compounds Composition, Astringency, and Color of Red Wine. J. Agric. Food Chem., 54, 4246-4252.

$>$ LORENZO, C.; PARDO, F.; ZALACAIN, A.; ALONSO, G.; SALINAS, M.R. (2005). Effect of red grapes co-winemaking in polyphenols and color wines. J. Agric. Food Chem., 53, 7609-7616. 
> MALIEN-AUBERT, C.; DANGLES, O.; AMIOT, M.J. (2001). Color stability of commercial based extracts in relation to the phenolic composition. Protective effects by intermolecular copigmentation. J. Agric. Food. Chem. 49: 170-176.

$>$ MALIEN-AUBERT, C.; DANGLES, O.; AMIOT, M.J. (2002). Influence of procyanidins on the color stability of oenoin solutions. J. Agric. Food. Chem. 50, 3299-3305.

$>$ MARAIS, J. (2003). Effect of different wine-making techniques on the composition and quality of Pinotage wine. I. Low-temperature skin contact prior to fermentation. S. Afr. J. Enol. Vitic. 24 (2): 70-75.

> MARIA-BURIN, V.; FREITAS-CASTA, L.; PIERRE-ROSIER, J.; BORDIGNON-LUIZ, M. (2011). Cabernet Sauvignon wines from two different clones, characterisation and evolution during bottle ageing. Food Science and technology 44: 1931-1938.

$>$ MATEUS, N.; OLIVEIRA, J.; GONZÁlEZ-PARAMÁS, A.M.; SANTOSBUELGA, C. Y DE FREITAS, V. (2005). Screening of Portisins (vinylpyranoanthocyanin pigment) in Port wine by LC/DAD-MS. Food Sci. Tech. Int., 11, 353-358.

$>$ MATEUS, N.; OLIVEIRA, J.; PISSARRA, J.; GONZÁLEZ-PARAMÁS, A.M.; RIVAS-GONZALO, J.C.; SANTOS-BUELGA, C.; SILVA, A.M.S. Y DE FREITAS, V. (2006). A new vinylpyranoanthocyanin pigment occurring in aged red wine. Food Chem., 97, 689-695.

$>$ MATEUS, N. Y FREITAS, V. (2001). Evolution and stability of anthocyaninderived pigments during port wine aging. J. Agric. Food Chem., 49, p. 5217-5222.

$>$ MATEUS, N.; CARVALHO, E.; CARVALHO, A.R.F.; MELO, A.; GONZALEZ-PARAMAS, A.; SANTOS-BUELGA, C.; SILVA, A.; DE FREITAS, V. (2003). Isolation and structural characterization of new acylated anthocyanin-vinil-flavanol pigments ocurring in aging red wines. J. Agric. Food. Chem. 51, 277-282.

$>$ MATEUS, N.; DE PASCUAL, S.; RIVAS-GONZALO, J.; SANTOS-BUELGA, C.; DE FREITAS, V. (2002), Structural diversity of anthocyanin-derived pigments in port wines . Food Chemistry 76: 335-342

$>$ MATEUS, N.; SILVA, A.; RIVAS-GONZALO, J.; SANTOS-BUELGA, C.; DE FREITAS, V. (2003). A new class of blue anthocyanin-derived pigments isolated from red wines. J. Agric. Food. Chem. 51, 1919-1923.

> MAYEN, M.; MÉRIDA, J.; MEDINA, M. (1995). Flavonoid and no-flavonoid compounds during fementation and post-fermentationstanding of must from Cabernet Sauvignon and Tempranillo grapes. American Journal of Enology and Viticulture, 46: 255-261.

MAZZA, G. y MINIATI, M. (1993). Anthocyanins in fruits, vegetables an grains. CRC Press, Boca Raton, Florida.

> MAZZA, G. Y BROUILLARD, R. (1987). Recent developments in the stabilization of anthocyanins in food products. Food. Chem. 25:207-225. 
MAZZA, G. (1995). Anthocyanins in grape and grape products. Critical reviews in Food Science and Nutrition 35: 341-371

> MAZZA, G.; FUKUMOTO, L.; DELAQUIS, P.; GIRARD,B.; EWERT, B. (1999). Anthocyanins, Phenolics, and Color of Cabernet Franc, Merlot, and Pinot Noir Wines from British Columbia J. Agric. Food Chem., 47, 4009-4017.

$>$ MCDONALD, M.S.; HUGHES, M.; BURNS, J.; LEAN, M.E.J.; MATTHEWS, D. Y CROZIERS, A. (1998). Survey of the free and conjugated myricetin and quercetin content of red wines of different geographical origins. J. Agric. Food Chem., 46, 368-375.

$>$ MCMAHON, M., ZOECKEIN, B., JASINSKI, Y. (1999). The effects of prefermentation maceration temperature and percent alcohol at press on the concentration of Cabernet Sauvignon grape glycosides and glycoside fractions. Am.J.Enol.Vitic. 50 (4): 385-390.

$>$ MIRABEL, M.; KAHN, N.; LAGUNE-AMMIRATI, L.; GLORIES, Y.; (1998). The copigmentation case in model wine solution : application to red wines". 2nd International Electronic conference on Synthetic Organic Chemistry.

$>$ MIRABEL, M.; SAUCIER, C.; GUERRA, C.; GLORIES, Y. (1999). Copigmentation model wine solutions: occurrence and relation to wine aging. Am. J. Enol. Vitíc. 50, 211-217.

> MISTRY, T. V.; CAÍ, Y.; LILLEY, T. H.; HASLAM, E. (1991). Polyphenol interactions. Part 5. Anthocyanin co-pigmentation. J. Chem. Soc. Perkin Trans. 2, 1287-1296.

$>$ MONAGAS, M.; GOMEZ-CORDOVES, C.; BARTOLOME, B. (2006). Evolution of the phenolic content of red wines fron Vitis Vinifera L. during aging in bottle. Food Chemistry 95: 405-412.

> MONAGAS, M.; NUÑEZ, V.; BARTOLOME, B.; GOMEZ-CORDOVES, C. (2003). Anthocyanin derived pigments in Graciano, Tempranillo and Cabernet Sauvignon wines made in Spain. Enol, and Vitic. 54:3, 163-169.

$>$ MONTEDORO, G. F. Y BERTUCCIOLI, M. (1988). Organoleptic importance of certain tannic fractions of aged red wines. Develop. Food Sci., 17, p. 687-696.

> MOUTOUnet, M., DuCOURnAU, P.; ChASSIN, M. Y LEMAIRE, T. (1995). Appareillage d'apport d'oxygène aux vins. Son interêt tecnologique. OEnologie 95, 5ème Symposium Internationale d'OEnologie, Ed. Lavoisier, Paris, p. 411-414.

$>$ MOUTOUNET, M. Y VIDAL, J.C. (2006). La medida de oxígeno disuelto en la bodega: ¿Nuevo criterio para garantizar la calidad? Revista Internet de Viticultura y Enología, 3/1, p. 1-5. (www.infowine.com)

$>$ MOUTOUNET, M. (2003). La técnica de microoxigenación. ACE Enología. www.acenologia.com 
$>$ MOUTOUNET, M. (2000). Apuntes del Curso de Tecnología Enológica. Maestría de Viticultura y Enología, FCA-UN Cuyo, ENSA-Montpellier, INTA Mendoza. Argentina.

$>$ NAGEL, C.W. y GLORIES, Y. (1991). Use of a modified dimethylaminocinnamaldehyde reagent for analysis of flavanols. Am. J. Enol. Vitic. 42, 364-366.

$>$ VIVAS, N., Y. GLORIES., L. LAGUNE., C. SAUCIER Y M. AUGUSTIN. (1994). Estimation du degré de polymerisation des procyanidines du raisin et du vin par la méthode au Dimethylaminocinnamaldéhyde. Journal International des Sciences de la vigne et du vin 28 (4) 319 - 336.

$>$ NAGEL, C.W. y WULF, L.W. Changes in the anthocyanins, flavonoids and hydroxycinnamic acid esters during fermentation and aging of Merlot and Cabernet Sauvignon wines. Am. J. Enol. Vitic. 30: 111-116 (1979).

$>$ NAISH, M., CLIFFORD, M.N. AND BIRCH, G.G. (1993). Sensory astringency of 5-O-caffeoylquinic acid, tannic acid and grape seed tannin by a time intensity procedure. J. Sci. Food Agric, 61, 57-64.

$>$ NOBLE, A.C. (1990). Bitterness and astringency in wine. In «Bitterness in food and beverages». Ed. R.L., Rousseff, Elsevier, Amsterdam, 145-158.

$>$ NUÑEZ, V.; MONAGAS, M.; GOMEZ-CPRDOVES, M.C.; BARTOLOME, B. (2004). Vitis Vinifera L. cv. Graciano grapes characterized by its anthocyanin profile. Postharvest Biology and Technology 31: 69-79.

$>$ OIV (1990). Recueil des Méthodes Internationales d'Analyse des Vins. Caractéristiques Chromatiques, p. 29-39.

> OKUBO, K.; GOTO-YAMAMOTO, N.; OKAZAKI, N. (2003). Effect of prefermentative cold soak on extraction of anthocyanin during red wine making. Nippon Jozo Kyokaishi, 98: 193-200.

$>$ OSAWA, Y. (1982). "Anthocyanins as Food colors" Markakis, Ed., London academic Press, London. Pg. 41.

$>$ PARENTI, A.; SPUGNOLI, P.; CALAMAI, L.; FERRARI, S.; GORI, C. (2004). Effects of cold maceration on red wine quality from Tuscan Sangiovesi grape. Eur. J. Food Res. Technol, 218: 360-366.

$>$ PARISH, M.; WOLLAN, D. Y PAUL, R. (2000). Micro-oxygenation a review. Austr. Grapegrower \& Winemaker, 438, 47-50.

$>$ PELEG, H.; GACON, K.; SCHLICH P. Y NOBLE, A. C. (1999). Bitterness and astringency of flavan-3-ol monomers, dimers and trimers. Journal of the Science of Food and Agriculture. 79, 1123-1128.

$>$ PEREZ-LAMELA, C.; GARCIA-FALCON, M.S.; SIMAL-GANDARA, J.; ORRIOLS-FERNANDEZ, I. (2007). Influence of grape variety, vine system and enological treatments on the color stability of young red wines. Food Chemistry 101: 601-606. 
> PÉREZ-MAGARIÑO, S. Y GONZÁLEZ-SANJOSÉ, M.L. (2002b). Prediction of red and rose wine CIELab parameters from simple absorbance measurements. J.Sci. Food Agric., 82, 1319-1324.

> PÉREZ-MAGARIÑO, S. Y GONZÁLEZ-SANJOSÉ, M.L. (2003a). Efecto de la aplicación de la microoxigenación durante la fermentación de vinos tintos. Tecnología del Vino, 14, 107-112.

$>$ PEYNAUD, E. (1987). “El gusto del vino”. Ed. Mundi - Prensa. Madrid.

$>$ POMPEI, C. y PERI, C. (1971) Determination of catechins in wines. Vitis, 9, 312-316.

$>$ PORTER, L.J.; HIRSTICH, L.N. Y CHANG, B.G. (1986). The conversion of procyanidins and prodelphinidins to cyanidin and delphinidin. Phytochem., 25, p. 223-230.

$>$ POUR-NIKFARDJAM, M.S. Y DYKES, S.I. (2003). Micro-oxygenation research at Lincoln University. Part 3: Polyphenolic analysis of Cabernet Sauvignon wine under the application of micro-oxygenation. Austr. New Zealand Grapegr. Winemaker, 468, 41-44.

$>$ PRICE, S. (1994). Sun Exposure and Flavanols in Grapes. Oregon State University. p. 90.

$>$ PRICE, S.F. (1995). Cluster sun exposure and quercetin in Pinot noir grapes and wine. American Journal of Enology and Viticulture, 46(2): 187-194.

$>$ PRINCE, S.F.; BREEN, P.J.; VALLADO, M; WATSON, B.T. (1994). Wine phenolic responses to cluster sun exposure. ASEV Tech. Abstr. 4

$>$ QUINTANA, A.M. (2001). Fraccionamiento y estudio preliminary de la material colorante del vino. Tesis doctoral. Universidad de Salamanca.

$>$ RAYNE, S.; SHEPPARD, S.; DI BELLO, T.; EGGERS, N.J. (2011). Chromatic Characteristics and Optically Derived Compositional Descriptors of Microoxygenated Wines from Vitis vinifera cv. Merlot and Cabernet Sauvignon. Food Bioprocess Technol 4: 254-265.

$>$ REIN, M.J. (2005). Copigmentation reactions and color stability of berry anthocyanins. EKT series 1331. University of Helsinki, Department of Applied Chemistry and Microbiology.

$>$ REMY, S.; FULCRAND, H.; LABARBE, B.; CHEYNIER, V.; MOUTOUNET, M. (2000). First confirmation in red wine of products resulting from direct anthocyanin-tannin reaction. J. Sci. Food Agric. 80: 745-751.

$>$ REVILLA, E.; ALONSO, E. Y ESTRELLA, M.I. (1986). Análisis of flavonol aglycones in wine extracts by high performance liquid chromatography. Chromatographia, 22, 157-159.

$>$ REVILlA, I.; PÉREZ-MAGARIÑO, S.; GONZÁLEZ-SANJOSÉ, M.L. Y BELTRÁN, S. (1999). Identification of anthocyanin derivaties in grape skin extracts and red wines by liquid chromatography with diode array and mass spectrometric detection. J. Chrom. A, 847, 83-90. 
$>$ REYNOLS, A.; CLIFF, M.; GIRARD, B; KOPP, T. (2001). Am. J. Enol. Vit. 52(3), 235-242.

$>$ RIBÉREAU-GAYON, P.; SUDRAUD, P.; MILHÉ, J.C.; CANBAS, A. (1970). Reserches technologiques sur les composes phenoliques des vins rouges II. Les factors de dissolution des composes phénoliques. Conn. Vigne Vin 4:133-144.

$>$ RIBÉREAU GAYON, P.; GLORIES, Y.; MAUJEAN, A. ; DUBOURDIEU, D. (1998a). Traité d'Oenologie.2. Chimie du vin. Stabilisation et traitements. Ed. Dunod, Paris.

> RIBÉREAU-GAYON, P.; DUBOURDIEU, D.; DONÈCHE, B.; LONVAUD, A. (1999). Handbook of Enology. The Microbiology of Wine and Vinification. Wiley and Sons Ltd. Ed., Chichester.

$>$ RIBEREAU-GAYON, P., GLORIES, Y., MAUJEAN, A.; DUBOURDIEU, D., (2000b). Handbook of Enology. Vol. 2. The Chemistry of Wine Stabilization and Treatments. John Wiley \& Sons Ltd.

> RIBÉREAU GAYON, P.; DUBOURDIEU, D.; DONÈCHE, B. ; LONVAUD, A. (1998b). Traité d' Oenologie 1. Microbiologie du vin. Vinifications. Ed. Dunod, Paris.

> RIBÉREAU-GAYON, P.; GLORIES, Y.; MAUJEAN. A. Y DUBOURDIEU, D. (2003a). Compuestos fenólicos. Tratado de Enología (volumen 2): Química del vino estabilización y tratamientos. Ed hemisferio sur y ediciones MundiPrensa.1 ed. Buenos Aires, 177-258.

$>$ RIBÉREAU-GAYON, P. y STRONESTREET E. (1965). Le dossage des anthocyanes dans le vin rouge. Bull. Soc. Chim., 9: 119-142.

> RIBEREAU-GAYON, P.; y NEDELTCHEV, N. Discussion et application des methodes modernes de dosage anthocyanes et des tanins dans les vins. Ann. Technol. Agric. 14:321-330 (1965).

$>$ RICARDO DA SILVA, J. M.; ROSEC, J.; BOURZEIX, M.; MOURGUES, J.; MOUTOUNET, M. (1992). Dimer and trimer procyanidins in Carignan and Mourvedre grapes and red wines. Vitis, 31: 55-63.

$>$ RICARDO DA SILVA, J.M.; CHEYNIER, V.; SAMSOM, A.; BOURZEIX, M., (1993). Effect of pomace contact, carbonic maceration, and hyperoxidation on the procyanidin composition of Grenache blanc wines. Am J. En. Vit, 44: 168-172.

$>$ RIVAS-GONZALO, J.C.; BRAVO-HARO, S. Y SANTOS-BUELGA, C. (1995). Detection of compounds formed through the reaction of malvidin 3monoglucoside and catechin in the presence of acetaldehyde. J. Agric. Food Chem., 43, 1444-1449.

> RIVAS-GONZALO, J.; SANTOS BUELGA, C; LOCK, O. (2003). Química y Estabilidad. 26-59. In: Muñoz, O (Ed). Antocianos y Betalainas, colorantes naturales de aplicación industrial CYTED. Editorial Salesianos, Santiago, Chile.

$>$ RIVAS-GONZALO, J.C.; BRAVO-HARO, S.; SANTOS-BUELGA, C. (1995). Detection of compounds formed through the reaction of malvidin 3- 
monoglucoside and catechin in the presence of acetaldehyde. J. Agric. Food Chem., 43, 1444-1449.

$>$ ROBICHAUD, J.L. Y NOBLE, A.C. (1990). Astringency and bitterness of selected phenolic in wine. J. Sci. Food Agric., 53, 343-353.

$>$ ROBINSON, G.M.; ROBINSON, R., 1931. "A survey of anthocyanins". Biochemical Journal, 25, 1687.

$>$ ROIG, G Y YÊRLE, S. (2003). Balance y perspectivas de 10 años de microoxigenación. ACE Enología. www.acenologia.com.

$>$ SACCHI, K.; BISSON, L.; ADAMS, D. (2005). A review of the effect of winemaking techniques on phenolic interaction in red wines. Am. J. Enol. Vitic. 53 (3): 197-206.

$>$ SAINT-CRIQ de GAULEJAC, N.; VIVAS, N.; GLORIES, Y., (1998). Maturation phenolique des raisins rouges. Relation avec la quelite des vins. Comparison des cepages Merlot et Tempranillo. Prog. Agric. Vitic., 115 (1314): 306-318.

> SÁNCHEZ-IGLESIAS, M.; PÉREZ-MAGARIÑO, S.; ORTEGA-HERAS, M.; HERRERA, P.; GONZÁLEZ-HUERTA, C. Y GONZÁLEZ-SANJOSÉ, M.L. (2005). Efecto de la microoxigenación en el color y familias fenólicas de vinos tintos de las D.O. de Castilla y León. XIX Reunión del Grupo de Trabajo de Experimentación en Viticultura y Enología (Leiro), 135-139.

$>$ SANTOS-BUELGA, C. (2001). Sustancias polifenólicas y color del vino tinto. En. Enología avui. Ed. A. Mas. Facultad de Enologia, Tarragona, p. 29-37.

$>$ SANTOS-BUELGA. C.; BRAVO-HARO, S.; RIVAS-GONZALO, J.C. (1995). Interactions between catechin and malvidine-3-monoglucoside $\mathrm{m}$ model solutions. Z Lebensm. Unters.

$>$ SARNI-MANCHADO, P.; FULCRAND, H.; SOUQUET, J.M.; CHEYNIER, V. Y MOUTOUNET, M. (1996). Stability and color of unreported wine anthocyanin-derived pigments. J. Food Sci., 61, 938-941.

$>$ SARNI-MANCHADO, P.; CHEYNIER, V. Y MOUTOUNET, M.; 1999a: Interactions of grape seed tannins with salivary proteins. Journal of Agricultural and Food Chemistry. 47(1): 42-47.

$>$ ARTINI, E.; ARFELli, G.; FABIANI, A.; PIVA, A. (2007). Influence of chips, lees and micro-oxygenation during aging on the phenolic composition of a red Sangiovese wine. Food Chemistry 104: 1599-1604.

$>$ SAUCIER, C. (1997). Les tanins du vin: Etude de leur stabilité colloïdale. Thesis, Université Bordeaux II, Francia.

$>$ SAUCIER, C.; GLORIES, Y.; ROUS, D. (2000). Interactions tanins-colloïdes: nouvelles avances concernant la notion de bons et mauvais tanins. Rev. Oenol. 94:9-10. 
$>$ SAUCIER, C.; GUERRA, C.; PIANET, I.; LAGUERRE, M.; GLORIES, Y. (1997). (+)-catechin-acetaldehyde condensation products $\mathrm{m}$ relation to wine ageing. Phytochemistry. 46, 229-234.

$>$ SCHWARZ, M.; PICAZO-BACETE, J.J.; WINTERHALTER, P.; HERMOSÍNGUTIÉRREZ, I. (2005). Effect of copigments and grape cultivar on the color of red wines fermented after the addition of copigments. J. Agric. Food Chem, 53, $8372-8381$.

$>$ SCHWARZ, M.; WALBNITZ, T.; WINTERHALTER, P. (2003). Pathway leading to the formation of anthocyanin-vinylphenol adducts and related pigments in red wines. J. Agric. Food. Chem. 51, 3682-3687.

$>$ SELlA, J.; ESPINAS, E.; VILLAROYA, A.; MÍNGUEZ, S. (1998). Factores agronómicos que inciden sobre la composición fenólica de la uva. En: Las materias fenólicas del vino. Villafranca del Penedés.

$>$ SILVA, A.; LAMBRI, M.; DE FAVERI, D.M. (2005). Influenza dell'ossigeno in macerazione sulla st5ructura polifenólica e aromatica di vini rossi di qualità. Revue des Oenologues. 251, 22-27.

$>$ SINGLETON, V. (1987). Oxygen with phenols and related reactions in musts, wines, and model systems: Observations and practical implications. Am. J. Enol. Vitic. Vol. 38, 1 (69-77).

$>$ SINGLETON, V.L. (1988).Wine phenolics. In Modern Methods of Plant Analysis, New Series. Vol. 6, Wine Analysis. H.F. Linskens, and J.F. Jackson (Eds.), 180-218. Springer-Verlag, Berlin.

$>$ SingletON, V.L.; ZAYA, J.; TROUSlADE, E., (1986). Compositional changes in ripening grapes: caftaric and coutaric acids. Vitis 25: 107-117.

$>$ SOMERS, T.C. (1971). The polymeric nature of wine pigments. Phytochemistry 10:2175-2186.

$>$ SOMERS, T.C. y EVANS, M. E. (1977).Spectral evaluation of young red wines: Anthocyanin equilibria, total phenols, free and molecular SO2 and chemical age. J. Sci. Food Agric. 28: 279-287.

$>$ SOTOMAYOR, J.P. (1982). Efecto de diferentes grados de ataques de Botrytis en frutos de vid cv. Sauvignonasse sobre las características del vino. Agricultura técnica. Volumen 42. 223-226.

$>$ SOTO-VAZQUEZ, E.; RIO-SEGADE, S.; ORRIOLS-FERNANDEZ, I. (2010). Effect of the winemaking technique on phenolic composition and chromatic characteristics in young red wines. European Food Research and Technology. 321: 789-802.

$>$ SOUQUET, J.; CHEYNIER, V.; BROUSSAUD, F. Y MOUTOUNET, M. (1996). Polymeric proanthocyanidins from grape skins. Phytochemistry, 43, 509-512.

$>$ SUN, B.; RICARDO DA SILVA, J.M.; SPRANGER, I. (1998). Critical Factors of Vanillin Assay for Catechins and Proanthocyanidins. J. Agric. Food Chem. $46,4267-4274$ 
$>$ SUN, J.; CAO, X.; BAI, W.; LIAO, X.; HU, X. (2010). Comparative analysis of copigmentation of cyanidin-3-glucoside and cyaniding-3-saphoroside from red raspberry fruits. Food Chemistry 120: 1131-1137.

$>$ TAO, J.; DYKES, S.; KILMARTIN, P. (2007). Effect of SO2 Concentration on Polyphenol Development during Red Wine Micro oxygenation. J. Agric. Food Chem., 55: 6104-6109.

$>$ THOMAS, C.J.C. Y LAWLESS, H.T. (1995). Astringents subquialities in acid. Chem. Senses. 20(6), 593-600.

$>$ THORNGATE, J.H. AND NOBLE, A.C. (1995) Sensory evaluation of bitterness and astringency of 3R(-)-epicatechin and 3S(+)-catechin. J. Sci. Food Agric, 67, 531-535.

$>$ THORNGATE, J. H. Y SINGLETON, V. L. (1994). Localization of procyanidins in grape seeds. American Journal of Enology and Viticulture, 45, 259-262.

> TIMBERLAKE, C.F. y BRIDLE, P. (1976).Interactions between anthocyanins, phenolic compounds, and acetaldehyde and their significance in red wines. Am. J. Enol. Vitic. 27: 97-105.

$>$ VALLS, J.; LAMPREAVE, M.; NADAL, M.; AROLA, L. (2000). Importancia de los compuestos fenólicos en la calidad de los vinos tintos de crianza. Revista Alimentacion, Equipos y Tecnologia. Marzo 119-124.

$>$ VANHOENACKER, G.; DE VILLIERS, A.; LAZOU, K.; DE KEUKELEIRE, D. Y SANDRA, P. (2001). Comparison of high-performance liquid chromatography-mass spectroscopy and capillary electrophoresis-mass spectroscopy for the analysis of phenolic compounds in diethyl ether extracts of red wine. Chromatographia, 54, 309-315.

$>$ VERSARI, A.; BOULTON, R.; PARPINELLO, G. (2008). A comparision of analytical methods for measuring the color components of red wines. Food Chemistry 397-402.

$>$ VIDAL, J.C.; BOULET, J.C.; MOUTOUNET, M. (2003). Les apports d’oxygène au cours du traitements des vins. Bilan des observations sur site, 2ère partie. Rev. Fr. Oenol., 201, 32-38.

$>$ VIDAL, J.C.; CARTALADE, D.; SOUQUET, J.M.; FULCRAND, H.; CHEYNIER, V. (2002). Changes in proanthocyanidin chain length in winelike model solutions. J. Agric. Food Chem., 50, 2261-2266.

$>$ VIVAR-QUINTANA, A. M.; SANTOS-BUELGA, C. Y RIVAS-GONZALO, C. (2002). Anthocyanin-derived pigments and colour of red wines. Analytica Chimica Acta, 458, 147-155.

$>$ VIVAS, N.; GLORIES, Y.; PIANET, I.; BARBE, B.; LAGUERRE, M. (1996). A complete structural and conformational investigation of procyanidin A2 dimer. Tetrahedron Lett., 37, 2015- 2018. 
$>$ VIVAS, N. Y GLORIES, Y. (1995). Ranking of red wines matured in barrels. A tentative classification of racking techniques. The Australian and New Zealand Wine Industry Journal, 10, 241-243.

$>$ VIVAS, N. (1995). Fenómenos ligados a la maduración de la madera de roble durante su secado. X Cursos Rioja ed. Ayuntamiento de Haro, 94- 109.

$>$ VIVAS, N.; GLORIES, Y.; LAGUNE, L.; SAUCIER, C.; AUGUSTIN, M., (1994). Estimation of the polymerisation level of procyanidins from grapes and winesby use of p-dimethylaminocinnamaldehyde. J. Int. Sci. Vigne Vin, 28: 319-336.

$>$ WATSON, B.T., S.F. PRICE, AND M. VALLADAO. (1995). Effect of fermentation

practices on anthocyanin and phenolic composition of Pinot noir wines. Abstr. Am. J. Enol. Vitic. 46: 404.

$>$ WIGHTMAN, J.; PRICE, S.; WATSON, B. Y WROLSTAD, R. (1997). Some effects of processing enzymes on anthocyanins and phenolics in Pinot noir and Cabernet Sauvignon wines. American Journal of Enology and Viticulture, 48, $39-48$.

$>$ WIRTH, J.; MOREL-SALMI, C.; SOUQUET, J.M.; DIEVAL, J.B.; AAGAARD, O.; VIDAL, S.; FULCRAND, H.; CHEYNIER, V. (2010). The impact of oxygen exposure before and after bottling on the polyphenolic composition of red wines. Food Chemistry 123: 107-116.

$>$ WULF, L.W. Y NAGEL, C.W. (1980). Identification and changes of flavonoids in Merlot and Cabernet Sauvignon wines. J. Food. Sci., 45, 479-484.

$>$ WULF, L.W. y NAGEL, C. W. (1978).High-pressure liquid chromatographic separation of anthocyanins in Vitis vinifera. Am. J. Enol. Vitic. 29:42-49

$>$ YÁNEZ, F.; DUQUE, M.C.; BRAVO DE MINGO, J. (1.998). Riego localizado en el viñedo. En: Reunión Anual del Grupo de Trabajo en Experimentación en Viticultura y Enología. Ministerio de Agricultura, Pesca y Alimentación (Ed.), La Guardia, Álava, pp: 1-18.

$>$ ZAFRILlA, P.; MORILlAS, J.; MULERO, J.; CAYUELA, J. M.; MARTÍNEZ-CACHA, A.; PARDO, F. Y LÓPEZ NICOLÁS, J. M. (2003). Changes during storage in conventional and ecological wine: phenolic content and antioxidant activity. Journal of Agriculture and Food Chemistry, 51, 46944700 .

> ZAMORA, F.; LUENGO, G.; MARGALEF, M.; MAGRIÑA,M.; AROLA,L. (1994). Efecto del sangrado sobre el color del vino tinto. Rev. Esp. Cienc. Tecnol. Aliment. 34, 663-671.

$>$ Zamora, F. (2004). El color del vi. Conferencia. La química y el vi. UB. Barcelona. 14-15 de Decembre.

ZAMORA, F. (2003). "Incidencia de las técnicas de vinificación sobre la extracción y estabilización de la materia colorante en función del grado de madurez de la uva". Cursos de verano Casado del Alisal. Hacia un mejor conocimiento del vino. 
ZAMORA, F. (2003). Elaboración y crianza del vino tinto: Aspectos científicos y prácticos. 21-22. AMV. Ediciones, Madrid.

> ZINI, S., CANUTI, V.; SILIANI, A.; BERTUCCIOLI, M. (2003). Criomacerazione in Toscana: Esperienze sul Sangiovese. Ind. Bev. 32:16-23.

> ZOU, H.; KILMARTIN, P.A.; INGLIS, M.J. Y FROST, A. (2002). Extraction of phenolic compounds during vinification of Pinot Noir examined by HPLC and cyclic voltammetry. Aust. J. Grape Wine Res., 8, 163-174. 


ANEXOS 
Tabla A.1. Valores medios de los parámetros polifenólicos analizados en los vinos de Tempranillo estudiados. PFML Vendimia 2006

\begin{tabular}{|c|c|c|c|c|c|c|c|c|c|c|c|c|c|}
\hline VINO & I. Folin & IC & Tono & $\begin{array}{c}\text { Ant. } \\
\text { Tot(mg/L) }\end{array}$ & $\begin{array}{l}\text { Cateq. } \\
(\mathrm{mg} / \mathrm{L})\end{array}$ & I. Dmach & I. Eth & I.PVPP & $\begin{array}{c}\text { Taninos } \\
(\mathrm{g} / \mathrm{L})\end{array}$ & $\begin{array}{l}\text { \%ANT. } \\
\text { COPIG. }\end{array}$ & $\begin{array}{l}\text { \% ANT. } \\
\text { LIBRES. }\end{array}$ & $\begin{array}{c}\text { \% ANT. } \\
\text { POL. }\end{array}$ & I. Gelatina \\
\hline S/A T & 29,05 & 11,72 & 67,74 & 322,89 & 159,13 & 58,07 & 28,73 & 48,91 & 1,64 & 8,89 & 52,96 & 38,15 & 65,92 \\
\hline ACF T & 31,56 & 11,25 & 67,38 & 333,33 & 167,76 & 56,32 & 28,95 & 47,60 & 1,65 & 20,33 & 45,63 & 34,04 & 62,66 \\
\hline RU T & 30,42 & 11,32 & 68,72 & 343,62 & 163,08 & 58,44 & 32,81 & 46,20 & 1,61 & 18,59 & 50,57 & 30,83 & 57,02 \\
\hline KT T & 30,09 & 11,25 & 66,93 & 326,76 & 190,32 & 55,87 & 27,55 & 45,46 & 1,64 & 17,88 & 48,60 & 33,52 & 61,67 \\
\hline PRO T & 31,33 & 11,09 & 67,66 & 381,62 & 186,97 & 58,95 & 36,99 & 48,48 & 1,57 & 25,49 & 47,81 & 26,70 & 50,46 \\
\hline TAN T & 30,95 & 11,62 & 63,94 & 363,78 & 168,41 & 59,90 & 30,12 & 49,42 & 1,47 & 24,11 & 50,30 & 25,59 & 38,08 \\
\hline S/A Mf & 28,71 & 10,28 & 68,81 & 426,51 & 137,00 & 57,18 & 30,13 & 33,59 & 1,70 & 22,30 & 45,77 & 31,88 & 60,95 \\
\hline ACF Mf & 30,75 & 10,50 & 68,54 & 421,65 & 156,46 & 65,83 & 27,31 & 38,21 & 1,34 & 23,71 & 41,79 & 34,52 & 43,80 \\
\hline RU Mf & 27,68 & 9,83 & 69,14 & 393,59 & 146,48 & 62,06 & 31,21 & 36,53 & 1,48 & 26,14 & 42,32 & 31,29 & 46,28 \\
\hline KT Mf & 29,98 & 10,86 & 70,64 & 466,21 & 184,92 & 58,03 & 29,63 & 36,50 & 1,77 & 25,63 & 42,69 & 31,71 & 43,92 \\
\hline PRO Mf & 31,36 & 11,47 & 71,03 & 465,92 & 176,46 & 55,57 & 29,48 & 36,22 & 1,76 & 27,25 & 40,26 & 32,23 & 32,70 \\
\hline TAN Mf & 29,93 & 11,02 & 69,96 & 481,24 & 187,68 & 50,10 & 26,70 & 36,20 & 1,92 & 31,55 & 41,78 & 26,67 & 35,12 \\
\hline S/A N & 31,63 & 10,40 & 70,79 & 416,02 & 150,43 & 49,02 & 37,83 & 36,48 & 1,83 & 28,64 & 40,36 & 31,01 & 56,34 \\
\hline ACF N & 30,45 & 9,55 & 69,15 & 343,00 & 142,39 & 49,54 & 31,64 & 37,94 & 1,73 & 29,31 & 36,94 & 33,76 & 45,29 \\
\hline RU N & 33,52 & 11,19 & 71,60 & 394,56 & 139,49 & 44,71 & 37,48 & 35,11 & 2,07 & 29,12 & 41,61 & 30,72 & 52,18 \\
\hline KT N & 33,46 & 10,89 & 70,03 & 446,72 & 164,45 & 47,80 & 38,50 & 35,87 & 2,17 & 33,64 & 38,16 & 28,19 & 62,49 \\
\hline PRO N & 33,41 & 10,40 & 69,50 & 451,79 & 155,49 & 70,90 & 33,78 & 35,59 & 1,37 & 34,73 & 38,97 & 26,31 & 38,19 \\
\hline TAN N & 32,16 & 9,94 & 68,95 & 465,30 & 155,24 & 64,91 & 31,67 & 34,07 & 1,47 & 38,22 & 36,92 & 24,74 & 39,89 \\
\hline
\end{tabular}


Tabla A.2. Valores medios de los parámetros polifenólicos analizados en los vinos de Tempranillo estudiados. 6 meses Vendimia 2006

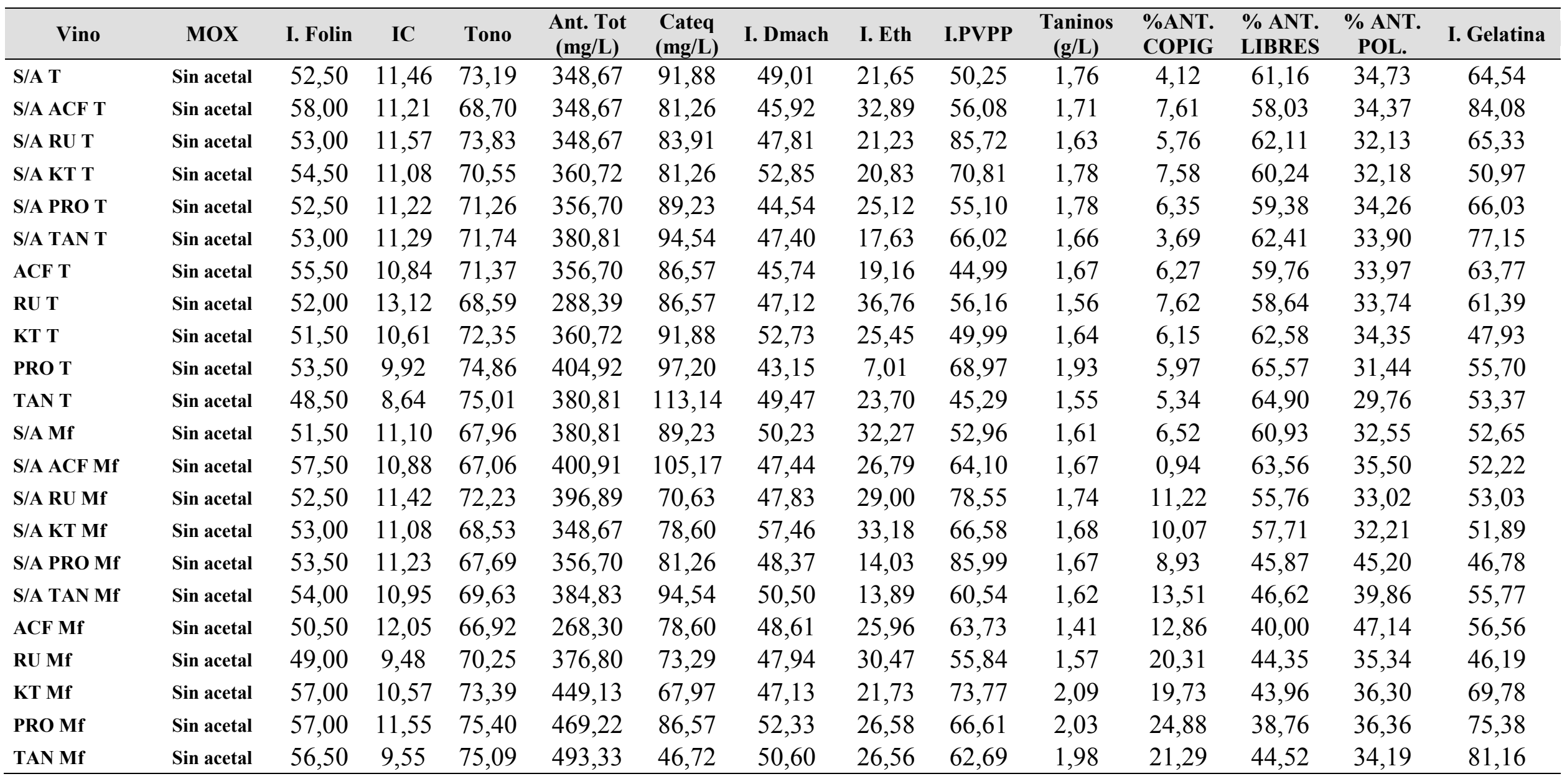


Tabla A.2 (Continuación). Valores medios de los parámetros polifenólicos analizados en los vinos de Tempranillo estudiados. 6 meses Vendimia 2006

\begin{tabular}{|c|c|c|c|c|c|c|c|c|c|c|c|c|c|c|}
\hline Vino & MOX & I. Folin & IC & Tono & $\begin{array}{l}\text { Ant. Tot } \\
\text { (mg/L) }\end{array}$ & $\begin{array}{l}\text { Cateq } \\
(\mathrm{mg} / \mathrm{L})\end{array}$ & I. Dmach & I. Eth & I.PVPP & $\begin{array}{c}\text { Taninos } \\
(\mathrm{g} / \mathrm{L})\end{array}$ & $\begin{array}{l}\text { \% ANT. } \\
\text { COPIG }\end{array}$ & $\begin{array}{l}\% \text { ANT. } \\
\text { LIBRES }\end{array}$ & $\begin{array}{l}\text { \% ANT. } \\
\text { POL. }\end{array}$ & I. Gelatina \\
\hline S/A N & Sin acetal & 52,00 & 9,39 & 73,12 & 416,98 & 54,69 & 46,45 & 18,10 & 66,63 & 1,81 & 19,15 & 43,62 & 37,23 & 67,71 \\
\hline S/A ACF N & Sin acetal & 56,50 & 9,57 & 72,28 & 433,05 & 78,60 & 47,07 & 10,05 & 57,98 & 1,80 & 24,13 & 42,41 & 33,46 & 69,11 \\
\hline S/A KT N & Sin acetal & 53,00 & 9,36 & 73,98 & 421,00 & 99,85 & 60,83 & 25,08 & 52,85 & 1,67 & 18,90 & 44,05 & 37,05 & 68,29 \\
\hline S/A PRO N & Sin acetal & 53,00 & 9,41 & 74,02 & 412,96 & 99,85 & 44,44 & 14,72 & 52,74 & 1,93 & 26,79 & 41,51 & 31,71 & 71,59 \\
\hline S/A TAN N & Sin acetal & 53,00 & 9,47 & 76,08 & 384,83 & 110,48 & 45,92 & 10,76 & 67,50 & 1,79 & 22,84 & 43,21 & 33,95 & 65,72 \\
\hline KT N & Sin acetal & 54,00 & 9,86 & 75,38 & 441,09 & 113,14 & 55,08 & 15,31 & 65,66 & 1,83 & 23,06 & 44,77 & 32,17 & 68,45 \\
\hline PRO N & Sin acetal & 53,50 & 9,07 & 76,89 & 469,22 & 91,88 & 51,28 & 17,64 & 13,75 & 1,79 & 23,84 & 45,55 & 30,60 & 67,89 \\
\hline TAN N & Sin acetal & 49,00 & 6,66 & 79,11 & 517,44 & 78,60 & 49,10 & 29,08 & 87,86 & 1,77 & 24,79 & 44,75 & 30,46 & 66,40 \\
\hline $\mathbf{S} / \mathbf{A} \mathbf{T}$ & Con acetal & 53,00 & 12,16 & 67,96 & 340,63 & 62,66 & 48,62 & 41,67 & 80,76 & 1,86 & 11,55 & 47,97 & 40,48 & 66,25 \\
\hline S/A ACF T & Con acetal & 57,00 & 12,48 & 68,67 & 328,57 & 60,00 & 41,06 & 24,64 & 76,27 & 1,84 & 15,42 & 41,95 & 42,62 & 67,23 \\
\hline S/A RU T & Con acetal & 53,00 & 12,80 & 70,88 & 316,52 & 54,69 & 47,03 & 17,63 & 75,95 & 1,74 & 11,27 & 46,13 & 42,61 & 69,59 \\
\hline RU T & Con acetal & 61,00 & 13,82 & 68,72 & 256,24 & 91,88 & 41,23 & 39,96 & 73,20 & 1,77 & 11,43 & 39,64 & 48,93 & 84,27 \\
\hline KT T & Con acetal & 62,50 & 12,38 & 69,05 & 312,50 & 86,57 & 48,28 & 51,03 & 76,37 & 1,89 & 9,64 & 44,07 & 46,30 & 83,28 \\
\hline PRO T & Con acetal & 65,00 & 11,22 & 68,75 & 376,80 & 36,09 & 39,36 & 37,29 & 66,28 & 1,97 & 12,31 & 48,46 & 39,23 & 80,71 \\
\hline TAN T & Con acetal & 58,50 & 9,03 & 73,93 & 356,70 & 83,91 & 43,93 & 28,88 & 77,15 & 1,71 & 13,54 & 49,52 & 36,94 & 78,81 \\
\hline
\end{tabular}


Tabla A.2 (Continuación). Valores medios de los parámetros polifenólicos analizados en los vinos de Tempranillo estudiados. 6 meses Vendimia 2006

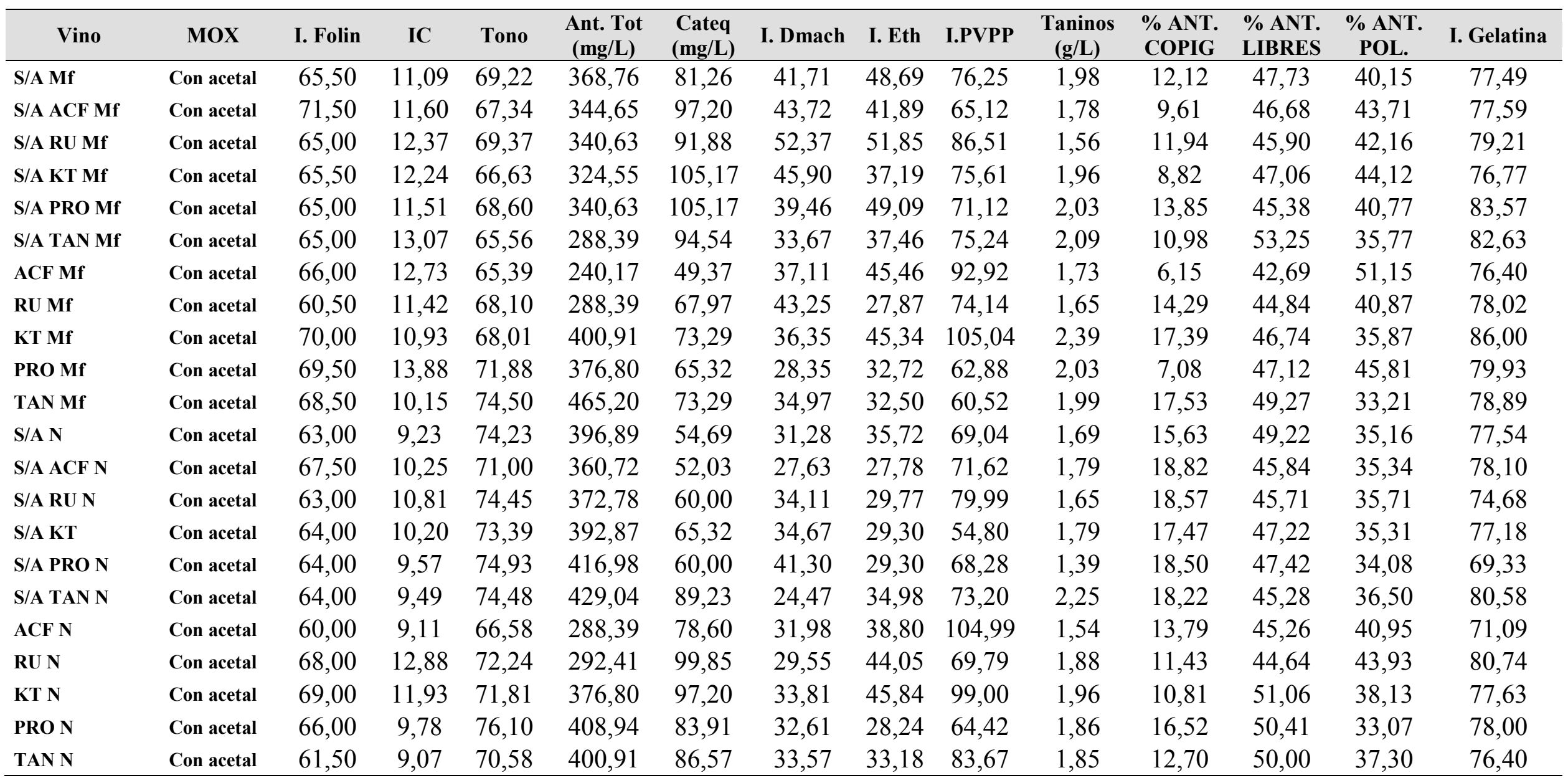


Tabla A.3. Valores medios de los parámetros polifenólicos analizados en los vinos de Tempranillo estudiados. 12 meses Vendimia 2006

\begin{tabular}{|c|c|c|c|c|c|c|c|c|c|c|c|c|c|c|}
\hline Vino & MOX & I. Folin & IC & Tono & $\begin{array}{c}\begin{array}{c}\text { Ant. Tot } \\
(\mathrm{mg} / \mathrm{L})\end{array} \\
\end{array}$ & $\begin{array}{c}\text { Cateq } \\
(\mathrm{mg} / \mathrm{L})\end{array}$ & I. Dmach & I. Eth & I.PVPP & $\begin{array}{c}\text { Taninos } \\
(\mathrm{g} / \mathrm{L})\end{array}$ & $\begin{array}{l}\text { \% ANT. } \\
\text { COPIG }\end{array}$ & $\begin{array}{l}\text { \% ANT. } \\
\text { LIBRES }\end{array}$ & $\begin{array}{c}\text { \% ANT. } \\
\text { POL. }\end{array}$ & I. Gelatina \\
\hline S/A T & Sin acetal & 52,64 & 12,03 & 76,51 & 310,84 & 47,13 & 50,13 & 44,95 & 79,90 & 2,11 & 8,81 & 40,68 & 50,51 & 55,64 \\
\hline S/A ACF T & Sin acetal & 56,48 & 12,63 & 74,41 & 295,58 & 46,70 & 49,44 & 45,22 & 86,34 & 2,13 & 2,78 & 43,64 & 53,58 & 55,07 \\
\hline S/A RU T & Sin acetal & 51,45 & 12,66 & 80,22 & 310,52 & 41,97 & 48,08 & 34,83 & 75,33 & 2,17 & 4,37 & 46,33 & 49,30 & 43,99 \\
\hline S/A KT T & Sin acetal & 53,76 & 12,18 & 76,29 & 312,86 & 51,93 & 61,75 & 30,25 & 79,18 & 2,20 & 4,48 & 44,88 & 50,65 & 45,29 \\
\hline S/A PRO T & Sin acetal & 51,83 & 12,41 & 76,13 & 316,84 & 52,04 & 49,29 & 30,61 & 75,19 & 2,30 & 3,30 & 46,06 & 50,64 & 65,36 \\
\hline S/A TAN T & Sin acetal & 53,64 & 12,39 & 76,21 & 325,75 & 44,59 & 58,57 & 37,52 & 81,40 & 1,95 & 4,48 & 45,94 & 49,58 & 48,04 \\
\hline ACF T & Sin acetal & 57,10 & 11,43 & 76,25 & 348,43 & 54,59 & 55,42 & 38,77 & 82,84 & 2,08 & 2,59 & 45,61 & 51,80 & 49,18 \\
\hline RU T & Sin acetal & 50,48 & 13,08 & 76,27 & 275,98 & 51,09 & 56,67 & 34,64 & 73,73 & 1,86 & 2,91 & 41,14 & 55,95 & 45,98 \\
\hline KT T & Sin acetal & 51,23 & 11,28 & 77,93 & 322,25 & 49,44 & 60,50 & 46,73 & 74,04 & 2,16 & 3,13 & 49,04 & 47,84 & 53,70 \\
\hline PRO T & Sin acetal & 55,60 & 10,70 & 79,17 & 341,99 & 44,16 & 52,94 & 43,30 & 66,63 & 2,21 & 3,01 & 52,60 & 44,39 & 57,62 \\
\hline TAN T & Sin acetal & 48,62 & 8,99 & 81,32 & 331,98 & 51,70 & 53,88 & 53,93 & 77,98 & 1,85 & 2,55 & 54,47 & 42,98 & 41,63 \\
\hline S/A Mf & Sin acetal & 52,97 & 12,17 & 71,64 & 303,30 & 42,07 & 43,96 & 40,06 & 72,62 & 2,01 & 10,21 & 40,93 & 48,86 & 67,38 \\
\hline S/A ACF Mf & Sin acetal & 52,95 & 11,02 & 71,30 & 262,87 & 36,84 & 43,93 & 36,91 & 93,10 & 1,86 & 9,22 & 33,90 & 56,88 & 69,59 \\
\hline S/A RU Mf & Sin acetal & 49,65 & 10,78 & 72,74 & 316,48 & 38,40 & 43,16 & 33,79 & 86,87 & 2,06 & 12,54 & 42,25 & 45,21 & 66,36 \\
\hline S/A KT Mf & Sin acetal & 59,78 & 11,76 & 75,52 & 374,83 & 56,78 & 41,14 & 36,16 & 77,29 & 2,29 & 13,56 & 42,21 & 44,24 & 60,89 \\
\hline S/A PRO Mf & Sin acetal & 55,24 & 12,52 & 76,40 & 403,32 & 49,88 & 40,38 & 30,51 & 69,72 & 2,20 & 9,46 & 46,00 & 44,54 & 58,46 \\
\hline S/A TAN Mf & Sin acetal & 56,40 & 11,05 & 75,35 & 392,79 & 49,66 & 36,56 & 36,63 & 83,36 & 2,38 & 14,08 & 45,49 & 40,43 & 64,59 \\
\hline ACF Mf & Sin acetal & 58,98 & 11,81 & 69,80 & 311,17 & 38,88 & 42,99 & 47,61 & 92,27 & 2,15 & 9,04 & 41,39 & 49,57 & 66,70 \\
\hline RU Mf & Sin acetal & 53,16 & 11,89 & 74,17 & 319,69 & 33,44 & 47,12 & 35,95 & 77,77 & 2,05 & 8,73 & 45,09 & 46,18 & 63,91 \\
\hline KT Mf & Sin acetal & 53,89 & 11,62 & 71,83 & 317,80 & 46,85 & 52,31 & 39,94 & 78,76 & 2,05 & 6,13 & 44,94 & 48,93 & 62,38 \\
\hline PRO Mf & Sin acetal & 50,21 & 11,84 & 70,49 & 293,77 & 39,29 & 45,03 & 26,47 & 61,17 & 2,05 & 3,79 & 46,45 & 49,76 & 62,36 \\
\hline TAN Mf & Sin acetal & 53,70 & 11,68 & 71,70 & 320,42 & 48,38 & 42,97 & 41,69 & 66,94 & 2,19 & 8,64 & 43,77 & 47,59 & 66,15 \\
\hline
\end{tabular}


Tabla A.3 (Continuación). Valores medios de los parámetros polifenólicos analizados en los vinos de Tempranillo estudiados. 12 meses Vendimia 2006

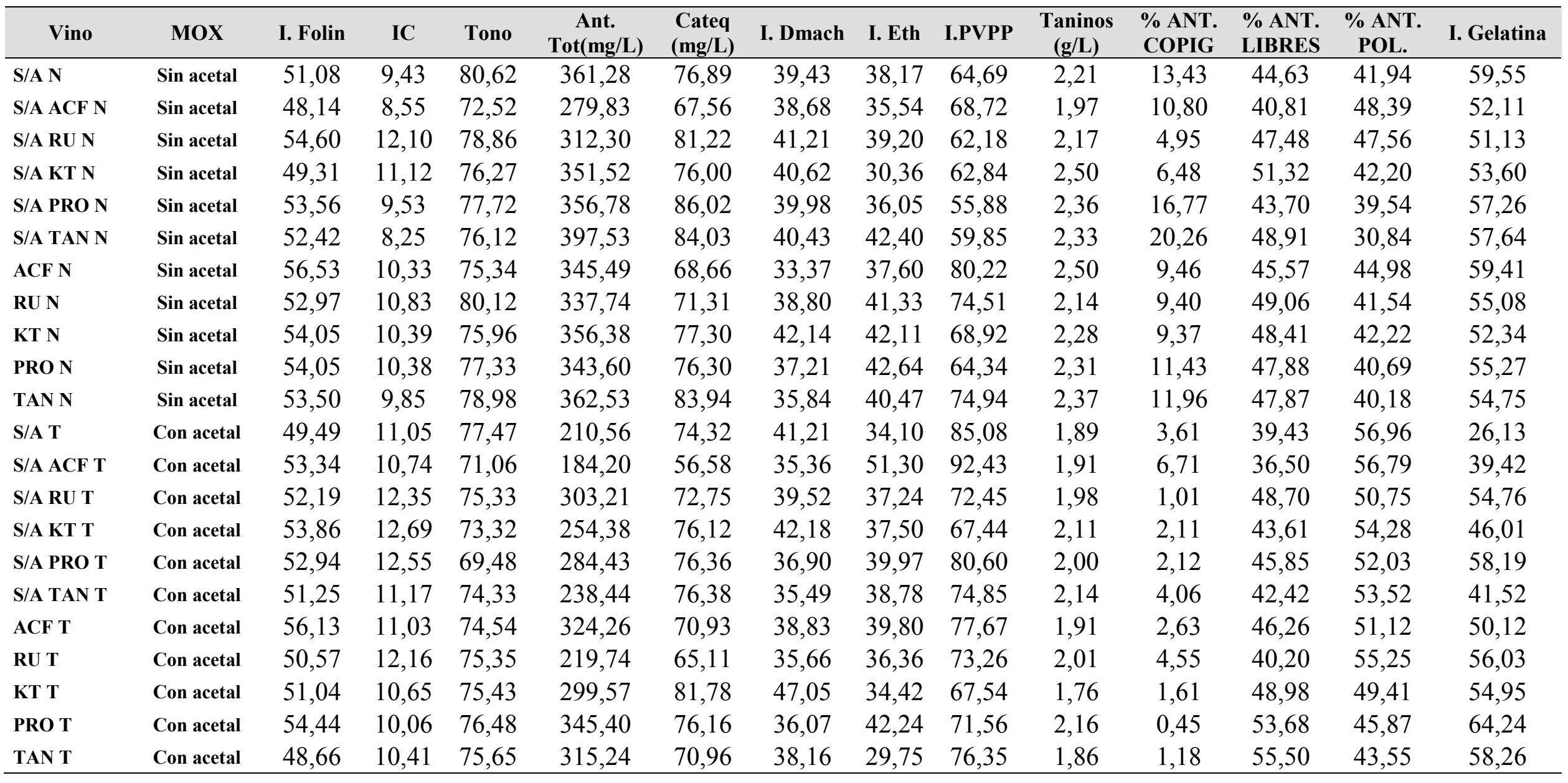


Tabla A.3 (Continuación). Valores medios de los parámetros polifenólicos analizados en los vinos de Tempranillo estudiados. 12 meses Vendimia 2006

\begin{tabular}{|c|c|c|c|c|c|c|c|c|c|c|c|c|c|c|}
\hline Vino & MOX & I. Folin & IC & Tono & $\begin{array}{l}\text { Ant. Tot } \\
\text { (mg/L) }\end{array}$ & $\begin{array}{l}\text { Cateq } \\
(\mathrm{mg} / \mathrm{L})\end{array}$ & I. Dmach & I. Eth & I.PVPP & $\begin{array}{c}\text { Taninos } \\
(\mathrm{g} / \mathrm{L})\end{array}$ & $\begin{array}{l}\text { \% ANT. } \\
\text { COPIG }\end{array}$ & $\begin{array}{l}\text { \% ANT. } \\
\text { LIBRES }\end{array}$ & $\begin{array}{l}\text { \% ANT. } \\
\text { POL. }\end{array}$ & $\begin{array}{c}\text { I. } \\
\text { Gelatina }\end{array}$ \\
\hline S/A Mf & Con acetal & 49,83 & 12,27 & 67,24 & 221,64 & 32,71 & 43,31 & 37,39 & 71,84 & 1,78 & 1,43 & 40,62 & 57,96 & 56,87 \\
\hline S/A ACF Mf & Con acetal & 52,21 & 11,20 & 69,17 & 226,86 & 26,81 & 50,91 & 38,12 & 64,91 & 1,58 & 4,85 & 34,48 & 60,66 & 56,66 \\
\hline S/A RU Mf & Con acetal & 47,56 & 11,49 & 67,20 & 184,27 & 26,48 & 36,35 & 43,49 & 71,94 & 1,73 & 1,94 & 38,63 & 59,60 & 62,50 \\
\hline S/A PRO Mf & Con acetal & 59,27 & 12,47 & 76,34 & 385,15 & 51,23 & 39,35 & 36,90 & 63,31 & 2,21 & 14,09 & 40,93 & 44,99 & 62,08 \\
\hline S/A TAN Mf & Con acetal & 55,57 & 11,40 & 73,91 & 337,13 & 49,31 & 38,76 & 35,11 & 65,55 & 2,14 & 7,63 & 45,63 & 46,73 & 65,50 \\
\hline ACF Mf & Con acetal & 53,93 & 11,82 & 66,20 & 197,61 & 31,66 & 40,85 & 38,23 & 86,99 & 1,93 & 1,15 & 38,78 & 60,07 & 56,44 \\
\hline KT Mf & Con acetal & 52,27 & 12,34 & 68,09 & 241,13 & 38,78 & 46,81 & 33,28 & 57,67 & 2,00 & 2,87 & 40,60 & 56,53 & 60,63 \\
\hline PRO Mf & Con acetal & 50,33 & 12,06 & 68,41 & 234,02 & 39,31 & 42,42 & 36,21 & 62,51 & 1,99 & 4,30 & 38,77 & 56,93 & 56,84 \\
\hline TAN Mf & Con acetal & 48,05 & 11,70 & 66,77 & 171,97 & 33,21 & 36,54 & 39,58 & 77,65 & 1,65 & 1,49 & 35,55 & 62,97 & 49,41 \\
\hline S/A N & Con acetal & 51,96 & 9,86 & 77,47 & 349,51 & 74,32 & 34,99 & 38,41 & 74,16 & 2,21 & 12,76 & 45,39 & 41,86 & 48,48 \\
\hline S/A ACF N & Con acetal & 47,16 & 9,42 & 71,06 & 246,39 & 56,58 & 30,27 & 41,61 & 88,77 & 2,23 & 2,53 & 45,18 & 52,28 & 46,80 \\
\hline S/A RU N & Con acetal & 53,73 & 12,06 & 75,33 & 271,19 & 72,75 & 36,18 & 39,76 & 76,71 & 2,17 & 3,53 & 44,41 & 52,06 & 55,32 \\
\hline RU N & Con acetal & 51,24 & 11,49 & 75,35 & 291,40 & 65,11 & 34,08 & 37,52 & 67,55 & 2,09 & 1,43 & 51,61 & 46,96 & 58,65 \\
\hline KT N & Con acetal & 52,06 & 10,22 & 75,43 & 335,77 & 81,78 & 39,05 & 36,22 & 67,51 & 2,12 & 8,01 & 48,49 & 43,50 & 57,49 \\
\hline PRO N & Con acetal & 52,89 & 9,74 & 76,48 & 343,24 & 76,16 & 36,97 & 39,82 & 77,44 & 2,11 & 9,73 & 47,94 & 42,33 & 56,04 \\
\hline TAN N & Con acetal & 51,91 & 10,61 & 75,65 & 331,23 & 70,96 & 31,05 & 35,60 & 77,00 & 2,27 & 9,67 & 46,67 & 43,66 & 63,59 \\
\hline
\end{tabular}


Tabla A.4. Valores medios de los parámetros polifenólicos analizados en los vinos de Tempranillo estudiados. PFML Vendimia 2007

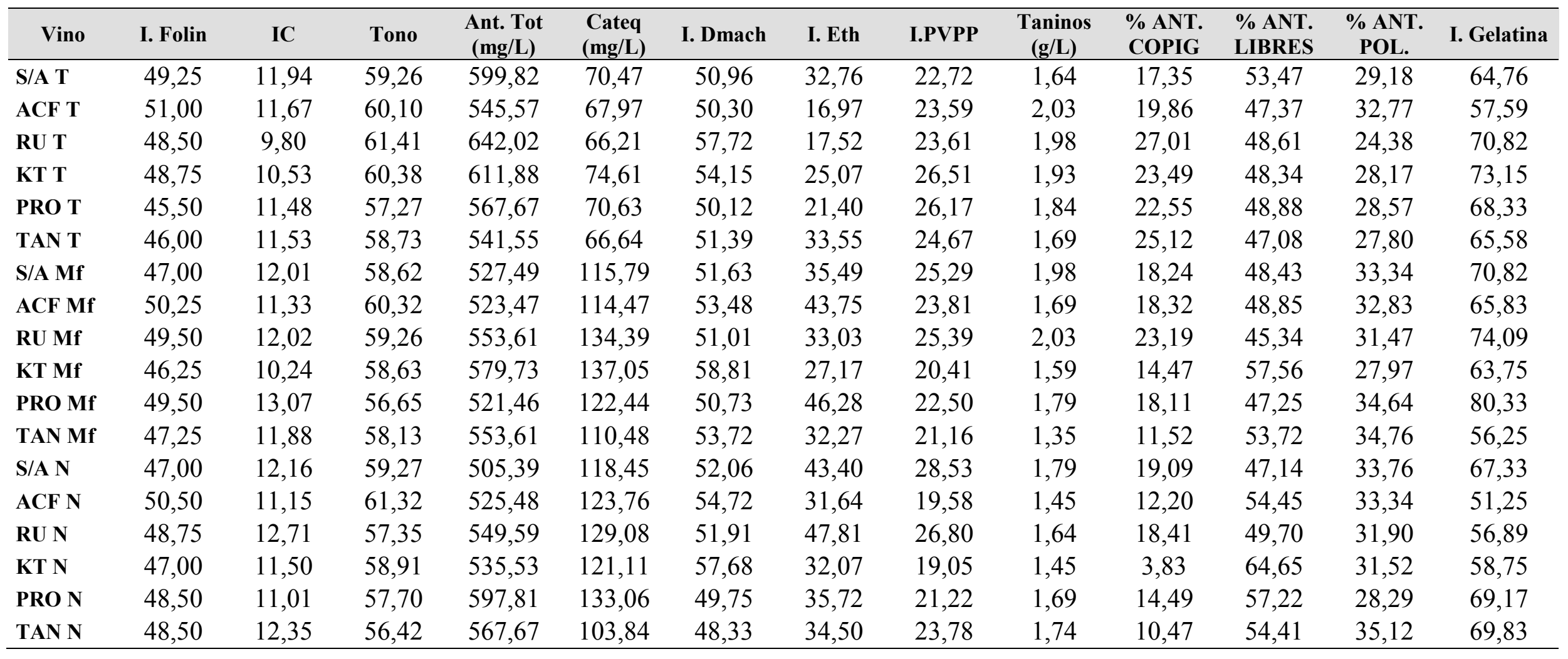


Tabla A.4 (Continuación). Valores medios (mg/L) de los parámetros polifenólicos analizados en los vinos de Tempranillo estudiados. PFML Vendimia 2007

\begin{tabular}{|c|c|c|c|c|c|c|c|c|c|c|c|}
\hline Vinos & Ac fenólicos & 3-flavanoles & Flavonoles & Df-3-glu & Cy-3-glu & Pt-3-glu & Pn-3-glu & Mv-3-glu & Antocianid. & Deriv. de ant & Total ant. \\
\hline RU T & 150,67 & 90,55 & 77,21 & 8,23 & 5,83 & 11,65 & 7,40 & 120,24 & 153,35 & 17,47 & 170,82 \\
\hline PRO T & 159,19 & 79,03 & 87,72 & n.d. & 3,06 & 13,04 & 14,36 & 155,65 & 186,12 & 22,54 & 208,66 \\
\hline TAN T & 156,41 & 62,04 & 96,07 & 8,21 & 4,89 & 15,98 & 12,24 & 122,33 & 163,65 & 17,97 & 181,62 \\
\hline S/A Mf & 147,12 & 93,50 & 72,24 & 18,64 & 3,58 & 16,84 & 16,40 & 95,08 & 150,54 & 29,99 & 180,53 \\
\hline KT Mf & 153,76 & 133,30 & 115,72 & 12,42 & 3,15 & 23,26 & 17,30 & 141,67 & 200,47 & 42,63 & 243,10 \\
\hline PRO Mf & 136,34 & 65,13 & 82,23 & 9,89 & 3,70 & 18,30 & 13,14 & 159,44 & 204,42 & 23,64 & 228,07 \\
\hline TAN Mf & 150,04 & 54,96 & 68,86 & 8,21 & 3,65 & 17,08 & 10,49 & 100,94 & 139,06 & 14,07 & 153,12 \\
\hline S/A N & 137,13 & 99,68 & 114,53 & 16,84 & 3,61 & 22,71 & 17,44 & 170,49 & 230,74 & 34,69 & 265,46 \\
\hline ACF $N$ & 216,44 & 111,93 & 116,63 & 14,82 & 3,18 & 20,68 & 17,88 & 164,36 & 226,03 & 56,26 & 282,29 \\
\hline
\end{tabular}


Tabla A.5. Valores medios de los parámetros polifenólicos analizados en los vinos de Tempranillo estudiados. 6 meses Vendimia 2007

\begin{tabular}{|c|c|c|c|c|c|c|c|c|c|c|c|c|c|c|}
\hline Vino & MOX & I. Folin & IC & Tono & $\begin{array}{l}\text { Ant. Tot } \\
\text { (mg/L) }\end{array}$ & $\begin{array}{c}\text { Cateq } \\
\text { (mg/L) }\end{array}$ & I. Dmach & I. Eth & I.PVPP & $\begin{array}{c}\text { Taninos } \\
(\mathrm{g} / \mathrm{L})\end{array}$ & $\begin{array}{l}\text { \% ANT. } \\
\text { COPIG }\end{array}$ & $\begin{array}{l}\text { \% ANT. } \\
\text { LIBRES }\end{array}$ & $\begin{array}{l}\text { \% ANT. } \\
\text { POL. }\end{array}$ & I. Gelatina \\
\hline S/A T & Sin acetal & 45,32 & 11,50 & 72,70 & 333,26 & 125,86 & 43,52 & 22,58 & 33,39 & 2,14 & 12,17 & 41,87 & 45,96 & 62,15 \\
\hline S/A ACF T & Sin acetal & 49,16 & 12,65 & 68,82 & 301,85 & 111,62 & 41,33 & 20,20 & 33,76 & 2,37 & 11,26 & 38,29 & 51,94 & 65,90 \\
\hline S/A RU T & Sin acetal & 47,41 & 11,47 & 72,50 & 336,05 & 126,02 & 47,97 & 21,82 & 33,03 & 2,18 & 13,25 & 40,02 & 46,73 & 55,77 \\
\hline S/A PRO T & Sin acetal & 46,39 & 12,68 & 69,96 & 301,97 & 118,84 & 46,17 & 18,64 & 32,27 & 2,26 & 11,31 & 43,03 & 48,65 & 66,58 \\
\hline S/A TAN T & Sin acetal & 46,66 & 14,15 & 74,40 & 285,41 & 110,30 & 41,86 & 15,19 & 32,16 & 2,08 & 15,32 & 44,45 & 50,34 & 68,08 \\
\hline KT T & Sin acetal & 46,25 & 11,82 & 70,02 & 329,58 & 101,19 & 44,92 & 30,26 & 32,69 & 2,13 & 13,82 & 42,38 & 43,80 & 68,68 \\
\hline PRO T & Sin acetal & 43,75 & 11,06 & 69,75 & 326,56 & 96,37 & 42,46 & 23,47 & 32,82 & 1,86 & 12,89 & 43,56 & 43,55 & 70,78 \\
\hline TAN T & Sin acetal & 40,72 & 11,97 & 69,36 & 291,08 & 90,70 & 43,75 & 20,74 & 33,70 & 1,88 & 10,38 & 42,31 & 47,31 & 60,30 \\
\hline S/A Mf & Sin acetal & 44,28 & 11,96 & 68,82 & 297,79 & 90,22 & 43,13 & 22,53 & 33,42 & 2,04 & 7,73 & 45,32 & 46,95 & 68,35 \\
\hline S/A ACF Mf & Sin acetal & 49,93 & 12,14 & 65,79 & 271,23 & 91,83 & 42,34 & 25,93 & 36,12 & 2,06 & 8,92 & 40,80 & 50,28 & 71,64 \\
\hline S/A RU Mf & Sin acetal & 45,27 & 12,10 & 72,80 & 294,01 & 95,80 & 43,19 & 22,41 & 33,98 & 2,05 & 9,13 & 45,24 & 45,63 & 72,40 \\
\hline RU Mf & Sin acetal & 43,14 & 13,18 & 69,08 & 273,68 & 118,96 & 43,85 & 25,85 & 34,33 & 2,09 & 12,04 & 38,25 & 49,71 & 78,90 \\
\hline KT Mf & Sin acetal & 43,52 & 10,68 & 71,50 & 293,61 & 130,65 & 47,39 & 23,70 & 33,32 & 2,16 & 9,97 & 41,76 & 48,26 & 72,13 \\
\hline PRO Mf & Sin acetal & 46,07 & 13,49 & 68,57 & 259,13 & 112,70 & 43,15 & 22,09 & 34,39 & 1,80 & 11,36 & 37,87 & 53,77 & 70,10 \\
\hline TAN Mf & Sin acetal & 45,15 & 11,55 & 70,93 & 324,92 & 107,68 & 45,17 & 27,95 & 31,28 & 2,21 & 11,17 & 42,57 & 48,26 & 68,48 \\
\hline
\end{tabular}


Tabla A.5 (Continuación). Valores medios (mg/L) de los parámetros polifenólicos analizados en los vinos de Tempranillo estudiados. 6 meses Año 2007

\begin{tabular}{|c|c|c|c|c|c|c|c|c|c|c|c|c|}
\hline Vino & MOX & Ac fenólicos & 3-flavanoles & Flavonoles & Df-3-glu & Cy-3-glu & Pt-3-glu & Pn-3-glu & Mv-3-glu & Antocianid. & Deriv. de ant & Total ant. \\
\hline $\mathbf{S} / \mathbf{A} \mathbf{T}$ & Sin acetal & 130,39 & 83,76 & 50,07 & 10,70 & 1,83 & 12,38 & 5,29 & 56,13 & 81,04 & 19,13 & 100,17 \\
\hline S/A RU T & Sin acetal & 183,39 & 109,09 & 72,16 & 10,46 & n.d. & 12,25 & 5,29 & 51,34 & 74,05 & 22,25 & 96,30 \\
\hline S/A PRO T & Sin acetal & 132,77 & 70,74 & 62,55 & 9,46 & n.d. & 16,80 & 5,29 & 84,32 & 93,78 & 23,93 & 117,71 \\
\hline S/A TAN T & Sin acetal & 159,28 & 98,28 & 105,75 & 8,80 & n.d. & 10,29 & 5,29 & 46,54 & 65,62 & 20,40 & 86,03 \\
\hline ACF T & Sin acetal & 229,81 & 74,58 & 62,73 & 7,59 & n.d. & 17,26 & 6,48 & 85,46 & 116,79 & 22,94 & 139,73 \\
\hline PRO T & Sin acetal & 150,65 & 75,41 & 73,26 & 6,59 & n.d. & 18,24 & 5,54 & 80,36 & 110,73 & 24,60 & 135,32 \\
\hline TAN T & Sin acetal & 134,21 & 72,15 & 102,73 & 5,64 & 2,46 & 17,69 & 5,31 & 69,54 & 100,64 & 19,34 & 119,98 \\
\hline S/A Mf & Sin acetal & 159,93 & 53,02 & 34,30 & 6,53 & n.d. & 17,79 & 4,48 & 34,82 & 63,61 & 22,31 & 85,92 \\
\hline S/A ACF Mf & Sin acetal & 210,56 & 44,56 & 35,32 & 6,73 & 2,31 & 17,68 & 4,62 & 34,74 & 66,07 & 34,32 & 100,40 \\
\hline S/A RU Mf & Sin acetal & 122,12 & 46,55 & 90,51 & 8,21 & n.d. & 19,25 & 5,19 & 43,01 & 75,66 & 22,96 & 98,62 \\
\hline RU Mf & Sin acetal & 144,56 & 78,62 & 105,23 & 6,49 & n.d. & 18,56 & 5,84 & 78,21 & 109,10 & 21,60 & 130,70 \\
\hline KT Mf & Sin acetal & 146,35 & 85,79 & 59,33 & 7,98 & n.d. & 17,32 & 5,46 & 76,54 & 99,32 & 20,30 & 119,62 \\
\hline PRO Mf & Sin acetal & 143,89 & 92,35 & 63,30 & 7,21 & n.d. & 16,53 & 5,79 & 86,59 & 116,12 & 21,41 & 137,53 \\
\hline TAN Mf & Sin acetal & 144,58 & 89,64 & 67,08 & 6,84 & n.d. & 18,36 & 6,03 & 85,60 & 116,83 & 23,86 & 140,69 \\
\hline
\end{tabular}


Tabla A.5 (Continuación). Valores medios de los parámetros polifenólicos analizados en los vinos de Tempranillo estudiados. 6 meses Vendimia 2007

\begin{tabular}{|c|c|c|c|c|c|c|c|c|c|c|c|c|c|c|}
\hline Vino & MOX & I. Folin & IC & Tono & $\begin{array}{l}\text { Ant. Tot } \\
\text { (mg/L) }\end{array}$ & $\begin{array}{l}\text { Cateq } \\
\text { (mg/L) }\end{array}$ & I. Dmach & I. Eth & I.PVPP & $\begin{array}{c}\text { Taninos } \\
(\mathrm{g} / \mathrm{L})\end{array}$ & $\begin{array}{l}\text { \% ANT. } \\
\text { COPIG }\end{array}$ & $\begin{array}{l}\text { \% ANT. } \\
\text { LIBRES }\end{array}$ & $\begin{array}{l}\text { \% ANT. } \\
\text { POL. }\end{array}$ & I. Gelatina \\
\hline S/A N & Sin acetal & 44,55 & 11,28 & 70,45 & 316,44 & 95,14 & 45,63 & 23,44 & 34,18 & 2,02 & 8,38 & 46,18 & 45,44 & 68,71 \\
\hline S/A ACF N & Sin acetal & 49,72 & 11,51 & 67,30 & 296,14 & 93,24 & 49,42 & 21,31 & 33,32 & 1,92 & 6,11 & 44,29 & 49,60 & 65,39 \\
\hline S/A KT N & Sin acetal & 45,31 & 11,16 & 70,51 & 324,59 & 109,03 & 45,96 & 19,01 & 34,04 & 1,93 & 10,16 & 44,78 & 45,06 & 68,87 \\
\hline S/A PRO N & Sin acetal & 45,37 & 11,11 & 70,30 & 322,59 & 98,04 & 45,13 & 27,43 & 34,84 & 1,87 & 9,67 & 46,09 & 44,24 & 63,31 \\
\hline S/A TAN N & Sin acetal & 44,94 & 11,58 & 74,73 & 318,08 & 90,07 & 51,41 & 30,53 & 34,72 & 1,72 & 12,41 & 45,30 & 42,29 & 70,64 \\
\hline KT N & Sin acetal & 44,48 & 11,18 & 70,52 & 318,12 & 92,98 & 47,73 & 31,94 & 32,83 & 1,67 & 13,76 & 41,99 & 44,25 & 63,15 \\
\hline PRO N & Sin acetal & 43,51 & 12,46 & 68,00 & 304,38 & 103,66 & 48,87 & 24,79 & 31,32 & 2,05 & 12,81 & 40,92 & 50,27 & 70,01 \\
\hline TAN N & Sin acetal & 44,14 & 11,54 & 70,97 & 293,81 & 107,56 & 42,94 & 26,87 & 32,90 & 1,96 & 11,80 & 40,06 & 51,15 & 73,10 \\
\hline $\mathbf{S} / \mathbf{A} \mathbf{T}$ & Con acetal & 45,35 & 14,67 & 70,15 & 314,91 & 91,62 & 41,64 & 28,28 & 33,54 & 2,39 & 10,66 & 37,33 & 64,01 & 63,93 \\
\hline S/A ACF T & Con acetal & 49,60 & 15,05 & 68,53 & 283,41 & 99,22 & 38,90 & 14,84 & 35,62 & 2,08 & 12,21 & 32,94 & 64,85 & 65,22 \\
\hline S/A RU T & Con acetal & 45,92 & 15,05 & 70,06 & 215,26 & 92,39 & 41,82 & 22,30 & 34,92 & 2,20 & 11,88 & 32,50 & 65,62 & 63,09 \\
\hline RU T & Con acetal & 47,28 & 10,12 & 75,55 & 349,51 & 140,66 & 48,56 & 16,83 & 29,58 & 2,60 & 12,37 & 43,98 & 43,65 & 71,02 \\
\hline KT T & Con acetal & 42,63 & 12,46 & 72,19 & 278,70 & 90,58 & 44,69 & 18,89 & 28,40 & 1,84 & 9,98 & 40,57 & 50,95 & 61,90 \\
\hline PRO T & Con acetal & 46,21 & 11,00 & 74,07 & 322,38 & 131,01 & 47,97 & 25,98 & 23,27 & 2,17 & 11,91 & 42,41 & 47,18 & 67,15 \\
\hline TAN T & Con acetal & 43,94 & 12,03 & 70,29 & 280,99 & 109,70 & 48,88 & 26,95 & 26,25 & 1,72 & 15,25 & 42,92 & 49,36 & 61,49 \\
\hline
\end{tabular}


Tabla A.5 (Continuación). Valores medios (mg/L) de los parámetros polifenólicos analizados en los vinos de Tempranillo estudiados. 6 meses Año 2007

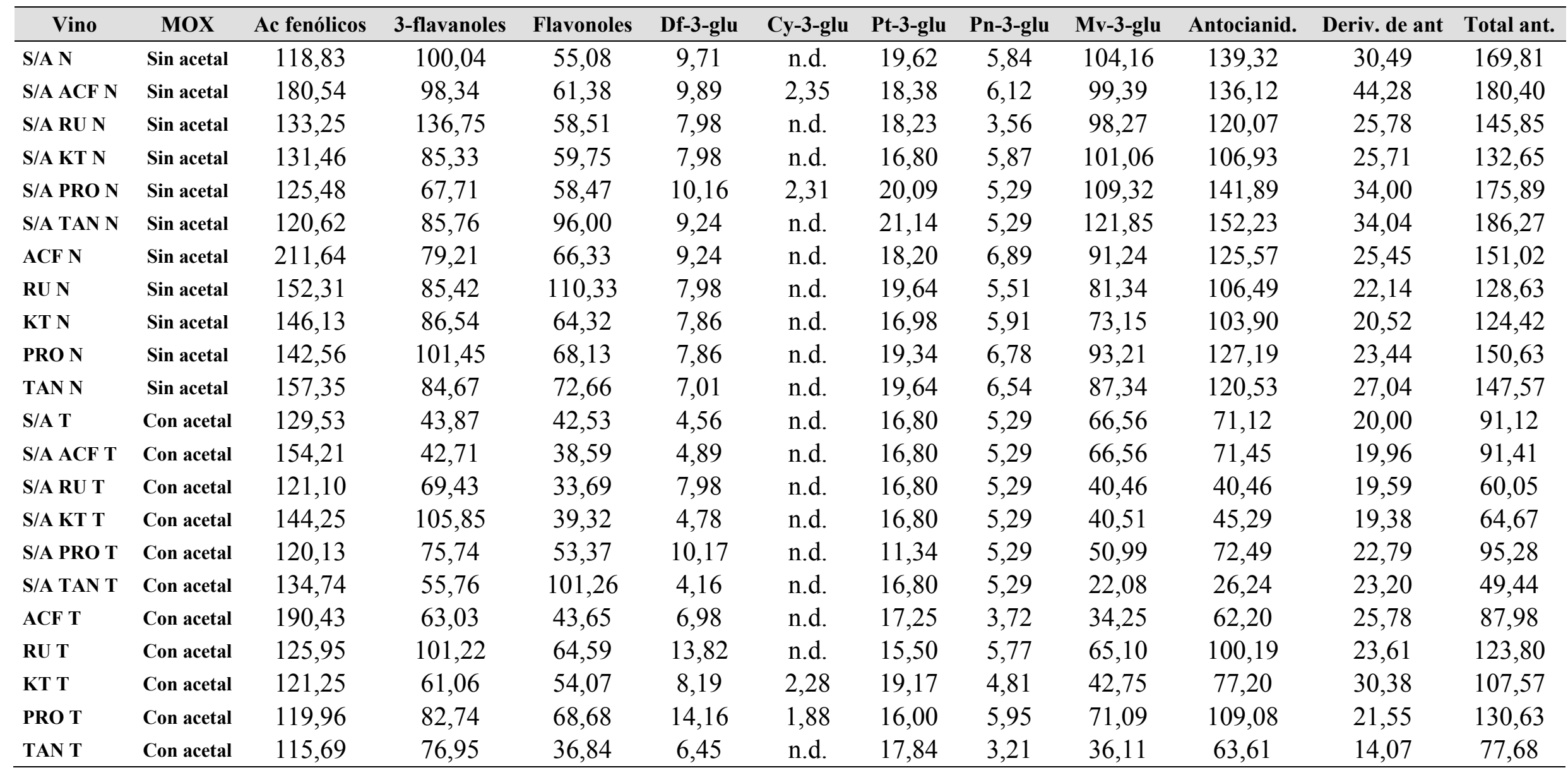


Tabla A.5 (Continuación). Valores medios de los parámetros polifenólicos analizados en los vinos de Tempranillo estudiados. 6 meses Vendimia 2007

\begin{tabular}{|c|c|c|c|c|c|c|c|c|c|c|c|c|c|c|}
\hline Vino & MOX & I. Folin & IC & Tono & $\begin{array}{c}\text { Ant. Tot } \\
\text { (mg/L) }\end{array}$ & $\begin{array}{c}\text { Cateq } \\
(\mathrm{mg} / \mathrm{L})\end{array}$ & I. Dmach & I. Eth & I.PVPP & $\begin{array}{c}\text { Taninos } \\
(\mathrm{g} / \mathrm{L})\end{array}$ & $\begin{array}{l}\text { \% ANT. } \\
\text { COPIG }\end{array}$ & $\begin{array}{l}\text { \% ANT. } \\
\text { LIBRES }\end{array}$ & $\begin{array}{c}\text { \% ANT. } \\
\text { POL. }\end{array}$ & I. Gelatina \\
\hline S/A Mf & Con acetal & 44,21 & 12,32 & 69,00 & 259,82 & 115,16 & 44,09 & 21,04 & 30,99 & 2,02 & 13,13 & 44,55 & 52,32 & 63,41 \\
\hline S/A ACF Mf & Con acetal & 49,62 & 11,91 & 67,43 & 288,71 & 117,83 & 41,64 & 19,09 & 30,62 & 1,89 & 10,01 & 38,46 & 54,53 & 63,70 \\
\hline S/A RU Mf & Con acetal & 44,44 & 12,77 & 73,08 & 274,89 & 106,14 & 43,70 & 22,74 & 28,73 & 1,96 & 10,90 & 41,96 & 50,64 & 65,82 \\
\hline S/A KT Mf & Con acetal & 45,47 & 12,86 & 70,07 & 243,58 & 118,49 & 39,31 & 31,74 & 29,91 & 1,72 & 11,61 & 40,44 & 53,94 & 59,32 \\
\hline S/A PRO Mf & Con acetal & 42,83 & 12,23 & 70,02 & 273,04 & 119,85 & 43,15 & 26,92 & 27,48 & 1,70 & 10,78 & 43,00 & 51,22 & 45,70 \\
\hline S/A TAN Mf & Con acetal & 45,48 & 11,16 & 71,34 & 307,92 & 123,96 & 45,17 & 25,66 & 28,58 & 1,79 & 11,08 & 40,57 & 48,35 & 41,98 \\
\hline KT Mf & Con acetal & 45,45 & 12,87 & 75,95 & 244,22 & 142,38 & 43,10 & 19,94 & 32,96 & 2,07 & 12,33 & 45,33 & 52,34 & 64,64 \\
\hline PRO Mf & Con acetal & 46,46 & 14,10 & 69,53 & 242,78 & 117,92 & 40,45 & 25,71 & 33,91 & 2,24 & 13,72 & 38,45 & 57,83 & 65,33 \\
\hline TAN Mf & Con acetal & 44,93 & 13,58 & 71,57 & 272,03 & 105,70 & 44,44 & 15,91 & 36,45 & 2,40 & 12,78 & 40,62 & 56,60 & 56,95 \\
\hline S/A N & Con acetal & 44,39 & 12,31 & 71,86 & 264,64 & 122,01 & 43,34 & 18,98 & 35,25 & 2,11 & 11,12 & 44,37 & 52,16 & 70,47 \\
\hline S/A ACF N & Con acetal & 49,43 & 13,11 & 68,05 & 271,31 & 122,00 & 43,92 & 19,30 & 37,71 & 2,09 & 11,45 & 39,14 & 57,91 & 50,44 \\
\hline S/A RU N & Con acetal & 44,47 & 12,70 & 76,02 & 286,78 & 132,56 & 45,16 & 22,12 & 32,19 & 2,33 & 11,66 & 45,03 & 50,32 & 72,81 \\
\hline RU N & Con acetal & 43,49 & 14,60 & 67,08 & 208,98 & 102,98 & 40,11 & 20,09 & 25,66 & 1,82 & 13,61 & 37,72 & 58,67 & 58,81 \\
\hline KT N & Con acetal & 44,50 & 11,81 & 72,93 & 301,21 & 109,80 & 42,94 & 20,13 & 32,91 & 2,07 & 12,91 & 46,69 & 50,40 & 71,92 \\
\hline PRO N & Con acetal & 44,96 & 13,93 & 72,60 & 273,64 & 116,49 & 40,93 & 19,87 & 35,61 & 2,18 & 13,55 & 41,79 & 54,66 & 58,94 \\
\hline TAN N & Con acetal & 44,83 & 13,86 & 71,11 & 223,41 & 121,95 & 42,21 & 16,14 & 32,88 & 2,29 & 12,03 & 39,35 & 58,62 & 57,27 \\
\hline
\end{tabular}


Tabla A.5 (Continuación). Valores medios (mg/L) de los parámetros polifenólicos analizados en los vinos de Tempranillo estudiados. 6 meses Año 2007

\begin{tabular}{|c|c|c|c|c|c|c|c|c|c|c|c|c|}
\hline Vino & MOX & Ac fenólicos & 3-flavanoles & Flavonoles & Df-3-glu & Cy-3-glu & Pt-3-glu & Pn-3-glu & Mv-3-glu & Antocianid. & Deriv. de ant & Total ant. \\
\hline S/A Mf & Con acetal & 102,70 & 69,78 & 56,39 & 6,98 & n.d. & 14,76 & 5,69 & 81,83 & 109,26 & 24,46 & 133,72 \\
\hline S/A RU Mf & Con acetal & 146,95 & 85,99 & 111,36 & 6,51 & n.d. & 13,19 & 5,53 & 75,60 & 100,84 & 28,67 & 129,51 \\
\hline S/A PRO Mf & Con acetal & 134,62 & 100,04 & 49,05 & 7,98 & n.d. & 14,09 & 5,46 & 84,07 & 103,61 & 25,38 & 129,00 \\
\hline S/A TAN Mf & Con acetal & 128,82 & 101,25 & 49,07 & 12,82 & 2,11 & 18,56 & 7,10 & 92,49 & 133,09 & 30,54 & 163,63 \\
\hline ACF Mf & Con acetal & 176,96 & 61,59 & 46,07 & 5,64 & n.d. & 16,80 & 5,29 & 14,90 & 20,54 & 21,28 & 41,82 \\
\hline PRO Mf & Con acetal & 119,97 & 81,49 & 51,12 & 5,11 & 1,89 & 12,72 & 4,82 & 30,64 & 55,18 & 12,17 & 67,35 \\
\hline TAN Mf & Con acetal & 132,72 & 67,34 & 46,98 & 6,04 & n.d. & 17,39 & 3,96 & 32,20 & 59,59 & 17,97 & 77,56 \\
\hline S/A N & Con acetal & 126,72 & 100,16 & 50,88 & 9,52 & n.d. & 16,61 & 5,13 & 87,25 & 118,50 & 30,11 & 148,61 \\
\hline S/A ACF N & Con acetal & 160,25 & 98,86 & 50,85 & 8,23 & n.d. & 16,80 & 5,03 & 74,04 & 87,30 & 49,38 & 136,68 \\
\hline S/A RU N & Con acetal & 113,50 & 104,72 & 114,64 & 10,01 & n.d. & 17,66 & 5,73 & 95,17 & 128,58 & 26,09 & 154,67 \\
\hline RU N & Con acetal & 112,97 & 51,30 & 43,63 & 5,89 & n.d. & 12,63 & 4,07 & 11,84 & 34,43 & 17,34 & 51,77 \\
\hline KT N & Con acetal & 123,75 & 87,99 & 51,99 & 10,14 & n.d. & 11,92 & 5,59 & 57,60 & 85,24 & 17,81 & 103,06 \\
\hline PRO N & Con acetal & 112,20 & 68,79 & 49,21 & 5,73 & n.d. & 17,42 & 4,11 & 33,33 & 60,59 & 17,67 & 78,26 \\
\hline TAN N & Con acetal & 146,67 & 81,25 & 54,23 & 4,68 & n.d. & 19,22 & 5,29 & 52,63 & 76,52 & 30,53 & 107,06 \\
\hline
\end{tabular}


Tabla A.6. Valores medios de los parámetros polifenólicos analizados en los vinos de Tempranillo estudiados. 12 meses Vendimia 2007

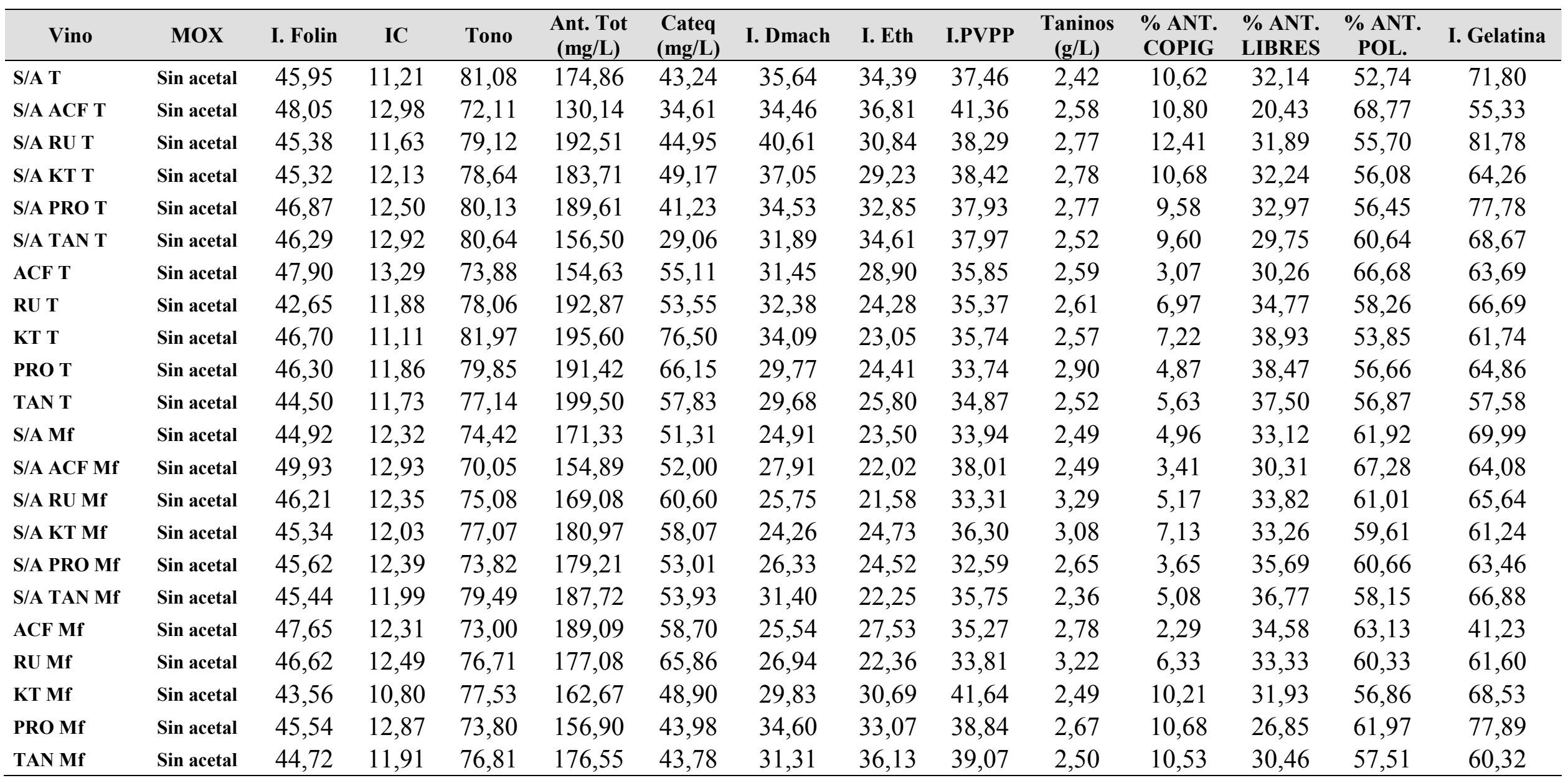


Tabla A.6 (Continuación). Valores medios (mg/L) de los parámetros polifenólicos analizados en los vinos de Tempranillo estudiados. 12 meses Año 2007

\begin{tabular}{|c|c|c|c|c|c|c|c|c|c|c|c|c|}
\hline Vino & MOX & Ac fenolicos & 3-flavanoles & Flavonoles & Df-3-glu & Сy-3-glu & Pt-3-glu & Pn-3-glu & Mv-3-glu & Antocianid. & Deriv. de ant & Total ant. \\
\hline $\mathbf{S} / \mathbf{A} \mathbf{T}$ & Sin acetal & 112,73 & 52,27 & 44,55 & 7,11 & n.d. & 9,67 & 3,58 & 20,40 & 40,76 & 17,18 & 57,94 \\
\hline S/A RU T & Sin acetal & 119,71 & 58,59 & 41,36 & 0,00 & n.d. & 9,42 & 3,67 & 19,24 & 28,66 & 15,20 & 43,86 \\
\hline S/A PRO T & Sin acetal & 109,48 & 55,50 & 31,75 & 0,00 & n.d. & 9,12 & 3,67 & 17,78 & 26,90 & 10,25 & 37,15 \\
\hline S/A TAN T & Sin acetal & 99,88 & 62,00 & 34,70 & 0,00 & n.d. & 9,32 & 3,67 & 18,41 & 27,73 & 13,58 & 41,31 \\
\hline ACF T & Sin acetal & 147,43 & 63,30 & 49,04 & 6,83 & n.d. & 9,64 & 4,13 & 19,90 & 40,50 & 18,27 & 58,77 \\
\hline PRO T & Sin acetal & 116,86 & 55,91 & 44,40 & 6,94 & n.d. & 9,73 & 3,57 & 21,83 & 42,07 & 16,12 & 58,19 \\
\hline TAN T & Sin acetal & 120,04 & 65,84 & 54,27 & 7,33 & 1,75 & 10,65 & 3,95 & 25,26 & 48,95 & 20,47 & 69,41 \\
\hline S/A Mf & Sin acetal & 118,14 & 69,54 & 52,77 & 6,99 & 1,62 & 10,08 & 3,75 & 24,21 & 46,64 & 21,11 & 67,75 \\
\hline S/A ACF Mf & Sin acetal & 163,62 & 71,60 & 54,38 & 7,21 & n.d. & 10,47 & 3,92 & 24,74 & 46,34 & 21,58 & 67,92 \\
\hline S/A RU Mf & Sin acetal & 119,45 & 79,73 & 61,82 & 7,30 & n.d. & 10,43 & 3,72 & 25,98 & 47,42 & 20,43 & 67,85 \\
\hline RU Mf & Sin acetal & 120,22 & 66,10 & 61,81 & 6,98 & n.d. & 10,02 & 3,68 & 24,59 & 45,27 & 17,85 & 63,12 \\
\hline KT Mf & Sin acetal & 110,48 & 62,80 & 51,73 & 6,89 & n.d. & 9,60 & 3,81 & 21,30 & 41,59 & 18,69 & 60,28 \\
\hline PRO Mf & Sin acetal & 117,36 & 62,91 & 46,29 & 7,27 & 1,93 & 10,58 & 3,55 & 21,68 & 34,43 & 16,69 & 51,13 \\
\hline TAN Mf & Sin acetal & 116,26 & 66,66 & 61,46 & 6,94 & n.d. & 10,07 & 4,06 & 23,76 & 44,83 & 20,42 & 65,25 \\
\hline
\end{tabular}


Tabla A.6 (Continuación). Valores medios de los parámetros polifenólicos analizados en los vinos de Tempranillo estudiados. 12 meses Vendimia 2007

\begin{tabular}{|c|c|c|c|c|c|c|c|c|c|c|c|c|c|c|}
\hline Vino & MOX & I. Folin & IC & Tono & $\begin{array}{c}\text { Ant. Tot } \\
(\mathrm{mg} / \mathrm{L})\end{array}$ & $\begin{array}{c}\text { Cateq } \\
(\mathrm{mg} / \mathrm{L})\end{array}$ & $\begin{array}{c}\text { I. } \\
\text { Dmach }\end{array}$ & I. Eth & $\begin{array}{c}\text { I.PVP } \\
\text { P }\end{array}$ & $\begin{array}{c}\text { Taninos } \\
(\mathrm{g} / \mathrm{L})\end{array}$ & $\begin{array}{l}\text { \% ANT. } \\
\text { COPIG }\end{array}$ & $\begin{array}{l}\text { \% ANT. } \\
\text { LIBRES }\end{array}$ & $\begin{array}{l}\text { \% ANT. } \\
\text { POL. }\end{array}$ & I. Gelatina \\
\hline S/A N & Sin acetal & 44,32 & 10,74 & 79,60 & 193,68 & 60,47 & 33,57 & 24,08 & 34,77 & 2,38 & 7,37 & 38,38 & 54,24 & 64,40 \\
\hline S/A ACF N & Sin acetal & 51,15 & 11,83 & 71,26 & 182,74 & 62,59 & 33,54 & 24,08 & 37,58 & 2,46 & 4,72 & 31,03 & 64,25 & 62,71 \\
\hline S/A RU N & Sin acetal & 45,15 & 11,01 & 81,78 & 242,42 & 62,19 & 35,99 & 23,61 & 35,10 & 2,77 & 5,44 & 40,96 & 53,59 & 54,46 \\
\hline S/A KT N & Sin acetal & 46,32 & 10,92 & 77,96 & 210,35 & 71,13 & 33,78 & 23,84 & 37,72 & 2,61 & 5,78 & 38,14 & 56,08 & 74,55 \\
\hline S/A PRO N & Sin acetal & 45,82 & 11,01 & 77,87 & 219,67 & 61,58 & 31,96 & 23,27 & 36,06 & 2,42 & 6,05 & 39,42 & 54,53 & 67,30 \\
\hline S/A TAN N & Sin acetal & 46,04 & 10,83 & 78,40 & 227,67 & 65,20 & 33,03 & 23,25 & 35,62 & 2,38 & 7,49 & 38,27 & 54,24 & 59,27 \\
\hline KT N & Sin acetal & 44,60 & 11,63 & 77,66 & 192,43 & 57,23 & 24,23 & 29,43 & 37,00 & 2,24 & 4,05 & 38,20 & 57,75 & 58,47 \\
\hline PRO N & Sin acetal & 44,39 & 11,87 & 73,70 & 182,10 & 43,16 & 36,58 & 37,39 & 40,47 & 2,49 & 9,79 & 30,68 & 58,53 & 46,09 \\
\hline TAN N & Sin acetal & 48,58 & 12,21 & 75,39 & 166,06 & 34,06 & 32,65 & 41,57 & 38,52 & 2,61 & 10,53 & 28,64 & 59,83 & 66,23 \\
\hline $\mathbf{S} / \mathbf{A} \mathbf{T}$ & Con acetal & 45,60 & 11,60 & 78,30 & 187,22 & 73,50 & 31,82 & 22,53 & 41,48 & 2,68 & 7,01 & 36,87 & 56,12 & 59,62 \\
\hline S/A ACF T & Con acetal & 44,44 & 10,95 & 71,63 & 112,10 & 39,97 & 28,17 & 28,13 & 46,23 & 2,44 & 2,33 & 24,50 & 73,17 & 51,74 \\
\hline S/A RU T & Con acetal & 39,16 & 10,34 & 79,00 & 119,45 & 36,98 & 24,65 & 31,64 & 45,49 & 2,39 & 1,90 & 27,05 & 71,05 & 47,85 \\
\hline RU T & Con acetal & 39,13 & 11,07 & 74,80 & 117,52 & 25,38 & 33,51 & 36,69 & 41,23 & 2,24 & 8,21 & 25,68 & 66,11 & 53,90 \\
\hline KT T & Con acetal & 46,72 & 12,22 & 77,41 & 122,95 & 43,37 & 36,33 & 38,74 & 38,58 & 2,66 & 6,67 & 28,10 & 65,22 & 77,69 \\
\hline PRO T & Con acetal & 46,17 & 11,92 & 79,66 & 168,40 & 57,48 & 35,37 & 36,30 & 38,87 & 2,66 & 9,26 & 31,82 & 58,93 & 76,16 \\
\hline TAN T & Con acetal & 44,25 & 10,36 & 80,23 & 201,43 & 49,57 & 35,57 & 36,64 & 40,31 & 2,49 & 12,30 & 34,75 & 52,95 & 71,93 \\
\hline
\end{tabular}


Tabla A.6 (Continuación). Valores medios (mg/L) de los parámetros polifenólicos analizados en los vinos de Tempranillo estudiados. 12 meses Año 2007

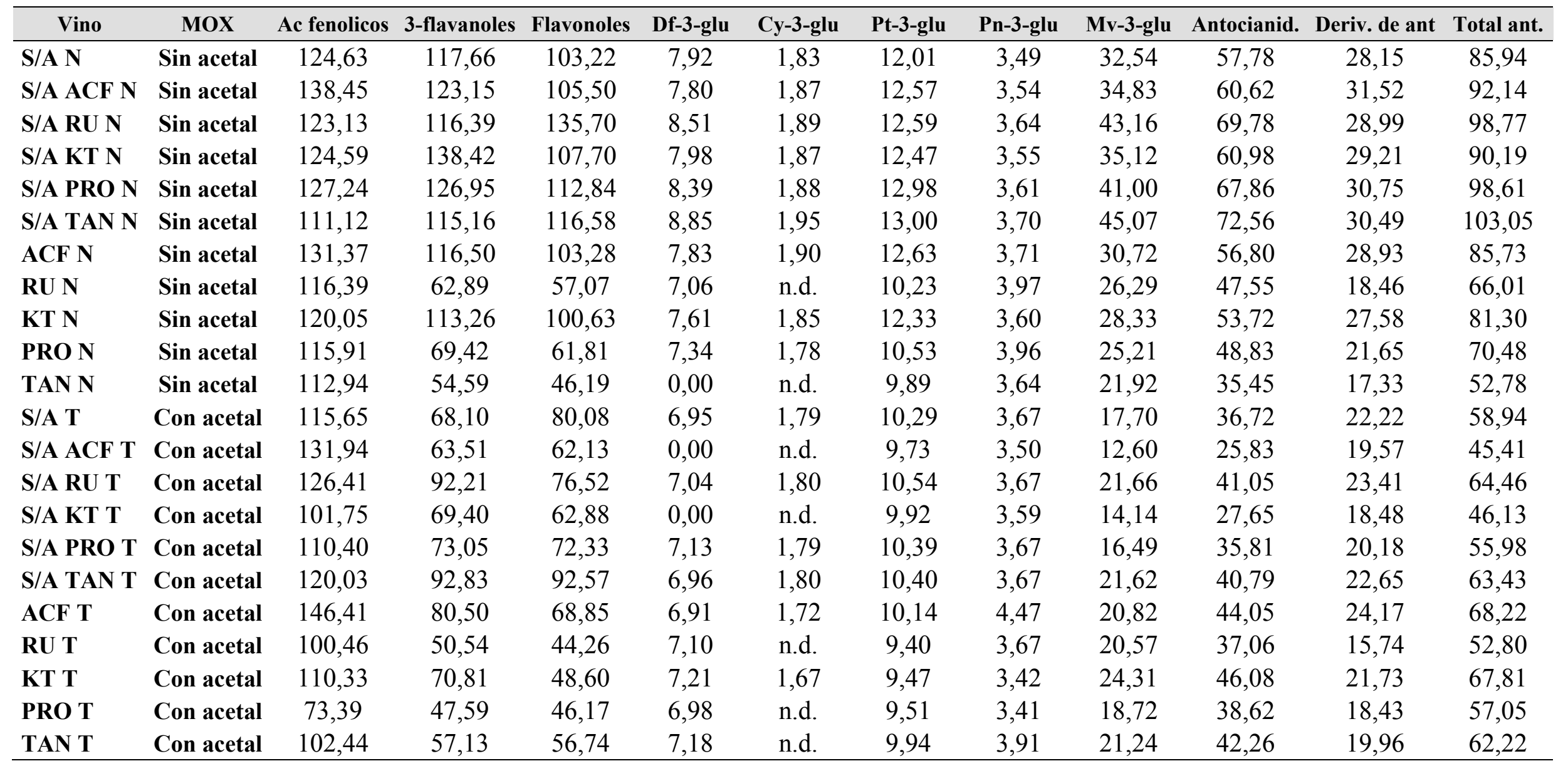


Tabla A.6 (Continuación). Valores medios de los parámetros polifenólicos analizados en los vinos de Tempranillo estudiados. 12 meses Vendimia 2007

\begin{tabular}{|c|c|c|c|c|c|c|c|c|c|c|c|c|c|c|}
\hline Vino & MOX & I. Folin & IC & Tono & $\begin{array}{c}\text { Ant. Tot } \\
\text { (mg/L) }\end{array}$ & $\begin{array}{l}\text { Cateq } \\
(\mathrm{mg} / \mathrm{L})\end{array}$ & I. Dmach & I. Eth & $\begin{array}{c}\text { I.PVP } \\
\text { P }\end{array}$ & $\begin{array}{c}\text { Taninos } \\
(\mathrm{g} / \mathrm{L})\end{array}$ & $\begin{array}{l}\text { \% ANT. } \\
\text { COPIG }\end{array}$ & $\begin{array}{l}\text { \% ANT. } \\
\text { LIBRES }\end{array}$ & $\begin{array}{c}\text { \% ANT. } \\
\text { POL. }\end{array}$ & I. Gelatina \\
\hline S/A Mf & Con acetal & 43,25 & 11,03 & 76,25 & 154,57 & 47,17 & 38,63 & 35,78 & 39,05 & 2,82 & 9,57 & 30,46 & 59,97 & 40,42 \\
\hline S/A ACF Mf & Con acetal & 47,52 & 12,25 & 71,18 & 133,64 & 51,20 & 33,73 & 35,77 & 43,19 & 2,69 & 8,81 & 23,82 & 67,38 & 40,93 \\
\hline S/A KT Mf & Con acetal & 42,53 & 11,85 & 77,33 & 127,89 & 50,28 & 37,05 & 38,58 & 41,14 & 2,42 & 6,59 & 28,61 & 64,81 & 34,54 \\
\hline S/A PRO Mf & Con acetal & 44,61 & 12,09 & 78,48 & 143,16 & 61,04 & 34,57 & 36,65 & 40,87 & 2,74 & 8,17 & 28,79 & 63,04 & 66,05 \\
\hline S/A TAN Mf & Con acetal & 45,84 & 11,24 & 81,85 & 171,77 & 72,82 & 37,28 & 25,52 & 42,11 & 2,53 & 8,32 & 33,46 & 58,23 & 53,60 \\
\hline KT Mf & Con acetal & 40,31 & 10,85 & 74,18 & 126,44 & 48,73 & 26,45 & 27,79 & 43,59 & 2,50 & 5,21 & 25,44 & 69,35 & 54,00 \\
\hline PRO Mf & Con acetal & 46,14 & 11,93 & 76,54 & 236,87 & 69,14 & 32,40 & 20,32 & 43,23 & 2,80 & 6,00 & 34,61 & 59,39 & 55,62 \\
\hline TAN Mf & Con acetal & 40,42 & 11,62 & 73,23 & 124,92 & 37,40 & 26,53 & 32,22 & 46,92 & 2,39 & 3,04 & 24,46 & 72,51 & 54,78 \\
\hline $\mathbf{S} / \mathbf{A} \mathbf{N}$ & Con acetal & 44,37 & 10,94 & 78,55 & 185,31 & 72,80 & 33,34 & 25,23 & 44,23 & 2,90 & 7,77 & 35,30 & 56,93 & 65,46 \\
\hline S/A ACF N & Con acetal & 46,73 & 12,13 & 70,82 & 171,29 & 60,23 & 33,39 & 24,96 & 45,72 & 2,84 & 1,61 & 29,79 & 68,60 & 59,00 \\
\hline S/A RU N & Con acetal & 43,85 & 11,48 & 80,09 & 215,65 & 59,06 & 33,80 & 24,59 & 45,71 & 2,53 & 6,14 & 32,41 & 61,46 & 55,86 \\
\hline RU N & Con acetal & 44,82 & 12,48 & 74,77 & 131,75 & 37,45 & 34,91 & 35,24 & 39,39 & 2,65 & 9,75 & 24,50 & 65,75 & 9,01 \\
\hline KT N & Con acetal & 42,94 & 12,14 & 77,15 & 173,66 & 55,79 & 32,84 & 30,20 & 43,81 & 2,63 & 2,12 & 33,76 & 64,12 & 54,68 \\
\hline PRO N & Con acetal & 42,25 & 11,96 & 72,63 & 158,75 & 40,65 & 31,81 & 30,53 & 45,56 & 2,51 & 2,75 & 30,48 & 66,77 & 50,24 \\
\hline TAN N & Con acetal & 42,30 & 12,04 & 72,28 & 155,34 & 52,71 & 31,82 & 25,56 & 43,74 & 2,45 & 2,29 & 29,03 & 68,68 & 45,62 \\
\hline
\end{tabular}


Tabla A.6 (Continuación). Valores medios (mg/L) de los parámetros polifenólicos analizados en los vinos de Tempranillo estudiados. 12 meses Año 2007

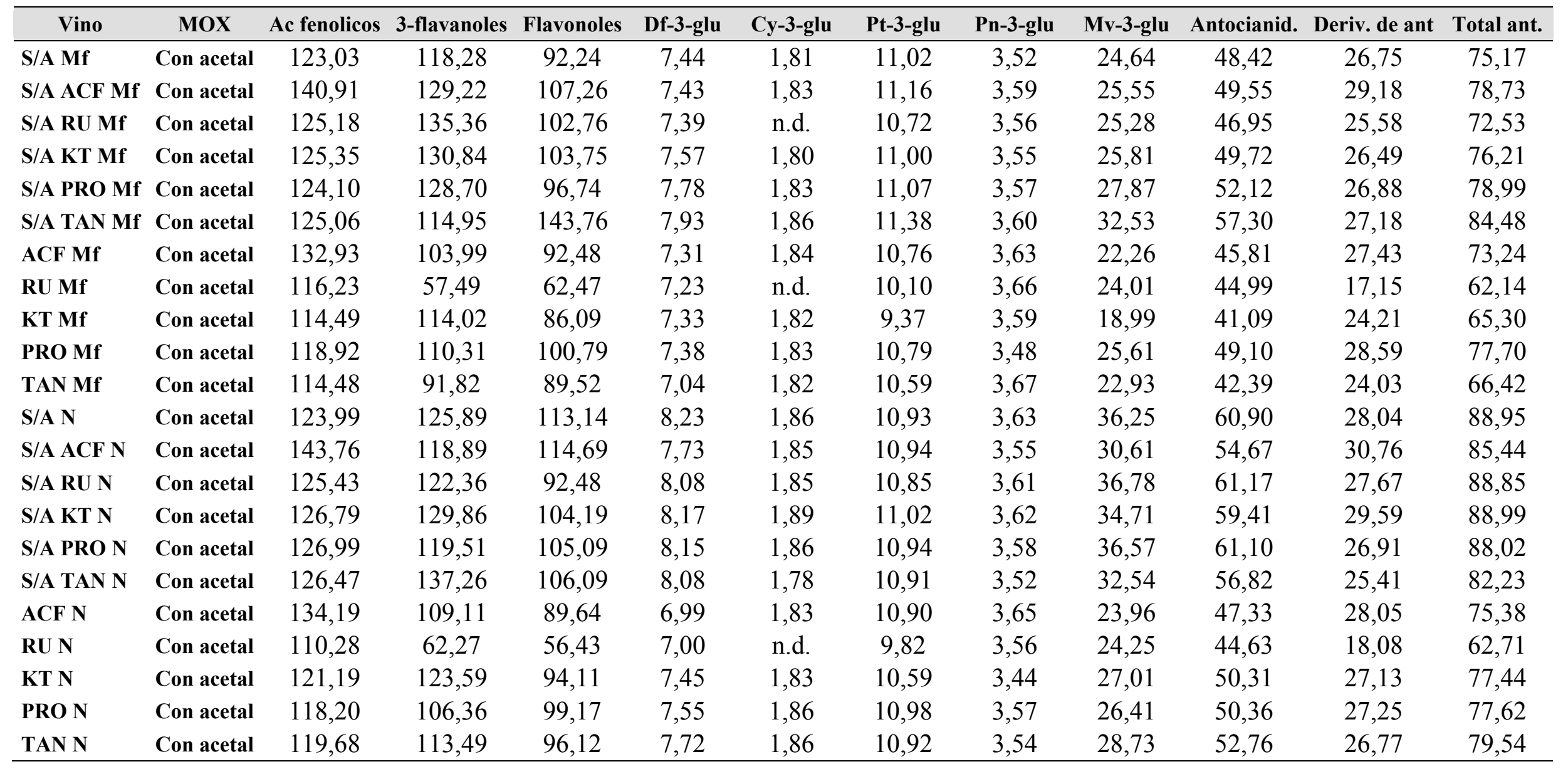


Tabla A.7. Valores medios de los parámetros polifenólicos analizados en los vinos de Tempranillo estudiados. PFML Vendimia 2008

\begin{tabular}{|c|c|c|c|c|c|c|c|c|c|c|c|c|c|}
\hline Vinos & I. Folin & IC & Tono & $\begin{array}{l}\text { Ant. Tot } \\
\text { (mg/L) }\end{array}$ & $\begin{array}{l}\text { Cateq } \\
\text { (mg/L) }\end{array}$ & I. Dmch & I. Eth & I.PVPP & Taninos & $\begin{array}{l}\text { \% ANT. } \\
\text { COPIG }\end{array}$ & $\begin{array}{l}\text { \% ANT. } \\
\text { LIBRES }\end{array}$ & $\begin{array}{l}\text { \% ANT. } \\
\text { POL. }\end{array}$ & I. Gelatina \\
\hline S/A T & 40,27 & 11,41 & 73,15 & 489,94 & 167,49 & 53,07 & 10,72 & 15,60 & 1,66 & 26,55 & 47,51 & 25,95 & 41,54 \\
\hline ACF T & 39,09 & 12,67 & 64,05 & 356,40 & 150,16 & 63,96 & 11,97 & 23,51 & 1,23 & 19,50 & 44,93 & 35,57 & 36,20 \\
\hline RU T & 40,40 & 11,55 & 72,44 & 444,19 & 198,02 & 55,24 & 9,38 & 17,23 & 1,46 & 30,41 & 41,85 & 27,74 & 54,40 \\
\hline KT T & 38,40 & 11,73 & 68,79 & 405,43 & 173,46 & 66,95 & 7,71 & 20,97 & 1,21 & 26,76 & 45,43 & 27,82 & 34,60 \\
\hline PRO T & 35,50 & 10,54 & 73,49 & 424,13 & 142,75 & 58,33 & 10,90 & 19,35 & 1,11 & 32,44 & 42,22 & 25,34 & 40,28 \\
\hline TAN T & 39,42 & 11,46 & 72,14 & 422,16 & 187,92 & 55,36 & 10,65 & 19,39 & 1,36 & 29,46 & 42,24 & 28,30 & 54,46 \\
\hline RU Mf & 40,56 & 11,44 & 72,43 & 375,19 & 185,63 & 48,53 & 16,20 & 17,04 & 1,67 & 24,84 & 44,71 & 30,45 & 53,83 \\
\hline KT Mf & 39,43 & 10,48 & 71,96 & 404,94 & 208,14 & 54,61 & 8,75 & 13,21 & 1,71 & 26,44 & 44,46 & 29,10 & 60,25 \\
\hline PRO Mf & 39,99 & 11,68 & 70,52 & 366,41 & 180,42 & 44,68 & 7,39 & 12,43 & 1,71 & 23,19 & 46,42 & 30,40 & 57,06 \\
\hline TAN Mf & 39,05 & 11,10 & 72,59 & 406,49 & 161,18 & 48,00 & 5,92 & 12,64 & 1,66 & 25,47 & 45,12 & 29,41 & 37,31 \\
\hline S/A N & 41,98 & 11,79 & 71,98 & 421,41 & 182,41 & 53,33 & 8,96 & 15,47 & 1,58 & 24,85 & 44,21 & 32,90 & 54,98 \\
\hline ACF N & 40,86 & 11,41 & 71,82 & 433,15 & 169,96 & 53,05 & 8,69 & 16,02 & 1,33 & 23,91 & 39,06 & 28,40 & 42,34 \\
\hline
\end{tabular}


Tabla A.7. (Continuacion). Valores medios (mg/L) de los parámetros polifenólicos analizados en los vinos de Tempranillo estudiados. PFML Año 2008

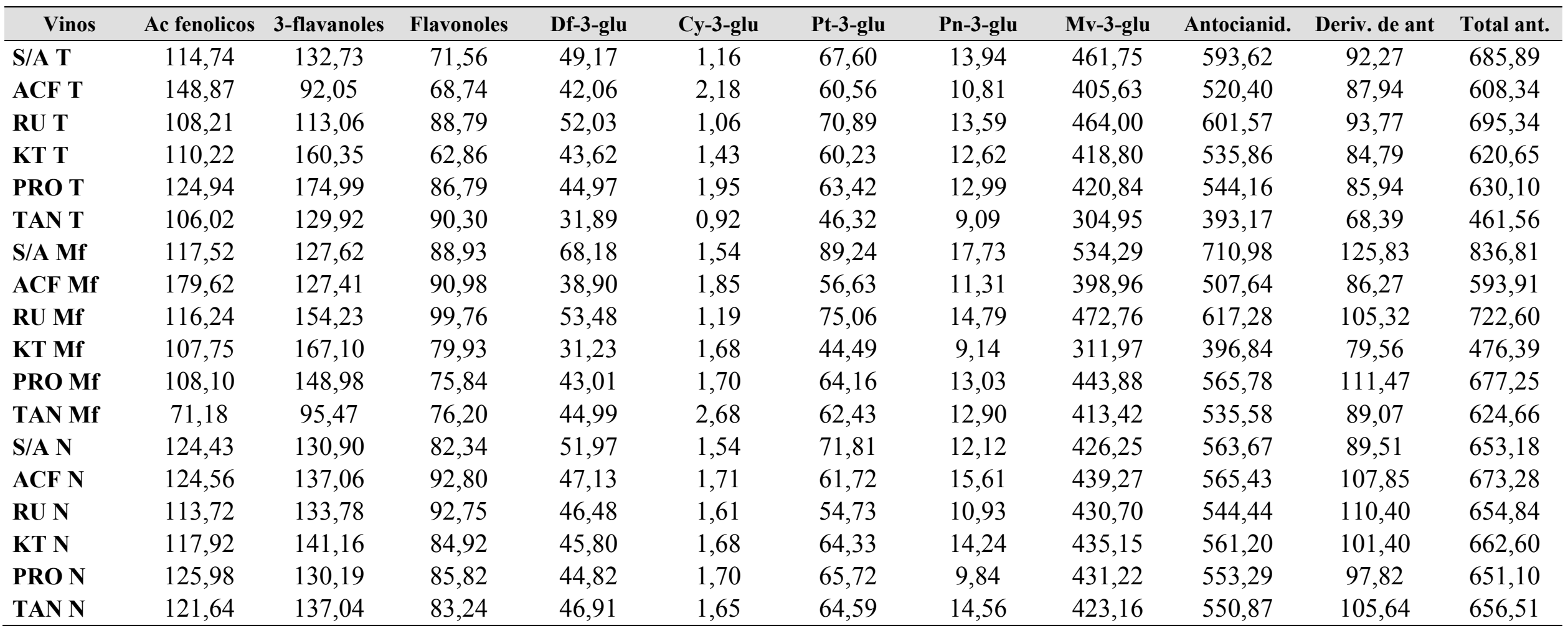


Tabla A.8. Valores medios (mg/L) de los parámetros polifenólicos analizados en los vinos de Tempranillo estudiados. 6 meses Vendimia 2008

\begin{tabular}{|c|c|c|c|c|c|c|c|c|c|c|c|c|c|c|}
\hline Vino & MOX & I. Folin & IC & Tono & $\begin{array}{c}\text { Ant. Tot } \\
(\mathrm{mg} / \mathrm{L})\end{array}$ & $\begin{array}{c}\text { Cateq } \\
(\mathrm{mg} / \mathrm{L})\end{array}$ & I. Dmach & I. Eth & I.PVPP & $\begin{array}{c}\text { Taninos } \\
(\mathrm{g} / \mathrm{L})\end{array}$ & $\begin{array}{l}\% \text { ANT. } \\
\text { COPIG }\end{array}$ & $\begin{array}{l}\text { \% ANT. } \\
\text { LIBRES }\end{array}$ & $\begin{array}{c}\text { \% ANT. } \\
\text { POL. }\end{array}$ & I. Gelatina \\
\hline $\mathbf{S} / \mathbf{A} \mathbf{T}$ & Sin acetal & 40,39 & 11,57 & 76,86 & 270,75 & 149,51 & 46,58 & 16,09 & 52,87 & 1,46 & 16,41 & 44,08 & 39,51 & 47,70 \\
\hline S/A ACF T & Sin acetal & 43,70 & 12,30 & 69,17 & 256,12 & 149,61 & 49,30 & 13,35 & 52,21 & 1,52 & 14,52 & 37,91 & 47,58 & 42,89 \\
\hline S/A RU T & Sin acetal & 39,36 & 11,67 & 79,27 & 282,04 & 147,44 & 66,11 & 11,33 & 53,85 & 1,55 & 16,36 & 44,59 & 39,05 & 53,63 \\
\hline S/A KT T & Sin acetal & 40,30 & 11,60 & 76,88 & 267,81 & 151,85 & 60,09 & 13,09 & 54,93 & 1,55 & 16,65 & 43,87 & 39,48 & 63,70 \\
\hline S/A PRO T & Sin acetal & 40,25 & 11,61 & 77,16 & 274,81 & 136,70 & 58,33 & 14,08 & 53,36 & 1,59 & 16,98 & 44,19 & 38,84 & 46,68 \\
\hline S/A TAN T & Sin acetal & 40,02 & 11,56 & 77,46 & 274,97 & 145,02 & 60,45 & 13,37 & 53,57 & 1,51 & 16,62 & 43,98 & 39,40 & 78,01 \\
\hline ACF T & Sin acetal & 37,31 & 11,89 & 68,48 & 213,89 & 129,08 & 53,87 & 9,70 & 54,68 & 1,37 & 14,60 & 34,63 & 50,76 & 52,27 \\
\hline RU T & Sin acetal & 38,19 & 11,57 & 78,61 & 251,34 & 125,09 & 66,48 & 11,58 & 44,17 & 1,52 & 16,07 & 42,49 & 41,44 & 34,23 \\
\hline KT T & Sin acetal & 37,64 & 11,49 & 74,39 & 227,99 & 125,52 & 76,07 & 9,92 & 42,97 & 0,96 & 12,76 & 43,15 & 44,09 & 14,40 \\
\hline PRO T & Sin acetal & 34,00 & 10,94 & 75,84 & 239,16 & 109,76 & 74,18 & 10,55 & 44,05 & 0,86 & 14,11 & 46,07 & 39,82 & 22,48 \\
\hline TAN T & Sin acetal & 37,12 & 11,58 & 76,06 & 252,06 & 139,84 & 72,90 & 11,28 & 41,41 & 1,07 & 14,86 & 43,50 & 41,65 & 18,94 \\
\hline S/A Mf & Sin acetal & 37,25 & 10,73 & 75,68 & 235,99 & 152,19 & 47,72 & 11,31 & 54,47 & 1,51 & 14,02 & 46,07 & 39,90 & 65,79 \\
\hline S/A ACF Mf & Sin acetal & 42,68 & 11,28 & 68,84 & 215,57 & 146,43 & 32,88 & 11,71 & 55,45 & 1,52 & 13,75 & 38,93 & 47,33 & 73,95 \\
\hline S/A RU Mf & Sin acetal & 37,96 & 10,53 & 80,71 & 244,59 & 155,03 & 50,87 & 11,92 & 53,78 & 1,51 & 17,16 & 45,51 & 37,34 & 73,80 \\
\hline S/A KT Mf & Sin acetal & 38,43 & 10,63 & 76,70 & 232,21 & 169,06 & 38,05 & 19,05 & 55,37 & 1,57 & 14,36 & 46,29 & 39,34 & 44,20 \\
\hline S/A PRO Mf & Sin acetal & 37,86 & 10,39 & 78,07 & 256,84 & 162,82 & 41,48 & 14,93 & 52,69 & 1,55 & 18,34 & 44,25 & 37,41 & 51,28 \\
\hline S/A TAN Mf & Sin acetal & 35,86 & 10,39 & 77,66 & 246,72 & 148,21 & 78,78 & 7,01 & 38,85 & 1,36 & 17,76 & 37,95 & 44,29 & 22,86 \\
\hline ACF Mf & Sin acetal & 38,13 & 11,61 & 65,80 & 206,21 & 145,76 & 65,54 & 11,18 & 40,27 & 1,24 & 16,43 & 32,88 & 50,69 & 23,16 \\
\hline RU Mf & Sin acetal & 38,67 & 12,14 & 74,45 & 240,69 & 154,45 & 61,03 & 9,25 & 41,77 & 1,37 & 15,86 & 39,91 & 44,23 & 26,34 \\
\hline KT Mf & Sin acetal & 37,38 & 11,06 & 75,56 & 217,22 & 174,27 & 79,05 & 9,70 & 40,45 & 1,24 & 16,48 & 40,92 & 42,60 & 33,30 \\
\hline PRO Mf & Sin acetal & 37,88 & 12,16 & 73,70 & 235,34 & 172,54 & 66,97 & 12,24 & 42,05 & 1,14 & 12,81 & 42,80 & 44,39 & 19,94 \\
\hline TAN Mf & Sin acetal & 36,58 & 11,72 & 75,11 & 259,45 & 175,60 & 69,70 & 8,37 & 43,52 & 1,24 & 15,27 & 43,01 & 41,72 & 15,30 \\
\hline
\end{tabular}


Tabla A.8. (Continuación) Valores medios (mg/L) de los parámetros polifenólicos analizados en los vinos de Tempranillo estudiados. 6 meses Año 2008

\begin{tabular}{|c|c|c|c|c|c|c|c|c|c|c|c|c|}
\hline Vino & MOX & Ac fenolicos & 3-flavanoles & Flavonoles & Df-3-glu & Cy-3-glu & Pt-3-glu & Pn-3-glu & Mv-3-glu & Antocianid. & Deriv. de ant & Total ant. \\
\hline S/A T & Sin acetal & 82,74 & 101,17 & 66,63 & 30,03 & 3,26 & 41,05 & 10,79 & 262,58 & 347,71 & 75,46 & 423,17 \\
\hline S/A RU T & Sin acetal & 84,26 & 100,29 & 102,84 & 31,26 & 3,45 & 42,15 & 11,77 & 266,31 & 354,94 & 76,49 & 431,43 \\
\hline S/A PRO T & Sin acetal & 80,40 & 111,83 & 68,08 & 29,48 & 3,48 & 43,15 & 11,64 & 264,97 & 352,72 & 79,49 & 432,21 \\
\hline S/A TAN T & Sin acetal & 82,67 & 102,73 & 68,45 & 30,95 & 3,65 & 39,15 & 10,96 & 263,99 & 348,7 & 80,64 & 429,34 \\
\hline ACF T & Sin acetal & 98,29 & 91,63 & 55,52 & 26,59 & 4,02 & 38,34 & 8,91 & 227,43 & 305,29 & 81,88 & 387,17 \\
\hline PRO T & Sin acetal & 81,77 & 106,23 & 58,65 & 26,45 & 3,55 & 39,67 & 10,69 & 240,15 & 320,51 & 71,49 & 392 \\
\hline TAN T & Sin acetal & 79,82 & 99,19 & 63,20 & 21,89 & 3,29 & 33,68 & 9,11 & 190,73 & 258,7 & 73,46 & 332,16 \\
\hline S/A Mf & Sin acetal & 84,48 & 103,73 & 68,30 & 37,89 & 3,89 & 48,12 & 12,56 & 293,65 & 396,11 & 92,16 & 488,27 \\
\hline S/A ACF Mf & Sin acetal & 111,83 & 101,29 & 67,00 & 36,46 & 3,69 & 49,57 & 12,47 & 283,45 & 385,64 & 94,53 & 480,17 \\
\hline S/A RU Mf & Sin acetal & 89,23 & 101,35 & 93,98 & 39,11 & 3,86 & 50,12 & 12,89 & 289,47 & 395,45 & 91,26 & 486,71 \\
\hline RU Mf & Sin acetal & 83,63 & 104,40 & 81,18 & 33,94 & 3,34 & 46,25 & 11,26 & 273,5 & 368,29 & 84,41 & 452,7 \\
\hline KT Mf & Sin acetal & 81,29 & 118,10 & 61,56 & 19,65 & 2,8 & 35,26 & 8,64 & 186,52 & 252,87 & 70,96 & 323,83 \\
\hline PRO Mf & Sin acetal & 81,44 & 99,77 & 68,15 & 28,45 & 3,46 & 38,21 & 11,03 & 259,68 & 340,83 & 88,46 & 429,29 \\
\hline TAN Mf & Sin acetal & 74,68 & 86,58 & 64,48 & 29,89 & 4,62 & 36,95 & 11,29 & 246,56 & 329,31 & 77,43 & 406,74 \\
\hline
\end{tabular}


Tabla A.8 (Continuación). Valores medios de los parámetros polifenólicos analizados en los vinos de Tempranillo estudiados. 6 meses Vendimia 2008

\begin{tabular}{|c|c|c|c|c|c|c|c|c|c|c|c|c|c|c|}
\hline Vino & MOX & I. Folin & IC & Tono & $\begin{array}{c}\text { Ant. Tot } \\
\text { (mg/L) }\end{array}$ & $\begin{array}{c}\text { Cateq } \\
(\mathrm{mg} / \mathrm{L})\end{array}$ & $\begin{array}{c}\text { I. } \\
\text { Dmach }\end{array}$ & I. Eth & I.PVPP & $\begin{array}{c}\text { Taninos } \\
(\mathrm{g} / \mathrm{L})\end{array}$ & $\begin{array}{l}\text { \% ANT. } \\
\text { COPIG }\end{array}$ & $\begin{array}{l}\text { \% ANT. } \\
\text { LIBRES }\end{array}$ & $\begin{array}{l}\text { \% ANT. } \\
\text { POL. }\end{array}$ & I. Gelatina \\
\hline S/A N & Sin acetal & 46,31 & 12,85 & 72,65 & 253,69 & 153,04 & 50,87 & 19,54 & 48,90 & 1,43 & 11,60 & 41,54 & 42,86 & 31,20 \\
\hline S/A ACF N & Sin acetal & 41,02 & 11,39 & 75,49 & 264,58 & 153,14 & 51,63 & 16,44 & 49,18 & 1,52 & 12,38 & 46,18 & 37,44 & 33,71 \\
\hline S/A RU N & Sin acetal & 45,26 & 11,45 & 74,36 & 225,69 & 151,24 & 55,42 & 14,31 & 48,32 & 1,42 & 10,11 & 44,29 & 41,60 & 30,39 \\
\hline S/A KT N & Sin acetal & 43,21 & 11,59 & 74,98 & 294,56 & 167,23 & 57,58 & 18,02 & 51,39 & 1,38 & 13,40 & 45,27 & 37,33 & 35,90 \\
\hline S/A PRO N & Sin acetal & 41,26 & 10,49 & 78,03 & 255,37 & 167,03 & 51,96 & 12,01 & 49,04 & 1,43 & 14,16 & 44,78 & 37,06 & 33,87 \\
\hline S/A TAN N & Sin acetal & 43,15 & 12,28 & 75,26 & 261,48 & 156,04 & 53,13 & 20,43 & 49,84 & 1,37 & 13,67 & 46,09 & 36,24 & 28,31 \\
\hline KT N & Sin acetal & 41,08 & 11,59 & 70,16 & 253,67 & 150,98 & 53,73 & 24,94 & 47,83 & 1,17 & 17,76 & 41,99 & 36,25 & 28,15 \\
\hline PRO N & Sin acetal & 40,59 & 10,48 & 74,69 & 215,48 & 161,66 & 54,87 & 17,79 & 46,32 & 1,55 & 16,81 & 40,92 & 42,27 & 35,01 \\
\hline TAN N & Sin acetal & 40,16 & 11,39 & 78,16 & 295,01 & 165,56 & 48,94 & 19,87 & 47,90 & 1,46 & 15,80 & 40,06 & 43,15 & 38,10 \\
\hline S/A T & Con acetal & 40,00 & 11,97 & 76,93 & 266,45 & 294,33 & 87,26 & 12,69 & 43,38 & 0,88 & 14,89 & 37,49 & 47,62 & 21,77 \\
\hline S/A ACF T & Con acetal & 44,89 & 12,75 & 69,62 & 242,22 & 126,10 & 69,52 & 13,98 & 45,82 & 1,39 & 16,17 & 40,96 & 42,87 & 16,75 \\
\hline S/A RU T & Con acetal & 40,85 & 12,12 & 78,84 & 271,99 & 127,86 & 92,89 & 13,98 & 46,42 & 1,30 & 20,58 & 39,57 & 39,85 & 20,81 \\
\hline RU T & Con acetal & 38,78 & 12,25 & 78,72 & 237,39 & 170,87 & 57,42 & 14,26 & 45,06 & 1,41 & 12,46 & 43,82 & 43,71 & 15,60 \\
\hline KT T & Con acetal & 37,87 & 11,86 & 75,67 & 215,61 & 155,25 & 73,38 & 14,00 & 49,31 & 1,32 & 9,00 & 45,99 & 45,01 & 26,70 \\
\hline PRO T & Con acetal & 34,30 & 11,56 & 76,80 & 215,33 & 111,94 & 25,68 & 17,94 & 53,70 & 1,56 & 12,04 & 46,86 & 41,10 & 24,84 \\
\hline TAN T & Con acetal & 38,08 & 12,12 & 76,90 & 226,78 & 158,67 & 39,77 & 19,23 & 43,62 & 1,59 & 13,46 & 43,72 & 42,82 & 27,90 \\
\hline
\end{tabular}


Tabla A.8 (Continuación). Valores medios (mg/L) de los parámetros polifenólicos analizados en los vinos de Tempranillo estudiados. 6 meses Año 2008

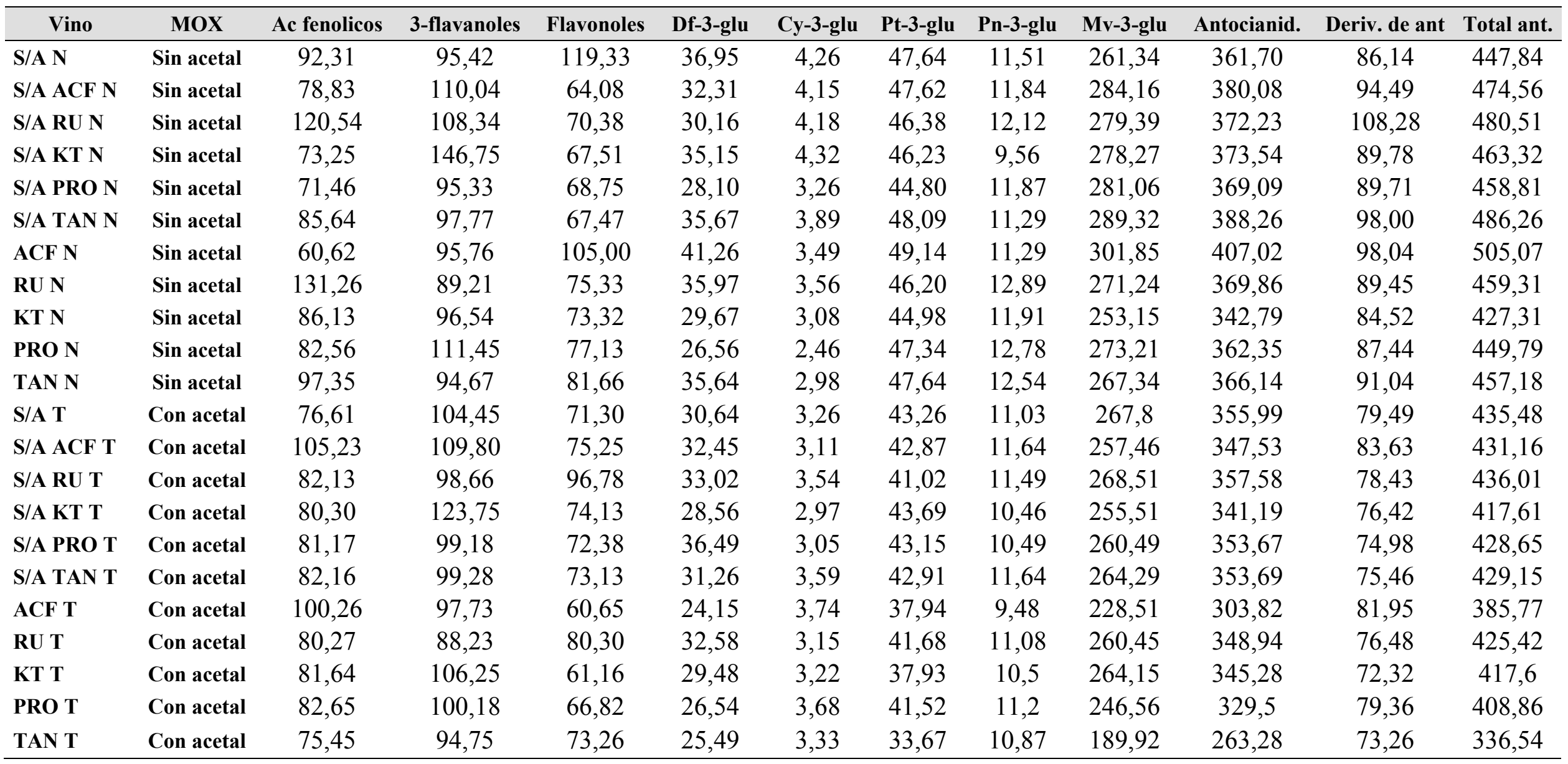


Tabla A.8 (Continuación). Valores medios de los parámetros polifenólicos analizados en los vinos de Tempranillo estudiados. 6 meses Vendimia 2008

\begin{tabular}{|c|c|c|c|c|c|c|c|c|c|c|c|c|c|c|}
\hline Vino & MOX & I. Folin & IC & Tono & $\begin{array}{c}\text { Ant. Tot } \\
\text { (mg/L) }\end{array}$ & $\begin{array}{l}\text { Cateq } \\
\text { (mg/L) }\end{array}$ & I. Dmach & I. Eth & I.PVPP & $\begin{array}{c}\text { Taninos } \\
(\mathrm{g} / \mathrm{L})\end{array}$ & $\begin{array}{l}\text { \% ANT. } \\
\text { COPIG }\end{array}$ & $\begin{array}{l}\text { \% ANT. } \\
\text { LIBRES }\end{array}$ & $\begin{array}{c}\text { \% ANT. } \\
\text { POL. }\end{array}$ & I. Gelatina \\
\hline S/A Mf & Con acetal & 37,63 & 11,54 & 77,52 & 210,31 & 190,10 & 60,48 & 14,94 & 46,43 & 1,56 & 13,81 & 43,23 & 42,96 & 20,97 \\
\hline S/A ACF Mf & Con acetal & 41,66 & 12,27 & 70,37 & 192,55 & 155,64 & 111,51 & 15,49 & 44,56 & 1,42 & 10,63 & 37,46 & 51,90 & 17,82 \\
\hline S/A RU Mf & Con acetal & 37,35 & 12,23 & 79,06 & 196,00 & 181,89 & 61,16 & 16,10 & 47,39 & 1,47 & 9,86 & 46,37 & 43,78 & 14,58 \\
\hline S/A PRO Mf & Con acetal & 38,48 & 11,82 & 76,45 & 201,27 & 171,64 & 59,45 & 17,73 & 44,03 & 1,53 & 12,02 & 44,08 & 43,90 & 28,88 \\
\hline S/A TAN Mf & Con acetal & 38,38 & 12,01 & 75,62 & 197,81 & 157,32 & 60,72 & 17,02 & 47,70 & 1,56 & 7,54 & 46,95 & 45,50 & 28,27 \\
\hline KT Mf & Con acetal & 39,20 & 11,62 & 76,87 & 193,31 & 188,35 & 52,64 & 16,09 & 48,15 & 1,79 & 8,24 & 45,14 & 46,62 & 33,29 \\
\hline PRO Mf & Con acetal & 39,20 & 12,59 & 75,42 & 226,70 & 182,98 & 59,60 & 15,01 & 45,16 & 1,91 & 11,04 & 43,27 & 45,68 & 39,52 \\
\hline TAN Mf & Con acetal & 38,26 & 12,58 & 76,20 & 230,92 & 164,20 & 65,45 & 14,62 & 45,63 & 1,41 & 11,68 & 43,73 & 44,60 & 22,34 \\
\hline S/A N & Con acetal & 39,64 & 11,82 & 82,84 & 258,95 & 160,98 & 46,11 & 13,09 & 40,66 & 1,32 & 17,61 & 37,72 & 50,67 & 23,81 \\
\hline S/A ACF N & Con acetal & 38,49 & 12,16 & 71,03 & 260,34 & 180,01 & 51,34 & 11,98 & 50,25 & 1,61 & 15,12 & 44,37 & 44,16 & 35,47 \\
\hline S/A RU N & Con acetal & 43,67 & 12,49 & 75,46 & 212,45 & 180,00 & 49,92 & 12,30 & 52,71 & 1,59 & 15,45 & 39,14 & 49,91 & 15,44 \\
\hline RU N & Con acetal & 40,39 & 13,26 & 71,46 & 255,48 & 181,50 & 47,85 & 21,66 & 50,28 & 1,80 & 17,87 & 41,76 & 46,37 & 29,60 \\
\hline KT N & Con acetal & 44,34 & 14,32 & 82,65 & 234,33 & 167,80 & 48,94 & 13,13 & 47,91 & 1,57 & 16,91 & 46,69 & 42,40 & 36,92 \\
\hline PRO N & Con acetal & 37,49 & 10,14 & 75,69 & 216,19 & 174,49 & 46,93 & 12,87 & 50,61 & 1,68 & 17,55 & 41,79 & 46,66 & 23,94 \\
\hline TAN N & Con acetal & 36,45 & 11,22 & 73,21 & 266,39 & 179,95 & 48,21 & 9,14 & 47,88 & 1,79 & 16,03 & 39,35 & 50,62 & 22,27 \\
\hline
\end{tabular}


Tabla A.8 (Continuación). Valores medios (mg/L) de los parámetros polifenólicos analizados en los vinos de Tempranillo estudiados. 6 meses Año 2008

\begin{tabular}{|c|c|c|c|c|c|c|c|c|c|c|c|c|}
\hline Vino & MOX & Ac fenolicos & 3-flavanoles & Flavonoles & Df-3-glu & Cy-3-glu & Pt-3-glu & Pn-3-glu & Mv-3-glu & Antocianid. & Deriv. de ant & Total ant. \\
\hline S/A Mf & Con acetal & ll $\quad 75,94$ & 68,30 & 62,98 & 37,49 & 3,81 & 51,49 & 12,45 & 289,95 & 395,19 & 93,37 & 488,56 \\
\hline S/A RU Mf & Con acetal & 81,77 & 90,61 & 97,89 & 34,15 & 3,76 & 50,26 & 11,49 & 282,56 & 382,22 & 91,79 & 474,01 \\
\hline S/A PRO Mf & Con acetal & 84,77 & 101,58 & 71,28 & 36,59 & 4,05 & 47,34 & 12,94 & 286,35 & 387,27 & 94,52 & 481,79 \\
\hline S/A TAN Mf & Con acetal & 85,51 & 102,56 & 72,33 & 35,24 & 3,75 & 48,1 & 13,64 & 287,46 & 388,19 & 92,16 & 480,35 \\
\hline ACF Mf & Con acetal & 110,49 & 101,28 & 70,71 & 23,16 & 3,5 & 35,26 & 9,54 & 225,45 & 296,91 & 82,57 & 379,48 \\
\hline PRO Mf & Con acetal & 79,62 & 96,77 & 67,73 & 29,64 & 3,61 & 43,65 & 11,23 & 263,31 & 351,44 & 94,56 & 446,00 \\
\hline TAN Mf & Con acetal & 71,15 & 83,74 & 69,78 & 32,32 & 4,25 & 41,3 & 13,24 & 245,16 & 336,27 & 85,42 & 421,69 \\
\hline S/A N & Con acetal & 92,54 & 91,23 & 52,63 & 31,28 & 3,58 & 40,63 & 10,07 & 191,84 & 277,40 & 81,34 & 358,74 \\
\hline S/A ACF N & Con acetal & 86,52 & 110,16 & 59,88 & 33,62 & 3,49 & 44,61 & 11,13 & 267,25 & 360,09 & 94,11 & 454,20 \\
\hline S/A RU N & Con acetal & 100,25 & 108,86 & 59,85 & 25,24 & 4,45 & 44,80 & 11,03 & 254,04 & 339,57 & 113,38 & 452,95 \\
\hline RU N & Con acetal & 116,97 & 82,60 & 56,90 & 28,64 & 3,65 & 44,80 & 11,36 & 230,14 & 318,60 & 108,61 & 427,21 \\
\hline KT N & Con acetal & 63,75 & 97,99 & 60,99 & 26,34 & 3,15 & 39,92 & 11,59 & 237,60 & 318,59 & 81,81 & 400,41 \\
\hline PRO N & Con acetal & 82,20 & 78,79 & 58,21 & 30,90 & 3,48 & 45,42 & 10,11 & 213,33 & 303,24 & 81,67 & 384,91 \\
\hline TAN N & Con acetal & 86,67 & 91,25 & 63,23 & 26,45 & 4,26 & 47,22 & 11,29 & 232,63 & 321,85 & 94,53 & 416,38 \\
\hline
\end{tabular}


Tabla A.9. Valores medios de los parámetros polifenólicos analizados en los vinos de Tempranillo estudiados. 12 meses Vendimia 2008

\begin{tabular}{|c|c|c|c|c|c|c|c|c|c|c|c|c|c|c|}
\hline Vino & MOX & I. Folin & IC & Tono & $\begin{array}{l}\text { Ant. Tot } \\
\text { (mg/L) }\end{array}$ & $\begin{array}{l}\text { Cateq } \\
(\mathrm{mg} / \mathrm{L})\end{array}$ & I. Dmach & I. Eth & I.PVPP & $\begin{array}{c}\text { Taninos } \\
(\mathrm{g} / \mathrm{L})\end{array}$ & $\begin{array}{l}\% \text { ANT. } \\
\text { COPIG }\end{array}$ & $\begin{array}{l}\text { \% ANT. } \\
\text { LIBRES }\end{array}$ & $\begin{array}{l}\text { \% ANT. } \\
\text { POL. }\end{array}$ & I. Gelatina \\
\hline S/A T & Sin acetal & 35,84 & 11,65 & 79,82 & 240,09 & 136,36 & 53,21 & 9,83 & 92,54 & 1,63 & 18,69 & 35,79 & 45,52 & 18,53 \\
\hline S/A ACF T & Sin acetal & 41,71 & 12,59 & 70,74 & 233,66 & 128,60 & 48,01 & 22,51 & 91,18 & 1,74 & 18,37 & 25,53 & 56,10 & 16,33 \\
\hline S/A RU T & Sin acetal & 37,02 & 12,18 & 79,70 & 242,46 & 130,91 & 48,37 & 27,47 & 84,85 & 1,71 & 15,60 & 38,19 & 46,21 & 18,53 \\
\hline S/A KT T & Sin acetal & 37,57 & 11,54 & 80,54 & 281,07 & 145,15 & 58,04 & 7,92 & 85,35 & 1,81 & 17,32 & 36,16 & 46,52 & 22,77 \\
\hline S/A PRO T & Sin acetal & 36,94 & 11,85 & 79,28 & 242,74 & 137,92 & 51,65 & 10,65 & 82,73 & 1,72 & 16,79 & 37,59 & 45,62 & 17,38 \\
\hline S/A TAN T & Sin acetal & 37,67 & 11,59 & 80,44 & 230,04 & 143,32 & 51,85 & 26,38 & 80,73 & 1,78 & 20,11 & 34,46 & 45,42 & 14,33 \\
\hline KT T & Sin acetal & 35,48 & 11,82 & 76,32 & 183,51 & 91,27 & 52,43 & 13,96 & 71,55 & 1,54 & 12,89 & 36,39 & 50,72 & 24,01 \\
\hline PRO T & Sin acetal & 32,35 & 11,01 & 80,47 & 196,48 & 82,69 & 43,60 & 17,35 & 68,54 & 1,50 & 14,58 & 39,06 & 46,36 & 30,08 \\
\hline TAN T & Sin acetal & 36,29 & 12,07 & 78,86 & 203,40 & 113,85 & 43,64 & 16,25 & 70,22 & 1,89 & 13,89 & 37,86 & 48,26 & 45,12 \\
\hline S/A Mf & Sin acetal & 36,05 & 10,60 & 78,50 & 206,93 & 151,61 & 43,60 & 22,68 & 82,45 & 2,04 & 17,73 & 36,39 & 45,88 & 32,95 \\
\hline S/A ACF Mf & Sin acetal & 40,52 & 11,24 & 70,17 & 206,29 & 148,55 & 50,46 & 26,17 & 86,33 & 1,74 & 17,32 & 26,78 & 55,90 & 24,25 \\
\hline S/A RU Mf & Sin acetal & 36,78 & 11,67 & 81,58 & 200,34 & 146,96 & 53,59 & 28,68 & 84,39 & 1,61 & 16,68 & 36,81 & 46,51 & 12,75 \\
\hline RU Mf & Sin acetal & 37,80 & 12,14 & 77,48 & 195,72 & 123,37 & 57,14 & 17,11 & 68,99 & 1,59 & 14,28 & 35,22 & 50,50 & 23,24 \\
\hline KT Mf & Sin acetal & 37,15 & 11,25 & 78,38 & 180,57 & 146,93 & 52,61 & 16,03 & 68,00 & 2,09 & 13,31 & 36,53 & 50,17 & 43,32 \\
\hline PRO Mf & Sin acetal & 37,53 & 12,71 & 75,71 & 192,31 & 114,81 & 53,23 & 19,69 & 64,74 & 1,77 & 13,14 & 34,75 & 52,11 & 36,55 \\
\hline TAN Mf & Sin acetal & 36,27 & 12,10 & 77,20 & 216,06 & 114,57 & 45,12 & 16,98 & 71,06 & 1,74 & 9,72 & 40,27 & 50,01 & 26,62 \\
\hline
\end{tabular}


Tabla A.9 (Continuación). Valores medios (mg/L) de los parámetros polifenólicos analizados en los vinos de Tempranillo estudiados. 12 meses Año 2008

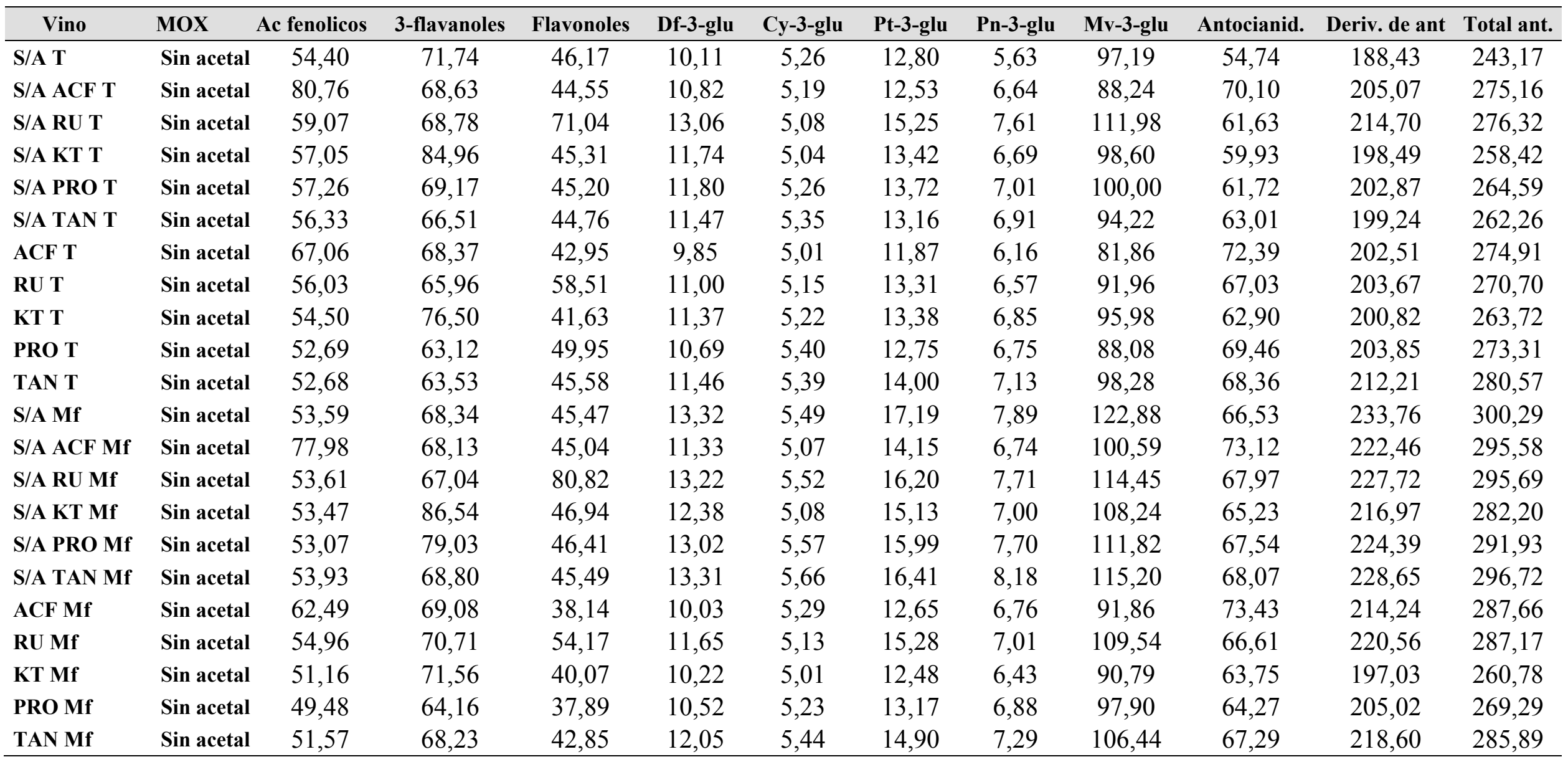


Tabla A.9 (Continuación). Valores medios de los parámetros polifenólicos analizados en los vinos de Tempranillo estudiados. 12 meses Vendimia 2008

\begin{tabular}{|c|c|c|c|c|c|c|c|c|c|c|c|c|c|c|}
\hline Vino & MOX & I. Folin & IC & Tono & $\begin{array}{l}\text { Ant. Tot } \\
(\mathrm{mg} / \mathrm{L})\end{array}$ & $\begin{array}{c}\text { Cateq } \\
(\mathrm{mg} / \mathrm{L})\end{array}$ & I. Dmach & I. Eth & I.PVPP & $\begin{array}{c}\text { Taninos } \\
(\mathrm{g} / \mathrm{L})\end{array}$ & $\begin{array}{l}\text { \% ANT. } \\
\text { COPIG }\end{array}$ & $\begin{array}{l}\text { \% ANT. } \\
\text { LIBRES }\end{array}$ & $\begin{array}{l}\text { \% ANT. } \\
\text { POL. }\end{array}$ & I. Gelatina \\
\hline S/A N & Sin acetal & 36,55 & 12,66 & 79,23 & 230,26 & 137,90 & 43,33 & 25,56 & 75,17 & 1,99 & 13,75 & 39,45 & 47,81 & 47,80 \\
\hline S/A ACF N & Sin acetal & 35,32 & 11,74 & 83,60 & 233,68 & 140,47 & 50,57 & 21,08 & 75,77 & 1,58 & 16,37 & 43,38 & 41,24 & 40,40 \\
\hline S/A KT N & Sin acetal & 37,32 & 10,92 & 81,96 & 250,35 & 151,13 & 50,78 & 20,84 & 78,72 & 1,81 & 14,78 & 43,14 & 43,08 & 50,55 \\
\hline S/A PRO N & Sin acetal & 36,82 & 11,01 & 81,87 & 259,67 & 141,58 & 48,96 & 20,27 & 77,06 & 1,62 & 15,05 & 44,42 & 41,53 & 43,30 \\
\hline S/A TAN N & Sin acetal & 37,04 & 10,83 & 82,40 & 267,67 & 145,20 & 50,03 & 20,25 & 76,62 & 1,58 & 16,49 & 43,27 & 41,24 & 35,27 \\
\hline KT N & Sin acetal & 35,60 & 11,63 & 81,66 & 232,43 & 137,23 & 41,23 & 26,43 & 78,00 & 1,44 & 13,05 & 43,20 & 44,75 & 34,47 \\
\hline PRO N & Sin acetal & 35,39 & 11,87 & 77,70 & 222,10 & 123,16 & 53,58 & 34,39 & 81,47 & 1,69 & 18,79 & 35,68 & 45,53 & 22,09 \\
\hline TAN N & Sin acetal & 39,58 & 12,21 & 79,39 & 206,06 & 114,06 & 49,65 & 38,57 & 79,52 & 1,81 & 19,53 & 33,64 & 46,83 & 42,23 \\
\hline $\mathbf{S} / \mathbf{A} \mathbf{T}$ & Con acetal & 36,47 & 12,33 & 79,22 & 214,69 & 75,76 & 45,62 & 12,02 & 72,74 & 1,67 & 12,91 & 39,61 & 47,47 & 39,69 \\
\hline S/A ACF T & Con acetal & 40,98 & 13,51 & 70,33 & 185,19 & 99,14 & 49,88 & 13,46 & 79,18 & 1,65 & 14,04 & 27,85 & 58,11 & 26,60 \\
\hline S/A RU T & Con acetal & 37,37 & 12,69 & 80,47 & 207,94 & 91,70 & 54,12 & 18,15 & 75,20 & 1,56 & 12,93 & 39,21 & 47,86 & 19,46 \\
\hline RU T & Con acetal & 33,80 & 12,30 & 85,86 & 200,99 & 134,39 & 51,00 & 9,12 & 94,52 & 1,54 & 15,48 & 37,33 & 47,18 & 46,53 \\
\hline KT T & Con acetal & 36,46 & 12,02 & 81,94 & 203,04 & 128,09 & 51,17 & 38,76 & 86,06 & 1,58 & 13,47 & 37,48 & 49,05 & 35,18 \\
\hline PRO T & Con acetal & 32,92 & 11,80 & 82,38 & 231,41 & 97,78 & 45,30 & 35,55 & 93,83 & 1,43 & 13,90 & 39,83 & 46,27 & 36,60 \\
\hline TAN T & Con acetal & 36,58 & 12,59 & 80,83 & 234,14 & 125,38 & 40,62 & 38,38 & 87,77 & 1,83 & 12,53 & 38,52 & 48,96 & 31,30 \\
\hline
\end{tabular}


Tabla A.9 (Continuación). Valores medios (mg/L) de los parámetros polifenólicos analizados en los vinos de Tempranillo estudiados. 12 meses Año 2008

\begin{tabular}{|c|c|c|c|c|c|c|c|c|c|c|c|c|}
\hline Vino & MOX & Ac fenolicos & 3-flavanoles & Flavonoles & Df-3-glu & Cy-3-glu & Pt-3-glu & Pn-3-glu & Mv-3-glu & Antocianid. & Deriv. de ant & Total ant \\
\hline S/A N & Sin acetal & 50,39 & 24,89 & 11,07 & 11,06 & 5,08 & 13,23 & 7,97 & 196,29 & 233,63 & 62,46 & 296,09 \\
\hline S/A ACF N & Sin acetal & 58,63 & 79,66 & 57,22 & 11,92 & 5,08 & 15,01 & 7,49 & 202,54 & 242,03 & 72,15 & 314,19 \\
\hline S/A RU N & Sin acetal & 72,45 & 85,15 & 59,50 & 11,80 & 5,12 & 15,57 & 7,54 & 204,83 & 244,87 & 75,52 & 320,39 \\
\hline S/A KT N & Sin acetal & 58,59 & 100,42 & 61,70 & 11,98 & 5,12 & 15,47 & 7,55 & 205,12 & 245,23 & 73,21 & 318,44 \\
\hline S/A PRO N & Sin acetal & 61,24 & 88,95 & 66,84 & 12,39 & 5,13 & 15,98 & 7,61 & 211,00 & 252,11 & 74,75 & 326,86 \\
\hline S/A TAN N & Sin acetal & 45,12 & 77,16 & 70,58 & 12,85 & 5,20 & 16,00 & 7,70 & 215,07 & 256,81 & 74,49 & 331,30 \\
\hline ACF N & Sin acetal & 57,13 & 78,39 & 89,70 & 12,51 & 5,14 & 15,59 & 7,64 & 213,16 & 254,03 & 72,99 & 327,02 \\
\hline RU N & Sin acetal & 65,37 & 78,50 & 57,28 & 11,83 & 5,15 & 15,63 & 7,71 & 200,72 & 241,05 & 72,93 & 313,98 \\
\hline KT N & Sin acetal & 54,05 & 75,26 & 54,63 & 11,61 & 5,10 & 15,33 & 7,60 & 198,33 & 237,97 & 71,58 & 309,55 \\
\hline PRO N & Sin acetal & 49,91 & 31,42 & 15,81 & 11,34 & 5,03 & 13,53 & 7,96 & 195,21 & 233,08 & 65,65 & 298,73 \\
\hline TAN N & Sin acetal & 46,94 & 16,59 & 0,19 & 4,00 & 5,03 & 12,89 & 7,64 & 191,92 & 221,48 & 61,33 & 282,81 \\
\hline S/A T & Con acetal & 44,66 & 34,86 & 40,64 & 10,29 & 4,68 & 12,35 & 6,25 & 92,71 & 59,95 & 192,62 & 252,57 \\
\hline S/A ACF T & Con acetal & 75,63 & 64,30 & 43,22 & 9,95 & 5,03 & 11,91 & 6,36 & 84,73 & 70,12 & 201,59 & 271,71 \\
\hline S/A RU T & Con acetal & 52,37 & 59,25 & 72,95 & 11,89 & 5,39 & 14,57 & 7,20 & 105,71 & 62,93 & 210,60 & 273,54 \\
\hline S/A KT T & Con acetal & 50,47 & 76,87 & 45,76 & 9,34 & 4,61 & 11,28 & 5,76 & 82,53 & 58,06 & 179,30 & 237,36 \\
\hline S/A PRO T & Con acetal & 53,22 & 70,82 & 49,93 & 9,92 & 5,28 & 11,80 & 5,67 & 81,59 & 57,72 & 177,80 & 235,52 \\
\hline S/A TAN T & Con acetal & 55,67 & 70,83 & 49,04 & 11,74 & 5,57 & 13,72 & 7,05 & 96,53 & 63,35 & 202,12 & 265,47 \\
\hline ACF T & Con acetal & 66,19 & 69,85 & 49,23 & 9,93 & 5,01 & 11,92 & 6,22 & 81,38 & 73,94 & 204,62 & 278,56 \\
\hline RU T & Con acetal & 55,57 & 70,78 & 61,89 & 11,04 & 5,35 & 14,12 & 6,52 & 96,43 & 67,46 & 208,85 & 276,31 \\
\hline KT T & Con acetal & 53,41 & 69,41 & 46,69 & 10,75 & 5,20 & 12,90 & 6,49 & 88,87 & 62,22 & 192,57 & 254,79 \\
\hline PRO T & Con acetal & 51,75 & 62,04 & 49,07 & 11,72 & 5,57 & 14,94 & 7,03 & 102,33 & 68,94 & 217,24 & 286,19 \\
\hline TAN T & Con acetal & 52,86 & 59,60 & 49,47 & 11,17 & 5,47 & 14,94 & 7,20 & 103,64 & 69,68 & 219,78 & 289,46 \\
\hline
\end{tabular}


Tabla A.9 (Continuación). Valores medios de los parámetros polifenólicos analizados en los vinos de Tempranillo estudiados. 12 meses Vendimia 2008

\begin{tabular}{|c|c|c|c|c|c|c|c|c|c|c|c|c|c|c|}
\hline Vino & MOX & $\begin{array}{c}\text { I. } \\
\text { Folin }\end{array}$ & IC & Tono & $\begin{array}{l}\text { Ant. Tot } \\
\text { (mg/L) }\end{array}$ & $\begin{array}{c}\text { Cateq } \\
(\mathrm{mg} / \mathrm{L})\end{array}$ & I. Dmach & I. Eth & I.PVPP & $\begin{array}{c}\text { Taninos } \\
(\mathrm{g} / \mathrm{L})\end{array}$ & $\begin{array}{l}\text { \% ANT. } \\
\text { COPIG }\end{array}$ & $\begin{array}{l}\text { \% ANT. } \\
\text { LIBRES }\end{array}$ & $\begin{array}{c}\text { \% ANT. } \\
\text { POL. }\end{array}$ & I. Gelatina \\
\hline S/A Mf & Con acetal & 35,72 & 11,07 & 82,40 & 227,23 & 153,09 & 55,06 & 36,44 & 85,82 & 1,59 & 17,81 & 36,61 & 45,58 & 20,75 \\
\hline S/A ACF Mf & Con acetal & 37,03 & 11,64 & 81,78 & 194,60 & 126,05 & 47,82 & 19,04 & 89,52 & 1,72 & 13,35 & 28,37 & 58,28 & 28,58 \\
\hline S/A KT Mf & Con acetal & 34,83 & 11,95 & 84,36 & 181,46 & 139,94 & 59,32 & 24,48 & 86,64 & 1,64 & 11,86 & 38,96 & 49,19 & 36,16 \\
\hline S/A PRO Mf & Con acetal & 31,17 & 13,18 & 78,94 & 155,05 & 106,04 & 46,51 & 35,20 & 82,38 & 1,53 & 7,00 & 36,48 & 56,52 & 34,42 \\
\hline S/A TAN Mf & Con acetal & 34,51 & 11,48 & 85,02 & 188,29 & 141,72 & 47,45 & 47,88 & 82,71 & 1,72 & 14,50 & 39,30 & 46,19 & 39,10 \\
\hline KT Mf & Con acetal & 35,84 & 11,99 & 82,47 & 176,47 & 172,60 & 52,37 & 33,60 & 86,19 & 1,72 & 11,37 & 38,54 & 50,09 & 47,32 \\
\hline PRO Mf & Con acetal & 37,04 & 12,69 & 82,31 & 202,59 & 156,36 & 50,02 & 53,42 & 88,47 & 1,68 & 13,29 & 37,31 & 49,40 & 45,89 \\
\hline TAN Mf & Con acetal & 36,07 & 13,23 & 81,04 & 196,36 & 118,53 & 45,61 & 40,24 & 95,33 & 1,66 & 14,71 & 35,00 & 50,30 & 39,19 \\
\hline $\mathbf{S} / \mathbf{A} \mathbf{N}$ & Con acetal & 35,82 & 12,48 & 78,77 & 171,75 & 117,45 & 51,91 & 32,24 & 80,39 & 1,85 & 18,75 & 29,50 & 52,75 & 42,23 \\
\hline S/A ACF N & Con acetal & 35,37 & 10,94 & 82,55 & 225,31 & 152,80 & 50,34 & 22,23 & 85,23 & 2,10 & 16,77 & 40,30 & 43,93 & 41,46 \\
\hline S/A RU N & Con acetal & 37,73 & 12,13 & 74,82 & 211,29 & 140,23 & 50,39 & 21,96 & 86,72 & 2,04 & 10,61 & 34,79 & 55,60 & 35,00 \\
\hline RU N & Con acetal & 33,64 & 10,82 & 77,78 & 180,35 & 119,91 & 44,81 & 26,63 & 87,20 & 1,86 & 10,66 & 31,64 & 58,70 & 35,30 \\
\hline KT N & Con acetal & 33,94 & 12,14 & 81,15 & 213,66 & 135,79 & 49,84 & 27,20 & 84,81 & 1,83 & 11,12 & 38,76 & 51,12 & 30,68 \\
\hline PRO N & Con acetal & 33,25 & 11,96 & 76,63 & 198,75 & 120,65 & 48,81 & 27,53 & 86,56 & 1,71 & 11,75 & 35,48 & 53,77 & 26,24 \\
\hline TAN N & Con acetal & 33,30 & 12,04 & 76,28 & 195,34 & 132,71 & 48,82 & 22,56 & 84,74 & 1,65 & 11,29 & 34,03 & 55,68 & 21,62 \\
\hline
\end{tabular}


Tabla A.9 (Continuación). Valores medios (mg/L) de los parámetros polifenólicos analizados en los vinos de Tempranillo estudiados. 12 meses Año 2008

\begin{tabular}{|c|c|c|c|c|c|c|c|c|c|c|c|c|}
\hline Vino & MOX & Ac fenolicos & 3-flavanoles & Flavonoles & Df-3-glu & Cy-3-glu & Pt-3-glu & Pn-3-glu & Mv-3-glu & Antocianid. & Deriv. de ant & Total ant. \\
\hline S/A Mf & Con acetal & 50,31 & 73,51 & 49,56 & 12,12 & 5,04 & 15,76 & 6,79 & 112,89 & 65,57 & 222,18 & 287,75 \\
\hline S/A ACF Mf & Con acetal & 75,15 & 78,78 & 50,95 & 11,27 & 5,53 & 13,87 & 7,08 & 95,23 & 76,27 & 222,35 & 298,62 \\
\hline S/A RU Mf & Con acetal & 53,26 & 67,04 & 73,22 & 12,07 & 5,13 & 15,24 & 7,28 & 102,80 & 68,45 & 216,88 & 285,33 \\
\hline S/A KT Mf & Con acetal & 52,51 & 91,04 & 51,51 & 12,63 & 5,58 & 15,22 & 7,54 & 104,99 & 67,34 & 217,23 & 284,57 \\
\hline S/A PRO Mf & Con acetal & 51,27 & 68,65 & 50,78 & 12,60 & 5,43 & 15,74 & 7,60 & 109,73 & 67,68 & 222,54 & 290,22 \\
\hline S/A TAN Mf & Con acetal & 51,93 & 66,87 & 49,18 & 12,48 & 5,52 & 15,22 & 7,40 & 106,05 & 69,39 & 221,71 & 291,10 \\
\hline ACF Mf & Con acetal & 60,92 & 74,99 & 42,98 & 10,12 & 5,36 & 12,58 & 6,61 & 90,19 & 72,43 & 210,91 & 283,35 \\
\hline RU Mf & Con acetal & 52,78 & 60,60 & 58,75 & 11,24 & 5,38 & 14,50 & 6,89 & 99,98 & 67,40 & 212,30 & 279,70 \\
\hline KT Mf & Con acetal & 53,14 & 68,27 & 44,67 & 10,20 & 5,21 & 13,49 & 6,52 & 96,64 & 65,03 & 205,03 & 270,06 \\
\hline PRO Mf & Con acetal & 49,04 & 58,07 & 44,75 & 10,63 & 5,46 & 14,28 & 6,93 & 103,47 & 66,75 & 214,71 & 281,46 \\
\hline TAN Mf & Con acetal & 49,82 & 61,54 & 47,60 & 11,31 & 5,56 & 14,78 & 6,93 & 104,52 & 68,31 & 218,36 & 286,67 \\
\hline S/A N & Con acetal & 44,28 & 24,27 & 10,43 & 11,00 & 5,03 & 12,82 & 7,56 & 194,25 & 230,66 & 62,08 & 292,74 \\
\hline S/A ACF N & Con acetal & 57,99 & 87,89 & 67,14 & 12,23 & 5,11 & 13,93 & 7,63 & 206,25 & 245,15 & 72,04 & 317,20 \\
\hline S/A RU N & Con acetal & 77,76 & 80,89 & 68,69 & 11,73 & 5,10 & 13,94 & 7,55 & 200,61 & 238,92 & 74,76 & 313,69 \\
\hline S/A KT N & Con acetal & 60,79 & 91,86 & 58,19 & 12,17 & 5,14 & 14,02 & 7,62 & 204,71 & 243,66 & 73,59 & 317,24 \\
\hline S/A PRO N & Con acetal & 60,99 & 81,51 & 59,09 & 12,15 & 5,11 & 13,94 & 7,58 & 206,57 & 245,35 & 70,91 & 316,27 \\
\hline S/A TAN N & Con acetal & 60,47 & 99,26 & 60,09 & 12,08 & 5,03 & 13,91 & 7,52 & 202,54 & 241,07 & 69,41 & 310,48 \\
\hline ACF N & Con acetal & 59,43 & 84,36 & 46,48 & 12,08 & 5,10 & 13,85 & 7,61 & 206,78 & 245,42 & 71,67 & 317,10 \\
\hline RU N & Con acetal & 68,19 & 71,11 & 43,64 & 10,99 & 5,08 & 13,90 & 7,65 & 193,96 & 231,58 & 72,05 & 303,63 \\
\hline KT N & Con acetal & 55,19 & 85,59 & 48,11 & 11,45 & 5,08 & 13,59 & 7,44 & 197,01 & 234,56 & 71,13 & 305,69 \\
\hline PRO N & Con acetal & 52,20 & 68,36 & 53,17 & 11,55 & 5,11 & 13,98 & 7,57 & 196,41 & 234,61 & 71,25 & 305,87 \\
\hline TAN N & Con acetal & 53,68 & 75,49 & 50,12 & 11,72 & 5,11 & 13,92 & 7,54 & 198,73 & 237,01 & 70,77 & 307,79 \\
\hline
\end{tabular}


